\title{
PALINOBIOESTRATIGRAFIA DO SUBGRUPO ITARARÉ, CARBONÍFERO/PERMIANO, NA PORÇÃO NORDESTE DA BACIA DO PARANÁ (SP/PR, BRASIL)
}

\section{PAULO ALVES DE SOUZA}

Orientador: Prof. Dr. Setembrino Petri

TESE DE DOUTORAMENTO

COMISSÃO JULGADORA

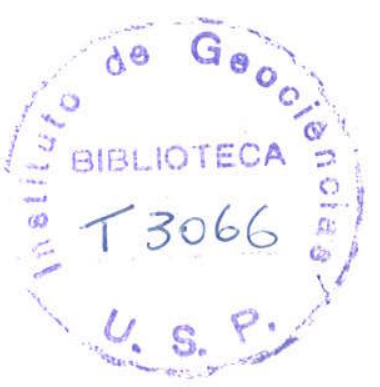

Nome

Presidente: Prof. Dr. Setembrino Petri

Examinadores: Dr. Almério Barros França

Prof. Dr. Antonio Carlos Rocha Campos

Prof. Dr. Carlos Azcuy

Prof ${ }^{\text {a. }} \mathrm{Dr}^{\mathrm{a} \cdot}$ Marleni Marques Toigo

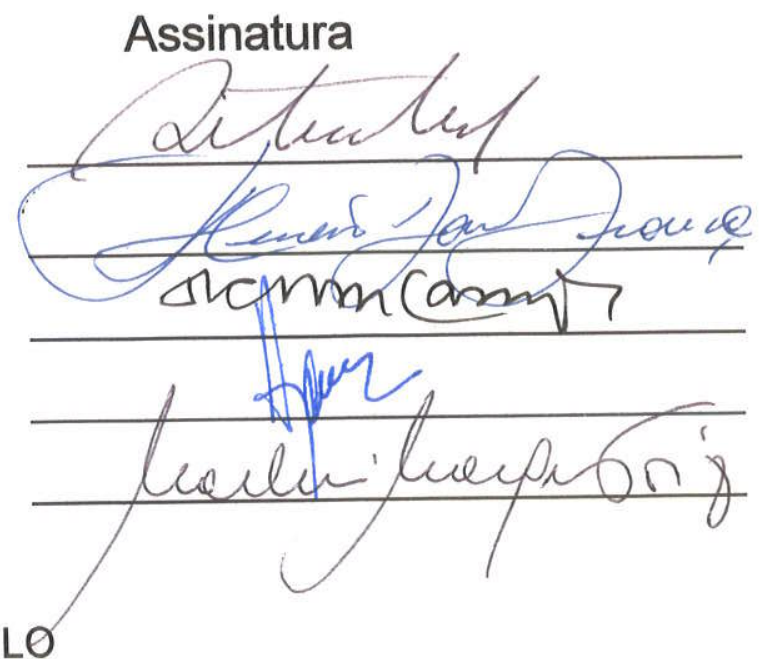

SÃO PAULO

2000 


\section{UNIVERSIDADE DE SĀO PAULO INSTITUTO DE GEOCIENCIAS}

\section{PALINOBIOESTRATIGRAFIA DO SUBGRUPO ITARARÉ, CARBONÍFERO/PERMIANO, NA PORÇĀO NORDESTE DA BACIA DO PARANÁ (SPIPR, BRASIL)}

Paulo Alves de Souza

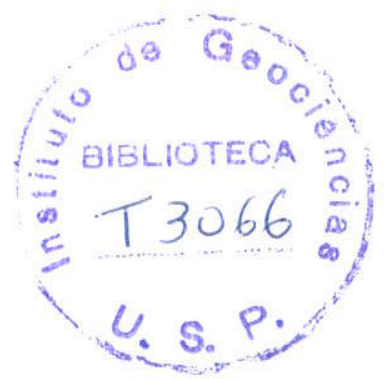

Orientador: Prof. Dr. Setembrino Petri

TESE DE DOUTORAMENTO

Programa de Pós-Graduação em Geologia Sedimentar

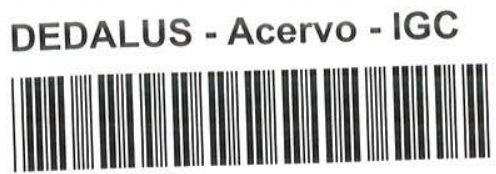

30900006305

SÃO PAULO

2000 
Em memória de Murilo Rodolfo de Lima e Roberto Ferreira Daemon, pela inestimável contribuição ao conhecimento palinológico no Brasil

A minha querida mãe, minha maior lição de amor e vida 
SOUZA, P.A. de. 2000. Palinobioestratigrafia do Subgrupo Itararé, Carbonífero/Permiano, na porção nordeste da Bacia do Paraná (SP/PR, Brasil). São Paulo, 199p., inédito (Tese de Doutoramento, Instituto de Geociências da USP).

\section{RESUMO}

O conhecimento palinológico da porção nordeste da Bacia do Paraná tem sido significativamente aprimorado nas duas últimas décadas, a partir do registro de palinomorfos inéditos e pela consideração dos esporos como elementos de valor bioestratigráfico. Dessa forma, foi possível a indicação de idades carboníferas para algumas localidades do Subgrupo Itararé, contrariando os posicionamentos geocronológicos vigentes e demonstrando a necessidade de profunda revisão e melhor compartimentação palinobioestratigráfica da unidade.

A seqüência sedimentar considerada neste estudo é referente ao Subgrupo Itararé na porção nordeste da bacia nos estados de São Paulo e Paraná, com base em amostras de afloramentos e testemunhos de sondagem de 28 poços.

Das 139 espécies de palinomorfos verificadas, 95 são descritas e ilustradas. O conteúdo palinológico é constituído por 51 espécies de esporos, 41 de grãos de pólen, duas de algas e uma de Acritarcha. Oito espécies são noticiadas pela primeira vez na Bacia do Paraná. Além disso, são verificadas 13 espécies de palinomorfos retrabalhados do Devoniano e Carbonífero Inferior.

Com base na distribuiçăo estratigráfica dos esporomorfos, é proposto um esquema bioestratigráfico formal para a seção estudada, constituído de duas zonas-de-intervalo, delimitadas pelo aparecimento e desaparecimento de táxons selecionados: Zona Biointervalo Ahrensisporites cristatus e Zona Biointervalo Potonieisporites neglectus, relativas às porções inferior e média do Subgrupo Itararé, respectivamente. Ambas apresentam características quantitativas semelhantes, com o domínio de esporos e grãos de pólen monossacados. Grãos de pólen bissacados e teniados, quando presentes, ocorrem em baixas freqüências percentuais. Onze espécies são restritas na primeira, enquanto que na segunda, somente uma é restrita.

$\mathrm{Na}$ Bacia do Paraná, as zonas propostas correspondem, em parte, a alguns intervalos palinológicos informais (Pré-G, $G, H_{1}, H_{2}$ ). No âmbito gondwânico, as melhores correlações são entre as unidades da América do Sul, especialmente algumas zonas carboníferas das bacias de Tarija, Chacoparaná e do Grupo Paganzo, com características gerais similares e espécies em comum.

As espécies de valor bioestratigráfico, as correlações realizadas e a análise do comportamento geral das associações sugerem o posicionamento das biozonas propostas no Carbonífero Tardio, relativo ao Westphaliano (Zona Biointervalo Ahrensisporites cristatus) e ao Westphaliano/Stephaniano (Zona Biointervalo Potonieisporites neglectus).

A Subzona Protohaploxypinus goraiensis, definida na base do Grupo Tubarão na porção meridional da Bacia do Paraná e com posicionamento no Permiano Inicial (Asseliano/Sakmariano), foi identificada na porção superior do Subgrupo Itararé. As associações desta Subzona são marcadas pela expressiva participação, em abundância e diversidade, de grăos de pólen teniados e poliplicados, sendo correlatas à Zona Cristatisporites inferior (Bacia Chacoparaná), na América do Sul, e Zona Pseudoreticulatispora confluens, na Austrália. 
Adicionalmente é proposta a renomeação da Zona Cannanoropollis korbaensis para Zona Vittatina e da Subzona Caheniasaccites ovatus para Subzona Caheniasaccites flavatus, mantendose suas definições originais.

As implicações dos resultados palinológicos com alguns aspectos referentes à reconstrução ambiental, à evolução geológica do Subgrupo Itararé e às relações com as demais unidades litoestratigráficas da bacia são discutidas. 
SOUZA, P.A. de. 2000. Palinobioestratigrafia do Subgrupo Itararé, Carbonífero/Permiano, na porção nordeste da Bacia do Paraná (SP/PR, Brasil). [Palynobiostratigraphy of the Itararé Subgroup, Carboniferous/Permian, in the Northeastern Paraná Basin (SP/PR, Brazil)]. São Paulo, 199p., inédito (Tese de Doutoramento, Instituto de Geociências da USP).

\section{ABSTRACT}

The Palynological knowledge of the Northeastern Paraná Basin has been meaningfully improved during the past two decades, specially from the record of unpublished palynomorphs and the introduction of spores as biostratigraphic guides. In this context, Carboniferous ages have been proposed to some localities concerning the Itararé Subgroup. This approach modifies the traditional concepts and demonstrates the need of deeper palynological revision and palynobiostratigraphical analysis to this unit in this portion.

The sedimentary sequence studied is related to the Itarare Subgroup in the Northeastern Paraná Basin, based on samples from outcrops and cores from twenty-eight boreholes, in the States of Säo Paulo and Paraná.

From the one hundred and thirty-nine species of palynomorphs recorded, ninety-five selected ones are described and illustrated. The palynological content is made up of fifty-one species of spores, forty-one of pollen grains, two of Algae and one of Acritarcha. Eight species are recorded for the first time in the Paraná Basin. Besides, thirteen species from Devonian and Lower Carboniferous Strata are also recorded

Based on the vertical and lateral distribution of the sporomorphs, two interval biozones are formally proposed: the Ahrensisporites cristatus Interval Zone and the Potonieisporites neglectus Interval Zone, concerning the lower and medium portions of Itararé Subgroup, respectively. Both zones show similar quantitative characteristics, with spores and monosaccate pollen grains dominance. When present, disaccate and taeniate pollen grains occur in low percentual rates. Eleven species are restricted to the first biozone, while only one is restricted to the second biozone.

In the Paraná Basin, the biozones correspond partially to some informal palynological intervals (Pre-G, G, $H_{1}$, and $H_{2}$ ). In the Gondwanic context, the best correlations are between palynozones of South America, specially to the Late Carboniferous ones of the Tarija and Chacoparaná basins and the Paganzo Group, which exhibit similar characteristics and common species.

The biostratigraphical important species, the correlation, and the analysis of the general characteristics of the associations suggest their positioning in the Late Carboniferous, probably related to the Westphalian (Ahrensisporites cristatus Interval Zone) and to the Westphalian/Stephanian (Potonieisporites neglectus Interval Zone) in age.

The Subzone Protohaploxypinus goraiensis, defined in the basal portion of the Tubarão Group in the Southern Paraná Basin, is identified in the upper portion of the Itarare Subgroup in the Northeastern Paraná Basin. The palynological associations of this subzone are characterised by an expressive abundance and diversity of taeniate and poliplicate pollen grains, being correlated to the lower Cristatisporites Zone (Chacoparaná Basin, in South America), and to the 
Pseudoreticulatispora confluens Zone (Australia). This subzone is related to the Early Permian (Asselian/Sakmarian).

Besides, the renaming of the Cannanoropollis korbaensis Interval Zone to Vittatina and the Caheniasaccites ovatus Subzone to Caheniasaccites flavatus is proposed, keeping their original concepts.

The palynological results and their implications with some aspects related to the environmental reconstrutions, the geological evolution of the Itararé Subgroup and its relations with the other lithostratigraphic units are also discussed. 


\section{AGRADECIMENTOS}

Ao Programa de Pós-Graduação em Geologia Sedimentar do IG/USP pela infra-estrutura e suporte técnico. À CAPES pela concessão de bolsa (1996). À FAPESP, no âmbito do Projeto Temático "Levantamento da composição e sucessão paleoflorísticas do NeocarboníferoEopermiano (Grupo Tubarão) do Estado de São Paulo" (Processo 97/03639-8), sob a coordenação das Profas. Dras. Mary E. C. Bernardes de Oliveira e Rosemarie Rohn Davies (substituta), que permitiu a realização de várias ações relacionadas ao desenvolvimento deste trabalho.

Ao Instituto Geológico/SMA pela infra-estrutura, apoio técnico e liberação de algumas das amostras de poço. À PETROBRÁS S.A. pela concessão de algumas das amostras estudadas dos poços profundos.

Ao Prof. Dr. Setembrino Petri pela orientação, transmissão de conhecimento científico e humano e constante estímulo.

À Profa. Dra. Mary E. C. Bernardes de Oliveira, que tem me acompanhado em várias etapas de minha formação profissional, pela amizade, expressiva colaboração e auxílio.

Aos Profs. Drs. Carlos L. Azcuy e Mercedes Di Pasquo pela orientação científica em Palinologia, apoio e amizade. Aos Profs. Drs. Antônio R. Saad e Maria Judite Garcia pelo apoio e estímulo constantes.

Aos Drs. Fernando Cilento Fittipaldi, Amélia João Fernandes, Percy Corrêa Vieira, Mírian Ramos Gutjahr e Eduardo Olgado pela revisão de algumas partes do texto e sugestões apresentadas. Aos Profs. Drs. Cláudio Riccomini, Thomas R. Fairchild, Paulo R. dos Santos, Antonio C. Rocha-Campos, Vicente J. Fúlfaro, José A. J. Perinotto, Mário L. Assine, Rosemarie Rohn Davies, Marlení Marques-Toigo, Roberto lannuzzi, Oscar Rösler, Almério B. França, Edson J. Milani, Luiz P. de Quadros, Rodolfo Dino, Mitsuru Arai, Luiz E. Anelli e Maria Amélia V. da Cruz Barros pelo apoio, sugestões e troca salutar de informações científicas.

Aos amigos e colegas de várias instituições pelo companheirismo e apoio em algumas das etapas de trabalho: Ricardo Esquivel, Rita P. Conde, Elizete D. Salvador, Lucí H. Nunes, Ricardo Vedovello, Renato Tavares, Geraldo H. Oda, Lídia K. Tominaga, Maria de Lourdes Gomes, Fernando Vesely, Edival Lopes, Fernando A. Pires, Carla C. Campos, Carolina Moldan, Felipe Bandeira, Leandra C. Lages, Carla V. Batezelli, Ana Paula Zampirolli, Cristina Fernandes, Osvair L. Castro, José M. de Almeida Júnior, José M. de A. Sobrinho, Márcia Longhim, Antônio L. Teixeira, Francisco Negri, Hélio Shimada, Maria Cristina Holl, Andréa Amarante, José A. Ferrari, Cláudio José Ferreira, Márcia M. Nogueira Pressinotti, César A. Munhoz e Ivone Casseb.

Ao Gilberto A. Kaulfuss e à Rosângela Carvalho pelo grande auxílio na confecção de algumas das ilustraçóes. Aos vários funcionários do IG/USP e IG/SMA pelo apoio e suporte técnico, especialmente Ana Paula Cabanal, Magalí Rizzo, Claudionor Barboza, Dalton Machado, José Alves de Andrade, Sandra Moni, Paula César Padilha e Maria A. Quadrado.

Aos meus grandes amigos Annabel Pérez Aguilar, Cláudia R. Passarelli, Luiz Fernando Lozano, Mírian C. Shinzato, Silvio T. Hiruma, Elaine L. Silva, Aristides Ravel, Norman Mascarenhas Ramos, minha irmä Solange Aives de Souza e meus pais Josefa Barbosa de Souza e Arlindo Alves de Souza. 
ÍNDICE GERAL

Resumo

Abstract

Agradecimentos

Índice Geral.

Índice das Figuras

Índice dos Quadros

índice das Tabelas

\section{CAPÍTULO I-ASPECTOS INTRODUTÓRIOS}

1 INTRODUÇÃO

2 DELIMITAÇÃO DO PROBLEMA

3 OBJETIVOS

4 ÁREA E MATERIAIS

5 MÉTODOS

\section{CAPÍTULO II-ARCABOUÇO ESTRATIGRÁFICO E PALEONTOLÓGICO}

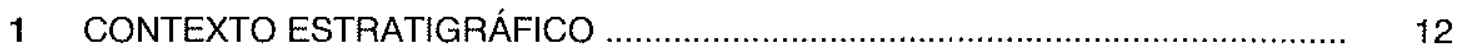

1.1 O Subgrupo Itararé na Bacia do Paraná ......................................................... 12

1.2 A Tabela do Tempo Geológico .................................................................. 18

2 O REGISTRO PALEONTOLÓGICO DO SUBGRUPO ITARARÉ …......................... 20

3 REVISÃO DA PALINOBIOESTRATIGRAFIA …................................................. 24

\section{CAPÍTULO III - PALINOLOGIA}

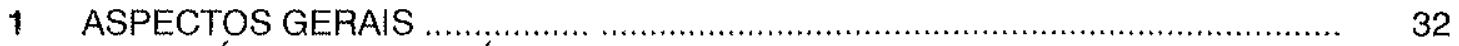

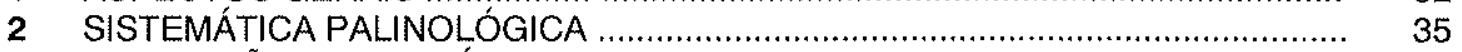

3 DESCRIÇÕES SISTEMÁTICAS ................................................................... 40

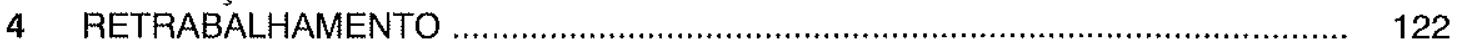

\section{CAPITULO IV - BIOESTRATIGRAFIA}

1 COMPARTIMENTAÇÃO PALINOBIOESTRATIGRÁFICA ….............................. 128

1.1 Aspectos Gerais ................................................................... 128

1.2 Biozoneamento .................................................................... 130

1.2.1 Zona Biointervalo Ahrensisporites cristatus ............................. 130

1.2.2 Zona Biointervalo Potonieisporites neglectus .............................. 135

1.2.3 Zona Biointervalo Vittatina ........................................................ 139

1.3 Distribuição Geral das Biozonas …....................................................... 143

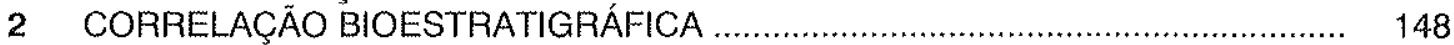

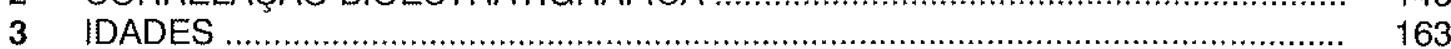

4 SIGNIFICADO PALEOAMBIENTAL DAS BIOZONAS ..................................... 165

\section{CAPITULLO V - ASPECTOS FINAIS}

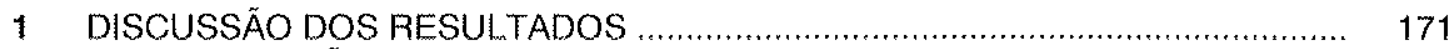

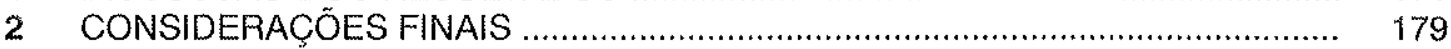

Referências Bibliográficas

Anexo 1-Listagem dos táxons, por ordem alfabética, com indicação das descriçóes e ilustrações

Estampas Fotomicrográficas

Anexo 2 - Relação dos materiais estudados e distribuição das espécies em algumas localidades 


\section{ÍNDICE DE FIGURAS}

I.1 Contexto geológico e localização dos afioramentos e poços estudados*.

II.1 Localização da Bacia do Paraná no Brasil, com a distribuição das unidades aloestratigráficas (modificado de Milani, 1997).

II.2 Coluna litoestratigráfica do Paleozóico Superior da Bacia do Paraná (modificado de Milani et al., 1994).

II.3 Posicionamento biocronoestratigráfico das várias ocorrências fossilíferas do Subgrupo Itararé (modificado de Petri \& Souza, 1993).

IV.1 Descrição geológica do poço A-IG-85 (Araçoiaba da Serra, SP), estratótipo da Zona Biointervalo Ahrensisporites cristatus e amostragem palinológica. (litoestratigrafia conforme Massoli, 1991).

IV.2 Descrição geológica e paleontológica do poço IG-01 (Itaporanga, SP), estratótipo da Zona Biointervalo Potonieisporites neglectus e amostragem palinológica (a partir de Mezzalira, 1956).

IV.3 Seção A: Compartimentação bioestratigráfica proposta para o Subgrupo Itararé dos poços estudados do centro da bacia entre os estados de São Paulo e Paraná (litoestratigrafia conforme França \& Potter, 1988).

IV.4 Seção B: Compartimentação bioesilatigráfica proposta para o Subgrupo ltararé dos poços estudados do centro da bacia do Estado de São Paulo (litoestratigrafia conforme França \& Potter, 1988).

IV.5 Seção C: Compartimentação bioestratigráfica proposta para o Subgrupo ltararé nos poços da região do Médio Tietê (SP), maiores informações sobre a litoestratigrafia na região, ver Petri et al., (1996).

IV.6 Freqüência (em percentagem) dos morfogrupos de palinomorfos em alguns níveis do poço A-lG-85 (Araçoiaba da Serra, SP), estratótipo da Zona Biointervalo Ahrensisporites cristatus.

IV.7 Freqüência (em percentagem) dos morfogrupos de palinomorfos em alguns níveis do poço IG-01 (Itaporanga, SP), estratótipo da Zona Biointervalo Potonieisporites neglectus.

IV.8 Freqüência (em percentagem) dos morfogrupos de palinomorfos em dois níveis de subsuperfície de ocorrência da Subzona Protohaploxypinus goraiensis.

V.1 Distribuição das unidades palinobioestratigráficas no Subgrupo Itararé, com correlação na porção meridional da Bacia do Paraná (em destaque os resultados deste trabalho).

V.2 Reconstrução paleogeográfica para a América do Sul entre o Carbonífero Médio (A) e limite Carbonífero/Permiano (B), conforme Conti \& Rapalini (1993). 


\section{ÍNDICE DE QUADROS}

Il.1 Divisão litoestratigráfica do Grupo Tubarão nas várias porções da Bacia do Paraná, de acordo com várias proposiçōes disponíveis na literatura.

II.2 Tabela do tempo geológico para os sistemas Carbonífero e Permiano.

II.3 Situação e correlação das propostas palinobioestratigráficas para o Paleozóico Superior da Bacia do Paraná.

III.1 Afinidades botânicas dos gêneros de esporomorfos verificados.

III.2 Sistemática das categorias supragenéticas dos táxons verificados.

IV.1 Distribuição das espécies selecionadas nas biozonas propostas do Subgrupo ttararé (este trabalho) e na Formação Rio Bonito (com base em trabalhos publicados).

IV.2 Ocorrência das espécies verificadas no Subgrupo Itararé em algumas bacias circunvizinhas gondwânicas sul-americanas.

IV.3 Correlação do palinozoneamento do Subgrupo Itararé com os principais esquemas da Bacia do Paraná e das bacias gondwânicas sul-americanas.

\section{INNDICE DE TABELAS}

IIl.1 Dimensões das espécies dos gêneros Cannanoropollis Potonié \& Sah, Plicatipollenites Lele e Crucisaccites Lele \& Maithy (ne: número de espécimes medidos; deqt: diâmetro equatorial total; cc: corpo central; r: recobrimento do saccus no corpo central; valores em . m).

III.2 Dimensões das espécies dos gêneros Potonieisporites (Bharadwaj) Bharadwaj e Divarisaccus Venkatachala \& Kar (ne: número de espécimes medidos; EL: eixo longitudinal; ET: eixo transversal; Ip: largura da prega; valores em .m).

IV.3 Dimensōes das espécies dos gêneros Scheuringipollenites Tiwari, Limitisporites (Leschik) Schaarschmidt, Protohaploxypinus (Samoilovich) Hart e Striatoabieites (Sedova) Hart (ne: número de espécimes medidos; ELT: eixo longitudinal total; ET: eixo transversal; valores em .m).

IV.4 Dimensões das espécies dos gêneros Hamiapollenites (Wilson) Tschudy \& Kosanke, Complexisporites Jizba, Vittatina (Lüber) Wilson e CostapollenitesTschudy \& Kosanke (ne: número de espécimes medidos; ELT: eixo longitudinal total; EL: eixo longitudinal; ET: eixo transversal; valores em .m). 


\section{CAPÍTULO I}

ASPECTOS INTRODUTÓRIOS 


\section{INTRODUÇÃo}

Um dos assuntos mais interessantes da geologia da Bacia do Paraná é a história deposicional do Subgrupo Itararé, cujo registro sedimentar apresenta complexa variedade de fácies e ambientes sedimentares associados, em grande parte relacionados a uma das mais marcantes fases de glaciaçāo do Fanerozóico, que afetou extensas áreas do Gondwana durante o Neopaleozóico.

Entretanto, o registro paleontológico da unidade é relativamente escasso, como resultado das rigorosas condições climáticas que, de certa forma, limitaram a distribuição dos organismos. Em decorrência disso, os zoneamentos bioestratigráficos são menos numerosos e têm maiores problemas, seja pela raridade de organismos cosmopolitas ou pela ausência de elementos de correlação com a coluna geológica padrão, além de que são poucas as datações absolutas no Paleozóico Șuperior da Bacia do Paraná.

Diante desse quadro, a Palinologia tem se destacado por tratar de elementos que são encontrados em relativa abundância no Subgrupo Itararé, ensejando a realização de vários palinobiozoneamentos. Estes esquemas, bem como as idades apontadas para os mesmos, têm sido utilizados como ponto de partida nos trabalhos de empilhamento litoestratigráfico e reconstituição da história deposicional do Subgrupo ltararé.

É a partir do norte do Estado do Paraná em direção ao norte da bacia que os depósitos das porções inferior e média dessa unidade estão melhor representados. Os trabalhos palinológicos mais recentes realizados nessas áreas têm indicado idades carboníferas para grande parte desse intervalo, diferentemente do que se supunha até então, como sintetizado em Souza (1997).

Este trabalho retoma o estudo palinológico como ferramenta principal para a melhor definição de unidades palinobioestratigráficas e datação das porções inferior e média do Subgrupo Itararé, postulando a maior representatividade de depósitos de idades carboníferas na bacia, alterando alguns dos conceitos anteriormente estabelecidos.

O zoneamento de Daemon \& Quadros (1970) ainda apresenta as bases bioestratigráficas mais concretas para o Paleozóico Superior da Bacia do Paraná, embora seja carente de atualização e modificações em virtude dos novos dados palinológicos publicados mais recentemente. Para a porção meridional da bacia o esquema de Marques-Toigo (1988, 1991) representa um avanço no estabelecimento da sucessão palinobioestratigráfica, além de ser o único definitivamente formalizado. A seção do Paleozóico Superior nos estados de São Paulo e Paraná, especialmente do Subgrupo Itararé, ainda não apresenta qualquer proposição de modificação bioestratigráfica bem fundamentada. Contudo, as associações palinológicas são ricas e passíveis de correlações, demonstrando grande potencial de resoluçăo estratigráfica. 


\section{DELIMITAÇÃO DO PROBLEMA}

Embora tenha sido realizado com intuito operacional e por isso menos atrelado à sistemática e à bioestratigrafia formais, o esquema palinobioestratigráfico proposto por Daemon \& Quadros (1970) apresenta, até o momento, as bases mais concretas para o reconhecimento de "linhas-de-tempo" do Paleozóico Superior da Bacia do Paraná.

Outros zoneamentos palinobioestratigráficos foram realizados na mesma seção, com abrangências estratigráfica e geográfica e métodos de elaboraçāo diferenciados, como detalhadamente apresentados no Capítulo II Aquele realizado por Marques-Toigo $(1988,1991)$ constitui o único zoneamento formal da bacia, atendendo às normas do Código Brasileiro de Nomenclatura Estratigráfica. As palinozonas propostas foram definidas com base em material do Permiano da Bacia do Paraná nos estados do Rio Grande do Sul e Santa Catarina, referentes, em termos litoestratigráficos, à seção desde a porção superior do Subgrupo Itararé até a Subgrupo Irati.

Os depósitos sedimentares das porções inferior e média do Subgrupo Itararé estão melhor representados na região setentrional da Bacia do Paraná, como verificado a partir do mapa de isópacas dos intervalos $\mathrm{G}$ e $\mathrm{H}$ de Daemon \& Quadros (op. cit.) ou mesmo em Daemon (1981).

Embora represente um espesso pacote sedimentar, alcançando quase um milhar de metros, muitas das questões relativas à sua reconstrução geológica e amarração estratigráfica ainda não estão resolvidas.

Em termos palinobioestratigráficos, essas porções do Subgrupo Itararé não foram adequadamente estudadas, embora o trabalho de Sundaram (1987) represente o maior esforço nesse fim para o Estado de São Paulo. As palinozonas propostas nessa seção estratigráfica são referentes aos intervalos $\mathrm{G}-\mathrm{H}_{1}$ de Daemon \& Quadros (op. cit.), Microflora 1 de Saad (1977), Fases Pré-Striatiti/Protohaploxypinus de Arai (1980), Palinozonas A e B de Sundaram (1980), intervalo Pré-G de Lima et al. (1983), Zona Potonieisporites novicus de Daemon \& Marques-Toigo (1991) ou Associação Ahrensisporites \& Ancistrospora de Souza et al. (1996), de proveniências, composiçōes e idades distintas. Entretanto, todas essas proposiçōes são carentes de formalização e de caracterização palinológica adequada.

Dentre os zoneamentos propostos para esse intervalo, o de Bharadwaj et al. (1976) e Sundaram (1980) săo baseados em número muito reduzido de amostras, enquanto que aqueles de Saad (1977) e Arai (1980) refletem muito mais as variaçōes paleoambientais do que a sucessão palinoestratigráfica, embora todos estejam, de maneira geral, bem inseridos no contexto da evolução paleoflorística do Eogondwana. As palinozonas A e B de Sundaram (1987) näo foram diferenciadas em muitos dos perfis apresentados pelo autor, o que denota dificuldades para a individualização dessas zonas. A essas limitaçōes, soma-se ainda a questão da precariedade no tratamento sistemático. Em Saad (1977), Arai (1980) e Sundaram (1980) os palinomorfos são tratados em nível genérico. 
Outro aspecto importante é que os gräos de pólen sempre foram considerados os mais importantes palinomorfos para fins do zoneamento da Bacia do Paraná, pela sua dispersão e maior distribuição areal. Entretanto, os esporos têm sido também utilizados para os mesmos fins, seja em estratos gondwânicos (e.g. Evans, 1969; Hart, 1971; Kemp et al., 1977; Azcuy \& Jelin, 1980) ou europeus (e.g. Clayton et al., 1977). Essa ausência dificulta as correlações. Por isso, Lima et al. (1983) propuseram o intervalo informal Pré-G, a partir de material de Araçoiaba da Serra (SP), com base na constatação de esporos primitivos característicos de zonas do Carbonífero Superior da Argentina e Austrália. Da mesma forma, Souza et al. (1990, 1993ab, 1997) e Souza (1996) verificaram esporos de importante valor bioestratigráfico comuns em algumas das zonas supra citadas, resultando na proposição da Associação Ahrensisporites \& Ancistrospora (Souza et al., 1996).

O intervalo G é caracterizado por um conjunto de 13 espécies de grãos de pólen incluindo monossacados (e.g. Potonieisporites spp., Plicatipollenities, Cannanoropollis) e teniados (Protohaploxypinus). A verificação somente desses grãos de pólen, posicionaria os estratos de Araçoiaba da Serra (Lima et al., 1983; Souza, 1996), Buri (Souza et al., 1993a) e Monte Mor (Souza et al., 1993b, 1997) nesse intervalo. As espécies ocorrentes no intervalo $G$ são longevas e ocorrem, inclusive, em estratos permianos. Somente pelo exame completo dos conjuntos palinológicos, considerando-se também os esporos, pôde-se inserir modificações no esquema.

A questão das idades apontadas para os intervalos ou zonas bioestratigráficas é um outro aspecto de grande relevância no contexto estratigráfico da Bacia do Paraná. Infelizmente, faltam elementos de maior precisão e melhor amarração com a coluna geocronológica padrão, como também ocorre na maior parte das áreas gondwânicas, o que tem impedido melhores correlações e determinações de idades.

Até pouco tempo atrás, as idades apontadas para os intervalos do zoneamento de Daemon \& Quadros (1970) vinham sendo aceitas como originalmente propostas. Em decorrência disso, vários eventos geológicos foram reconstruídos com posicionamento temporal duvidoso. Baseado nessas idades, Eyles (1993) reconstruiu um quandro sobre a glaciação do Neopaleozóico gondwânico, no qual os registros da Bacia do Paraná foram posicionados mais tardiamente, entre o Stephaniano $\mathrm{C}$ e o Kunguriano; enquanto isso, em estratos circunvizinhos, da Argentina, Bolívia e Paraguai, o evento glacial teria se iniciado antes (e.g. no Namuriano da Argentina, conforme González, 1996) e não teria ultrapassado o Carbonífero.

Note-se também que a unidade litoestratigráfica correspondente ao Subgrupo Irati na Bacia do Karroo, Formação Whitehill, tem idade situada no Artinskiano, com base em tetrápodes e crustáceos (Anderson, 1977), enquanto que na Bacia do Paraná corresponderia ao Kazaniano, conforme propuseram Daemon \& Quadros (op. cit.), constituindo em uma grande controvérsia, desde que ambas unidades possuem conteúdo paleontológico muito 
similar. Além disso, uma idade kazaniana para o Subgrupo Irati implicaria que a deposição das unidades suprajacentes do Grupo Passa Dois teria se processado no "que restou" do Permiano, resultando em altas taxas de sedimentação (Cunha \& França, 1993), ou teria se estendido até o Triássico.

Segundo Araújo-Barberena (1989), os répteis fósseis da Formaçāo Rio do Rasto no Rio Grande do Sul demonstram afinidades com gêneros similares das zonas Cistecephalus e Deptocephalus, do topo do Permiano da África do Sul.

Uma das amarrações cronoestratigráficas do esquema de Daemon \& Quadros (1970) foi a delimitação do aparecimento do gênero Vittatina somente a partir dos estratos artinskianos europeus, o que os levou a posicionar a base do intervalo $\mathrm{H}_{3}$ no Artinskiano. Há vários trabalhos que apontam o aparecimento do gênero a partir do Stephaniano, tanto para estratos euroamericanos (ver síntese em Owens, 1996), quanto para gondwânicos (e.g. Vergel, 1993).

Apesar desses problemas e face às dificuldades de datações absolutas para os estratos neopaleozóicos gondwânicos, a bioestratigrafia se constitui em uma das principais ferramentas de trabalho nas correlações e datações de camadas, embora muitos cuidados devam ser tomados.

De acordo com Wagner (1993), a extrema diferenciação climática observada entre áreas de diferentes paleolatitudes dificulta o estabelecimento da compartimentação do Carbonífero Superior, com base, exclusivamente, na bioestratigrafia. Rohn \& Rösler (1987) e Sundaram (1987) já haviam chamado a atenção para o risco de se estabelecer correlaçōes de associações fitofossiliferas que poderiam refletir as similaridades de paleoclimas em diferentes regiões, de idades distintas. Segundo Wagner (1993), o ideal é se aliar as evidências das mudanças climáticas com a cronoestratigrafia regional baseada em critérios físicos (ciclotemas, transgressões eustáticas) e, em parte, em biozoneamentos. Para o Gondwana, limites com expressão bioestratigráfica poderiam ser reconhecidos, relacionados ao evento de aquecimento, de nível global, ocorrido a partir do Stephaniano.

Como síntese, são apresentados os seguintes aspectos problemáticos da palinobioestratigrafia da porçāo nordeste da Bacia do Paraná:

- ausência de bons elementos marcadores, de correlações mais amplas e de amarração com a coluna geológica padrão;

- Palinologia com tratamento sistemático precário na maioria dos zoneamentos;

-os principais zoneamentos palinológicos são baseados somente em grupos de grăos de pólen;

-posicionamento geocronológico dos intervalos bioestratigráficos inadequado;

- proliferação de proposiçöes informais de intervalos bioestratigráficos, sem caracterização palinológica satisfatória;

- necessidade da formalizaçäo dos intervalos palinológicos: 


\section{OBJETIVOS}

A principal idéia que suscita o desenvolvimento deste trabalho é a da maior representação de sedimentos carboníferos na Bacia do Paraná. As raras ocorrências datadas como carboníferas carecem de melhor caracterização palinológica e definição bioestratigráfica.

Dessa forma, considerando os argumentos já expostos e o status quo da palinobioestratigrafia da Bacia do Paraná, especialmente para as seções inferior e média do Subgrupo Itararé, os principais objetivos deste trabalho são:

- Reconhecimento de novas localidades palinofossiliferas no Subgrupo Itararé, a partir de coleta sistemática de amostras, em superfície e subsuperfície;

-Caracterização palinológica das associações das novas localidades;

- Reestudo e reavaliação taxonômica das informações palinológicas já publicadas no tema: consiste em novas coletas para análise e reanálise das lâminas de material já divulgado, para melhor caracterização e posicionamento taxonômico;

-Descrição sistemática e de forma completa dos táxons selecionados, com documentação fotográfica;

-Apresentar um esquema palinobioestratigráfico formal válido para a seção carbonífera da Bacia do Paraná;

- Fornecer subsídios para a melhor determinação da história geológica do Subgrupo Itararé na região nordeste da Bacia do Paraná, com destaque especial aos seus intervalos inferior e médio. 


\section{4. ÁREA E MATERIAIS}

A área escolhida para estudo localiza-se na região nordeste da Bacia do Paraná, no intervalo correspondente ao Subgrupo Itararé nos Estados de São Paulo e norte do Estado do Paraná. Conforme já citado anteriormente, é nessa área que os mapas de isópacas dos intervalos G e H de Daemon \& Quadros (1970) apresentam maiores espessuras, bem como alguns trabalhos mais localizados na borda aflorante têm noticiado assembléias palinológicas de idades carboníferas (Lima et al., 1983; Souza et al., 1990, 1993ab, 1997; Daemon \& França, 1993; Souza, 1996).

$O$ estudo se baseia em amostras de superfície e de subsuperfície (testemunhos de sondagem). A distribuição dos poços estudados pode ser verificada através da Figura 1.1, enquanto que as principais informações dos poços estudados (nome, localização geográfica) estão apresentadas no Quadro 2.1 do Anexo $2^{*}$. Os testemunhos de sondagem dos poços selecionados para estudo foram aqueles disponibilizados pelas instituições realizadoras das perfurações, quais sejam: Petrobrás S.A. (que também detém os testemunhos perfurados pela extinta Paulipetro), Instituto Geológico/SMA (IG/SMA) e CESP/IPT. Contudo, nem todos os intervalos solicitados foram cedidos, em virtude de limitações impostas pelas instituições.

É importante salientar que, inicialmente, alguns dos níveis em subsuperfície dos subgrupos Guatá e Irati (poços 2-PN-1-SP, 1-CP-1-SP, 2-GU-3-SP, 2-TB-1-SP, 2-LA-1-SP, 2PP-1-SP, 1-PA-1-SP, 1-SJ-1-PR e 2-JT-1-PR) foram alvos de estudo deste trabalho, tendo sido estudados preliminarmente. Entretanto, seguindo orientação da banca examinadora no exame de qualificação, procurou-se dar ênfase somente à seçāo carbonífera do Subgrupo Itararé. De certa forma, o exame palinológico prévio até então realizado auxiliou na análise bioestratigráfica conseguinte.

Em relação ao material de superfície, os afloramentos selecionados no Estado de São Paulo são: níveis de carvão e litologias associadas em Buri; Monte Mor e Itapeva; ritmitos das pedreiras de Itu e Jundiaí; diamictito da Serra dos Paes; níveis pelíticos aflorantes na seção Araçoiaba da Serra-Itapetininga (SP-270) e em Capivari. No Estado do Paraná, foram estudadas as seçōes aflorantes nas rodovias BR-153 (Ventania-lbaiti); PR-090 (VentaniaCuriúva); PR-272 (Pinhalão-Tomazina). Na Figura 1.1 pode-se visualizar a distribuição dessas localidades na área aflorante do Subgrupo Itararé, enquanto que no Quadro 2.2 do Anexo $2^{*}$ estão apresentadas as principais informaçōes referentes à localização desses afloramentos.

Algumas das amostras estão sendo estudadas com outros pesquisadores relacionados ao Projeto Temático FAPESP ao qual esta Tese está vinculada (novas coletas de Cerquilho, Araçoiaba da Serra, Rod. dos Bandeirantes, Sorocaba,Seçäo Itu-Salto e Itapeva). Dessa forma, seus resultados não säo apresentados mais detalhadamente.

\footnotetext{
algumas amostras de pogos (2-GU-3-SP, 2-GU-4-SP. 1-PA-1-SP, 1-LA-1-SP a 1-QT-1-PR) e afforamentos (Césari Latnge, $\mathrm{SP}^{3}$ e seçäo Ventania Curiúva, $\mathrm{PR}$ ) năo foram incluidas no estudo face à baixa representatividade palinológica.
} 


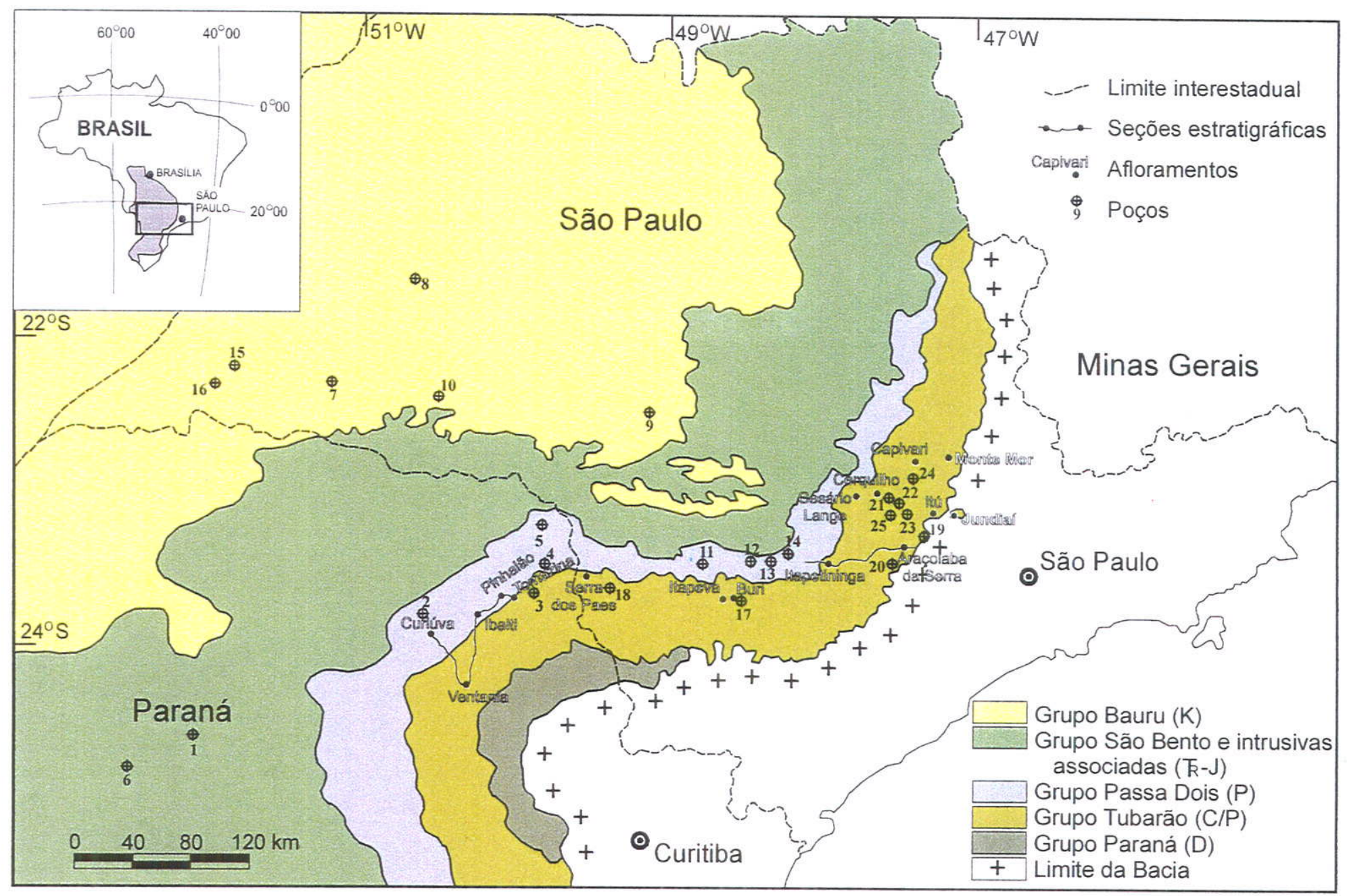

Figura I.1 - Contexto geológico e localização dos afloramentos e poços estudados*.

${ }^{*}$ Poços 1: 1-RO-1-PR, 2: 1-SJ-1-PR, 3: 1-QT-1-PR, 4: 2-JT-1-PR, 5: 2-J-1-PR, 6: 2-CS-1-PR, 7: 2-TB-1-SP, 8: 2-LA-1-SP, 9: 1-PA-1-SP, 10: 2-PP-1-SP 11: 2-PN-1-SP, 12: 1-CP-1-SP, 13: 2-GU-4-SP, 14: 1-GU-3-SP, 15: 2-CB-1-SP, 16: 3-CB-3-SP, 17: BI-8-SP, 18: IG-01 (Itaporanga), 19: IT-IG-85, 20: AIG-85, 21: J-IG-93, 22: T-IG-93, 23: T1-IG-91, 24: C-IG-93, 25: poços da região de Cerquilho (SR-09, SR-14, SR-23 e SR-25. 


\section{MÉTODOS}

\section{Análise bibliográfica}

O exame da literatura disponível sobre os aspectos mais importantes da estratigrafia do Subgrupo Itararé e de seu conteúdo palentológico constituiu a etapa inicial da pesquisa, inclusive orientando a escolha dos materiais. De igual forma, foi necessário buscar apoio adicional da literatura sobre o conhecimento da palinologia e dos principais eventos geológicos relacionados às unidades gondwânicas circunvizinhas do Paleozóico Superior, principalmente aquelas que comportam sucessões semelhantes. Cabe ressaltar que a análise da literatura especializada constitui tarefa que transcorreu paralelamente durante o desenvolvimento das itens subseqüentes, quais sejam a sistemática palinológica, bioestratigrafia e discussão dos ressultados.

\section{Seleção da área}

A seleção da área para a constatação das assembléias palinológicas carboníferas na Bacia do Paraná foi orientada a partir da verificação de trabalhos preliminares. Dentre esses, destaca-se o de Daemon \& Quadros (1970) que aponta as maiores espessuras dos intervalos $\mathrm{G}$ e $\mathrm{H}$ na região setentrional (nordeste e noroeste) da bacia. Adicionalmente, Lima et al. (1983), Sundaram (1980, 1987), Souza et al. (1990, 1993ab, 1997), Daemon \& França (1993) e Souza (1996) forneceram as mesmas indicações para os estados de Sāo Paulo e Paraná.

Com relação à amostragem de superfície, procurou-se reestudar os principais afloramentos palinofossilíferos conhecidos do Subgrupo Itararé no Estado de São Paulo. Adicionalmente, foram incluídos outros afloramentos, face a verificação de seu potencial palinológico e bioestratigráfico.

\section{Coleta de materiais}

A coleta do material de subsuperfície ocorreu em várias etapas junto às instituições responsáveis e detentoras dos testemunhos. Alguns dos materiais cedidos diretamente por pesquisadores relacionados às mesmas, como aqueles do poço A-IG-85 e da CESP/IPT, cedidos pelos Profs. Drs. Setembrino Petri (IG/SMA), Antônio Roberto Saad (então IPT/UNESP Rio Claro) e José A. de J. Perinotto (UNESP Rio Claro). Grande parte das amostras foi coletada junto à litoteca do NEXPAR/PETROBRÁS, em duas etapas de visitaçāo no ano de 1996. O material adicional advindo do IG/SMA foi coletado durante a perfuração e/ou selecionado de perfuraçöes mais antigas disponíveis em sua litoteca.

O material de superfície foi coletado em várias etapas de trabaiho, envolvendo formas e equipes distintas. Em alguns setores, como aqueles entre Araçoiaba da Serra-Itapetininga 
(SP) e Ventania-lbaiti (PR), foi possível coletar sistematicamente as amostras, enquanto que em outras localidades, obteve-se amostras pontuais de afloramentos.

\section{Registro e processamento das amostras}

Inicialmente, todas as amostras foram devidamente registradas na Palinoteca do IG/SMA, recebendo numeraçāo contínua, após a codificação "IG.P". Para materiais com mais de uma lâmina, utilizou-se seqüenciamento alfabético (IG-P: 293A, 293B....). Todas esas lâminas são referenciadas nos quadros do Anexo 2. O estudo incluiu ainda lâminas depositadas na coleção científica do Instituto de Geociências da USP, sob codificação GP/4E e GP/4T.

Adicionalmente, parte de cada amostra foi arquivada para eventuais reprocessamentos e análise.

O material selecionado para processamento, sob mesma numeração, foi tratado no Laboratório de Sedimentologia do IG/SMA, excetuando-se algumas unidades coletadas pelo Prof. Dr. Antônio Roberto Saad, processadas no Laboratório de Geociências da Universidade Guarulhos.

O tratamento empregado para separação do resíduo palinológico é aquele habitual para amostras pré-mesozóicas, conforme detalhadamente apresentado por Quadros \& Melo (1987), embora tenham sido aplicadas pequenas modificaçōes, em função da natureza das amostras e características laboratoriais.

Inicialmente, cada amostra foi triturada em almofariz, de modo a concentrar uma fração granulométrica entre, aproximadamente, $1-5 \mathrm{~mm}$. As amostras carbonáticas foram submetidas a $\mathrm{HCl}$ à frio, até dissolução completa dos minerais e substâncias carbonáticas. Em seguida, empregoumse HF até dissolução completa dos minerais silicáticos, com até $48 \mathrm{~h}$ de reação. Logo após, as mesmas foram submetidas a $\mathrm{HCl}$ à quente (até $60^{\circ} \mathrm{C}$ ), objetivando-se a dissolução dos fluorsilicatos e sílica-gel neoformados. Após completa dissolução dos componentes inorgânicos, cada resíduo foi preliminarmente observado em microscópio óptico, para verificação do estado da matéria orgânica. Aqueles julgados passíveis de clareamento, foram submetidos à $\mathrm{HNO}_{3}$, até ligeira oxidação, por teste visual. A separação dos reagentes ácidos em cada uma das etapas apresentadas foi realizada com água destilada a partir de lavagens por decantação.

A separação da fração para estudo foi feita por peneiramento em malhas de 0,025 $0,250 \mathrm{~mm}$, de modo a concentrar o resíduo palinológico entre essas duas fraçōes, sendo então acondicionado em cápsulas plásticas em meio aquoso.

As lâminas foram montadas a partir da homogeneização do resíduo, coleta de pequena fração e uniformizaçāo em lamínulas de vidro, com uso de goma sintética Cellosizze (produto e marca da Union Carbide do Brasil). As lamínulas foram aderidas nas làminas, utilizando-se 
cola sintética Entellan (Merck). Dispôs se de um total de 458 lâminas para estudo, 156 referentes a afloramentos e as demais a níveis de subsuperfície.

\section{Estudo e análise palinológica}

A leitura das lâminas foi realizada no microscópio Zeiss-Jenaval do IG/SMA, com aumentos de 100 até $1000 x$. Inicialmente, cada lâmina foi totalmente "varrida", com o registro de seu conteúdo palinológico em fichas. Formas facilmente reconhecidas já eram fichadas com a respectiva designação taxonômica, enquanto que as desconhecidas e/ou com feições mais complexas foram agrupadas de acordo com os caracteres morfológicos básicos, para análise posterior.

Após a leitura de todas as lâminas, procedeu-se a análise sistemática, reunindo-se todas as formas semelhantes, com classificação, na grande maioria, em nível específico. Essa etapa foi a mais demorada e, provavelmente, a mais importante do ponto de vista palinológico, pois consistiu na observação das características morfológicas básicas, medições, descrições e comparação com o material publicado na literatura, incluindo ainda algumas comparações com material-tipo.

Aproximadamente 2300 espécimes de palinomorfos in situ foram sistematicamente estudados. Além disso, foi detectada a presença de 97 espécimes de esporos, acritarcas e incertae sedis retrabalhados, alguns dos quais, apresentados em item especial nesta Tese.

Constam nas descriçōes sistemáticas somente aqueles táxons ocorrentes em, pelo menos, duas localidades. O número total de táxons in situ identificados é de 139, enquanto que somente 95 foram selecionados e sistematicamente descritos. Alguns dentre aqueles não selecionados são de grande valor bioestratigráfico e inéditos para a Bacia do Paraná e serão posteriormente apresentados em separado por localidade.

Para cada táxon identificado, foi confeccionada uma ficha, onde estão registradas as informações básicas dos espécimes representativos: proveniência, lâmina, coordenada England Finder ${ }^{*}$, medidas de seus principais parâmetros, descriçāo detalhada e anotaçōes diversas (comparaçōes, observações, seleção para documentação fotomicrográfica etc.), conforme descrições apresentadas no Capítulo III.

Nas descrições, são apresentadas as informações morfológicas básicas, de modo a atender à diagnose de cada táxon. As comparações apresentadas são aquelas com as formas mais similares, da Bacia do Paraná e de outras regiões do mundo. Quando necessárias, são feitas observaçōes para determinados táxons. A distribuição estratigráfica na Bacia do Paraná é com base na sinonímia. Adicionalmente, procurou-se obter o máximo de informação da distribuição dos táxons em outras regiōes, assim mencionada em distribuição estratigráfica mundial. A lista de sinonímia é para a Bacia do Paraná. Notar que todos os táxons descritos e

lâmina de vidro codificada com coordenadas para localização e registro dos espécimes. 
ilustrados nos trabalhos originais foram consultados; menções de táxons em resumos, abstracts, sem descrição e/ou documentação fotomicrográfica, não foram consideradas.

Também constituiu importante etapa o reestudo de materiais já publicados a partir da leitura das lâminas originais disponíveis, depositadas em coleções científicas, tais como, o material de Araçoiaba da Serra (Lima et al., 1983; Souza, 1996) ,Buri (Souza et al., 1990, 1993a) e Monte Mor (Souza et al., 1993b, 1997). Nesses casos, as lâminas depositadas foram reestudadas na tentativa da melhor análise taxonômica e registro de outras espécies. Além disso, quando se dispôs dos resíduos palinológicos, foram confeccionadas novas lâminas, com os mesmos objetivos. Essas novas lâminas foram depositadas na Palinoteca do IG/SMA. Os métodos de leitura e análise foram os mesmos descritos no item anterior.

\section{Estudo e análise bioestratigráfica}

$\mathrm{Na}$ confecção do zoneamento proposto foram observados alguns critérios para sua validação formal conforme instrui o Código e Guia Brasileiro de Nomenclatura Estratigráfica. A partir da identificação do biócrono de cada espécie no intervalo estudado, foram escolhidas, para caracterização do zoneamento, aquelas com ocorrência em, pelo menos, duas localidades separadas geograficamente, de fácil reconhecimento e determinação taxonômica e de valor estratigráfico. Maiores esclarecimentos sobre a análise bioestratigráfica são apresentados no Capítulo IV.

\section{Análise quantitativa}

Para a indicação dos grupos característicos das biozonas e nas discussōes de ordem paleoambiental, alguns importantes níveis foram selecionados, quais sejam: do poço A-lG-85, IG-01 (Itaporanga), os quais constituem os estratótipos das duas zonas propostas para as seções inferior e média do Subgrupo Itararé, respectivamente; dos poços 2-PN-1-SP e 2-TB-1$\mathrm{SP}$, onde ocorre a Subzona Protohaploxypinus goraiensis, reconhecida no terço superior da unidade.

Em cada nível foram contados, no mínimo, 200 espécimes de palinomorfos, cuja quantificação é apresentada na forma de histogramas que mostram as relações percentuais dos diversos "morfogrupos" presentes.

\section{Documentação fotomicrográfica}

As fotomicrografias foram realizadas no Microcópio Axiophot 2 (Zeiss) do Instituto de Geociências da USP (Laboratório de Óptica do Departamento de Geologia Sedimentar e Ambiental), em aumentos entre 300-1150 vezes, em filmes coloridos Kodak Prolmage Asa 100. Para realçar a morfologia, utilizou se contraste de interferência "DIC". Os espécimes selecionados para ilustraçäo säo aqueles que melhor representam as relativas espécies. 
CAPÍTULO II

ARCABOUÇO ESTRATIGRÁFICO E PALEONTOLÓGICO 


\section{CONTEXTO ESTRATIGRÁFICO}

\subsection{O SUBGRUPO ITARARÉ NA BACIA DO PARANÁ}

A Bacia do Paraná é uma ampla sinéclise situada em sua maior parte na porção centro-meridional da América do Sul, cuja área ultrapassa $1.400 .000 \mathrm{Km} 2$, a maior parte em território brasileiro, incluindo ainda áreas expostas no Uruguai e na Bolívia, além de estratos correlatos em subsuperfície na adjacente Bacia Chacoparaná.

A bacia tem formato geral alongado na direção NNE-SSW, com aproximadamente $1750 \mathrm{Km}$ de comprimento e largura média de $900 \mathrm{Km}$. Além da cobertura sedimentar, apresenta derrames e instrusões de rochas magmáticas básicas. Os valores máximos de espessura total dos sedimentos e rochas magmáticas chegam a ultrapassar 6000m (Zalán et al., 1990).

Segundo Milani (1997), seis unidades estratigráficas, de ampla escala, representam o preenchimento sedimentar-magmático desta sinéclise, desenvolvida entre o Ordoviciano e o Mesozóico sobre crosta continental estabilizada pelos processos geotectônicos ligados ao Ciclo Brasiliano. Os eventos geológicos que se desenvolveram, incluindo deposição, erosão e não-deposição, são resultados de processos tectono-sedimentares complexos que se alternaram no tempo e no espaço, motivo pelo qual Zalán et al. (1990) fazem referência a diversas "bacias do Paraná", em virtude de apresentar várias configuraçōes durante o Fanerozóico.

O registro sedimentar da bacia não é contínuo e compreende um conjunto de superseqüências referentes a uma "sucessão de unidades de ordem II distribuídas de modo descontínuo entre os 450 M.a. e os 65 M.a." (Milani, 1997, p. 68). O reconhecimento pioneiro do arcabouço aloestratigráfico na Bacia do Paraná é devido a Fúlfaro \& Landim (1976), que se referem às Seqüências I a VI, com modificações em Soares et al. (1977). As subdivisões propostas posteriormente foram congnominadas em alusão à tabela do tempo geológico (e.g. Zalán et al., 1990). Mais recentemente, Milani (1997) se referiu aos seis intervalos como constituídos por pacotes rochosos que materializam intervalos temporais, delimitados por superfícies de discordância de caráter inter-regional, assim denominados: Superseqüências Rio Ivaí (Caradociano-Landoveriano), Paraná (Lockoviano-Frasniano), Gondwana I (Westphaliano-Scythiano), Gondwana II (Neoanisiano-Eonoriano), Gondwana III (Neojurássico* Berriasiano) e Bauru (Aptiano-Maastrichtiano).

A Superseqüência Gondwana | constitui um grande ciclo transgressivo-regressivo e é referente, em termos da nomenclatura litoestratigráfica, aos grupos Tubaräo e Passa Dois (ver Figura II.1). A coluna estratigráfica do Paleozóico Superior da Bacia do Paraná apresentada na Figura 11.2 sintetiza o empilhamento das unidades que compōem o grande ciclo transgressivoregressivo, relativas à Superseqüência Gondwana I. Sua construção é baseada, principalmente, em Milani et al. (1994), com algumas modificaçōes posteriores incorporadas 
(e.g. Hachiro, 1996). Vale ressaltar que procurou-se manter os termos geocronológicos originais da coluna, cuja estrutura geral difere daquela utilizada neste trabalho. Para a bioestratigrafia, utilizou-se o único palinobiozoneamento formalizado para a bacia (Marques. Toigo, 1988, 1991); as seções inferior e média do Grupo Tubarão são relativas aos intervalos informais $\mathrm{G}-\mathrm{H}_{1}$ (Daemon \& Quadros, 1970), Pré-G (Lima et al., 1983) ou Associação Ahrensisporites \& Ancistrospora (Souza et al., 1996).

O Grupo Tubarão constitui a base do registro neopaleozóico da Bacia do Paraná, com espesso pacote sedimentar. Sua subvidisão estratigráfica ainda é carente de estudos mais detalhados, pela existência de temas controversos, como a idade e a correlação da Formação Aquidauana com o restante do Grupo Tubarão e da existência e abrangência da Formação Tietê (Fúlfaro et al., 1991) no Estado de São Paulo, entre o Subgrupo Itararé e a Formaçāo Tatuí.

Segundo Petri (1964), a primeira referência a rochas que hoje constituem o Grupo Tubarão deve-se a Andrada \& Silva (1827 apud Petri, 1964), que cita um "grês" esbranquiçado entre Itu e Piracicaba na publicação "Voyage mineralogique dans la Province de Saint Paul au Brésil". Nos meados do século XIX, vários trabalhos exploratórios são desenvolvidos, principalmente em atenção ao potencial carbonífero, suscitando as primeiras descobertas fossilíferas.

Entretanto, o primeiro agrupamento estratigráfico do conjunto de estratos que compõem a Bacia do Paraná, incluindo o Grupo Tubarão, é devido a White (1908), que a denominou de "Sistema de Santa Catarina", constituído pelas séries "Tubarão", "Passa Dois" e "São Bento". Este arranjo geral tem se mantido até hoje, embora inúmeras modificações de nomenclatura e de detalhamento tenham sido incorporadas, em níveis local ou regional.

Em Rocha-Campos (1967) é apresentado o quadro histórico das várias proposições de nomenclatura do Grupo Tubarão, que variaram em função das diferentes áreas da bacia, resultado dos diversos processos sedimentares e tectônicos que atuaram durante a sua deposição.

Foi somente a partir do trabalho de Northfleet et al. (1969) e Schneider et al. (1974) que foi aperfeiçoado o conhecimento do preenchimento da "Superseqüência Gondwana I" (sensu Milani, 1997), em decorrência da maior abrangência geográfica dos estudos e apoio em dados de subsuperfície, com a proposição de colunas estratigráficas mais regionalizadas.

De acordo com Petri (1964), o pacote rochoso "Itararé" com influência glacial, base do Grupo Tubarão, deve ser tratado na categoria de Subgrupo. As unidades superiores, pósglaciais, seriam relativas ao Subgrupo Guatá: com a Formaçäo Rio Bonito na base e Palermo no topo, ambas tendo como correspondente na porção nordeste da bacia, a partir do Estado de São Paulo, a Formação Tatuí. 


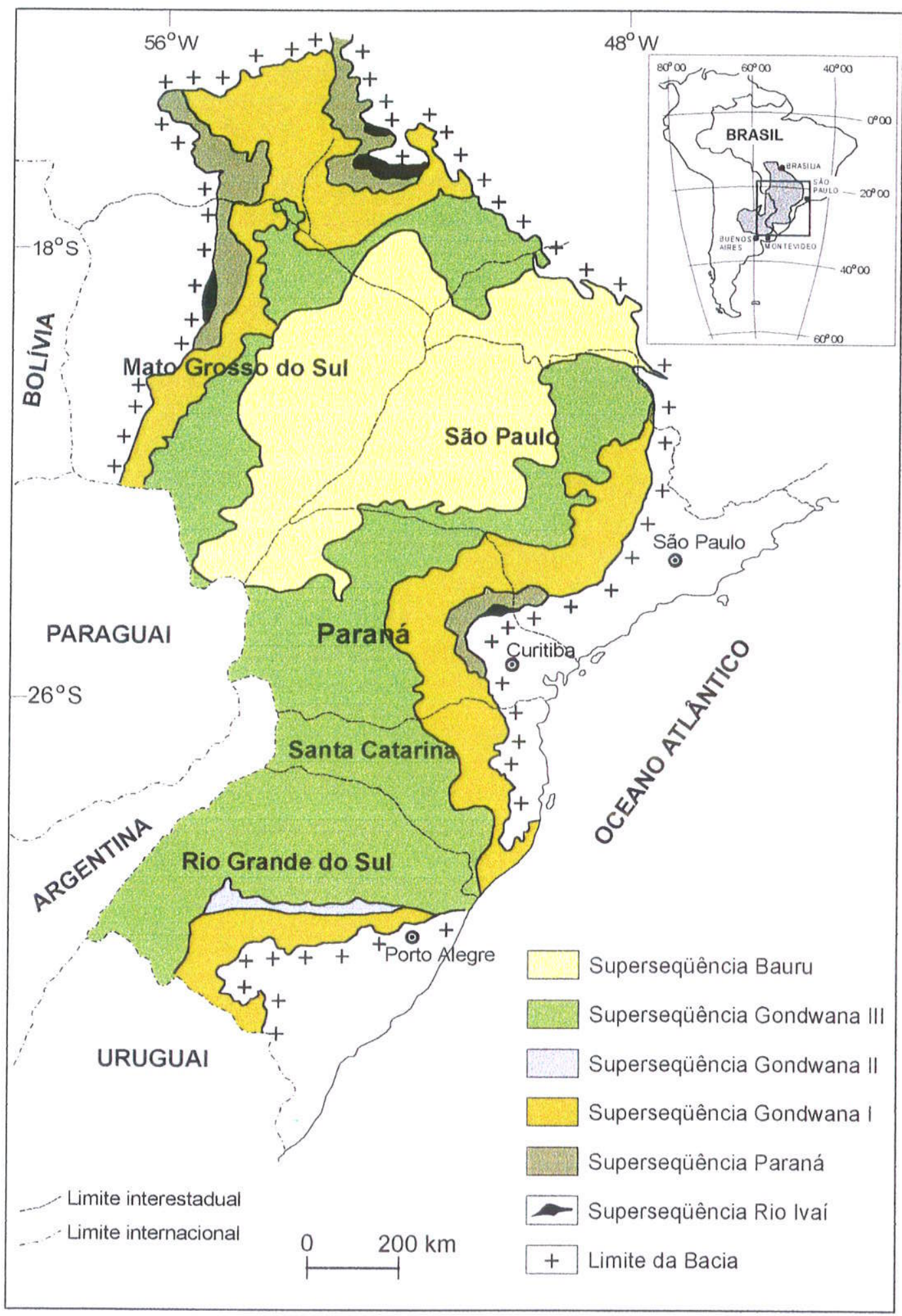

Figura II.1 - Localizaçāo da Bacia do Paraná no Brasil, com a distribuição das unidades aloestratigráficas (modificado de Milani, 1997). 


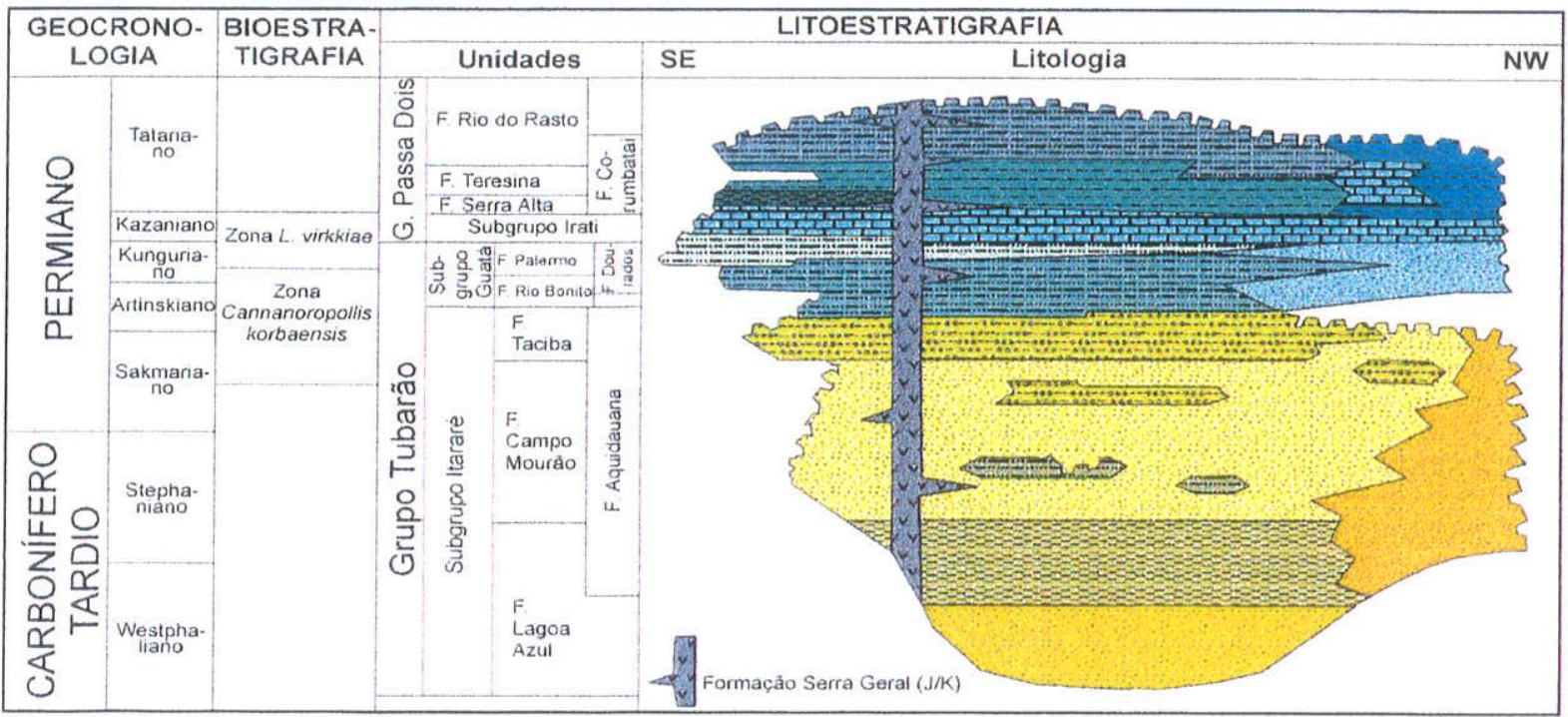

Figura II.2 - Coluna litoestratigráfica do Paleozóico Superior da Bacia do Paraná (modificado de Milani et al., 1994).

O conjunto sedimentar arenoso avermelhado da borda oeste da bacia e mesmo aqueles aflorantes a partir do nordeste do Estado de São Paulo, é tratado como Formação Aquidauana, como apresentado por Milani et al. (1994), com correlação estratigráfica com o Subgrupo Itararé na porção nordeste da bacia, embora a primeira ainda seja carente de datações e dados bioestratigráficos mais precisos.

Segundo Milani et al. (1994), na porção centro-oeste da bacia ocorre um pacote predominantemente arenoso, fino a muito fino, cronocorrelato às formações Rio Bonito e Palermo, denominado de Formação Dourados. A unidade assenta-se discordantemente sobre a Formação Aquidauana e passa gradativamente para a Subgrupo Irati (Hachiro, 1996).

Com relação ao Estado de São Paulo, foi a partir dos trabalhos de Saad (1977), Soares et al. (1977) e Santos (1979) que foram iniciadas análises mais pormenorizadas de suas fácies e sistemas deposicionais, com ensaios de correlaçōes estratigráficas e tentativas de reconstituições paleogeográficas.

Sem se preocuparem com designações estratigráficas formais para os níveis estudados, vários autores passaram a reconhecer conjuntos litoestratigráficos ou associações faciológicas, denominadas com símbolos alfa-numéricos (e.g. Caetano-Chang, 1984; Souza Filho, 1986). Posteriormente, novas subdivisỏes formais foram propostas para a seqüência, seja para a bacia como um todo (França \& Potter, 1988) ou mais localmente (Stevaux et al., 1987). 
Cabe aqui destacar a proposição de França \& Potter (1988) por constituir a última e mais abrangente proposta de subdivisão da unidade, fundamentada em amostragem de subsuperfície ao longo da bacia. O intervalo relativo ao Subgrupo Itararé foi dividido em três unidades, a basal Formação Lagoa Azul (Membros Cuiabá Paulista e Tarabai), a intermediária Formação Campo Mourão e a superior Formação Taciba (Membros Rio Segredo, Chapéu do Sol e Rio do Sul). Essas três unidades corresponderiam a três grandes ciclos deposicionais, associados a três lobos de geleiras que teriam penetrado na Bacia do Paraná durante o Neopaleozóico.

Entretanto, verifica-se extrema dificuldade de reconhecimento dessas unidades na faixa aflorante do Subgrupo Itararé, uma vez que as litofácies são recorrentes e que há carência de camadas-guia e controle bioestratigráfico.

O Quadro II.1 ilustra as diferentes unidades litoestratigráficas que compõem o Grupo Tubarão, variando conforme a região da bacia, de acordo com várias propostas (Petri, 1964; França \& Potter, 1988; Fúlfaro et al., 1991; Milani et al., 1994).

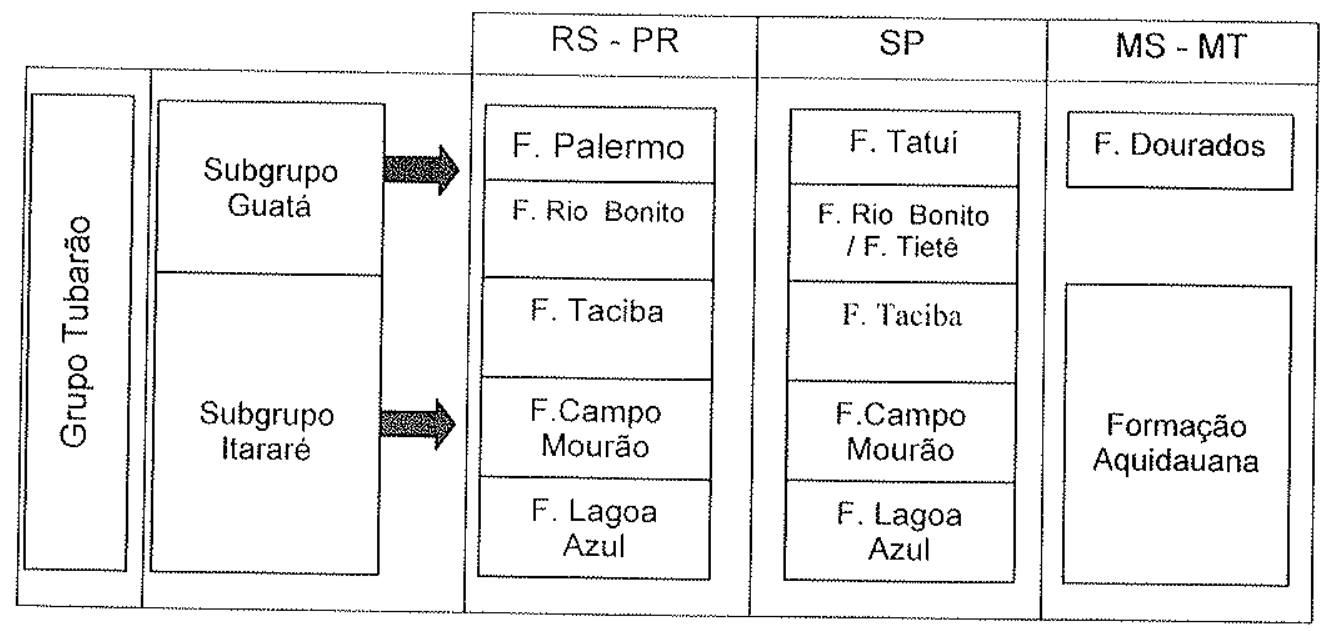

Quadro II.1 - Divisão litoestratigráfica do Grupo Tubarão nas várias porções da Bacia do Paraná, de acordo com várias proposições disponiveis na literatura.

Foi somente a partir do estabelecimento do esquema bioestratigráfico de Daemon \& Quadros (1970), baseado na distribuição de grãos de pólen, com proposição de linhas-detempo em escala regional, que grandes avanços se tornaram possiveis sobre os aspectos da evolução geológica do Subgrupo Itararé e das unidades suprajacentes.

No próprio trabalho de França \& Potter (1988) ou em outros de caráter mais amplo (e.g. Milani et al., 1994; Milani, 1997), o zoneamento é utilizado como marcador temporal dos intervalos estratigráficos abrangidos. 
O Subgrupo Itararé representa o registro mais extenso, contínuo e espesso da glaciação neopaleozóica do Gondwana, chegando a ultrapassar, na porção setentrional da bacia, $1.300 \mathrm{~m}$ de espessura. Outros intervalos correlacionáveis ocorrem no Uruguai (Formação San Gregório), Paraguai e Argentina (subsuperfície, Bacia Chacoparaná).

O registro litológico da unidade é variado e, segundo Eyles et al., (1993), predominam quatro litotipos: diamictitos, conglomerados, arenitos e depósitos finos, com o predomínio das fácies arenosas. No modelo deposicional para a unidade, os autores defendem uma contribuição predominante de fluxos gravitacionais, com presença de fácies de ressedimentação em todos os domínios da bacia, denotando a irregularidade do substrato e a elevada taxa de sedimentação.

Importantes observações abordando as dificuldades na distinção entre os vários tipos de depósitos glaciais foram feitas por Caetano-Chang (1984) e Santos (1987), sendo que a primeira autora destacou como errônea a idéia de que toda a sedimentação do Subgrupo Itararé seria glacial. Santos et al. (1996) abordaram alguns dos principais aspectos da influência glacial e produtos registrados na unidade. A existência de glaciação durante o "tempo Itararé" e a complexidade do registro desses sedimentos são fatos inquestionáveis devido à presença de inúmeras feições glaciais. No entanto, este regime não é o responsável direto pela deposição de todo o registro da unidade, tendo, os depósitos de origens lacustre, fluvial, paludal e marinho, recebido melhor definição sobre suas origens e processos associados somente nas três últimas décadas.

Segundo vários autores, a sucessão sedimentar do Subgrupo Itararé constitua vários "ciclos" deposicionais incompletos (e.g. Leinz, 1937; Frakes \& Figueiredo-Filho, 1967; Canuto et al., 1997), englobando representantes glácio-terrestres, glácio-marinhos e marinhos. A quantificação e as características litofaciológicas desses "ciclos" variam ao longo da bacia, o que denota a irregularidade dos processos e do registro geológico. Na parte superior da unidade, é comum o reconhecimento de fácies de ressedimentação associadas à deglaciação (Gama Jr. et al., 1991; Petri \& Pires, 1992; Santos et al., 1996). De maneira geral, pelo menos para o Estado de São Paulo, a unidade apresenta um conjunto de litofácies que denotam uma progressiva transgressão (Gama Jr. \& Perinotto, 1992; Gama Jr. et al., 1991; Petri \& Pires, 1992), que culmina com a deposiçäo do Subgrupo Guatá, pós-glacial.

As isópacas do Subgrupo Itararé demostram forte controle da sedimentação ao longo da direção NW; a distribuição de suas fácies indicam um padrão de subsidência controlado por abatimento de blocos, relacionados às estruturas do embasamento subjacente (Eyles et al., 1993). 


\subsection{A TABELAA DO TEMPO GEOLÓGico}

Os estudos relativos à divisão formal do Sistema Carbonífero têm se intensificado, com várias propostas de modificaçōes, gerando diversidade nas formas de compartimentação, sugestões de estratótipos e datações ao longo das últimas décadas, em decorrência da imprecisão das datações absolutas nos estratótipos do sistema, principalmente da Plataforma Russa, Europa Ocidental e América do Norte (Metcalfe, 1997).

A partir de 1998, por decisão dos membros titulares da Subcomissão sobre a Estratigrafia do Carbonífero (SCS), o Carbonífero passou a ser subdividido em dois sistemas, o Mississipiano, na base e o Pensilvaniano, no topo. A decisão já foi incorporada na "Nota Explanatória da Tabela Estratigráfica Internacional" (IUGS/UNESCO, sem data). Com isso, o Carbonífero passou a ser o único sistema do Fanerozóico com subsistemas formalizados.

Conforme opinião de J. Roberts (2000. Texto de Abertura do volume 18 do Newsletter on Carboniferous Stratigraphy, p.1), então presidente da SCS, os dois subsistemas não podem ser identificados com precisão na maioria das áreas gondwânicas. Por esse motivo o autor orientou, pelo menos para o Carbonífero Superior dessas áreas, o uso das antigas unidades, principalmente da Europa. Por essa razão, os termos Inicial, Médio e Tardio são utilizados, informalmente, neste trabalho para o Carbonífero (Inicial e Tardio) e Permiano (Inicial, Médio e Tardio), conforme apresentado no Quadro 11.2. Entretanto, quando as informações são provenientes da consulta de trabalhos publicados, os termos referentes às idades são mantidos como citados.

Outra questão relevante é com relação às datações dos estratótipos propostos. As datações da base do Asseliano, que definiriam o limite Carbonífero/Permiano, são estimadas entre 290 e 298 M.a. (Cowie \& Bassett, 1989; Harland et al., 1989; Wagner \& Winkler Prins, 1994; Menning, 1995; Gradstein \& Ogg, 1996). Essa variação é resultado das diferentes áreas de proveniência dos dados e das técnicas de datação utilizadas.

Em atenção à recomendação de Roberts (2000, op cit.), a tabela geológica de tempo utilizada neste trabalho para o Sistema Carbonífero é baseada em Harland et al. (1989), Wagner \& Winkler Prins (1994) e Gradstein \& Ogg (1996), cuja seleção é, principalmente, devida à consideração do Autuniano e das idades apresentadas para o limite C/P. 


\begin{tabular}{|c|c|c|c|c|c|}
\hline $\begin{array}{r}\text { idades } \\
\text { absolutas } \\
\text { en Ma. }\end{array}$ & Sistema & Subsistemas & $\begin{array}{l}\text { Idades formais da } \\
\text { IUGS }\end{array}$ & $\begin{array}{c}\text { Subdivisão da } \\
\text { Europa Ocidental }\end{array}$ & $\begin{array}{l}\text { Unidades } \\
\text { Informais }\end{array}$ \\
\hline \multirow{13}{*}{290} & \multirow{8}{*}{ 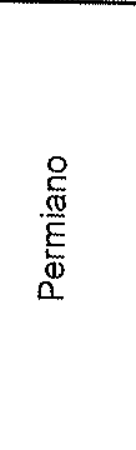 } & Lonpigiano & $\begin{array}{l}\text { Changhsingiano } \\
\text { Wuchiapigiano }\end{array}$ & \multirow[t]{2}{*}{ Tatariano } & Tardio \\
\hline & & \multirow{3}{*}{ Guadalupiano } & Capitaniano & & \multirow{3}{*}{ Médio } \\
\hline & & & Wordiano & Kazaniano & \\
\hline & & & Roadiano & \multirow[t]{2}{*}{ Kunguriano } & \\
\hline & & \multirow{4}{*}{ Cisuraliano } & Kunguriano & & \multirow{4}{*}{ Inicial } \\
\hline & & & Artinskiano & Artinskiano & \\
\hline & & & Sakmariano & Sakmariano & \\
\hline & & & Asseliano & \multirow[t]{2}{*}{ Asseliano } & \\
\hline & \multirow{8}{*}{ 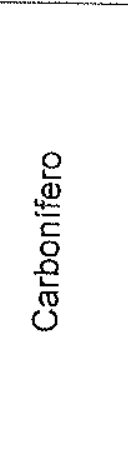 } & \multirow{5}{*}{ Pensilvaniano } & Autusiano & & \multirow{5}{*}{ Tardio } \\
\hline & & & Gzheliano & \multirow{3}{*}{ Stephaniano } & \\
\hline & & & Kazimoviano & & \\
\hline & & & Moscoviano & & \\
\hline & & & Bashkiriano & Westphaliano & \\
\hline \multirow[b]{3}{*}{354} & & \multirow{3}{*}{ Mississipiano } & Serpukhoviano & Namuriano & \multirow{3}{*}{ Inicial } \\
\hline & & & Viseano & Viseano & \\
\hline & & & Tournaisiano & Tournaisiano & \\
\hline
\end{tabular}

Quadro II.2 - Tabela do tempo geológico para os sistemas Carbonífero e Permiano. 


\section{O REGISTRO PALEONTOLÓGICO DO SUBGRUPO ITARARÉ}

O documentário paleontológico do Subgrupo Itararé é relativamente diversificado, incluindo: 1) microfósseis vegetais; 2) macrofósseis vegetais; 3) invertebrados: moluscos (gastrópodes e bivalves), braquiópodes, insetos, foraminíferos, espículas de esponjas, equinodermas (crinóides, ofiuróides, asteróides), ostracodes, escolecodontes, icnofósseis; 4) vertebrados: peixes e referências duvidosas a anfíbios.

De acordo com Rocha-Campos (1967) e Petri \& Souza (1993), que apresentaram sínteses detalhadas sobre o conteúdo paleontológico e a bioestratigrafia do Subgrupo Itararé, esses elementos ocorrem em diferentes posições estratigráficas desde o Estado do Rio Grande do Sul ao Mato Grosso, considerando somente a porção brasileira da unidade (Figura II.3).

De uma forma geral, os invertebrados marinhos fósseis oferecem melhores subsídios para as correlações e datações das seqüências onde ocorrem. No entanto, ainda não foi possível o proposição de um esquema bioestratigráfico para o Subgrupo Itararé baseado neste grupo fóssil.

Segundo Simões (1992), a fauna fóssil do Subgrupo ltararé ocorre em raros jazigos fossiliferos, esparsos e com pouca diversificação, as espécies são geralmente atribuídas a gêneros cosmopolitas; somente após a deposição da Formação Palermo teria se iniciado o isolamento da Província Gondwânica, no que tange à Bacia do Paraná.

As localidades com invertebrados fósseis mais importantes do Subgrupo Itararé no Estado de São Paulo são Capivari (gastrópodes, braquiópodes, bivalves, colunas de crinóides indeterminadas), Itaporanga (bivalves, braquiópode), Araçoiaba da Serra (foramininíferos, braquiópode, restos de peixes), Hortolândia (bivalves), Monte Mor (inseto, restos de peixes); no Paraná: arredores de Teixeira Soares, incluindo as localidades de Baitaca, Rio d'Areia e o Folhelho Passinho (braquiópodes, gastrópodes, insetos, escamas de peixes), Folhelho Guaraúna (braquiópodes, bivalves); em Santa Catarina: Mafra/Butiá (baquiópodes, bivalves); no Rio Grande do Sul: Acampamento Velho (braquiópodes e moluscos), Cerro Formoso (braquiópodes), Budó (bivalves, braquiópodes, espículas de poríferos, peixes) e Cambaí Grande (braquiópodes e moluscos).

As seqüências sedimentares do Grupo Tubarão representam uma grande fase transgressiva, dominada por condições climáticas frias. A baixa diversidade e abundância de espécimes e a ausência de corais rugosos, amonóides, fusulinídeos, conodontes e bivalves típicos de climas mais quentes (Acanthopecten, Pteronites, pseudomonotídeos) corroboram a deduçäo dessas condições climáticas (Simões et al., 1998). Vários gêneros de bivalves, incluindo Nuculana, ter-se-íam adaptado, gradualmente, à progressiva transgressão documentada nas porções mais superiores do Subgrupo itararé (passagem das litofácies Rio da Areia/Baitaca para o Folhelho Passinho), cujos registros litológicos sāo representados, nas porções mais superiores, pelas formaçöes Rio Bonito e Palermo. 
A fauna de invertebrados fósseis do Subgrupo Itararé tem sido associada à fauna de "Eurydesma" (gêneros Eurydesma, Merismoptera e Deltopecten), constituída por gêneros típicos de águas frias do Gondwana australiano (Rocha-Campos \& Rösler, 1978), relacionados aos sedimentos glaciogênicos da Austrália, Índia, América do Sul e África, geralmente com idades posicionadas no Eopermiano. Informações mais recentes têm posicionado a origem de Eurydesma no Carbonífero (González, 1998). Por outro lado, nenhuma espécie verificada na América do Sul seria verdadeira representante deste gênero, ou mesmo de Merismoptera, senāo associações precursoras destes gêneros (González, op. cit.), desenvolvidas no desenrolar da fase glacial, desde o Viseano/Namuriano, pelo menos, nas seqüencias argentinas e que guardam, na América do Sul, os estratos mais antigos da glaciação gondwânica. Somente após o final da glaciação, novas espécies ocuparam a bacia, com o aparecimento de formas tipicamente gondwânicas.

De acordo com González (1996), a glaciação do Paleozóico Superior do Gondwana teria se iniciado, provavelmente, próximo ou no limite Viseano/Namuriano e o aparecimento da fauna de águas frias, acima deste limite, pode se constituir em um nível de referência para a estratigrafia do Gondwana.

Do ponto de vista paleobotânico, sāo diversas as ocorrências de macrofitofósseis no Subgrupo Itararé, tendo os trabalhos de Rösler (1978) e Millan (1987) relacionado seu conteúdo e registrado as mais importantes tentativas de empilhamento estratigráfico.

Conforme proposta de Rösler (1978), a tafoflora mais antiga do Neopaleozóico da Bacia do Paraná é a de Monte Mor (SP), na porção basal do Subgrupo Itararé. Representante da "Tafoflora A", a associação seria caracterizada por Paracalamites, Paranocladus, Lycopodiopsis pedroanus e Samaropsis, como formas comuns e pela presença de Botrychiopsis, Noeggerathiopsis e Buriadia. A ausência dos gêneros Gangamopteris e Glossopteris confere à Tafofora A o caráter pré-glossopterídeo. A "Tafofiora B", com elementos típicos da Flora de Glossopteris, corresponderia à parte basal da Formação Rio Bonito.

A tafoflora registrada em Cerquilho (SP) foi denominada "Tafoflora transicional A/B" e é caracterizada pela ocorrência de Gangamopteris ou "folhas gangamopteróides" (Rösler, op. cit.). Mais recentemente, quatro espécies do gênero Gangamopteris foram definitivamente confirmadas em Cerquitho por Millan (1989), enquanto que lannuzzi \& Rohn (1995) noticiaram a primeira ocorrência de Glossopteris. A presença deste gênero constituiria importante indicadora do limite Carbonífero /Permiano (C/P) das bacias gondwânicas sulamericanas (Archangelsky et al., 1980).

A proposição bioestratigráfica de Millan (1987) é baseada no conteúdo macrofitofossilífero dos carvões do Estado de São Paulo e camadas associadas. Conforme este autor, a ocorrência de Monte Mor caracterizaria o "Piso Montemorense", mais inferior; enquanto que a de Cerquilho, o "Piso Cerquilhense", mais superior. Entre esses dois "pisos", o "Piso Medianense" seria relativo à reunião das ocorrências de Buri ("Subpiso Buriense"), Cesário Lange ("Subpiso Cesário Langense") e Itapeva ("Subpiso Itapevense"). 
As ocorrências de Buri, Cesário Lange e Itapeva são, relativamente, mais escassas. Note-se que em Buri, somente um espécime atribuído ao gênero Notorhacopteris foi registrado (Rösler \& Perinotto, 1985) e, em Cesário Lange, somente caules, folhas incertae sedis de licófitas (cf.) (Millan et al., 1980) e paleorraízes in situ (Millan, 1987).

Dentre as três ocorrências relacionada ao "Piso Medianense", a de Itapeva é a melhor representada qualitativamente, com o registro de Botrychiopsis plantiana, Paracalamites australis, Sphenoplyllum cf. S. churulianum, Sphenophyllum sp., Cordaites sp., Cordaicarpus sp. e caules indeterminados (Millan, 1987). Do ponto de vista bioestratigráfico, há a sugestão de correlação da tafoflora de Itapeva com a de Monte Mor (Rohn \& Rösler, 1987; Zampirolli et al., 1999).

É importante salientar que a distribuição dos elementos macroflorísticos é resultado de adaptações aos vários ambientes, como produto, principalmente, das alterações climáticas. Isto posto, deve ser considerada a hipótese das migrações florísticas do Gondwana sulamericano, assunto retomado por lannuzzi \& Rösler (2000). Assim, níveis com diferentes composições podem possuir idades coetâneas e, por outro lado, aqueles com composições similares podem não corresponder às mesmas idades.

Esse provável diacronismo de distribuição pode influenciar também a distribuição dos elementos microflorísticos, ainda que estes consigam extrapolar, geograficamente, os limites de ocorrências das macrofloras. Somando-se também os fatores tafonômicos no registro das assembléias, verificam-se dificuldades para as correlações bioestratigráficas, o que implica na extrema cautela na utilização de fitofósseis para esses fins.

A problemática relativa a esses esquemas de sucessão macroflorística vem se estendendo ao longo dos últimos anos e é devida, principalmente, ao escasso conhecimento das ocorrências que, embora apresentem grandes quantidades de espécimes, nem sempre estes se encontram bem preservados, dificultando as atribuições sistemáticas.

A revisão do conteúdo de algumas dessas ocorrências tem suscitado o incremento e a discussão de seu significado bioestratigráfico. Qualitativamente, as tafofloras mais importantes são, sem dúvida, as de Monte Mor e Cerquilho, que marcam dois estágios significativamente distintos da evolução florística registrada na Bacia do Paraná.

Associações macroflorísticas registradas no sul da bacia são mais jovens, conforme o zoneamento de Guerra-Sommer \& Cazzulo-Klepzig (1993), que correlacionaram a Zona Botrychiopsis plantiana, corresponde ao Subgrupo Itararé no Rio Grande do Sul, à Zona Gangamopteris do Permiano Inferior argentino. Por outro lado, as associações do nordeste da bacia têm sido relacionadas às zonas NBG (Noeggerathiopsis - Botrychiopsis Gangamopteris) e intervalo, do Carbonífero Superior argentino.

Com relação aos megásporos, a associação descrita por Trindade (1970) em Monte Mor é a mais importante do Subgrupo Itararé na porção nordeste da bacia. Nove espécies, relativas a cinco gêneros (Trileites, Lagenoisporites, Calamospora, Duosporites e Setosisporites) foram descritas posteriormente, modificando o conceito de monotonia 
anteriormente postulado (Sommer \& Trindade, 1966). A composição apresenta poucos elementos comuns com aquelas do sul da bacia, da Formação Rio Bonito (e.g. Marques-Toigo et al., 1975; Arai \& Rösler, 1984). Vale acrescentar ainda que os dois primeiros gêneros detectados em Monte Mor também foram registrados em Buri (Arai, 1980).

Para Trindade (1970), os gêneros verificados sugerem uma interdigitação das floras austral e boreal durante o Carbonífero e os níveis associados do carvão de Monte Mor seriam relativos ao Carbonífero Superior e testemunham a interdigitação das floras boreal e austral no Brasil. A maioria tem distribuição longeva, desde o Carbonífero Inferior, e não fornece, no entanto, melhor resolução cronológica.

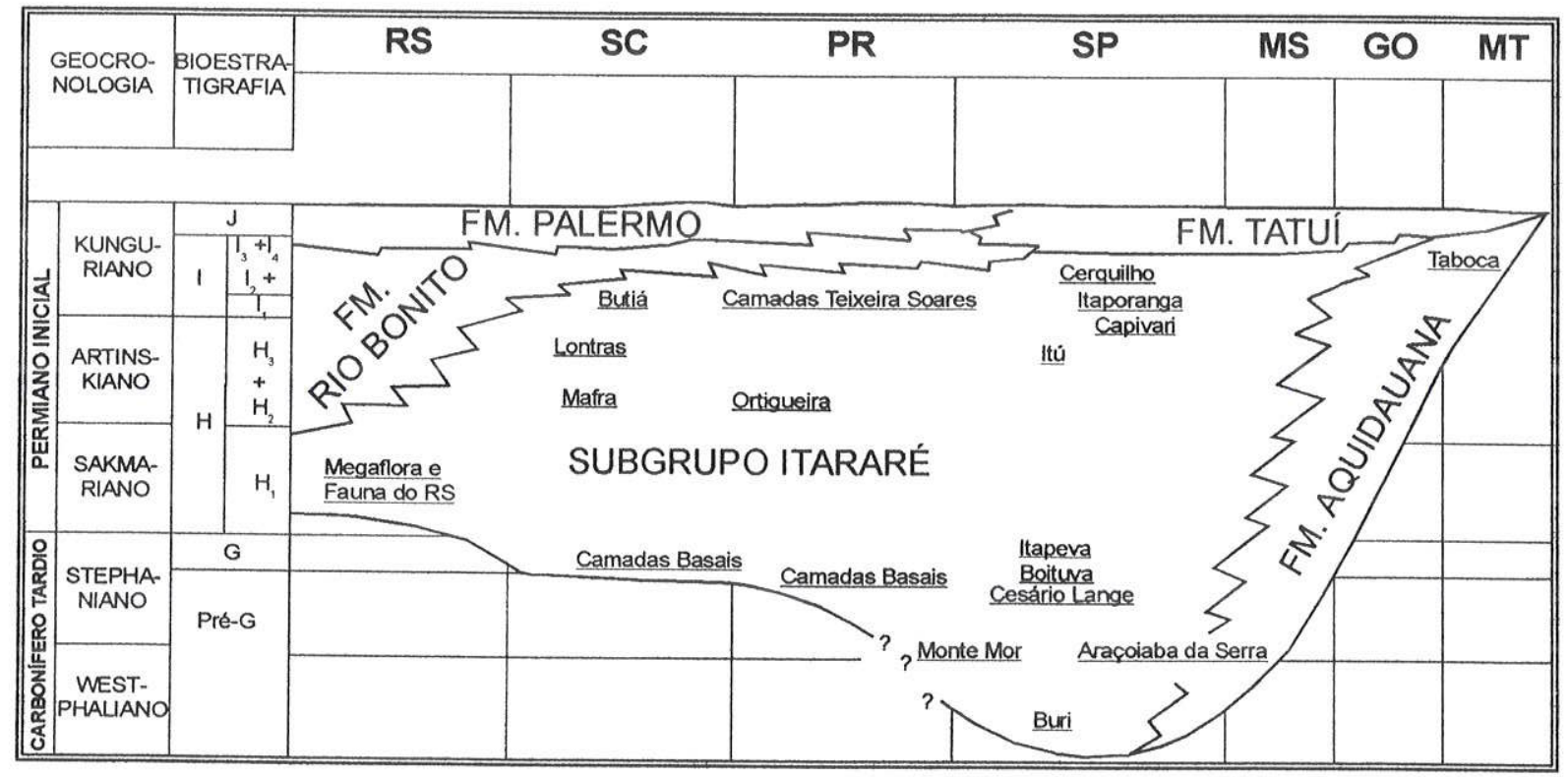

Figura II.3 - Posicionamento biocronoestratigráfico das várias ocorrências fossiliferas do Subgrupo Itararé (modificado de Petri \& Souza, 1993). 


\section{REVISÃO DA PALINOBIOESTRATIGRAFIA}

O Paleozóico Superior do Gondwana tem despertado o interesse de muitos especialistas, tendo em vista a captação de recursos minerais, dos quais se destacam as jazidas de carvão. Esse aspecto exploratório e a potencialidade dos palinofósseis presentes nos estratos, com potencial de resolução bioestratigráfica, resultaram em muitos trabalhos publicados, apresentando as associações palinofossilíferas e palinobiozoneamentos de alguns dos seus setores. Entretanto, o número de trabalhos na Bacia do Paraná ainda é reduzido, quando comparado com a produção científica dos estratos do hemisfério norte no tema e mesmo de algumas bacias circunvizinhas sul-americanas.

Quase todos os zoneamentos palinológicos efetuados para o Paleozóico Superior da Bacia do Paraná envolvem os níveis do Subgrupo Itararé no Estado de São Paulo. Enquanto que os trabalhos de Daemon (1966) e Marques Toigo $(1988,1991)$ se restringem ao estados do sul da bacia, os trabalhos de Bharadwaj et al. (1976), Saad (1977), Arai (1980) e Sundaram $(1980,1987)$ são referentes às suas partes mais setentrionais. Somente o trabalho de Daemon \& Quadros (1970) possui caráter mais amplo, abrangendo, basicamente, todo o Paleozóico Superior da bacia. Estes zoneamentos são apresentados, como propostos, sinteticamente a seguir, procurando-se realçar suas principais características.

O primeiro zoneamento palinoestratigráfico efetuado para a Bacia do Paraná é o de Daemon (1966), baseado na distribuição dos grãos de pólen monossacados, bissacados e monoletes na seqüência que envolve desde o Subgrupo Itararé até a Formação Teresina, a partir de três furos realizados pela Petrobrás em Santa Catarina (Barra Nova, Canoinhas e Caçador) e um no Paraná (União da Vitória).

A partir da seleção de 46 gêneros reconhecidos, codificados com numeração arábica, o autor separou a seqüência em três zonas principais, duas das quais ainda subdivididas em subzonas. A unidade mais antiga, Zona P3, é caracterizada pela alta freqüência de espécies do gênero Florinites, além de outros monossacados, como Vestigisporites e Vesicaspora. A Zona P3 corresponde, em termos litoestratigráficos, às partes inferior-média do Subgrupo Itararé. A unidade intermediária, Zona P2, que abrange a porção superior do Subgrupo Itararé e a inferior-média da Formação Rio Bonito, caracteriza-se pelo aparecimento de grande número de táxons, destacando-se Vestigisporites e Nukoisporites, bem como Limitisporites e Vittatina; é subdividida em 4 subzonas: P2a, P2b, P2c e P2d, marcadas pela concorrência de táxons selecionados. A unidade mais nova, Zona P1, abrange a seqüência superior do intervalo, desde o topo da Formação Rio Bonito até a Formação Teresina, tendo sido subdividida em duas subzonas: P1a e P1b, cujo limite entre as duas corresponde à passagem da Formação Palermo para o Subgrupo Irati. A Zona P1 caracterizase pela predominância dos grãos de pólen bissacados; monossacados estariam presentes até a Subzona P1b. 
O mais abrangente e utilizado esquema palinobioestratigráfico efetuado para a Bacia do Paraná é, sem dúvida, o de Daemon \& Quadros (1970). Com base na distribuição de 40 espécies selecionadas de grãos de pólen sacados, monoletes e monocolpados, além de representantes de Tasmanales, em 13 afloramentos e 31 poços exploratórios da Petrobrás, os autores propuseram a divisão do Paleozóico Superior da Bacia do Paraná em seis intervalos, designados pelas letras G, H, I, J, K e L. Trata-se de intervalos baseados na concorrência de táxons, alguns dos quais subdividos, por sua vez, em subintervalos, a saber: $\mathrm{H}_{1}, \mathrm{H}_{2}$ e $\mathrm{H}_{3} ; \mathrm{I}_{1}$, $\mathrm{I}_{2}+\mathrm{I}_{3}+\mathrm{I}_{4} ; \mathrm{L}_{1}, \mathrm{~L}_{2}$ e $\mathrm{L}_{3}$.

Nesse zoneamento, grãos de pólen monossacados dominam até o Subintervalo $\mathrm{H}_{2}$, destacando-se os gêneros Potonieisporites, Plicatipollenites e Virkkipollenites (=Cannanoropollis). As formas bissacadas teniadas são raras nos intervalos $G, H_{1}$ e $H_{2}$, representadas pelo gênero Protohaploxypinus (P-486). A partir do Subintervalo $\mathrm{H}_{3}$ essas formas bissacadas teniadas tornam-se mais freqüentes e diversificadas, com o aparecimento do gênero Vittatina. Nos intervalos I e J os grãos de pólen monossacados e bissacados são registrados com a mesma freqüência, sendo mais comuns as espécies do gênero Vittatina. No topo do intervalo J, o gênero Plicatipollenites, muito comum nos intevalos anteriores, diminui em freqüência, tornando-se então ausente na base do intervalo L. A partir do intervalo $\mathrm{J}$, os grãos de pólen bissacados teniados passam a dominar na coluna, sendo raros os monossacados e marcante a presença de Lueckisporites virkkiae, imprimindo importante característica aos intervalos $\mathrm{J}$ e K, cujo limite é considerado datum bioestratigráfico para a bacia.

Comparando as espécies reconhecidas e utilizadas como guias com outras registradas em regiões distintas, principalmente, do hemisfério norte, Daemon \& Quadros (op. cit.) admitiram os seguintes posicionamentos geocronológicos aos intervalos estabelecidos: Stephaniano C/Sakmariano aos intervalos $\mathrm{G}$ e $\mathrm{H}_{1}$; Artinskiano aos subintervalos $\mathrm{H}_{2}$ e $\mathrm{H}_{3}$; Kunguriano aos intervalos I e J; Kazaniano aos intervalos Ke L. Em Daemon (1981), as idades se encontram melhor relacionadas, sendo o intervalo $G$ equivalente ao Carbonífero (Stephaniano C); H ao Sakmariano/Artinskiano; I e J ao Kunguriano; K e L ao Kazaniano.

Segundo os autores proponentes, o intervalo G não foi encontrado em todos os poços estudados. Suas isópacas mostram maiores espessuras na região setentrional da bacia, a partir do norte do Estado do Paraná onde, provavelmente, teria iniciado a deposição de seus litotipos, transgredindo somente no intervalo $\mathrm{H}_{1}$ no Estado de Santa Catarina e $\mathrm{I}_{1}$, no Estado do Rio Grande do Sul. Além disso, as camadas da parte superior do Subgrupo Itararé seriam, em muitos locais, sincrônicas com aquelas da Formação Rio Bonito que, por sua vez, transgridem o datum de modo indiscriminado, demonstrando sua recorrência no tempo.

De maneira geral, observa-se que abaixo do datum estabelecido (limite $\mathrm{J} / \mathrm{K}$ ), os intervalos bioestratigráficos se comportam de maneira irregular, correspondendo à fase de 
ajustamento da bacia. Acima do datum, é constatada constância mais acentuada no registro, dado o melhor paralelismo dos limites dos intervalos.

A partir do estudo de 45 gêneros incluindo 66 espécies de 12 amostras provenientes de afloramentos das bacias do Paraná e Parnaíba, Bharadwaj et al. (1976) registraram a ocorrência de quatro assembléias de esporomorfos na Bacia do Paraná (zonas de associação $A, B, C$ e $D$ ) e três na Bacia do Parnaíba ( $A, B$ e $C$ ). As zonas foram correlacionadas entre si, com a proposição de seis intervalos bioestratigráficos distintos, alguns dos quais comuns em ambas as bacias. Do mais antigo para o mais jovem, receberam designação numérica de 1 a 6.

Embora com boa representação número de espécies registradas, os problemas na utilização deste zoneamento são inúmeros, devidos, principalmente, à pouca representatividade da amostragem em termos litoestratigráficos, irregularmente distribuída nas duas bacias.

Com base nos resultados palinológicos de 70 amostras provenientes de oito perfis estratigráficos realizados transversalmente à faixa de afloramentos do Subgrupo Itararé no Estado de São Paulo, Saad (1977) reconheceu três assembléias microflorísticas distintas, caracterizadas pela composição qualitativa e quantitativa de gêneros de algas, esporos e grãos de pólen. As assembléias receberam a designação informal de Microfloras I, II e III, da mais antiga para a mais nova e caracterizariam intervalos relativos a zonas de associação.

A Microflora I, correspondente à porção inferior do Subgrupo Itararé, é caracterizada pela predominância de esporos (até $80 \%$ ), com quantidades subsidiárias de grãos de pólen monossacados (até $20 \%$ ), monocolpados (2-3\%), bissacados teniados (até cerca de $3 \%$ ) e não teniados. Grande parte dos componentes desta microflora alcançam os níveis superiores da Microflora II. Dessa forma, seu aspecto marcante parece ser o quantitativo, destacando-se a baixíssima freqüência de grãos de pólen teniados (Striomonosaccites, Protohaploxypinus), a alta freqüência de esporos e, subordinadamente, de monossacados (Plicatipollenites, Potonieisporites).

A Microflora II, correspondente à porção média do Subgrupo Itararé, é mais diversificada, com o aparecimento de alguns esporos dos gêneros Punctatisporites, Retusotriletes, Acanthotriletes e incremento na participação de grãos de pólen teniados dos gêneros Protohaploxypinus e Taeniaesporites, além de Cycadopites. O gênero Virkkipollenites (Cannanoropollis), presente na Microflora I, desaparece na porção basal do intervalo que caracteriza a Microflora II. Nesta, nota-se pequeno decréscimo na freqüência de esporos e acréscimo de grãos de pólen bissacados teniados e não teniados, cujas percentagens médias ultrapassam 10\%. Limitados a este intervalo, estão os gêneros Verrucososporites, Microbaculispora, Pustulatisporites, Brochotriletes, Striatoabieites e Alisporites.

A assembléia mais jovem, Microflora III, correspondente à porção superior da unidade, apresenta decréscimo na freqüência dos esporos e por outro lado, contínuo aumento na participação dos grãos de pólen teniados, presentes em cerca de $30 \%$. A mesma relação se 
dá também entre os grãos de pólen monossacados, que baixam ligeiramente em freqüência e os monocolpados, que atingem cerca de $4 \%$. É marcante a presença restrita de Cyclogranisporites, Lycospora e Hamiapollenites, além de algas do tipo Tasmanites nesta Microflora, estas últimas em até $5 \%$ de freqüência.

Arai (1980) reconheceu 42 gêneros de esporomorfos em amostras procedentes de vários afloramentos da seqüência neopaleozóica da Bacia do Paraná nos estados de São Paulo, Paraná e Santa Catarina, tendo proposto um zoneamento baseado na sucessão dos grãos de pólen teniados. De uma maneira geral, estes seriam raros nos estratos basais e, em alguns casos, não foram encontrados (Cesário Lange, Capivari e Buri). Progressivamente, aumentam em percentagem nas assembléias, com decréscimo de esporos triletes. Qualitativamente, formas teniadas de contorno haploxilonóide, que dominam nas porções basais, cedem lugar à formas do tipo Vittatina e outras com contorno diploxilonóide como Taeniaesporites, Striatopodocarpites e Striatoabieites.

Dessa forma, Arai (op. cit.) propôs a subdivisão da coluna em seis unidades designadas informalmente de "Fases". A Fase Pré-Striatiti, mais inferior na coluna, é caracterizada pela ausência de grãos de pólen teniados, alta freqüência de monossacados, dos quais Potonieisporites e Vestigisporites são os mais relevantes, e pela abundância de Vallatisporites. A seguinte, Fase Protohaploxypinus, é caracterizada pela presença de grãos de pólen teniados, sobretudo do gênero que the nomeia, ainda subordinados aos esporos triletes e grãos de pólen monossacados presentes, que persistem da fase anterior. Na fase Vittatina I ocorre um equilíbrio na percentagem de grãos de pólen teniados e monossacados, com a presença do gênero Vittatina. Este gênero ultrapassa 50\% na Fase Vittatina II, chegando, em alguns casos, a revelar freqüências superiores a 90\%. Grãos de pólen teniados de contorno diploxilonóide, com sacci bem desenvolvidos, são característicos da Fase Striatiti Superior, cuja base é marcada pelo aparecimento dos gêneros Taeniaesporites, Striatopodocarpites e Striatoabieites. A Fase Lueckisporites, superior na seqüência, caracteriza-se pela constatação do gênero que the dá o nome e pela predominância absoluta de grãos de pólen teniados, com presença subordinada de bissacados lisos.

Com base no estudo palinológico de dez amostras do Subgrupo Itararé no Estado de São Paulo (Buri e Cesário Lange) e da Formação Rio Bonito nos estados do Paraná e Santa Catarina, Sundaram (1980) reconheceu duas assembléias palinológicas distintas, designadas, informalmente, de Palinozonas A e B. A mais antiga, Palinozona A, observada nas amostras do Subgrupo Itararé, é dominada por esporos triletes, especialmente formas cinguladas e zonadas, representadas pelos gêneros Vallatisporites, Kraeuselisporites, Cingulatisporites, Cirratriradites, Acanthotriletes, entre outros, que perfazem até $70-80 \%$ da assembléia. Grãos de pólen monossacados, em torno de $20 \%$, são representados por Cannanoropollis, Plicatipollenites e Parasaccites. A Palinozona B, detectada nas amostras da Formação Rio Bonito, apresenta grande quantidade de grãos de pólen bissacados, que chegam a $60-65 \%$, enquanto que os esporos triletes não ultrapassam $20 \%$. Os bissacados 
mais comuns nesta assembléia são Scheuringipollenites, Platysaccus, Faunipollenites e, entre os teniados e poliplicados, Protohaploxypinus, Striatopodocarpites e Vittatina.

Comparando o conteúdo microflorístico das duas palinozonas com outras assembléias gondwânicas, Sundaram (op. cit.) propôs correspondência da Palinozona A com algumas das bacias vizinhas da América do Sul, Paganzo e Chacoparaná (Palinozona I de Azcuy, 1979 e Unidade II de Kemp et al., 1977). A Palinozona B foi correlacionada com palinozonas de outras regiões gondwânicas (Palinozona Zonati de Hart, 1971; Palinozona III de Azcuy, 1979; Unidade V de Kemp et al., 1977).

A última tentativa de zoneamento palinoestratigráfico para o Subgrupo Itararé no Estado de São Paulo foi realizada por Sundaram (1987), com base nas amostras coletadas ao longo das seções estratigráficas descritas por Saad (op. cit.). Embora a distribuição das amostras férteis tenha sido irregular ao longo das seções e a distribuição dos palinomorfos na parte basal da seqüência amostrada não pudesse ser estabelecida completamente em nenhuma das seções, o autor reconheceu três intervalos, correspondentes a zonas de associações informalmente designadas, da mais antiga para a mais nova, Palinozonas A, B e C.

A Palinozona A corresponde à metade inferior do Subgrupo Itararé e teria como formas características Cirratriradites saturni, Cirratriradites megaspinosus, Densosporites annulatus e Laevigatosporites desmoinenses. Segundo Sundaram (1980), esses elementos, que mundialmente ocorreriam no Eocarbonífero, conferem uma conotação de antiguidade à seqüência.

A Palinozona B, correspondente à parte média do Subgrupo Itararé, a Palinozona B se caracterizaria pela presença de Punctatisporites ( $P$. gretensis forma minor, $P$. minutus, $P$. gretensis), Cyclogranisporites minutus, Apiculatisporis levis, A. spinosaetosus, Microbaculispora tentula e Horriditriletes curvibaculosus. A Palinozona C, correspondente à metade superior da unidade, teria como elementos característicos Striomonosaccites ovatus, Protohaploxypinus chaloneri, P. jacobii, Vittatina vittifera, Cycadopites follicularis e Marsupipollenites striattus.

Grãos de pólen monossacados ocorreriam a partir da Palinozona C, juntamente com grãos de pólen bissacados e teniados, o que levou o autor a aventar a hipótese da reunião das Palinozonas $\mathrm{A}$ e $\mathrm{B}$. Contudo, a Palinozona $\mathrm{A}$ foi correlacionada com aquelas mais primitivas do Eogondwana, a saber: "Stage" 1 (Evans, 1969) e Unidade I (Kemp et al., 1977) da Austrália, Zona de Ancistrospora (Azcuy \& Jelin, 1980) da Argentina e, na Bacia do Paraná, ao intervalo G ou relativo ao intervalo Pré-G sugerido por Lima et al. (1983). As palinozonas conseguintes seriam relativas aos intervalos $\mathrm{H}_{1}+\mathrm{H}_{2}$ e $\mathrm{H}_{3}+\mathrm{l}$, respectivamente.

Uma questão importante é a ausência de grãos de pólen na Palinozona A, relativa à porção inferior do Subgrupo Itararé, diferentemente do observado por Saad (1977), com mesma amostragem, e mesmo no intervalo G, com o qual a Palinozona é correlacionada. 
O modelo proposto por Marques-Toigo $(1988,1991)$ constitui o único zoneamento palinobioestratigráfico formal para a Bacia do Paraná, baseado nas associações microflorísticas dos principais níveis de carvão de superfície e subsuperfície do Estado do Rio Grande do Sul e sul de Santa Catarina, compreendendo o intervalo desde o Subgrupo Itararé até o Subgrupo Irati.

Baseada nas distribuições verticais e laterais dos grãos de pólen monossacados, bissacados e teniados, bem como sua abundância relativa, a autora dividiu a seqüência em duas zonas-de-intervalo, denominadas Cannanoropollis korbaensis e Lueckisporites virkkiae.

A Zona Cannanoropollis korbaensis foi definida pela distribuição da espécie que Ihe dá o nome e, na sua ausência, por Potonieisporites simplex, de igual amplitude, ou ainda pelos níveis de extinção de Limitisporites vesiculosus e Hamiapollenites karroensis. A zona é subdividida em 3 subzonas de intervalo, (1) Subzona Protohaploxypinus goiraiensis: correspondente ao Subgrupo Itararé e à base da Formação Rio Bonito naqueles estados, com idade posicionada entre o Sakmariano e o Artinskiano; (2) Subzona Caheniasaccites ovatus: correspondente à parte média da Formação Rio Bonito, com idade situada entre o Artinskiano e o Kunguriano; (3) Subzona Hamiapollenites karroensis: correspondente ao topo da Formação Rio Bonito, de idade kunguriana.

A Zona Lueckisporites virkkiae, definida pela distribuição da espécie que the dá o nome ou, na sua ausência, por Marsupipollenites trirradiatus, Staurosaccites cordubensis, Striatopodocarpites pantii, Lunatisporites variesectus e Protohaploxypinus perfectus, de igual amplitude, é correspondente à Formação Palermo e ao Subgrupo Irati, com idade atribuída entre o Kazaniano e o Tatariano (intervalos K-L).

Posteriormente, Daemon \& Marques-Toigo (1991) propuseram a integração dos trabalhos de Daemon \& Quadros (1970) e Marques-Toigo (1988, 1991), com a criação da Zona Potonieisporites novicus, mais antiga que a Zona Cannanoropollis korbaensis e correspondente aos intervalos G-H $\mathrm{H}_{1}$ de Daemon \& Quadros (op. cit.). Em Milani et al. (1994) e Holz \& Dias (1998), verifica-se a utilização desta Zona e de uma nova nomenclatura para a Zona Cannanoropollis korbaensis (Zona Vittatina) e respectivas subzonas no quadro que compõe a coluna estratigráfica da Bacia do Paraná, refletindo os trabalhos dos autores retrocitados. Entretanto, até o momento não foi publicada qualquer caracterização da Zona Potonieisporites novicus, tampouco as justificativas das renomeações da Zona Cannanoropollis korbaensis e suas subzonas.

Procurando relacionar a sucessão palinológica com a evolução geológica do Neopaleozóico da Bacia do Paraná, Daemon et al., (1996) associaram ao pacote sedimentar do Subgrupo Itararé quatro eventos geológicos, denominados I, II, III e IV.

O evento geológico I incluiria as formações Aquidauana, Lagoa Azul e a porção inferior da Formação Campo Mourão (França \& Potter, 1988) e seria representado pelos registros de esporos e grãos de pólen monossacados, correspondendo ao intervalo $\mathrm{G}-\mathrm{H}_{1}$. 
O subintervalo $\mathrm{H}_{2}$ seria equivalente ao registro do evento geológico II, que inclui a porção inferior (-média ?) da Formação Campo Mourão. Os principais registros fossilíferos da unidade seriam relativos a "restos faunísticos" e algas, de pouca representatividade e estariam relacionados às primeiras ingressões marinhas do Neopaleozóico, caracteristicamente de condições hipossalinas.

A porção superior da Formação Campo Mourão corresponderia ao evento geológico III, relacionado ao subintervalo $\mathrm{H}_{3}$ e marcado por grandes quantidades de grãos de pólen teniados e maior abundância do gênero de algas Tasmanites. Conforme os autores, este evento seria relativo à amenização do clima e ao recuo pronunciado ou a ausência total da influência glacial.

$\mathrm{O}$ evento geológico IV seria relativo ao subintervalo $\mathrm{H}_{4}$ e à porção basal do intervalo I ( $I_{1}$ ?), incluindo a porção superior da Formação Campo Mourão e toda a Formação Taciba. Segundo os autores, o predomínio seria de sedimentação marinha (fauna de bivalves), com progressiva melhoria climática, evidenciada pela abundância de grãos de pólen teniados. A parte superior da Formação Taciba seria relativa ao intervalo I, contemporânea à porção inferior da Formação Rio Bonito.

Notam-se alterações nas atribuições cronológicas dos intervalos bioestratigráficos de Daemon \& Quadros (1970), com posicionamento dos intervalos $\mathrm{G}-\mathrm{H}_{1}$ no Westphaliano/Stephaniano; $\mathrm{H}_{2}$ e $\mathrm{H}_{3}$ no Sakmariano; $\mathrm{H}_{4}$ e base do I no Artinskiano. Estas modificações sugerem a aceitação, por parte dos autores, de que grande parte da porção basal do Subgrupo Itararé seria relativa ao Carbonífero.

As proposições dos intervalos informais Pré-G (Lima et al. 1983) ou Associação Ahrensisporites \& Ancistrospora (Souza et al., 1996), baeadas nas ocorrências palinológicas do Subgrupo Itararé em Araçoiaba da Serra (SP), são devidas, principalmente, à não correlação com o intervalo $\mathrm{G}$ e pela constatação de espécies de esporos característicos do Carbonífero Superior argentino e australiano. Essas proposições são melhor analisadas no Capítulo IV, por fazer parte do escopo principal deste trabalho.

No Quadro II.3 os zoneamentos palinobioestratigráficos da Bacia da Paraná, formais e informais, são apresentados, conforme proposições originais. 


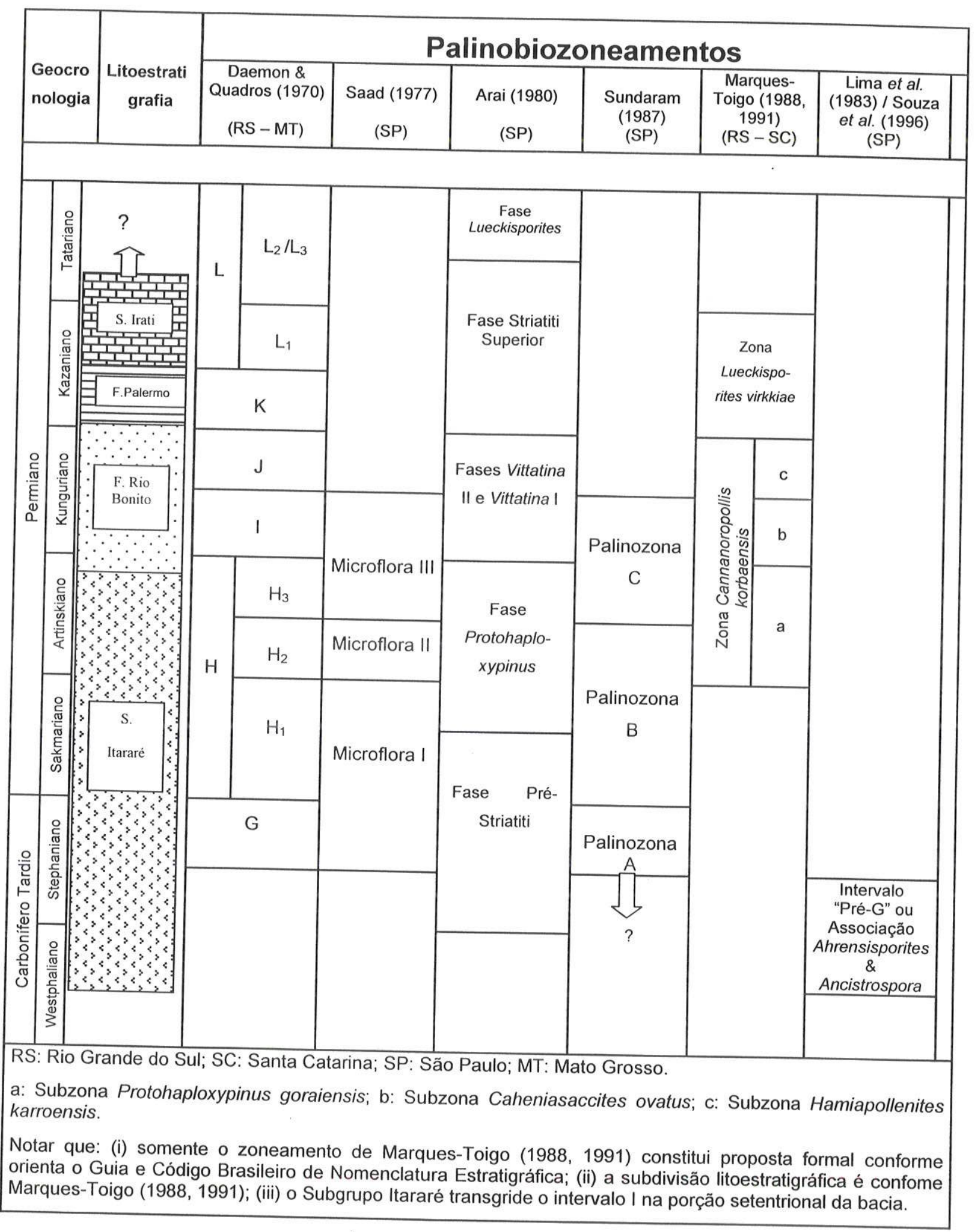

Quadro II.3 - Situação e correlação das propostas palinobioestratigráficas para o Paleozóico Superior da Bacia do Paraná. 
CAPÍTULO III

PALINOLOGIA 


\section{ASPECTOS GERAIS}

\section{Definição de alguns termos}

O termo Palynology foi, pioneiramente, empregado por Hyde \& Williams (1944), correspondendo ao estudo dos grãos de pólen e outros esporos, sua dispersão e aplicações. $\mathrm{O}$ termo, proveniente do verbo grego paluno (palunein: espalhar, pulverizar) e do substantivo pale (pó fino), foi amplamente utilizado nos trabalhos intitulados "Pollen Analysis Circular", durante a década de 40 e início dos anos 50, nos EUA, cuja temática relacionava-se ao estudo do espectro polínico de sedimentos lacustres e pantanosos.

Com o uso progressivo desses microfósseis, principalmente para fins de prospecção de recursos minerais energéticos (carvão, petróleo), a concepção do termo foi ampliada: $A$ Palinologia é referente ao estudo da matéria orgânica microscópica que persiste após a dissolução dos componentes inorgânicos de uma rocha, em reação com $\mathrm{HCl}$ e HF; o material que resta, excetuando-se minerais neoformados durante o processo de dissolução química, compreende os "palinomorfos".

Nesse aspecto, a Palinologia envolve grande variedade de organismos, incluindo diversas categorias taxonômicas (vegetais, animais e protistas), assim melhor agrupados:

Esporomorfos: esporos de fungos, briófitas e vasculares sem sementes (pteridófitas), grãos de pólen de gimnospermas e angiospermas;

Fitoplâncton: cistos de dinoflagelados; prasinofíceas; cianobactérias; clorococcales; rodofíceas; acritarcas; fitoclastos (cutículas, tecidos lenhosos, opacos, matéria orgânica amorfa etc.);

Zoomorfos: escolecodontes; quitinozoários e foraminíferos quitinosos.

\section{Grupos vegetais representados}

Em decorrência da forma de dispersão no meio, os esporomorfos, principais formas verificadas nesse trabalho, são recuperados separadamente (sporae dispersae), geralmente sem conexão física com os organismos botânicos geradores o que, pelo menos para o Paleozóico, resulta em dificuldades no estabelecimento das afinidades biológicas.

Os trabalhos que versam sobre suas afinidades botânicas são baseados no registro de esporomorfos em frutificações relacionadas a megafósseis vegetais ou nas peculiaridades morfológicas exclusivas de certos grupos vegetais, como discutido por Vergel (1986a).

Os principais grupos vegetais representados são as "pteridófitas" e as gimnospermas, conforme sintetizado no Quadro III.1. A hieraquização das divisões botânicas é de acordo com 
Stewart \& Rothwell (1993). As afinidades botânicas são apresentadas conforme proposição de vários autores, devidamente mencionados, por gênero, nas descrições sistemáticas. Note-se que o termo "pteridófita" não constitui uma ordem hierárquica na classificação botânica e não tem significado natural (Traverse, 1988, p. 55). No entanto, o termo é intensamente utilizado na Palinologia do Paleozóico Superior, em alusão às criptógamas vasculares, produtoras de esporos e que não produziam verdadeiras sementes: samambaias (Filicopsida) e outras afins (principalmente Psilopsida, Rhyniopsida, Zosterosphyllopsida, Trimerophytopsida, Lycopsida e Sphenopsida).

\begin{tabular}{|c|c|c|c|}
\hline \multirow{7}{*}{ 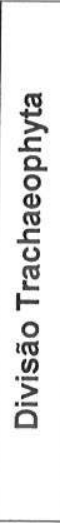 } & \multicolumn{2}{|c|}{ Classes / Ordens } & Gêneros \\
\hline & \multicolumn{2}{|l|}{ Psilopsida } & Retusotriletes \\
\hline & \multicolumn{2}{|l|}{ Lycopsida } & $\begin{array}{lll}\begin{array}{l}\text { Foveosporites, } \\
\text { Kraeuselisporites, } \\
\text { ?Bascaudaspora }\end{array} & \begin{array}{r}\text { Lundbladispora, } \\
\text { Vallatisporites, }\end{array} & \begin{array}{l}\text { Densosporites, } \\
\text { Cristatisporites, }\end{array} \\
\end{array}$ \\
\hline & \multicolumn{2}{|l|}{ Sphenopsida } & Calamospora, Reticulatisporites \\
\hline & \multicolumn{2}{|l|}{ Filicopsida } & $\begin{array}{l}\text { Punctatisporites, Leiotriletes, Granulatisporites, } \\
\text { Cyclogranisporites, Verrucosisporites, Apiculatisporis, } \\
\text { Raistrickia, Convolutispora, Horriditriletes }\end{array}$ \\
\hline & \multirow[t]{2}{*}{ Gymnospermopsida } & Coniferales & 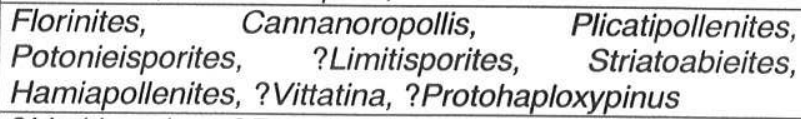 \\
\hline & & Pteridospermales & ?Limitisporites, ?Protohaploxypinus, ?Vittatina \\
\hline
\end{tabular}

Quadro III.1 - Afinidades botânicas dos gêneros de esporomorfos verificados.

\section{Produção e função dos esporomorfos}

Dada a natureza deste trabalho, serão apresentadas apenas breves descrições das formas de produção dos esporomorfos e seu papel no ciclo de vida das pteridófitas e gimnospermas, com base nos trabalhos de Brasier (1980), Haven et al., (1996), Jarzen \& Nichols (1996) e Playford \& Dettmann (1996).

Os esporos constituem elementos importantes no ciclo de vida germinativo das briófitas e criptógamas vasculares (pteridófitas). Todas as pteridófitas apresentam, alternadamente, as fases esporofítica (reprodução assexuada por esporos) e gametofítica (reprodução sexuada por gametas masculinos e femininos), com o predomínio da primeira. Isto é, enquanto nas hepáticas, antóceros e musgos, o gametófito é maior e estruturalmente mais complexo que o esporófito, nas plantas vasculares, o esporófito é a fase dominante do ciclo de vida, sendo maior estruturalmente e muito mais complexo que o gametófito. As plantas vasculares mais primitivas produzem apenas um tipo de esporos (isósporos). Neste caso, incluem-se as plantas denominadas homosporadas das classes Psilopsida, Rhyniopsida, Zosterophyllopsida, Trimerophytopsida, Sphenopsida, algumas Lycophyta e quase todas as samambaias (Filicopsida). 
O esporófito apresenta porte variado e produz, em determinadas épocas do ano, cápsulas contendo esporos chamadas esporângios (sporangia). Inicialmente, as células-mãe, contidas no esporângio (sporangium), apresentam o mesmo número de cromossomos do esporófito (condição diplóide, $2 \mathrm{~N}$ ). Por meiose, cada célula-mãe divide seu conteúdo em quatro novas células, formando uma tétrade de esporos. Cada um desses esporos contém metade da quantidade de cromossomos da célula-mãe (condição haplóide, $1 \mathrm{~N}$ ) e quando são do tipo isósporos produzem gametófitos bissexuados, ou seja, gametófitos que produzem tanto anterídios, onde se formam anterozóides, quanto arquegônios, onde se forma a oosfera. Nestes casos, o anterozóide móvel necessita de água para locomover-se até o arquegônio (oosfera).

A heterosporia, produção de dois tipos de esporos em dois esporângios diferenciados, ocorre em algumas licófitas, esfenófitas e filicófitas fósseis, bem como em todas as plantas com sementes (espermatófitas). Os dois tipos de esporos são chamados micrósporos e megásporos, produzidos, respectivamente, em microsporângios e megasporângios. Quando amadurecidos, os micrósporos dão origem a gametófitos masculinos (microgametófitos) e os megásporos dão origem a gametófitos femininos (megagametófitos).

Quanto às gimnospermas, considerando os pinheiros, por exemplo, assim como na maioria das outras coníferas, microsporângios e megasporângios nascem sobre cones (estróbilos) na mesma árvore. Estróbilos microsporangiados são comuns nos ramos inferiores, enquanto que os megasporangiados são comuns nos ramos superiores, embora em alguns espécimes possam nascer no mesmo ramo.

Um microsporângio jovem contém muitos microsporócitos, células-mães de micrósporos. No começo da primavera, os microsporócitos sofrem meiose e cada um dá origem a quatro micrósporos haplóides. Cada micrósporo se desenvolve vindo a constituir um grão de pólen alado, que é o gametófito masculino jovem. Nessa fase, grandes quantidades de grãos de pólen são liberados pelos microesporângios e transportados pelo vento.

$\mathrm{Na}$ fertilização, os grãos de pólen se depositam sobre escamas ovulíferas, que portam óvulos que, com seus integumentos, envolvem megasporângios no interior, dos quais um megásporo funcional origina o gametófito feminino portador da oosfera. A germinação, com a formação de um tubo polínico no grão de pólen (micropyle) para fecundar a oosfera, é demorada, chegando a alcançar, no caso dos pinheiros, períodos de 15 meses, até a transformação do óvulo em sementes. 


\section{SISTEMÁTICA PALINOLÓGICA}

\section{Categorias sistemáticas e terminologia}

Os esporos e grãos de pólen fósseis são referentes a morfogêneros, tendo em vista sua natureza (sporae dispersae). De acordo com o Artigo 3.3. do Código Internacional de Nomenclatura Botânica (ICBN), tratam-se de fragmentos orgânicos e não devem ser agrupados em nível de família, embora possam ser compreendidos em categorias maiores (e.g. Gimnospermae).

Os esquemas utilizados para classificação dos esporomorfos constituem, do ponto de vista da sistemática biológica (natural), esquemas neutros e são baseados nos caracteres morfológicos, excetuando-se as duas categorias maiores: Anteturmas Sporites (Proximegerminantes) e Pollenites (Variegerminantes). Em linhas gerais, trata-se de um esquema parataxonômico que divide os esporomorfos em duas turmas, nas quais agrupam-se várias infraturmas, com subdivisões intermediárias (suprasubturma, subturma e subinfraturma).

Traverse (1996) apresenta importantes comentários a respeito dos principais problemas relativos à taxonomia dos esporomorfos e das implicações com o Código Internacional de Nomenclatura de Botânica, que rege a sistemática palinológica.

Em Playford \& Dettmann (1996), é apresentado um quadro de classificação supragenérica para os esporos fósseis, baseado nos trabalhos clássicos de Potonié \& Kremp (1954), Potonié (1956, 1970), Dettmann (1963) e Smith \& Butterworth (1967). As informações são reproduzidas no Quadro III.2, apresentando-se, adicionalmente, a classificação para os grãos de pólen, compreendendo somente as categorias verificadas neste trabalho. 


\begin{tabular}{|c|c|c|c|c|c|c|c|c|c|c|c|c|c|c|c|}
\hline Posição sistemática & \multicolumn{15}{|c|}{ Categorias Supragenéricas } \\
\hline Anteturma & \multicolumn{9}{|c|}{ Proximegerminantes } & \multicolumn{6}{|c|}{ Variegerminantes } \\
\hline Turma & \multicolumn{8}{|c|}{ 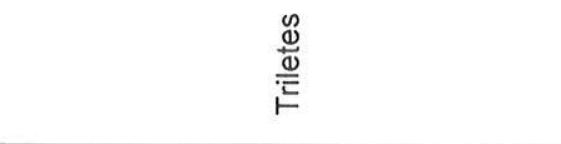 } & 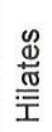 & \multicolumn{5}{|c|}{ 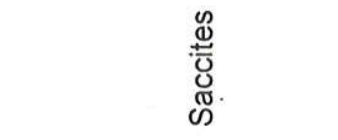 } & 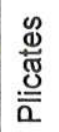 \\
\hline Subturma & \multicolumn{4}{|c|}{ 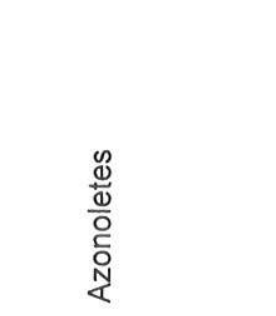 } & & 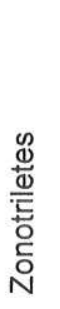 & 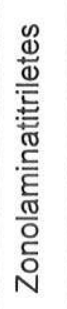 & 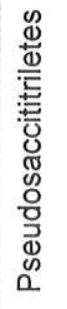 & & \multicolumn{3}{|c|}{ 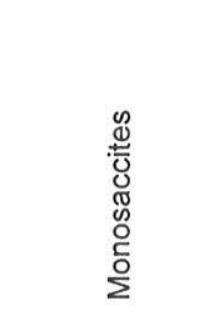 } & \multicolumn{2}{|c|}{ 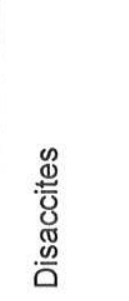 } & 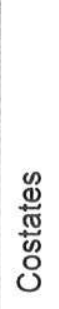 \\
\hline Infraturma & 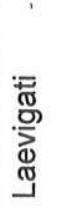 & 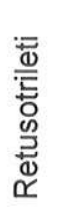 & $\begin{array}{l}\frac{\bar{\pi}}{\frac{\pi}{3}} \\
\frac{0}{0} \\
\frac{0}{\alpha}\end{array}$ & $\begin{array}{l}\text { 焉 } \\
\text { 닌 } \\
\text { 文 }\end{array}$ & 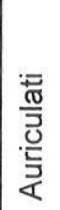 & 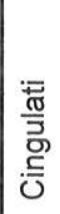 & 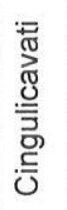 & $\begin{array}{l}0 \\
0 \\
0 \\
0 \\
0 \\
00 \\
0 \\
0 \\
\text { ¿ }\end{array}$ & & 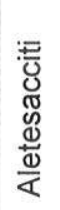 & 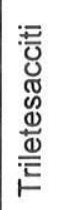 & 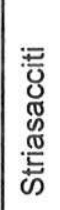 & 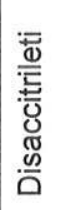 & 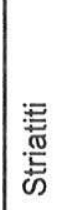 & 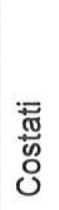 \\
\hline
\end{tabular}

Quadro III.2 - Sistemática das categorias supragenéticas dos táxons verificados.

\section{Listagem dos táxons}

São apresentadas 95 espécies de palinomorfos autóctones, correspondo a 51 espécies de esporos (relativas a 29 gêneros), 41 de grãos de pólen (16 gêneros), duas de algas e uma de Acritarca.

Dentre os táxons autóctones registrados, oito são noticiados pela primeira vez na Bacia do Paraná: Granulatisporites austroamericanus Archangelsky \& Gamerro, 1979; G. confluens Archangelsly \& Gamerro, 1979; Dibolisporites disfacies Jones \& Truswell, 1992; Convolutispora muriornata Menéndez, 1965; Cristatisporites spinosus (Menéndez \& Azcuy) Playford emend. Césari, 1985; Cirratriradites veeversi Playford, 1971; Protohaploxypinus panaki Utting, 1994 e Costapollenites ellipticus Tschudy \& Kosanke, 1956.

No Anexo 1, onde constam as ilustrações fotomicrográficas, todos os táxons selecionados são relacionados em ordem alfabética, para melhor consulta, com indicação das páginas de suas descrições, estampas e figuras.

Três espécies de Acritarca: Gorgonisphaeridium sp., Veryhachium trispinosus (Eisenack) Deunff, 1954, V. flagelliferum Wall \& Downie, 1962, uma de alga: Leiosphaeridia sp. e uma de Incertae Sedis: Chomotriletes cf. C. dejerseyi Hart, 1964 também foram verificadas. No entanto, não são apresentadas em razão de dúvidas quanto ao seu significado autóctone nas associações. 
Adicionalmente são tratadas à parte neste Capítulo 13 espécies de palinomorfos (esporos, algas e zoomorfo), considerados alóctones, dadas suas ocorrências restritas em estratos mais primitivos.

\section{ESPOROS TRILETES}

Lisos

Retusóides

Ornamentados

Muronados

Auriculados

Cingulados

Cingulicavados
Leiotriletes virkkii Tiwari, 1965

Calamospora hartungiana Schopf in Schopf, Wilson \& Bentall, 1944

Calamospora liquida Kosanke, 1950

Punctatisporites gretensis Balme \& Hennelly, 1956

Punctatisporites lucidulus Playford \& Helby, 1968

Retusotriletes nigritellus (Lüber) Foster, 1979

Granulatisporites triconvexus Staplin, 1960

Granulatisporites varigranifer Menéndez \& Azcuy, 1971

Granulatisporites austroamericanus Archangelsky \& Gamerro, 1979

Granulatisporites confluens Archangelsky \& Gamerro, 1979

Cyclogranisporites firmus Jones \& Truswell, 1992

Verrucosisporites microtuberosus (Loose) Smith \& Butterworth, 1967

Verrucosisporites morulatus Smith \& Butterworth, 1967

Apiculiretusispora variornata (Menéndez \& Azcuy) Menéndez \& Azcuy, 1971

Apiculatisporis sp.

Anapiculatisporites argentinensis Azcuy, 1975

Dibolisporites disfacies Jones \& Truswell, 1992

Horriditriletes uruguaiensis (Marques-Toigo) Archangelsky \& Gamerro, 1979

Raistrickia pinguis Playford, 1971

Raistrickia paganciana Azcuy, 1975

Raistrickia rotunda Azcuy, 1975

Convolutispora muriornata Menéndez, 1965

Convolutispora ordoñenzii Archangelsky \& Gamerro, 1979

Dictyotriletes muricatus (Kosanke) Smith \& Butterworth, 1967

Foveosporites hortonensis (Playford) Azcuy, 1975

Ahrensisporites cristatus Playford \& Powis, 1979

Reticulatisporites pseudopalliatus Staplin, 1960

Reticulatisporites passaspectus Ottone, 1991

Stenozonotriletes clarus Ischenko, 1958

Lundbladispora braziliensis (Marques-Toigo \& Pons) Marques-Toigo \& Picarelli, 1984

Lundbladispora riobonitensis Marques-Toigo \& Picarelli, 1984

Densosporites triangularis Kosanke, 1950

Densosporites annulatus (Loose) Smith \& Butterworth, 1967

Densosporites stellatus Azcuy, 1975

Kraeuselisporites volkheimerii Azcuy, 1975

Vallatisporites vallatus Hacquebard, 1957 
Vallatisporites ciliaris (Lüber) Sullivan, 1964

Vallatisporites spinosus Cauduro, 1970

Vallatisporites arcuatus (Marques-Toigo) Archangelsky \& Gamerro, 1979

Vallatisporites punctatus (Marques-Toigo) comb. nov.

Cristatisporites indignabundus (Potonié \& Kremp) Staplin \& Jansonius, 1964

Cristatisporites connexus Potonié \& Kremp, 1955

Cristatisporites menendezii (Menéndez \& Azcuy) Playford emend. Césari, 1985

Cristatisporites spinosus (Menéndez \& Azcuy) Playford emend. Césari, 1985

Cristatisporites inordinatus (Menéndez \& Azcuy) Playford, 1978

Cristatisporites inconstans Archangelsky \& Gamerro, 1979

Bascaudaspora canipa Owens, 1983

Cirratriradites veeversi Playford, 1971

Monopseudossacados Spelaeotriletes ybertii (Marques-Toigo) Playford \& Powis, 1979

Velamisporites sp.

Hilados Psomospora detecta Playford \& Helby, 1968

\section{GRÃOS DE PÓLEN}

Monossacados Simetria radial Cannanoropollis janakii Potonié \& Sah, 1960

Cannanoropollis triangularis (Mehtae) Bose \& Maheshwari, 1968

Cannanoropollis densus (Lele) Bose \& Maheshwari, 1968

Cannanoropollis perfectus (Bose \& Maheshwari) Dias-Fabrício, 1981

Plicatipollenites malabarensis (Potonié \& Sah) Foster, 1975

Plicatipollenites gondwanensis (Balme \& Hennelly) Lele, 1964

Plicatipollenites trigonalis Lele, 1964

Plicatipollenites densus Srivastava, 1970

Crucisaccites latisulcatus Lele \& Maithy, 1964

Crucisaccites monoletus Maithy, 1965

Simetria bilateral Florinites sp.

Potonieisporites novicus Bharadwaj emend. Poor \& Veld, 1997

Potonieisporites neglectus Potonié \& Lele, 1961

Potonieisporites triangulatus Tiwari, 1965

Potonieisporites barrelis Tiwari, 1965

Potonieisporites densus Maheshwari, 1967

Potonieisporites congoensis Bose \& Maheshwari, 1968

Potonieisporites brasiliensis (Nahuys et al.) Archangelsky \& Gamerro, 1979

Potonieisporites magnus Lele \& Karim, 1971

Divarisaccus stringoplicatus Ottone, 1991

Caheniasaccites flavatus Bose \& Kar emend. Azcuy \& Di Pasquo, 2000

Caheniasaccites sp.

Teniados

Bissacados Não-teniados
? Striomonosaccites sp.

Scheuringipollenites maximus Tiwari, 1973

Limitisporites rectus Leschik, 1956 


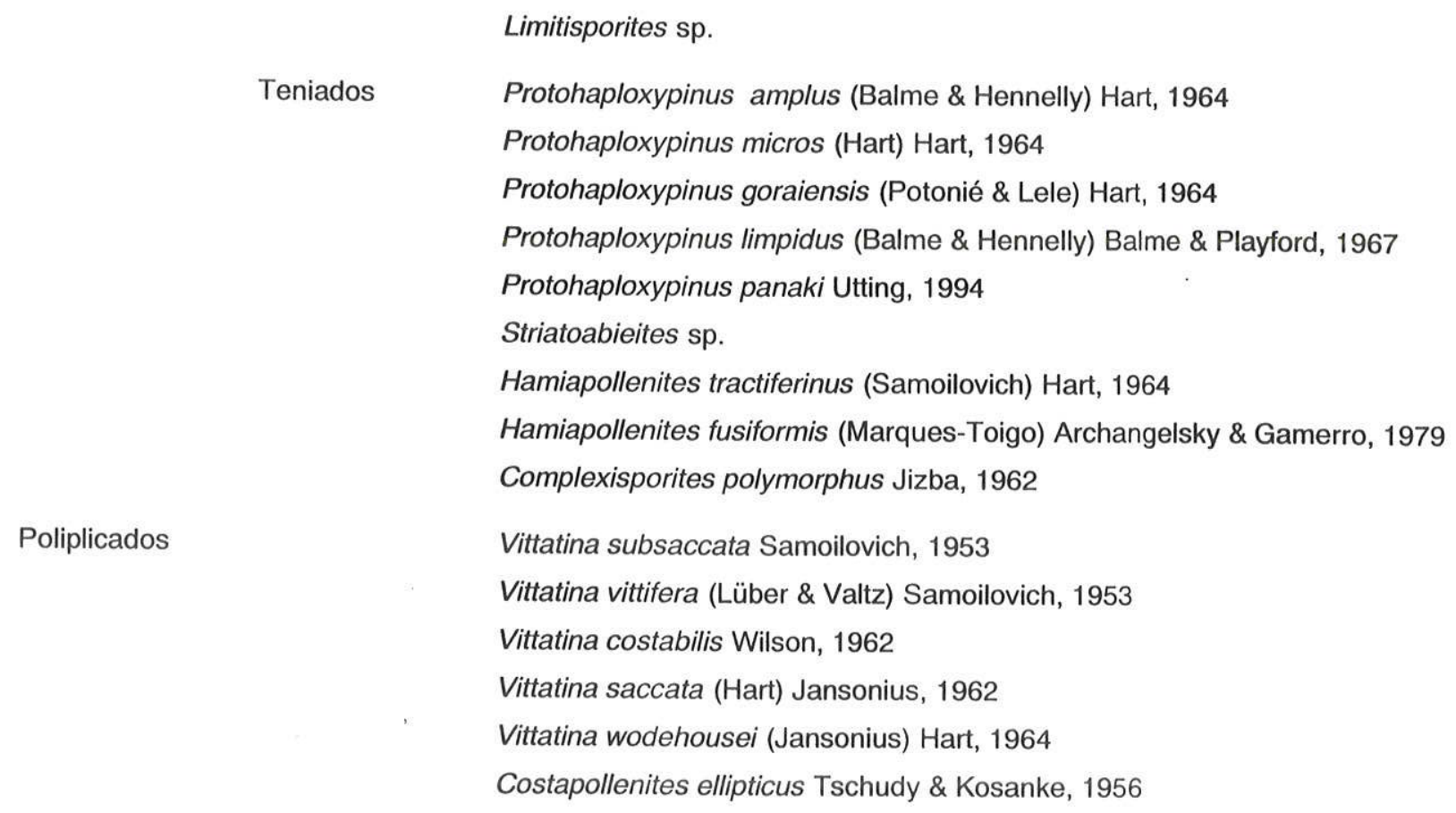

Algas prasinofíceas Tasmanites $\mathrm{sp}$.

ALGAS CLOROcocácEAS Botryococcus braunii Kützing, 1849

ACRITARCA

Deusilites tenuistriatus Gutiérrez, Césari \& Archangelsky, 1997 


\section{DESCRIÇOES SISTEMÁTICAS}

Nas descrições sistemáticas dos palinomorfos foram adotadas padronizações, algumas das quais comentadas a seguir. O sistema supragenérico de turmas, que caracteriza a parataxonomia utilizada para os esporomorfos, é grafado diferentemente no que tange aos nomes dos autores e datas, conforme proposta de Traverse (1996, p. 17), visto não tratar-se do sistema de nomenclatura formal.

A lista de sinonímia é referente aos registros prévios das espécies na Bacia do Paraná. Citações sem ilustrações e/ou descrições não foram consideradas. Para melhor análise, alguns táxons já registrados em publicações foram revisados a partir das lâminas originais (Lima et al., 1983; Souza et al., 1990, 1993ab, 1997).

Em "Diagnose" são apresentados, de forma abreviada, o trabalho original de proposição da espécie e, em seguida, sua localidade-tipo, com as informações, geográficas e estratigráficas, disponíveis nos originais. Na maioria dos casos, as descrições são breves. Em "Dimensões", são apresentados o total de espécimes e os principais caracteres mensurados; algumas medidas, de aspectos mais detalhados, já constam nas descrições. Comparações e observações foram feitas quando necessárias.

Em "Distribuição estratigráfica na Bacia do Paraná" são mencionados os registros prévios das espécies nessa unidade geológica, com base na sinonímia. No caso do zoneamento bioestratigráfico de Marques-Toigo $(1988,1991)$ a Zona Vittatina é utilizada no lugar de Zona Cannanoropollis korbaensis, mantendo-se seu sentido original, com modificação comente na nomenclatura, conforme apresentado no Capítulo IV.1. Da mesma forma, a Subzona Caheniasaccites flavatus é utilizada no lugar de Subzona Caheniasaccites ovatus. Em "Ocorrência, relaciona-se os registros relativos a este trabalho. Para a "Distribuição estratigráfica mundial", são citadas as ocorrências dos táxons por região, as idades são mencionadas como nos trabalhos originais. 
Anteturma ProximegerminANTES [Potonié, 1970]

Turma TRILETES \{ [Reinsch] Dettman, 1963 \}

Suprasubturma ACAVATITRILETES \{ [Lüber] Dettman, 1963 \}

Subturma AZONOLETES \{ [Lüber] Dettman, 1963 \}

Infraturma LAEVIGATI \{ [Bennié \& Kidston] Potonié, 1956 \}

Gênero Leiotriletes (Naumova) Potonié \& Kremp, 1956

Espécie-tipo: Leiotriletes sphaerotriangulus (Loose) Potonié \& Kremp, 1954.

Afinidade botânica: PTERIDOPHYTA-FILICOPSIDA (Potonié, 1962).

\section{Leiotriletes virkkii Tiwari, 1965}

Estampa I, figura 1

1968 L. virkkii, in Nahuys et al., fig. 4-5.

1975 L. virkkii, in Ybert, est. 1, fig. 2-3.

1978 L. virkkii, in Burjack, est. I, fig. 8.

1981 L. virkkii, in Dias-Fabrício, est. 1, fig. 2.

1987 L. virkkii, in Picarelli et al., est. 1, fig. 2.

1988 L. virkkii, in Marques-Toigo, est. I, fig. 7.

1991 L. virkkii, in Piccoli et al., fig. 1b.

1993 L. virkkii, in Dias, est. 1, fig. 2.

1995 L. virkkii, in Quadros et al., p. 74.

Diagnose: Tiwari [1965. Palaeobot., 13(2): p. 170-1; est. 1, fig. 2-3].

Localidade-tipo: Korba Coalfield, Permiano da Índia (Estágio Barakar).

Descrição: esporo radial trilete, isopolar; contorno equatorial triangular, lados retos a levemente convexos e ângulos arredondados. Raios da marca trilete distintos, retos, se estendendo até $1 / 2-5 / 5$ do raio total, às vezes acompanhados de lábios (1-4 $\mu \mathrm{m}$ de largura). Exina fina $(0,5-2,5 \mu \mathrm{m})$ e lisa, muitas vezes com aspecto escabrado quando corroída.

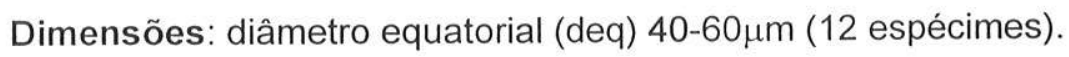

Ocorrência: Zonas Biointervalo Ahrensisporites cristatus, Potonieisporites neglectus e Subzona Protohaploxypinus goraiensis.

Comparações: a espécie mais semelhante é L. directus Balme \& Hennelly, 1956 que apresenta menores dimensões [23(28)36 $\mu \mathrm{m}]$. Entretanto, a julgar somente pelas diferenças de tamanho, é muito provável que $L$. directus e $L$. virkkiae constituam o mesmo táxon, com grande variação nas dimensões.

Observações: Segundo Tiwari (1965), L. virkkiae foi transferido para Microfoveolatispora Bharadwaj, 1962, o que não parece procedente tendo em vista a natureza não estruturada da exina de L. virkkii 
Distribuição estratigráfica na Bacia do Paraná: Subgrupo Itararé (Picarelli et al., 1987; Marques-Toigo, 1988; Piccoli et al., 1991; Dias, 1993), Formação Rio Bonito (Nahuys et al., 1968; Ybert, 1975; Burjack, 1978; Dias-Fabrício, 1981; Picarelli et al., 1987; Marques-Toigo, 1988; Piccoli et al., 1991), Formação Palermo (Marques-Toigo, 1988) e Subgrupo Irati (Picarelli et al., 1987). Zonas Vittatina e Lueckisporites virkkiae.

Distribuição estratigráfica mundial: Zona Cristatisporites Superior da Bacia Chacoparaná (Césari et al., 1995; Vergel, 1998), Argentina. Permiano Inferior do Uruguai (Fasolo \& Vergel, 1994; Beri \& Aguilar, 1998; Mautino et al., 1998a), Antártica (Lindström, 1995), Austrália (Backhouse, 1991), África (Maheshwari \& Bose, 1969) e Índia (Tiwari, 1965). Carbonífero Superior/Permiano Inferior do Omã e Arábia Saudita (Stephenson \& Filatoff, 2000).

\section{Gênero Calamospora Schopf, Wilson \& Bentall, 1944}

Espécie-tipo: Calamospora hartungiana Schopf in Schopf, Wilson \& Bentall, 1944.

Afinidade botânica: PTERIDOPHYTA-SPHENOPSIDA (Kosanke, 1950; Potonié \& Kremp, 1954; Courvousier \& Phillips, 1975; Bek \& Oplustil, 1998).

\section{Estampa I, figura 2 \\ 1996 C. hartungiana, in Souza, est. 1, fig. 4. \\ 1996 C. sp. in Souza, est. 1, fig. 6.}

Calamospora hartungiana Schopf in Schopf, Wilson \& Bentall, 1944

Diagnose: Schopf et al. (1944. State Geol. Surv. Illinois, Rep. Inv. 91: p. 51, fig. 1).

Localidade-tipo: Carvão Macoupin, Rio Salt Fork of Vermilion, Illinois, E.U.A.

Descrição: esporo radial trilete, isopolar; contorno equatorial circular. Raios da marca trilete geralmente indistintos, finos e retos, alcançando até $1 / 3$ do raio. Exina fina (1-1,5 $\mu \mathrm{m})$, lisa, geralmente corroída, apresentando grandes dobras $(5-13 \mu \mathrm{m}$ de largura $\times 30-90 \mu \mathrm{m}$ de comprimento), irregularmente distribuídas.

Dimensões: deq: 45(52)100 $\mu \mathrm{m}$ (33 espécimes).

Ocorrência: Zonas Biointervalo Ahrensisporites cristatus, Potonieisporites neglectus e Subzona Protohaploxypinus goraiensis.

Distribuição estratigráfica na Bacia do Paraná: Subgrupo Itararé (Souza, 1996).

Distribuição estratigráfica mundial: Carbonifero Superior a Permiano Inferior da Argentina (Césari \& Gutiérrez, 1984; Césari, 1985a, 1986; Ottone \& Azcuy, 1986, 1989; 1990; Césari \& Vazques-Nístico, 1988; Gutiérrez \& Césari, 1988; Ottone, 1991; Di Pasquo \& Azcuy, 1997a, 1999a; Di Pasquo, 1999). Tournaisiano a Westphaliano B dos E.U.A. (Felix \& 
Burbridge, 1967). Westphaliano do Canadá (Barss, 1967) e França (Venkatachala \& Kar, 1962). Carbonifero Superior da China (Zhou, 1994).

\section{Calamospora liquida Kosanke, 1950}

Estampa I, figura 3

1975 C. liquida, in Ybert, est 1, fig. 13

1976a C. liquida, in Pons, est. I, fig. 4.

1978 C. liquida, in Bortoluzzi et al., est. III, fig. 7.

1988 C. liquida, in Marques-Toigo, est. I, fig. 2.

1993 C. liquida, in Dias, est. 1, fig. 8.

1996 C. liquida, in Souza, est. 1, fig. 5.

Diagnose: Kosanke (1950. State Geol. Surv. Illinois, Bull. 74: p. 41, est. 9, fig. 1).

Localidade-tipo: Shoal Creek Coal Bed, Bond County, Illinois, Pensilvaniano dos E.U.A.

Descrição: esporo radial trilete, isopolar; contorno equatorial circular. Raios da marca trilete finos e retos, alcançando até $2 / 3$ do raio. Exina fina $(0,5-1,5 \mu \mathrm{m})$, lisa, com aspecto translúcido e, geralmente, com preguas na região equatorial.

Ocorrência: Zonas Biointervalo Ahrensisporites cristatus, Potonieisporites neglectus e Subzona Protohaploxypinus goraiensis.

Dimensões: deq: 42-62 $\mu \mathrm{m}$ (6 espécimes).

Comparações: a espécie mais similar é C. smileyana Menéndez, 1965, cujas dimensões da

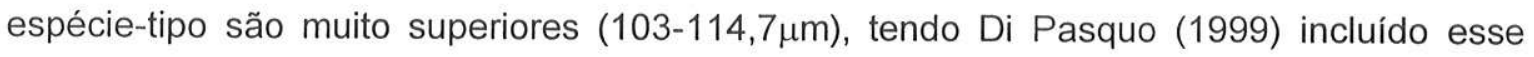
táxon na sinonímia de C. liquida.

Distribuição estratigráfica na Bacia do Paraná: Subgrupo Itararé (Pons, 1976a; MarquesToigo, 1988; Dias, 1993; Souza, 1996), Formação Rio Bonito (Ybert, 1975; Bortoluzzi et al., 1978; Marques-Toigo, 1988) e Formação Palermo (Marques-Toigo, 1988). Zonas Vittatina e Lueckisporites virkkiae.

Distribuição estratigráfica mundial: Zona Cristatisporites Inferior da Bacia Chacoparaná (Vergel, 1992); Carbonífero Superior da Argentina (Di Pasquo \& Azcuy, 1997a, 1999a), Canadá (Barss, 1967). Permiano Inferior do Uruguai (Beri \& Aguilar, 1998). Pensilvaniano dos E.U.A. (Kosanke, 1950). Devoniano a Carbonífero Inferior da Irlanda (Higgs, 1975).

\section{Gênero Punctatisporites (Ibrahim) Potonié \& Kremp, 1954}

Espécie-tipo: Punctatisporites punctatus Ibrahim, 1933.

Afinidade botânica: PTERIDOPHYTA-FILICOPSIDA (Potonié \& Kremp, 1956; Eggert \& Taylor, 1966; Courvoisier \& Phillips, 1975). 


\section{Punctatisporites gretensis Balme \& Hennelly, 1956}

Estampa I, figura 4

1965 P. gretensis, in Pant \& Srivastava, est. 1, fig. 12-3.

1967 P. gretensis, in Tiwari \& Navale, est. I, fig. 1.

1970 P. gretensis forma minor, in Cauduro, est. I, fig. 1-2.

1974 P. gretensis forma minor, in Marques-Toigo \& Pons, est. 1, fig. 1.

1974 P. sp., in Marques-Toigo \& Pons, est. 1, fig. 2.

1975 P. gretensis forma minor, in Corrêa-da-Silva \& Marques-Toigo, est. II, fig. 1.

1975 P. gretensis forma minor, in Pons, est. I, fig. 1-2.

1975 P. gretensis forma minor, in Ybert, est. 1, fig. 16-18.

1975 P. gretensis, in Kemp, est. 29l, fig. 14.

1976 P. gretensis forma minor, in Dellazzana, est. I, fig. 1-3.

1976a P. gretensis forma minor, in Pons, est. I, fig. 1.

1978 P. gretensis forma minor, in Burjack, est. I, fig. 2.

1978 P. gretensis, in Burjack, est. I, fig. 1.

1978 P. gretensis, forma minor, in Bortoluzzi et al., est. III, fig. 1.

1981 P. gretensis forma minor, in Dias-Fabrício, est. I, fig. 1.

1986 P. gretensis forma minor, in Picarelli, est. 1, fig. 1.

1987 P. gretensis forma minor, in Picarelli et al., est. 1, fig. 1.

1987 P. gretensis forma minor, in Sundaram, est. I, fig. 7.

1987 P. gretensis, in Sundaram, est. I, fig. 11.

1988 P. gretensis forma minor, in Marques-Toigo, est. I, fig. 1.

1991 P. gretensis forma minor, in Piccoli et al., fig. 1 a.

1993 P. gretensis forma minor, in Dias, est. 1, fig. 1.

1993a P. gretensis forma minor, in Souza et al., est. I, fig. 2.

1993a P. gretensis, in Souza et al., est. I, fig. 1.

1995 P. gretensis forma minor, in Quadros et al., p. 108.

1996 P. gretensis, in Souza, est. 1, fig. 1.

1997 P. gretensis, in Souza et al., est. I, fig. 1 e 6.

Diagnose: Balme \& Hennelly [1956. Austral. Journ. Bot., 4(3): p. 245-6; est. 2, fig. 11-13].

Localidade-tipo: Greta Coal Measures, New South Wales, Permiano da Austrália.

Descrição: esporo radial trilete, isopolar; contorno equatorial circular a subcircular; margem lisa. Raios da marca trilete retos a levemente sinuosos, estendendo-se até $1 / 2-4 / 5$ do raio, acompanhados por lábios [1(2) $5 \mu \mathrm{m}$ de largura]. Exina fina [1(2) $4 \mu \mathrm{m})$, lisa, com reduzido infrapunteamento $(<0,5 \mu \mathrm{m})$.

Dimensões: deq 33(54)94 $\mu \mathrm{m}$ (86 espécimes). 
Ocorrência: Zonas Biointervalo Ahrensisporites cristatus, Potonieisporites neglectus e Subzona Protohaploxypinus goraiensis.

Observações: as formas designadas como P. g. forma minor (Balme \& Hennelly) Hart, 1965 são incluídas nesta espécie, levando-se em consideração a proposta de Ottone (1991, p. 122), pela qual não é aconselhável a separação deste táxon seguindo-șe critérios de dimensões.

Distribuição estratigráfica na Bacia do Paraná: Subgrupo Itararé (Kemp, 1975; Pons, 1976a; Picarelli, 1986; Picarelli et al., 1987; Sundaram, 1987; Marques-Toigo, 1988; Piccoli et al., 1991; Dias, 1993; Souza et al., 1993a, 1997; Souza, 1996), Formação Rio Bonito (Pant \& Srivastava, 1965; Tiwari \& Navale, 1967; Cauduro, 1970; Marques-Toigo \& Pons, 1974; Corrêa-da-Silva \& Marques-Toigo, 1975; Ybert, 1975; Burjack, 1978; Bortoluzzi et al., 1978; Dias-Fabrício, 1981; Picarelli, 1986; Picarelli et al., 1987; Marques-Toigo, 1988; Piccoli et al., 1991), Formação Palermo (Picarelli, 1986; Picarelli et al., 1987; Marques-Toigo, 1988) e Subgrupo Irati (Delazzana, 1976; Picarelli, 1986; Picarelli et al., 1987). Zonas Vittatina e Lueckisporites virkkiae.

Distribuição estratigráfica mundial: Zonas Potonieisporites-Lundbladispora, Cristatisporites e Striatites (Archangelsky \& Gamerro, 1979; Russo et al., 1980; Césari et al., 1995) da Bacia Chacoparaná; Carbonífero Superior a Permiano Inferior da Argentina (Azcuy et al., 1982; Césari, 1985a; Vergel, 1986b, 1987a, 1998; Césari \& Vázquez-Nístico, 1988; Ottone, 1989, 1991; Ottone \& Azcuy, 1989, 1990; Limarino \& Gutiérrez, 1990; Vergel \& Luna, 1992; Vergel et al., 1993; Garcia, 1995; Césari \& Bercowski, 1997; Di Pasquo \& Azcuy, 1997a, 1999a; Di Pasquo, 1999). Permiano Inferior do Uruguai (Marques-Toigo, 1973; Beri, 1987, 1988; Fasolo \& Vergel, 1994; Beri \& Aguilar, 1998; Mautino et al., 1998a), África (Maheshwari \& Bose, 1969; Falcon, 1975), Índia (Tiwari, 1965, 1968), Antártica (Lindström, 1995) e Austrália (Balme \& Hennelly, 1956; Foster, 1979; Foster \& Waterhouse, 1988; Gilby \& Foster, 1988; Jones \& Truswell, 1992). Carbonífero Superior/Permiano Inferior de Omã e Arábia Saudita (Stephenson \& Filatoff, 2000).

\section{Punctatisporites lucidulus Playford \& Helby, 1968}

Estampa I, figura 5

1997 P. resolutus, in Souza et al., est. I, fig. 2.

Diagnose: Playford \& Helby [1968. Journ. Geol. Soc. Austral., 15(1): p. 107, est. 9, fig. 1-2].

Localidade-tipo: Balickera, New South Wales, Formação Italia Road, Westphaliano/Stephaniano da Austrália.

Descrição: esporo radial trilete, isopolar; contorno equatorial circular a subcircular. Raios da marca trilete retos, alcançando $1 / 2$ a $5 / 5$ do raio total; podendo apresentar lábios de até $1 \mu \mathrm{m}$ 
de largura. Exina fina [(2)3 $\mu \mathrm{m}]$, lisa, comportando fina e densa intragranulação, geralmente menor que 0,5 $\mu \mathrm{m}$ de diâmetro e maior em espécimes corroídos.

Dimensões: deq 41(54)60 $\mu \mathrm{m}$ (17 espécimes).

Ocorrência: Zonas Biointervalo Ahrensisporites cristatus e Potonieisporites neglectus.

Comparações: P. subtritus Playford \& Helby, 1968 e P. resolutus Playford, 19.71 apresentam exina relativamente mais espessa (respectivamente 3,5-4,5 $\mu \mathrm{m}$ e 3-5 $\mu \mathrm{m}$ ).

Distribuição estratigráfica na Bacia do Paraná: Subgrupo Itararé (Souza et al., 1997).

Distribuição estratigráfica mundial: Carbonífero Superior da Argentina (Gutiérrez \& Césari, 1988). Namuriano a Tastubiano da Austrália (Playford \& Helby, 1968; Jones \& Truswell, 1992). Permiano Inferior da Antártica (Lindström, 1995). Carbonífero Superior/Permiano Inferior de Omã e Arábia Saudita (Stephenson \& Filatoff, 2000).

Infraturma RETUSOTRILETI [Streel, 1964]

Gênero Retusotriletes (Naumova) Streel, 1964

Espécie-tipo: Retusotriletes simplex Naumova, 1953.

Afinidade botânica: PTERIDOPHYTA-PSILOPSIDA (Azcuy, 1978).

\section{Retusotriletes nigritellus (Lüber) Foster, 1979}

Estampa I, figura 6

1975 Calamospora nigritella, in Ybert, est. 1, fig. 14.

1978 Calamospora nigritella, in Burjack, est. I, fig. 5.

1981 Calamospora nigritella, in Dias-Fabrício, est. I, fig. 8.

1981 Calamospora nigritella, in Leipnitz, est. I, fig. 2.

1983 R. sp., in Lima et al., est. II, fig. 1.

1987 R. nigritellus, in Sundaram, est. II, fig. 2.

1988 Calamospora nigritella, in Marques-Toigo, est. I, fig. 5.

1993 Calamospora nigritella, in Dias, est. 1, fig. 4.

1995 R. nigritellus, in Quadros et al., p. 111.

1996 R. nigritellus, in Souza, est. 1, fig. 10.

Diagnose: Foster (1979. Geol. Surv. Queensland, Publ. Esp. 372: p. 30, est. 1, fig. 7 e 16).

Localidade-tipo: Bacia de Kuznetz, Permiano de Erynakova, ex-URSS.

Descrição: esporo radial trilete, isopolar; contorno equatorial circular a subcircular. Raios da marca trilete simples e retos, alcançando $1 / 2-2 / 3$ do raio. Exina fina $(1,5-2 \mu \mathrm{m})$, lisa a levemente escabrada. Área de contato escurecida na região inter-radial, delimitada, equatorialmente, por curvaturae imperfectae. 
Dimensões: deq 35-48 $\mu$ m (5 espécimes).

Ocorrência: Zonas Biointervalo Ahrensisporites cristatus, Potonieisporites neglectus e Subzona Protohaploxypinus goraiensis.

Distribuição estratigráfica na Bacia do Paraná: Subgrupo Itararé (Lima et al., 1983; Sundaram, 1987; Marques-Toigo, 1988; Dias, 1993; Souza, 1996), Formações Rio Bonito (Ybert, 1975; Burjack, 1978; Dias-Fabrício, 1981; Marques-Toigo, 1988) e Palermo (Leipnitz, 1981). Zona Vittatina.

Distribuição estratigráfica mundial: Westphaliano a Tastubiano (Jones \& Truswell, 1992) e Permiano Inferior a Superior da Austrália (Foster, 1979). Permiano Inferior da Antártica (Lindström, 1995). Carbonífero Superior/Permiano Inferior do Omã (Stephenson \& Filatoff, 2000).

$$
\begin{aligned}
& \text { Infraturma APICULATI \{ [Bennié \& Kidston] Potonié, } 1956 \text { \} } \\
& \text { Subinfraturma GRANULATI [Dybová \& Jachowicz, 1957] }
\end{aligned}
$$

\section{Gênero Granulatisporites (Ibrahim) Potonié \& Kremp, 1954}

Espécie-tipo: Granulatisporites granulatus Ibrahim, 1933.

Afinidade botânica: PTERIDOPHYTA-FILICOPSIDA (Potonié \& Kremp, 1956; Grauvogel-Stamm \& Doubinger, 1975; Millay \& Taylor, 1982).

\section{Granulatisporites triconvexus Staplin, 1960}

\section{Estampa I, figura 7}
? 1978 G. triconvexus, in Burjack, est. II, fig. 12.
? 1987 G. triconvexus, in Sundaram, est. II, fig. 13.
1996 G. triconvexus, in Souza, est. 1, fig. 16.

Diagnose: Staplin (1960. Palaeontogr., Abt B, 107: p. 15, est. 3, fig. 10).

Localidade-tipo: Formação Golata, West-Central Alberta, Viseano do Canadá.

Descrição: esporo radial trilete; contorno equatorial triangular, lados convexos e ângulos arredondados. Raios da marca trilete levemente sinuosos, alcançando 4/5-5/5 do raio,

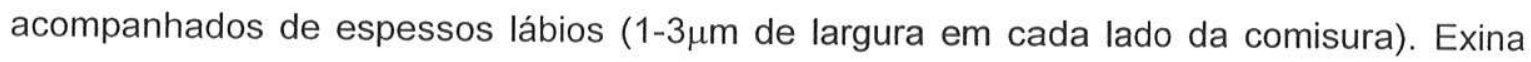
fina $(1-1,5 \mu \mathrm{m})$ e densamente granulosa $(<0,5 \mu \mathrm{m}$ de base $\mathrm{x}<0,5 \mu \mathrm{m}$ de altura).

Dimensões: deq 28-44 $\mu \mathrm{m}$ (3 espécimes).

Ocorrência: Zona Ahrensisporites cristatus.

Observações: as espécies descritas por Burjack (1978) e Sundaram (1987) são sinonimizadas com restrições, visto que os autores não mencionam as dimensões da ornamentação. 
Distribuição estratigráfica na Bacia do Paraná: Subgrupo Itararé (Sundaram, 1987; Souza, 1996) e Formação Rio Bonito (Burjack, 1978).

Distribuição estratigráfica mundial: Viseano (Barss, 1967) a Mississipiano Superior (Staplin, 1960) do Canadá.

\section{Granulatisporites varigranifer Menéndez \& Azcuy, 1971}

Estampa I, figura 9

1996 G. varigranifer, in Souza, est. 1, fig. 15.

1997 G. varigranifer, in Souza et al., est. I, fig. 10.

Diagnose: Menéndez \& Azcuy [1971. Amegh. VIII(1): p. 31, est. III, fig. 3-4].

Localidade-tipo: Formação Lagares, La Rioja, Grupo Paganzo, Namuriano/Westphaliano da Argentina.

Descrição: esporo radial trilete, isopolar; contorno equatorial triangular, lados retos a levemente convexos e ângulos arredondados. Raios da marca trilete simples e retos, alcançando $4 / 5-5 / 5$ do raio. Exina fina $(0,5-1 \mu \mathrm{m})$, ornamentada por grânulos de tamanhos variados $(0,5-2 \mu \mathrm{m}$ de base $\times 0,5-1 \mu \mathrm{m}$ de altura), com espaçamento de 1-2x o diâmetro das bases.

Dimensões: deq 31-48 $\mu$ m (4 espécimes).

Ocorrência: Zona Ahrensisporites cristatus.

Distribuição estratigráfica na Bacia do Paraná: Subgrupo Itararé (Souza, 1996; Souza et al., 1997).

Distribuição estratigráfica mundial: Palinozona de Ancistrospora (Azcuy \& Jelin, 1980); Carbonifero Superior a Permiano Inferior da Argentina (Azcuy, 1975a; Menéndez \& Azcuy, 1971; González-Amicón, 1973; Ottone, 1989; Vergel, \& Luna, 1992; Garcia, 1995; Di Pasquo \& Azcuy, 1997a, 1999a; Di Pasquo, 1999). Permiano Inferior do Uruguai (Mautino et al., 1998a).

\section{Granulatisporites austroamericanus Archangelsky \& Gamerro, 1979}

Estampa I, figura 8

Diagnose: Archangelsky \& Gamerro [1979. Rev. Esp. Microp., XI(3): p. 421-2, est. I, fig. 4].

Localidade-tipo: Poço CdO es-1, Bacia Chacoparaná, Permiano Inferior da Argentina.

Descrição: esporo radial trilete,. isopolar; contorno equatorial triangular, lados retos a levemente convexos e ângulos arredondados. Raios da marca trilete levemente sinuosos, alcançando $4 / 5$ a $5 / 5$ do raio, geralmente mais engrossados na região equatorial $(0,5-$ $1,5 \mu \mathrm{m})$. Exina fina $(1 \mu \mathrm{m})$, lisa na face proximal; ornamentada distalmente por diminutos 
grânulos $(\sim 0,5 \mu \mathrm{m}$ de base $\times 0,5 \mu \mathrm{m}$ de altura), uniformemente distribuídos, com espaçamento geralmente igual ao diâmetro da base.

Dimensões: deq 33-42 $\mu \mathrm{m}$ (6 espécimes).

Ocorrência: Zonas Biointervalo Ahrensisporites cristatus, Potonieisporites neglectus e Subzona Protohaploxypinus goraiensis.

Distribuição estratigráfica na Bacia do Paraná: inédita.

Distribuição estratigráfica mundial: Zonas Potonieisporites-Lundbladispora e Cristatisporites (Césari, 1986; Vergel, 1986b; 1987a, 1998; Césari et al., 1995), Bacia Chacoparaná; Carbonífero Superior a Permiano Inferior da Argentina (Garcia \& Azcuy , 1987; Ottone, 1989; Garcia, 1995; Di Pasquo \& Azcuy, 1997a, 1999a; Di Pasquo, 1999). Permiano Inferior do Uruguai (Fasolo \& Vergel, 1994; Beri \& Aguilar, 1998; Mautino et al., 1998a).

\title{
Granulatișporites confluens Archangelsky \& Gamerro, 1979
}

\author{
Estampa I, figura 10
}

Diagnose: Archangelsky \& Gamerro [1979. Rev. Esp. Microp., XI(3): p. 422-3, est. I, fig. 5-6].

Localidade-tipo: Poços CdO es-1, CdCA es-1 e CdS es-1, Bacia Chacoparaná, Permiano Inferior da Argentina.

Descrição: esporo radial trilete, isopolar; contorno equatorial triangular, lados retos a levemente convexos e ângulos arredondados. Raios da marca trilete levemente sinuosos,

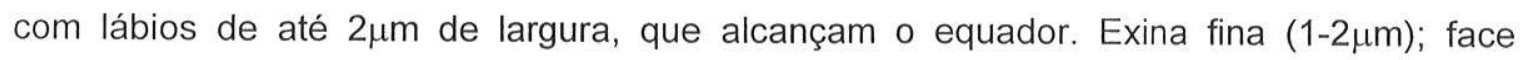
proximal lisa; face distal ornamentada por grânulos $[(1-1,5) 3 \mu \mathrm{m}$ de base $\times 1 \mu \mathrm{m}$ de altura], com espaçamento entre $0,5-1 \mu \mathrm{m}$.

Dimensões: deq 54-57 $\mu \mathrm{m}$ (3 espécimes).

Ocorrência: Subzona Protohaploxypinus goraiensis.

Observações: Backhouse (1991) transferiu G. confluens para o gênero Pseudoreticulatispora (Bharadwaj \& Srivastava) emend. Price \& Foster in Price, 1983 tendo por base que os exemplares verificados nos estratos australianos continham, no mínimo, pequenos grânulos na face proximal. Embora não muito bem preservado, a ornamentação não foi verificada no material do Subgrupo Itararé, pelo que se utiliza a espécie como originalmente proposta.

Distribuição estratigráfica na Bacia do Paraná: inédita.

Distribuição estratigráfica mundial: Zonas Potonieisporites-Lundbladispora e Cristatisporites da Bacia Chacoparaná (Russo et al., 1980; Césari, 1986; Vergel, 1986b, 1993, 1998; Césari et al., 1995; Di Pasquo, 1999; Di Pasquo \& Azcuy, 1999a), Carbonifero Superior a Permiano Inferior da Argentina. Permiano Inferior do Uruguai (Beri, 1987; Beri \& Aguilar, 1998). Zonas P. confluens (=G. confluens), Asseliano e Sakmariano/Tastubiano da Austrália (Foster \& Waterhouse, 1988; Backhouse, 1991). Carbonifero Superior/Permiano Inferior do Omã (Stephenson \& Filatoff, 2000). 


\section{Gênero Cyclogranisporites Potonié \& Kremp, 1954}

Espécie-tipo: Cyclogranisporites leopoldi (Kremp) Potonié \& Kremp, 1954.

Afinidade botânica: PTERIDOPHYTA-FILICOPSIDA (Potonié \& Kremp, 1956; Laveine, 1969).

\section{Cyclogranisporites firmus Jones \& Truswell, 1992}

Estampa I, figuras 11 e 12

1996 C. parvigranulosos, in Souza, est. 1, fig. 14.

Diagnose: Jones \& Truswell (1992. BMR Journ. Austral. Geol. \& Geophys., 13: p. 163, est. 8, fig. s, est. 9, fig. k-I, o-v).

Localidade-tipo: Formação Jericho, Bacia Galilee, Namuriano/Asseliano da Austrália.

Descrição: esporo radial trilete, isopolar; contorno equatorial circular. Raios da marca trilete retos, simples ou acompanhados por finos lábios [1-2 $\mu \mathrm{m}$ ], alcançando $1 / 2-2 / 2$ do raio. Exina fina $(1-2 \mu \mathrm{m})$, densamente ornamentada por grânulos com $(0,5)-1,2 \mu \mathrm{m}$ de base $\times 0,3-0,5 \mu \mathrm{m}$ de altura, espaçados em até $1 x$ o diâmetro da base. Os elementos ornamentais geralmente se apresentam anastomosados, constituindo um pseudoretículo negativo fino.

Dimensões: deq 41(51)71 $\mu$ m (32 espécimes).

Ocorrência: Zonas Biointervalo Ahrensisporites cristatus e Potonieisporites neglectus.

Comparações: C. flexuosus Playford, 1962 apresenta lábios elevados (até $6 \mu \mathrm{m}$ ) e C. pisticus Playford, 1978 não possuem lábios.

Observações: Jones \& Truswell (1992) mencionam dimensões mais reduzidas para os lábios $(<1 \mu \mathrm{m}$ de largura e algura). Na emenda de C. parvigranulosos (Leschik) Ybert, 1975 há ausência das dimensões dos grânulos (Ybert, 1975), o que dificulta a comparação do material com aquele assinalado na Formação Rio Bonito.

Distribuição estratigráfica na Bacia do Paraná: Subgrupo Itararé (Souza, 1996).

Distribuição estratigráfica mundial: Namuriano/Asseliano da Austrália (Jones \& Truswell, 1992). Carbonífero Superior da Argentina (Di Pasquo, 1999).

Subinfraturma VERRUCATI [Dybová \& Jachowicz, 1957]

Gênero Verrucosisporites (Ibrahim) Smith, 1971

Espécie-tipo: Verrucosisporites verrucosus (Ibrahim) Ibrahim, 1933.

Afinidade botânica: PTERIDOPHYTA-FILICOPSIDA (Laveine, 1969, 1971; Millay \& Taylor, 1982). 


\section{Verrucosisporites microtuberosus (Loose) Smith \& Butterworth, 1967}

Estampa II, figura 1

1986 V. microtuberosus, in Picarelli, est. 1, fig. 9.

1987 V. microtuberosus, in Picarelli et al., est. 1, fig. 9.

1988 V. microtuberosus, in Marques-Toigo, est. III, fig. 6.

1993 V. microtuberosus, in Dias, est. 3, fig. 5.

1995 V. microtuberosus, in Quadros et al., p. 132.

Diagnose: Smith \& Butterworth (1967. Special Paper in Palaeontology, vol. 1: p. 150, est. 5, fig. 9-11).

Descrição: esporo radial trilete, isopolar; contorno equatorial subcircular. Raios da marca trilete retos, alcançando 2/3-3/3 do raio, podendo estar acompanhados de finos lábios (1,5$2 \mu \mathrm{m}$ de largura). Exina fina [1,5(2)2,5 $\mu \mathrm{m}]$, ornamentada por elementos verrucosos (verrugas irregulares e verrugas cônicas), de ápices acuminados e aplainados, irregularmente distribuídos e de dimensões variadas [1(2)2,5 $\mu \mathrm{m}$ de base $\times 1-3 \mu \mathrm{m}$ de altura].

Dimensões: deq 50-53 $\mu$ m (5 espécimes).

Ocorrência: Zonas Biointervalo Ahrensisporites cristatus, Potonieisporites neglectus e Subzona Protohaploxypinus goraiensis.

Distribuição estratigráfica na Bacia do Paraná: Subgrupo Itararé (Dias, 1993), Formações Rio Bonito e Palermo (Picarelli, 1986; Picarelli et al., 1987; Marques-Toigo) e Subgrupo Irati (Picarelli, 1986; Picarelli et al., 1987). Zonas Vittatina e Lueckisporites virkkiae.

Distribuição estratigráfica mundial: Namuriano da China (Zhu-Huaicheng, 1993). Westphaliano da Europa (Smith \& Butterworth, 1967; Clayton et al., 1977).

\section{Verrucosisporites morulatus (Knox) Smith \& Butterworth, 1967}

Estampa II, figura 2

1981 V. morulatus, in Dias-Fabrício, est. 2, fig. 9.

1987 V. morulatus, in Picarelli et al., est. 1, fig. 11.

1988 V. morulatus, in Marques-Toigo, est. III, fig. 7.

1993 V. morulatus, in Dias, est. 3, fig. 7.

1995 V. morulatus, in Quadros et al., p. 133.

1996 V. cf. V. morulatus, in Souza, est. 1, fig. 18

1996 V. sp., in Souza. est. 1, fig. 19.

1996 V. verrucosus, in Souza, est. 1, fig. 17. 
Diagnose: Smith \& Butterworth (1967. Special Paper in Palaeontology, vol. 1: p. 151, est. 5, fig. 15-16).

Localidade-tipo: Sulphur Seam, Lindsay Colliery, Namuriano A da Escócia.

Descrição: esporo radial trilete, isopolar; contorno equatorial subcircular. Raios da marca trilete simples e retos, alcançando $2 / 3-3 / 3$ do raio. Exina fina $(1-3 \mu \mathrm{m})$, ornamentada por verrugas discretas, irregularmente espaçadas $(0,5-3 \mu \mathrm{m})$, com ápices aplainados a arredondados, de dimensões variadas $[1-4 \mu \mathrm{m}$ de base $\times 1-2 \mu \mathrm{m}$ de altura].

Dimensões: deq 36(53)66 $\mu \mathrm{m}$ (6 espécimes).

Ocorrência: Zonas Biointervalo Ahrensisporites cristatus, Potonieisporites neglectus e Subzona Protohaploxypinus goraiensis.

Comparações: V. verrucosus (Ibrahim) Ibrahim, 1933 possui ornamentação mais densamente arranjada.

Distribuição estratigráfica na Bacia do Paraná: Subgrupo Itararé (Dias, 1993; Souza, 1996), formações Rio Bonito e Palermo (Picarelli et al., 1987; Marques-Toigo, 1988) e Subgrupo Irati (Picarelli et al., 1987). Zonas Vittatina e Lueckisporits virkkiae.

Distribuição estratigráfica mundial: Viseano a Namuriano da Inglaterra (Neves, 1961; Smith \& Butterworth, 1967).

Subinfraturma NODATI [Dybová \& Jachowicz, 1957]

Gênero Apiculiretusispora (Ibrahim) Potonié \& Kremp, 1954

Espécie-tipo: Apiculiretusispora brandtii Strell, 1964.

Afinidade botânica: sem referências.

Apiculiretusispora variornata (Menéndez \& Azcuy) Menéndez \& Azcuy, 1971

Estampa II, figura 3

1996 Retusotriletes baculiferus, in Souza, est. 1, fig. 9.

1996 Retusotriletes golatensis, in Souza, est. 1, fig. 8.

1996 Apiculiretusispora sp., in Souza, est. 2, fig. 1.

1997 Retusotriletes golatensis, in Souza et al., est. I, fig. 3.

Diagnose: Menéndez \& Azcuy [1969. Amegh., VI(2): p. 88-90, est. III, fig. A-H).

Localidade-tipo: Formação Lagares; Grupo Paganzo, La Rioja, Namuriano/Westphaliano da Argentina.

Descrição: esporo radial trilete, anisopolar; contorno equatorial circular a subcircular. Raios da marca trilete bem marcados, simples e retos, alcançando a margem equatorial, onde formam uma curvaturae, delimitando a área de contato. Exina fina $(06,-1,5 \mu \mathrm{m})$, distalmente 
ornamentada por projeções espini-, coni- e baculiformes $(0,5-2 \mu \mathrm{m}$ de base $\times 0,5-2 \mu \mathrm{m}$ de altura), bem espaçadas, projetando-se na margem equatorial.

Dimensões: deq 20-42,5 $\mu \mathrm{m}$ (13 espécimes).

Ocorrência: Zonas Biointervalo Ahrensisporites cristatus e Potonieisporites neglectus.

Comparações: As espécimes sinonimizadas, assinaladas no gênero Retusotriletes, são melhor agrupadas em Apiculiretusispora, conforme proposição de Streel (1964), que aí inclui as formas que apresentam curvaturae perfectae e exina distalmente ornamentada.

Distribuição estratigráfica na Bacia do Paraná: Subgrupo Itararé (Souza, 1996; Souza et al., 1997).

Distribuição estratigráfica mundial: Carbonífero Superior a Permiano Inferior da Argentina (Menéndez \& Azcuy, 1971; Azcuy et al., 1982; Césari, 1985a; Gutiérrez \& Césari, 1988; Ottone, 1989, 1991; Limarino \& Gutiérrez, 1990; Garcia, 1995).

\section{Gênero Apiculatisporis (Ibrahim) Potonié \& Kremp, 1956}

Espécie-tipo: Apiculatisporis aculeatus Ibrahim, 1933.

Afinidade botânica: PTERIDOPHYTA-FILICOPSIDA (Galtier \& Scott, 1979).

\section{Apiculatisporis sp.}

Estampa II, figuras 4 a 6

1983 Acanthotriletes castanea, in Lima et al., est. II, fig. 11.

1983 Baculatisporites sp. 1, in Lima et al., est. II, fig. 14.

1983 Baculatisporites sp. 2, in Lima et al., est. II, fig. 15.

1983 Baculatisporites sp. 3, in Lima et al., est. II, fig. 16.

Descrição: esporo radial trilete, isopolar; contorno equatorial circular a subcircular; margem com contorno irregular devido à projeção da ornamentação. Raios da marca trilete simples, alcançando até $3 / 4$ do raio, pouco visivel, pela densidade da ornamentação. Exina fina $(1,5-$ $2,5 \mu \mathrm{m})$, ornamentada proxima- e distalmente por espinhos de extremos arredondados, báculas, cones acuminados e elementos lanceolados. Pregas subequatoriais são quase sempre presentes.

Dimensões (39 espécimes): deq 42(53)78 $\mu \mathrm{m}$; elementos ornamentais $0,5(1,5) 5 \mu \mathrm{m}$ de base $x$ $1(3-4) 7 \mu \mathrm{m}$ de altura.

Ocorrência: Zonas Biointervalo Ahrensisporites cristatus e Potonieisporites neglectus.

Comparações: alguma semelhança se observa com o exemplar de Neoraistrickia ramosa (Balme \& Hennelly) Hart, 1960, ilustrado por Menéndez (1971, est. II, fig. 7), do qual se separa pelo predomínio de báculas, ornamentação menos variada e ausência de pregueamento marginal. O exemplar de Horriditriletes pathakheraensis Anand-Prakash, 
1970 ilustrado por Quadros et al. (1995, p. 68) apresenta certa similaridade, mas sua forma é claramente triangular e o diâmetro equatorial menor. Raistrickia cf. aculeata Kosanke, 1950 ilustrada por Menéndez \& Azcuy (1971, est. III, fig. 1) se separa pela ornamentação mais robusta, com menor proporção de cones. Em A. rallus Menéndez, 1965 a ornamentação é mais esparsa e de menores dimensões (até $2,9 \mu \mathrm{m}$ de altura). A. hericinus Menéndez, 1965 apresenta ornamentação menos variada (cones tubulares e espinhos) de

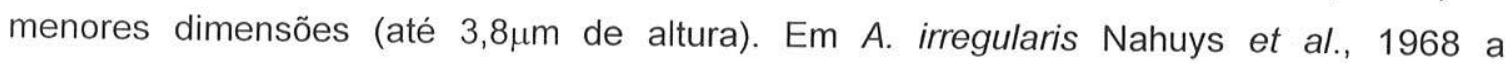

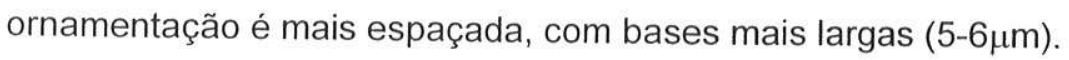

Observações: fora da Bacia do Paraná, Acanthotriletes sp. descrito por Ottone (1991, est. I, fig. 1-3) e aquelas designadas como Apiculatisporites sp. descritas por Garcia (1995, est. II, fig. 3 e 4) e Césari \& Bercowski (1997, est. I, fig. 9) apresentam perfeita similaridade com a espécie aqui descrita. As espécies assinaladas no Subgrupo Itararé por Lima et al. (1983) são sinonimizadas após revisões das lâminas originais.

Distribuição estratigráfica na Bacia do Paraná: Subgrupo Itararé (Lima et al., 1983).

Distribuição estratigráfica mundial: Formações Tupe (Ottone, 1991), Jejenes (Césari \& Bercowski, 1997) e El Imperial (Garcia, 1995), Carbonifero Superior da Argentina.

\section{Gênero Anapiculatisporis (Potonié \& Kremp) Smith \& Butterworth, 1967}

Espécie-tipo: Anapiculatisporis isselburgensis Potonié \& Kremp, 1954.

Afinidade botânica: sem referências.

\section{Anapiculatisporis argentinensis Azcuy, 1975}

Estampa II, figuras 7 e 8

1993a Granulatisporites cf. G. varigranifer, in Souza et al., et. 1, fig. 4.

Diagnose: Azcuy [1975. Amegh., XII(1): p. 42-44, est. XIII, p. 76-80].

Localidade-tipo: Formação Malazán (Membro Estratos Carbonosos), Grupo Paganzo, Namuriano/Westphaliano da Argentina.

Descrição: esporo radial trilete, anisopolar; contorno equatorial triangular, lados retos a levemente convexos e ângulos arredondados. Raios da marca trilete simples e retos, alcançando $3 / 4$ do raio. Exina fina $(<1 \mu \mathrm{m})$, finamente microgranulada. Face distal com forte

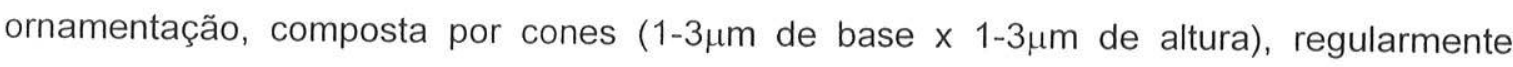
distribuídos e espaçados ( $1 \times$ ou menos), ausentes na periferia inter-radial.

Dimensões: deq 36-48 $\mu \mathrm{m}$ (5 espécimes).

Ocorrência: Zona Ahrensisporites cristatus.

Distribuição estratigráfica na Bacia do Paraná: Subgrupo Itararé (Souza et al., 1993a). 
Distribuição estratigráfica mundial: Palinozona de Ancistrospora (Azcuy \& Jelin, 1980), Carbonifero Superior da Argentina (Limarino \& Gutiérrez, 1990; Garcia, 1995; Di Pasquo, 1999; Di Pasquo \& Azcuy, 1999a).

\section{Gênero Dibolisporites (Richardson) Playford, 1976}

Espécie-tipo: Dibolisporites echinaceus (Eisenack) Richardson, 1965.

Afinidade botânica: sem referências.

\section{Dibolisporites disfacies Jones \& Truswell, 1992}

Estampa II, figuras 10 e 11

Diagnose: Jones \& Truswell (1992. BMR Journ. Austral. Geol. \& Geophys., 13: p. 167, fig. 11A-M).

Localidade-tipo: Formação Jericho, Bacia Galilee, Queensland, Namuriano/Tastubiano da Austrália.

Descrição: esporo radial trilete; contorno equatorial subcircular a subovalado. Raios da marca trilete e face proximal raramente presentes. Face distal e região equatorial ornamentada por elementos biformes discretos, de bases verrucosas (1-2,5 $\mu \mathrm{m}$ de base $\times 1-2 \mu \mathrm{m}$ de altura), circular em plano, com espinhos no topo $(0,5 \mathrm{~m}$ de base $\mathrm{x}$ até $1 \mu \mathrm{m}$ de altura), espaçados entre $0,5-1 \mu \mathrm{m}$.

Dimensões: deq 38-64 $\mu \mathrm{m}$ (8 espécimes).

Ocorrência: Zonas Biointervalo Ahrensisporites cristatus e Potonieisporites neglectus.

Observações: Lophosphaeridium sp. ilustrada por Lindström (1995, est. XIV, fig. 5), do Permiano Inferior da Antártica, é muito similar à D. disfacies.

Distribuição estratigráfica na Bacia do Paraná: inédita.

Distribuição estratigráfica mundial: Carbonífero Superior da Argentina (Di Pasquo, 1999), Omã e Arábia Saudita (Besems \& Schuurman, 1987; Stephenson \& Filatoff, 2000).

Subinfraturma BACULATI [Dybová \& Jachowicz, 1957]

Gênero Horriditriletes Bharadwaj \& Salujha, 1964

Espécie-tipo: Horriditriletes curvibaculosus Bharadwaj \& Salujha, 1964.

Afinidade botânica: PTERIDOPHYTA-FILICOPSIDA (Gould \& Delevoryas, 1977, Vergel, 1986a).

Horriditriletes uruguaiensis (Marques-Toigo) Archangelsky \& Gamerro, 1979

Estampa II, figuras 9 e 12

1975 Lophotriletes-Horriditriletes sp., in Kemp, est. 29I, fig. 3-4. 
1988 H. uruguaiensis, in Marques-Toigo, est. II, fig. 6.

1993 H. uruguaiensis, in Dias, est. 2, fig. 9.

1997 H. uruguaiensis, in Souza et al., est. I, fig. 11.

Diagnose: Marques-Toigo [1974. An. Acad. bras. Ci., 46(3/4): p. 262, est. I fig. 4-5].

Localidade-tipo: Paso de las Bochas, Formação San Gregório, Permiano Inferior do Uruguai.

Descrição: esporo radial trilete, isopolar; contorno equatorial triangular, lados retos a ligeiramente côncavos e ângulos arredondados. Raios da marca trilete retos, alcançando 4/5-5/5 do raio, simples, raramente engrossados (1-1,5 $\mu \mathrm{m}$ de largura). Exina fina (1-1,5 $\mu \mathrm{m})$, ornamentada por, predominantemente, báculas e verrugas, apresentando subordinadamente cones, espinhos e elementos papiliformes.

Dimensões: deq 30(40)50 $\mu$ m (20 espécimes).

Ocorrência: Zonas Biointervalo Ahrensisporites cristatus, Potonieisporites neglectus e Subzona Protohaploxypinus goraiensis.

Comparações: em H. curvibaculosus Bharadwaj \& Salujha, 1964 os raios da marca trilete não alcançam a margem equatorial ( $1 / 2$ a $3 / 4$ do raio).

Distribuição estratigráfica na Bacia do Paraná: Subgrupo Itararé (Kemp, 1975; MarquesToigo, 1988; Dias, 1993; Souza et al., 1997) e Formação Rio Bonito (Marques-Toigo, 1988). Zona Vittatina (Subzonas Protohaploxypinus goraiensis e Caheniasaccites flavatus).

Distribuição estratigráfica mundial: Zonas Potonieisporites-Lundbladispora e Cristatisporites na Bacia Chacoparaná (Archangelsky \& Gamerro, 1979; Vergel, 1986b, 1987a, 1993, 1998; Césari et al., 1995); Carbonífero Superior a Permiano Inferior da Argentina (Gutiérrez \& Césari, 1988; Ottone, 1989; Ottone \& Azcuy, 1989; Garcia, 1995). Permiano Inferior do Uruguai (Marques-Toigo, 1973; Beri, 1987; Fasolo \& Vergel, 1994; Beri \& Aguilar, 1998).

\section{Gênero Raistrickia (Schopf, Wilson \& Bentall) Potonié \& Kremp, 1954}

Espécie-tipo: Raistrickia grovensis Schopf, Wilson \& Bentall, 1944.

Afinidade botânica: PTERIDOPHYTA-FILICOPSIDA (Potonié \& Kremp, 1956; Eggert \& Taylor, 1966; Laveine, 1969; Andrews et al., 1970; Grauvogel-Stamm \& Doubinger, 1975).

\section{Raistrickia pinguis Playford, 1971}

Estampa III, figuras 1 e 2

1993a R. sp., in Souza et al., est. 1, fig. 11.

1993a R. rotunda, in Souza et al., est. 1, fig. 10.

Diagnose: Playford (1971. Miner. Resour. Geol. and Geophys. Austral., Bull. 115: p. 22-3, est. 5, fig. 9-12).

Localidade-tipo: Bonaparte Beds, Bonaparte Gulf Basin, Viseano do Oeste da Austrália. 
Descrição: esporo radial trilete, isopolar; contorno equatorial subcircular a convexamente subtriangular. Raios da marca trilete finos e retos, quase alcançando a margem equatorial. Exina grossa, com até $2,5 \mu \mathrm{m}$ de espessura, densamente ornamentada por projeções baculosas e funjiformes proeminentes, de bases arredondadas, lados retos e topos poligonais, aplainados e arredondados.

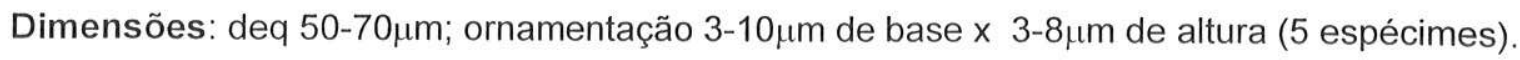

Ocorrência: Zona Ahrensisporites cristatus.

Comparações: em $R$. rotunda, os elementos ornamentais são menos robustos, com topos amplamente arredondados.

Distribuição estratigráfica na Bacia do Paraná: Subgrupo Itararé (Souza et al., 1993a).

Distribuição estratigráfica mundial: Viseano da Austrália (Playford, 1971; Playford \& Satterthwait, 1986).

\section{Raistrickia paganciana Azcuy, 1975}

Estampa III, figuras 3 e 6

? 1983 R. sp. cf. R. paganciana, in Lima et al., est. II, fig. 18.

1993 R. paganciana, in Dias, est. 1, fig. 16.

1993a R. paganciana, in Souza et al., est. 1, fig. 13.

1993a R. cf. R. paganciana, in Souza et al., est. 1, fig. 14.

Diagnose: Azcuy [1975. Amegh., XII(1): p. 60, est. XVI, fig. 106-7; est. XVII, est. 108-9].

Localidade-tipo: Formação Malazán (Membro Estratos Carbonosos), Grupo Paganzo, Namuriano/Westphaliano da Argentina.

Descrição: esporo radial trilete, isopolar; contorno equatorial subcircular a ovalado. Raios da marca trilete simples e retos, por vezes indistintos, alcançando a margem equatorial. Exina grossa $(3-4 \mu \mathrm{m})$, ornamentada por grandes projeções vesiculosas $(5-14 \mu \mathrm{m}$ de base $\times 3$ $7,5 \mu \mathrm{m}$ de altura), baculiformes, de distribuição e espaçamento irregular.

Dimensões: deq 38-75 $\mu$ m (5 espécimes).

Ocorrência: Zonas Biointervalo Ahrensisporites cristatus, Potonieisporites neglectus e Subzona Protohaploxypinus goraiensis.

Distribuição estratigráfica na Bacia do Paraná: Subgrupo Itararé (Lima et al., 1983; Dias, 1993; Souza et al., 1993a).

Distribuição estratigráfica mundial: Palinozona de Ancistrospora (Azcuy \& Jelin, 1980), Carbonífero Superior da Argentina (Azcuy, 1975a; Ottone 1991; Di Pasquo \& Azcuy, 1997a, 1999a; Di Pasquo, 1999). 


\section{Raistrickia rotunda Azcuy, 1975}

Estampa III, figuras 4 e 5

1983 R. rotunda, in Lima et al., est. II, fig. 20.

1993a R. rotunda, in Souza et al., est. 1, fig. 12.

1996 R. rotunda, in Souza, est. 2, fig. 3.

1997 R. rotunda, in Souza et al., est. 1, fig. 12.

Diagnose: Azcuy [1975. Amegh., XII(1): 60-62, est. XVII, fig. 110-3; est. XVIII, fig. 118].

Localidade-tipo: Formação Malazán (Membro Estratos Carbonosos), Grupo Paganzo, Namuriano/Westphaliano da Argentina.

Descrição: esporo radial trilete, isopolar; contorno equatorial subcircular a circular. Raios da marca trilete simples, retos, alcançando a margem equatorial, às vezes indistintos devido à forte ornamentação. Exina grossa (2,5-3.tm), ornamentada por projeções fungiformes, papilas e báculas de ápices amplamente arredondados $(2-10 \mu \mathrm{m}$ de base $\times 2-8 \mu \mathrm{m}$ de altura).

Dimensões: deq 46-66 $\mu \mathrm{m}$ (9 espécimes).

Ocorrência: Zonas Biointervalo Ahrensisporites cristatus e Potonieisporites neglectus.

Distribuição estratigráfica na Bacia do Paraná: Subgrupo Itararé (Lima et al., 1983; Dias, 1993).

Distribuição estratigráfica mundial: Palinozona de Ancistrospora (Azcuy \& Jelin, 1980); Carbonifero Superior a Permiano Inferior da Argentina (Ottone, 1989, 1991; Vergel \& Luna, 1992; Garcia, 1995; Di Pasquo \& Azcuy, 1997a, 1999a; Di Pasquo, 1999).

Infraturma MuRoRnatI [Potonié \& Kremp, 1954]

Gênero Convolutispora Hoffmeister, Staplin \& Malloy, 1955

Espécie-tipo: Convolutispora florida Hoffmeister, Staplin \& Malloy, 1955.

Afinidade botânica: PTERIDOPHYTA.FILICOPSIDA (Laveine, 1969).

\section{Convolutispora muriornata Menéndez, 1965}

Estampa III, figura 7

Diagnose: Menéndez [Rev. Mus. Arg: Ci. Nat. Bern. Riv., 1(3): p. 59-60, est. II, fig. 2; est. II, fig. 6-8].

Localidade-tipo: Sierra de Famatina, Grupo Paganzo, Westphaliano da Argentina.

Descrição: esporo radial trilete, isopolar; contorno equatorial circular a subcircular. Raios da marca tritete simples, alcançando $2 / 3$ do raio total, geralmente obscurecidos pela densidade 
da ornamentação. Exina ornamentada por muros de $2-5 \mu \mathrm{m}$ de largura $\times 2-3 \mu \mathrm{m}$ de altura, anastomosados, com diminuta ornamentação granulosa nos topos $(\ll<1 \mu \mathrm{m})$.

Dimensões: deq 50-57ım (5 espécimes).

Ocorrência: Zonas Biointervalo Ahrensisporites cristatus e Potonieisporites neglectus.

Distribuição estratigráfica na Bacia do Paraná: inédita.

Distribuição estratigráfica mundial: Zona Cristatisporites inferior-média da Bacia Chacoparaná (Vergel, 1993, 1998), Permiano Inferior; Palinozona de Ancistrospora (Azcuy \& Jelin, 1980), Carbonifero Superior da Argentina (Menéndez, 1965; González Amicón, 1973; Azcuy, 1975b; Césari \& Gutiérrez, 1984; 1988; Césari, 1985; Gutiérrez \& Césari, 1988; Ottone, 1989, 1991; Limarino \& Gutiérrez, 1990; Garcia, 1995).

\section{Convolutispora ordoñenzii Archangelsky \& Gamerro, 1979}

Estampa III, figura 8

$1993 a$ C. sp., in Souza et al., est. I, fig. 7.

Diagnose: Archangelsky \& Gamerro [1979. Rev. Esp. Microp., XI(3): p, 429-30, est. III, fig. 13].

Localidade-tipo: Poço CdO es-1, Bacia Chacoparaná, Permiano Inferior da Argentina.

Descrição: esporo radial trilete, isopolar; contorno equatorial subcircular. Raios da marca trilete raramente visiveis devido à forte ornamentação. Exina densamente vermiculada, composta por rúgulas muito sinuosas e verrugas distintas $(2-6 \mu \mathrm{m}$ de largura $x$ até $4 \mu \mathrm{m}$ de altura), com espaçamento inferior ao diâmetro das bases, de modo a formar auréolas.

Dimensões: deq 42-58нm (23 espécimes).

Ocorrência: Zonas Biointervalo Ahrensisporites cristatus e Potonieisporites neglectus.

Observações: embora Archangelsky \& Gamerro (1979) não tenham indicado as dimensões da ornamentação na diagnose original da espécie, os espécimes aqui verificados são muito semelhantes com os descritos e ilustrados por esses autores.

Distribuiçăo estratigráfica na Bacia do Paraná: Subgrupo Itararé (Souza et al., 1993a).

Distribuiçăo estratigráfica mundial: Zona Cristatisporites e Striatites da Bacia Chacoparaná (Vergel, 1986b; Aceñolaza \& Vergel, 1987; Césari et al., 1995); Carbonífero Superior a Permiano da Argentina (Césari \& Gutiérrez, 1984; Ottone, 1989, 1991; Césari \& Bercowski, 1997; Di Pasquo, 1999). Permiano Inferior do Uruguai (Mautino et al., 1998a).

Gênero Dictyotriletes (Naumova) Smith \& Butterworth, 1967

Espécie-tipo: Dictyotriletes bireticulatus (Ibrahim) Potonié \& Kremp, 1954.

Afinidade botânica: PTERIDOPHYTA/ ?SPHENOPSIDA (Hamer \& Rothwell, 1983). 
Dictyotriletes muricatus (Kosanke) Smith \& Butterworth, 1967

Estampa IV, figura 9

1996 D. muricatus, in Souza, est. 2, fig. 7.

1996 D. sp., in Souza, est. 2, fig. 9.

Diagnose: Kosanke (1950. State Geol. Surv. Illinois, Bull. 74: p. 27, est. 4, fig. 7).

Localidade-tipo: La Salle Coal Bed, Bureau County, Illinois, Pensilvaniano dos E.U.A.

Descrição: esporo radial trilete, isopolar; contorno equatorial subcircular. Raios da marca trilete retos, alcançando $4 / 5$ do raio. Exina espessa $(3 \mu \mathrm{m})$, esculturada por muros em ambas as faces, estendendo-se até $12 \mu \mathrm{m}$ além do corpo central, $2.5 \mu \mathrm{m}$ de largura. Lúmina

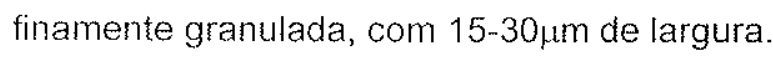

Dimensões: deq 50-70 $\mathrm{mm}$ ( 3 espécimes).

Ocorrência: Zonas Biointervalo Ahrensisporites cristatus e Potonieisporites neglectus.

Comparações: Dictyotriletes sp., descrita na Formação Tupe, Argentina (Césari, 1985a), é muito similar, ainda que as lúminas sejam menos desenvolvidas (até $23 u m$ ).

Distribuição estratigráfica na Bacia do Paraná: Subgrupo Itararé (Souza, 1996).

Distribuição estratigráfica mundial: Namuriano (Clayton et al., 1977) a Westphaliano (Smith \& Butterworth, 1967; Van Wijhe et al., 1974; Owens et al., 1977; Turner \& Spinner, 1993; Turner et al., 1995) da Europa.

\section{Gênero Foveosporites Balme, 1957}

Espécie-tipo: Foveosporites canalis Balme, 1957.

Afinidade botânica: PTERIDOPHYTA-LYCOPSIDA (Césari \& Gutiérrez, 1986).

\section{Foveosporites hortonensis (Playford) Azcuy, 1975}

Estampa III, figura 9

1993a F. hortonensis, in Souza et al., est. 2, fig. 2.

1997 F. hortonensis, in Souza et al., est. l, fig. 7.

Diagnose: Playford (1964. Geol. Surv. Canada, Bull. 107: p. 28, est. 8, fig. 3-4).

Localidade-tipo: Grupo Horton, Nova Scotia, Viseano do Canadá.

Descrição: esporo radial trilete, isopolar; contorno equatorial circular a subcircular. Raios da marca trilete simples e retos, alcançando $2 / 3-3 / 4$ do raio. Exina grossa $(2-5 \mu \mathrm{m})$, esculturada por fovéolos poligonais, regularmente distribuidos em ambas as faces, com diâmetro variando de $1-3 \mu \mathrm{m}$, profundidades de atè $2 \mu \mathrm{m}$ e espaçamento de até $4.6 \iota \mathrm{m}$. 
Dimensões: deq 37(55)58 $\mu$ m (12 espécimes).

Ocorrência: Zona Ahrensisporites cristatus.

Comparações: F. insculptus Playford, 1962 apresenta exina mais grossa (até $5 \mu \mathrm{m}$ ) e maiores dimensões (63-97 $\mu \mathrm{m})$. F pellucidus Playford \& Helby, 1968 apresenta fovéolos mais espaçados (até $10 \mu \mathrm{m}$ ), além de ausência e/ou redução de estrutura na face proximal. $F$. appositus Playford, 1971 apresenta escultura vermiculada, com projeções na margem.

Distribuição estratigráfica na Bacia do Paraná: Subgrupo Itararé (Souza et al., 1993a, 1997).

Distribuição estratigráfica mundial: Zona Potonieisporites-Lundbladispora (Subzona RaistrickiamPlicatipollenites) (Césari, 1986), Carbonifero Superior da Argentina (Azcuy, 1975b; Azcuy \& Gutiérrez, 1985; Césari, 1985; Césari \& Gutiérrez, 1986; Ottone, 1989, 1991). Viseano do Canadá (Playford, 1964).

Subturma ZONOTRILETES [Waltz, 1935]

Infraturma AURICULATI \{ [Schopf] Dettman, 1963\}

Gênero Ahrensisporites Potonié \& Kremp, 1954

Espécie-tipo: Ahrensisporites guerickei (Horst) Potonié \& Kremp, 1954.

Afinidade botânica: sem referências.

Ahrensisporites cristatus Playford \& Powis, 1979

Estampa IV, figuras 1 e 2

1996 A. cristatus, in Souza, est. 2, fig. 15.

Diagnose: Playford \& Powis [1979. Pol. et Spor, XXI(3): 384-5, est II, fig. 6; est. III, fig. 1-7]. Localidade-tipo: Formação Grant, Bacia de Canning, Namuriano/Westphaliano da Austrália.

Descrição: esporo radial trilete; contorno equatorial subtriangular a triangular. Margens interradiais lisas a finamente franjeada e extremidades radiais expandidas, constituindo cristas conadas e arcuadas de até $8 \mu \mathrm{m}$ de altura. Raios da marca trilete labiados $(2,5-5 \mu \mathrm{m}$ de espessura), alcançando a margem equatorial. Face distal apresentando três cristas, constituindo quirtoma, mais ou menos contínuo e desenvolvido entre os ângulos da marca trilete, com cones e elementos espinhosos (2-6 $\mu \mathrm{m}$ de base $\times 4-7 \mu \mathrm{m}$ de altura).

Dimensöes: deq 70-105 $\mu \mathrm{m}$ (6 espécimes).

Ocorrência: Zona Ahrensisporites cristatus.

Distribuição estratigráfica na Bacia do Paraná: Subgrupo Itararé (Souza, 1996). Segundo Dino \& Playford (1997), também ocorre no carvão de Buri, Subgrupo Itararé (SP). 
Distribuição estratigráfica mundial: Carbonifero Superior da Argentina (Azcuy et al., 1982; Ottone, 1989; 1991; Césari \& Bercowski, 1997; Di Pasquo, 1999). Namuriano/Westphaliano da Austrália (Jones \& Truswell, 1992).

$$
\text { Infraturma CinguLATI \{[Potonié \& Klaus] Dettman, 1963 \} }
$$

Gênero Reticulatisporites (Ibrahim) Neves, 1964

Espécie-tipo: Reticulatisporites reticulatus Ibrahim, 1933.

Afinidade botânica: PTERIDOPHYTA-SPHENOPSIDA (Schopf et al., 1944).

\section{Reticulatisporites pseudopalliatus Staplin, 1960}

Estampa III, figura 10

1975 R. pseudopalliatus, in Corrêa-da-Silva \& Marques-Toigo, est. II, fig. 7.

1975 R. pseudopalliatus, in Ybert, est. 2, fig. 47-8.

1988 R. pseudopalliatus, in Marques-Toigo, est. Ill, fig. 8.

1993 R. pseudopalliatus, in Dias, est. 3, fig. 6.

1995 R. pseudopalliatus, in Quadros et al., p. 109.

1997 R. sp., in Souza et al., est. I, fig. 8.

Diagnose: Staplin (1960. Palaeontogr., Abt B 107: p. 13, est. 2, fig. 24).

Localidade-tipo: Formação Golata, Alberta, Mississipiano Superior do Canadá.

Descrição: esporo radial trilete, isopolar; contorno equatorial circular a subcircular. Raios da marca trilete finos e retos, alcançando até $2 / 3$ do raio, geralmente indistintos pela densidade da esculturação. Exina microgranulada a punteada, esculturada por muros arredondados (1$2 \mu \mathrm{m}$ de largura $\times 2-5 \mu \mathrm{m}$ de altura) e de superfície lisa, com disposição irregular, intensamente ondulados, delimitando lúminas poligonais com até $8 \mu \mathrm{m}$ de largura.

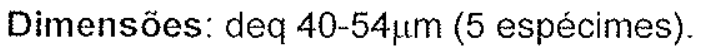

Ocorrência: Zonas Biointervalo Ahrensisporites cristatus, Potonieisporites neglectus e Subzona Protohaploxypinus goraiensis.

Distribuiçăo estratigráfica na Bacia do Paraná: Subgrupo Itararé (Marques-Toigo, 1988; Dias, 1993; Souza et al., 1997) e Formação Rio Bonito (Corrêa-da-Silva \& Marques-Toigo, 1975; Ybert, 1975). Zona Vittatina (Subzona Protohaploxypinus goraiensis).

Distribuição estratigráfica mundial: Bacia Chacoparaná (Césari et al., 1995; Vergel, 1998), Permiano Inferior da Argentina. 
Reticulatisporites passaspectus Ottone, 1991

Estampa III, figura 11

1996 Dictyotriletes pseudopalliatus, in Souza, est. 2, fig. 8.

Diagnose: Ottone [1991. Rev. Microp., 34(23): p, 127, est. 2, fig. 4 e 6].

Localidade-tipo: Mina Esperanza, San Juan, Carbonifero Superior da Argentina.

Descrição: esporo radial trilete; contorno equatorial subcircular a subtriangular. Raios da marca trilete, finamente labiados, estendendo-se até $3 / 4$ do raio. Exina $(2-2,5 \mu \mathrm{m})$ esculturada por muros arredondados e de superficie lisa (2-4 $\mu \mathrm{m}$ de largura $\times 2,5-5 \mu \mathrm{m}$ de altura), delimitando lúminas de até $18 \mu \mathrm{m}$ e rúgulas sinuosas sobre a área de contato, mais desenvolvidas na face distal.

Dimensões: deq 46(52)62,6 4 m (23 espécimes).

Ocorrência: Zonas Biointervalo Ahrensisporites cristatus e Potonieisporites neglectus.

Comparações: se diferencia de R. pseudopalliatus pela escultura menos desenvolvida na face proximal e maiores dimensões nos muros e lúminas.

Distribuição estratigráfica na Bacia do Paraná: Subgrupo Itararé (Souza, 1996).

Distribuição estratigráfica mundial: Carbonifero Superior da Argentina (Ottone, 1991; Di Pasquo \& Azcuy, 1997a, 1999a; Di Pasquo, 1999).

\section{Gênero Stenozonotriletes (Naumova) Ischenko, 1952}

Espécie-tipo: Stenozonotriletes conformis Naumova, 1953.

Afinidade botânica: desconhecida.

\section{Stenozonotriletes clarus Ischenko, 1958}

Estampa III, figura 12

1993a S. clarus, in Souza et al., est. II, fig. 5.

Diagnose: Ischenko (1958. Nauk. Ser. Strat. Palaeont., 11).

Localidade-tipo: Bacia de Dnieper-Danetz. Devoniano-Viseano da ex-URSS.

Descrição: esporo radial trilete, isopolar; contorno equatorial subcircular. Raios da marca trilete retos, estendendo-se até 4/5-5/5 do raio do corpo central. Exina fina e lisa. Corpo central com exina lisa, circundado equatorialmente por um cíngulo estreito, liso e uniforme, alcançando, em dimensões, $20 \%$ do raio do corpo central.

Dimensões: deq 44-55ım ( 3 espécimes).

Ocorrência: Zonas Biointervalo Ahrensisporites cristatus e Potonieisporites neglectus. 
Distribuição estratigráfica mundial na Bacia do Paraná: Subgrupo ltararé (Souza et al., 1993a)

Distribuição estratigráfica mundial: Viseano do Canáda (Barss, 1967), Alemanha (Doubinger \& Rauscher, 1966). Carbonifero Inferior de Spitsbergen (Hughes \& Playford, 1961; Playford, 1962). Namuriano da China (Zhu-Huaicheng, 1993).

Suprasubturma LAMINATITRILETES [Smith \& Butterworth, 1967]

Subturma ZONOLAMINATITRILETES [Smith \& Butterworth, 1967]

Infraturma CINGULICAVATI [Smith \& Butterworth, 1967]

\section{Gênero Lundbladispora (Balme) Playford, 1965}

Espécie-tipo: Lundbladispora wilmotti (Balme) Playford, 1965.

Afinidade botânica: PTERIDOPHYTA-LYYCOPSIDA (Balme, 1963; Marques-Toigo \& Picarelli, 1984)

Lundbladispora braziliensis (Marques-Toigo \& Pons) Marques-Toigo \& Picarelli, 1984 Estampa IV, figura 11

1967 Densosporites braziliensis, Tiwari \& Navale, est. I, fig. 14-5.

1974 L. braziliensis, in Marques Toigo \& Pons, est. 1, fig. 10-12.

1975 L. braziliensis, in Corrêa-da-Silva \& Marques-Toigo, est. II, fig. 13ab.

1978 L. braziliensis, in Burjack, est. III, fig. 3.

1978 L. braziliensis, in Bortoluzzi et al, est. III, fig. 19.

1981 L. braziliensis, in Dias-Fabrício, est. 5, fig. 9.

1981 L. braziliensis, in Leipnitz, est. II, fig. 1-2.

1983 L. sp., in Lima et al., est. III, fig. 8.

1986 L. braziliensis, in Picarelli, est. 1, fig. 14-5.

1987 L. braziliensis, in Picarelli et al., est. 1, fig. 14-5.

1988 L. braziliensis, in Marques-Toigo, est. IV, fig. 8.

1991 L. braziliensis, in Piccoli et al., fig. If.

1993 L. braziliensis, in Dias, est. 4, fig. 8.

1993a L. braziliensis, in Souza et al., est. 2, fig. 16.

1995 L. braziliensis, in Quadros et al., p. 84.

1996 L. braziliensis, in Souza, est. 2, fig. 16

1997 L. braziliensis, in Souza et al., est. I, fig. 17.

Diagnose: Marques-Toigo \& Picarelli (1984. Bol. IG-USP, 15: p. 48, est. II, fig. 1A, 2-4, 7-8). 
Localidade-tipo: Carvão de Candiota (RS), Formaçăo Rio Bonito, Permiano Inferior da Bacia do Paraná, Brasil.

Descrição: esporo radial trilete, anisopolar, cavado, cingulado. Contorno equatorial subtriangular a triangular, com ângulos arredondados. Raios da marca trilete finos, estendendo-se até quase a margem equatorial. Exoexina fina; face proximal do corpo central lisa a finamente escabrada; face distal e cíngulo com pequenos cones e projeçóes espiniformes de $1-5 \mu \mathrm{m}$ de base $\times 1-3 \mu \mathrm{m}$ de altura. Cíngulo espesso e uniforme, com margem irregular, devido à projeção dos elementos ornamentais; grânulos e verrugas são raros.

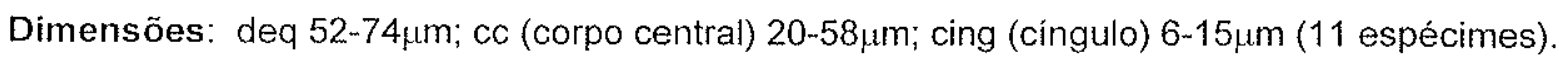

Ocorrência: Zonas Biointervalo Ahrensisporites cristatus, Potonieisporites neglectus e Subzona Protohaploxypinus goraiensis.

Distribuição estratigráfica na Bacia do Paraná: Subgrupo Itararé (Lima et al., 1983; Marques-Toigo, 1988; Piccoli et al., 1991; Dias, 1993; Souza et al., 1993a, 1997; Souza, 1996), Formação Rio Bonito (Tiwari \& Navale, 1967; Marques-Toigo \& Pons, 1974; Corrêada-Silva \& Marques-Toigo, 1975; Burjack, 1978; Bortoluzzi et al., 1978; Dias-Fabrício, 1981; Picarelli, 1986; Picarelli et al., 1987; Marques-Toigo, 1988; Piccoli et al., 1991) e Formação Palermo (Leipnitz, 1981; Picarelli, 1986; Picarelli et al., 1987; Marques-Toigo, 1988). Zonas Vittatina e Lueckisporites virkkiae.

Distribuição estratigráfica mundial: Zonas Potonieisporites-Lundbladispora, Cristatisporites e Striatiti da Bacia Chacoparaná (Archangelsky \& Gamerro, 1979; Russo et al., 1980; Césari, 1986; Vergel, 1986b, 1987a, 1993, 1998), Carbonifero Superior a Permiano Inferior da Argentina (Azcuy \& Gutiérrez, 1985; Césari, 1985a; Césari \& Gutiérrez, 1986; Garcia \& Azcuy, 1987; Vázquez-Nístico \& Césari, 1987; Gutiérrez \& Césari, 1988; Césari \& VázquezNístico, 1988; Archangelsky \& Césari, 1990; Ottone, 1989, 1991; Vergel \& Luna, 1992; Vergel et al., 1993; Garcia, 1995; Césari \& Bercowski, 1997; Di Pasquo \& Azcuy, 1997a, 1999a; Di Pasquo, 1999). Permiano Inferior do Uruguai (Beri, 1988; Fasolo \& Vergel, 1994; Beri \& Aguilar, 1998; Mautino et al., 1998a) e África (Maheshwari \& Bose, 1969). Carbonifero Superior/Permiano Inferior do Omã e Arábia Saudita (Stephenson \& Filatoff, 2000).

\section{Lundb/adispora riobonitensis Marques-Toigo \& Picarelli, 1984}

\section{Estampa IV, figura 10}

1986 L. riobonitensis, in Picarelli, est. 1, fig. 12-3.

1987 L. riobonitensis, in Picarelli et al., est. 1, fig. 12-3.

1988 L. riobonitensis, in Marques-Toigo, est. IV, fig. 7.

1991 L. riobonitensis, in Piccoli et al., fig. $1 \mathrm{~g}$.

1993 L. riobonitensis, in Dias, est. 4, fig. 9. 
1995 L. riobonitensis, in Quadros et al., p. 86.

1996 L. riobonitensis, in Souza, est. 2, fig. 17.

1996 L. sp., in Souza, est. 2, fig. 18.

Diagnose: Marques-Toigo \& Picarelli (1984. Bol. IG-USP, 15: p. 48-9, est. I, fig. 1-3, est. II, fig. $1 \mathrm{~B}, 5-6)$.

Localidade-tipo: Carvão de Iruí (RS), Formação Rio Bonito, Permiano Inferior da Bacia do Paraná, Brasil

Descrição: esporo radial trilete, anisopolar, cavado, cingulado; contorno equatorial subtriangular a triangular, com ângulos arredondados. Raios da marca trilete distintos, levemente sinuosos, acompanhados de lábios, estendendo-se até a margem equatorial. Exoexina fina. Face proximal do corpo central lisa a finamente escabrada; face distal escabrada, com aparência esponjosa. Cíngulo uniformemente espessado, com projeções espiniformes e coniformes na margem $(0,5-1,5 \mu \mathrm{m}$ de base $\times 0,5-2 \mu \mathrm{m}$ de altura).

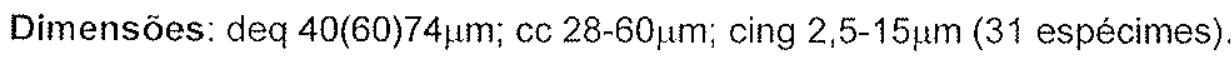

Ocorrência: Zonas Biointervalo Ahrensisporites cristatus, Potonieisporites neglectus e Subzona Protohaploxypinus goraiensis.

Comparações: L. irregularis (Menéndez) Césari, 1985 apresenta cones e ocasionais espinhos na face distal da exoexina, presentes somente na margem externa do cíngulo em $L$. riobonitensis. Esta espécie é separada de L. braziliensis com base em que nesta última a face distal é predominantemente equinada, enquanto que em $L$. riobonitensis a face distal é esponjosa.

Distribuição estratigráfica na Bacia do Paraná: Subgrupo Itararé (Marques-Toigo, 1988; Piccoli et al., 1991; Dias, 1993; Souza, 1996), Formação Rio Bonito (Picarelli, 1986; Picarelli et al., 1987; Marques-Toigo, 1988; Piccoli et al., 1991) e Formação Palermo (Picarelli, 1986; Picarelli et al., 1987). Zona Vittatina.

Distribuição estratigráfica mundial: Zonas Potonieisporites-Lundbladispora e Cristatisporites na Bacia Chacoparaná (Vergel, 1986b, 1987a, 1998; Césari et al., 1995); Carbonifero Superior a Permiano Inferior da Argentina (Ottone, 1989, 1991; Ottone \& Azcuy, 1990; Garcia, 1995; Di Pasquo \& Azcuy, 1997a, 1999a; Di Pasquo, 1999). Permiano Inferior do Uruguai (Mautino et al., 1998a). Carbonífero Superior/Permiano Inferior do Omã (Stephenson \& Filatoff, 2000).

\section{Gênero Densosporites (Berry) Butterworth et al., 1964}

Espécie-tipo: Densosporites covexis Berry, 1937.

Afinidade botânica: PTERIDOPHYTA-LYCOPSIDA (Azcuy, 1978). 
Densosporites triangularis Kosanke, 1950

Estampa IV, figura 3

1987 D. triangularis, in Sundaram, est. IV, fig. 11.

1997 D. simplex, in Souza et al., est. I, fig. 13.

Diagnose: Kosanke (1950. State Geol. Surv. Illinois, Bull. 74: p. 34, est. 7, fig. 1).

Localidade-tipo: Sub-Babylon Coal Bed, Fulton County, Illinois, Pensilvaniano dos E.U.A.

Descrição: esporo radial trilete, anisopolar, cavado, cingulado; contorno equatorial subtriangular a triangular, com ângulos arredondados. Corpo central subtriangular, face proximal lisa, face distal com grânulos $(1-2,5 \mu \mathrm{m}$ de base $\times 2,5 \mu \mathrm{m}$ de aitura). Cíngulo espesso e uniforme, ornamentado por elementos espiniformes a coniformes (1-1,5 $\mu \mathrm{m}$ de base $x$ até $3 \mu \mathrm{m}$ de altura), que se projetam na margem, apresentando aspecto finamente recortado.

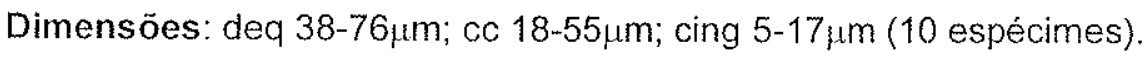

Ocorrência: Zonas Biointervalo Ahrensisporites cristatus, Potonieisporites neglectus e Subzona Protohaploxypinus goraiensis.

Comparações: D. spinifer Holffmeister, Staplin \& Malloy, 1955 apresenta espinhos mais longos (até $6 \mu \mathrm{m}$ de altura). D. annulatus possui cones e margem equatorial mais fortemente recortada.

Distribuição estratigráfica na Bacia do Paraná: Subgrupo Itararé (Sundaram, 1987; Souza et al., 1997).

Distribuição estratigráfica mundial: Pensilvaniano dos E.U.A. (Kosanke, 1950). Viseano a Namuriano da Inglaterra (Smith \& Butterworth, 1967).

\section{Densosporites annulatus (Loose) Smith \& Butterworth, 1967}

Estampa IV, figura 4

1987 D. annulatus, in Sundaram, est. IV, fig. 10.

1996 D. triangularis, in Souza, est. 3 , fig. 3.

1996 D. sp., in Souza, est. 3, fig. 4.

Diagnose: Potonié \& Kremp (1956. Geol. Jb., 69: p. 112).

Localidade-tipo: Bismark Seam, Ruhr Coalfield, Westphaliano B da Alemanha.

Descrição: esporo radial trilete, anisopolar, cavado, cingulizonado; contorno equatorial subtriangular a triangular, com ângulos arredondados. Raios da marca trilete distintos, levemente sinuosos, com lábios (2-2,5 $\mu$ m de largura). Corpo central com faces proximal e 


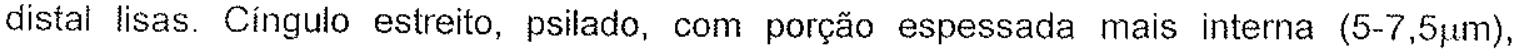
afinando-se na borda externa (2-5 $\mu \mathrm{m})$; margem lisa.

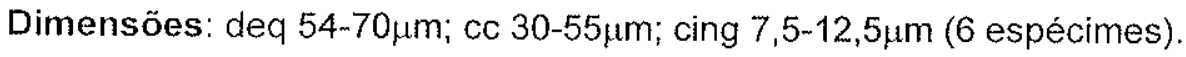

Ocorrência: Zonas Biointervalo Ahrensisporites cristatus, Potonieisporites neglectus e Subzona Protohaploxypinus goraiensis.

Comparações: $D$. sp. in Souza (1996, est. 3, fig. 4) é incluido nesta espécie após revisão do material original. Os cones citados pelo autor (p. 60-1) tratam-se de efeitos de corrosão, dada a irregularidade na distribuição e padrão. O espécime designado como $D$. triangularis por Souza (1996, est. 3, fig. 3) é também incluído nesta espécie, tendo em vista as pequenas dimensões do cingulo.

Distribuição estratigráfica na Bacia do Paraná: Subgrupo Itararé (Sundaram, 1987; Souza, 1996).

Distribuição estratigráfiça mundial: Viseano a Stephaniano da Europa (Smith \& Butterworth, 1967; Van Wijhe et al., 1974; Clayton et al., 1977; Turner \& Spinner, 1993; Coquel \& Rodriguez, 1994; Turner et al., 1994, 1995; Wierich \& Vogt, 1997). Namuriano da China (Zhu-Huaicheng, 1993). Westphaliano dos E.U.A. (Gupta, 1970).

Densosporites stellatus Azcuy, 1975

Estampa IV, figura 5

Diagnose: Azcuy [1975. Amegh., XII(2): p. 124-5, est. XXI, fig. 136-7; est. XXII, fig. 140-2].

Localidade-tipo: Formação Malazán (Membro Divisoria), Grupo Paganzo, Namuriano/Westphaliano da Argentina.

Descrição: esporo radial trilete, anisopolar, cavado, cingulado; contorno equatorial triangular a subtriangular, com ângulos arredondados. Raios da marca trilete nem sempre distintos, sinuosos e simples, alcançando a borda interna do cíngulo. Corpo central com face proximal lisa a finamente punteada, face distal com verrugas espaçadas $(3-6 \mu \mathrm{m}$ de base $\times 2-3 \mu \mathrm{m}$ de altura), às vezes coalescentes. Cingulo de espessura uniforme $(3-10 \mu \mathrm{m})$, correspondendo a aproximadamente $1 / 3-1 / 4$ do raio total, apresentando cones e espinhos de tamanhos

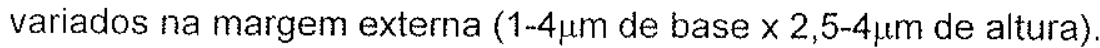

Ocorrência: Zonas Biointervalo Ahrensisporites cristatus e Potonieisporites neglectus.

Observações: Gutiérrez (1988) relocou a espécie D. stellatus para o gênero Cristatisporites com base na fusão dos elementos ornamentais na face distal e na cingulizona. Entretanto, utiliza-se a espécie como proposto, visto que o trabalho de Gutiérrez (1988) não atende às normas do Código Internacional de Botânica, por não ter sido publicado (Tese).

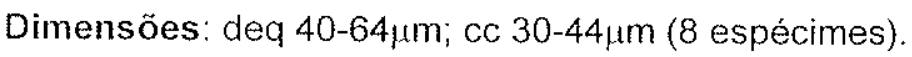

Distribuição estratigráfica na Bacia do Paraná: inédita. 
Distribuição estratigráfica mundial: Carbonífero Superior da Argentina (Gutiérrez, 1988; Limarino \& Gutiérrez, 1990; Vergel \& Luna, 1992; Di Pasquo \& Azcuy, 1997a, 1999a; Di Pasquio 1999).

\section{Gênero Kraeuselisporites (Leschik) Jansonius, 1962}

Espécie-tipo: Kraeuselisporites dentatus Leschik, 1955.

Afinidade botânica: PTERIDOPHYTA-LYYCOPSIDA (Marques-Toigo, 1988).

\section{Kraeuselisporites volkheimerii Azcuy, 1975}

Estampa IV, figuras 6 a 8

1996 K. sp., in Souza, est. 3, fig. 12.

1996 Cristatisporites mammilatus, in Souza, est. 3, fig. 18.

Diagnose: Azcuy [1975. Amegh., XII(2): p. 130-2, est. XXIV, fig. 155-8].

Localidade-tipo: Formação Malazán (Membro Estratos Carbonosos), Grupo Paganzo, Namuriano/Nestphaliano da Argentina.

Descrição: esporo radial trilete, anisopolar, cavado, zonado; contorno equatorial subtriangular, com ângulos arredondados. Raios da marca trilete nem sempre visíveis, finos e retos. Face proximal do corpo central lisa; face distal com projeções discretas: mamóides de base circular e extremos aguçados, às vezes recurvados; cones e espinhos $[1(2,5) 5 \mu \mathrm{m}$ de base $x$ $1(3,5) 7 \mu \mathrm{m}$ de altura]. Zona larga, alcançando até $1 / 2$ do raio total do corpo central, com as mesmas projeções da face distal na porção adjacente ao corpo central.

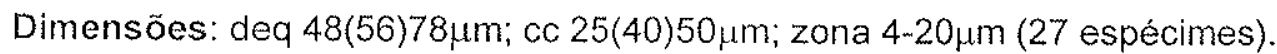

Ocorrência: Zonas Biointervalo Ahrensisporites cristatus e Potonieisporites neglectus.

Distribuição estratigráfica na Bacia do Paraná: Subgrupo Itararé (Souza, 1996).

Distribuição estratigráfica mundial: Palinozona de Ancistrospora (Azcuy \& Jelin, 1980), Carbonifero Superior a Permiano Inferior da Argentina (Ottone, 1989; Limarino \& Gutiérrez, 1990; Césari \& Bercowski, 1997; Di Pasquo \& Azcuy, 1997a, 1999a; Di Pasquo, 1999).

\section{Gênero Vallatisporites Hacquebard, 1957}

Espécie-tipo: Vallatisporites vallatus Hacquebard, 1957.

Afinidade botânica: PTERIDOPHYTA-LYCOPSIDA (Azcuy, 1978; Taylor, 1981).

Vallatisporites vallatus Hacquebard, 1957

Estampa $V$, figura 1

1970 V. vallatus, in Cauduro, est. V, fig. 1 
1975 V. cf. vallatus, in Ybert, est. 2, fig. 62-3.

1981 V. vallatus, in Dias-Fabricio, est. 4, fig. 6.

1983 V. vallatus, in Lima et al., est. III, fig. 12.

1988 V. cf. V. vallatus, in Marques-Toigo, est. IV, fig. 5.

1993 V. vallatus, in Dias, est. 3, fig. 8.

1996 V. vallatus, in Souza, est. 3, fig. 5.

Diagnose: Hacquebard [1957. Micropaleont, 3(4): p. 312-3, est. 2, fig. 12].

Localidade-tipo: Grupo Horton (West Gore e Blue Beach), Nova Scotia, Mississipiano do Canadá.

Descrição: esporo radial trilete, zonado, exoexina unida ou separada da intexina (corpo central); contorno subtriangular, com ângulos arredondados. Raios da marca trilete levemente sinuosos, altos (até $2 \mu \mathrm{m}$ ), se estendendo até a margem do corpo central. Corpo central acompanhando o contorno geral; face proximal lisa, margeada por fileira de cones discretos $(0,5-2,5 \mu \mathrm{m}$ de base $\times 1-2,5 \mu \mathrm{m}$ de altura), raramente coalescentes. Zona vacuolada na porção interna, com espinhos e cones dispersos $(2-2,5 \mu \mathrm{m}$ de base $\times 2-3 \mu \mathrm{m}$ de altura); porção externa mais espessada, com diminutos espinhos e cones $(1-2 \mu \mathrm{m}$ de base $\times 0,5-2, \mu m$ de altura).

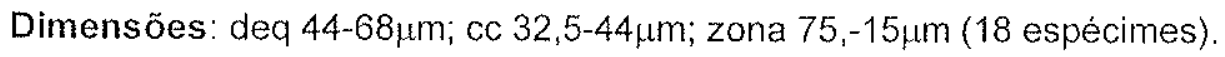

Ocorrência: Zonas Biointervalo Ahrensisporites cristatus, Potonieisporites neglectus e Subzona Protohaploxypinus goraiensis.

Comparações: V. ciliaris (Lüber) Sullivan, 1964 apresenta elementos ornamentais mais desenvolvidos.

Distribuição estratigráfica na Bacia do Paraná: Subgrupo Itararé (Marques-Toigo, 1988; Lima et al., 1983; Dias, 1993; Souza, 1996) e Formaçäo Rio Bonito (Cauduro, 1970; Ybert, 1975; Dias.Fabrício, 1981; Marques Toigo, 1988). Zona Vittatina (Subzonas Protohaploxypinus goraiensis e Caheniasaccites flavatus).

Distribuição estratigráfica mundial: Devoniano/Carbonifero Inferior do Canadá (Playford, 1964; Barss, 1967; Playford \& McGregor, 1993). Tournaisiano/Niseano da Europa (Sullivan, 1968; Clayton et al., 1977; Higgs et al., 1992; Turner et al., 1995). Struniano/Tournaisiano de Marrocos (RahmanimAntari, 1990).

\section{Vallatisporites ciliaris (Lüber) Sullivan, 1964}

Estampa $V$, figuras 2 e 3

1976a V. sp. 1, in Pons, est. II, fig. 21.

1983 V. ciliaris, in Lima et al., est. III, fig. 14.

1983 V. splendens, in Lima et al., est. Ill, fig. 13. 
1993a V. cf. V. ciliaris, in Souza et al., est. 3, fig. 1.

1993a V. spinosus, in Souza et al., est. 3, fig. 3.

1996 V. ciliaris, in Souza, est. 3, fig. 7.

1997 V. cf. V. ciliaris, in Souza et al., est. 1, fig. 15.

Diagnose: Sullivan [1964. Palaeont, 7(3): p. 370-1, est. 59, fig. 14-5, text-fig. 3].

Localidade-tipo: Arenito Drybrook, Bacia Forest of Dean, Gloucestershire, Carbonifero Inferior a Westphaliano do Reino Unido.

Descrição: esporo radial trilete, anisopolar, cavado, exoexina separada ou unida à intexina. Contorno equatorial triangular a subtriangular, com ângulos arredondados. Corpo central subtriangular. Raios da marca trilete alcançando a margem externa da zona. Exoexina ornamentada distalmente por espinhos, cones e elementos mamóides (galeae) discretos $[1(2,5) 5 \mu \mathrm{m}$ de base $\times 1(3) 6 \mu \mathrm{m}$ de altura] que se distribuem até a zona, onde diminuem em dimensões $(0,5-2 \mu \mathrm{m}$ de base $\times 0,5-3 \mu \mathrm{m}$ de altura). Face proximal do corpo central com margem anelar, punteada, com espinhos e cones ocasionais e reduzidos. Zona translúcida, membranosa, com engrossamento radial na porção mediana-externa, em forma de anel.

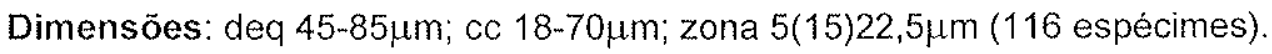

Ocorrência: Zonas Biointervalo Ahrensisporites cristatus, Potonieisporites neglectus e Subzona Protohaploxypinus goraiensis.

Comparações: após novos exames do material, sinomizou-se aqui $V$. splendens ilustrado em Lima et al., (1983, est. III, fig. 13), por não apresentar ornamentação coalescente.

Distribuição estratigráfica na Bacia do Paraná: Subgrupo Itararé (Pons, 1976a; Lima et al., 1983; Souza et al., 1993a, 1997; Souza, 1996).

Distribuição estratigráfica mundial: Palinozona de Ancistrospora (Azcuy \& Jelin, 1980), Zona Potonieisporites-Lundbladispora (Subzona Raistrickia-Plicatipollenites) (Césari, 1986; Vergel, 1993); Carbonífero Superior a Permiano da Argentina (Azcuy, 1975b; Césari, 1985a; Garcia \& Azcuy, 1987; Césari \& Vázquez-Nístico, 1988; Vergel \& Luna, 1992; Vergel et al., 1993; Garcia, 1995; Di Pasquo \& Azcuy, 1997a, 1999a; Di Pasquo, 1999). Permiano Inferior do Uruguai (Fasolo \& Vergel, 1994; Mautino et al., 1998a). Viseano a Westphaliano da Europa (Sullivan, 1964; Clayton et al., 1977). Struniano a Tournaisiano de Marrocos (Rahmani-Antari, 1990).

\section{Vallatisporites spinosus Cauduro, 1970}

Estampa $V$, figuras 5 e 6

1996 V.cf. V. spinosus, in Souza, est. 3, fig. 10.

1996 V. banffensis, in Souza, est. 3, fig. 8. 
Diagnose: Cauduro (1970. Esc. Geol., Publ. Esp. 17: p. 12-13, est. V, fig. 48-50).

Localidade-tipo: São Sepé (RS), Formação Rio Bonito, Permiano Inferior da Bacia do Paraná, Brasil.

Descrição: esporo radial trilete, anisopolar, cavado, zonado, exoexina unida ou separada da intexina. Contorno equatorial triangular a subtriangular, com ângulos arredondados. Face proximal do corpo central lisa a finamente punteada, com aspecto esponjoso.

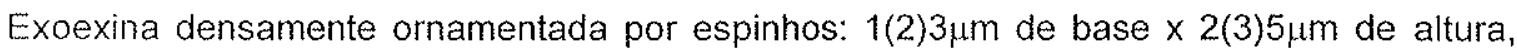
que diminuem em dimensões na periferia e margem da zona. Raios da marca trilete proeminentes, levemente sinuosos, alcançando a porção média da zona. Zona ampla, membranosa, com engrossamentos radiais irregulares.

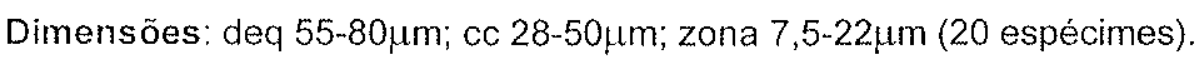

Ocorrência: Zonas Biointervalo Ahrensisporites cristatus, Potonieisporites neglectus e Subzona Protohaploxypinus goraiensis.

Distribuição estratigráfica na Bacia do Paraná: Subgrupo Itararé (Souza, 1996) e Formação Rio Bonito (Cauduro, 1970).

\section{Vallatisporites arcuatus (Marques-Toigo) Archangelsky \& Gamerro, 1979}

\section{Estampa $V$, figuras 4 e 7}

1988 V. arcuatus, in Marques-Toigo, est. IV, fig. 1.

1991 V. arcuatus, in Piccoli et al., fig. 1 i.

1993 V. arcuatus, in Dias, est. 3, fig. 9.

1995 V. arcuatus, in Quadros et al., p. 129.

1996 V. arcuatus, in Souza, est. 3, fig. 6.

1997 V. arcuatus, in Souza et al., est. I, fig. 14.

Diagnose: Marques-Toigo [1974. An. Acad bras. Ci., 46(3/4): p. 605, est. I, fig. 6-7].

Localidade-tipo: Passo de las Bochas, Formação San Gregório, Permiano Inferior do Uruguai.

Descrição: esporo radial trilete, anisopolar, cavado, exoexina separada ou unida à intexina. Contorno equatorial triangular a subtriangular, com ângulos arredondados. Corpo central subtriangular. Raios da marca trilete alcançando a margem do corpo central. Exoexina ornamentada distalmente por espinhos e cones discretos $(3 \mu \mathrm{m}$ de base $\times 3-4 \mu \mathrm{m}$ de altura). Corpo central com margem anelar na face proximal e espinhos $(1-1,5 \mu \mathrm{m}$ de base $\times 1,5-$ $7 \mu \mathrm{m}$ de altura). Zona apresentando porção interna com engrossamentos radiais, formando arcos; porção externa membranosa, com projeçöes espiniformes discretas ( $1 \mu \mathrm{m}$ de base $\mathrm{x}$ $2 \mu \mathrm{m}$ de altura); margem denteada.

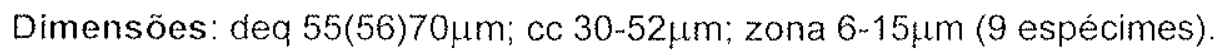


Ocorrência: Zonas Biointervalo Ahrensisporites cristatus, Potonieisporites neglectus e Subzona Protohaploxypinus goraiensis.

Comparações: em V. russoi Archangelsky \& Gamerro, 1979 os elementos ornamentais na face distal da exoexina formam cristas de contornos definidos, se anastomosam e constituem, com freqüência, auréolas.

Distribuição estratigráfica na Bacia do Paraná: Subgrupo Itararé (Marques-Toigo, 1988; Piccoli et al., 1991; Dias, 1993; Souza, 1996; Souza et al., 1997) e Formação Rio Bonito (Marques-Toigo, 1988; Piccoli et al., 1991). Zona Vittatina (Subzonas Protohaploxypinus goraiensis e Caheniasaccites flavatus).

Distribuição estratigráfica mundial: Zona Potonieisporites-Lundbladispora, Bacia Chacoparaná (Archangelsky \& Gamerro, 1979; Russo et al., 1980; Vergel, 1986b; 1987a, 1998; Césari et al., 1995); Carbonífero Superior a Permiano Inferior da Argentina (Ottone, 1989, 1991; Garcia, 1995; Di Pasquo \& Azcuy, 1997a, 1999a; Di Pasquo, 1999). Carbonífero Superior do Omã e Arábia Saudita (Stephenson \& Filatoff, 2000).

\section{Vallatisporites punctatus (Marques-Toigo) comb. nov.}

Estampa $V$, figura 8

1996 V. punctatus (Marques-Toigo) comb. nov., in Souza, est. 3, fig. 9.

Diagnose: Marques-Toigo [1974. An. Acad. bras. Ci., 46(3/4); p. 605-607, est. II, fig. 1-2]. Permanece como proposto, ampliando-se aqui somente as dimensões estabelecidas.

Localidade-tipo: Passo de las Bochas, Formação San Gregório, Permiano Inferior do Uruguai.

Descrição: esporo radial trilete, cavado, zonado, exoexina unida ou separada da intexina. Contorno equatorial triangular a subtriangular, com ângulos arredondados. Corpo central com o contorno geral do esporo, com borda anelada (2-5.tm), apresentando pequenos elementos espiniformes $(<1 \mu \mathrm{m}$ de base $\mathrm{x}$ até $2 \mu \mathrm{m}$ de altura); face proximal lisa a finamente punteada, com aparência esponjosa. Raios da marca trilete distintos, com lábios pronunciados (até $2 \mu \mathrm{m}$ de altura), alcançando os vértices do esporo. Exoexina densamente punteada na face distal; zona engrossada na porção média e membranosa na porção externa, com pequenos elementos espiniformes $(<0,5 \mu \mathrm{m}$ de base $\mathrm{x}$ até $1 \mu \mathrm{m}$ de altura); porção interna vacuolada.

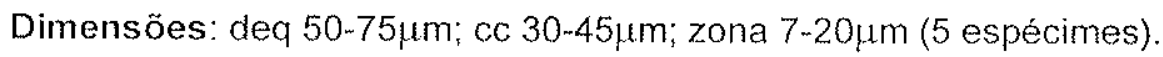

Ocorrência: Zonas Biointervalo Ahrensisporites cristatus, Potonieisporites neglectus e Subzona Protohaploxypinus goraiensis.

Observação: Kraeuselisporites punctatus Marques-Toigo, 1974 é transferido para o gênero Vallatisporites pela presença de vacúolos e cunículo, diagnóstico do gênero Vallatisporites, 
assim como procederam Archangelsy \& Gamerro (1979) com Vallatisporites

(Kraeuselisporites) arcuatus.

Distribuição estratigráfica na Bacia do Paraná: Subgrupo Itararé (Souza, 1996).

Distribuição estratigráfica mundial: Permiano Inferior do Uruguai (Marques-Toigo, 1974).

\section{Gênero Cristatisporites (Potonié \& Kremp) Butterworth et al., 1964}

Espécie-tipo: Cristatisporites indignabundus (Potonié \& Kremp) Staplin \& Jansonius, 1964.

Afinidade botânica: PTERIDOPHYTA-LYCOPSIDA (Chaloner, 1962).

Observaçöes gerais: com base em material da Bacia de Drummond, Carbonifero Inferior da Austrália, Playford (1978) relocou as espécies de Ancistrospora Menéndez \& Azcuy, 1972 ao gênero Cristatisporites (Potonié \& Kremp) Butterworth et al., 1964, modificando seus epitetos (Cristatisporites inordinatus $=$ Ancistrospora inordinata; $C$. menendezii $=A$. verrucosa; C. spinosus=A. spinosa), tendo Césari (1985a) modificado a diagnose de C. menendezii e C. spinosus. Algumas considerações a respeito da preferência do uso do gênero Ancistrospora já foram apresentadas por Souza (1996, p. 73), que enfatizou os seguintes caracteres de distinção entre esse gênero e Cristatisporites: (i) ornamentação na face proximal do corpo central; (ii) natureza e modo da ornamentação da exoexina na face distal; (iii) engrossamento equatorial da exoexina. Adota-se aqui a nomenclatura vigente na literatura, ressaltando-se a necessidade de uma profunda reavaliação dessas espécies com base nos caracteres mencionados.

\section{Cristatisporites indignabundus (Potonié \& Kremp) Staplin \& Jansonius, 1964} Estampa $V_{1}$, figura 1

? 1978 C. indignabundus, in Bortoluzzi et al., est. III, fig. 21.

1987 C. indignabundus, in Sundaram, est. III, fig. 10.

1996 C. indignabundus, in Souza, est. 3, fig. 13.

Diagnose: Staplin \& Jansonius (1964. Palaeontogr., Abt B 114: p. 108, est. 19, fig. 7-9, 12, 14 e 20, fig. 2c).

Localidade-tipo: Bismark Seam, Ruhr Coalfield, Westphaliano B da Alemanha.

Descrição: esporo radial trilete, cavado, cingulizonado; contorno equatorial subtriangular. Raios da marca trilete finos, retos, alcançando a margem interna da cingulizona. Face proximal do corpo central finamente punteada, margeada por projeções espiniformes a mameliformes, de disposição e forma irregular, de $2-5 \mu \mathrm{m}$ de altura $\times 1-1,5 \mu \mathrm{m}$ de base, projetadas na zona. Exoexina ornamentada por verrugas coalescentes, irregularmente $e$ fracamente distribuidas na face distal, com até 4 ım de largura. No equador os elementos 
ornamentais são menores e mais escassos, coniformes e espiniformes, alcançando até $2 \mu \mathrm{m}$ de altura. Margem densamente recortada, pela projeção da ornamentação.

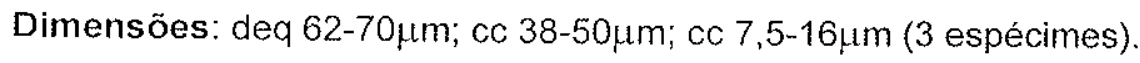

Ocorrência: Zona Biointervalo Ahrensisporites cristatus.

Distribuição estratigráfica na Bacia do Paraná: Subgrupo Itararé (Sundaram, 1987; Souza, 1996) e Formação Rio Bonito (Bortoluzzi et al., 1978).

Distribuição estratigráfica mundial: Namuriano a Stephaniano da Europa (Smith \& Butterworth, 1967; Van Wijhe et al., 1974; Clayton et al., 1977; Owens et al., 1977; Kmiecik, 1986; Turner et al., 1995; Bek \& Oplustil. 1998).

\section{Cristatisporites connexus Potonié \& Kremp, 1955}

Estampa Vl, figura 2

? 1978 C. connexus, in Bortoluzzi et al, est. III, fig. 22.

? 1987 C. connexus, in Sundaram, est. III, fig. 9.

Diagnose: Potonié \& Kremp (1955. Palaeontogr., Abt. B 98: p. 106).

Localidade-tipo: Gas Boring Km 1, Ascheburg, Westphaliano da Alemanha.

Descrição: esporo radial trilete, cavado, cingulizonado. Contorno equatorial subtriangular, com ângulos arredondados. Raios da marca trilete finos e retos, alcançando a margem interna da cingulizona. Face proximal do corpo central lisa. Exoexina distalmente ornamentada por verrugas, de bases coalescentes (1-6um de base $\times 2-7 \mu \mathrm{m}$ de altura), formando cristas. Cingulizona espessada e sem elementos ornamentais na porção interna; porção externa com notável densidade de elementos mameliformes e espiniformes $(2-6 \mu \mathrm{m}$ de base $\times 2$ 5 um de altura).

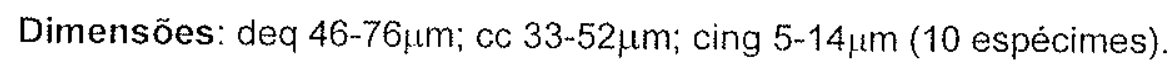

Ocorrência: Zonas Biointervalo Ahrensisporites cristatus, Potonieisporites neglectus e Subzona Protohaploxypinus goraiensis.

Comparações: $C$. indignabundus apresenta elementos ornamentais mais variados. Sundaram (1987) registrou a espécie no Subgrupo Itararé sem, no entanto, mencionar em sua descrição fusão na base dos elementos ornamentais.

Observações: a assinalação nesta espécie é baseada na descrição e ilustração de Smith \& Butterworth (1967), que mencionam verrugas como únicos elementos ornamentais. formando cristas no cingulo.

Distribuição estratigráfica na Bacia do Paraná: Subgrupo Itararé (Sundaram, 1987) e ? Formação Rio Bonito (Bortoluzzi et al., 1978).

Distribuição estratigráfica mundial: Westphaliano da Europa (Love \& Neves, 1963; Navale, 1964; Smith \& Butterworth, 1967; Van Wijhe et al., 1974). 


\section{Cristatisporites menendezii (Menéndez \& Azcuy) Playford emend. Césari, 1985}

Estampa $V$, figura 9

non 1993a Cristatisporites menendezii, in Souza et al., est. 2, fig. 12.

1996 A. verrucosa, in Souza, est. 4, fig. 1.

1997 Cristatisporites menendezii, in Souza et al., est. 1, fig. 18.

Diagnose: Menéndez \& Azcuy [1972. Rev. Esp. Microp., IV(2): p. 162-163, est. 1; est. 3, fig, 35; fig. 1 e 2A]. Diagnose emendada: Césari [1985. Amegh., 22(3/4): p. 203-4, est. I, fig. 4]. Localidade-tipo: Formação Lagares, Grupo Paganzo, Namuriano/Westphaliano da Argentina. Descrição: esporo radial trilete, cavado, cingulado; contorno equatorial subtriangular a subcircular. Raios da marca trilete finos, alcançando a margem interna do cíngulo. Face proximal do corpo central lisa a finamente punteada. Exoexina densamente ornamentada por elementos biformes de base verrucosa ampla $(2,5-8 \mu \mathrm{m})$, com projeçóes espiniformes, até $6 \mu \mathrm{m}$ de altura, em forma de curvada ("gancho"). Os elementos estão geralmente fusionados na base, notadamente na região equatorial, onde delimitam cristas com topos espinhosos.

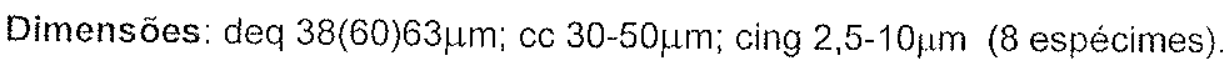

Ocorrência: Zona Biointervalo Ahrensisporites cristatus.

Distribuição estratigráfica na Bacia do Paraná: Subgrupo Itararé (Souza, 1996; Souza et al., 1997).

Distribuição estratigráfica mundial: Namuriano da Bacia do Amazonas (Quadros et al., 1995, p. 42). Palinozona de Ancistrospora (Azcuy \& Jelin, 1980); Zona PotonieisporitesLundbladispora (Subzona Raistricia-Plicatipollenites) (Césari, 1986; Vergel, 1998), Bacia Chacoparaná; Carbonifero Superior da Argentina (Menéndez \& Azcuy, 1972; Azcuy, 1975b; Azcuy \& Laffitte, 1981; Césari, 1985a; Ottone, 1989; Ottone \& Azcuy, 1990; Vergel et al., 1993; Garcia, 1995; Di Pasquo \& Azcuy, 1997a, 1999a). Viseano da Austrália (Playford, 1978; Playford \& Satterthwait, 1988). Carbonífero Superior/Permiano Inferior do Omã (Stephenson \& Filatoff, 2000).

\section{Cristatisporites spinosus (Menéndez \& Azcuy) Playford emend. Césari, 1985 Estampa $V$, figuras 10 e 11}

Diagnose: Menéndez \& Azcuy [1972. Rev. Esp. Microp., IV(2): p. 163-7, est. II, Fig. 2C]. Diagnose emendada: Césari [1985. Amegh., 22(3/4): p. 204, est. II, fig. 6].

Localidade-tipo: Formação Lagares, Grupo Paganzo, Namuriano Westphaliano da Argentina.

Descrição: esporo radial trilete, cavado, cingulado; contomo equatorial subcircular a subtriangular, ângulos amplamente arredondados. Raios da marca trilete finos, alcançando 
a margem interna do cíngulo. Corpo central fracamente delimitado, acompanhado o contorno geral; face proximal finamente punteada. Exoexina densamente ornamentada por elementos espiniformes de bases largas com extremos encurvados e alguns cones (2-6 $\mu \mathrm{m}$ de base $\times 2-6 \mu m$ de altura), geralmente, fusionados nas bases, formando cristas na região equatorial.

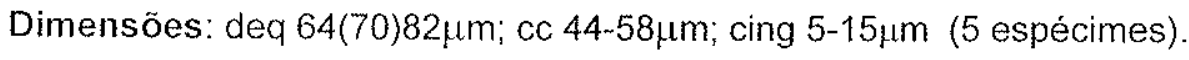

Ocorrência: Zona Biointervalo Ahrensisporites cristatus.

Distribuição estratigráfica na Bacia do Paraná: inédita.

Distribuição estratigráfica mundial: Zona Potonieisporites-Lundbladispora (Subzona Raistrickia-Plicatipollenites) da Bacia Chacoparaná (Césari, 1986). Carbonifero Superior da Argentina (Menéndez \& Azcuy, 1972; Césari, 1985a; Ottone, 1991; Di Pasquo \& Azcuy, 1997a, 1999a). Viseano da Austrália (Playford \& Satterthwait, 1988).

\title{
Cristatisporites inordinatus (Menéndez \& Azcuy) Playford, 1978
}

\author{
Estampa $V$, figura 12
}

1983 A. inordinata, in Lima et al., est. 111, fig. 11.

1993a Cristatisporites inordinatus, in Souza et al., est. 2, fig. 9.

1996 A. inordinata, in Souza, est. 4, fig. 2.

Diagnose: Menéndez \& Azcuy [1972. Rev. Esp. Microp., IV(2): p. 167-8, est. III, fig. 1-2; fig. $2 \mathrm{C}]$.

Localidade-tipo: Formação Lagares, Grupo Paganzo, Namuriano/Nestphaliano da Argentina.

Descrição: esporo radial trilete, cavado, cingulado; contorno equatorial triangular a subtriangular, ângulos arredondados. Raios da marca trilete finos e distintos, alcançando a margem interna do cingulo. Corpo central fracamente delimitado. Exoexina fortemente ornamentada por papilas, cones e espinhos $(3-5 \mu \mathrm{m}$ de base $\times 2-5 \mu \mathrm{m}$ de altura), de bases coalescentes, disposição irregular, com maior concentração na região equatorial, onde delimitam um engrossamento continuo.

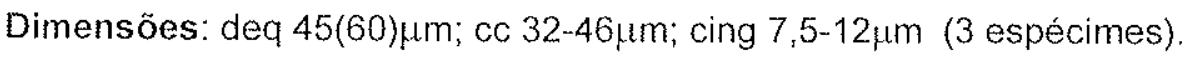

Ocorrência: Zona Biointervalo Ahrensisporites cristatus.

Comparações: difere das demais espécies do gênero pela diversidade dos elementos ornamentais, além de que o contorno equatorial é mais fortemente triangular.

Distribuição estratigráfica na Bacia do Paraná: Subgrupo ltararé (Lima et al., 1983; Souza et al., 1993a; Souza, 1996).

Distribuição estratigráfica mundial: Carbonifero Superior da Argentina (Menéndez \& Azcuy, 1972; Azcuy, 1975b; Di Pasquo \& Azcuy, 1997a, 1999a). Carbonifero Superior/Permiano Inferior do Omã (Stephenson \& Filatoff, 2000). 
Cristatisporites inconstans Archangelsky \& Gamerro, 1979

Estampa VI, figuras 3 e 6

1987 C. inconstans, in Sundaram, est. III, fig. 8.

1993 C. inconstans, in Dias, est. 4, fig. 4.

1995 C. inconstans, in Quadros et al., p. 40.

1996 C. inconstans, in Souza, est. 3, fig. 14 e 15.

1996 C. sp., in Souza, est. 3, fig. 19.

Diagnose: Archangelsky \& Gamerro [1979. Rev. Esp. de Microp., XI(3): p. 435, est. V, fig. 1-5]. Localidade-tipo: Poços CdO es-1 e CdCA es-1, Bacia Chacoparaná, Permiano Inferior da Argentina.

Descrição: esporo radial trilete, cavado, cingulizonado; contorno equatorial subtriangular, ângulos arredondados. Raios da marca trilete levemente sinuosos, alcançando a base da cingulizona, labiados (até $3 \mu \mathrm{m}$ de largura). Corpo central subtriangular, com face proximal lisa a finamente punteada, espinhos menores que 1 1. m de diâmetro e base concentrados ao redor do equador. Exoexina com elementos ornamentais de forma e distribuição irregular, com projeções espini- e baculiformes, mais grossas na face distal $[1(2,5) 4 \mu \mathrm{m}$ de base $\times 2$ $5 \mu m$ de altura]. Cingulizona incompleta, mais desenvolvida nos vértices, com projeções baculi-espiniformes e raramente mamóides, algumas apicalmente bifurcadas.

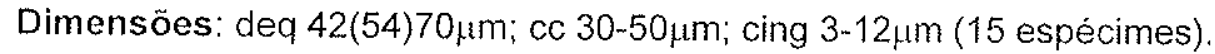

Ocorrência: Zonas Biointervalo Ahrensisporites cristatus, Potonieisporites neglectus e Subzona Protohaploxypinus goraiensis.

Distribuição estratigráfica na Bacia do Paraná: Subgrupo Itararé (Sundaram, 1987; Dias, 1993; Souza, 1996).

Distribuição estratigráfica mundial: Zonas Potonieisporites-Lundbladispora e Cristatisporites na Bacia Chacoparaná (Russo et al., 1980; Césari, 1986; Vergel, 1986b, 1987a, 1998; Césari et al., 1995); Carbonifero Superior a Permiano Inferior da Argentina (Ottone, 1989, 1991; Vergel et al., 1993; Di Pasquo, 1999; Di Pasquo \& Azcuy, 1997a, 1999a).

\section{Gênero Bascaudaspora Owens, 1983}

Espécie-tipo: Bascaudaspora canipa Owens, 1983.

Afinidade botânica: PTERIDOPHYTA-LYCOPSIDA?.

\section{Bascaudaspora canipa Owens, 1983}

Estampa VI, figuras 4 e 5

1996 Ancistrospora reticulata sp. nov., in Souza, est. 4, fig. 3 e 5. 
Diagnose: Owens (1983. Rep. Inst. Geol. Sci., 83/10: p. 46-8, est. 1, fig. 1-9).

Localidade-tipo: Mousegill Beck, Satinmore, Cumbria, Namuriano da Inglaterra.

Descrição: esporo radial trilete, cavado, cingulizonado; contorno equatorial subtriangular a subcircular, com ângulos arredondados. Raios da marca trilete finos, levemente sinuosos, alcançando a margem interna do cingulo. Face proximal do corpo central lisa. Exoexina espessa equatorialmente formando um cingulo de espessura uniforme e distinto; distalmente com intensa reticulação, com muros de $2-8 \mu \mathrm{m}$ de largura e até $5 \mu \mathrm{m}$ de altura, delimitando lacunas poligonais de até $10 \mu \mathrm{m}$ de diâmetro.

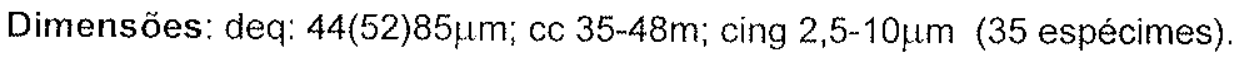

Ocorrência: Zonas Biointervalo Ahrensisporites cristatus e Potonieisporites neglectus.

Comparações: a estrutura reticulada da exoexina diferencia esta espécie daquelas assinaladas no gênero ex-Ancistrospora.

Distribuição estratigráfica na Bacia do Paraná: Subgrupo Itararé (Souza, 1996).

Distribuição estratigráfica mundial: Namuriano da Inglaterra (Owens, 1983).

\section{Gênero Cirratriradites Wilson \& Coe, 1940}

Espécie-tipo: Cirratriradites maculatus Wilson \& Coe, 1940.

Afinidade botânica: sem referências.

\section{Cirratriradites veeversi Playford, 1971}

Estampa VI, figura 7

Diagnose: Playford (1971. Bur. Miner. Res. Geol. \& Geophys. Austral., Bull. 115: p. 41-2, est. 16, fig. 1-2).

Localidade-tipo: Bonaparte Gulf Basin, Bonaparte Beds, Viseano do Oeste da Austrália.

Descrição: esporo radial trilete, cavado, cingulizonado; contorno equatorial subtriangular, com lados arredondados. Corpo central com faces proximal e distal finamente escabradas; raios da marca trilete acompanhados por lábios grossos $(4-5 \mu \mathrm{m})$. estendendo-se até margem interna da cingulizona; corpo central com anel marginal (com aparência de zona interna), espesso ( $64 \mathrm{~m})$, denso, escabrado a finamente equinado. Zona radialmente estriada na porção interna; fina a membranosa externamente, de margem ondulada.

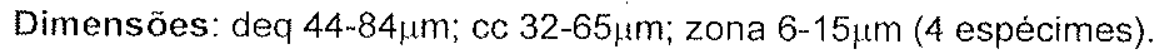

Ocorrência: Zona Biointervalo Ahrensisporites cristatus.

Comparações: Em C. saturnii (lbrahim) Schopf, Wilson \& Bentall, 1944 e C. annulatus Kosanke, 1950 os raios da marca trilete alcançam a borda externa da zona.

Distribuição estratigráfica na Bacia do Paraná: inédita. 
Distribuição estratigráfica mundial: Viseano das bacias de Drummond (Playford, 1978) e Bonaparte Gulf (Playford, 1971; Playford \& Satterthwait, 1988), Austrália.

Suprasubturma PSEUDOSACITRILETES [Richardson, 1965] Infraturma MONOPSEUDOSACCITI [Smith \& Butterworth, 1967]

\section{Gênero Spelaeotriletes Neves \& Owens, 1966}

Espécie-tipo: Spelaeotriletes triangulus Neves \& Owens, 1966.

Afinidade botânica: sem referências.

Spelaeotriletes ybertii (Marques-Toigo) Playford \& Powis, 1979

Estampa V1, figura 8

1983 Anabaculites yberti, in Lima et al., est. II, fig. 13.

1993 S. ybertii, in Dias, est. 5, fig. 9.

1995 S. ybertii, in Quadros et al., p. 116.

1996 S. sp., in Souza, est. 4, fig. 9.

1996 S. triangulus, in Souza, est. 4, fig. 7.

1996 S. ybertii, in Souza, est. 4, fig. 6.

Diagnose: Playford \& Powis [1979. Poll. et Spor., XXI(3): p. 388-92, est. IV, fig. 1-6, est. V, fig. 3].

Localidade-tipo: Paso de Las Bochas, Formação San Gregório, Permiano Inferior do Uruguai.

Descrição: esporo radial trilete; contorno equatorial subcircular a ovalado. Raios da marca triłete distintos, estendendo-se até a margem equatorial, retos a levemente sinuosos. Exina fina $[1(1,5) 2 \mu \mathrm{m}]$, proximalmente punteada a lisa. Face distal ornamentada por elementos desde coniformes, espiniformes a baculiformes, discretos ou basalmente coalescentes, com projeções na margem equatorial, de distribuição e tamanho irregulares $(0,5-3 \mu \mathrm{m}$ de base $\mathrm{x}$ 0,5-5 $\mu \mathrm{m}$ de altura). Corpo central nítido a obscuro, liso proximalmente.

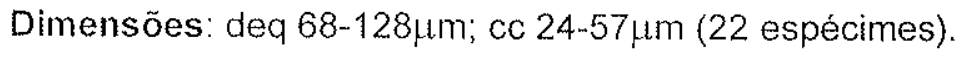

Ocorrência: Zonas Biointervalo Ahrensisporites cristatus, Potonieisporites neglectus e Subzona Protohaploxypinus goraiensis.

Observações: o espécime assinalado em S. triangulus Neves \& Owens, 1966 ilustrado por Souza (1996, est. 4, fig. 7) é incluido aqui em $S$. ybertii pelas suas dimensões mais reduzidas e pela sua ornamentação não comportar verrugas, tratando-se, nesta última espécie, de elementos de base subcircular, poligonal em contorno, com topos acuminados, como ilustrado por Playford \& Powis (1979, fig. 3, p. 390) para S. ybertii. 
Distribuição estratigráfica na Bacia do Paraná: Subgrupo Itararé (Lima et al., 1983; Dias, 1993; Souza, 1996).

Distribuição estratigráfica mundial: Zonas Potonieisporites-Lundbladispora e Cristatisporites (Archangeisky \& Gamerro, 1979; Césari, 1986; Vergel, 1987a; Césari et al., 1995), Bacia Chacoparaná; Carbonífero Superior a Permiano Inferior da Argentina (Césari, 1985a; Césari \& Gutiérrez, 1986; Garcia \& Azcuy, 1987; Ottone, 1989, 1991; Vergel \& Luna, 1992; Garcia, 1995; Di Pasquo, 1999; Di Pasquo \& Azcuy, 1997a, 1999a). Permiano Inferior do Uruguai (Marques-Toigo, 1973, 1974). Carbonífero Superior da Austrália (Playford \& Powis, 1979).

\section{Gênero Velamisporites Bharadwaj \& Venkatachala, 1962}

Espécie-tipo: Velamisporites rugosus Bharadwaj \& Venkatachala, 1962.

Afinidade botânica: sem referências.

\section{Velamisporites sp.}

Estampa VI, figuras 10 e 11

1996 Lycospora sp. 2, in Souza, est. 3, fig. 2.

Descrição: esporo radial triłete; contorno equatorial subcircular a subtriangular; inteiramente circundado por fina membrana (perisporo), lisa a finamente dobrada, com aspecto rugoso, constituído por rúgulas finas, de $0,2-0,5 \mu \mathrm{m}$ de largura. Corpo central fino $(1 \mu \mathrm{m})$ e liso; raios da marca trilete simples e retos, alcançando $2 / 3$ a $3 / 3$ (mais comum) do raio total. Perisporo geralmente desenvolvido em até $7,5 \mu \mathrm{m}$ além do corpo central na margem equatorial.

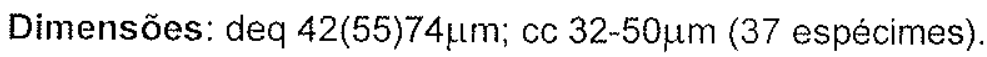

Ocorrência: Zonas Biointervalo Ahrensisporites cristatus e Potonieisporites neglectus.

Comparações: as espécies mais semelhantes: V. rugosus Bharadwaj \& Venkatachala, 1962, V. descretus Bharadwaj \& Venkatacha, 1962 e V. vermiculatus Felix \& Brubridge, 1967

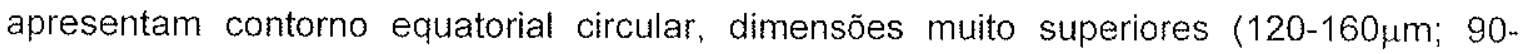
$110 \mu \mathrm{m} ; 115-200 \mu \mathrm{m}$, respectivamente), além de que o perisporo da primeira espécie é finamente granulado. Em V. pukraensis Venkatachala \& Kar, 1968, do Estágio Barakar da India, o perisporo não se expande além do corpo central. Os espécimes aqui descritos são muito similares a $V$. perinatus (Hughes \& Playford) Playford, 1971, descrito para o Carbonifero Inferior de Spitsbergen, que, no entanto, apresenta o perisporo liso a levemente granulado. V. lacertosus Playford, 1971 possui contorno equatorial predominantemente triangular e dimensões maiores $(93-156 \mu \mathrm{m})$. Em V. irrugatus Playford, 1978 as rúgulas são mais espessas $(0,8-4 \mu \mathrm{m})$. 
Observações: o intenso e fino dobramento do perisporo, normalmente constituindo convoluções de até $1 \mu \mathrm{m}$ de espessura, imprime aparência corrugada ou rugosa/pseudovermicular aos espécimes assinalados nesta espécie.

Distribuição estratigráfica na Bacia do Paraná: Subgrupo Itararé (Souza, 1996).

TURMa HILATES [Dettmann, 1963]

Gênero Psomospora Playford \& Helby, 1968

Espécie-tipo: Psomospora detecta Playford \& Helby, 1968

Afinidade botânica: hepáticas ? (Playford \& Helby, 1968).

Psomospora detecta Playford \& Helby, 1968

Estampa $\mathrm{VI}$, figuras 9 e 12

Diagnose: Playford \& Helby [1968. Joum. Geol. Soc. Austral., 15(1): p. 114, est. 11, fig. 8-14].

Localidade-tipo: Formação Italia Road, Hunter Valley, New South Wales, Carbonífero da Austrália.

Descrição: esporo radial trilete, hilado; contorno equatorial subcircular. Raios da marca trilete finos $(1-1,5 \mu \mathrm{m})$, estendendo-se até $3 / 4$ ou mais do raio. Exina fina $(1-2,5 \mu \mathrm{m})$ e lisa, mais translúcida na região proximal polar, delimitando uma área com forma subtriangular (hilum) de abertura subtriangular, triradiada.

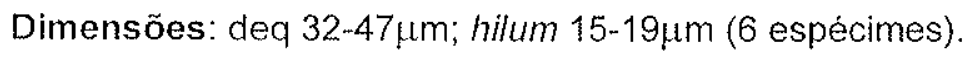

Ocorrência: Zona Biointervalo Ahrensisporites cristatus.

Distribuição estratigráfica na Bacia do Paraná: Dino \& Playford (1997) noticiaram a ocorrência desta espécie no carvão de Buri (Subgrupo Itararé).

Distribuição estratigráfica mundial: Namuriano/Westphaliano da Argentina (Azcuy, 1975b). Namuriano a Tastubiano da Austrália (Gilby \& Foster, 1988; Jones \& Truswell, 1992). Permiano Inferior da Antártica (Lindström, 1995). Carbonifero Superior/Permiano Inferior do Omã (Stephenson \& Filatoff, 2000). 


\author{
Anteturma VARIEgERMINANTES [Potonié, 1970] \\ Turma SACCITES [Erdtmann, 1947] \\ Subturma Monosaccites \{[Chitaley] Potonié \& Kremp, 1954 \} \\ Infraturma ALETESACCITI [Leschik, 1955]
}

\title{
Gênero Florinites (Schopf, Wilson \& Bentall) Millay \& Taylor, 1974
}

Espécie-tipo: Florinites antiquus Schopf, Wilson \& Bentall, 1944.

Afinidade botânica: CORDAITALES/CONIFERALES (Potonié \& Kremp, 1956; Potonié, 1970;

Azcuy, 1978).

\section{Florinites sp.}

Estampa VII, figura 1

Descrição: grão de pólen monossacado, longitudinalmente alongado. Corpo central circular a subcircular, levemente alongado transversalmente. Lesura não distinta. Saccus intrareticulado; raizes distais subequatoriais, com recobrimento de até $2 / 3$ no raio do corpo central [5(7)10 $\mathrm{m}]$, associadas a pregas radiais.

Ocorrência: Zonas Biointervalo Ahrensisporites cristatus e Potonieisporites neglectus.

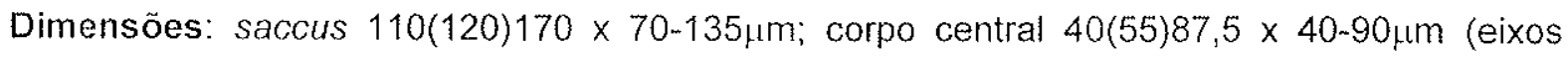
longitudinais e transversais, respectivamente) ( 11 espécimes).

Comparações: a ausência de pregas associadas às raízes distais e a não-biconstrução lateral separam esta espécie, respectivamente, daquelas dos gêneros Potonieisporites e Caheniasaccites. As dimensões de F. eremus são geralmente mais reduzidas (e.g. Foster, 1979; Lindström, 1996). Contudo, espécimes com dimensões maiores, como aqui constatado, já foram divulgados (ver http: www. geoscience.net/May_.1998, em 13.08.1999) para a espécie, com até $145 \mu \mathrm{m}$ no eixo longitudinal. Vale reassaltar ainda que, embora mais comum em estratos permianos, F. eremus já foi registrado no Westphaliano do Canadá (Barss, 1967) e na passagem C/P da Espanha (Broutin, 1981).

Infraturma TRILETESACCITI [Leschik, 1955]

Gênero Cannanoropollis Potonié \& Sah, 1960

Espécie-tipo: Cannanoropollis janakii Potonié \& Sah, 1960.

Afinidade botânica: CONIFERALES (Staplin et al., 1967; Archangelsky \& Cuneo, 1987). 


\section{Cannanoropollis janakii Potonié \& Sah, 1960}

Estampa VII, figura 2

1970 Virkkipollenites cf. obscurus, in Daemon \& Quadros, est. 3 e 4, forma P522.

1980 C. janakii, in Thomaz, est. 1, fig. 7.

1986 C. janakii, in Picarelli, est. 3, fig. 1 e 3.

1987 C. janakii, in Sundaram, est. VI, fig. 7.

Diagnose: Potonié \& Sah [1960. Palaeobot, 7(2): est. 2, fig. 15].

Localidade-tipo: Cannanore Beach, Malabar Coast, Permiano da India.

Descrição: grão de pólen monossacado, de simetria radial, contorno equatorial circular a subtriangular. Corpo central circular a subtriangular, geralmente acompanhando o contorno geral; face proximal apresentando marca trilete, cujos raios alcançam até $2 / 3$ do raio do corpo central. Saccus finamente intrareticulado, com largura relativamente ampla, correspondendo a $1 / 2$ ou mais do raio do corpo central; raiz distal no corpo central subequatorial, com recobrimento de $5-15 \mu \mathrm{m}$, a partir do qual podem irradiar pregas discretas, que se estendem até a margem.

Dimensões: ver Tabela III.1.

Ocorrência: Zonas Biointervalo Ahrensisporites cristatus e Potonieisporites neglectus e Subzona Protohaploxypinus goraiensis.

Comparações: C. perfectus apresenta intenso pregueamento do saccus a partir da raiz distal no corpo central. As formas apresentadas por Daemon \& Quadros (1970) como Virkkipollenites sp. (P384) provavelmente são relativas a Cannanoropollis korbaensis, pelo aspecto bem delimitado do corpo central e recobrimento reduzido no saccus.

Distribuição estratigráfica na Bacia do Paraná: Subgrupo Itararé (Daemon \& Quadros, 1970; Sundaram, 1987), Formação Rio Bonito (Daemon \& Quadros, 1970; Thomaz, 1980; Picarelli, 1986) e Palermo (Daemon \& Quadros, 1970). Intervalos G-K.

Distribuição estratigráfica mundial: Namuriano da Bacia do Parnaíba, Solimões e Amazonas (Melo et al., 1999). Carbonifero Superior a Permiano Inferior da Argentina (Ottone \& Azcuy, 1986, 1989; Ottone, 1989; Gutiérrez, 1993; Di Pasquo \& Azcuy, 1997a, 1999a; Azcuy \& Di Pasquo, 2000). Permiano Inferior do Uruguai (Mautino et al., 1998b), África (Bose \& Maheshwari, 1968), Índia (Potonié \& Sah, 1960) e Antártica (Lindström, 1995). Namuriano (Jones \& Truswell, 1992) a Permiano Superior da Austrália (Foster, 1979; De Jersey, 1979; Foster \& Waterhouse, 1988; Gilby \& Foster, 1988). Carbonifero Superior do Omã e Arábia Saudita (Stephenson \& Filatoff, 2000). 


\section{Cannanoropollis triangularis (Mehtae) Bose \& Maheshwari, 1968}

Estampa VII, figura 3

1970 Virkkipollenites cf. triangularis, in Daemon \& Quadros, est. 1, forma P501.

1993 C. triangularis, in Dias, est. 6, fig. 5.

non 1996 C. perfectus, in Souza, est. 5, fig. 4.

1996 C. triangularis, in Souza, est. 5 , fig. 8.

Diagnose: Mehta (1944. Proc. Natn. Acad. Sci. India, 14: est. 1, fig. 1).

Localidade tipo: Pali, South Rewa Gondwana Basin, Pemiano da Índia.

Descrição: grão de pólen monossacado, de simetria radial, contorno equatorial triangular a subtriangular, margem ondulada. Corpo central ovalado a subcircular; face proximal apresentando marca trilete, cujos raios alcançam $2 / 3$ do raio do corpo central. Saccus finamente intrareticulado, amplo $(15-25 \mu \mathrm{m}$ além do corpo central); raiz distal no corpo central subequatorial distalmente, com recobrimento de até $12,5 \mu \mathrm{m}$, e equatorial proximalmente, definindo cápula ovalada. Dobras radiais são geralmente presentes.

Dimensões: ver Tabela III.1.

Ocorrência: Zonas Biointervalo Ahrensisporites cristatus e Potonieisporites neglectus e Subzona Protohaploxypinus goraiensis.

Distribuição estratigráfica na Bacia do Paraná: Subgrupo Itararé (Daemon \& Quadros, 1970; Dias, 1993; Souza, 1996). Intervalo G.

Distribuição estratigráfica mundial mundial: Carbonifero Superior da Argentina (Gutiérrez, 1993; Di Pasquo \& Azcuy, 1997a, 1999a; Di Pasquo, 1999; Azcuy \& Di Pasquo, 2000).

\section{Cannanoropollis densus (Lele) Bose \& Maheshwari, 1968}

Estampa VII, figura 4

1970 Virkkipollenites densus, in Daemon \& Quadros, est. 1, forma P498.

1975 Parasaccites cf. P. mehtae, in Kemp, est. 291, fig. 30.

1983 Virkkipollenites densus, in Lima et al., est. IV, fig. 6.

1987 C. densus, in Sundaram, est. VI, fig. 5.

1993 C. densus, in Dias, est. 6, fig. 8.

1996 C. densus, in Souza, est. 5, fig. 7.

1996 C. mehtae, in Souza, est. 5, fig. 5.

Diagnose: Bose \& Maheshwari (1968. Ann. Mus. Royal L'Áfrique Centrale, Sc. Geol., 60: p.34, est. $V$, fig. 3).

Localidade-tipo: South Rewa Basin, Pemiano da Índia (Estágio Talchir). 
Descrição: grão de pólen monossacado, de simetria radial, contorno equatorial subtriangular a subcircular. Corpo central circular a subtriangular, bem definido, denso; raios da lesura geralmente alcançando $1 / 2$ do raio do corpo central. Saccus intrareticulado, de largura relativamente ampla, correspondendo a $1 / 2$ ou mais do raio do corpo central; raiz distal no corpo central subequatorial, com recobrimento de $5-20 \mu \mathrm{m}$, a partir da qual podem irradiar pregas discretas, que se estendem até a margem.

Dimensões: ver Tabela III.1.

Ocorrência: Zonas Biointervalo Ahrensisporites cristatus e Potonieisporites neglectus e Subzona Protohaploxypinus goraiensis.

Distribuição estratigráfica na Bacia do Paraná: Subgrupo Itararé (Daemon \& Quadros, 1970; Kemp, 1975; Lima et al., 1983; Sundaram, 1987; Dias, 1993; Souza, 1996) e ?Formação Rio Bonito (Daemon \& Quadros, 1970). Intervalos G-?J.

Distribuiçăo estratigráfica mundial: Zonas Lundbladispora-Potonieisporites e Cristatisporites na Bacia Chacoparaná na Argentina (Archangelsky \& Gamerro, 1979; Césari et al., 1995; Vergel, 1987ab); Carbonífero Superior a Permiano Inferior da Argentina (Césari, 1984; Azcuy \& Gutiérrez, 1985; Barreda, 1986; Ottone \& Azcuy, 1986, 1989, 1990; Césari \& Vazquez-Nístico, 1988; Ottone, 1989; Vergel \& Luna, 1992; Gutiérrez, 1993; Vergel, 1993; Garcia, 1996; Di Pasquo \& Azcuy, 1997a, 1999a; Di Pasquo, 1999; Azcuy \& Di Pasquo, 2000). Permiano Inferior do Uruguai (Beri, 1988; Beri \& Aguilar, 1998; Mautino et al., 1998b), África (Bose \& Maheshwari, 1968) e Índia (Talchir: Lele, 1964, Lele \& Karim, 1971; Karharbari: Lele \& Srivastava, 1979). Carbonífero Superior/Permiano Inferior do Omã (Stephenson \& Filatoff, 2000).

\section{Cannanoropollis perfectus (Bose \& Maheshwari) Dias-Fabrício, 1981}

Estampa VII, figura 5

1981 C. perfectus, in Dias-Fabrício, est. 7, fig. 4.

1988 C. perfectus, in Marques-Toigo, est. V, fig. 4.

1993 C. perfectus, in Dias, est. 7, fig. 1.

1995 C. perfectus, in Quadros et al., p. 34.

1997 C. perfectus, in Souza et al., est. II, fig. 1.

Diagnose: Dias-Fabricio (1981. Pesquisas, 14: p. 84, est. VII, fig. 4).

Localidade-tipo: camadas de carvão próximo ao lago Tanganyka, sul de Albertville, Luanda e Kabangu, Permiano do Congo:

Descrição: grão de pólen monossacado, de simetria radial, contorno equatorial subtriangular. Corpo central acompanhando o contorno geral; raios da lesura geralmente alcançando $1 / 2$ do raio do corpo central. Saccus intrareticulado, de largura relativamente ampla, correspondendo a $1 / 2$ ou mais do raio do corpo central; raiz distal no corpo central 
subequatorial, com recobrimento de 5-12,5 $\mathrm{m}$; a partir da qual se desenvolve forte sistema de pregueamento, que irradiam até a margem.

Dimensões: ver Tabela III.1.

Ocorrência: Zonas Biointervalo Ahrensisporites cristatus e Potonieisporites neglectus e Subzona Protohaploxypinus goraiensis.

Comparações: o intenso pregueamento do saccus a partir da raiz distal no corpo central separa esta espécie das demais descritas do gênero. C. korbaensis e C. singrauliensis apresentam dimensões relativas menores na largura do saccus a partir do corpo central.

Observações: a transferência de P. perfectus Bose \& Maheswari, 1968 para C. perfectus realizada por Dias-Fabrício (1981) é baseada nas dificuldades de observação da forma de aderência do saccus no corpo central, que distingue os dois gêneros. No primeiro, o saccus é aderido proximal- e distalmente subequatorialmente, enquanto que no segundo é proximal equatorial/subequatorial e distal subequatorialmente. Os exemplares verificados apresentam as condições para uma assinalação no segundo gênero, bem como alguns outros descritos na Bacia do Paraná. Entretanto, a combinação realizada por Dias-Fabrício (1981) é contestada tendo em vista que somente a partir da não-observância da "paracondição" nos holótipos de P. perfectus seria possivel a transferência da espécie para o gênero Cannanoropollis. Provavelmetne se trata de uma nova espécie, muito comum nos estratos da Bacia do Paraná, se diferenciando de C. janakii pela largura reduzida do saccus e, principalmente, presença de intenso dobramento radial no saccus.

Distribuição estratigráfica na Bacia do Paraná: Subgrupo Itararé (Marques-Toigo, 1988; Dias, 1993; Souza et al., 1997), Formação Rio Bonito (Dias-Fabrício, 1981; Marques-Toigo, 1988) e Formação Palermo (Marques-Toigo, 1988). Zonas Vittatina e Lueckisporites virkkiae.

Distribuição estratigráfica mundial: Permiano Inferior da África (Bose \& Maheshwari, 1968).

\section{Gênero Plicatipollenites Lele, 1964}

Espécie-tipo: P. malabarensis (Potonié \& Sah) Foster, 1975.

Afinidade botânica: CONIFERALES (Clement-Westerhof, 1984).

\section{Plicatipollenites malabarensis (Potonié \& Sah) Foster, 1975}

Estampa VII, figuras 6 e 8

1970 P. indicus, in Daemon \& Quadros, forma P550.

1975 P. sp. cf. P. indicus, in Kemp, est. 29l, fig. 31.

1976 P. indicus, in Bharadwaj et al., est. 4, fig. 49.

1981 P. malabarensis, in Dias-Fabricio, est. 7, fig. 5.

1983 P. indicus, in Lima et al., est. IV, fig. 1.

1983 P. sp. 2, in Lima et al., est. IV, fig. 4. 
1984 P. malabarensis, in Burjack, est. I, fig. 3-4.

1986 P. malabarensis, in Picarelli, est. 3, fig. 2 e 4.

1987 P. malabarensis, in Sundaram, est. V, fig. 13.

1988 P. malabarensis, in Marques-Toigo, est. V, fig. 5.

1993 P. malabarensis, in Dias, est. 6, fig. 7.

1995 P. malabarensis, in Quadros et al., p. 94.

1996 P. cf. P. malabarensis, in Souza, est. 6, fig. 5.

1996 P. malabarensis, in Souza, est. 6, fig. 6-7.

1997 P. malabarensis, in Souza et al., est. II, fig. 3.

Diagnose: Foster (1975. Palaeontogr. Abt. B, 154: p. 141-2, est. 5, fig. 1).

Localidade-tipo: Cannanore Beach, Malabar Coast, Permiano Inferior da Índia.

Descrição: grão de pólen monossacado, de simetria radial; contorno equatorial circular a subcircular. Corpo central circular a subcircular, intramicroreticulado; raios da lesura trilete alcançando 1/3-2/3 do raio do corpo central, às vezes aberta. Saccus intramicroreticulado, de margem lisa, levemente crenulada quando presentes pregas radiais (raras). Sistema de pregas associado à raiz distal no corpo central, subperiférico, contínuo ou com contatos levemente angulares.

Dimensões: ver Tabela III.1.

Ocorrência: Zonas Biointervalo Ahrensisporites cristatus e Potonieisporites neglectus e Subzona Protohaploxypinus goraiensis.

Distribuição estratigráfica na Bacia do Paraná: Subgrupo Itararé (Daemon \& Quadros, 1970; Kemp, 1975; Bharadwaj et al., 1976; Lima et al., 1983; Sundaram, 1987; MarquesToigo, 1988; Dias, 1993; Souza, 1996; Souza et al., 1997), Formação Rio Bonito (Daemon \& Quadros, 1970; Dias-Fabricio, 1981; Picarelli, 1986; Marques-Toigo, 1988), Palermo (Daemon \& Quadros, 1970; Bharadwaj et al., 1976; Picarelli, 1986; Marques-Toigo, 1988) e Subgrupo Irati (Bharadwaj et al., 1976; Burjack, 1984; Marques-Toigo, 1988). Intervalos G$\mathrm{K}$, zonas Vittatina e Lueckisporites virkkiae.

Distribuição estratigráfica mundial: zonas Potonieisporites-Lundbladispora e Cristatisporites superior (Vergel, 1993) Bacia Chacoparaná, Permiano Inferior (Archangelsky \& Gamerro, 1979; Vergel, 1987ab; Césari et al., 1995); Carbonífero Superior a Permiano Inferior da Argentina (Azcuy \& Gutiérrez, 1985; Barreda, 1986; Ottone \& Azcuy, 1986, 1989; Aceñolaza \& Vergel, 1987; Vázquez-Nístico \& Césari, 1987; Ottone, 1989; Vergel \& Luna, 1992; Gutiérrez, 1993; Di Pasquo \& Azcuy, 1997a; Di Pasquo \& Azcuy, 1999a; Di Pasquo, 1999; Azcuy \& Di Pasquo, 2000). Permiano Inferior do Uruguai (Beri, 1987; Santa Ana et al., 1993; Beri \& Aguilar, 1998; Mautino et al., 1998b), África (Bose \& Maheshwari, 1968), Antártica (Lindström, 1995), İndia (Talchir: Lele, 1964; Srivastava, 1970; Lele \& Karim, 1971; Chandra \& Lele, 1979; Lele \& Shukla, 1980). Permiano Inferior (Foster, 1975, 1979; Foster 
\& Waterhouse, 1988; Gilby \& Foster, 1988) a Superior (De Jersey, 1979) da Austrália. Permiano Inferior a Superior do Paquistão (Balme, 1970).

\section{Plicatipollenites gondwanensis (Balme \& Hennelly) Lele, 1964}

Estampa VIII, figura 1

1970 P. gondwanensis, in Daemon \& Quadros, est. 7, forma P906.

1976 Parasaccites gondwanensis, in Menéndez, est. I, fig. 7.

1984 P. gondwanensis, in Burjack, est. I, fig. 5.

1986 P. gondwanensis, in Picarelli, est. 3, fig. 5.

1987 P. gondwanensis, in Sundaram, est. V, fig. 11.

1988 P. gondwanensis, in Marques-Toigo, est. V, fig. 6.

1995 P. gondwanensis, in Quadros et al., p. 93.

1996 P. gondwanensis, in Souza, est. 6, dig. 4 e 8.

Diagnose: Lele [1964. Palaeobot, 12(2): p. 154-156, est. 2, fig. 11].

Localidade-tipo: Big Ben Seam, Bloomfield Colliery, Permiano da Austrália.

Descrição: grão de pólen monossacado, de simetria radial, contorno circular e margem lisa. Corpo central circular a levemente subcircular. Lesura nem sempre distinta, trilete, com raios geralmente reduzidos a $1 / 3$ do raio do corpo central. Saccus intramicroreticulado, com raiz distal no corpo central cobrindo até $1 / 3$ do raio deste e associada a um sistema de pregas poligonal, com largura variável $(5-20 \mu \mathrm{m})$. Pregas radiais são raras.

Dimensões: ver Tabela III.1.

Ocorrência: Zonas Biointervalo Ahrensisporites cristatus e Potonieisporites neglectus e Subzona Protohaploxypinus goraiensis.

Distribuição estratigráfica na Bacia do Paraná: Subgrupo Itararé (Daemon \& Quadros, 1970; Sundaram, 1987; Marques-Toigo, 1988; Souza, 1996), Formação Rio Bonito (Daemon \& Quadros, 1970; Picarelli, 1986, Marques-Toigo, 1988) e Palermo (Daemon \& Quadros, 1970) e Subgrupo Irati (Menéndez, 1976; Burjack, 1984). Intervalos I-K.

Distribuição estratigráfica mundial: Carbonifero Superior a Permiano Inferior da Argentina (Césari, 1984; Ottone, 1989; Ottone \& Azcuy, 1989; Gutiérrez, 1993; Vergel, 1993; Garcia, 1996; Di Pasquo \& Azcuy, 1997a, 1999a; Di Pasquo, 1999: Azcuy \& Di Pasquo, 2000). Permiano Inferior do Uruguai (Maurino et al., 1998), Antártica (Lindström, 1995), África (Bose \& Maheshwari, 1968; Maheshwari \& Bose, 1969; Broutin et al., 1990), Austrália (Foster, 1975, 1979; De Jersey, 1979; Foster \& Waterhouse. 1988; Gilby \& Foster, 1988; Jones \& Truswell, 1992), Índia (Talchir: Lele, 1964; Srivastava, 1970; Lele \& Karim, 1971; Lele \& Shukla, 1980; Karharbari: Lele \& Srivastava, 1979) e Pasquistão (Chandra \& Lele, 1979). Carbonifero Superior/Permiano Inferior do Omã (Stephenson \& Filatoff, 2000). Passagem C/P da Espanha (Broutin, 1981). 


\section{Plicatipollenites trigonalis Lele, 1964}

Estampa VII, figura 7

1970 P. sp., in Daemon \& Quadros, est. 1, forma P490.

1993a P. indicus, in Souza et al., est. 3, fig. 6.

1993 P. trigonalis, in Dias, est. 6, fig. 6.

1995 P. trigonalis, in Quadros et al., p. 95.

1996 P. trigonalis, in Souza, est. 6, fig. 1-2.

Diagnose: Lele [1964. Palaeobot. 12(2): p. 156-157, est. 1, fig. 13-14, text-fig. 6a e 12d].

Localidade-tipo: South Rewa Basin, Permiano Inferior da Índia (Estágio Talchir).

Descrição: grão de pólen monossacado, de simetria radial, contorno circular a subtriangular; margem lisa, crenulada quando presentes pregas radiais no saccus. Corpo central triangular a subcircular; raios da lesura nem sempre distintos, alcançando $1 / 4-1 / 2$ do raio do corpo central. Saccus intramicroreticulado, de largura variável; raiz distal associada a um sistema de pregas de arranjo triangular, composto por 3 a 4 pregas de largura variável (5-18 $\mu \mathrm{m})$.

Dimensões: ver Tabela lll.1.

Ocorrência: Zonas Biointervalo Ahrensisporites cristatus e Potonieisporites neglectus e Subzona Protohaploxypinus goraiensis.

Observações: em alguns casos, o sistema de pregas associado à raiz distal do saccus é formado por 4 pregas, com forma geral triangular, acompanhando a forma do corpo central.

Distribuição estratigráfica na Bacia do Paraná: Subgrupo Itararé (Daemon \& Quadros, 1970; Dias, 1993; Souza et al., 1993a; Souza, 1996). Intervalo G.

Distribuição estratigráfica mundial: Permiano Inferior da Bacia Chacoparaná (Césari et al, 1995); Carbonifero Superior a Permiano Inferior da Argentina (Azcuy \& Gutiérrez, 1985; Ottone \& Azcuy, 1990; Gutiérrez, 1993; Vergel, 1993; Garcia, 1996; Di Pasquo \& Azcuy, 1997a, 1999a; Di Pasquo, 1999; Azcuy \& Di Pasquo, 2000). Permiano Inferior da Bolivia (Ottone et al., 1998) e Índia (Talchir: Lele, 1964; Srivastava, 1970; Chandra \& Lele, 1979).

Plicatipollenites densus Srivastava, 1970

Estampa VIII, figura 2

1987 P. densus, in Sundaram, est. V, fig. 12.

1993 P. densus, in Dias, est. 7, fig. 3.

1996 P. densus, in Souza, est. 6, fig. 3.

Diagnose: Srivastava [1970. Palaeobot., 18(2): p. 159-160, est. I, fig. 7].

Localidade-tipo: Dera Coliery, Carvão Talchir, Permiano Inferior da India (Estágio Barakar). 
Descrição: grão de pólen monossacado, de simetria radial, contorno equatorial circular a levemente subcircular; margem lisa, crenulada pela presença de pregas radiais. Corpo central circular a subtriangular. Raios da lesura nem sempre distintos, alcançando $1 / 3$ do raio do corpo central. Saccus intramicroreticulado, com raízes distais no corpo central associadas a um sistema de pregas de largura variável $(2,5-12,5 \mu \mathrm{m})$ e quase sempre continuo. Largura do saccus entre $1 / 2 \mathrm{e} 3 / 4$ do raio do corpo central.

Dimensões: ver Tabela III.1.

Ocorrência: Zonas Biointervalo Ahrensisporites cristatus e Potonieisporites neglectus e Subzona Protohaploxypinus goraiensis.

Comparações: a largura relativa do saccus, geralmente maior que $1 / 2$ do raio do corpo central, separa esta espécie de P. malabarensis.

Distribuição estratigráfica na Bacia do Paraná: Subgrupo Itararé (Sundaram, 1987; Dias, 1993; Souza, 1996).

Distribuição estratigráfica mundial: Zonas Potonieisporites-Lundbladispora, Cristatisporites e Striatites da Bacia Chacoparaná (Archangelsky \& Gamerro, 1979; Vergel, 1987b; Césari et al., 1995); Carbonífero Superior a Permiano Inferior da Argentina (Azcuy \& Gutiérrez, 1985; Barreda, 1986; Ottone \& Azcuy, 1990; Garcia, 1996). Namuriano (Jones \& Truswell, 1992) a Permiano Inferior (Foster, 1975, 1979) da Austrália. Permiano Inferior do Uruguai (Beri, 1988; Beri \& Aguilar, 1998), África (Broutin et al., 1990) e Índia (Talchir: Srivastava, 1979; Lele \& Karim, 1971; Chandra \& Lele, 1979). Passagem C/P da Espanha (Broutin, 1981).

\section{Gênero Crucisaccites Lele \& Maithy, 1964}

Espécie-tipo: C. latisulcatus Lele \& Maihty, 1964.

Afinidade botânica: GYMNOSPERMOPSIDA? (Gutiérrez, 1993).

\section{Crucisaccites latisulcatus Lele \& Maithy, 1964}

Estampa VIII, figuras 3 e 4

1995 C. latisulcatus, in Quadros et al., p. 46.

Diagnose: Lele \& Maithy [1964. Palaeobot., 12(3): p. 309-12, est. 1, fig. 1-6, Text-fig. 1, 2].

Localidade-tipo: Central Pit, Serampur Colliery, Giridith Coalfield, Permiano Inferior da India (Estágio Karharbari).

Descrição: grão de pólen monossacado, longitudinalmente alongado. Corpo central distinto, acompanhando o contorno geral do grão. Aderência do saccus bilateralmente nas faces distal e proximal, ortogonais entre si, com áreas livres relativamente largas (10-17,5 $\mathrm{m})$, retangulares e cruzadas. Saccus finamente intrareticulado.

Dimensöes: ver Tabela III. 1 . 
Ocorrência: Zonas Biointervalo Ahrensisporites cristatus e Potonieisporites neglectus e Subzona Protohaploxypinus goraiensis.

Distribuição estratigráfica na Bacia do Paraná: ?Subgrupo Itararé/Formação Rio Bonito (Quadros et al., 1995).

Distribuição estratigráfica mundial: Zona Potonieisporites-Lundbladispọa (Césari \& Vázquez-Nistico, 1988), Carbonifero Superior a Permiano Inferior (Gutiérrez, 1993; Césari \& Bercowski, 1997; Di Pasquo \& Azcuy, 1997a, 1999a; Di Pasquo, 1999) da Argentina. Passagem C/P da Espanha (Broutin, 1981).

\section{Crucisaccites monoletus Maithy, 1965}

Estampa VIII, figura 5

1987 C. monoletus, in Sundaram, est. VII, fig. 6.

1995 C. monoletus, in Quadros et al., p. 47.

Diagnose: Maithy [1965. Palaeobot., 15(3): est. 3, fig. 18].

Localidade-tipo: Giridish Coalfield, Bihar, Permiano Inferior da Índia.

Descrição: grão de pólen monossacado, monolete, de simetria radial, contorno ovalado. Corpo central pouco diferenciado do saccus, fracamente definido, com forma acompanhando o contorno geral. Área livre ampla, longitudinalmente alongada $(7,5-10 \mu \mathrm{m}$ de abertura). Saccus intramicroreticulado, com inserção cruzada distal e proximalmente no corpo central

Dimensões: ver Tabela III.1.

Ocorrência: Zona Biointervalo Potonieisporites neglectus.

Distribuição estratigráfica na Bacia do Paraná: Subgrupo Itararé (Sundaram, 1987; Quadros et al., 1995).

Distribuição estratigráfica mundial: Carbonifero Superior (Césari, 1984; Ottone \& Azcuy, 1986, 1989, 1990; Vázquez-Nístico \& Césari, 1987; Césari \& Vázquez-Nístico, 1988; Ottone, 1991; Gutiérrez, 1993; Garcia, 1996) a Permiano Inferior da Austrália (Foster, 1979) e India (Maithy, 1965; Lele \& Maithy, 1969). 


\begin{tabular}{lccccc}
\hline & n.e. & deqt & cc & Is & r \\
\hline C. janakii & 22 & $82,5-112,5$ & $37,5(62,5) 83$ & $7,5-20$ & $5-20$ \\
C. trangularis & 13 & $65-112,5$ & $40-75$ & $15-25$ & $5-12,5$ \\
C. densus & 22 & $65(90) 150$ & $35(60) 95$ & $10(17,5) 32,5$ & $5(10) 20$ \\
C. perfectus & 7 & $55-110$ & $37,5-62,5$ & $8(10) 27,5$ & $5(7,5) 12,5$ \\
P. malabarensis & 128 & $65(110) 200$ & $44(80) 125$ & $8(18) 30$ & $2,5(6) 15$ \\
P. gondwanensis & 11 & $76-160$ & $46-105$ & $11-45$ & $5(7,5) 20$ \\
P. trigonalis & 23 & $80(110) 160$ & $45(70) 92,5$ & $5(18) 40$ & $5-18$ \\
P. densus & 18 & $77,5(110) 130$ & $40(55) 70$ & $18-30$ & $2,5(5) 12,5$ \\
C. latisulcatus & 02 & $120-125$ & $80-110$ & - & - \\
C. monoletus & 03 & $87,5-128$ & $85-90$ & - & - \\
\hline
\end{tabular}

Tabela III.1 - Dimensōes das espécies dos gêneros Cannanoropollis Potoniè \& Sah, Plicatipollenites Lele e Crucisaccites Lele \& Maithy (ne: número de espécimes medidos; deqt: diâmetro equatorial total; cc: corpo central; Is: largura do saccus; r: recobrimento do saccus no corpo central; valores em $\mu \mathrm{m})$.

Infraturma VESICULoMONORADITI [Pant, 1954]

\section{Gênero Potonieisporites (Bharadwaj) Bharadwaj, 1964}

Espécie-tipo: Potonieisporites novicus (Bharadwaj) Poort \& Veld, 1997.

Afinidade botânica: CONIFERALES (Nygreem \& Bourm, 1967; Staplin et al., 1967; Rothwell, 1982; Taylor, 1982; Clement-Westhof, 1984).

Potonieisporites novicus Bharadwaj emend. Poort \& Veld, 1997

Estampa $\mid X$, figuras 1 e 2

1970 P. sp., in Daemon \& Quadros, est. 2 e 6, formas P410 e P417.

1976b P. novicus, in Pons, est. I, fig. 1.

1980 P. sp., in Thomaz, est. 1, fig. 4b.

1983 Potonieisporites simplex, in Lima et al., est. IV, fig. 9.

1983 P. novicus, in Lima et al., est. IV, fig. 10.

1983 Plicatipollenites sp. 1, in Lima et al., est. IV, fig. 3.

1993 P. simplex, in Dias, est. 7, fig. 2.

1996 P. novicus, in Souza, et. 7 , fig. 1.

1996 P. simplex, in Souza, est. 8, fig. 3.

Diagnose emendada: Poort \& Veld [1997. Acta Bot. Neert., 46(2): p. 167, fig. 1-4]. Localidade-tipo: Pfalz, Labachgrube, Grenkohlenflox, Stephaniano $\mathrm{C}$ da Alemanha. 
Descrição: grão de pólen monossacado, de simetria bilateral, longitudinalmente alongado. Corpo central circular a levemente ovalado longitudinalmente. Marca monolete nem sempre visivel, alcançando as dimensões do raio do corpo central. Saccus intrareticulado; raiz distal no corpo central associada a dois sistemas de pregas continuos, submarginais ao corpo central.

Dimensões: ver Tabela III.2.

Ocorrência: Zonas Biointervalo Ahrensisporites cristatus e Potonieisporites neglectus e Subzona Protohaploxypinus goraiensis.

Distribuição estratigráfica na Bacia do Paraná: Subgrupo Itararé (Daemon \& Quadros, 1970; Pons, 1976b; Lima et al., 1983; Dias, 1993; Souza, 1996) e Formação Rio Bonito (Daemon \& Quadros, 1970; Thomaz, 1980). Intervalos G-14.

Distribuição estratigráfica mundial: Zonas Potonieisporites-Lundbladispora e Cristatisporites da Bacia Chacoparaná (Archangelsky \& Gamerro, 1979; Césari et al., 1995; Vergel, 1987ab), Carbonífero Superior a Permiano inferior da Argentina (Ottone, 1989; Ottone \& Azcuy, 1989; Vergel \& Luna, 1992; Gutiérrez, 1993; Vergel, 1993; Garcia, 1996; Di Pasquo \& Azcuy, 1997a, 1999a; Di Pasquo, 1999; Azcuy \& Di Pasquo, 2000). Permiano Inferior do Uruguai (Mautino et al., 1998b), Bolivia (Ottone et al., 1998) e Antártica (Lindström, 1995). Zonas P. confluens (Backhouse, 1991) e Zonas Verrucosisporites basiliscutis a Asperispora reticulatispinosus (Jones \& Truswell, 1992), Namuriano a Asseliano da Austrália. Autuniano da Nigéria da África (Broutin et al., 1990), Zona Virkkipollenites-Plicatipollenites da Bacia do Karroo (Falcon, 1975). Wolfcampiano do Canadá (Barss, 1967). Artinskiano/Guadalupiano do Paquistão (Balme, 1970). Passagem C/P da Espanha (Broutin, 1981) e Stephaniano/Autuniano da Espanha (Doubinger \& Broutin, 1976) e França (Broutin et al., 1986). Carbonifero Superior/Permiano Inferior do Omã e Arábia Saudita (Stephenson \& Filatoff, 2000).

\title{
Potonieisporites neglectus Potonié \& Lele, 1961
}

Estampa VIII, figuras 6 a 8

\author{
1970 P. sp., in Daemon \& Quadros, est. 1, forma P500. \\ non 1976b P. neglectus, in Pons, est. 1, fig. 2. \\ 1988 P. neglectus, in Marques-Toigo, est. V, fig. 7. \\ non 1983 P. neglectus, in Lima et al., est. IV, fig. 7. \\ non 1993 P. neglectus, in Dias, est. 3, fig. 5 e 10. \\ 1996 P. novicus, in Souza, est. 7, fig. 2. \\ 1996 P. neglectus, in Souza, est. 8, fig. 4.
}

Diagnose: Potonié \& Lele [1961. Paleobot., 8(1-2): p. 30, fig. 60-2 e 64-5]. Localidade-tipo: Goraia, South Rewa Gondwana Basin, Permiano Inferior da India. 
Descrição: grão de pólen monossacado, de simetria bilateral, longitudinalmente alongado. Corpo central alongado no eixo maior do grão. Saccus intrareticulado; raiz distal no corpo central associada a um sistema de pregas retangular, alongado e transpassando o corpo central transversalmente.

Dimensões: ver Tabela III.2.

Ocorrência: Zonas Biointervalo Ahrensisporites cristatus e Potonieisporites neglectus.

Distribuição estratigráfica na Bacia do Paraná: Subgrupo Itararé (Daemon \& Quadros, 1970; Souza, 1996; Marques-Toigo, 1988); Formações Rio Bonito e Palermo e Subgrupo Itararé (Marques-Toigo, 1988). Intervalos $\mathrm{G}-\mathrm{H}_{1}$, Zonas Vittatina e Lueckisporites virkkiae.

Distribuição estratigráfica mundial: Westphaliano a Permiano Superior das bacias do Amazonas e Solimões (Quadros et al., 1995). Zonas Potonieisporites-Lundbladispora e Cristatisporites da Bacia Chacoparaná (Césari \& Vazquez-Nistico, 1988; Ottone \& Azcuy, 1989), Zona de Potonieisporites (Azcuy \& Jelin, 1980), Carbonífero Superior (Césari, 1984; Ottone, 1989; Ottone \& Azcuy, 1989, 1990; Gutiérrez, 1993; Garcia, 1996; Di Pasquo \& Azcuy, 1997a, 1999a; Di Pasquo, 1999; Azcuy \& Di Pasquo, 2000) da Argentina. Permiano Inferior da Bolivia (Ottone et al., 1998), India (Estágio Talchir: Chandra \& Lele, 1979). Zona Puncatosporites minutus, Westphaliano de Israel (Horowitz, 1974).

\section{Potomieisporites triangulatus Tiwari, 1965}

Estampa IX, figura 3

1996 P. cf. P. triangulatus, in Souza, est. 9, fig. 1.

Diagnose: Tiwari [1965. Palaeobot., 13(2): p. 186; est. 4, fig. 83].

Localidade-tipo: Korba Coalfield, Bihar, Permiano Inferior da İndia (Estágio Barakar).

Descrição: grão de pólen monossacado, de simetria bilateral. longitudinalmente alongado. Corpo central subtriangular, com vértices arredondados a angulosos. Marca monolete nem sempre visivel. Saccus intrareticulado; raiz distal associada a um sistema de pregueamento triangular, acompanhando o formato do corpo central, delimitando um leptoma triangular.

Dimensões: ver Tabela III.2.

Ocorrência: Zonas Biointervalo Ahrensisporites cristatus e Potonieisporites neglectus.

Distribuição estratigráfica na Bacia do Paraná: Subgrupo Itararé (Souza, 1996).

Distribuição estratigráfica mundial: Carbonifero Superior a Permiano Inferior da Argentina (Ottone \& Azcuy, 1989; Gutiérrez, 1993; Di Pasquo \& Azcuy, 1997a, 1999a; Di Pasquo, 1999; Azcuy \& Di Pasquo, 2000). Permiano Inferior da Bolivia (Ottone et al., 1998) e India (Talchir: Chandra \& Lele, 1979; Barakar: Tiwari, 1965). 


\section{Potonieisporites barrelis Tiwari, 1965}

Estampa IX, figuras 5 e 6

1996 Florinites guttatus, in Souza, est 5, fig. 6.

Diagnose: Tiwari [1965. Palaeobot., 13(2): p. 186-7; est. 4, fig. 85-6].

Localidade-tipo: Korba Coalfield, Bihar, Permiano Inferior da Índia (Estágio Barakar).

Descrição: grão de pólen monossacado, de simetria bilateral, alongado longitudinalmente. Corpo central transversalmente alongado, com os dois lados maiores convexos, os menores retos, formando ângulos bem definidos. Marca monolete proximal, alcançando $1 / 2$ a $2 / 3$ do eixo transversal do corpo central. Saccus intrareticulado; raiz distal associada a duas pregas semi-lunares, bem marcadas e paralelas ao eixo maior do corpo central, delimitando um leptoma subretangular.

Dimensões: ver Tabela III.2.

Ocorrência: Zonas Biointervalo Ahrensisporites cristatus e Potonieisporites neglectus.

Comparações: o corpo central em forma de "barrilete" diferencia esta espécie de P. magnus, que também apresenta corpo central mais alongado transversalmente e duas pregas associadas à raiz distal do saccus.

Distribuição estratigráfica na Bacia do Paraná: Subgrupo Itararé (Souza, 1996).

Distribuição estratigráfica mundial: Carbonifero Superior/ Permiano Inferior da Argentina (Gutiérrez, 1993; Di Pasquo \& Azcuy, 1997a, 1999a; Di Pasquo, 1999; Azcuy \& Di Pasquo, 2000). Permiano Inferior do Uruguai (Mautino et al., 1998b), África (Bose \& Maheshwari, 1968) e Índia (Estágio Barakar: Tiwari, 1965).

\section{Potonieisporites densus Maheshwari, 1967}

Estampa IX, figura 4

1970 Florinites sp., in Cauduro, est. XI, fig. 78.

1996 Florinites sp., in Souza, est 5, fig. 2.

Diagnose: Maheshwari [1967. Palaeobot., 15(3): p. 268-70, est. 4, fig. 32].

Localidade-tipo: Bargo, Bansloi Valley, Bihar, Permiano Inferior da Índia.

Descrição: grão de pólen monossacado, de simetria bilateral, alongado longitudinalmente. Corpo central de forma irregular; trapezoidal a subcircular. Lesura não distinta. Saccus intrareticulado; raízes distais associadas a um sistema de pregas trapezoidal a romboidal.

Dimensões: ver Tabela III.2.

Ocorrência: Zonas Biointervalo Ahrensisporites cristatus e Potonieisporites neglectus e Subzona Protohaploxypinus goraiensis. 
Comparações: o sistema de inserção do saccus na face distal do corpo central, de forma trapezoidal a romboidal, separa esta espécie das demais do gênero. As espécies do gênero Florinites não apresentam qualquer tipo de pregueamento associado às raizes distais do saccus, como observado nos espécimes ilustrados e descritos por Cauduro (1970) e Souza (1996), para a Formação Rio Bonito e Subgrupo Itararé, respectivamente.

Distribuição estratigráfica na Bacia do Paraná: Subgrupo Itararé (Souza, 1996) e Formação Rio Bonito (Cauduro, 1970).

Distribuição estratigráfica mundial: Carbonífero Superior a Permiano Inferior da Argentina (Gutiérrez, 1993; Garcia, 1996; Di Pasquo \& Azcuy, 1997a, 1999a; Azcuy \& Di Pasquo, 2000). Passagem C/P da Espanha (Broutin, 1981).

\section{Potonieisporites congoensis Bose \& Maheshwari, 1968}

Estampa $\mid X$, figuras 7 e 8

1993 P. neglectus, in Dias, est. 8, fig. 1.

1996 P. congoensis, in Souza, est. 8, fig. 2.

Diagnose: Bose \& Maheshwari (1968. Ann. Mus. Royal de L'África Centrale, Sc. Geol. n ${ }^{0} 60, \mathrm{p}$. 52-3, est. XV, fig.6, est. XII, fig. 2-3, text-fig. 11).

Localidade-tipo: sul de Albertville, Luanda, Permiano do Congo.

Descrição: grão de pólen monossacado, de simetria bilateral, alongado longitudinalmente. Corpo central ovalado. Saccus intrareticulado; raiz distal associada a um sistema composto por quatro pregas, de forma quadrangular, às vezes com maior alongamento no eixo transversal.

Dimensões: ver Tabela III.2.

Ocorrência: Zonas Biointervalo Ahrensisporites cristatus e Potonieisporites neglectus e Subzona Protohaploxypinus goraiensis.

Distribuição estratigráfica na Bacia do Paraná: Subgrupo Itararé (Dias, 1993; Souza, 1996).

Distribuição estratigráfica mundial: Carbonifero Superior da Argentina (Gutiérrez, 1993; Di Pasquo \& Azcuy, 1997a, 1999a; Di Pasquo, 1999; Azcuy \& Di Pasquo, 2000). Permiano Inferior da África (Bose \& Maheswhari, 1968) e India (Estágio Talchir: Chandra \& Lele, 1979).

\section{Potonieisporites brasiliensis (Nahuys, Alpern \& Ybert) Archangelsky \& Gamerro, 1979}

Estampa $X$, figuras 3 e 4

1968 Vestigisporites brasiliensis, in Nahuys et al., figs. 57-61.

1981 P. brasiliensis, in Dias-Fabricio, est. 7, fig. 8.

1988 P. brasiliensis, in Marques-Toigo, est. V, fig. 8 -9. 
1993 P. brasiliensis, in Dias, est. 7, fig. 7.

1995 P. brasiliensis, in Quadros et al., p. 96.

1996 P. brasiliensis, in Souza, est. 7, fig. 3 e 4.

1996 P. sp. 2, in Souza, est. 9, fig. 3.

1996 Caheniasaccites sp. 2, est. 10, fig. 4.

Diagnose: Archangelsky \& Gamerro [1979. Rev. Esp. de Microp., XI(3): p. 445-6, est. VII, fig. 10, est. VIII, fig. 1-4].

Localidade-tipo: Carvão de Charqueadas (RS), Formação Rio Bonito, Permiano Inferior da Bacia do Paraná, Brasil.

Descrição: grão de pólen monossacado, de simetria bilateral, longitudinalmente alongado. Corpo central subcircular a ovalado; marca monolete nem sempre distinta, com raios curtos, alcançando $1 / 3$ do diâmetro total do corpo. Saccus intrareticulado; raizes distais associadas a um sistema de pregueamento contínuo, delimitando um leptoma distal de forma similar ao corpo central; a partir das raízes distais se desenvolvem pregas que se irradiam pelo saccus, bem desenvolvidas no seu eixo menor, imprimindo aspecto de biconstrução lateral, com forte ondulação.

Ocorrência: Zonas Biointervalo Ahrensisporites cristatus e Potonieisporites neglectus e Subzona Protohaploxypinus goraiensis.

Dimensões: ver Tabela III.2.

Distribuição estratigráfica na Bacia do Paraná: Subgrupo Itararé (Marques-Toigo, 1988; Dias, 1993; Souza, 1996), formações Rio Bonito (Nahuys et al., 1968; Dias-Fabrício, 1981; Marques-Toigo, 1988) e Palermo e Subgrupo Irati (Marques-Toigo, 1988). Zonas Vittatina e Lueckisporites virkkiae.

Distribuição estratigráfica mundial: Zonas Potonieisporites-Lundbladispora e Cristatisporites da Bacia Chacoparaná (Archangelsky \& Gamerro, 1979; Vergel, 1987ab, 1993; Césari et al., 1995); Carbonifero Superior a Permiano Inferior da Argentina (Barreda, 1986; Ottone, 1989; Vergel \& Luna, 1992; Gutiérrez, 1993; Garcia, 1996; Di Pasquo \& Azcuy, 1997a, 1999a; Di Pasquo, 1999; Azcuy \& Di Pasquo, 2000). Permiano Inferior do Uruguai (Santa Ana et al., 1993). Carbonífero Superior/Permiano Inferior do Omã (Stephenson \& Filatoff, 2000).

\section{Potonieisporites magnus Lele \& Karim, 1971}

\section{Estampa $X$, figuras 1 e 2}

1970 Florinites sp., in Cauduro, est. XI, fig. 77.

1976b P. novicus, in Pons, est. I, fig. 1.

1984 P. neglectus, in Burjack, est. II, fig. 1.

1991 P. brasiliensis, in Piccoli, est. 2, fig. a

1993a P. brasiliensis, in Souza et al., est. 3 , fig. 8. 
1996 P. magnus, in Souza, est. 8, fig. 1.

Diagnose: Lele \& Karim [1971. Palaeobot. 19(1): p. 58-59, est. 2, fig. 16].

Localidade-tipo: Patharjore Nala, Bihar, Permiano Inferior da India (Estágio Talchir).

Descrição: grão de pólen monossacado, de simetria bilateral, alongado longitudinalmente. Corpo central transversalmente ovalado. Saccus intrareticulado; raiz distal associada a 2 pregas semi-lunares, bem marcadas e paralelas ao eixo maior do corpo central, às vezes se juntando nas extremidades.

Dimensões: ver Tabela III.2.

Ocorrência: Zonas Biointervalo Ahrensisporites cristatus e Potonieisporites neglectus e Subzona Protohaploxypinus goraiensis.

Distribuição estratigráfica na Bacia do Paraná: Subgrupo Itararé (Pons, 1976b; Piccoli et al., 1991; Souza et al., 1993a; Souza, 1996); Formação Rio Bonito (Cauduro, 1970) e Subgrupo Irati (Burjack, 1984).

Distribuição estratigráfica mundial: Namuriano da Bacia do Parnaíba, Solimões e Amazonas (Melo et al., 1999). Zonas de Potonieisporites (Azcuy \& Jelin, 1980), PotonieisporitesLundbladispora e Cristatisporites (Césari \& Vázques-Nistico, 1988; Ottone \& Azcuy, 1989; Césari et al., 1995); Carbonífero Superior a Permiano Inferior da Argentina (Azcuy \& Gutiérrez, 1985; Garcia \& Azcuy, 1987; Ottone, 1989; Gutiérrez, 1993; Garcia, 1996; Di Pasquo \& Azcuy, 1997a, 1999a; Di Pasquo, 1999; Azcuy \& Di Pasquo, 2000). Permiano Inferior da Índia (Estágio Talchir: Lele \& Karim, 1971; Chandra \& Lele, 1979).

Gênero Divarisaccus Venkatachala \& Kar, 1966

Espécie-tipo: D. lelei Venkatachala \& Kar, 1966

Afinidade botânica: sem referências.

\section{Divarisaccus stringoplicatus Ottone, 1991}

Estampa $X_{1}$ figuras 5 e 6

1970 Crucisaccites cf. C. latisulcatus, in Daemon \& Quadros, est. 1, forma P516. 1993a Divarisaccus sp., in Souza et al., est. 3, fig. 7.

1996 P. sp. 1, in Souza, est. 9, fig. 2.

Diagnose: Ottone [1991. Rev. Micropal., 31(2): p. 128, est. 3, fig. 2, 4 e 8]

Localidade-tipo: Mina Esperanza, San Juan, Carbonifero Superior da Argentina.

Descrição: grão de pólen monossacado, de contorno ovalado e margem ondulada. Corpo central longitudinalmente ovalado. Sistema de pregueamento intexinal associados às raizes do saco, subequatorial proximalmente, constituido por duas pregas continuas, bilaterais e 
subparalelas, alongadas longitudinalmente, que ultrapassam o corpo central. Lesura pouco nítida. Saccus intrareticulado, com pregas radiais.

Dimensões: Ver Tabela III.2.

Ocorrência: Zonas Biointervalo Ahrensisporites cristatus e Potonieisporites neglectus.

Distribuição estratigráfica na Bacia do Paraná: Subgrupo Itararé (Souza et al., 1993a; Souza, 1996). Intervalo G.

Distribuição estratigráfica mundial: Carbonífero Superior da Argentina (Ottone, 1991; Di Pasquo, 1997a, 1999a).

\begin{tabular}{lcccccc}
\hline & \multicolumn{2}{c}{ Saccus } & \multicolumn{2}{c}{ Corpo central } \\
\hline P. novicus & 33 & $95-212,5$ & $55-150$ & $50(80) 110$ & $45(90) 117,5$ & $5(7) 10$ \\
P. neglectus & 23 & $120(150) 200$ & $82(100) 140$ & $55(65) 92,5$ & $54(72) 95$ & $5(10) 22,5$ \\
P. triangulatus & 6 & $112,5-165$ & $75-125$ & $52,5-87,5$ & $65-87,5$ & $5-17,5$ \\
P. barrelis & 9 & $90(120) 177,5$ & $70-125$ & $50-100$ & $60-105$ & $5(10) 15$ \\
P. densus & 02 & 140 & $105-115$ & $62,5-70$ & $70-75$ & $7,5-10$ \\
P. congoensis & 26 & $110(150) 210$ & $75(100) 150$ & $62,5(75) 92,5$ & $55(70) 90$ & $5(10) 25$ \\
P. brasiliensis & 37 & $92,5-232$ & $60(80) 145$ & $42,5(70) 92,5$ & $42,5-116$ & $2,5-15$ \\
P. magnus & 31 & $65(135) 190$ & $42,5(100) 135$ & $32,5(70) 95$ & $40(90) 120$ & $5(10) 15$ \\
D. stringoplicatus & 16 & $96-126$ & $92-132$ & $80-96$ & $54-91$ & $4-12$ \\
\hline
\end{tabular}

Tabela III.2 - Dimensões das espécies do gênero Potonieisporites (Bharadwaj) Bharadwaj e Divarisaccus Venkatachala \& Kar (ne: número de espécimes medidos; EL: eixo longitudinal; ET: eixo transversal; Ip: largura da prega; valores em $\mu \mathrm{m}$ ).

\section{Gênero Caheaniasaccites Bose \& Kar emend. Azcuy \& Di Pasquo, 2000}

Espécie-tipo: Caheaniasaccites flavatus Bose \& Kar, 1966.

Afinidade botânica: CONIFERALES (Archangelsky \& Cuneo, 1987).

\section{Caheniasaccites flavatus Bose \& Kar emend. Azcuy \& Di Pasquo, 2000 \\ Estampa XI, figuras 1, 2 e 4}

1970 Vestigisporites cf. diffusus, in Daemon \& Quadros, est. 3, forma P479.

1976 C. ovatus, in Bharadwaj et al., est. 4, fig. 54.

1980 Potonieisporites sp., in Thomaz, est. 1, fig. 8.

1981 C. ovatus, in Dias-Fabrício, est. 8, fig. 3.

1983 C. ovatus, in Lima et al., est. V, fig. 2.

1983 Potonieisporites triradialis, in Lima et al., est. V. fig. 1. 


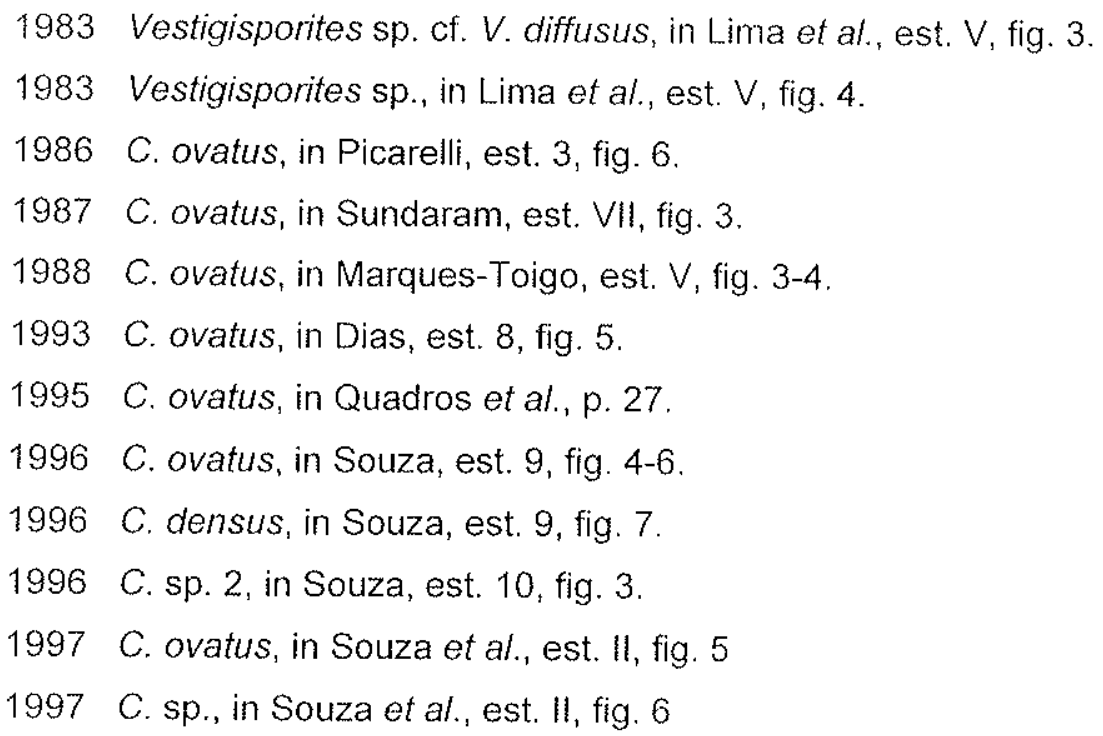

Diagnose emendada: Azcuy \& Di Pasquo (2000. Palaeontogr., Abt. B 253: p. 127).

Localidade-tipo: Mabuita, região de Walikale, Permiano Inferior do Congo.

Descrição: grão de pólen monossacado, de simetria bilateral, com caráter de biconstrução lateral, haplo- a diploxilonóide. Corpo central circular a longitudinalmente ovalado, com exina de espessura e densidade de coloração variável. Raízes do saccus aderidas subequatorialmente. Saccus intrareticulado, com freqüentes pregas radiais, a partir da inserção no corpo central.

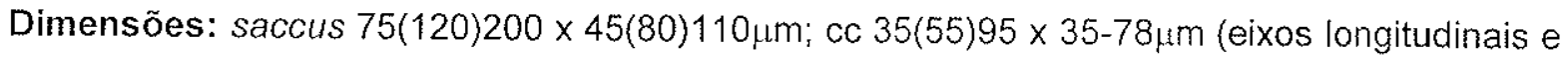
transversais, respectivamente) (71 espécimes).

Ocorrência: Zonas Biointervalo Ahrensisporites cristatus e Potonieisporites neglectus e Subzona Protohaploxypinus goraiensis.

Observações: Como demonstrado por Azcuy \& Di Pasquo (2000), não há diferenças que suportem qualquer separação específica entre C. ovatus e C. flavatus, uma vez que na análise dos valores dos coeficientes entre eixo horizontal/vertical do grão, fôra constatada uma gradação entre os valores das duas espécies. Além disso, há dificuldades na observação da real espessura da intexina do corpo central, caráter que separaria $C$. densus. Por essas razões, adota-se, neste trabalho, a proposição de Azcuy \& Di Pasquo (2000), que consideram C. flavatus sinonimia júnior de C. ovatus (Bose \& Kar) Gutiérrez. 1993, C. ellipticus Bose \& Maheshwari, 1968, C. diffusus Lele \& Maithy, 1969, C. indicus Srivastava, 1970 e C. densus (Lele \& Karim) Gutiérrez, 1993.

Distribuição estratigráfica na Bacia do Paraná: Subgrupo Itararé (Daemon \& Quadros, 1970; Bharadwaj et al., 1976; Lima et al., 1983; Sundaram, 1987; Marques-Toigo, 1988; Dias, 1993; Souza, 1996; Souza et al., 1997), Formação Rio Bonito (Daemon \& Quadros, 1970; Bharadwaj et al., 1976; Thomaz, 1980; Dias-Fabricio, 1981; Picarelli, 1986; MarquesToigo, 1988) e Formação Palermo (Daemon \& Quadros, 1970). Intervalos G-L. Z Zona Vittatina. 
Distribuição estratigráfica mundial: Zonas Potonieisporites-Lundbladispora e Cristatisporites da Bacia Chacoparaná (Archangelsky \& Gamerro, 1979; Vergel, 1987ab; Césari et al., 1995); Carbonífero Superior a Permiano Inferior da Argentina (Césari, 1984; Barreda, 1986; Ottone \& Azcuy, 1986; Garcia \& Azcuy, 1987; Césari \& Vásquez-Nístico, 1988; Ottone, 1989; Gutiérrez, 1993; Vergel, 1993; Garcia, 1996; Di Pasquo \& Azcuy, 1997a, 1999a; Di Pasquo, 1999; Azcuy \& Di Pasquo, 2000). Permiano Inferior do Uruguai (Marques Toigo, 1973, 1974; Beri, 1987, 1988; Santa Ana et al, 1993; Beri \& Aguilar, 1998), Austrália (Foster \& Waterhouse, 1988; Gilby \& Foster, 1988), Antártica (Lindström, 1995), África (Bose \& Maheshwari, 1968; Maheshwari \& Bose, 1969) e Índia (Estágio Talchir: Lele \& Karim, 1971; Chandra \& Lele, 1979; Estágio Karharbari: Lele \& Srivastava, 1979). Carbonifero Superior/Permiano Inferior do Omã e Arábia Saudita (Stephenson \& Filatoff, 2000).

\section{Caheniasaccites sp.}

Estampa XI, figuras 3, 5 e 6

1970 Não identificado, in Daemon \& Quadros, est. 2, forma P489.

1996 Caheniasaccites sp. 1, in Souza, est. 10, fig. 1-2.

Descrição: grão de pólen monossacado, bilateralmente simétrico, longitudinalmente alongado, de aparência trissacada. Corpo central subcircular a levemente longitudinalmente ovalado; face proximal apresentando marca monolete, nem sempre distinta. Saccus intrareticulado, com sistema de pregas radiais a partir do corpo central, inserção subequatorial, geralmente delimitando área-livre retangular a subcircular.

Dimensões: saccus $105-160 \times 60-100 \mu \mathrm{m}$; cc $45-75 \times 42,5-65 \mu \mathrm{m}$ (eixos longitudinais e transversais, respectivamente) (8 espécimes).

Ocorrência: Zonas Biointervalo Ahrensisporites cristatus e Potonieisporites neglectus e Subzona Protohaploxypinus goraiensis.

Observações: esta espécie é separada de C. flavatus considerando seu aspecto trissacado. Daemon \& Quadros (1970) descreveram formas semelhantes (C. sp.: P489), interpretadas como "formas abortivas" do gênero.

Distribuição estratigráfica na Bacia do Paraná: Subgrupo Itararé (Daemon \& Quadros, 1970; Souza, 1996) e Formação Rio Bonito (Daemon \& Quadros, 1970). Intervalos G-11.

Infraturma STRIASACCITI [Bharadwaj, 1962]

\section{Gênero Striomonosaccites (Bharadwaj) Hart, 1965}

Espécie-tipo: Striomonosaccites ovatus Bharadwaj, 1962.

Afinidade botânica: sem referências. 


\section{? Striomonosaccites sp. \\ Estampa $\mathrm{X}$, figuras 7 e 8}

1970 Protohaploxypinus sp., in Daemon \& Quadros, est. 2, forma A-P486.

1981 Striomonosaccites cf. S. ovatus, in Dias-Fabricio, est. 8, fig. 6.

1983 Protohaploxypinus sp., in Lima et al., est. V, fig. 7.

1996 Protohaploxypinus sp., in Souza, est. 12, fig. 6.

1996 Striomonosaccites sp. 1, in Souza, est. 11, fig. 2.

1996 Striomonosaccites sp. 2 , in Souza, est. 11, fig. 3.

Descrição: grão de pólen monossacado, de simetria bilateral. Corpo central subcircular, transversalmente alongado; face proximal apresentando $4(8) 13$ tenias longitudinais, separadas por finas estrias. Raiz distal do saccus no corpo central associada a um sistema de pregas, delimitando cápula retangular a subretangular de tamanho variável, geralmente $1 / 3$ do diâmetro do corpo central longitudinalmente. Saccus alongado longitudinalmente.

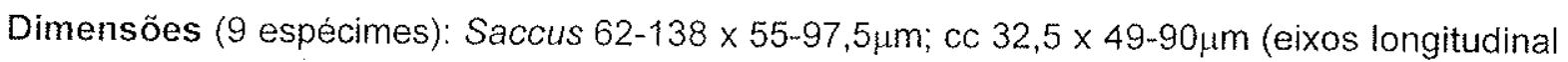
e transversal); cápula $10(25) 40 \mu \mathrm{m}$.

Ocorrência: Zonas Biointervalo Ahrensisporites cristatus e Potonieisporites neglectus e Subzona Protohaploxypinus goraiensis.

Comparações: na Bacia do Paraná, Menéndez (1976) descreveu S. sp. (est. I, fig. 5) no Subgrupo Irati, que apresenta corpo central mais alongado longitudinalmente. Também no Subgrupo Irati, Burjack (1984) descreveu S. sp. (est. VI, fig. 5-6), que apresenta dimensões reduzidas e corpo central subcircular. A forma AP486 descrita por Daemon \& Quadros (1970), designada como Proxophaploxypinus sp. e ocorrente nos intervalos G e H, se enquadra perfeitamente na descrição das espécies aqui registrađas. S. cf. S. ovatus ilustrado por Dias-Fabrício (1981) também é similar, especialmente com o espécime ilustrado por Souza (1996, est. 11, fig. 2). A forma ilustrada por Lima et al. (1983) no Subgrupo Itararé designada como Protohaploxypinus sp. é sinonimizada após re-exames do material. Fora da Bacia do Paraná, também há vários registros de formas semelhantes: Barss (1967) ilustrou S. sp. do Stephaniano do Canadá, com reduzido número de tenias (6?) e ausência de pregas associadas à raiz distal do saccus. ?S. sp. descrita por Bose \& Maheshwari (1968) no Permiano Inferior da África, inclui as mesmas caracteristicas, com reduzido número de tenias (5-6). As formas descritas por Ottone (1989) na Formação Santa Máxima, Argentina, ?S. sp. A e ?S. sp. B são muito semelhantes, embora apresente número de tenias variáveis entre si (7-8 e 11-14, respectivamente). ?S. sp., descrita para a Formação Guadancol por Ottone \& Azcuy (1989) também é muito semelhante, ainda que apresente elevado número de estrias (14-16). 'Striomonosaccites' sp., ilustrado por Jones \& Truswell (1992, est. 15, fig. H-K) para o Carbonifero Superior a Permiano Inferior da Austrália, é perfeitamente semelhante, o que também ocorre com Gen. et sp. indet. descrito 
por Garcia (1996, est. III, fig. 10) para o Carbonifero Superior da Argentina. Embora não se disponha das desrições, Striomonosaccites sp. 1 e 2, ilustrado por Di Pasquo (1999), da Bacia de Tarija, apresentam os mesmos caracteres gerais.

Observações: não há na literatura qualquer gênero que inclua grãos de pólen monossacados, teniados, com simetria bilateral e cápula retangular a subretangular. Ao gênero Striomonosaccites (Bharadwaj) Hart, 1965 são referidas as formas de simetria radial. No entanto, várias formas similares às descritas têm sido assinaladas neste gênero, relativas à material gondwânico e do Canadá. Bharadwaj (1960) descreveu o gênero Faunipollenites como grão de pólen bissacado estriado, embora em algumas das ilustrações a aparência seja de somente um saccus. Verifica-se a necessidade da inclusão das espécies aqui registradas e comparadas em um novo gênero, que envolva todos os grãos de pólen monossacados teniados, de simetria bilateral.

Distribuição estratigráfiça na Bacia do Paraná: Subgrupo Itararé (?Daemon \& Quadros, 1970; Lima et al., 1983; Souza, 1996) e Formação Rio Bonito (?Daemon \& Quadros, 1970; Dias-Fabricio, 1981).

\author{
Subturma DISACCITES \{[Cookson, 1947]\} \\ Infraturma DisAccitriLETI \{[Leschik] Potonié, 1958 \}
}

\title{
Gênero Scheuringipollenites Tiwari, 1973
}

Espécie-tipo: S. maximus (Hart) Tiwari, 1973

Afinidade botânica: ? GYMINOSPERMAE (Quadros et al., 1995).

\section{Scheuringipollenites maximus Tiwari, 1973}

\author{
Estampa Xl, figuras 7 e 8
}

1988 S. maximus, in Marques-Toigo, est. VI, fig. 6.

1995 S. maximus, in Quadros et al., p. 112.

Diagnose: Tiwari [1973. Sencjenberg. Lethaea, 54(1): p. 107-8, est. 2, fig. 6-7, Text-fig. 2].

Localidade-tipo: Vale do rio Mchuchuma, Permiano Inferior da Tanzânia.

Descrição: grão de pólen bissacado, haploxilonóide, de contorno equatorial circular a subcircular a longitudinalmente ovalado. Corpo central fino, geralmente indistinto, ovalado. Sacci intramicroreticulado, semicircular, cobrindo parcialmente o corpo central, reunindo-se na porção mediana da face distal. Sulcus indistinto.

Dimensões: ver Tabela III.3.

Ocorrência: Zona Biointervalo e Potonieisporites neglectus e Subzona Protohaploxypinus goraiensis. 
Distribuição estratigráfica na Bacia do Paraná: Formação Rio Bonito (Marques-Toigo, 1988; Quadros et al., 1995). Zona Vittatina (Subzona Caheniasaccites flavatus).

Distribuição estratigráfica mundial: Permiano Inferior da África (Hoeg \& Bose, 1960), Antártica (Balme \& Playford, 1967; Lindström, 1995) e Austrália (Segroves, 1969; Foster, 1979; Backhouse, 1991). Passagem C/P da Espanha (Broutin, 1981).

\section{Gênero Limitisporites (Leschik) Schaarschmidt, 1963}

Espécie-tipo: Limitisporites rectus Leschik, 1956.

Afinidade botânica: PTERIDOSPERMALES-Glossopteridales (Gould \& Delevoryas, 1977); CONIFERALES (Clement-Westerhof, 1984).

\section{Limitisporites rectus Leschik, 1956}

Estampa XII, figura 1

1970 L. cf. rectus, in Daemon \& Quadros, est. 6, forma P390.

1988 L. cf. L. rectus, in Marques-Toigo, est. VI, fig. 12.

1993 L. rectus, in Dias, est. 9, fig. 10.

1996 L. delasaucei, in Souza, est. 11, fig. 6.

1996 L. sp. 1, in Souza, est. 11, fig.7.

Diagnose: Leschik (1956. Palaeontogr. Abt, B, 199: p. 133, est. 21, fig. 15).

Localidade-tipo: Neuhof, oeste da Alemanha.

Descrição: grão de pólen bissacado, haploxilonóide a levemente diploxilonóide; contorno longitudinalmente alongado. Corpo central subovalado, com lados retos no sentido longitudinal; marca monolete geralmente mal definida, alcançando $2 / 3$ do corpo central no eixo maior. Sacci semicirculares, intrareticulados; raizes distais associadas a uma prega semilunar no corpo central, delimitando uma área-livre (cápula) relativamente ampla (até $45 \mu \mathrm{m}$ ). Em alguns espécimes ocorre a presença de fina ponte exinal unindo lateralmente os sacci.

Dimensões: ver Tabela III.3.

Ocorrência: Zonas Biointervalo Ahrensisporites cristatus e Potonieisporites neglectus e Subzona Protohaploxypinus goraiensis.

Comparações: L. delasaucei (Potonié \& Klaus) Schaarschmidt, 1963 apresenta dimensões relativamente muito mais reduzidas (eixo maior: $54-79 \mu \mathrm{m}$ ). L. hexagonalis Bose \& Maheshwari, 1968 apresenta contorno geral diploxilonóide, corpo central relativamente mais reduzido e com formato nitidamente hexagonal.

Distribuição estratigráfica na Bacia do Paraná: Subgrupo Itararé (Daemon \& Quadros, 1970; Marques-Toigo, 1988; Dias, 1993; Souza, 1996) e Formaçäo Rio Bonito (Daemon \& 
Quadros, 1970; Marques-Toigo, 1988). Intervalos G-14; Zona Vittatina (Subzonas Protohaploxypinus goraiensis e Caheniasaccites flavatus).

Distribuição estratigráfica mundial: Zonas Cristatisporites (Césari et al., 1995), Carbonífero Superior/Permiano Inferior da Argentina (Gutiérrez, 1993; Garcia, 1996; Di Pasquo \& Azcuy, 1997a, 1999a). Permiano Inferior do Uruguai (Beri \& Aguilar, 1998), Bolívia (Ottone et al., 1998) e Austrália (Segroves, 1969; Foster, 1979; Foster \& Waterhouse, 1988; Backhouse, 1991). Permiano Inferior a Superior da Antártica (Lindström, 1995, 1996).

\section{Limitisporites $\mathrm{sp}$.}

Estampa XII, figuras 2 e 4

1970 L. sp., in Daemon \& Quadros, est. 5, forma P430.

1996 L. sp. 2, in Souza, est. 11, fig. 8.

Descrição: grão de pólen bissacado, diplo a haploxilonóide, longitudinalmente alongado. Corpo central subcircular a levemente ovalado transversalmente. Marca monolete ampla, estendendo-se por todo, ou quase todo, o eixo longitudinal do corpo central, aberta (entre 2$18 \mu \mathrm{m})$, com margem dobrada $(2,5-15 \mu \mathrm{m})$. Sacci semi-esféricos, ligados lateralmente por fina ponte exinal; raizes distais associadas a pregas aderidas no corpo central, com área-

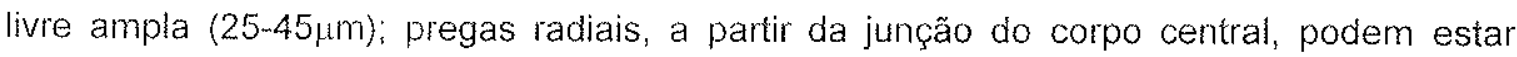
associadas.

Dimensões: ver Tabela III.3.

Ocorrência: Zonas Biointervalo Ahrensisporites cristatus e Potonieisporites neglectus e Subzona Protohaploxypinus goraiensis.

Comparações: a ampla abertura e o dobramento associado da exina da marca monolete diferenciam esta espécie das demais do gênero. L. spp. ilustrados por Zhu-Haicheng (1993, est. VIII, fig. 1-4), do Namuriano da China, são muito semelhantes, embora não se disponha das descrições. As formas P430 descritas por Daemon \& Quadros (1970) se encaixam perfeitamente na descrição, caracterizando-se pela marca monolete que atravessa o corpo central de uma extremidade a outra, no eixo longitudinal, como enfatizado pelos autores.

Distribuição estratigráfica na Bacia do Paraná: Subgrupo Itararé (Daemon \& Quadros, 1970; Souza, 1996) e Formação Rio Bonito (Daemon \& Quadros, 1970). Intervalo I.

Infraturma STRIATITI [Pant, 1954]

Gênero Protohaploxypinus (Samoilovich) Hart, 1964

Espécie-tipo: Protohaploxypinus latissimus (Lüber \& Waltz) Samoilovich, 1953.

Afinidade botânica: PTERIDOSPERMALES-GLOSSOPTERIDALES (Gould \& Delevoryas, 1977). 


\section{Protohap/oxypinus amplus (Balme \& Hennelly) Hart, 1964}

Estampa XII, figuras 3 e 5

1970 Protohaploxypinus sp., in Daemon \& Quadros, forma P383.

1981 P. amplus, in Leipnitz, est. III, fig. 1-2.

1988 P. amplus, in Marques-Toigo, est. VII, fig. 6.

1993 P. amplus, in Dias, est. 9, fig. 12.

1995 P. amplus, in Quadros et al., p. 101.

1996 P. samoilovich, in Souza, est. 12, fig. 2.

1996 P. amplus, in Souza, est. 12, fig. 3.

1996 P. chaloneri, in Souza, est. 12, fig. 4.

1996 P. dvinensis, in Souza, est. 12, fig. 5.

1997 P. amplus, in Souza et al, est. II, fig. 7.

Diagnose: Hart (1964. C.R. $5^{\text {eme }}$. Congr. Int. Strat. Géol. Carb., II: p. 1179, Text-fig. 10). Localidade-tipo: South Wallarah borehole, New South Wales, Permiano da Austrália.

Descrição: grão de pólen bissacado, de contorno diplo a haploxilonóide. Corpo central semicircular; face proximal apresentando 8-12 tênias longitudinais. Sacci semi-circulares, geralmente levemente menores que o corpo central.

Dimensões: ver Tabela III.3.

Ocorrência: Zonas Biointervalo Ahrensisporites cristatus e Potonieisporites neglectus e Subzona Protohaploxypinus goraiensis.

Comparações: as formas descritas por Souza (1996) como $P$. samoilovich, $P$. chaloneri e $P$. dvinensis, embora apresente cápula de dimensões variáveis, se encaixam na descrição de P. amplus.

Distribuição estratigráfica na Bacia do Paraná: Subgrupo Itararé (Daemon \& Quadros, 1970; Marques-Toigo, 1988; Dias, 1993; Souza, 1996; Souza et al., 1997), Formação Rio Bonito (Daemon \& Quadros, 1970; Marques-Toigo, 1988) e Palermo (Leipnitz, 1981). Zonas Vittatina e Lueckisporites virkkiae.

Distribuição estratigráfica mundial: Carbonifero Superior a Permiano Inferior da Argentina (Menéndez, 1971; Azcuy \& Jelin, 1980; Gutiérrez, 1993; Césari et al., 1995). Permiano Inferior do Uruguai (Mautino et al., 1998b), Antártica (Lindström, 1995) e África (Anderson, 1977). Permiano da Austrália (Foster, 1979). Carbonífero Superior/Permiano Inferior do Omã e Arábia Saudita (Stephenson \& Filatoff, 2000).

\section{Protohaploxypinus micros (Hart) Hart, 1964}


Diagnose: Hart (1964. C.R. $5^{\text {eme }}$. Congr. Int. Strat. Géol. Carb., IIl: p. 1180, Text-fig. 12).

Localidade-tipo: South Wallarah Borehole, New South Wales, Austrália.

Descrição: grão de pólen bissacado, haploxilonóide, longitudinalmente alongado. Corpo central circular a subcircular; face proximal apresentando 5-6 tênias longitudinais (4-6 $\mu \mathrm{m}$ de largura). Sacci intrareticulados, semi-circulares, de dimensões aproximadamente iguais ao corpo central.

Dimensões: ver Tabela III.3.

Ocorrência: Subzona Protohaploxypinus goraiensis.

Distribuição estratigráfica na Bacia do Paraná: Subgrupo Itararé (Pons, 1976b).

Distribuição estratigráfica mundial: Zonas Potonieisporites-Lundbladispora (Vergel, 1993) e Cristatisporites (Vergel, 1987b; Césari et al., 1995), Bacia Chacoparaná, Argentina. Permiano Inferior da África (Faicon, 1975).

\title{
Protohaploxypinus goraiensis (Potonié \& Lele) Hart, 1964
}

\author{
Estampa XII, figuras 7 e 8
}

1968 P. goraiensis, in Nahuys et al., fig. 70-2 e 75.

1970 Protohaploxypinus? sp., in Daemon \& Quadros, forma P391.

1988 P. goraiensis, in Marques-Toigo, est. VII, fig. 2-3.

1993 P. goraiensis, in Dias, est. 10, fig. 3.

Diagnose: Hart (1964. C.R. $5^{\text {eme }}$. Congr. Int. Strat. Géol. Carb., Ill: p. 1880, Text-fig. 13). Localidade-tipo: South Rewa Basin, Permiano Inferior da Índia (Estágio Talchir).

Descrição: grão de pólen bissacado, de contorno haploxilonóide a levemente diploxilonóide. Corpo central pobremente definido, subcircular a levemente alongado transversal ou longitudinalmente; face proximal apresentando (8)10 tênias longitudinais. Sacci hemisféricos, intrareticulados; cápula de aproximadamente $1 / 5$ do diâmetro do corpo central.

Dimensões: ver Tabela III.3.

Ocorrência: Subzona Protohaploxypinus goraiensis.

Comparações: o corpo central fracamente delimitado em vista polar, a cápula estreita e o número de tênias longitudinais separam esta espécie das demais do gênero. A forma P391 descrita por Daemon \& Quadros (1970) se enquadra perfeitamente em P. goraiensis.

Distribuição estratigráfica na Bacia do Paraná: Subgrupo Itararé (Daemon \& Quadros, 1970; Marques-Toigo, 1988; Dias, 1993). Formação Rio Bonito (Nahuys et al., 1968; Daemon \& Quadros, 1970; Marques-Toigo, 1988). Intervalos I, J e K. Embora transgrida os limites bioestratigráficos, diferentemente do observado por Marques-Toigo (op. cit.), a espécie está restrita ao Subgrupo Itararé e Formação Rio Bonito. 
Distribuição estratigráfica mundial: Westphaliano a Tastubiano da Austrália (Jones \& Truswell, 1992). Permiano Inferior do Uruguai (Mautino et al., 1998b), Antártica (Lindström, 1995), África (Falcon, 1975), Índia (Estágio Talchir: Lele \& Karim, 1971) e Paquistão (Balme, 1970).

\title{
Protohaploxypinus limpidus (Balme \& Hennelly) Balme \& Playford, 1967 \\ Estampa XIII, figuras 1 e 2
}

\author{
1981 P. cf. P. goraiensis, in Leipnitz, est. III, fig. 3. \\ 1986 P. limpidus, in Picarelli, est. 4, fig. 5. \\ 1988 P. limpidus, in Marques-Toigo, est. VII, fig. 7. \\ 1993 P. limpidus, in Dias, est. 9, fig. 5.
}

Diagnose: Balme \& Playford (1967. Rev. Microp., 3: p. 185, est. I, fig. 15).

Localidade-tipo: Permiano da Austrália.

Descrição: grão de pólen bissacado, de contorno haploxilonóide a levemente diploxilonóide. Corpo central subovalado, transversalmente alongado; face proximal apresentando (5) 8 tênias, assimetricamente dispostas, anastomosadas, de largura variável $[2,5(7,5) 12 \mu \mathrm{m}]$. Sacci semi-lunares, intrareticulados.

Dimensões: ver Tabela III.3.

Ocorrência: Zona Biontervalo Potonieisporites neglectus e Subzona Protohaploxypinus goraiensis.

Comparações: P. cf. P. goraiensis descrito por Leipnitz (1981) na Formação Palermo não corresponde a $P$. goraiensis por apresentar menores dimensões $(80-85 \mu \mathrm{m}$ no eixo longitudinal) e reduzido número de tênias (6-8).

Distribuição estratigráfica na Bacia do Paraná: Subgrupo Itararé (Dias, 1993); Formação Rio Bonito (Picarelli, 1986; Marques Toigo, 1988); Formação Palermo e Subgrupo Irati (Leipnitz, 1981; Marques-Toigo, 1988). Zonas Vittatina e Lueckisporites virkkiae.

Distribuição estratigráfica mundial: Carbonífero Superior/Permiano inferior do Omã e Arábia Saudita (Stephenson \& Filatoff, 2000). Permiano Inferior da Austrália (Segroves, 1969; Foster, 1975, 1979; Foster \& Waterhouse, 1988; Backhouse, 1991) e Paquistão (Balme, 1970). Permiano Inferior (Lindström, 1995) a Superior (Balme \& Playford, 1967; De Jersey, 1979; Lindström, 1996) da Antártica. Tatariano da Rússia (Gormankov et al., 1998).

\section{Protohaploxypinus panaki Utting, 1994}

Estampa XIII, figuras 3 e 4

Diagnose: Utting (1994. Geol. Surv. Canada. Bull.: 478: p. 55, est. 6, fig. 30-1; est. 7, fig. 1-3). 
Localidade-tipo: Sabine Bay, Assistence and Trold Fiord Formations, Permiano Inferior do Canadá.

Descrição: Grão de pólen bissacado, de contono haploxilonóide, transversalmente ovalado. Corpo central distinto, subcircular a transversalmente ovalado; face proximal apresentando $6(7) 9$ tênias longitudinais, largas $(5-10 \mu \mathrm{m})$. Sacci hemisféricos, reduzidos, intrareticulados; cápula ovalada.

Dimensões: ver Tabela III.3.

Ocorrência: Subzona Protohaploxypinus goraiensis.

Comparações: o tamanho reduzido dos sacci separa esta espécie das demais do gênero. $P$. perfectus e $P$. suchonensis (Sedova) Hart, 1964 apresentam sacci reduzidos relativamente ao corpo central.

Distribuição estratigráfica na Bacia do Paraná: inédita.

\section{Gênero Striatoabieites (Sedova) Hart, 1964}

Espécie-tipo: Striatoabieites brickii Sedova, 1956.

Afinidade botânica: CONIFERALES (Azcuy, 1978).

\section{Striatoabieites sp.}

Estampa XIII, figura 11

1996 Protohaploxypinus latissimus, in Souza, est. 12, fig. 1.

Descrição: grão de pólen bissacado, de contorno haploxilonóide. Corpo central alongado longitudinalmente; face proximal apresentando 8-11 tênias alongadas longitudinalmente, com 2,5-5 $\mu \mathrm{m}$ de largura. Sacci reduzidos longitudinalmente.

Dimensões: ver Tabela III.3.

Ocorrência: Zona Biointervalo Ahrensisporites cristatus.

Comparações: S. multistriatus (Balme \& Hennelly) Hart, 1964 apresenta sacci semi-circulares mais alongados longitudinalmente. As espécies de Hamiapollenites, que apresentam uma faixa engrossada transversal na porção mediana do corpo central, possuem, invariavelmente, sacci mais reduzidos transversalmente. É muito semelhante à Striatoabieites sp. A do Permiano Inferior da Bacia de Arckaringa, Austrália (Gilby \& Foster. 1988, est. 7, fig. 26).

Distribuição estratigráfica na Bacia do Paraná: Subgrupo Itararé (Souza, 1996). 


\begin{tabular}{lrcccc} 
& \multicolumn{2}{c}{ Sacci } & \multicolumn{2}{c}{ cc } \\
\hline S. maximus & 17.e. & ELT & ET & EL & ET \\
L. rectus & 5 & $40-50$ & $82-116$ & $68-116$ & $68-100$ \\
L. sp. & 29 & $95-210$ & $45-125$ & $55(60) 110$ & $45-120$ \\
P. amplus & 15 & $60-200$ & $35-125$ & $35-112,5$ & $37,5-105$ \\
P. micros & 45 & $105(110) 170$ & $60-110$ & $30(50) 95$ & $30(55) 100$ \\
P. limpidus & 14 & $45-72,5$ & $25-45$ & $17,5(30) 42,5$ & $17,5(30) 45$ \\
P. goraiensis & 15 & $52,5-77,5$ & $42,5-60$ & $35-65$ & $42,5-60$ \\
P. panaki & 09 & $70-100$ & $45-75$ & $47,5-65$ & $37,5-75$ \\
S. sp. & 4 & $42,5-52,5$ & $32,5-45$ & $30-40$ & $45-50$ \\
& 7 & $60(70) 80$ & $22,5-45$ & $30-65$ & $30-65$ \\
\hline
\end{tabular}

Tabela III.3 - Dimensões das espécies dos gêneros Scheuringipollenites Tiwari, Limitisporites (Leschik) Schaarschmidt; Protohaploxypinus (Samoilovich) Hart e Striatoabieites (Sedova) Hart (ne: número de espécimes medidos; ELT: eixo longitudinal total; ET: eixo transversal; valores em $\mu \mathrm{m})$.

\section{Gênero Hamiapollenites (Wilson) Tschudy \& Kosanke, 1966}

Espécie-tipo: Hamiapollenites saccatus Wilson, 1962.

Afinidade botânica: CONIFERALES (Potonié, 1967; Azcuy, 1978).

\section{Hamiapollenites tractiferinus (Samoilovich) Hart, 1964}

Estampa XIII, figura 6

1988 H. tractiferinus, in Marques-Toigo, est. VII, fig. 18.

1995 H. tractiferinus, in Quadros et al., p. 65.

Diagnose: Hart (1964. C.R. $5^{\text {eme }}$. Congr. Int. Strat. Géol. Carb., III: 1194-5, Text-fig. 58). Localidade-tipo: Western-Urals, Solikamsk, Permiano da ex-URSS.

Descrição: grão de pólen bissacado, de contorno equatorial diploxilonóide. Corpo central longitudinalmente ovalado; face proximal apresentando $7(8) 10$ tênias longitudinais $(2,5-8 \mu \mathrm{m}$ de largura). Costela transversal no corpo central, na porção mediana, com 5-7,5um de largura. Sacci reduzidos em relação às dimensões do corpo central.

Dimensões: ver Tabela III.4.

Ocorrência: Subzona Protohaploxypinus goraiensis.

Distribuição estratigráfica na Bacia do Paraná: Formação Rio Bonito e Palermo (MarquesToigo, 1988). Zonas Vittatina (Subzona Hamiapollenites karroensis) e Lueckisporites virkkiae. primeiro registro no Subgrupo Itararé. 


\section{Hamiapollenites fusiformis (Marques-Toigo) Archangelsky \& Gamerro, 1979 \\ Estampa XIII, figura 9}

1993 H. fusiformis, in Dias, est. 10, fig. 9.

1995 H. fusiformis, in Quadros et al., p. 63.

Diagnose: Archangelsky \& Gamerro (1979. Rev. Esp. Microp., XI: p. 457-61, est. XII, fig. 6-7).

Localidade-tipo: Paso de las Bochas, Rio Negro, Formação San Gregório, Permiano Inferior do Uruguai.

Descrição: grão de pólen bissacado, de contorno equatorial diploxilonóide. Corpo central longitudinalmente ovalado; face proximal apresentando 10-12 tênias longitudinais $(2,5$ -

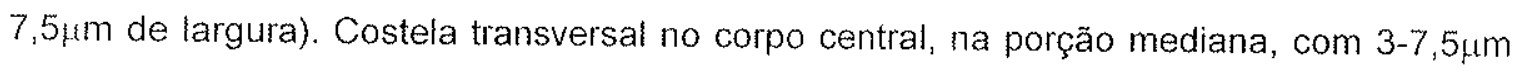
de largura. Sacci reduzidos em relação às dimensões do corpo central.

Dimensões: ver Tabela III.4.

Ocorrência: Subzona Protohaploxypinus goraiensis.

Distribuição estratigráfica na Bacia do Paraná: Subgrupo Itararé (Dias, 1993).

Distribuição estratigráfica mundial: Zonas Potonieisporites-Lundbladispora, Cristatisporites e Striatites (Archangelsky \& Gamerro, 1979; Vergel, 1987b; 1993; Césari et al., 1995; Garcia, 1996), Bacia Chacoparaná, Argentina. Permiano Inferior do Uruguai (MarquesToigo, 1974; Beri, 1988; Beri \& Aguilar, 1998). Carbonífero Superior/Permiano Inferior do Omã (Stephenson \& Filatoff, 2000).

\section{Gênero Complexisporites Jizba, 1962}

Espécie-tipo: Complexisporites polymorphus Jizba, 1962.

Afinidade botânica: sem referências.

\section{Complexisporites polymorphus Jizba, 1962}

Estampa XIII, figura 12

1970 C. polymorphus, in Daemon \& Quadros, est. 5, forma P425.

1993 C. polymorphus, in Dias, est. 10, fig. 12.

1995 C. polymorphus, in Quadros et al., p. 36.

Diagnose: Jizba [1962. Joum. Paleont., 36(5): p. 879-80, est. 121, fig. 5].

Localidade-tipo: Pensilvaniano (Virgiliano) dos E.U.A.

Descrição: grão de pólen bissacado, haploxilonóide, levemente alongado longitudinalmente.

Corpo central longitudinalmente ovalado a subcircular, apresentando 2-6 tênias, com 
$5(7,5) 15 \mu \mathrm{m}$ de largura, sulco (cavidade entre as tênias) entre $2-2,5 \mu \mathrm{m}$ e cápula entre 3$7,5 \mu \mathrm{m}$.

Dimensões: ver Tabela III.4.

Ocorrência: Subzona Protohaploxypinus goraiensis.

Comparações: este gênero difere dos demais teniados verificados pelo espaçamento entre as tênias, constituindo verdadeiros sulcos de até $2,5 \mu \mathrm{m}$ de largura. Utting (1994) descreveu $P$. sp. A nas formações Sabine Bay e Trold Fiord, do Permiano Médio a Superior do Canadá, com características muitos similares ao gênero Complexisporites.

Distribuição estratigráfica na Bacia do Paraná: Subgrupo Itararé (Daemon \& Quadros, 1970; Dias, 1993), Formação Rio Bonito e Palermo (Daemon \& Quadros, 1970). Intervalos $\mathrm{H}_{3}-\mathrm{H}_{4}$.

Distribuição estratigráfica mundial: Westphaliano dos E.U.A. (Habib, 1966; Gupta, 1970). Carbonifero Superior/Permiano Inferior do Omã e Arábia Saudita (Stephenson \& Filatoff, 2000). Passagem C/P da Espanha (Broutin, 1981).

Turma Plicates \{ [Naumova] Potonié, 1960 \}

Subturma Costates [Potonié, 1970]

Infraturma Costaiı [Jansonius, 1962]

Gênero Vituatima (Lüber) Wilson, 1962

Espécie-tipo: Vittatina subsaccata Samoilovich, 1953.

Afinidade botânica: CONIFERALES (Potonié, 1967; Bharadwaj, 1975); PTERIDOSPERMALES GNETALES (Azcuy, 1978).

\section{Vittatina subsaccata Samoilovich, 1953}

Estampa XIII, figura 7

1968 V. subsaccata, in Nahuys et al., fig. 80-7.

1970 V. subsaccata, in Cauduro, est. XVII, fig. 115-6.

$1975 V$. subsaccata, in Ybert, est. 5, fig. 105.

1975 V. sp. cf. V. subsaccata, in Kemp, est. 29!, fig. 29.

1981 V. subsaccata, in Leipnitz, est. III, fig. 12.

1987 V. subsaccata, in Sundaram, est. IX, fig. 10.

1988 V. subsaccata, in Marques-Toigo, est. VIII, fig. 9.

1993 V. subsaccata, in Dias, est. 11, fig. 14.

Diagnose: Samoilovich (1953. Paleobot. Sbornik., Trudy VNGR, 75: p. 44, est. 9, fig. 4a). Localidade-tipo: Western-Urals, Solikamsk, Permiano da ex-URSS. 
Descrição: grão de pólen poliplicado; contorno equatorial ovalado longitudinalmente. Face proximal apresentando 9-12 tenias $(2,5-7 \mu \mathrm{m}$ de largura). Sacci rudimentares nos extremos longitudinais.

Dimensões: ver Tabela Ill.4.

Ocorrência: Subzona Protohaploxypinus goraiensis.

Comparações: as espécimes assinaladas em $V$. saccata possuem sacci rudimentares com maior recobrimento na face proximal.

Distribuição estratigráfica na Bacia do Paraná: Subgrupo Itararé (Kemp, 1975; Sundaram, 1987; Marques-Toigo, 1988; Dias, 1993), formações Rio Bonito (Nahuys et al., 1968; Cauduro, 1970; Ybert, 1975; Marques-Toigo, 1988), Palermo e Subgrupo Irati (MarquesToigo, 1988). Zonas Vittatina e Lueckisporites virkkiae.

Distribuição estratigráfica: Zonas Potonieisporites-Lundbladispora, Cristatisporites e Striatites (Vergel, 1987ab, 1993; Aneñolaza \& Vergel, 1987; Césari et al., 1995), Bacia Chacoparaná, Argentina. Permiano Inferior do Uruguai (Beri \& Aguilar, 1998; Mautino et al., 1998b), Canadá (Barss, 1967; Utting, 1994) e Tatariano da Rússia (Gomankov et al., 1998). Carbonifero Superior/Permiano Inferior do Omã (Stephenson \& Filatoff, 2000).

Vittatina vittifera (Lüber \& Valtz) Samoilovich, 1953

Estampa XIII, figura 10

1970 V. cf. V. vittifera, in Daemon \& Quadros, est. 5, forma P392.

1970 V. vittifera, in Cauduro, est. XVII, fig. 118.

$1975 V$. vittifera, in Ybert, est. 5, fig. 106.

1978 V. vittifera, in Bortoluzzi et al., est. V, fig. 13.

1981 V. vittifera, in Dias-Fabrício, est. 10, fig. 8.

1987 V. vittifera, in Sundaram, est. IX, fig. 11.

1988 V. vittifera, in Marques-Toigo, est. VIII, fig. 11.

1995 V. vittifera, in Quadros et al., p. 140.

Diagnose: Samoilovich (1953. Paleobot. Sbornik., Trudy VNGR, 75: p. 44).

Localidade-tipo: Western-Urals, Solikamsk, Permiano da ex-URSS.

Descrição: grão de pólen poliplicado; contorno equatorial ovalado longitudinalmente. Face proximal apresentando $7(8) 10$ tênias $(2-7,5 \mu \mathrm{m}$ de largura). Borda equatorial de estrutura

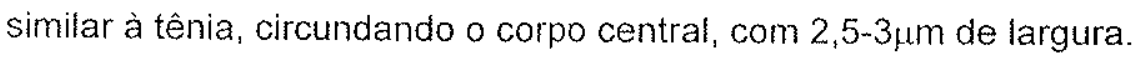

Dimensões: ver Tabela III.4.

Ocorrência: Subzona Protohaploxypinus goraiensis.

Distribuição estratigráfica na Bacia do Paraná: Subgrupo Itararé (Daemon \& Quadros, 1970; Sundaram, 1987; Marques-Toigo. 1988), Formaçăo Rio Bonito (Daemon \& Quadros, 
1970; Cauduro, 1970; Ybert, 1975; Bortoluzzi et al., 1978; Dias-Fabricio, 1981; MarquesToigo, 1988) e Palermo (Marques-Toigo, 1988). Intervalos $\mathrm{H}_{3} \mathrm{l}_{4}$; Zonas Vittatina e Lueckisporites virkkiae.

Distribuição estratigráfica mundial: Zona Cristatisporites da Bacia Chacoparaná (Vergel, 1987a). Permiano Inferior do Uruguai (Beri, 1988; Beri \& Aguilar, 1998) e Canadá (Barss, 1967; Utting, 1994). Kunguriano a Tatariano da Finlândia (Mangerud, 1994).

\section{Vittatina costabilis Wilson, 1962}

Estampa XIII, figuras 5 e 8

1975 V. costabilis, in Kemp, est. 291, fig. 22.

1981 V. costabilis, in Leipnitz, est. IV, fig. 2.

1984 V. costabilis, in Burjack, est. XII, fig. 10-13.

1986 V. costabilis, in Picarelli, est. 5, fig. 3.

1988 V. costabilis, in Marques-Toigo, est. VIII, fig. 12-3.

1991 V. costabilis, in Piccoli, est. 2, fig. b.

1993 V. costabilis, in Dias, est. 11, fig. 6.

1995 V. costabilis, in Quadros et al., p. 137.

Diagnose: Wilson (1962. Oklahoma Geol. Sur., Circ. 49: p. 25-6, est. III, fig. 12).

Localidade-tipo: Flowerpot Formation, Western Oklahoma, Permiano Superior dos E.U.A.

Descrição: grão de pólen poliplicado; contorno equatorial ovalado longitudinalmente. Face proximal apresentando 8-12 tênias longitudinais $(2,5-7,5 \mu \mathrm{m}$ de largura). Face distal com espessamento transversal na porção média, em forma de quilha, com 5-12,5 $\mu \mathrm{m}$ de largura.

Dimensões: ver Tabela III.4.

Ocorrência: Subzona Protohaploxypinus goraiensis.

Distribuição estratigráfica na Bacia do Paraná: Subgrupo Itararé (Kemp, 1975; Piccoli et al., 1991; Dias, 1993), formações Rio Bonito (Picarelli, 1986; Marques-Toigo, 1988; Piccoli et al., 1991) e Palermo (Leipnitz, 1981; Marques-Toigo, 1988) e Subgrupo Irati (Burjack, 1984; Marques-Toigo, 1988). Zonas Vittatina (Subzonas Caheniasaccites flavatus e Hamiapollenites karroensis) e Lueckisporites virkkiae.

Distribuição estratigráfica mundial: Zona Cristatisporites (Césari et al., 1995) da Bacia Chacoparaná, Argentina. Permiano Inferior do Uruguai (Mautino et al., 1998b), África (Maheshwari \& Bose, 1969; Broutin et al., 1990), Canadá (Barss, 1967) e França (Broutin et al. 1986). Autuniano da Europa (Clayton et al., 1977). Kunguriano a Tatariano da Filândia (Mangerud, 1994). Carbonifero Superior/Permiano Inferior do Omã e Arábia Saudita (Stephenson \& Filatoff, 2000). 


\section{Vittatina saccata (Hart) Jansonius, 1962}

Estampa XIV, figura 2

1970 V. saccata, in Cauduro, est. XVII, fig. 117.

1975 V. saccata, in Ybert, est. 5, fig. 108 9.

$1976 b$ V. saccata, in Pons, est. III, fig. 17.

1988 V. saccata, in Marques-Toigo, est. VIII, fig. 10.

1993 V. saccata, in Dias, est. 11, fig. 2.

1995 V. saccata, in Quadros et al., p. 138.

Diagnose: Hart (1960. Geol. Sur. Tanganyika, Bull., 30: p. 8, est. 1, fig. 1-2).

Localidade-tipo: llima Colliery, Sangwe-Kiwira Coalfield, Tanganyika, Permiano do Congo.

Descrição: grão de pólen poliplicado; contorno equatorial subcircular, longitudinalmente ovalado. Face proximal apresentando $7(8) 10$ tênias longitudinais na face proximal $(3-10 \mu \mathrm{m}$ de largura). Sacci rudimentares nos extremos longitudinais cobrindo até $1 / 4$ do corpo central.

Dimensões: ver Tabela Ill.4.

Ocorrência: Subzona Protohaploxypinus goraiensis.

Distribuição estratigráfica na Bacia do Paraná: Subgrupo Itararé (Pons, 1976b; MarquesToigo, 1988; Dias, 1993), Formação Rio Bonito (Cauduro, 1970; Ybert, 1975; MarquesToigo, 1988) e Palermo (Marques-Toigo, 1988). Zonas Vittatina e Lueckisporites virkkiae.

Distribuição estratigráfica mundial: Zona Cristatisporites (Vergel, 1987ab, 1993), Bacia Chacoparaná, Argentina. Permiano Inferior do Uruguai (Beri \& Aguilar, 1998; Mautino et al., 1998b). Kunguriano a Tatariano da Finlândia (Mangerud, 1994).

\section{Vittatina wodehousei (Jansonius) Hart, 1964 \\ Estampa XIV, figura 1}

1970 Vittatina cf. V. wodehousei, n Daemon \& Quadros, est. 7, forma P386.

1976 V. wodehousei, in Dellazana, est. IV, fig. 4-8.

1981 V. wodehousei, in Leipnitz, est. IV, fig. 3.

1993 V. wodehousei, in Dias, est. 11, fig. 3.

1995 V. wodehousei, in Quadros et al., p. 141.

Diagnose: Hart (1964. C.R. $5^{\text {eme }}$. Congr. Int. Strat. Géol. Carb., III: p. 1196, Text-fig. 69). Localidade-tipo: Flowerpot Formation, Western Oklahoma, Permiano Superior dos E.U.A.

Descrição: grão de pólen poliplicado; contorno equatorial eliptico, ovalado longitudinalmente. Face proximal apresentando $6 \sim 10$ tênias $(2,5-7,5 \mu \mathrm{m}$ de largura) no sentido do eixo maior. Sacci rudimentares muito discretos nos extremos longitudinais.

Dimensöes: ver Tabela III.4. 
Ocorrência: Subzona Protohaploxypinus goraiensis.

Comparações: $V$. saccata apresenta sacci mais desenvolvidos e V. subsaccata maior número de tênias.

Distribuição estratigráfica na Bacia do Paraná: Subgrupo Itararé (Daemon \& Quadros, 1970; Dias, 1993), Formação Rio Bonito (Daemon \& Quadros, 1970; Dellazzana, 1976) e Palermo (Leipnitz, 1981). Intervalos $I_{2} I_{4}$.

Distribuição estratigráfica mundial: Permiano Inferior do Uruguai (Beri, 1988; Beri \& Aguilar, 1998). Permiano Superior do Canadá (Jansonius, 1962).

\section{Gênero Costapollenites Tschudy \& Kosanke, 1956}

Espécie-tipo: C. ellipticus Tschudy \& Kosanke, 1956

Afinidade botânica: sem referências.

\section{Costapollenites ellipticus Tschudy \& Kosanke, 1956 \\ Estampa XIV, figuras 3 e 4}

Diagnose: Tschudy \& Kosanke [1956. Palaeobot., 15(1/2): p. 62-3, est. I, fig. 14-6].

Localidade-tipo: Permiano Inferior (Wolfcampiano) do Texas, E.U.A.

Descrição: grão de pólen de simetria bilateral, eliptico. Corpo central com cerca de 11 tênias subparalelas, orientadas segundo o eixo maior do grão e separadas por estrias de até $1 \mu \mathrm{m}$ de largura. Saccus finamente intrareticulado; marca de germinação não observada.

Dimensões: ver Tabela III.3.

Ocorrência: Subzona Protohaploxypinus goraiensis.

Comparações: difere das demais espécies de Vittatina pela presença de um definitivo e desenvolvido saccus, com intrareticulação, envolvendo completamente o corpo central.

Observações: embora possa fazer parte do "Vittatina-complex" pelas características morfológicas apresentadas, com feições gerais muito próximas da categoria $4 f$ de Gomankov et al. (1998), os espécimes verificados apresentam saccus desenvolvido, o que, para Wilson (1962, p. 25) separam as espécies de Vittatina.

Distribuição estratigráfica na Bacia do Paraná: primeira ocorrência na Bacia do Paraná.

Distribuição estratigráfica mundial: passagem C/P da Espanha (Broutin, 1981). Drabkova (1996) fez menção ao gênero também no Stephaniano da República Tcheca. 


\begin{tabular}{lcccccc}
\hline & & & \multicolumn{2}{c}{ Sacci } & \multicolumn{2}{c}{ Corpo central } \\
\hline H. tractiferinus & ne & ELT & EL & ET & EL & ET \\
H. fusiformis & 8 & $60-87,5$ & $7,5-15$ & $30-37,5$ & $40-70$ & $40-50$ \\
C. polymorphus & 3 & $65-80$ & $10-20$ & $27,5-50$ & $37,5-45$ & $50-55$ \\
V. subsaccata & 2 & - & $52,5-67,5$ & $34-60$ & $27,5-45$ & $22,5-50$ \\
V. saccata & 8 & $60-85$ & $12,5-22,5$ & $40-55$ & $35-60$ & $50-62,5$ \\
V. vittifera & 19 & $45-75$ & - & - & $40-70$ & $32,5-55$ \\
V. costabilis & 19 & $45(60) 82,5$ & $5-15$ & $25(30) 42,5$ & $42,5-70$ & $45-65$ \\
V. wodehousei & 14 & $52,5-87,5$ & $5-10$ & $20-37,5$ & $40-60$ & $37,5-55$ \\
C. ellipticus & 5 & $65-107,5$ & - & - & $45-75$ & $32,5-85$ \\
\hline
\end{tabular}

Tabela III.4 - Dimensöes das espécies dos gêneros Hamiapollenites (Wilson) Tschudy \& Kosanke, Complexisporites Jizba, Vittatina (Lüber) Wilson e CostapollenitesTschudy \& Kosanke (ne: número de espécimes medidos; ELT: eixo longitudinal total; EL: eixo longitudinal; ET: eixo transversal; valores em $\mu \mathrm{m}$ ).

Divisão PRASINOPHYTA Round, 1971

Ordem PTEROSPERMATALES

Familia TASMANITACEAE (Sommer) Sommer \& Van Boekel, 1963

Gênero Tasmanites Newton, 1875

Espécie-tipo: Tasmanites punctatus Newton, 1875.

\section{Tasmanites sp.}

Estampa XIV, figuras 5 e 6

1970 Tasmanites spp., in Daemon \& Quadros, forma P524.

1987 Tasmanites sp., in Sundaram, est. X, fig. 12.

1993 Tasmanites sp., in Dias, est. 12, fig. 5.

Descrição: vesicula originalmente esférica, circular a subcircular; margem lisa. Parede fina $(0,5-1,0 \mu \mathrm{m})$, lisa a finamente punteada, com dobras sem padrão de forma e distribuição irregular.

Dimensões: $50-138 \mu \mathrm{m}$ (10 espécimes).

Ocorrência: Zonas Biointervalo Ahrensisporites cristatus e Potonieisporites neglectus e Subzona Protohaploxypinus goraiensis.

Comparações: Ottone (1991) descreveu Tasmanites sp. B na Formação Tupe e Guadancol. Carbonifero Superior da Argentina, com grande semelhança ao material estudado. 
Distribuição estratigráfica na Bacia do Paraná: Subgrupo itararé (Daemon \& Quadros, 1970; Sundaram, 1987; Dias, 1993) e Formação Rio Bonito (Daemon \& Quadros, 1970). Intervalos $\mathrm{H}_{2} \mathrm{H}_{4}$. Daemon \& Quadros (1970) consideram a forma P525, atribuida a Tasmanites sp., como confinada a determinados intervalos bioestratigráficos na Bacia do Paraná, referentes à porção superior do Subgrupo Itararé e ao Subgrupo Irati. No presente trabalho, a espécie é verificada desde a base do Subgrupo Itararé (poço 2-PN-1-SP). Vários autores têm registrado este gênero em estratos eogondwânicos: e.g. Carbonifero Superior da Argentina (Ottone, 1991) e Permiano Inferior da Antártica (Lindström, 1995).

Divisão Chlorophyta Pascher, 1914

Ordem CHLoRococcalles (Marchand) Pascher, 1915

Familia BotryococcAcEA Wille, 1909

Gênero Botryococcus Kützing, 1849

Espécie-tipo: Botryococcus braunii Kützing, 1849.

\section{Botryococcus braunii Kützing, 1849}

Estampa XIV, figuras 9 e 10

1981 Forma indeterminada, in Leipnitz, est. VI, fig. 13.

1986 B. braunii, in Picarelli, est. 6, fig. 7-8.

1987 B. braunii, in Picarelli et al., est. 6, fig. 7-8.

1987 B. braunii, in Cazzulo-Klepzig \& Dias-Fabricio, est. I, fig. 6.

1988 B. braunii, in Marques-Toigo, est. IX, fig. 10-11.

1991 B. browni, in Piccoli et al., fig. $2 f$.

1993 B. braunii, in Dias, est. 12, fig. 6.

1994 B. braunii, in Alves, est. 18, fig. 1-6.

Descrição: algas coloniais, com aparência botroidal em vista polar e de cálice em vista equatorial; contorno circular a oval e margem crenulada, resultado da projeção das células, radialmente arranjadas e alargadas na periferia.

Dimensões: células individuais $34-54 \mu \mathrm{m}$; colônia $72-163 \mu \mathrm{m}$ (função do número de células que compõem a colônia); (5 ocorrências).

Ocorrência: Zonas Biointervalo Ahrensisporites cristatus e Potonieisporites neglectus e Subzona Protohaploxypinus goraiensis.

Observações: espécie relacionada às condições de águas rasas, doces a salobras, calmas, entre as faixas tropical e subártica (Guy-Ohlson, 1992; Batten \& Grenfell, 1996).

Distribuição estratigráfica na Bacia do Paraná: Subgrupo Itararé (Marques-Toigo, 1988; Piccoli et al., 1991; Dias, 1993), formações Rio Bonito (Picarelli, 1986; Marques-Toigo, 
1988) e Palermo (Leipnitz, 1981; Picarelli, 1986; Cazzullo-Klepzig \& Dias-Fabricio, 1987; Marques-Toigo, 1988) e Subgrupo Irati (Picarelli et al., 1987; Alves, 1994). Zonas Vittatina e Lueckisporites virkkiae.

Distribuição estratigráfica mundial: Trata-se de uma espécie de distribuição estratigráfica longeva, do Pré-Cambriano ao Recente. Como exemplos de ocorrência no Eogondwana: Carbonífero Superior da Argentina (Di Pasquo \& Azcuy, 1997a, 1999a; Di Pasquo, 1999) e Permiano Inferior do Uruguai (Mautino et al., 1998b).

Grupo ACRITARCHA [Evitt, 1963]

\section{Gênero Deusilites Hemer \& Nygreen, 1967}

Espécie-tipo: Deusilites tentus Hemer \& Nygreen, 1967.

Deusilites tenuistriatus Gutiérrez, Césari \& Archangelsky, 1997

Estampa XIV, figuras 7 e 8

1975 Cf. Deusilites, in Kemp, est. 29l, fig. 32.

1992 Navifusa sp., in Daemon et al., est. 19, fig. 111.

1993 Dactylofusa sp., in Dias, est. XII, fig. 2.

1996 Navifusa baccilum, in Souza, est. 12, fig. 8.

1996 Navifusa sp., in Souza, est. 12, fig. 9-10.

1998 Deusilites tenuistriatus, in Souza, fig. 3a-c.

Diagnose: Gutiérrez et al. [1997. Amegh., 34(2): p. 248m, fig. 1-3].

Localidade-tipo: Poço YPF-AB.x-1 (Árbol Blanco), Santiago del Estero, Permiano Inferior da Bacia Chacoparaná, Argentina.

Descrição: vesícula fusiforme a elipsoidal, com extremos arredondados, obtusos a levemente acuminados; largura máxima na metade do eixo longitudinal, com adelgaçamento em direção aos extremos, podendo às vezes apresentar leve encurvação; transversalmente simétrica. Parede simples e fina $(1-1,5 \mu \mathrm{m})$, escabrada, ornamentada por finas estrias (1. $3 \nmid \mathrm{m}$ de largura), distribuidas longitudinalmente, paralelas (nos espécimes corroídos não são distintas). Relação comprimento (eixo longitudinal) $\times$ largura (eixo transversal) entre $1,7(2-3) 5,6$.

Dimensões: comprimento $70(110) 176 \mu \mathrm{m}$; largura 20(36)68 $\mu \mathrm{m} ; \mathrm{n}^{\circ}$ de estrias $10(16) 20(61$ espécimes).

Ocorrência: Zonas Biointervalo Ahrensisporites cristatus e Potonieisporites neglectus e Subzona Protohaploxypinus goraiensis. 
Comparações: é muito provável que as formas atribuídas a Navifusa sp. por Dias (1993, est. $X I I$, fig. 1 e 3) sejam referentes a $D$. tenuistriatus, visto que se diferenciam somente por apresentar parede lisa, o que pode ser reflexo do estado de preservação, como também verificado em alguns casos neste trabalho.

Distribuição estratigráfica na Bacia do Paraná: Subgrupo Itararé (Kemp, 1975; Daemon et al., 1992; Dias, 1993; Souza, 1996, 1998).

Distribuição estratigráfica mundial: Zonas Potonieisporites-Lundbladispora e Cristatisporites, Bacia Chacoparaná (Gutiérrez et al., 1997) e Bacia de Tarija (Di Pasquo, 1999), Argentina. 


\section{RETRABALHAMENTO}

\section{Características gerais e critérios de reconhecimento}

Além dos táxons considerados autóctones, foram verificados 13 táxons comuns do Devoniano Superior ao Carbonífero Inferior, relativos a nove espécies de esporos, três algas e um escolecodonte (anelídeo).

Os critérios geralmente utilizados para o reconhecimento de palinofósseis retrabalhados são o grau de preservação e o padrão de coloração. Geralmente as ocorrências de retrabalhamento são marcadas por espécimes mal preservados e com colorações escuras (Stanley, 1955, 1956; Muller, 1959; Wilson, 1964).

Os níveis basais do Subgrupo Itararé nos poços 1-QT-1-PR, 2-PP-1-SP, 2-TB-1-SP, 1 CP-1-SP, 3-CB-3-SP e 2.PN-1-SP são os que apresentam as maiores incidências de palinofósseis retrabalhados. No primeiro poço, o número de espécies autóctones é muito reduzido. Em alguns desses níveis predominam espécimes mal preservados e com coloração diferenciada, geralmente mais escurecidas, sendo mais fácil o reconhecimento como formas alóctones.

Entretanto, essas feições não constituem regra, impondo maior cautela na distinção dos palinomorios autóctones dos alóctones. Espécimes de Grandispora spinosa Hoffmeister et al., 1995, muito comum em estratos do Devoniano Superior/Carbonífero Inferior, foram detectados por McLean (1995) no Carbonífero Superior da Inglaterra, em tétrades e exibindo melhor preservação e cores mais claras que o material considerado autóctone. Na América do Sul há registros de ocorrências de palinofósseis retrabalhados apresentando boa preservação, representados por número muito reduzido de espécimes (Mautino \& Anzótegui, 2000) ou em percentagens consideráveis (Azcuy \& Laffitte, 1981; Di Pasquo, 1999; Di Pasquo \& Azcuy, 1997b, 1999b). Na América do Norte, Barss (1972) identificou espécies retrabalhadas do Devoniano e Carbonífero Inferior em estratos do limite Pensilvaniano/Permiano, mostrando melhor preservação que os espécimes autóctones.

Souza \& Petri (1998) divulgaram palinofósseis do Devoniano e Carbonífero Inferior retrabalhados presentes no Subgrupo Itararé no poço A-IG-85, chamando atenção para os problemas de distinção e sobre a importância de seu registro. Da mesma forma que no poço retrocitado, a grande parte das espécies retrabalhadas verificadas neste trabalho encontra-se bem preservada e em número reduzido. A análise taxonômica e estratigráfica de cada espécie contituem a melhor forma de distinção entre as espécies alóctones e autóctones. 


\section{Ocorrência e distribuição estratigráfica}

Os palinofósseis alóctones säo apresentados a seguir, procurando-se ressaltar seu significado estratigráfico. O número de espécies retrabalhadas é, possivelmente, maior, visto que alguns espécimes não foram reconhecidos, como resultado do grau de preservação e das dificuldades inerentes na determinação taxonômica. O registro fotomicrográfico é parte do Anexo 1, seguindo o das espécies autóctones.

\section{ESPOROS}

\section{Retusotriletes crassus Clayton et al., 1980}

Estampa XV, figura 1

Localidade-tipo: Fameniano/Tournaisiano da Bélgica [R. sp. A, in Higgs, 1975. Microp., 21(4): p. 395, est. 1, fig. 13].

Registro prévio na Bacia do Paraná: retrabalhamento no Subgrupo Itararé (Souza, 1996, est. 1, fig. 13; Souza \& Petri, 1998. fig. 2b).

Ocorrência (4 espécimes): Poços 1“CP-1-SP (1508.5m); A-lG-85 (45.0m); 2-TB-1-SP (3701.2m); seção BR-053/Km 141.5 no Estado do Paraná.

Distribuição estratigráfica mundial: limite Devoniano/Carbonifero da Irlanda (Higgs, 1996) e Europa (Clayton et al., 1977); Fameniano a Tournaisiano da Bélgica (Higgs, 1996); Carbonífero Inferior da Arábia Saudita (Clayton, 1995) e Alemanha (Wierich \& Vogt, 1997).

\section{Emphanisporites rotatus McGregor, 1961}

Estampa $X V$, figura 2

Localidade-tipo: Formaçōes Sextanty e Battery Point, Península Gaspé, Ontário, Devoniano Superior do Canadá (McGregor, 1961. Geol. Surv. Canadá, Bull. 76: p. 3, fig. I, fig. 1-4).

Registro prévio na Bacia do Paraná: Formaçăo Furnas (Dino \& Rodrigues, 1995) e retrabalhamento no Subgrupo Itararé (Souza, 1996; Petri \& Souza, 1998).

Ocorrência (15 espécimes): Poços A-lG-85 (152.5m); 1-QT-1-SP (622.6m); 3-CB-3-SP (4424.3, 4444.5, 4448m); 2-PN-1-SP (1389.5m); IT-IG-85 (228.0m); (IG-01/Itaporanga 36.5, 37, $54 \mathrm{e}$ $76 \mathrm{~m})$; Jundiaí.

Distribuição estratigráfica mundial: Siluriano da Jordânia (Keegan et al., 1990); Devoniano Médio/Superior (Ottone, 1996) e Carbonífero Inferior (Césari \& Limarino, 1995) da Argentina. Retrabalhamento no Carbonífero Superior da Bacia de Tarija, Argentina (Di Pasquo \& Azcuy, 1997b). 


\title{
Emphanisporites annulatus McGregor, 1961
}

Estampa XV, figura 3

Localidade-tipo: Formações Sextanty e Battery Point, Península Gaspé, Ontário, Devoniano Superior do Canadá. (McGregor, 1961. Geol. Surv. Canadá, Bull. 76: p. 3-4, fig. I, fig. 5-6).

Registro prévio na Bacia do Paraná: inédita.

Ocorrência (1 espécime): Poço 2-PN-1-SP (1389.5m).

Distribuição estratigráfica mundial: Devoniano Inferior do Marrocos (Rahmani-Antari, 1990); Devoniano Médio da África (Jardiné \& Yapaudjian, 1968); Devoniano Superior do Canadá (Cloutier et al., 1996). Retrabalhamento no Carbonífero Superior da Bacia de Tarija, Argentina (Di Pasquo \& Azcuy, 1997b).

\section{Indotriradites dolianitii (Daemon) Loboziak et al., 1999}

\author{
Estampa $X V$, figura 10
}

Localidade-tipo: Poço 2-|Z-1-MA, Formação Poti, Bacia do Parnaíba, Viseano do Brasil. (Loboziak et al. 1999. Rev. Palaeob. Palyn., 107: p. 18-20, est. l, fig. 6-14).

Registro prévio na Bacia do Paraná: inédita.

Ocorrência (7 espécimes): poços 2.PN-1-SP (1389.5m); 2-PP-1-SP (3444m); itu (Pedreira Ituana).

Distribuição estratigráfica mundial: Viseano da Bacia do Amazonas e Parnaíba (Daemon, 1974b; Loboziak et al., 1998, 1999); limite Devoniano/Carbonífero do Saara algeriano (Lanzoni \& Magloire, 1969).

\section{Indotriradites cf. I. daemonii Loboziak et al., 1999}

Estampa XV, figura 8

Localidade-tipo: Poço 1-CA-1-MA, Formação Poti, Bacia do Parnaíba, Carbonífero Inferior do Brasil (Loboziak et al. 1999. Rev. Palaeob. Palyn., 107: p. 18-20, est. l, fig. 6-14).

Registro prévio na Bacia do Paraná: inédita.

Ocorrência (2 espécimes): Poço 1-JT-1-PR (737m); seção BR-053/Km. 141.5 no Estado do Paraná. Distribuiçäo estratigráfica mundial: Viseano da Bacia do Amazonas e Parnaíba (Loboziak et al., 1998; 1999; Melo et al., 1999).

\section{Grandispora uncata (Hacquebard) Playford, 1971}

Estampa $X V$, figura 9

Localidade-tipo: Horton Group, West Gore Blue Beach samples, Nova Scotia, Tournaisiano do Canadá [Hacquebard, 1957. Micropaleont., 3(4): p. 316, est. 3, fig. 8-10].

Registro prévio na Bacia do Paraná: inédita.

Ocorrência (1 espécime): Poço 2"TB-1-SP (2841m).

Distribuição estratigráfica mundial: Struniano-Tournaisiano do Marrocos (Rahmani-Antari, 1990). 


\section{Grandispora brevispinosa Menéndez \& Pöthe de Baldis, 1967}

Estampa XV, figura 7

Localidade-tipo: Poço Picuíba 1 (1222m), Devoniano Médio a Superior, noroeste do Paraguai (Menéndez \& Pöthe de Baldis, 1967. Rev. Paleob. Palyn., 1: p. 166, est. I, fig. H).

Registro prévio na Bacia do Paraná: retrabalhamento no Subgrupo Itararé (Souza, 1996; Souza \& Petri, 1998).

Ocorrência (1 espécime): Poço A-lG-86 (152.5m).

Distribuição estratigráfica mundial: Devoniano Médio a Superior da Bacia de Tarija, Argentina (Ottone, 1996).

\section{Grandispora pseudoreticulata (Menéndez \& Pöthe de Baldis) Ottone, 1996 \\ Estampa XV, figura 5}

Localidade-tipo: Poço Picuíba 1 (1222, 1160, 1358 e 1400?m), Devoniano Médio a Superior, noroeste do Paraguai (Menéndez \& Pöthe de Baldis, 1967. Rev. Paleob. Palyn., 1: 168-9, est. ।, fig. C-E).

Registro prévio na Bacia do Paraná: inédita.

Ocorrência (4 espécimes): Poço IG-01/ttaporanga (36.5 e 76m).

Distribuição estratigráfica mundial: Devoniano Médio do Paraguai (Menéndez \& Pöthe de Baldis, 1967); Devoniano Médio a Superior da Bacia de Tarija, Argentina (Ottone, 1996); Fameniano da Bolívia e Peru (Díaz-Martínez et al., 1999); Givetiano a Frasniano (Ottone \& Rossello, 1996) e Carbonifero Inferior da Bolívia (Azcuy \& Ottone, 1987).

\section{Retispora lepidophyta (Kedo) Playford, 1976 \\ Estampa XV, figura 6}

Registro prévio na Bacia do Paraná: inédita.

Ocorrência (3 espécimes): poços 2-PP-1-SP (3444m) e 2-TB-1-SP (3700.2 e 3071.2m).

Distribuição estratigráfica mundial: Fameniano da Bolívia, Líbia e Peru (Díaz-Martínez et al., 1999; Vavrdová \& Isaacson, 1999); Struniano a Tournaisiano do Marrocos (Rahmani-Antari, 1990); Fameniano da Alemanha (Hartkopf-Fröder \& Strell, 1993); Fameniano a Struniano da Bacia do Amazonas e Parnaíba (Daemon, 1974b); limite Devoniano/Carbonífero da Bolívia (Vavrdová et al., 1993), Canadá (Playford \& McGregor, 1993), Inglaterra (Neves \& Dolby, 1967; Dolby \& Neves, 1970) e Irlanda (Clayton et al., 1974; Higgs, 1975). Retrabalhamento no Westphaliano da Holanda (Van de Laar \& Fermont, 1990). 
ALGAS

\section{Maranhites braziliensis (Brito) Burjack \& Oliveira, 1989}

Estampa XV, figura 13

Localidade-tipo: Devoniano Superior da Bacia do Parnaíba, Pernambuco, Brasil (Burjack \& Oliveira, 1989. Bol. IG-USP, 7: p. 49-51, est. I, fig. 1-2, 4-5, 8-9).

Registro prévio na Bacia do Paraná: Formação Ponta Grossa (para sinonímia e distribuição estratigráfica completas, ver Oliveira, 1997).

Ocorrência (1 espécime): Poço IT-IG-85 (228m).

Distribuição estratigráfica mundial: limite Devoniano/Carbonífero da Bacia do Parnaíba (Brito, 1978), Bolívia (Vavrdová et al., 1993) e Canadá (Playford \& Mcgregor, 1993); Frasniano a Tournaisiano da Bacia do Amazonas e Parnaíba (Daemon, 1974b; Quadros, 1985); Fameniano da Bolívia e Peru (Díaz-Martínez et al., 1999); Carbonífero Inferior da Argentina (Césari \& Limarino, 1992). Retrabalhamento no Carbonifero Superior da Bacia de Tarija, Argentina (Azcuy \& Laffitte, 1981).

\section{Maranhites insulatus Burjack \& Oliveira, 1989}

Estampa XV, figura 12

Localidade-tipo: Poço RSP-1, Formação Ponta Grossa, Devoniano Superior (Frasniano) da Bacia do Paraná, Mato Grosso, Brasil (Burjack \& Oliveira, 1989. Bol. IG-USP, 7: p. 52-4, est. I, fig. 7 , $10,12)$.

Registro prévio na Bacia do Paraná: Frasniano a Neofameniano, Formação Ponta Grossa (Daemon et al., 1967; Burjack \& Oliveira, 1989; Oliveira, 1991, 1997). Para sinonímia e distribuição estratigráfica completas ver Oliveira (1997).

Ocorrência (1 espécime): Poço IT-IG-85 (228m).

Distribuição estratigráfica mundial: Devoniano Médio a Superior da Bacia de Tarija, Argentina (Ottone, 1996); Frasniano a Tournaisiano da Bacia do Amazonas e Parnaíba (Daemon, 1974b). Devoniano Superior a Tournaisiano do Saara algeriano (Lanzoni \& Magloire, 1969); Ghana (Anan-Yorke, 1974) e Bacia do Amazonas (Daemon \& Contreiras, 1971). Retrabalhamento na Bacia de Tarija, Argentina (Di Pasquo \& Azcuy, 1997b).

\section{Duvernaysphaera angelae Deunff, 1964}

Estampa XV, figura 11

Localidade-tipo: Devoniano do Tunísia, África (Deunff, 1964. Grana Palyn., 5: p. 211-2, fig. 1).

Registro prévio na Bacia do Paraná: Frasniano a Neofameniano, Formação Ponta Grossa (Oliveira, 1991, 1997).

Ocorrência (6 espécimes): Poços 1-QT-1-SP (622.6m); 3-CB-3-SP (4424.3 e 4444.5m); IG$01 /$ taporanga (54m). 
Distribuição estratigráfica mundial: Devoniano Médio a Superior da Bacia de Tarija, Argentina (Ottone, 1996); Givetiano a Frasniano da Bolivia (Ottone \& Rossello, 1996).

\section{ANELIDEO}

\section{Staurocephalites sp.}

Estampa XV, figura 4

Registro prévio na Bacia do Paraná: retrabalhamento na Formação Rio Bonito (Thomaz, 1980).

Ocorrência (1 espécime): poço 3-CB-3-SP (4444.5m).

Distribuição estratigráfica mundial: Devoniano Médio a Superior (Ottone, 1996) e Carbonífero Inferior da Argentina (Césari \& Limarino, 1992). 
CAPÍTULO IV

BIOESTRATIGRAFIA 


\section{COMPARTIMENTAÇÃO PALINOBIOESTRATIGRÁFICA}

\subsection{ASPECTOS GERAIS}

A proposição de biozonas e de bio-horizontes é resultado do comportamento do registro fossilifero nos estratos rochosos, envolvendo sua distribuição estratigráfica (amplitudes vertical e horizontal) e seu comportamento em termos evolutivos, de abundância e até mesmo ausência, parâmetros que norteiam a organização bioestratigráfica.

A devida compreensão dos diversos fatores que influenciam e, de certa forma, controlam a distribuição dos palinomorfos em uma sucessão estratigráfica é imprescindível. Di Pasquo (1999, p. 357-9) abordou alguns desses aspectos, ressaltando o controle (i) do paleoambiente, (ii) da paleoecologia, (iii) das migraçōes e (iv) o retrabalhamento, alguns dos quais constatados no intervalo estudado do Subgrupo ltararé, evidenciando as dificuldades de sua compartimentação palinobioestratigráfica.

Qualquer controle ambiental, litofaciológico ou ecológico somente é verificado com minuncioso trabalho que avalie o comportamento quantitativo e qualitativo das associações palinológicas, de modo a subsidiar as determinações bioestratigráficas.

Segundo Couper (1958), dois métodos podem ser utilizados nas determinações: o primeiro levando-se em consideração a presença de formas-guias de curta distribuição estratigráfica; o segundo baseado na abundância relativa de certas espécies, as quais não são, necessariamente, formas-guias. Esse último método pode refletir condiçóes paleoecológicas particulares, perdendo valor em termos de correlação bioestratigráfica. De acordo com Couper (op. cit.), a importância das formas-guias deve ser avaliada levando-se em consideração o número de localidades onde ocorrem e desconsiderando-se sua abundância.

No Guia Brasileiro de Nomenclatura Estratigráfica, Petri et al. (1986a, p. 392) orientam que "Devem-se preferir unidades baseadas em taxa abundantes, amplamente distribuídos e facilmente identificáveis". Pelo menos para os palinomorfos, as duas últimas orientações são julgadas pertinentes. Entretanto, a abundância só foi considerada na caracterização das biozonas quando os padrōes de distribuição foram similares em litologias distintas.

Esses critérios básicos foram considerados na determinação das unidades bioestratigráficas apresentadas, de modo a minimizar os erros de interpretação. Evidentemente, estudos mais detalhados em quaisquer das seções estudadas podem revelar resultados diferentes, principalmente, por se tratar de avaliação subjetiva.

Dessa forma e para validar a proposição bioestratigráfica como formal, procurou-se atender ao Código Brasileiro de Nomenclatura Estratigráfica (Petri et al., 1986b) e ao Guia de Nomenclatura Estratigráfica (Petri et al., 1986a), ambos em acordo com o Guia Estratigráfico Internacional (versão reduzida em Murphy \& Salvador, 1999). 
Entre as espécies estudadas, verificam-se várias de distribuição estratigráfica longeva, principalmente aquelas relativas a grãos de pólen monossacados de simetria radial (principalmente dos gêneros Cannanoropollis e Plicatipollenites) e bilateral (Potonieisporites e Caheniasaccites). A utilização desses grupos para fins bioestratigráficos não é recomendada, visto que muitas de suas espécies ocorrem em várias unidades bioestratigráficas do Paleozóico Superior do Gondwana. Por esse motivo, procurou-se integrar suas ocorrências com os esporos, cuja importância do registro só foi ressaltada, para a Bacia do Paraná, a partir do trabalho de Lima et al. (1983).

Embora algumas espécies de esporos sejam de valor estratigráfico, não foram selecionadas para caracterização das biozonas (determinação de limites inferior e superior), tendo em vista as dificuldades de seu reconhecimento morfológico e taxonômico (e.g. Calamospora hartungiana, Punctatisporites lucidulus, Cristatisporites indignabundus, Cirratriradites veeversii, Velamisporites sp. e Florinites sp.). Além disso, só foram considerados os táxons ocorrentes em, pelo menos, dois niveis estratigráficos distintos, sem se priorizar a abundância.

Embora a quantidade de táxons verificados no Subgrupo Itararé tenha sido relativamente grande (95 selecionados dentre 139 registrados), as amostras apresentaram padrão irregular em abundância e diversidade. Os níveis de subsuperfície melhor representados são aqueles do poço A-IG-85 (Araçoiaba da Serra, SP). Em termos de superfície, a falta de um padrão comum é mais acentuada. Destacam-se, em abundância, alguns níveis de carvões (Buri e Monte Mor). Com relação à variedade taxonômica os níveis de carvão e litologias associadas e os poços A-IG-85 e IG-01 (Itaporanga) apresentam relativa abundância e diversificação.

O grau de preservaçāo também é variável, sendo geralmente bom. Em alguns níveis, principalmente aqueles relativos à porção superior do Subgrupo ltararé, somente fol possível a determinação taxonômica de espécies previamente reconhecidas em associações melhor preservadas.

Os palinomorfos representados são relativos a esporos triletes, grãos de pólen monossacados, bissacados, teniados, poliplicados, elementos algálicos, Acritarcas e Incertae Sedis.

Para facilitar a leitura, a distribuição dos 95 táxons selecionados e descritos no Capítulo III é apresentada na forma de diversos quadros no Anexo 2 (Quadros 2.3 a 2.26), com as informaçöes básicas dos poços e afloramentos (profundidade, quando de subsuperfície, biozoneamento e lâminas de referência).

A compartimentação palinobioestratigráfica que será apresentada a seguir é fundamentada na distribuição dos esporomorfos. Os outros elementos, cuja importância é relevante em termos paleoambientais, não foram utilizados com fins bioestratigráficos, tendo em vista sua distribuição mais longeva. 


\subsection{BIOZONEAMENTO}

Com base na distribuição dos táxons registrados e na análise de sua importância bioestratigráfica, propõe-se duas unidades bioestratigráficas: as Zonas Biointervalos Ahrensisporites cristatus e Potonieisporites neglectus. Reconhece-se ainda a Subzona Protohaploxypinus goraiensis, base da Zona Cannanoropollis korbaensis estabelecida para o topo do Subgrupo Itararé e base da Formação Rio Bonito no sul da bacia (Marques-Toigo, $1988,1991)$. As três unidades bioestratigráficas verificadas são relativas, conforme ordem mencionada, às porções inferior, média e superior do Subgrupo Itararé na área estudada. Adicionalmente, a Zona Biointervalo Cannanoropollis korbaensis e a Subzona Caheniasaccites ovatus (Marques-Toigo, op. cit.) são renomeadas.

Nos itens que se seguem serão apresentados os critérios e os atributos necessários para a formalização das biozonas propostas, na ordem da mais primitiva para a mais nova, contemplando as normas do Código e do Guia Brasileiros de Nomenclatura Estratigráfica (Petri et al., 1986ab). Após as apresentações da compartimentação palinobioestratigráfica, é mostrada no Quadro IV.1 a distribuição das espécies que melhor caracterizam as biozonas propostas.

\subsubsection{Zona Biointervalo Ahrensisporites cristatus}

\section{Justificativas}

A seção inferior do Subgrupo Itararé apresenta associações palinofossiliferas bastante distintas daquelas das seçōes média e superior da unidade. Algumas localidades onde a Zona ocorre já foram estudadas previamente, com a proposição de zonas informais: intervalo Pré-G (Lima et al., 1983) ou Associação Ahrensisporites \& Ancistrospora (Souza et al., 1996). No entanto, o intervalo é carente de melhor determinação bioestratigráfica e formalização definitiva.

Trata-se de uma Zona Biointervalo bem caracterizada e delimitada, materializada em, pelo menos, $212 \mathrm{~m}$ de sedimentos do Subgrupo Itararé, com a presença de elementos-chave de fácil reconhecimento morfológico e taxonômico, ocorrentes em, no mínimo, duas localidades distintas, relativamente bem separadas geograficamente, e de curta distribuição estratigráfica.

\section{Categoria, tipo de biozona e nome}

A categoria da compartimentação é Zona, tendo em consideração os elementos -chave diagnósticos e a ampla distribuição geográfica. A zona é do tipo zona-de-intervalo, mais propriamente chamada de zona biointervalo (Petri et al., 1996b, p. 390), delimitada por 
biohorizontes, que registram o aparecimento e o desaparecimento de espécies de esporomorfos selecionados.

A espécie selecionada para nomeação fol escolhida em razão de sua ocorrência em mais de um nível estratigráfico distantes entre sí e com biócrono reduzido no Carbonífero gonvânico, embora não apresente abundância em nenhuma das localidades onde ocorra, o que, todavia, não limita seu uso.

\section{Estratótipo}

A seção do poço A-lG-85 é a que melhor representa a Zona Biointervalo Ahrensisporites cristatus, referente à porção inferior do Subgrupo Itararé na região de Araçoiaba da Serra (SP), Estado de São Paulo. A descrição litológica do poço é apresentada por Massoli (1991), reproduzida aqui na Figura IV.1. A seção é constituída por cerca de $212 \mathrm{~m}$ de sedimentos, incluindo siltitos, ritmitos, argilitos e arenitos, com alto grau de recorrência, assentada sobre rochas graníticas pré-cambrianas.

Adicionalmente, o nível de carvão de Buri (Souza et al., 1990; 1993a) pode constituir o paraestratótipo da Zona. A seção estratigráfica ideal para os níveis de carvão de Buri e litologias associadas é aquela apresentada em Souza Filho (1986).

\section{Limites inferior e superior}

O limite inferior da Zona é delimitado por:

-presença, ou aparecimento, das seguintes espécies de esporos: Granulatisporites varigranifer, Apiculiretusispora variornata, Anapiculatisporites argentinensis, Raistrickia pinguis, R. rotunda, R. paganciana, Convolutispora ordoñenzii, C. muriornata, Foveosporites hortonensis, Ahrensisporites cristatus, Cristatisporites menendezii, C. spinosus, C. inordinatus, Bascaudaspora canipa e Psomospora detecta.

-presença, ou aparecimento, de um número significativo de espécies de grãos de pólen monossacados, principalmente: Cannanoropollis (C. janakii, C. triangularis, C. densus), Plicatipollenites ( $P$. malabarensis, $P$. gondwanensis, $P$. trigonalis, $P$. densus), Potonieisporites ( $P$. novicus, $P$. neglectus, $P$. triangulatus, $P$. barrelis, $P$. densus, $P$. congoensis, $P$. brasiliensis, $P$. magnus), Divarisaccus stringoplicatus, Cahenisaccites (C. flavatus, $C$. sp.). A partir da base da Zona, podem também ocorrer grāos de pólen bissacados (Limitisporites rectus, L. sp.) e teniados (Protohaploxypinus amplus). Quando presentes, ocorrem em quantidades subsidiárias.

O limite superior é delimitado pelo desaparecimento das seguintes espécies: Granulatisporites varigranifer, Anapiculatisporites argentinensis, Raistrickia pinguis, Foveosporites hortonensis, Ahrensisporites cristatus, Cristatisporites menendezii, C. spinosus, 
C. inordinatus, Psomospora detecta e pelo aparecimento de Crucisaccites monoletus e Scheuringipollenites maximus, que delimitam a base da Zona Biointervalo subsequente.

\section{Extensāo estratigráfica}

A Zona Biointervalo Ahrensisporites cristatus ocorre na porção inferior do Subgrupo Itararé, em subsuperfície (poços A-IG-85, 2-PP-1-SP, 2-J-1-PR, 1-RO-1-PR, 1-CS-1-PR, T-IG93, 2-TB-1-SP e 2-PN-1-SP) e em superfície (carvões e litologias associadas de Monte Mor, Buri, Itapeva e seções aflorantes na SP-270 em Araçoiaba da Serra).

Alguns intervalos caracterizados pela ausência de espécies típicas da zona subseqüente, pouca freqüência de grãos de pólen e expressiva ausência de grãos de pólen teniados são incluídos na zona, ressaltando-se a necessidade de detalhamentos posteriores (níveis basais do poço T1-JG-91, 1CP-1-SP, 2-J-1-PR, 2-JT-1-PR, 1-RO-1-PR, 3-CB-3-SP, 1. SJ-1-PR, 1-CS-1-PR, 2-TB-1-SP).

\section{Distribuição das espécies}

A Zona Biointervalo Ahrensisporites cristatus é composta por um conjunto numeroso de espécie de esporomorfos, num total de 77 espécies, das quais 51 são relativas a esporos, 21 de monossacados não-teniados, 1 de monossacado teniado (? Striomonosaccites sp.), 2 de bissacados não-teniados (Limitisporites rectus e $L$. sp.) e 2 de bissacados teniados (Protohaploxypinus amplus e Striatoabieites sp.).

\section{Espécies exclusivas}

A lista de elementos exclusivos desta Zona é também considerável, sendo composta somente por esporos, num total de 11 espécies: Granulatisporites varigranifer, Anapiculatisporites argentinensis, Raistrickia pinguis, Foveosporites hortonensis, Ahrensisporites cristatus, Cristatisporites indignabundus, C. menendezii, C. inordinatus, C. spinosus, Cirratriradites veeversii e Psomospora detecta.

\section{Espécies dominantes e características}

As seguintes espécies apresentam distribuições quantitativas consideráveis nas associações: Calamospora hartungiana, Punctatisporites gretensis, Raistrickia rotunda, Foveosporites hortonensis, Lundbladispora braziliensis, L. riobonitensis, Vallatisporites ciliaris, Bascaudaspora canipa, Cannanoropollis janakii, Plicatipollenites malabarensis, $P$. trigonalis, $P$. densus, Potonieisporites brasiliensis, $P$. novicus e Caheniasaccites flavatus. Entre as espécies características da Zona, além das dominantes supra-citadas, inclui-se ainda Cristatisporites menendezii, C. inordinatus, C. spinosus. 


\section{Características gerais da zona}

As principais características são o predomínio de grãos de pólen monossacados de simetrial radial e bilateral e/ou de esporos, principalmente os cingulizonados e lisos, em quase todas as associações. O estado de preservaçāo é geralmente muito bom e reflete pouco transporte das associações a partir das plantas geradoras. A freqüência de esporomorfos denota o predomínio das Lycopsidas, Filicopsidas e Gyminospermopsidas (Coniferales), características muito comuns nos estratos do Carbonífero Superior mundial. Grãos de pólen teniados (?Pteridospermales/?Coniferales), quando presentes, estäo em quantidades subsidiárias $(<5 \%)$.

É muito comum a ocorrência de palinofósseis retrabalhados do Devoniano e Carbonífero Inferior nesta Zona, conforme discutido separadamente no Capítulo III.

\section{Trabalhos preliminares}

Os trabalhos versando o conteúdo palinológico de Araçoiaba da Serra (Lima et al., 1983; Souza, 1996), Monte Mor (Souza et al., 1993b, 1997) e Buri (Souza et al., 1990, 1993a) foram devidamente revisados e analisados. O material detectado pelos autores citados deve, sem restrições, fazer parte da Zona Biointervalo Ahrensisporites cristatus. De igual forma também dois dos afloramentos da Rodovia Raposo Tavares (SP-270) estudados por Kemp (1975): Km 121.9 (mencionado como 121.5) e Km 124.0. Com relaçāo a outros trabalhos desenvolvidos em Buri (Arai, 1980; Sundaram, 1980; Dino \& Playford, 1997), a análise é prejudicada, face à ausência de descrições e/ou ilustraçốes. No entanto, pelo conteúdo palinológico mencionado, as associações citadas também podem corresponder à zona, principalmente pela presença de Ahrensisporites cristatus e Psomospora detecta, citados no último trabalho. 


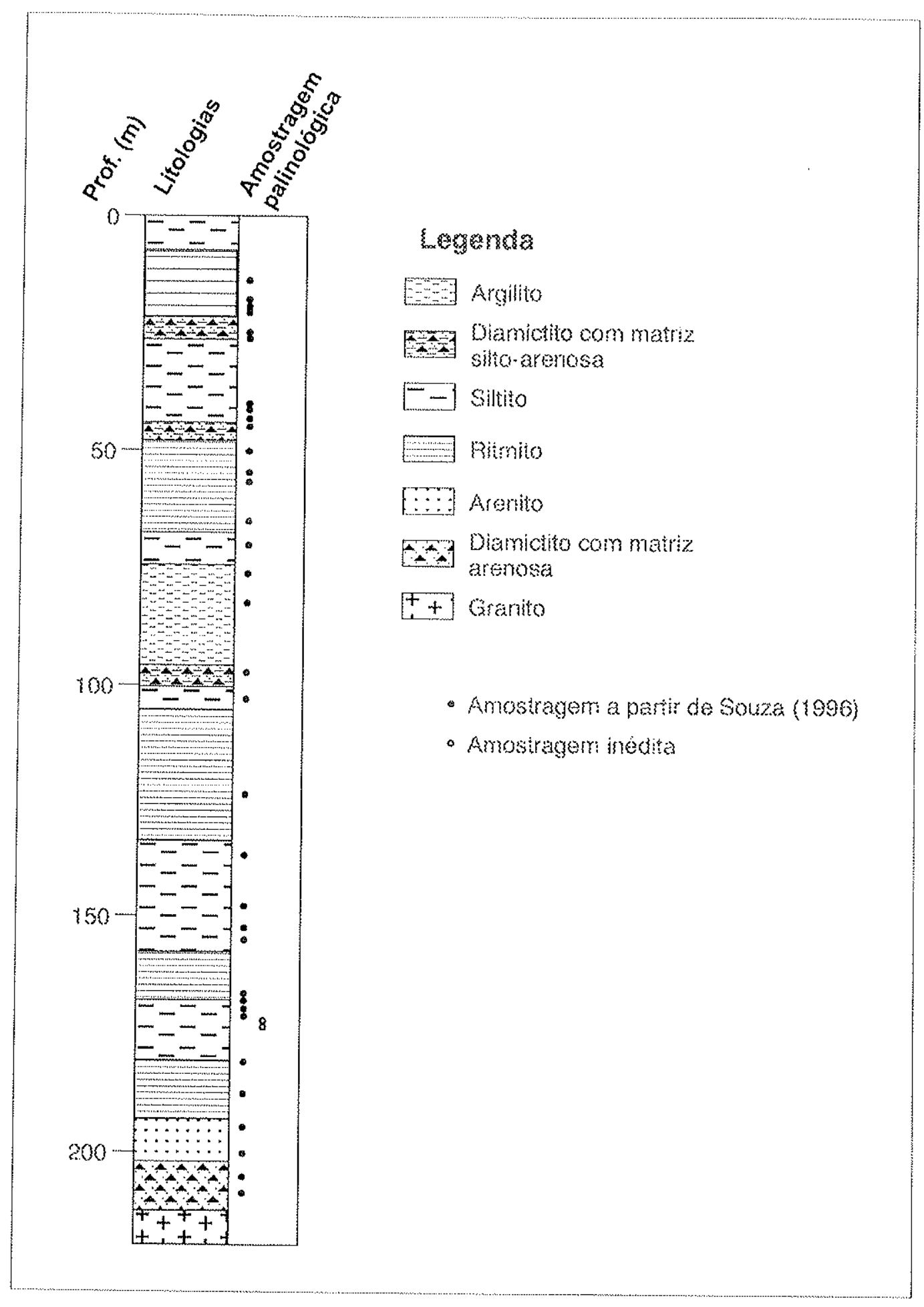

Figura IV.1 - Descrição geológica do poço A-IG-85 (Araçoiaba da Serra, SP), estratótipo da Zona Biointervalo Ahrensisporites cristatus e amostragem palinológica. (litoestratigrafia conforme Massoli, 1991). 


\subsubsection{Zona Biointervalo Potonieisporites neglectus}

\section{Justificativas}

Embora possua, comparativamente às biozonas sub- e supracentes, um número menor de palinofósseis restritos, a porção média do Subgrupo Itararé comporta associações palinológicas com domínio de grãos de pólen monossacados de simetria radial (gêneros Cannanoropollis, Plicatipollenites, Crucisaccites, Divarisaccus) e bilateral (Potonieisporites, Caheniasaccites), com ausência da maioria dos esporos característicos da Zona Biointervalo Ahrensisporites cristatus. As zonas da Bacia do Paraná com as quais a Zona Biointervalo Potonieisporites neglectus é correlacionada são informais e são reavaliadas neste trabalho.

Trata-se de uma Zona Biointervalo bem característica, com constituintes de fácil reconhecimento morfológico e taxonômico, com ocorrência em, pelo menos, duas localidades distintas, relativamente bem separadas geograficamente, ocorrente em espesso pacote sedimentar, relativo a cerca de $800 \mathrm{~m}$ de sedimentos do Subgrupo Itararé.

É muito provável que com estudos mais minunciosos, com maior amostragem de subsuperfície e seções estratigráficas mais completas na área aflorante, a Zona possa ser subdividida em subzonas, com melhor controle estratigráfico.

\section{Categoria, tipo de biozona e nome}

A categoria da compartimentação é Zona, tendo em consideraçāo os elementos-chave diagnósticos e a ampla distribuição geográfica. A Zona é do tipo biointervalo, delimitada por biohorizontes que registram o aparecimento e o desaparecimento de espécies de esporomorfos selecionados.

A espécie eleita para sua nomeação foi escolhida em razão de sua ocorrência em mais de um nível estratigráfico distantes entre sí, tratar-se de uma espécie abundante no estratótipo, de fácil reconhecimento morfológico e taxonômico. Por existirem controvérsias a respeito da classificação de algumas espécies do gênero Potonieisporites, é necessário esclarecer que a identificação da espécie é com base no trabalho de Azcuy \& Di Pasquo (2000).

De acordo com Marques-Toigo (1988), verifica-se que a espécie $P$. neglectus ocorre entre os subgrupos Itararé e Irati (zonas Vittatina e Lueckisporites virkkiae) nos estados do Rio Grande do Sul e Santa Catarina. Na porção setentrional da bacia, sua ocorrência está restrita ao Subgrupo Itararé (Daemon \& Quadros, 1970; este trabalho). De acordo com o Código e o Guia Brasileiros de Nomenclatura Estratigráfica e a definição de biozonas do tipo intervalo (biointervalo), a maior duração de um táxon não impede seu uso para nomeaçāo de unidades bioestratigráficas. 


\section{Estratótipo}

A seção do poço IG-01, perfurado pela empresa Pamec Ltda., na década de 40, e estudado pelo antigo Instituto Geográfico e Geológico (IGG), atual IG/SMA, no município de Itaporanga (SP), é a que melhor representa a Zona (ver Figura IV.2). Embora não haja uma descrição completa dos litotipos, o intervalo é dominado por arenitos sílticos e siltitos, com ocorrência de invertebrados (Nuculana limai, Orbiculoidea sp.), restos de peixes e icnofósseis (Mezzalira, 1956).

Adicionalmente, os níveis de ritmitos da região de Jundiaí (SP), ocorrentes na Pedreira Nivolonem podem constituir o paraestratótipo da Zona, com estudo litofaciológico detalhado em Batezelli (2000).

\section{Limites inferior e superior}

O limite inferior da Zona é delimitado pelo desaparecimento das espécies que constituem o limite superior da Zona Biointervalo Ahrensisporites cristatus e pelo aparecimento de Crucisaccites monoletus e Scheuringipollenites maximus.

O limite superior é delimitado:

-pelo desaparecimento das seguintes espécies: Calamospora hartungiana, Punctatisporites lucidulus, Cyclogranisporites firmus, Apiculiretusispora variornata, Apiculatisporis sp., Dibolisporites disfacies, Raistrickia rotunda, Convolutispora ordoñenzii, C. muriornata, Reticulatisporites passaspectus, Stenozonotriletes clarus, Kraeuselisporites volkheimerii, Velamisporites sp., Florinites sp., Crucisaccites monoletus, Potonieisporites neglectus, P. triangulatus, P. barrelis, Divarisaccus stringoplicatus; e,

-pelo aparecimento das seguintes espécies: Protohaploxypinus goraiensis, P. micros, P. panaki, P. limpidus, Complexisporites polymorphus, Hamiapollenites tractiferinus, $H$. fusiformis, Vittatina wodehousei, V. vittifera, V. subsaccata, V. saccata, V. costabilis e Costapollenites ellipticus.

\section{Extensão estratigráfica}

A Zona Biointervalo Potonieisporites neglectus ocorre na porção média do Subgrupo Itararé, tendo sido detectada em subsuperfície (poços 1-CP-1-SP, IT-IG-85, T1-IG-91, 2-JT-1PR, 2-J-1-PR, 1-SJ-1-PR), além do poço IG-01 (estratótipo), e em superfície: Jundiaí, ltu (SP), seção aflorante da Rodovia BR-053 entre Ventania e lbaiti, excluindo o lixão de Ibaiti (PR). A distribuiçäo da Zona nas várias localidades aflorantes e em subsuperfície é apresentada nos Quadros do Anexo 2. 


\section{Distribuição das espécies}

A Zona é também composta por um conjunto numeroso de espécie de esporomorfos, num total de 66 espécies, das quais 39 são relativas a esporos, 22 de monossacados nãoteniados, 1 de monossacado teniado (? Striomonosaccites sp.), 3 de bissacado não-teniado (Scheuringipollenites maximus, Limitisporites rectus e L. sp.) e 1 de bissacado teniado (Protohaploxypinus amplus).

\section{Expécies exclusivas}

Somente a espécie de grão de pólen monossacado de simetria radial Crucisaccites monoletus é exclusiva a esta Zona. Entretanto, não nomeia a zona por apresentar freqüência relativamente muito baixa.

\section{Espécies dominantes e características}

As seguintes espécies apresentam distribuições quantitativas consideráveis nas associações: Calamospora hartungiana, Punctatisporites gretensis, Convolutispora ordoñenzii, C. muriornata, Vallatisporites ciliaris, Kraeuselisporites volkheimerii, Velamisporites $\mathrm{sp}$., Cannanoropollis janakii, Plicatipollenites malabarensis, P. trigonalis, $P$. densus, Potonieisporites brasiliensis, $P$. novicus, $P$. neglectus, Caheniasaccites flavatus e Limitisporites rectus.

\section{Características gerais da zona}

Da mesma forma que a anterior, a Zona é dominada pelos mesmos elementos relacionados às Lycopsidas, Filicopsidas e Gyminospermopsidas (Coniferales), com ocorrência subsidiária de teniados (?Coniferales/?Pteridospermales). A baixa freqüência deste último grupo é uma característica nas zonas do Carbonífero Superior gondwânico, associadas a sedimentos glaciogênicos. A Zona é diferenciada da subjacente pela ausência de 11 espécies de esporos e pelo aparecimento de duas (Crucisaccites monoletus e Scheuringipollenites maximus).

\section{Trabalhos preliminares}

As associaçōes palinológicas das pedreiras de Jundiaí já foram estudadas preliminarmente por Batezelli et al. (1999) e Souza et al. (2000) e são devidamente incluídas nesta Zona. Das associaçōes provenientes do varvitos de ltu (correlatas ao "Parque Ecológico do Varvito de Itu"), constam os trabalhos de Daemon \& Quadros (1970), Kemp (1975) e Arai 
(1980). Os táxons registrados não permitem melhores deduções, dado o número reduzido de espécies verificadas pelos autores citados. Notar que, a julgar pela composição palinológica mencionada, os níveis estudados por Dino et al. (1987) näo correspondem a esta Zona e são, possivelmente, equivalentes à ritmitos da seção superior do Subgrupo Itararé, face à relativa abundância e diversificação de grãos de pólen teniados e do gênero Vittatina.

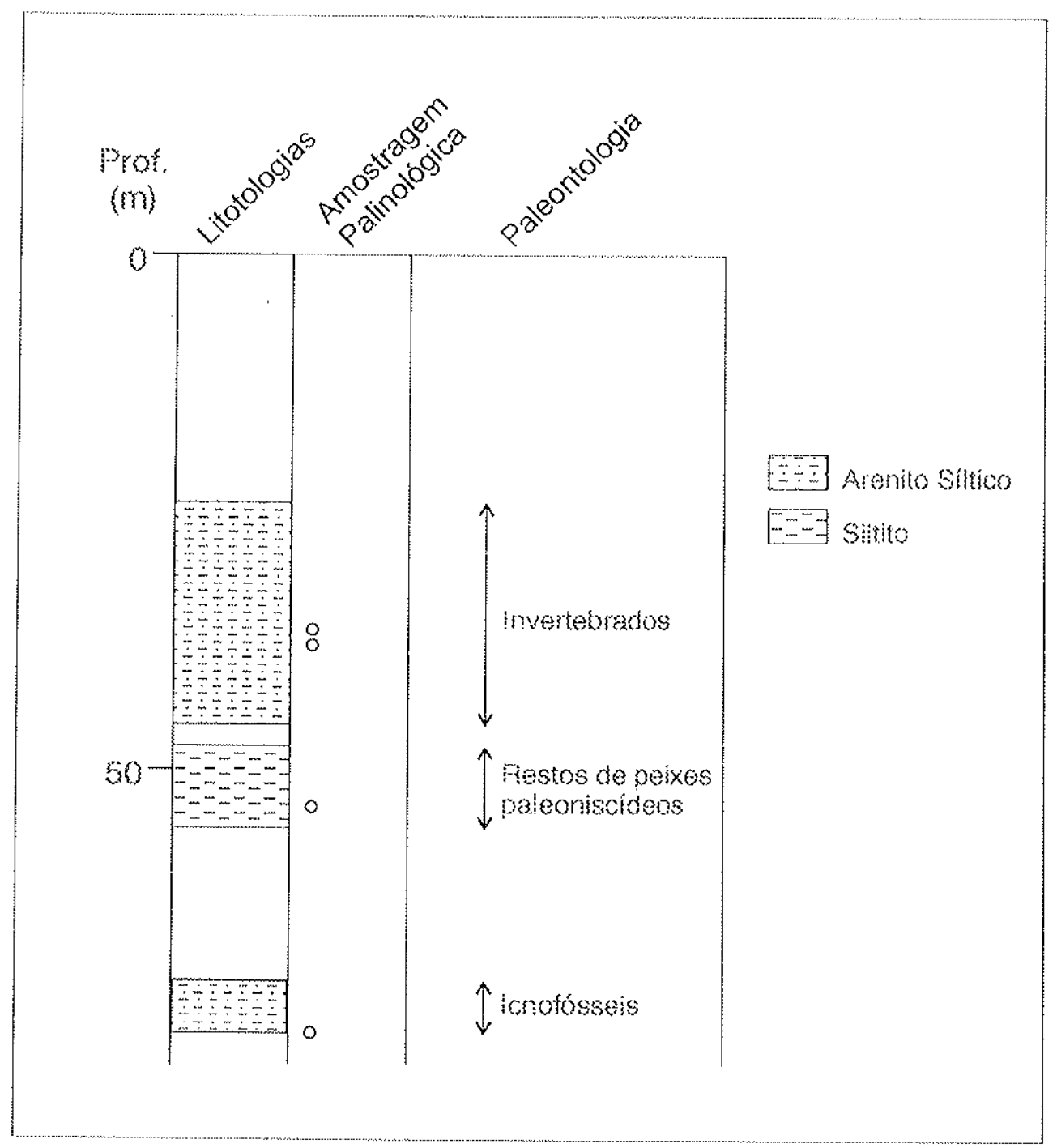

Figura IV.2 - Descriçäo geológica e paleontológica do poço IG-01 (Itaporanga, SP), estratótipo da Zona Biointervalo Potonieisporites neglectus e amostragem palinológica (a partir de Mezzalira, 1956). 


\subsubsection{Zona Biointervalo Vittatina}

A Zona-de-Intervalo Cannanoropollis korbaensis foi proposta para a seção relativa ao Subgrupo Itararé e a Formaçāo Rio Bonito nos estados do Rio Grande do Sul e Santa Catarina (Marques-Toigo, 1988, 1991) e juntamente com a Zona Lueckisporites virkkiae (Formaçāo Palermo e Subgrupo Irati) constituem o único palinobiozoneamento formal para a Bacia do Paraná. Em virtude de ter sido reconhecida no material estudado, pelo menos sua parte inferior, é necessária a discussāo de alguns aspectos relevantes.

Em Milani et al. (1994) e Holz \& Dias (1998) utiliza-se a denominação Zona Vittatina em substituição ao nome Cannanoropollis korbaensis em atenção aos trabalhos de integração desenvolvidos por R.F.Daemon e M. Marques-Toigo, com síntese em Daemon \& MarquesToigo (1991).

Do ponto de vista taxonômico, não é fácil o reconhecimento específico das espécies do gênero Cannanoropollis e sua distinção das espécies do gênero Parasaccites, em virtude das dificuldades de observação da "para-condição", característica do segundo gênero. Trata-se de uma espécie relativamente abundante nas unidades superiores do Grupo Tubarão e rara nas zonas aqui propostas, com grande dificuldade de separação taxonômica.

Segundo Foster (1975, p. 140), a posição da aderência do saccus no corpo central é de difícil determinaçăo e ilustração, o que constituiria em caráter de significado genérico dúbio, tendo sinonimizado ao gênero Cannanoropollis, os gêneros Parasaccites Bharadwaj \& Tiwari, 1964 e Virkkipollenites Lele, 1964. A espécie só seria distinguida das demais espécies do gênero pelo estreita cobertura do saccus (1/4 a $1 / 2$ do radio do corpo central) e pelo seu corpo central bem definido (Foster, op. cit.). Para Azcuy \& Di Pasquo (2000), a espécie é restrita a forma com aderência do saccus simétrica.

Por outro lado, o gênero Vittatina é de fácil reconhecimento taxonômico e tem seu aparecimento muito bem delimitado na Bacia do Paraná, além de estar representado por mais de sete espécies, a partir de seu primeiro aparecimento, horizonte que marca significativa mudança na constituição das associações palinológicas, com o incremento (diversidade e abundância) de grãos de pólen teniados e poliplicados, testemunhando profundas e progressivas transformações de ordem climática refletidas no registro sedimentar.

Por esses motivos e, em consideração às intenções expressadas em Daemon \& Marques-Toigo (1991), como utilizado em Milani et al. (1994), propõe-se aqui a renomeação formal da Zona Cannanoropollis korbaensis para Zona Biointervalo Vittatina, mantendo-se sua caracterização conforme Marques-Toigo (1988, 1991). 


\section{Subzona Protohaploxypinus goraiensis}

A Subzona Protohaploxypinus goraiensis, base da Zona Biointervalo Vittatina, foi reconhecida na porção superior do Subgrupo Itararé na área estudada, em superfície e subsuperfície.

No intervalo estudado, seu limite inferior é marcado pelo desaparecimento de espécies comuns na Zona Biointervalo Potonieisporites neglectus, tais como: Cyclogranisporites firmus, Apiculiretusispora variornata, Apiculatisporis sp., Dibolisporites disfacies, Raistrickia rotunda, Convolutispora muriornata, C. ordoñenzii, Reticulatisporites passaspectus, Dictyotriletes muricatus, Stenozonotriletes clarus, Kraeuselisporites volkheimerii, Velamisporites sp., Florinites sp., Potonieisporites neglectus, P. triangulatus, $P$. barrelis, Divarisaccus stringoplicatus e Crucisaccites monoletus.

$O$ aparecimento de várias espécies dos gêneros Protohaploxypinus ( $P$. goraiensis, $P$. limpidus, $P$. panaki, P. micros), Hamiapollenites $(H$. fusiformis, $H$. tractiferinus), Vittatina ( $V$. wodehousei, V. subsaccata, V. saccata, V. vittifera, V. costabilis) e Complexisporites polymorphus é o caráter mais importante da base da zona. Estas espécies dominam as associações até o topo da seção estudada. O limite superior desta Subzona com a Subzona Caheniasaccites ovatus ( $=C$. flavatus), correspondente à base da Formação Rio Bonito nos estados do Rio Grande do Sul e Santa Catarina, nāo foi verificado no material estudado e é marcado pelo nível de extinção de Protohaploxypinus goraiensis.

Muitas espécies do zoneamento de Marques-Toigo (op. cit.) apresentam distribuição distinta para a porção nordeste da bacia (e.g. Retusotriletes baculiferus, R. golatensis, P. neglectus, Scheuringipollenites maximus, Hamiapollenites tractiferinus, Vittatina costabilis). Algumas dessas espécies ocorrem indiferenciadamente nas Zonas Biointervalo Ahrensisporites cristatus e Potonieisporites neglectus. Como exemplo, pode-se citar a distribuição de $V$. costabilis, que nos estados meridionais da bacia ocorre somente a partir do topo da Formação Rio Bonito; nos estados de São Paulo e Paraná foi verificada desde o topo do Subgrupo Itararé (este trabalho). Essas diferenças são devidas à falta de conhecimento e melhor detalhamento das seções basal e média do Subgrupo Itararé e, provavelmente, ao comportamento ecológico das associaçōes. As espécies mais significativas de reconhecimento da Subzona na seção estudada são: Protohaploxypinus goraiensis, P. limpidus e Complexisporites polymorphus.

A Subzona foi verificada nos afloramentos de Capivari e Serra dos Paes (SP) e no topo das seções levantadas no Estado do Paraná. Em subsuperfície ocorre em todo o poço C-1G-93 e J-IG-93 e no topo dos poços T1-IG-91, 1-SJ-PR, 2-CB-1-SP, 2-TB-1-SP e 2-PN-1-SP.

Neste intervalo estratigráfico ocorre decréscimo acentuado na participação de esporos e grãos de pólen monossacados, com aumento expressivo na participação de grãos de pólen teniados e poliplicados. Algumas espécies desses grupos delimitam, juntamente com a extinção de táxons da Zona subjacente, seu limite inferior. Trata-se do primeiro grande 
intervalo que testemunha o incremento de teniados e poliplicados nas associações, relacionado às melhorias climáticas que afetaram o Eogondwana a partir do limite Carbonífero/Permiano, com correspondência na maioria dos estratos gondwânicos.

A julgar pelos palinofósseis mencionados por Daemon (1974a) e Arai (1980), os níveis contendo invertebrados marinhos de Capivari (SP) podem ser correlacionados a esta Subzona, embora não se disponha de ilustrações e/ou descrições para melhor análise.

Tendo como base novas revisões e análises, os níveis de carvão e litologias associadas do bairro Aliança em Cerquilho (SP) noticiados por Souza et al. (1993c) são correlacionados à Zona, juntamente com a associação descrita por Souza et al. (1999) proveniente de um diamictito da Serra dos Paes, Barão de Antonina (SP).

\section{Subzona Caheniasaccites flavatus}

A Subzona Caheniasaccites ovatus é relativa à porção média da Formação Rio Bonito e não foi detectada nos níveis estudados. Entretanto, como contribuição, propõe-se aqui sua renomeação para Caheniasaccites flavatus em virtude da sinonimização da espécie proposta por Azcuy \& Di Pasquo (2000). Trata-se de uma espécie com distribuição expressiva na Bacia do Paraná e com relativo grau de variedade morfológica, cujas particularidades (e.g. relação das dimensões dos eixos longitudinais e transversais do corpo central) näo justificam separação específica, tendo Azcuy \& Di Pasquo (op. cit.) priorizado o uso de C. flavatus. 


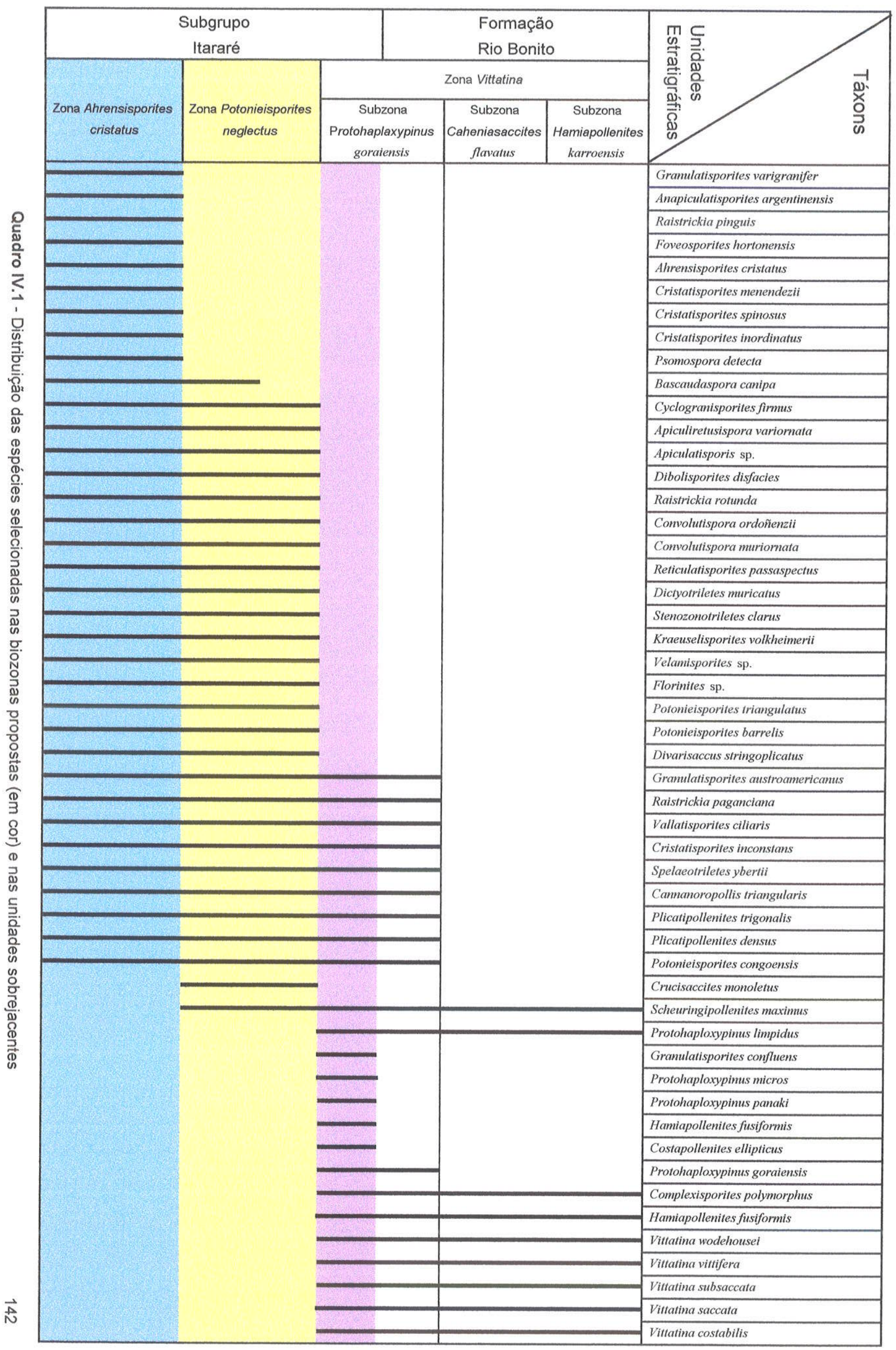




\subsection{DISTRIBUIÇÃO GERAL DAS BIOZONAS}

A distribuição das biozonas propostas em subsuperfície é apresentada nas Figuras IV.3, IV.4 e IV.5, relativas a três seções de correlação dos poços estudados. Entretanto, como a amostragem de subsuperfície não é contínua, muitos dos limites das biozonas são inferidos, levando-se em consideraçāo a proximidade geográfica e a subdivisão litoestratigráfica. Somente no caso dos poços perfurados pelo IG/SMA a amostragem é contínua, permitindo melhor delimitação das biozonas, embora sejam poços relativamente rasos (até $300 \mathrm{~m}$ ).

As informações litoestratigráficas das seções A (Figura IV.3) e B (Figura IV.4) foram extraídas dos perfis dos poços disponíveis (Petrobrás e Paulipetro) e do trabalho de França \& Potter (1988). Para a seção C (Figura. IV.5), as informações são provenientes de Petri et al., (1996).

Uma tentativa de correlação é apresentada, sendo necessárias algumas considerações.

A Zona Biointervalo Ahrensisporites cristatus é verificada na maioria dos níveis basais da Formação Lagoa Azul, assentando-se diretamente sobre o embasamento cristalino précambriano ou sobre a Formação Ponta Grossa (Devoniano). Os níveis do poço 2-PP-1-SP, onde o intervalo $\mathrm{G}$ foram originalmente detectados (Daemon \& Quadros, op cit.), são incluídos nesta Zona.

A Zona Biointervalo Potonieisporites neglectus é mais amplamente distribuída e corresponde aos níveis superiores da Formaçāo Lagoa Azul e grande parte da Formação Campo Mourão.

Já a Subzona Protohaploxypinus goraiensis na maioria das vezes ocorre em intervalo restrito do topo do Subgrupo Itararé, na Formação Taciba, embora também tenha sido verificada na Formação Campo Mourão (poço 2-PP-1-SP).

Não é possível traçar qualquer paralelelismo entre os limites bio e litoestratigráficos, como também constatado em Daemon \& Quadros (1970), o que é reflexo da instabilidade tectônica, com efeito no registro sedimentar.

Com relação à ocorrência das biozonas nos poços perfurados pelo IG/SMA (seção C), a problemática é bem mais acentuada, face da nāo-correlação de muitos poços próximos geograficamente.

Os poços A-IG-85 e IT-IG-85 são os mais afastados de todos, apresentando somente as Zonas Biointervalo Ahrensisporites cristatus e Potonieisporites neglectus, respectivamente. A primeira zona também ocorre no intervalo T-1G-93, o qual, por sua vez, localiza-se muito próximo do poço T1-IG-91, onde ocorrem as zonas Ahrensisporites cristatus e Potonieisporites neglectus.

Nos poços C-IG-93 e J-IG-93 ocorre apenas a Subzona Protohaploxypinus goraiensis, valendo ressaltar que no último poço o Subgrupo Itararé grada para siltitos e arenitos avermelhados da Formação Tatuí, que se mostraram estéreis palinologicamente. 
A irregularidade desse arranjo é principalmente devida ao forte controle tectônico que se impôs na região da Depressão Periférica do Estado de São Paulo, como verificado por vários autores (e.g. Vieira, 1982; Petri et al., 1996). A região apresenta intenso falhamento e movimentação de blocos, colocando lado a lado, seqüências estratigraficamente não correlacionáveis.

Em alguns dos poços, a representação palinológica é bastante escassa, não sendo possível qualquer delimitação palinobioestratigráfica.

No poço 2-LA-1-SP foram constatadas as presenças de Plicatipollenites malabarensis e Potonieisporites brasiliensis a $2634.3 \mathrm{~m}$ de profundidade (lâmina IG-P:224); os níveis de 2317.0 (lâmina IG-P:222) e 2634.1 (lâmina IG-P:223) mostraram-se estéreis.

A espécie Vittatina costabilis foi a única verificada no nível de 877.5 (lâmina IG-P:203) do poço 1-PA-1-SP.

No poço 2-GU-3-SP, dos dois níveis estudados, 605.7 (lâmina IG-P:230) e 908.0m (lâmina IG-P:231), somente no último ocorre a espécie Plicatipollenites gondwanensis.

No poço 2-GU-4-SP, ocorrem as espécies Vallatisporites vallatus e V. ciliaris a $902.5 \mathrm{~m}$ (lâmina IG-P:234); enquanto que no nível de 631.9m (lâmina IG-P:233) só ocorre a última; o nivel a 354.5m (lâmina IG-P:232) mostrou-se estéril.

No nível de $622.6 \mathrm{~m}$ (lâmina IG-P:217) do poço 1-QT-1-PR ocorrem as espécies Punctatisporites gretensis e Chomotriletes cf. C. dejerseyi. 


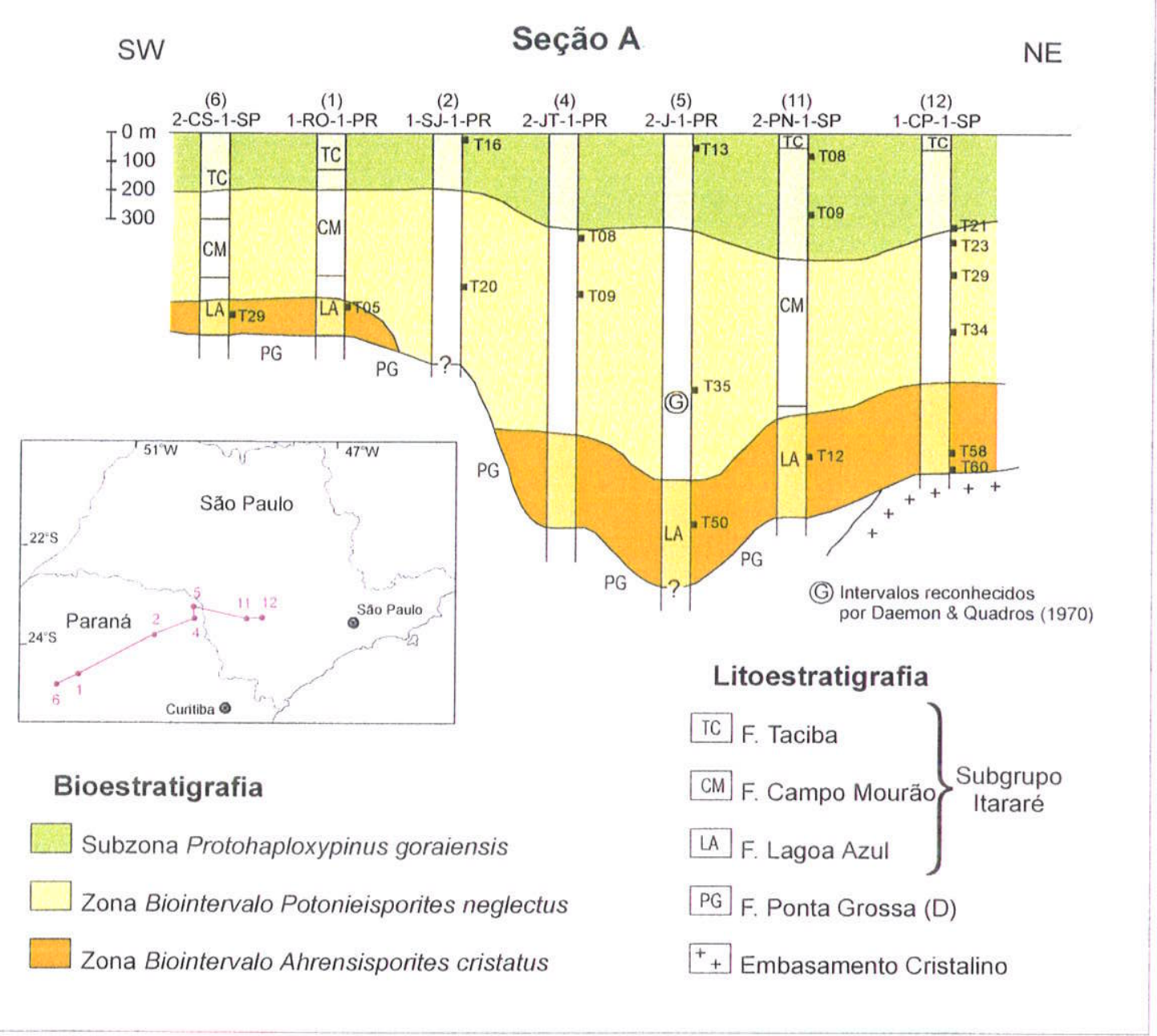

Figura IV. 3 - Seção A: Compartimentação bioestratigráfica proposta para o Subgrupo Itararé dos poços estudados do centro da bacia entre os estados de São Paulo e Paraná (litoestratigrafia conforme França \& Potter, 1988). 


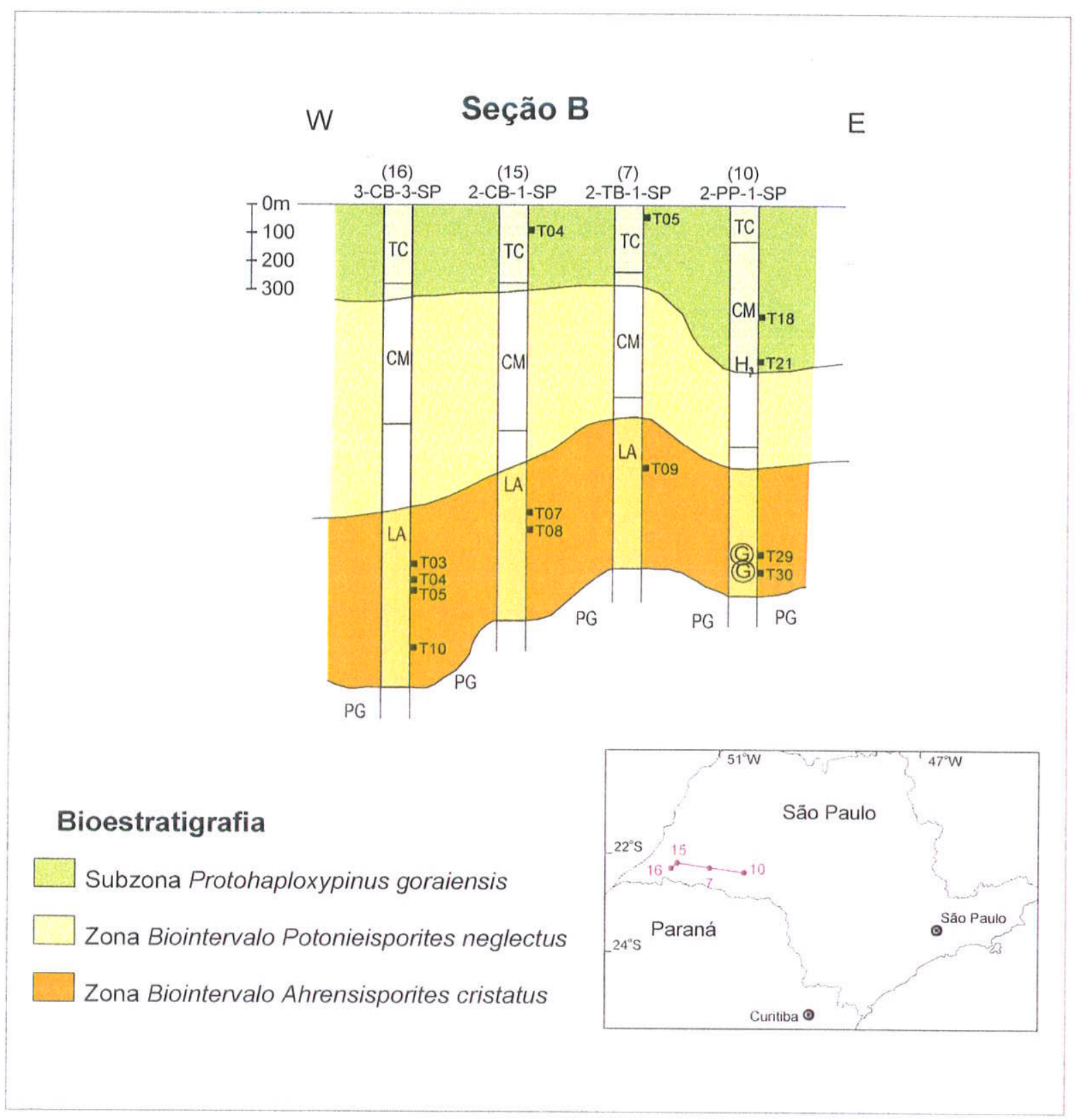

Figura IV.4 - Seção B: Compartimentação bioestratigráfica proposta para o Subgrupo Itararé dos poços estudados do centro da bacia do Estado de São Paulo (litoestratigrafia conforme França \& Potter,1988). 


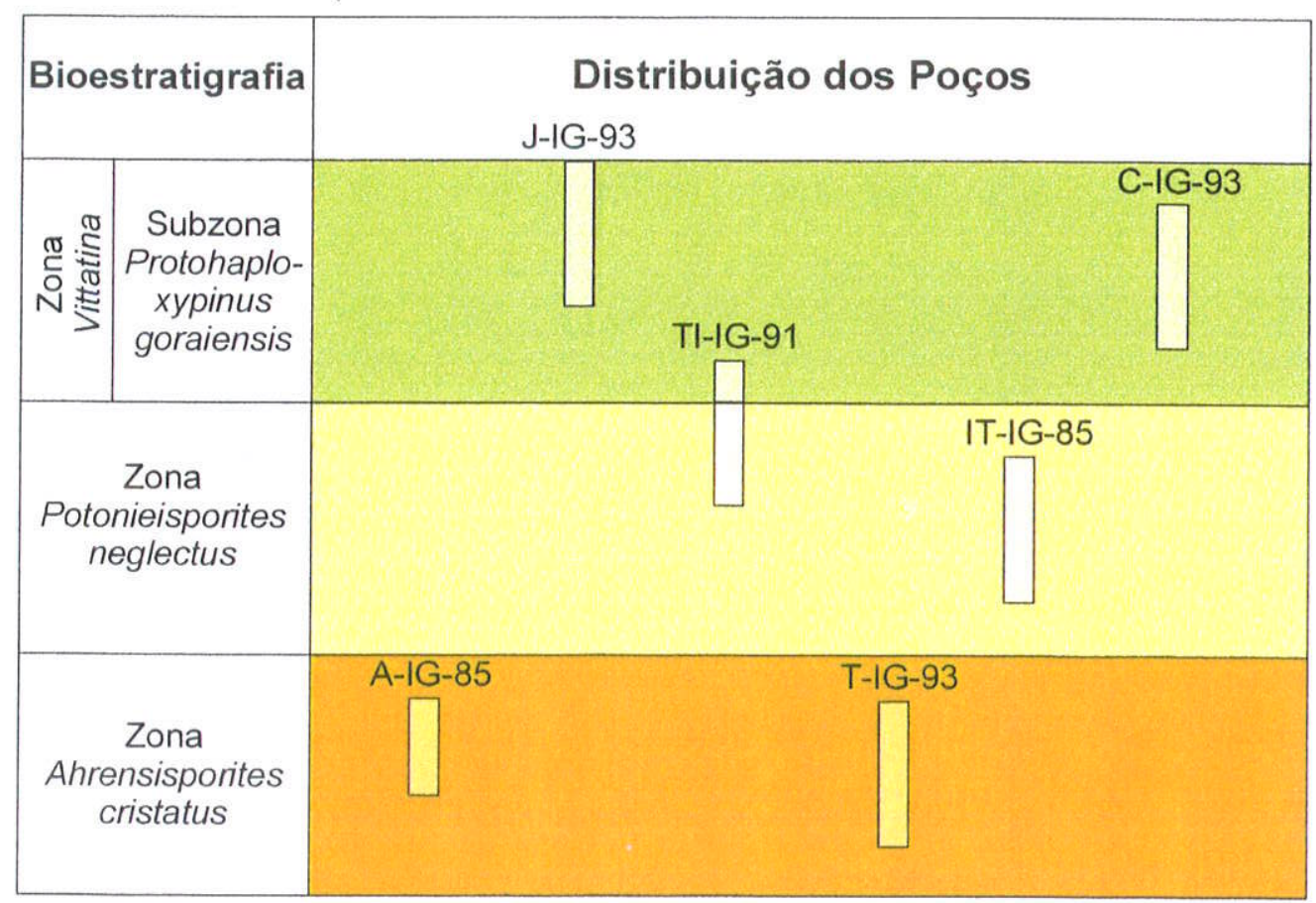

Figura IV.5 - Seçăo C: Compartimentação bioestratigráfica proposta para o Subgrupo Itararé nos poços da região do Médio Tietê (SP), maiores informações sobre a litoestratigrafia na região, ver Petri et al., (1996). 


\section{CORRELAÇÃO BIOESTRATIGRÁFICA}

Nas comparações entre associações fósseis deve ser considerada uma série de aspectos que, em alguns casos, restringem as correlações. O grau de similaridade entre as palinobiozonas gondwânicas diminui quanto maior for a distância entre as áreas comparadas. Além disso, observam-se certas discrepâncias na distribuição de alguns táxons, entre regiōes até não muito afastadas, como constataram Stephenson \& McLean (1999) em associaçōes do sul da África e América do Sul.

Essas diferenças são devidas, principalmente, às rigorosas condições climáticas nas quais as comunidades se desenvolveram, diferentemente do observado nos estratos euroamericanos. Por essa razão, as comparações devem ser feitas com muita cautela, de modo a não se correlacionar paleoambientes cujos registros palinológicos seriam relativamente semelhantes.

Além disso, há que se observar que as floras registraram sensivel diferenciação a partir do Carbonífero tendo, já no Carbonífero Tardio, estabelecido províncias florísticas bem caracterizadas. A Flora da Bacia do Paraná está relacionada à Província Gondwânica, que também apresenta diferenças nas composições de local para local. Horizontes com os mesmos táxons podem refletir idades distintas, uma vez que a flora não se estabeleceu em todos os domínios ao mesmo tempo. Nesse aspecto, o trabaiho de lannuzzi \& Rösler (2000) constitui importante contribuição, relacionando o controle paleoclimático e a posição latitudinal da placa sul-americana na distribuição dos elementos florísticos.

A seguir, serão feitas algumas comparações e correlações bioestratigráficas das biozonas propostas com aquelas mais importantes da América do Sul, outras áreas gondwânicas e do Hemisfério Norte. O destaque é dado aos esquemas do Brasil e das bacias circunvizinhas sulamericanas, que registram associações semelhantes e ocuparam, no Carbonífero Tardio e Permiano Inicial, posições latitudinais não muito distintas.

Para as demais áreas, não é possível realizar melhores correlações, embora apresentem as mesmas "características gerais" das palinofloras da Bacia do Paraná, quais sejam: o domínio de esporos de triletes e grãos de pólen monossacados nas associaçōes carboníferas, com progressivo declínio e substituição por grãos de pólen bissacados e bissacados teniados, os quais, a partir do Permiano Inicial dominam, as associações.

\section{Correspondência na Bacia do Paraná}

Grande parte dos táxons observados no Subgrupo Itararé na área estudada é restrita à porção nordeste da Bacia do Paraná, principalmente com relação aos esporos, como pode ser observado no Quadro 2.27 do Anexo 2, que apresenta a distribuiçăo das 92 espécies de esporomorfos registrados nas várias unidades do Grupo Tubarăo na Bacia do Paraná. Notar 
que, para os estados do Mato Grosso e Mato Grosso do Sul os dados são relativos somente a grãos de pólen, por terem sido extraídos do trabalho de Daemon \& Quadros (1970).

Os palinobiozoneamentos mais importantes da Bacia do Paraná são os propostos por Daemon \& Quadros (1970) e Marques-Toigo (1988, 1991), com status informal e formal, respectivamente. Outros esquemas informais serāo discutidos inicialmente, excluindo-se aqueles relativos ao Intervalo Pré-G (Lima et al., 1983) e Associaçāo Ahrensisporites \& Ancistrospora (Souza et al., 1996), face à sua substituição formal e melhor determinação neste trabalho.

Com o zoneamento proposto por Bharadwaj et al. (1976) as correlações são muito difíceis, uma vez que o material relativo ao Subgrupo Itararé é referente a apenas três amostras e as descrições sistemáticas são insuficientes para comparaçōes mais aprofundadas. As formas em comum são: Plicatipollenites malabarensis ( $P$. indicus) $e$ Caheniasaccites flavatus ( $=C$. ovatus), que ocorrem, indiscriminadamente, no Subgrupo Itararé e Formação Rio Bonito.

Embora não se disponha de descrições, llustrações ou da taxonomia em nível específico, é possível realizar comparação com o esquema proposto por Saad (1977) para o Subgrupo Itararé no Estado de São Paulo. Tendo como base somente os dados quantitativos (Saad, op. cit., p. 65) e a distribuição estratigráfica dos gêneros verificados (p. 66), a Microflora I seria comparável a qualquer uma das duas zonas mais inferiores do Subgrupo thararé propostas, principalmente pela ausência do gênero Vittatina, que ocorre somente a partir da Microflora II. Por este motivo, tanto a Microflora II quanto à Microflora III, estariam mais relacionadas à Subzona Protohaploxypinus goraiensis. Entretanto, faltam elementos de melhor confiabilidade para qualquer correlação.

A "Fase Pré-Striatiti" proposta por Arai (1980) é caracterizada pelo domínio de grãos de pólen monossacados e esporos, com ausência de grãos de pólen teniados em boa parte da seção, embora o autor tenha correlacionado a Fase ao intervalo G (Daemon \& Quadros, op. cit.), onde ocorre o gênero Protohaploxypinus. A "Fase Protohaploxypinus" apresenta as mesmas características quantitativas da Fase anterior, com a ocorrência mais constante do gênero que the nomeia.

Por não se dispor de ilustrações e descrições para comparações e a listagem taxonômica ser em nível genérico, as características gerais apresentadas por Arai (1980) permitem somente uma comparação bastante generalizada dessas duas fases com as duas zonas propostas neste trabalho, visto que, qualitativamente, não há diferenças significativas entre as duas fases.

Por outro lado, a "Fase Vittatina l", caracterizada pela presença do gênero que the nomeia e de outros teniados e pelo equilíbrio entre grăos de pólen e esporos, pode ser correlacionada com a Subzona Protohaploxypinus goraiensis.

Sundaram (1980) fez importantes comentários a respeito dos resultados palinológicos de algumas amostras do Subgrupo Itararé (Buri e Cerquilho) e da Formação Rio Bonito. 
Embora não tenha descrito detalhamente o conteúdo palinológico e referenciado devidamente as localidades e o posicionamento estratigráfico das amostras e o tratamento taxonômico apresentado ter sido em nivel genérico, suspeitou da antigüidade das associaçōes do Subgrupo Itararé (provavelmente de Buri), sem correlação com estratos da Índia ou da África do Sul e com correspondência nas bacias prémpermianas argentinas.

As zonas propostas para o Subgrupo Itararé no Estado de São Paulo por Sundaram (1987), palinozonas A, B e C, foram caracterizadas com base na composição geral das associações (Sundaram, op. cit., p. 58), embora no seu Quadro 5 (p. 52) seja possível identificar um esquema baseado na concorrência de táxons. Os principais esporos que caracterizam a Palinozona A (Cirratriradites saturni, C. megaspinosus, Densosporites annulatus e Laevigatosporites desmoinensis) não são exclusivos, o que demonstra as dificuldades de diferenciação entre as palinozonas propostas pelo autor.

A Palinozona $\mathrm{C}$ é marcada pelo aparecimento de grãos de pólen poliplicados (Vittatina vittifera), teniados (Protohaploxypinus chaloneri, P. jacobii, Striomonossaccites ovatus), praecolpados (Marsupipollenites striatus) e colpados (Cycadopites follicularis), demonstrando sensível diferença composicional, que é refletida também nas análises quantitativas. Essa Palinozona seria, grosso modo, correlacionável à Subzona Protohaploxypinus goraiensis, enquanto que as inferiores, Palinozonas $A$ e B, cuja individualização não foi recomendada pelo próprio autor (Sundaram, op. cit., p. 65), não apresentam correspondência com as duas inferiores propostas do Subgrupo Itararé, embora sejam, litoestratigraficamente, correspondentes ao mesmo intervalo.

Com relação ao trabalho de Daemon \& Quadros (1970), é necessária uma análise particular, dada a sua importância, sendo apresentados alguns problemas sobre a duração de algumas espécies e a delimitação dos intervalos, que justificam as modificações e correlações que seguem.

a) o intervalo $G$ foi constatado no testemunho 36 (T36) do poço 2-J-1-PR (1450m). A amostra do T35 (1410.5m) foi estudada, tendo sido detectada a presença de $C$. janakii (P384), a qual segundo Daemon \& Quadros (op. cit.), se distribuiria somente a partir do Subintervalo $\mathrm{H}_{2}$;

b) as espécies Tasmanites spp. (P524) se distribuem entre os subintervalos $\mathrm{H}_{2} \mathrm{I}_{4}$. Neste trabalho, ocorre desde a base (Itapeva, SP) até a porção média do Subgrupo Itararé (ltaporanga, SP);

c) é muito provável que a espécie $P$. grandis (P431) seja correspondente a $P$. novicus, que se distribui desde a base do Subgrupo Itararé (Araçoiaba da Serra, SP). Os caracteres morfológicos apresentados nas suas ilustrações e descrições não permitem melhor análise. Contudo, o espécime se encaixa na diagnose emendada para a espécie, proposta por Poort \& Veld (1997); se isso for verdadeiro, o biócrono da espécie se estenderia para a base do Subgrupo Itararé (notar que o aparecimento da espécie marcaria a base do subintervalo $\mathrm{H}_{2}$ ); 
d) das três formas restritas ao intervalo $\mathrm{G}$, duas delas, Plicatipollenites trigonalis (P490) e Cannanoropollis triangularis (P501), foram também verificadas no topo do Subgrupo Itararé no Rio Grande do Sul (Dias, 1993);

e) Plicatipollenites gondwanensis (P906), que marcaria a base do subintervalo $\mathrm{I}_{1}$, ocorre desde a base do Subgrupo Itararé (Souza, 1996);

f) grande parte, ou quase todos os grãos de pólen monossacados dos intervalos $\mathrm{G}$ e H se distribuem indiscriminadamente nas seções inferior e média do Subgrupo Itararé, muitos dos quais alcançando o terço superior (subintervalo $\mathrm{H}_{3}-\mathrm{I}$ );

g) o primeiro horizonte bem delimitado do zoneamento, base do intervalo $\mathrm{H}_{3}$, marcado pelo aparecimento de Complexisporites polymorphus e Vittatina vittifera, é também identificado em outros zoneamentos informais da bacia (Saad, 1977; Arai, 1980; Sundaram, 1987), o que demonstra a constância deste limite bioestratigráfico em outras seções do intervalo.

h) outro fator que dificulta a análise satisfatória e uso do zoneamento como proposto é a designaçāo da mesma numeração a formas com características muito distintas, correspondentes, após minuncioso exame, a diferentes táxons. É o caso, por exemplo, das formas P486A e B; a primeira referente a ? Striomonosaccites $\mathrm{sp}$., e a segunda a Protohaploxypinus amplus. Marques-Toigo (1988, p. 201-2) fez consideraçöes semelhantes com respeito às formas $\mathrm{P} 360 \mathrm{~A}, \mathrm{~B}$ e $\mathrm{C}$.

Diante do exposto e com base no reestudo de alguns níveis nos quais os intervalos $G$ e $H$ foram originalmente detectados (poços 2-PP-1-SP e 2-J-1-PR) pelos autores proponentes, propõe-se a reunião do intervalo $\mathrm{G}$ (parte) com os subintervalos $\mathrm{H}_{1}$ e $\mathrm{H}_{2}$, com correspondência com a Zona Biointervalo Potonieisporites neglectus.

Parte do intervalo $G$, notadamente em suas porções basais, é diferenciada e correlacionada à Zona Ahrensisporites cristatus. Embora não seja passível sua citação bibliográfica, pela não disposição das informaçōes básicas (título, autor, ano), à página 12 de um dos relatórios internos da Petrobrás é citado: "É oportuno registrar que no exame da amostragem da base da Formação Itararé, do poço 2-PP-1-SP (Paraguaçú Paulista), foi encontrado material retrabalhado do Devoniano, fato êste verificado em outros poços. Porém, no poço em aprêço, dependendo de um exame mais minuncioso, é possível que sejam identificadas formas de esporos do Carbonifero, mais antigas que as do intervalo G."

Essas evidências foram constatadas na faixa aflorante e em subsuperfície, o que ampara a correlação de parte do intervalo $\mathrm{G}$ com a Zona Ahrensisporites cristatus. A porção superior do intervalo estudado, Subzona Protohaploxypinus goraiensis, é correlacionada com o subintervalo $\mathrm{H}_{3}-1$, pela ocorrência comum de P. goraiensis (forma P391) e Vittatina wodehousei (P386), dentre outras espécies.

Do zoneamento estabelecido por Marques-Toigo $(1988,1991)$ para a seqüência entre o Subgrupo Itararé e o Subgrupo Irati nos estados do Rio Grande do Sul e Santa Catarina, só foi verificada, no material estudado, a subzona mais basal, Subzona Protohaploxypinus goraiensis. 


\section{Correspondência na América do Sul}

As maiores similaridades das biozonas reconhecidas no Subgrupo Itararé são com as das bacias sul-americanas vizinhas, notadamente das bacias de Tarija, Chacoparaná e das unidades do Grupo Paganzo, distribuídas na Argentina, Bolivia, Paraguai e Uruguai. Embora haja também variações na distribuição de alguns táxons, o padrão geral de distribuição é muito semelhante, com muitas espécies em comum. No Quadro IV.2 são apresentadas as ocorrências de 65 espécies comuns nessas localidades.

Da Palinozona de Ancistrospora, estabelecida na base do Grupo Paganzo, Argentina (Azcuy \& Jelin, 1980), caracteristicamente dominada por esporos triletes (95\%), dez espécies de esporos são comuns: G. varigranifer, C. muriornata, R. paganciana, $R$. rotunda, $A$. argentinensis, $F$. hortonensis, $K$. volkheimerii, C.inordinatus e $C$. menendezii. Na palinozona seguinte, de Potonieisporites, ocorre um decréscimo na freqüência de esporos $(73 \%)$, persistência de espécies da Palinozona de Ancistrospora e aparição de $P$. magnus, $P$. malabarensis e do gênero Protohaploxypinus. A Palinozona III apresenta características bastante distintas, com um aumento da freqüência de grãos de pólen teniados e grande participação do gênero Vittatina.

Segundo Césari (1985b), muitas das espécies das duas palinozonas inferiores são comuns em outras unidades do Grupo Paganzo, em associação com elementos típicos da Palizonona de Potonieisporites-Lundbladispora, da Bacia Chacoparaná. Césari (1986) propôs a subdivisão da Zona nas subzonas Raistrickia-Plicatipollenites e Intervalo. Da primeira, dez espécies, de distribuição restrita, são ocorrentes no Subgrupo Itararé: $A$. variornata, $C$. muriornata, $R$. rotunda, $F$. hortonensis, $C$. menendezii, $C$. spinosus, $V$. ciliaris, $C$. monoletus, $P$. malabarensis e $P$. neglectus, além dos gêneros Cycadopites e Striatoabieites. As espécies $P$. gretensis, C. inconstans, C. densus, P. malabarensis, C. flavatus, C. hartungiana, $L$. braziliensis, $S$. ybertii, também comuns no Subgrupo Itararé, ocorrem nas duas subzonas, enquanto que $V$. arcuatus, $P$. densus, $P$. novicus, $H$. uruguaiensis, $G$. austroamericanus e $G$. confluens são restritas à Subzona Intervalo.

Para Azcuy (1986), a Palizonona de Ancistrospora não tem representação na Bacia Chacoparaná e as maiores similaridades da Palinozona Potonieisporites-Lundbladispora são com as Palinozonas de Potoneisporites e III. Por isso, o autor manteve a nomenclatura proposta em Azcuy \& Jelin (1980) e reuniu as três zonas na Superzona Plicatipollenites. 


\begin{tabular}{|c|c|c|c|c|c|c|c|c|c|c|c|c|c|c|c|c|c|c|c|}
\hline Unidades & 1 & 2 & 3 & 4 & 5 & 6 & 7 & 8 & 9 & 10 & 11 & 12 & 13 & 14 & 15 & 16 & 17 & 18 & 19 \\
\hline Leiotriletes virkkii & & & & & & & & & & & & & $x$ & $x$ & & $x$ & $\mathbf{x}$ & $\mathbf{x}$ & \\
\hline Calamospora hartungiana & $\mathbf{x}$ & $x$ & $x$ & $x$ & & $x$ & & & & $\mathbf{x}$ & $x$ & $\mathbf{x}$ & & & & & & & \\
\hline Calamospora liquida & & & & & & & & & & & $x$ & & & $\mathbf{x}$ & & $\mathbf{x}$ & & & \\
\hline Punctatisporites gretensis & $x$ & & $x$ & $x$ & & $x$ & & $\mathbf{x}$ & & $x$ & $x$ & $x$ & $x$ & $x$ & $x$ & $x$ & $x$ & $\mathbf{x}$ & \\
\hline Punctatisporites lucidulus & & $\mathbf{x}$ & & & & & & & & & & & & & & & & & \\
\hline Granulatisporites varigranifer & $x$ & $\mathrm{x}$ & $x$ & & $\mathbf{x}$ & & & $x$ & $\mathbf{x}$ & $x$ & $\mathrm{x}$ & $\mathbf{x}$ & & & & & & $x$ & \\
\hline Granulatisporites austroamericanus & $x$ & & & & & & & $\mathrm{x}$ & & $x$ & $x$ & & $\mathbf{x}$ & $\mathbf{x}$ & & $\mathbf{x}$ & $x$ & $x$ & \\
\hline Granulatisporites confluens & & & & & & & & & & & $x$ & & $\mathrm{x}$ & $\mathbf{x}$ & & $x$ & $\mathbf{x}$ & & \\
\hline Cyclogranisporites firmus & & & & & & & & & & & $x$ & & & & & & & & \\
\hline Apiculiretusispora variornata & $x$ & $\mathbf{x}$ & & $\mathbf{x}$ & & $\mathbf{x}$ & & $x$ & & $x$ & & & & & & & & & \\
\hline Apiculatisporis sp. & & & $x$ & & & $x$ & & & & $x$ & & & & & & & & & \\
\hline Anapiculatisporites argentinensis & $x$ & & & & & & & & $x$ & & $?$ & $?$ & & & & & & & \\
\hline Dibolisporites disfacies & & & & & & & & & & & $x$ & $\mathrm{x}$ & & & & & & & \\
\hline Horriditriletes uruquaiensis & & $\mathrm{x}$ & & & & $x$ & & $x$ & & $x$ & & & $x$ & $\mathbf{x}$ & & $\mathbf{x}$ & $x$ & & \\
\hline Raistrickia paganciana & & & & $x$ & & & & $x$ & $x$ & & $x$ & & & & & & & & \\
\hline Raistrickia rotunda & $\mathbf{x}$ & & & $x$ & & $x$ & & $x$ & $\mathrm{x}$ & $\mathbf{x}$ & $x$ & $\mathbf{x}$ & & & & & & & \\
\hline Convolutispora muriomata & $x$ & $\mathbf{x}$ & $x$ & $x$ & $x$ & $x$ & & $\mathbf{x}$ & & $\mathbf{x}$ & & & & $\mathrm{x}$ & & & & & \\
\hline Convolutispora ordoñenzii & & $\mathbf{x}$ & $x$ & $x$ & & $x$ & & $x$ & $x$ & & $x$ & & & $x$ & $\mathbf{x}$ & & & $\mathbf{x}$ & \\
\hline Foveosporites hortonensis & $x$ & $x$ & $\mathbf{x}$ & $x$ & $x$ & $x$ & & $x$ & & $\mathrm{x}$ & & & $\mathbf{x}$ & & & & & & \\
\hline Ahrensisporites cristatus & $x$ & & $\mathbf{x}$ & $x$ & & $\mathrm{x}$ & & $x$ & & $x$ & & $\mathbf{x}$ & & & & & & & \\
\hline Reticulatisporites pseudopalliatus & & & & & & & & & & & & & $x$ & $x$ & & & & & \\
\hline Reticulatisporites passaspectus & & & & $\mathrm{x}$ & & $x$ & & & & & $x$ & & & & & & & & \\
\hline Lundbladispora braziliensis & $x$ & $x$ & $x$ & $x$ & & $x$ & & $x$ & & & $x$ & $x$ & $x$ & $x$ & $x$ & $\mathrm{x}$ & $x$ & $x$ & \\
\hline Lundbladispora riobonitensis & & & & $x$ & & $x$ & & $x$ & & $x$ & $x$ & $x$ & $x$ & $x$ & & $\mathbf{x}$ & $x$ & $\mathbf{x}$ & \\
\hline Densosporites stellatus & & $x$ & & & $x$ & & & & & & $x$ & $\mathbf{x}$ & & & & & & & \\
\hline Kraeuselisporites volkheimerii & $x$ & & $x$ & & & & & $\mathbf{x}$ & & & $x$ & $x$ & & & & & & & \\
\hline Vallatisporites vallatus & & & & & & & & & & & $x$ & $x$ & & & & & & & \\
\hline Vallatisporites ciliaris & $x$ & & & $\mathrm{x}$ & $x$ & & & & & $x$ & $x$ & $x$ & $x$ & & & & $\mathbf{x}$ & $x$ & \\
\hline Vallatisporites arcuatus & & & & $x$ & & $\mathbf{x}$ & & $x$ & & $x$ & $x$ & $x$ & $x$ & $\mathbf{x}$ & & $\mathbf{x}$ & $\mathrm{x}$ & $\mathbf{x}$ & \\
\hline Cristatisporites menendezii & $x$ & $x$ & & $x$ & $x$ & & & $\mathbf{x}$ & $x$ & $x$ & $x$ & $x$ & $\mathrm{x}$ & & & & & & \\
\hline Cristatisporites spinosus & & & & $x$ & & $\mathrm{x}$ & & & & & $x$ & $x$ & $x$ & & & & & & \\
\hline Cristatisporites inordinatus & & $x$ & & & $x$ & & & & $x$ & & $x$ & $\mathrm{x}$ & & & & & & & \\
\hline Cristatisporites inconstans & $x$ & & & $\mathbf{x}$ & & $\mathbf{x}$ & & $x$ & & & $x$ & $x$ & $x$ & $\mathbf{x}$ & & $x$ & $x$ & $x$ & \\
\hline Spelaeotriletes ybertii & $x$ & $x$ & $x$ & $x$ & & $x$ & & $\mathbf{x}$ & & $\mathbf{x}$ & $x$ & $x$ & $x$ & $x$ & & & & & \\
\hline Psomospora detecta & & & & & $x$ & & & & & & & & & & & & & & \\
\hline Cannanoropollis janakii & $\mathbf{x}$ & & & & & $\mathbf{x}$ & & $x$ & & & $x$ & $\mathbf{x}$ & & & & & & $x$ & \\
\hline Cannanoropollis triangularis & $\mathbf{x}$ & & & & & & & & & & $x$ & $x$ & & & & & & & \\
\hline Cannanoropollis densus & $x$ & & & $x$ & & $x$ & $x$ & $x$ & & $x$ & $x$ & $x$ & $\mathbf{x}$ & $\mathbf{x}$ & & $\mathrm{x}$ & $x$ & $x$ & \\
\hline Plicatipollenites malabarensis & $x$ & & & $x$ & & $\mathrm{x}$ & $x$ & $x$ & $x$ & $x$ & $x$ & $x$ & $\mathrm{x}$ & $\mathrm{x}$ & $\mathbf{x}$ & $\mathrm{x}$ & $\mathbf{x}$ & $x$ & \\
\hline Plicatipollenites gondwanensis & $x$ & & & $x$ & & $x$ & & $x$ & & $x$ & $x$ & $x$ & & & & & & $\mathrm{x}$ & \\
\hline Plicatipollenites trigonalis & $x$ & & & $x$ & & & & & & $x$ & $x$ & $x$ & $x$ & $x$ & & & & & $x$ \\
\hline Plicatipollenites densus & & & & $x$ & & & $x$ & & & $x$ & & & $x$ & $\mathbf{x}$ & $x$ & $\mathbf{x}$ & $\mathrm{x}$ & & \\
\hline Crucisaccites latisulcatus & $x$ & & $x$ & & & $\mathrm{x}$ & & & & & $x$ & $\mathbf{x}$ & & & & & & & \\
\hline Crucisaccites monoletus & $x$ & & & $\mathbf{x}$ & & $x$ & & $x$ & & $x$ & $x$ & & & & & & & & \\
\hline Potonieisporites novicus & $x$ & & & $\mathbf{x}$ & & $x$ & & $x$ & & $x$ & $x$ & $\mathbf{x}$ & $x$ & $\mathbf{x}$ & & & & $x$ & $x$ \\
\hline Potonieisporites neglectus & $x$ & & & $\mathbf{x}$ & & $x$ & & $x$ & & $x$ & $x$ & $x$ & & $\mathbf{x}$ & & & & & $\mathrm{x}$ \\
\hline Potonieisporites triangulatus & $x$ & & & & & $x$ & & & & & $x$ & $x$ & & & & & & & $\mathbf{x}$ \\
\hline Potonieisporites barrelis & $x$ & & & & & & & & & & $x$ & $x$ & & & & & & $x$ & \\
\hline Potonieisporites densus & $x$ & & & & & & & & & $x$ & $x$ & $\mathrm{x}$ & & & & & & & \\
\hline Potonieisporites congoensis & $\mathrm{x}$ & & & & & & & & & & $x$ & $x$ & & & & & & & \\
\hline Potonieisporites brasiliensis & $x$ & & & & & $\mathrm{x}$ & $\mathbf{x}$ & $\mathbf{x}$ & & $x$ & $x$ & $x$ & $x$ & $x$ & & $x$ & & & \\
\hline Potonieisporites magnus & $\mathbf{x}$ & & & & & $\mathrm{x}$ & & $x$ & $x$ & $x$ & $x$ & $x$ & $x$ & $x$ & & & & & \\
\hline Divarisaccus stringoplicatus & & & & $x$ & & $x$ & & & & & $x$ & $x$ & & & & & & & \\
\hline Caheniasaccites flavatus & $x$ & & & $x$ & & $\mathbf{x}$ & $x$ & $x$ & $x$ & $x$ & $x$ & $x$ & $x$ & $x$ & & $\mathrm{x}$ & $x$ & & \\
\hline ? Stromonosaccites sp. & & & & & & $?$ & & $?$ & & $?$ & $?$ & $?$ & & & & & & & \\
\hline Limitisporites rectus & $x$ & & & & & & & & & $\mathbf{x}$ & & & & $\mathrm{x}$ & $\mathrm{x}$ & $x$ & & & $\mathbf{x}$ \\
\hline Protohaploxypinus amplus & $x$ & & & & & & & & & & & & $\mathbf{x}$ & $\mathrm{x}$ & & & & $\mathbf{x}$ & \\
\hline Protohaploxypinus micros & & & & & & & & & & & & & $x$ & $x$ & $x$ & & & & \\
\hline Protohaploxypinus goraiensis & & & & & & & & & & & & & & & & & & $x$ & \\
\hline Hamiapollenites fusiformis & & & & & & & & & & $x$ & & & $x$ & $x$ & $x$ & $x$ & $\mathbf{x}$ & & \\
\hline Vittatina subsaccata & & & & & & & & & & & & & $x$ & $\mathrm{x}$ & $x$ & $x$ & & $x$ & \\
\hline Vittatina vittifera & & & & & & & & & & & & & & & & $x$ & $x$ & & \\
\hline Vittatina costabilis & & & & & & & & & & & & & & $x$ & & & & $x$ & \\
\hline Vittatina saccata & & & & & & & & & & & & & & $x$ & & $x$ & & $x$ & \\
\hline Vittatina wodehousei & & & & & & & & & & & & & & & & $x$ & $x$ & & \\
\hline
\end{tabular}

Quadro IV.2 - Ocorrência das espécies verificadas no Subgrupo Itararé em algumas bacias circunvizinhas sul-americanas*. 
Muitas das espécies restritas às unidades propostas tanto por Azcuy \& Jelin (1980) quanto por Césari (1986) estão distribuídas, indiferenciadamente, em ambas as novas zonas propostas para o Subgrupo Itararé (e.g. H. uruguaiensis, R. rotunda, V. arcuatus, V. ciliaris, $K$. volkheimerii, $C$. monoletus, $P$. novicus, $P$. magnus, $P$. densus, $P$. malabarensis e $P$. amplus). Somente as espécies $C$. inordinatus, $C$. menendezii, $G$. varigranifer, $A$. variornata, $F$. hortonensis e A. argentinensis são restritas à Zona Ahrensisporites cristatus. Por compartilharem esses elementos comuns, de ambas zonas do Grupo Paganzo, é mais prudente efetuar correlação das Zonas Biointervalo Ahrensisporites cristatus e Potonieisporites neglectus, de forma geral, com a Superzona Plicatipollenites (sensu Azcuy, 1986), com maior correspondência, tanto qualitativa quanto quantitativa, com a Subzona RaistrickiaPlicatipollenites (Césari, 1986), embora localmente haja melhores correlações com a Palinozona de Ancistrospora. A Palinozona III mostra maiores similaridades com a Subzona Protohaploxypinus goraiensis, pela participação mais efetiva de grãos de pólen teniados e aparição do gênero Vittatina.

\footnotetext{
* Argentina - Grupo Paganzo: 1. Formação Água Colorada (Carbonífero Tardio) (Menéndez, 1965; Azcuy et al., 1982; Césari \& Gutiérrez, 1986; Gutiérrez, 1988; Limarino \& Gutiérrez, 1990; Vergel \& Luna, 1992; Gutiérrez, 1993; Vergel et al., 1993); 2. Formação Lagares (Carbonifero Tardio) (Menéndez \& Azcuy, 1969, 1971, 1972, 1973; Azcuy, 1975ab; Césari \& Gutiérrez, 1984; Ottone \& Azcuy, 1986; Gutiérrez \& Césari, 1988); 3. Formação Jejenes (Carbonífero Tardio) (González-Amicón, 1973; Césari \& Gutiérrez, 1986; Césari \& Bercowski, 1997); 4. Formação Tupé (Neocarbonífero) (Césari, 1984, 1985a; Césari \& Gutiérrez, 1986; Ottone \& Azcuy, 1986, 1990; Archangelsky \& Césari, 1990; Ottone, 1991); 5. Formação Malazán (Carbonífero Tardio) (Azcuy, 1975ab); 6. Formação Guadancol (Carbonífero Tardio) (Ottone \& Azcuy, 1986; Vásquez-Nístico \& Césari, 1987; Césari \& Vásquez-Nístico, 1988; Ottone \& Azcuy, 1989; Ottone, 1991); 7. Formação Trampeadero (Carbonífero Tardio) (Barreda, 1986); 8. Formação Santa Máxima (Carbonífero Tardio/Permiano Inicial) (Ottone, 1989); 9. Estratos de Mascasín (Carbonífero Tardio) (Azcuy \& Jelin, 1980).

Argentina - Bacia San Rafael: 10. Formação El Imperial (Carbonífero Tardio a Permiano Inicial) (Azcuy \& Gutiérrez, 1985; Garcia \& Azcuy, 1987; Garcia, 1995, 1996).
}

Argentina - Bacia Tarija: 11. Grupo Madiyuti e 11. Machareti (Carbonífero Tardio) (Azcuy \& Laffitte, 1981; Di Pasquo \& Azcuy, 1997a, 1999a; Di Pasquo, 1999; Azcuy \& Di Pasquo, 2000).

Argentina - Bacia Chacoparaná: 13. Zona Potonieisporites-Lundbladispora (Stephaniano); 14. Zona Cristatisporites (Permiano Inicial); 15. Zona Striatites (Permiano Médio/Final) (Archangelsky \& Gamerro, 1979; Césari, 1986; Aceñolaza \& Vergel, 1987; Vergel, 1987ab; Césari et al, 1995; Vergel, 1998).

Uruguai - Bacia Chacoparaná: 16. Formação San Gregório (Permiano Inicial) (Marques-Toigo, 1973, 1974; Santa Ana et al., 1993; Beri \& Aguilar, 1998); 17. Formação Tres Islas (Permiano Inicial) (Beri, 1987, 1988; Fasolo \& Vergel, 1994); 18. Formaçäo Melo (Permiano Inicial/Médio) (Mautino et al., 1998ab).

Bolívia: 19. Grupo Copacabana (Carbonífero Tardio a Permiano inicial) (Ottone et al., 1998). 
Para a Bacia Chacoparaná, Vergel (1993) aperfeiçoou o zoneamento proposto por Russo et al. (1980), tendo redefinido as zonas Potonieisporites-Lundbladispora e Cristatisporites, esta última dividida em três subzonas (inferior, média e superior). A Zona Potonieisporites-Lundbladispora também apresenta grandes similaridades com as duas unidades basais do Subgrupo Itararé, seja pelo aspecto quantitativo (domínio de esporos triletes, grãos de pólen monossacados, ausência/presença esporádica de grãos de pólen teniados), ou pelo aspecto qualitativo. Dentre as espécies comuns com as Zonas Biointervalo Ahrensisporites cristatus e Potonieisporites neglectus, destacam-se: P. gretensis, $C$. menendezii, $C$. inconstans, $L$. braziliensis, $V$. arcuatus, $V$. ciliaris, $P$. novicus, $P$. neglectus, $P$. malabarensis, $C$. densus e $C$. flavatus).

Entretanto, alguns dos raros grãos de pólen teniados e poliplicados mencionados pela autora na Zona Potonieisporites-Lundbladispora, tais como P. limpidus, P. micros, $V$. subsaccata e Hamiapollenites fusiformis só são registradas na Bacia do Paraná a partir da Subzona Protohaploxypinus goraiensis. A expressiva mudança florística registrada nesta Subzona foi também constatada na Zona Cristatisporites. Por outro lado, algumas das espécies que marcam a base da Subzona Cristatisporites inferior já ocorrem, na Bacia do Paraná, desde as duas unidades inferiores do Subgrupo Itararé (C. liquida, L. braziliensis, $C$. muriornata). Embora o ajuste não seja também rigorosamente perfeito, sugere-se aqui a comparação da Subzona Protohaploxypinus goraiensis com a Subzona Cristatisporites inferior. A Zona Potonieisporites neglectus pode ser correlacionada, pelo menos parcialmente, à Zona Potonieisporites-Ludbladispora.

Com relação à Bacia de Tarija, o trabatho de Di Pasquo (1999) reúne e amplia o seu conhecimento palinológico, com 46 espécies de esporomorfos comuns no Subgrupo Itararé, 25 de esporos e 21 de grāos de pólen. A Superzona Kraeuselisporites volkheimerii Circumplicatipollis plicatus foi proposta para os grupos Macharetí e Mandiyutí no norte da Argentina e sul da Bolívia, sendo dividida em cinco zonas-de-intervalo, da mais primitiva para a mais jovem: Palinozonas (1) Cystoptychus azcuyi-Apiculiretusispora ottonei, (2) Raistrickia radiosa-Apiculatasporites spinulistriatus, (3) Dictyotriletes bireticulatus-Cristatisporites chacoparanensis, (4) Cyclogranisporites microgranulatus-Reticulatisporites reticulatus e (5) Marsupipollenites triradiatus-Lundbladispora braziliensis.

As espécies comuns do Subgrupo Itararé são aquelas ocorrentes na zona 1 (Striomonosaccites sp. 1), 2 (A. cristatus), entre as zonas 1 e 4 (C. menendezii, $K$. volkheimerii, $V$. vallatus), zonas 2 e 4 (C. inordinatus, R. rotunda, G. varigranifer), 2 e 5 (C. inconstans, $L$. ribonitensis, $V$. arcuatus, $C$. spinosus, $P$. gretensis, $A$. argentinensis, D. stringoplicatus), $3(C$. latisulcatus), 3 e 4 (S. ybertii), 3 e 5 (D. disfacies, V. ciliaris, P. gondwanensis), 4 (G. confluens, $C$. firmus, Striomonosaccites sp. 2), 4 e 5 (R. passaspectus, $C$. ordonienzii, $R$. paganciana, $C$. liquida, $L$. braziliensis, $L$. riobonitensis), 1 e 5 (C. hartungiana, $D$. stellatus, $P$. trigonalis, $P$. malabarensis, $P$. magnus, $P$. novicus, $P$. neglectus, $P$. brasiliensis, $P$. barrelis, $P$. congoensis, 
P. triangulatus, C. janakii, C. triangularis, C. densus, C. flavatus) e 5 (L. cf. L. rectus, C. monoletus).

Como também verificado nos zoneamento comparados anteriormente, há algumas divergências. Contudo, pelo menos $50 \%$ (46) dos esporomorfos verificados no Subgrupo Itararé (total de 92) ocorrem nas cinco zonas estabelecidas na Bacia de Tarija. A Subzona Protohaploxypinus goraiensis não tem correspondência na Bacia de Tarija. A maioria dos grãos de pólen ocorre em todas as zonas, não fornecendo base para melhores correlações. Entretanto, as associaçōes de esporos sugerem correlação entre as zonas 2 e 5 , como propusera Di Pasquo (op. cit.) para os intervalos Pré-G e $\mathrm{G}+\mathrm{H}_{1}$ na Bacia do Paraná (ver seu Quadro 7.8).

O Quadro IV.3 ilustra as correlaçốes das biozonas verificadas no Subgrupo Itararé, incluindo as propostas neste trabalho, com os principais zoneamentos da Bacia do Paraná e de outras bacias gondwânicas sul-americanas, com os quais as similaridades são bem mais acentuadas. 

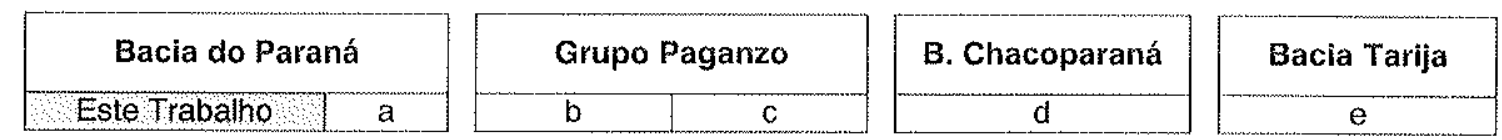

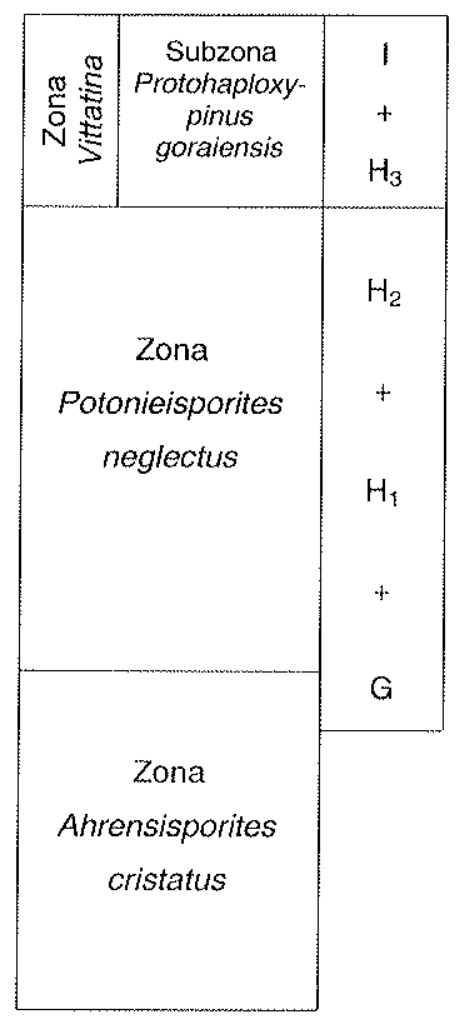
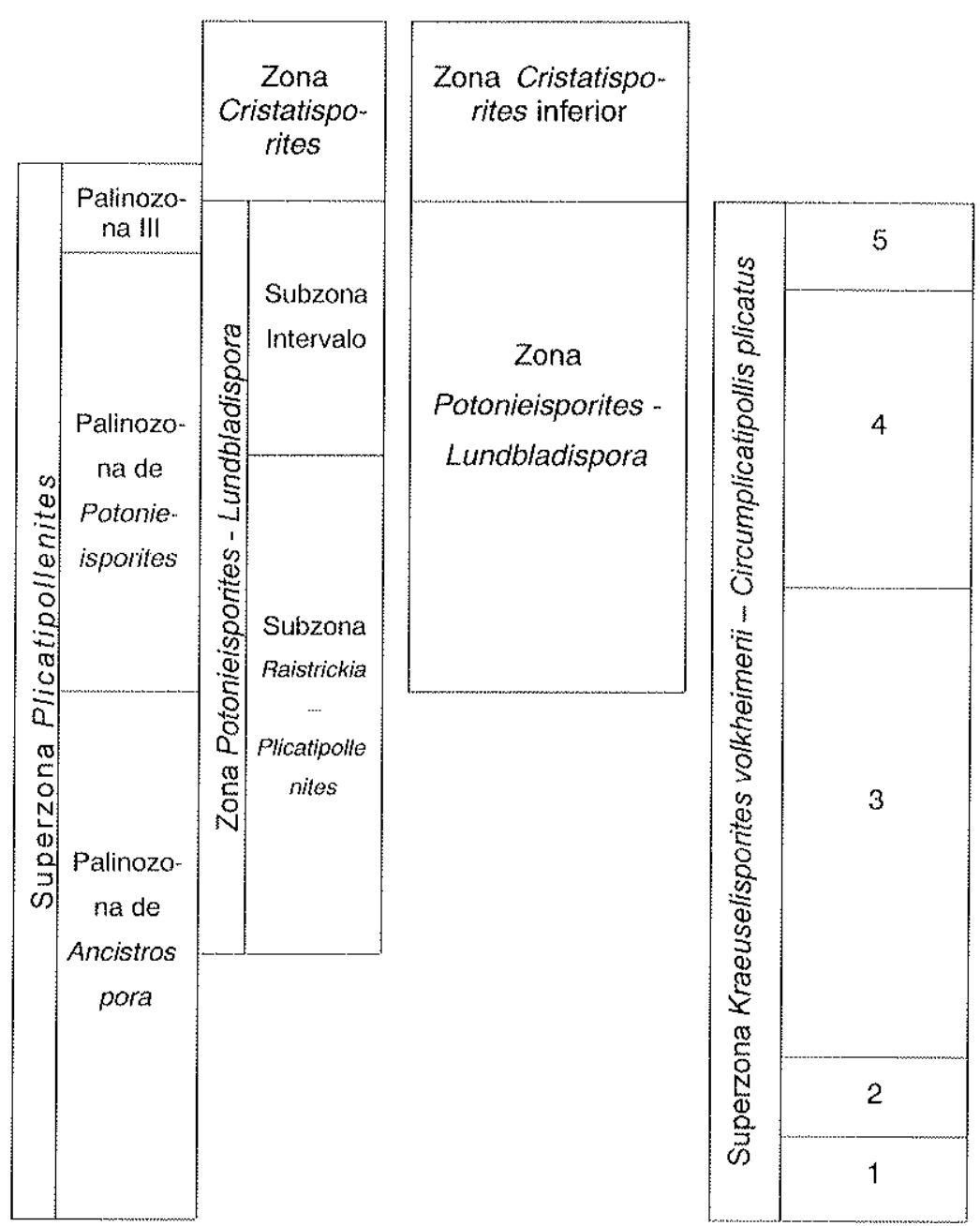

a: conforme Daemon \& Quadros (1970); b: Azcuy \& Jelin (1980) e Azcuy (1986); c: Césari (1986); d) Russo et al. (1980) e Vergel (1993); e) Di Pasquo (1999). (1) Zona C. azcuy-A.ottonei; (2) R. radiosaA. spinulistratus; (3) D. bireticulatus $C$. chacoparanensis; (4) C. microgranulatus $R$. reticulatus; (5) $M$. triradiatus- $L$. braziliensis.

Quadro IV.3 -.. Correlação do palinobiozoneamento do Subgrupo Itararé com os principais esquemas da Bacia do Paraná e das bacias gondwânicas suli-americanas. 


\section{Correspondência em Outras Áreas Gondwânicas}

\section{Austrália}

Das palinozonas estabelecidas para o Eogondwana australiano, merecem destaque os trabalhos clássicos de Evans (1969) e Kemp et al. (1977), referentes, respectivamente, à porção leste e oeste daquele país. Entretanto, seu grau de similaridade com as biozonas do Subgrupo Itararé não é expressivo, ainda que as características gerais e muitas espécies sejam comuns.

Da seqüência pré-glacial australiana (Kemp et al., op. cit.), as espécies comuns são: $R$. pinguis, da Microflora Granulatisporites frustulentus, Assembléia Apiculatisporites largus. Da Microflora Secarisporites, compartilha $S$. ybertii, presente nas assembléias Grandispora maculosa e Anabaculites ybertii. A Assembléia Potonieisporites, mais jovem desta última Microflora e equivalente ao "Stage" 1 de Evans (op. cit.) ou "Unit" 1 de Kemp et al. (op. cit.) é caracterizada pela abundância e diversificação de grãos de pólen monossacados de simetria radial e bilateral, feição comum nas associações carboniferas em todo o mundo, como também ocorre na Bacia do Paraná. O "Stage" 2, correspondente à base da "Unit" II, ainda apresenta o domínio de grãos de pólen monossacados, esporos e com presença rara de grãos de pólen teniados. A partir do "Stage" 3, ocorrem significativas mudanças nas composições, com a participação mais efetiva de grãos de pólen teniados, ainda que não dominantes, e com a persistência de muitas das espécies de esporos e grãos de pólen das unidades subjacentes.

A Zona Pseudoreticulatispora confluens (sensu Foster \& Waterhouse, 1988), estabelecida no oeste australiano, equivalente ao "Stage" 2 , é a que mais se assemelha à Subzona Protohaploxypinus goraiensis, embora muitas espécies sejam comuns nas zonas subjacentes, como também verificado na Bacia de Canning, onde a zona fôra proposta. Dentre as espécies comuns, destacam-se: $P$. gretensis, $R$. nigritellus, $G$. confluens, $P$. detecta, $C$. janakii, $P$. malabarensis, $P$. densus, $C$. flavatus, $L$. rectus, $P$. amplus e $P$. limpidus. É importante notar que a Zona é posicionada no Asseliano, com base na associação de fauna marinha (braquiópodes e bivalves), presente nos sedimentos glacígenos.

Foster \& Waterhouse (op. cit.) observam também que grãos de pólen teniados são verificados já a partir da Assembléia Spelaeotriletes ybertii, base da seqüência glacial australiana, o que invalidaria o critério de reconhecimento do "Stage" 2 somente pela introdução destes elementos.

Backhouse (1991) identificou profunda mudança florística na Bacia de Collie, reconhecendo a Zona Pseudoreticulatispora confluens, com formas comuns do Subgrupo Itararé ( $P$. amplus e $P$. limpidus), além de feições similares (abundância de grãos de pólen monossacados radiais e persistência de esporos das zonas inferiores) das unidades do Subgrupo Itararé. A duração de muitas espécies de esporos e grãos de pólen comuns nas associaçōes carboníferas também é atestada no trabalho de Foster (1979), a partir do registro de $P$. gretensis, $R$. nigritellus, $C$. janakii, $P$. malabarensis, $P$. gondwanensis, $P$. densus, $C$. 
monoletus, S. maximus, P. amplus e P. limipidus na "Blair Athol Coal Measures", unidade da base do Permiano, em Queensland, com grande similaridade com a Subzona Protohaploxypinus goraiensis.

$\mathrm{Na}$ Superzona Spelaeotriletes queenslandensis da Bacia de Galilee, leste da Austrália (Jones \& Truswell, 1992) é relativamente maior o número de espécies comuns ao Subgrupo Itararé. Da zona mais inferior para a superior, a Zona Verrucosisporites basiliscutis compartilha $P$. gretensis, $P$. lucidulus, $C$. firmus, $C$. janakii e $P$. novicus como espécies comuns. Da Zona Brevitriletes leptoacaina: $P$. gretensis, $P$. lucidulus, D. disfacies, A cristatus, $P$. detecta, $C$. firmus, $C$. janakii, $P$. novicus, $P$. densus e (?) Striomonosaccites sp. Das zonas Diatomozonotriles birkheadensis e Asperispora reticulatispinosus, as espécies comuns são: $P$. gretensis, P. lucidulus, C. firmus, A. cristatus, D. disfacies, P. detecta, C. janakii, Plicatipollenites densus, P. gondwanensis, P. novicus e (?) P. cf. P. goraiensis. Essas mesmas espécies e ainda $R$. nigritellus são as comuns na zona mais superior, Microbaculispora tentula.

Embora muitas espécies sejam comuns, não é possível correlação mais detalhada de quaisquer das zonas citadas da Austrália com as zonas mais inferiores do Subgrupo Itararé. Por outro lado, observam-se as mesmas características quantitativas e o grau de persistência de algumas espécies dos "Stages" 1 e 2 e da Superzona Spelaeotriletes queenslandensis. A Zona Pseudoreticulatispora confluens é a que melhor poderia corresponder à Subzona Protohaploxypinus goraiensis, dada a ocorrência da espécie que the define (=Granulatisporites confluens), ocorrente somente na porção superior do Subgrupo Itararé, e pela associação de P. goraiensis e $P$. limpidus.

\section{Antártica}

Kyle \& Schopf (1982) estabeleceram a Zona Parasaccites no "Tilito Darwin" nas Montanhas Transantárcticas, que é caracterizada pela abundância de grãos de pólen monossacados (Plicatipollenites e Cannanoropollis), raridade de grăos de pólen bissacados e variedade de esporos triletes. Na seqüência superior da "Weller Coal Measures" ocorre a Zona Protohaploxypinus, marcada pela abundância de grãos de pólen bissacados, dos quais mais da metade é relativa aos gêneros Protohaploxypinus e Striatopodocarpites, além da presença de grãos de pólen praecolpados (Marsupipollenites) e da baixa abundância de grãos de pólen monossacados. A primeira zona apresenta caraterísticas comuns com as duas inferiores da Bacia do Paraná. No entanto, alí os grãos de pólen teniados são ausentes, os quais ocorrem de forma rara nas associações brasileiras. Já a segunda zona citada apresenta similaridade com as subzonas mais superiores da Zona Vittatina, face à distribuição quantitativa e variedade de grãos de pólen teniados.

Lindström (1995) reconheceu a Zona Pseudoreticulatispora confluens na Antártica, cujas formas comuns com a Bacia do Paraná seriam: $L$. virkkii, $P$. gretensis, $P$. lucidulus, $R$. nigritellus, $P$. confluens (=Granulatisporites confluens), P. detecta, C. ovatus ( $=C$. flavatus), $C$. janakii, Plicatipollenites densus, P. malabarensis, P. novicus, L. rectus, S. maximus, $P$. amplus, 
P. goraiensis e P. limpidus, demonstrando alto grau de similaridade com a Subzona Protohaploxypinus goraiensis, ainda que a maioria esteja presente desde as unidades subjacentes.

india

O esquema geral apresentado por Venkatachala et al. (1995) sintetiza a sucessão palinológica nos referidos "estágios" Talchir, Karharbari, Barakar, Barren Measures e Raninganj. Verifica-se sucessivo declínio da freqüência dos esporos e grãos de pólen monossacados, que dominam no "Estágio" Talchir. A partir dos "estágios" subseqüentes, grãos de pólen bissacados teniados e não-teniados passam a dominar (Srivastava, 1980), embora já estivessem presentes desde o "Estágio" Talchir. Essas características refletem, de modo geral, as profundas mudanças climáticas que afetaram as regióes, com o aquecimento climático gradual (Banerjee \& D'Rozario, 1990).

O zoneamento estabelecido por Tiwari \& Tripathi (1992) para a sucessäo palinológica nas bacias Damodar e Rajmahal é o que mais chama a atenção, em virtude do detalhamento da seqüência relativa ao "Estágio" Talchir, unidade relacionada à glaciação neopaleozóica. A Zona Potonieisporites neglectus, base da seqüência naquelas bacias, é caracterizada por pouca diversificação, domínio de grãos de pólen de simetria radial e bilateral, com ausência total de bissacados teniados. A unidade subseqüente, Zona Plicatipollenites gondwanensis, é marcada pelo primeiro aparecimento de $P$. gretensis, Jayantisporites arcuatus, Parasaccites bilateralis e $C$. densus ( $=C$. flavatus). Na Zona Parasaccites korbaensis ocorrem os primeiros registros de grãos de pólen do tipo Cycadopites e Scheuringipollenites maximus. A zona superior, Zona Crucisaccites monoletus, ocorrente no "Estágio" Karharbari, é definida pelo aparecimento de $P$. limpidus e Crucisaccites monoletus.

Embora sejam evidentes as diferenças nas distribuições dos táxons, comparativamente com as zonas registradas no Subgrupo Itararé, as estabelecidas para o "Estágio" Talchir" são as que mais se assemelham com as duas inferiores propostas. A Zona C. monoletus seria relativa à Subzona Protohaploxypinus goraiensis, pela maior contribuiçāo de grāos de pólen teniados e presença de formas típicas ( $P$. goraiensis, $P$. limpidus), embora $C$. monoletus, já esteja presente deste a Zona Biointervalo Potonieisporites neglectus, aqui proposta.

\section{África}

As seqüências gondwânicas mais importantes da África são relativas ao "Sistema Karroo", constituído por unidades sedimentares distribuídas em várias partes do continente, principalmente na sua porção meridional. Hart (1971) apresentou um dos trabalhos pioneiros sobre seu conteúdo palinológico. A base da sucessão é representada por associações nas quais dominam grãos de pólen monossacados, caraterizando a Florizona 1. A reduçäo da freqüência deste grupo e o incremento de grăos de pólen teniados e não-teniados marcam a 
Florizona 2. Na unidade subseqüente o gênero Vittatina é abundante, embora já presente desde o Grupo Dwyka (Hart, 1969).

No Congo, o "Asisses glaciaires et periglaciaires", unidade basal da seqüência definida por Bose (1971), é marcada pelo domínio de grãos de pólen monossacados e bissacados, com fraca representação de esporos triletes, grãos de pólen poliplicados e monocolpados. Grãos de pólen teniados só ocorrem a partir do "Assise des schistes noir de Walikale", unidade subseqüente.

A Zona Virkkipollenites-Plicatipollenites estabelecida por Falcon (1975) para o Grupo Dwyka na antiga Rodésia apresenta, da base para o topo, a tendência geral de decréscimo de grãos de pólen monossacados e esporos triletes, com acréscimo contínuo de grāos de pólen bissacados e bissacados teniados, com presença rara do gênero Protohaploxypinus desde a base da unidade.

O zoneamento proposto por Anderson (1977) é um dos mais completos para o Sistema Karroo, relacionando o conteúdo palinológico e as ocorrências faunísticas. O Grupo Dwyka é marcado pelo domínio de grãos de pólen teniados e poliplicados, enquanto que somente a partir do Grupo Ecca os gêneros Vittatina e Weylandites são verificados.

Utting (1978) estabeleceu a Zona Cannanoropollis obscurus-Plicatipollenites indicus no Grupo Dwyka em Zâmbia, caracterizada pelo domínio de grãos de pólen monossacados (Potonieisporites, Plicatipollenites, Cannanoropollis). O Grupo Ecca seria representado pela Zona Scheuringipollenites maximus-Brevitriletes levis, onde ocorrem P. amplus, P. limpidus, V. saccata e S. maximus. Esta última zona tem maior correspondência com a Zona Vittatina da Bacia do Paraná, provavelmente com as subzonas Protohaploxypinus goraiensis e Caheniasaccites flavatus, relativas aos estratos da Formação Rio Bonito, assim como as ocorrências da Formação Gwembe em Zâmbia (Nyambe \& Utting, 1997), na qual ocorrem $S$. maximus, $P$. limpidus, $P$. amplus, $C$. flavatus, $V$. saccata, com idade posicionada entre o Artinskiano e o Kunguriano.

A Subzona Protohaploxypinus goraiensis tem elementos comuns com a Formação Morupule, base do Grupo Ecca em Botswana: G. austroamericanus, P. malabarensis, $P$. gondwanensis, C. janakii, P. limpidus, P. amplus, S. maximus e Vittatina spp. Entretanto, Stephenson \& McLean (1999) a correlacionaram com a Subzona Caheniasaccites flavatus e ressaltaram as discrepâncias nas distribuições dos táxons entre o sul da África e América do Sul.

\section{"Franja Equatorial"}

Com relação à "franja equatorial" do Gondwana na Península Arábica, há grandes similaridades das associaçōes do Subgrupo Itararé com aquelas da Formação Al Khalata, em Omãn e Arábia Saudia, conforme descrição de Stephenson \& Filatoff (2000). Os autores identificaram as seguintes espécies em comum: $P$. lucidulus, $R$. nigritellus, $H$. uruguaiensis, $D$. disfacies, $P$. detecta, $L$. braziliensis, $L$. riobonitensis, $V$. arcuatus, $C$. menendezii, $C$. 
inordinatus, $P$. malabarensis, $P$. novicus, $C$. flavatus $(=C$. ovatus), $L$. rectus, $P$. limpidus e $C$. polymorphus, tendo correlacionado a associação, ocorrente na base da unidade, com a Zona Potonieisporites-Lundbladispora, da Bacia do Chacoparaná.

A porção superior da unidade apresenta os seguintes elementos comuns: $L$. virkii, $G$. confluens, V. arcuatus, P. detecta, P. novicus, P. limpidus, P. amplus, V. subsaccata, V. costabilis, $V$. saccata, $C$. polymorphus e $H$. fusiformis. De acordo com os autores, a associação onde estes elementos ocorrem seria correlata à Zona Cristatisporites média/superior da Bacia do Chacoparaná. Entretanto, as maiores similaridades entre a seqüência glaciogênica do Permiano Inferior de Omãn seria com a Zona Pseudoreticulatispora confluens, da Austrália (Stephenson, 1998).

\section{Correspondência no Hemisfério Norte}

O trabalho de Utting \& Piasecki (1995) sintetiza as informações palinológicas do Permiano do Hemisfério Norte, constatando o mesmo padrão geral verificado no Gondwana, com o aparecimento dos grupos de grãos de pólen monossacados e bissacados (teniados e não-teniados) a partir do final do Carbonífero Inicial e explosão (diversificação e abundância) no Carbonífero Tardio (monossacados) e Permiano (bissacados), respectivamente.

Entretanto, nenhum dos zoneamentos do Hemistério Norte apresenta significativas similaridades com aqueles gondwânicos e, em particular, com o proposto neste trabalho. Alguns aspectos são muito similares, como já fôra constatado em comparação com as assembléias gondwânicas.

Para o Carbonífero e limite C/P, o zoneamento proposto por Clayton et al. (1977) é o que melhor expressa a sucessão palinológica para a Europa Ocidental. Entretanto, das espécies características das zonas, somente algumas ocorrem no Subgrupo Itararé: $V$. vallatus (Zona S. pretious- $R$. clavata, limite Devoniano/Carbonífero), V. ciliaris (Zona L. pusilla, Tournaisiano/Niseano), $V$. morulatus (Zona B. nitidus-R. carnosus, Namuriano), $C$. indignabundus e D. muricatus (Zona R. fulva-R. reticulatus, Namuriano). Nas zonas Vittatina costabilis e Disaccites striatiti (Autuniano) ocorre, de maneira geral, o domínio de grãos de pólen monossacados e bissacados e decréscimo dos esporos triletes, dominantes nas zonas subjacentes, principalmente Lycopsidas, sendo que na última a freqüência de bissacados estriados é muito expressiva.

Dentre os esporos, alguns dos cingulizonados $(C$. indignabundus, $C$. connexus e $D$. annulatus) e reticulados (D. muricatus), são comuns desde o Namuriano da Inglaterra (Turner et al., 1994; Turner \& Spinner, 1993), Polônia (Kmiecik, 1986) e Grã-Bretanha (Smith \& Butterworth, 1967). 


\section{IDADES}

O estabelecimento de idades nos estratos da Bacia do Paraná não é uma tarefa fácil ou isenta de controvérsias. Como em geral ocorre nas bacias gondwânicas, faltam dataçōes absolutas e fósseis de amarração com a coluna geológica padrão. Outro fator que compromete as precisões é o registro diácrono das paleofloras, levando-se em conta as migrações em respostas às melhorias climáticas.

Com base somente nas características gerais das biozonas verificadas no Subgrupo Itararé propõe-se uma idade Carbonifera Tardia para as zonas biointervalo Ahrensisporites cristatus e Potonieisporites neglectus, enquanto que a Subzona Protohaploxypinus goraiensis seria relativa ao Permiano ou, com dúvidas, ao limite Carbonífero/Permiano.

Dentre os palinomorfos verificados no Subgrupo Itararé, os melhores elementos para indicação de idades são os esporos, tendo em vista a grande longevidade estratigráfica dos gräos de pólen monossacados de simetrial radial e bilateral, bissacados e teniados nas seqüências entre o Namuriano e o Permiano Inferior em nível mundial, cujo comportamento geral de distribuição já foi mencionado anteriormente nas comparações das biozonas.

Foram verificados esporos primitivos típicos do Devoniano Superior, Carbonífero Inferior a Superior da Europa e América do Norte, raros nas associações gondwânicas (e.g. Raistrickia pinguis, D. muricatus, S. clarus, D. annulatus, D. triangularis, V. vallatus, $C$. connexus, $C$. indignabundus, B. canipa, $C$. veeversi).

Outras espécies se distribuem amplamente a partir do Carbonífero Tardio, com ocorrências mais raras ou duvidosas no Permiano Inicial (e.g. P. lucidulus, G. varigranifer, $G$. austroamericanus, $C$. firmus, $A$. variornata, $D$. disfacies, $R$. rotunda, $H$. uruguaiensis, $C$. muriornata, $C$. ordoñenzii, $C$. menendezii, $C$. inordinatus, $C$. inconstans, $R$. pseusopalliatus, $S$. ybertii, $P$. detecta, $V$. arcuatus, $V$. punctatus, V. ciliaris).

Algumas espécies são mais tipicamente verificadas em estratos de idade carbonifera ( $F$. hortonensis, C. liquida, A.cristatus, $R$. passaspectus, D. setellatus, $C$. spinosus) e permiana (e.g. L. virkkii, C. hartungiana, P. gretensis, R. nigritellus, G. confluens, Lundbladispora braziliensis, L. ribonitensis).

Baseando-se na comparação com associaçōes do Grupo Tubarão na Bacia do Paraná e na pela ocorrência de um número significativo de táxons comuns nas bacias circunvizinhas da América do Sul, notadamente do Grupo Paganzo, Bacia de Tarija e Chacoparaná, é possível posicionar as zonas biointervalo Ahrensisporites cristatus e Potonieisporites neglectus no Carbonífero Tardio.

Nesse contexto, uma idade westphaliana (Bashkiriano/Moscoviano) é proposta para a Zona Biointervalo Ahrensisporites cristatus. A Zona Biointervalo Potonieisporites neglectus se posicionaria entre o Westphaliano e o Stephaniano (Moscoviano/Gzheliano). 
Essas idades se coadunam dentro do contexto geral envolvendo os principais eventos geológicos que afetaram o Gondwana entre o Carbonífero Tardio e o Permiano Inicial, como será discutido posteriormente.

Marques-Toigo (1988, 1991) acredita que o conteúdo paleobotânico (macro e microflora) do Subgrupo Itararé nos estados mais meridionais da Bacia seja relativo ao Permiano Inicial (Sakmariano/Artinskiano). Por outro lado, os dados relativos aos insetos parecem sugerir idade Carbonífera Tardia (Pinto \& Ornellas, 1978; Pinto, 1990, 1995).

A composição palinológica da Subzona Protohaploxypinus goraiensis é compatível com a idade Permiana Inicial (Asseliano/Sakmariano), tendo como base a distribuição de alguns elementos presentes, tais como Protohaploxypinus goraiensis, P. limpidus e Vittatina spp. Embora esses gêneros ocorram já desde o Westphaliano e Stephaniano, respectivamente, em outras partes do mundo, é somente no Permiano que dominam as associações, em termos de abundância e diversificação, como verificado na Bacia do Paraná. 


\section{SIGNIFICADO PALEOAMBIENTAL DAS BIOZONAS}

A análise paleoambiental dos esporomorfos presentes nas seção estudadas é realizada com base (1) no reconhecimento de "morfogrupos", agrupando-se gêneros de características morfológicas similares, relacionados aos mesmos grupos florísticos, (2) na freqüência relativas desses morfogrupos e (3) nas características ecológicas das comunidades vegetais aos quais estāo relacionados.

Alguns aspectos relacionados às afinidades botânicas do esporomorfos já foram apresentados no Capítulo III. Com base nas propostas de afinidades de vários autores, os seguintes grupos botânicos são identificados no material estudado:

1. Lycopsidas e Sphenopsidas: representados por esporos triletes cavados (zonados, cingulizonados, pseudosacados), do gênero Vallatisporites, Cristatisporites, Lundbladispora, por exemplo, e lisos do gênero Calamospora. Os grupos vegetais relacionados são de características hidrófilas-higrófilas, referentes a plantas de ambientes aquáticos, terras baixas, total ou parcialmente inundadas.

2. Filicopsidas: representados por esporos triletes acavados, lisos, apiculados e murornados (e.g. Punctatisporites, Leiotriletes, Cyclogranisporites, Granulatisporites, Verrucosisporites). Os grupos vegetais correspondem a associaçōes higrófilas-mesófilas, relacionadas a ambiente entre terras baixas e altas, ocupando áreas marginais aos pântanos e lugares mais secos das planícies.

3. Gymnospermopsidas: compreendem os grãos de pólen monossacados (e.g. Cannanoropollis, Plicatipollenites, Potonieisporites, Caheniasaccites) e bissacados (Limitisporites, Scheuringipollenites, Protohaploxypinus) e outros grãos poliplicados (e.g. Hamiapollenites, Vittatina), representando uma vegetação mais arbustiva/arbórea. Essas plantas apresentam características mesófilas a xerófilas, de terras relativamente mais altas.

A freqüência típica dos vegetais representados na Zona Biointervalo Ahrensisporites cristatus é demonstrada na Figura IV.6, construída com base em quatro níveis do poço A-IG-85 (estratótipo da Zona). A freqüência dos morfogrupos em todos os niveis do poço pode ser verificada nas Tabelas 15 e 16 de Souza (1996). A distribuição dos morfogrupos do poço lG-01 (Itaporanga) é apresentada na Figura. IV.7, exemplificando o comportamento geral da Zona Biointervalo Potonieisporites neglectus.

As duas zonas apresentam padrões muito semelhantes, com o predomínio de esporos e grãos de pólen monossacados, demonstrando a influência da flora continental associada a grandes corpos de água em regiões baixas, com grande contribuição dos elementos de terras altas (Gymnospermopsidas), que alcançam longas distâncias na dispersăo.

Por outro lado, a Subzona Protohaploxypinus goraiensis apresenta uma expressiva participação de grãos de pólen teniados e poliplicados, os quais, nas zonas subjacentes, não ultrapassam 5\% das associaçöes. Em alguns níveis, ainda podem ocorrer grandes 
quantidades de esporos, não constituindo, entretanto, o padrão comum verificado na Subzona (ver Figura IV.8).

A influência marinha no Subgrupo Itararé é atestada nas três zonas reconhecidas neste trabalho. As Zonas Biointervalo Ahrensisporites cristatus e Potonieisporites neglectus e a Subzona Protohaploxypinus goraiensis foram reconhecidas nos níveis do Subgrupo itararé em Araçoiaba da Serra, Itaporanga e Capivari, respectivamente. Estas localidades apresentam espécies de invertebrados marinhos (e.g. foraminiferos, bivalves, gastrópodes, braquiópodes) que, embora não forneçam melhor precisão cronoestratigráfica, indicam a contribuiçāo da sedimentação marinha no Subgrupo Itararé nos três terços da unidade, inferior, médio e superior.

Outros elementos algálicos (Tasmanites, Botryococcus) e Acritarcha (Deusilites tenuistriatus) também foram verificados. Contudo, ainda há grandes controvérsias sobre seu significado paleoecológico nas comunidades.

O gênero Botryococcus é geralmente utilizado como indicador de ambientes de águas doces a salobras (Batten \& Grenfell, 1996). No entanto, Holz \& Dias (1998) interpretaram uma seqüência superior Subgrupo Itararé no Estado do Rio Grande do Sul, onde o gênero ocorre, como parte de um evento transgressiva de terceira ordem.

A espécie Deusilites tenuistriatus foi registrada em associaçôes de baixa salinidade, não marinhas da Argentina, juntamente com Botryococcus e Leiosphaeridia (Gutiérrez et al., 1997). No Brasil, ocorre com elementos microplanctônicos (Dias, 1993) e invertebrados marinhos (Itaporanga). Segundo Souza (1998), a espécie pode ter se adaptado em ambientes de diferentes salinidades, perdendo seu valor como indicadora paleambiental.

Outras formas de Acritarcha e Incertae Sedis também foram verificadas em diversos niveis do Subgrupo Itararé, principalmente aqueles relativos às Zonas Biointervalo Ahrensisporites cristatus e Potonieisporites neglectus, dentre os quais: Quadrisporites lobatus, Q. horridus, Gorgonisphaeridium spp., Veryhachium trispinosum, V. flagelliferum e Chomotriletes cf. C. dejerseyi. Essas formas apresentam distribuição estratigráfica relativamente ampla e são geralmente associadas a ambientes marinhos.

Em alguns casos, seu estado de preservação é muito ruim, podendo constituir material retrabalhado. No entanto, na maioria dos níveis onde ocorre, o estado de preservaçäo é muito bom, igualmente ao das formas consideradas autóctones.

No Subgrupo Itararé do Rio Grande do Sul, Dias (1993) verificou espécies de Acritarcha (Baltisphaeridium sp., Micrhystridium spp., Veryhachium sp., Exoderma sp.) e algas prasinofíceas (Tasmanites sp.) e cloroficeas (Botryococcus braunii), além de Incertae Sedis (Portalites gondwanensis, Tetraporina puntata, Pilasporites calculus, Brazilea spp.). A autora concluiu pela presença de uma ingressão marinha no final da deposição do Subgrupo Itararé no Rio Grande do Sul, com indicaçōes (dominância monoespecifica de Acritarcha e presença de Botryococcus) de mar interno. 
Algas prasinofíceas e Acritarcas também foram detectadas em estratos do Permiano Inicial de outras regiões do mundo (ver síntese em Ottone \& Garcia, 1996, p. 105), constituindo indicadores de ambientes marinhos das unidades onde ocorrem.

Essas constatações sugerem que grande parte parte dos sedimentos do Subgrupo Itararé tenha sido depositada em ambiente marinho. Entretanto, reassalta-se a necessidade da melhor definição da origem autóctone de alguns desses elementos e de seu significado paleoambiental. 


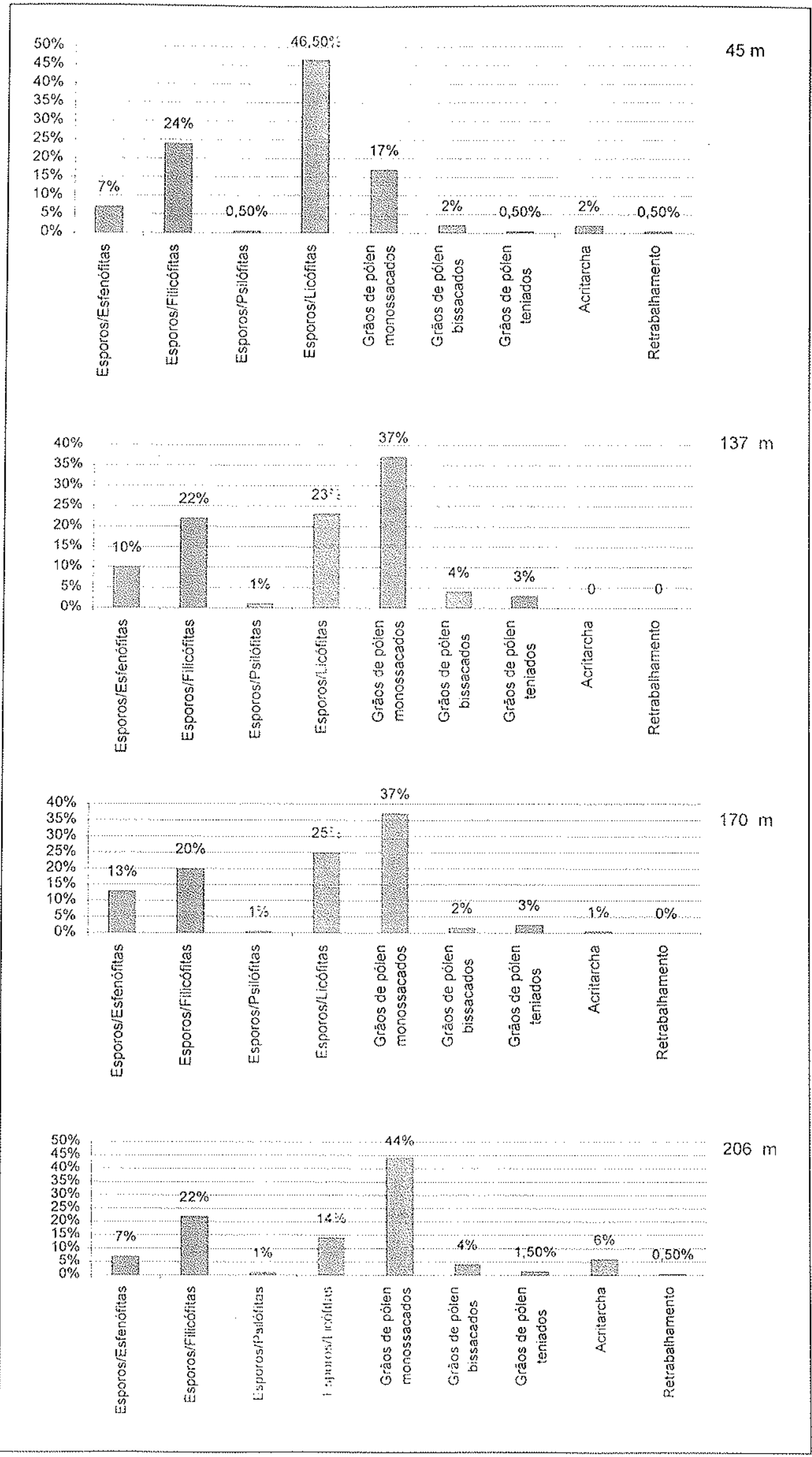

Figura IV.6 - Freqüência (em percentagem) dos morfogrupos de palinomorfos em alguns niveis do poşo A-1G-85 (Araçoiaba da Serra, SP), estratótipo da Zona Biointervalo Ahrensisporites cristatus 


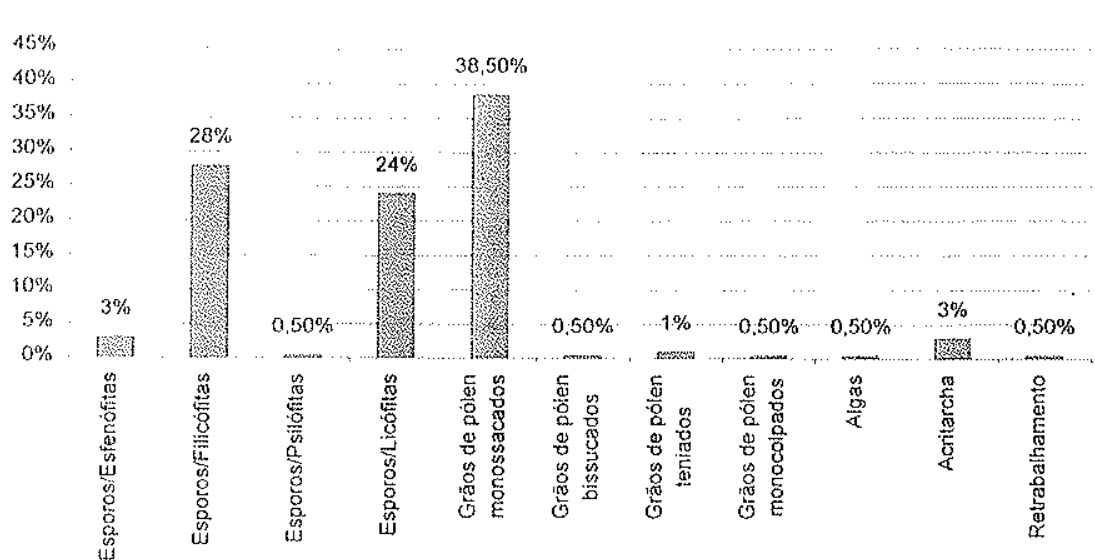

$36,5 \mathrm{~m}$
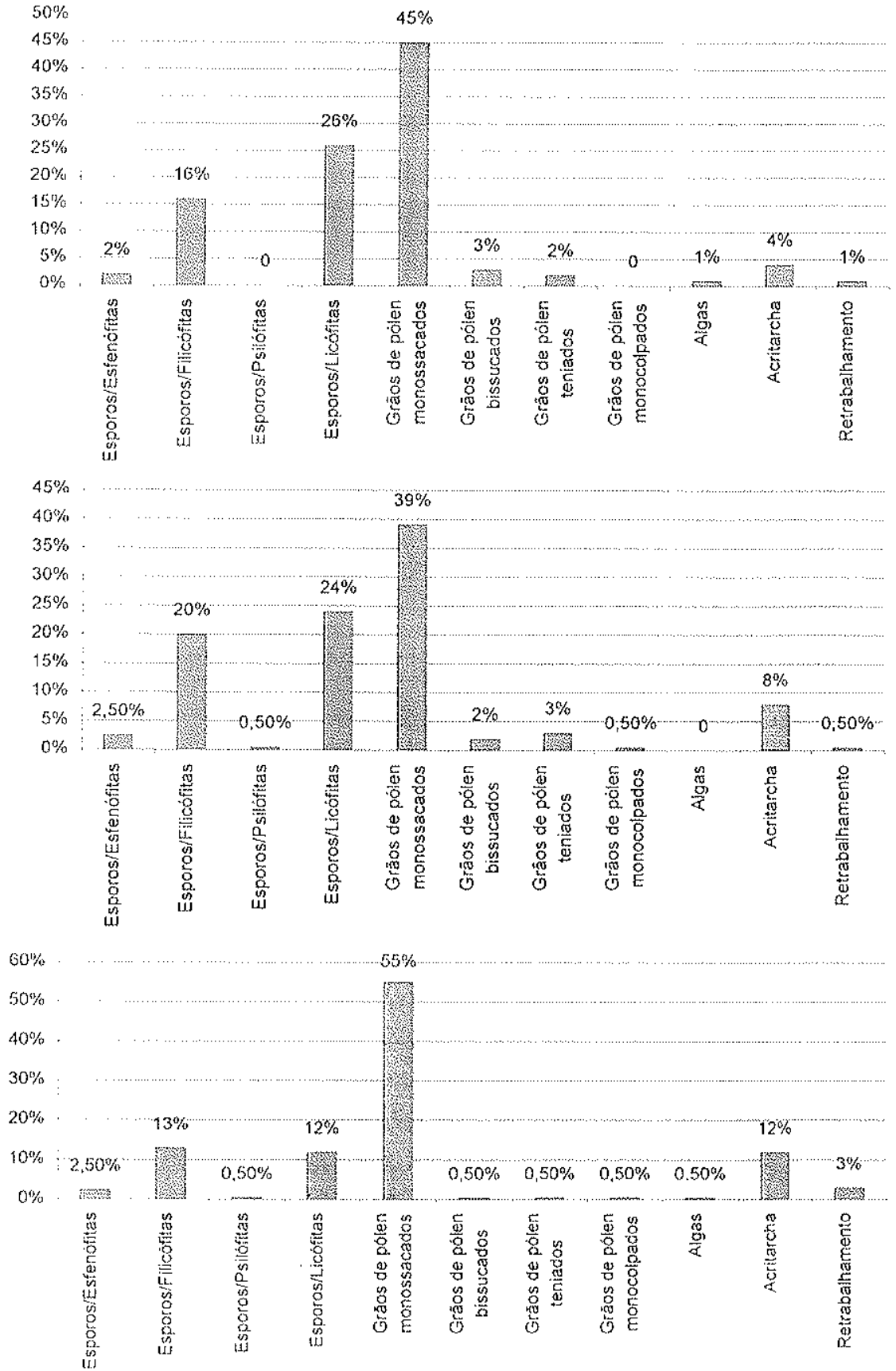

Figura IV. 7 - Freqüēencia (em percentagem) dos morfogrupos de palinomofos em alguns niveis do poşo 1G-01 (itaporanga, SP), estratótipo da Zona Biointervalo Potonieisporites neglectus. 


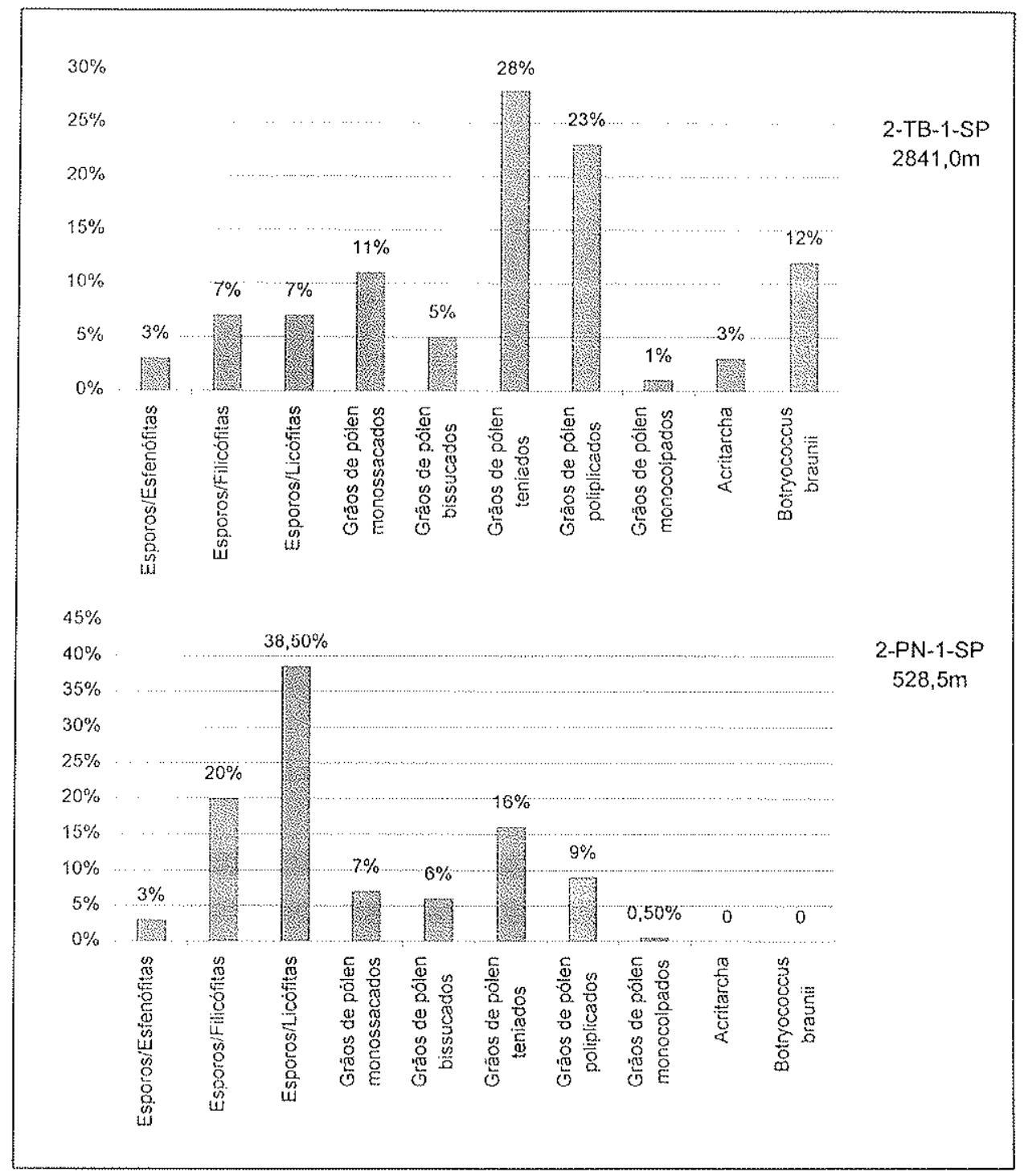

Figura IV.8 - Freqüência (em percentagem) dos morfogrupos de palinomorfos em dois niveis de subsuperficie de ocorrência da Subzona Protohaploxypinus goraiensis. 
CAPÍTULO V

ASPECTOS FINAIS 


\section{DISCUSSÃO DOS RESULTADOS}

As assembléias palinológicas verificadas, as biozonas propostas, as idades e correlações sugeridas, bem como a análise integrada dos dados disponiveis permitem uma nova concepção para a distribuição estratigráfica do Subgrupo Itararé. Na Figura V.1 estão sintetizados os resultados bioestratigráficos alcançados, integrando o zoneamento proposto neste trabalho para o nordeste da Bacia do Paraná, com aquele vigente para a sua porção meridional (Marques-Toigo, 1988, 1991).

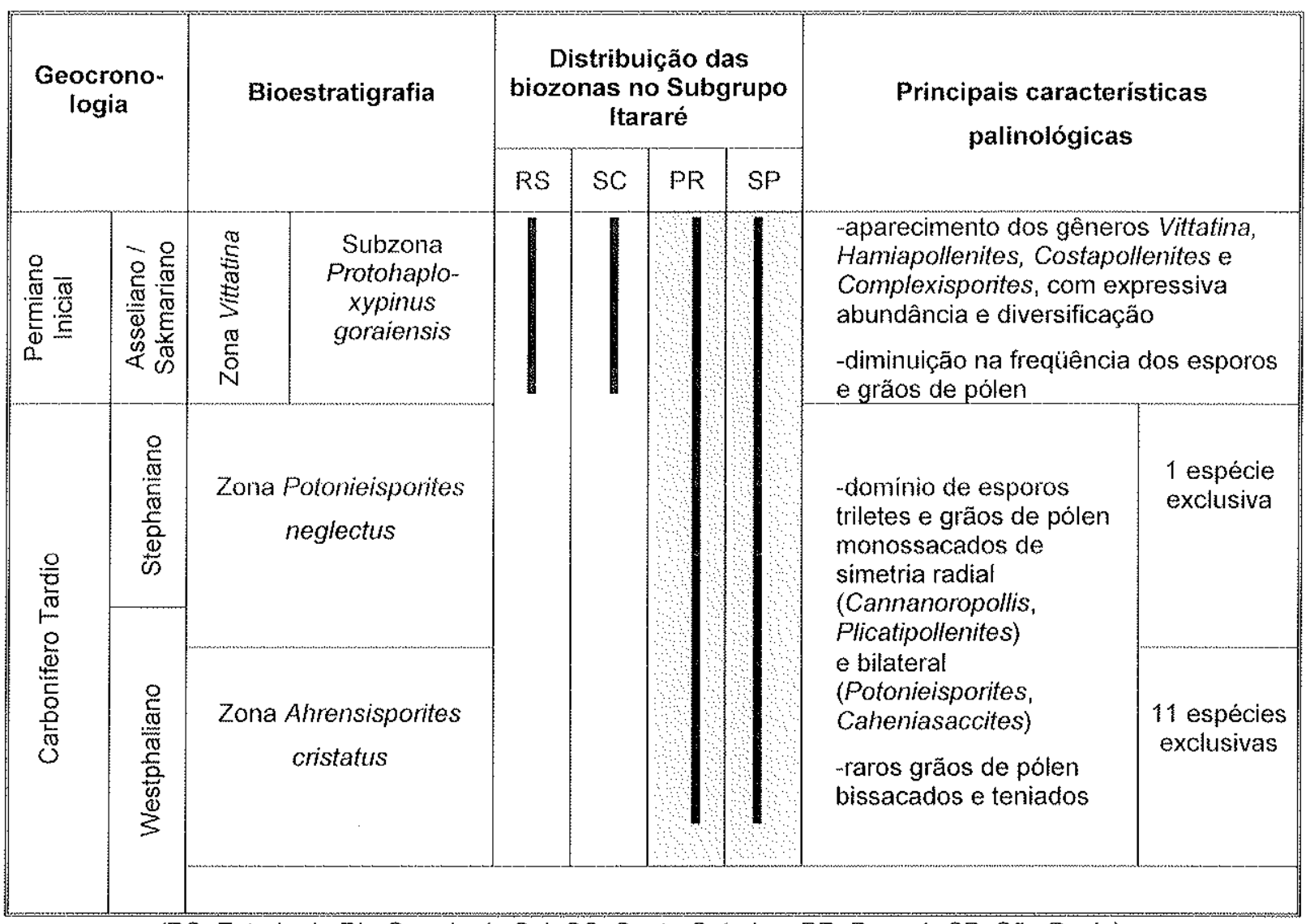

(RS: Estado do Rio Grande do Sul; SC: Santa Catarina; PR: Paraná; SP: São Paulo)

Figura V.1 -Distribuição das unidades palinobioestratigráficas no Subgrupo Itararé, com correlação na porção meridional da Bacia do Paraná (em destaque os resultados deste trabalho).

\section{Paleoambiente e evolução geológica do Subgrupo Itararé}

Os morfogrupos palinológicos das associações verificadas nas Zonas Biointervalo Ahrensisporites cristatus e Potonieisporites neglectus apresentam um mesmo padrão de freqüência, com domínio de esporos triletes (zonados e cingulizonados) e grãos de pólen 
monossacados (radial e bilateralmente simétricos). Grãos de pólen bissacados e teniados são freqüentes em ambas as zonas, em quantidades subsidiárias.

Os palinomorfos mais úteis nas interpretações ambientais são relativos às algas, acritarcas e outros organismos, excetuando-se os esporomorfos. Grandes avanços ainda não são possíveis nesse tema devido à presença subordinada destes grupos e pelas incertezas de seu significado paleoambiental.

As tendências quantitativas gerais das Zonas Biointervalo Ahrensisporites cristatus e Potonieisporites neglectus, com predomínio de esporos (Lycopsidas, Sphenopsidas, Filicopsidas) e grãos de pólen monossacados (Gymnospermopsidas), indicam forte contribuição da flora continental nos sedimentos do Subgrupo Itararé. Localmente (e.g. carvões), a maior freqüência dos esporos indicaria ambientes próximos a corpos d'água, com relativa estagnação.

A influência glacial na sedimentação do Subgrupo Itararé é documentada em distintas localidades e em vários níveis estratigráficos do Subgrupo ttararé (ver Santos et al., 1996). Contudo, a maioria dos depósitos estaria relacionada a processos desenvolvidos em ambiente marinho, com registros de deposição turbidítica a partir de fluxos gravitacionais, com expressiva presença de fácies de ressedimentação. Diversos autores advogam esta interpretação, seja para partes isoladas (e.g. Caetano-Chang, 1984; Pires \& Petri, 1991; Petri, 1992; Petri \& Pires, 1992) ou para a bacia como um todo (e.g. França \& Potter, 1988; Eyles et a/., 1993), com expressiva presença de fácies de ressedimentação.

As ocorrências de invertebrados fósseis, tanto na base (Araçoiaba da Serra, Zona Ahrensisporites cristatus), na porção média (Itaporanga, Zona Potonieisporites neglectus) e superior (Capivari, Subzona Protohaploxypinus goraiensis) demonstram a presença da influência marinha em todo o tempo de sedimentação do Subgrupo Itararé. Sedimentos continentais estavam associados, representados por depósitos flúvio-deltaicos em várias posições na unidade, denotado pelo registro de níveis de carvão tanto na base da unidade, em Monte Mor e Buri, quanto no topo da seqüência, em Cerquilho.

Alguns modelos propostos sobre a evolução geológica para o Grupo Tubarão são compatíveis com os resultados paleontológicos. Segundo Saad (1977, p. 97), os registros da influência marinha na porção nordeste da bacia estariam relacionados a uma ingressão mais generalizada e presente em todo o "tempo Itararé" (destaque deste autor). Para Gama Jr. \& Perinotto (1992), o Subgrupo Itararé testemunha um importante evento transgressivo associado à glaciação do Permocarbonífero.

As três unidades bioestratigráficas reconhecidas neste trabalho são relativas, grosso modo, às unidades litoestratigráficas propostas para o Subgupo ltararé em subsuperfície por França \& Potter (1988). As três biozonas ocorrem na faixa aflorante do Subgrupo Itararé nos estados de São Paulo e Paraná, o que contraria a observação de França \& Potter (op. cit.) pela qual, a faixa aflorante seria representada somente pela unidade superior, Formação Taciba. Vale destacar que a divisão litoestratigráfica de França \& Potter (1988) é baseada em 
material de subsuperfície, em grande parte, do centro da bacia, com menor amostragem na porção nordeste.

\section{O Subgrupo Itararé e os eventos geológicos de caráter global}

Segundo Wagner (1993), registros de eventos geológicos de natureza global (ciclotemas, maiores transgressões eustáticas) são melhores marcadores cronoestratigráficos que a bioestratigrafia baseada em grupos vegetais. Neste contexto, dois aspectos relevantes na geologia do Gondwana merecem destaque: (i) a glaciação do Paleozóico Superior $(\mathrm{C} / \mathrm{P})$, que é progressivamente sucedida pela (ii) transgressão marinha marcada pela ocorrência da fauna de Eurydesma (base do Permiano).

Vários autores apontam sinais de melhoria climática (aquecimento da temperatura) no início do Permiano, entre o Asseliano e o Sakmariano, seja com base em reconstruçōes paleogeográficas, ou nas mudanças florísticas registradas (e.g. Crowell, 1978; Veevers \& Powell, 1987; Isaacson et al., 1993; Scotese \& Langford, 1995; Visser, 1997). Segundo Wopfner (1998), esse aquecimento teria ocorrido repentinamente e nāo poderia ser atribuído às mudanças das posições das placas em relação ao polo, mas sim a uma mudança climática global mais substancial. Para Crowell (1995), o aquecimento do início do Permiano se deu de forma sincrônica no Gondwana e no Hemisfério Norte, entre o Sakmariano e o Artinskiano. O final da glaciação estaria relacionado à progressiva transgressão, que é registrada na maioria das bacias gondwânicas, marcada pelo gênero Eurydesma e elementos associados (Veevers \& Powell, 1987). Vale notar que durante o Carbonífero as temperaturas já eram relativamente mais altas nas províncias euroamericanas que no Gondwana, tendo em vista, por exemplo, o registro de florestas luxuriantes, de grande porte e as espessuras dos carvões naquelas regiões.

O evento transgressivo do início do Permiano é representado, na Bacia do Paraná, pelas camadas superiores do Subgrupo Itararé (Milani, 1997), as quais contém invertebrados marinhos em distintas localidades da bacia (e.g., Capivari, Passinho/Baitaca, Butiá) e que podem estar relacionados à fauna de Eurydesma (Rocha-Campos \& Rösler, 1978).

A Subzona Protohaploxypinus goraiensis ocorre no topo do Subgrupo Itararé e na base da Formaçäo Rio Bonito. A Subzona é correlacionada, em parte, com a Zona Cristatisporites inferior, da Bacia Chacoparaná, e com a Zona Pseudoreticulatispora confluens, da Austrália. $\mathrm{Na}$ África sedimentos correlacionáveis apresentam grandes similaridades litológicas, com camadas de carvões sucedendo a seqüência glacial (Wopfner, 1998).

Segundo Wagner (1993), o aquecimento global estaria refletido na composição palinológica das associaçōes e a Zona Cristatisporites representaria modificações climáticas e as conseqüentes migrações de plantas termófilas para altas paleolatitudes.

Com base em dados paleomagnéticos de diversas áreas gondwânicas, Conti \& Rapalini (1993) propuseram uma configuração paleogeográfica para a América do Sul, pela 
qual a Bacia do Paraná teria ocupado, durante o Namuriano, uma posição latitudinal na faixa de $75^{\circ} \mathrm{S}$. No limite Carbonífero/Permiano, a placa sul-americana estaria mais avançada para o norte, posicionando a porção nordeste da bacia na faixa dos $35-45^{\circ} \mathrm{S}$, não muito diferente da posição que ocuparam as bacias de Tarija, Chacoparaná e unidades do Grupo Paganzo (ver Figura V.2). Estas interpretações permitem supor que, pelos menos para o limite $C / P$, as correlações bioestratigráficas entre as biozonas gondwânicas da América do Sul implicaria em diacronismos pouco significativos, em decorrência das poucas diferenças.

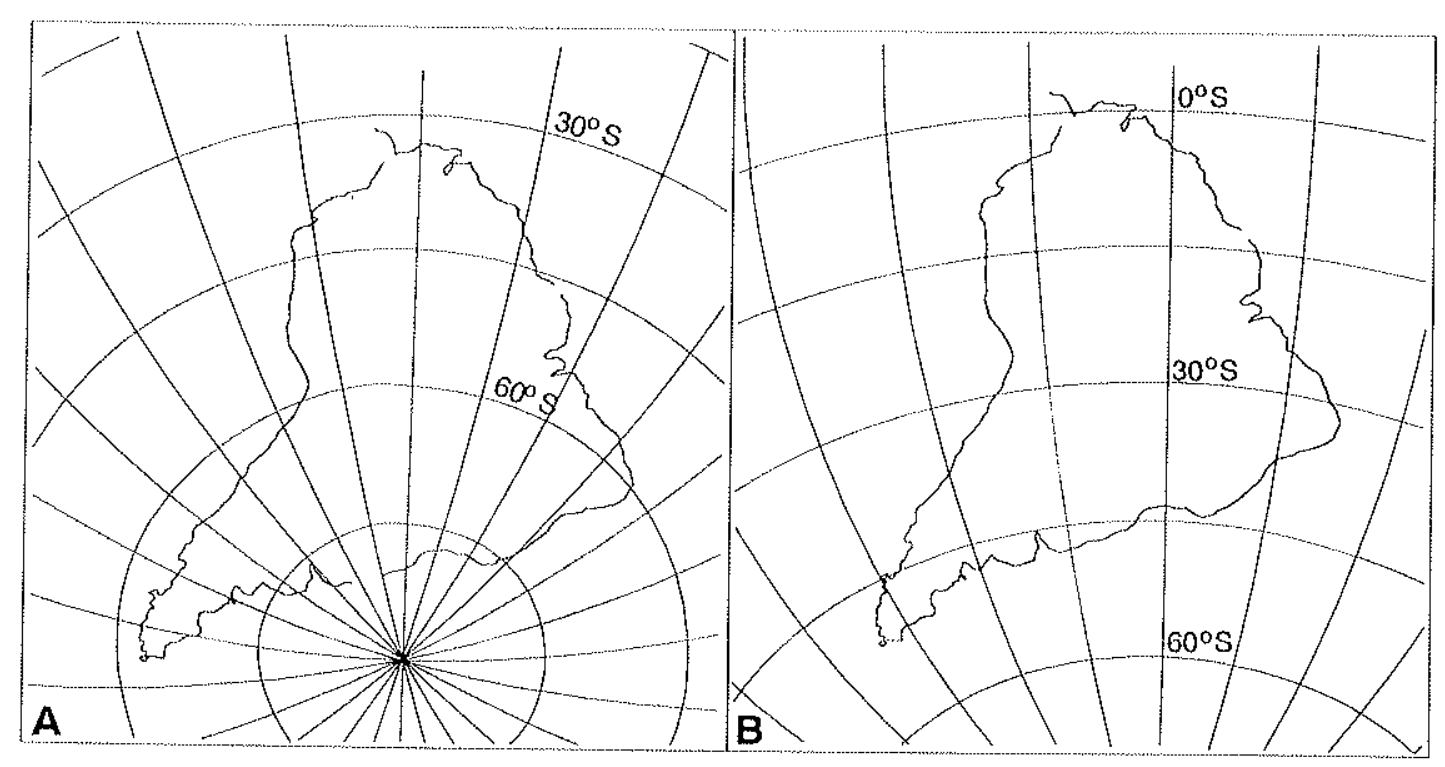

Figura V.2 - Reconstrução paleogeográfica para a América do Sul entre o Carbonífero Médio (A) e limite Carbonífero/Permiano (B), conforme Conti \& Rapalini (1993).

O evento glacial em outras regióes da América do Sul teria se estendido na Bolívia, Paraguai e Argentina entre o Namuriano e o Westphaliano/Stephaniano (Eyles, 1993; González, 1996).

Também para o Grupo Dwyka, na África, as idades apontadas a partir de datações absolutas (SHRIMP-Zircão) e invertebrados fósseis sugerem que a influência glacial foi mais expressiva durante o Carbonifero (Bangert et al., 1998; Strell \& Theron, 1999; Stollhofen et al., 2000).

Essas observações corroboram o posicionamento de grande parte do ltararé no Carbonífero. Somente o topo da unidade, onde ocorre a Subzona Protohaploypinus goraiensis, 
seria relativa ao Permiano Inicial (Sakmariano), ainda com influências diretas da glaciação registradas em várias partes da bacia.

\section{Idades}

Em termos paleobotânicos, os elementos registrados em Monte Mor, Buri e Itapeva (SP) são tipicamente pré-permianos, com posicionamento no Carbonífero Tardio (Rösler, 1978; Millan, 1987; Zampirolli et al., 1999).

A Subzona Gangamopteris obovata (Guerra-Sommer \& Cazzulo-Klepzig, 1993) foi definida para o Subgrupo Itararé no Rio Grande do Sul, tendo sido posicionada no Permiano Inicial (Sakmariano/Artinskiano). Segundo vários autores (e.g. Cazzulo-Klepzig \& GuerraSommer, 1983; Millan, 1989), o topo do Subgrupo Itararé, mais precisamente a tafoflora de Cerquilho (Rösler, 1978; Millan, 1987), não corresponderia ao topo da unidade no Rio Grande do Sul, dada a ausência de espécies típicas do gênero Glossopteris. Mais recentemente, no entanto, lannuzzi \& Rohn (1995) noticiaram espécies do gênero na localidade, o que pode constituir em elemento de correlação com a Subzona Gangamopteris obovata.

O posicionamento dos níveis do topo do Subgrupo Itararé no Permiano Inicial é corroborado ainda pelas indicações palinológicas em nível mundial. Segundo Dunn (2000), o estratótipo da base do Permiano no Cazaquistão é marcado pela ocorrência de espécies de conodontes, amonóides e fusulinídeos e caracteriza-se, em termos palinológicos, pela abundância e diversidade de grãos de pólen bissacados teniados (e.g. Protohaploxypinus spp., Hammiapollenites bullaeformis, Striatoabieites sp.) e variedade do gênero Vittatina ( $V$. costabilis, $V$. vittifera, $V$. saccifer, $V$. subsaccata, $V$. simplex); grãos de pólen monossacados e esporos são menos freqüentes.

A verificação de grãos de pólen teniados (?Striomonosaccites sp., Protohaplopxypinus amplus, Striatoabieites sp.) nas zonas Ahrensisporites cristatus e Potonieisporites neglectus não contraria seu posicionamento no Carbonífero Tardio, visto que ocorrem em quantidades subsidiárias (até $5 \%$ ) e também estão presentes, sem expressão quantitativa, em outras regiões carboníferas do mundo. Como exemplo podem ser citadas: a Europa Ocidental (Alpern, 1964; Doubinger \& Broutin, 1976; Clayton et al., 1977; Zwan et al., 1993; McLean, 1999), Europa Oriental (Górecka \& Górecka-Nowak, 1990; Drabkova, 1996), América do Norte (Habib, 1966; Peppers, 1997), Ásia (Zhu-Huaicheng, 1993; 1995; Zhou, 1994; Shu \& Huaicheng, 1998), América do Sul (Vergel, 1993; Marques-Toigo et al., 1995; Loboziak et al., 1997) e Hemisfério Norte (Owens, 1996). Em muitas destas localidades, as idades carboníferas são corroboradas por invertebrados marinho.

Matos (1999) datou níveis filmes argilosos cauliníticos intercalados com bancos de carvão da mina de Candiota, relacionados à tufos piroclásticos, na Formação Rio Bonito no Estado do Rio Grande do Sul, tendo obtido idades entre $267 \pm 3.4$ M.a. (SHRIMP-Zircão), o que significaria, utilizando a tabela geológica do tempo conforme Gradstein \& Ogg (1996), uma 
idade artinskiana para a unidade, corroborando as indicações palinológicas para a Formação Rio Bonito. O topo do Subgrupo Itararé seria posicionado abaixo deste datum, em concordância com a idade permiana inicial também indicada pelos palinomorfos.

As idades apontadas para o topo do Subgrupo Itararé na porção nordeste da bacia a partir do Daemon \& Quadros (1970), entre o Artinskiano e o Kunguriano (intervalos $\mathrm{H}_{3}-1$ ), não são corroboradas, com reflexo no posicionamento das unidades sobrejacentes.

O Subgrupo Irati, base do Grupo Passa Dois, é estratigraficamente correlacionável às formações Whitehill e Huab (África) e Black Rock Member (Ilhas Falklands), com base em dados geoquímicos da matéria orgânica e carbonatos (Faure \& Cole, 1999) e ocorrências de Mesossaurídeos (Oelofsen \& Araújo, 1983). As unidades africanas foram posicionadas no Artinskiano, pela associação com outros invertebrados presentes no Grupo Ecca (Anderson, 1977). Entretanto, o posicionamento do Subgrupo Irati na Bacia do Paraná, segundo o zoneamento de Daemon \& Quadros (op. cit.), seria no Kazaniano.

Com base no zoneamento de Daemon \& Quadros (1970) ou mesmo nos dados apresentados por Daemon et al. (1996), o posicionamento da Formação Rio do Rasto seria no Triássico Inferior. Contudo, os registros de macrofitofósseis, conchostráceos e tetrápodes indicam idade pré-triássica. Para Barberena et al. (1985), a idade da Formação Rio do Rasto seria tatariana. Rohn \& Stollhofen (2000) correlacionaram o Membro Serrinha com a Formação Gai-As da Namíbia, com base em bivalves lacustres. Tufos vulcânicos da unidade africana foram datados (SHRIMP-Zircão) em 265 \pm 2.5 M.a. (Rohn \& Stollhofen, op. cit.).

\section{Retrabalhamento}

A origem e a distância das áreas-fontes dos sítios deposicionais podem ser deduzidas a partir da presença de palinofósseis retrabalhados (e.g. Muller, 1959; Legault \& Norris, 1982; Van de Laar \& Fermont, 1990). Possivelmente, as formações Furnas e Ponta Grossa tenham servido como área-fonte para os depósitos do Subgrupo Itararé (Caetano-Chang, 1984), dada a proximidade geográfica e a identificação de palinofósseis comuns em ambas as unidades devonianas, cujo registro palinológico pode ser verificado em Dino \& Rodrigues (1995) e Oliveira $(1991,1997)$. No entanto, as reconstruções paleogeográficas do mar devoniano da Formação Ponta Grossa (ver Oliveira, 1997, p. 166) não incluem grande parte do leste do Estado de São Paulo, principalmente a atual borda da bacia.

Os palinofósseis retrabalhados ocorrentes em Jundiaí e na região de ltu documentado neste trabalho indicam maior proximidade do mar devoniano no Estado de São Paulo do que mostram as reconstruções paleogeográficas. Considerando o estado de preservação e coloração dos palinomorfos retrabalhados, seu transporte náo deve ter envolvido grandes distâncias, mesmo em se tratando de condiçōes climáticas frias, nas quais a destruição da matéria orgânica é menos intensa. 
A presença de esporos retrabalhados do Carbonifero Inferior (Indotriradites dolianitii el. cf. I. daemonii) lança a possibilidade da deposição de sedimentos dessa idade na Bacia do Paraná. Durante o Carbonifero Inicial a bacia estava tectonicamente instável e esses depósitos teriam sido registrados em "calhas isoladas". As dificuldades de sua verificação e mapeamento podem ser devidas a sua destruição (erosão e remobilização) ou pelas limitações nas datações e diferenciação com a base do Carbonífero Tardio do Subgrupo Itararé.

\section{Relaçóes com os depósitos pós-glaciais do Subgrupo Guatá}

Muitos dos palinomorfos verificados no Subgrupo Itararé sāo comuns na Formaçāo Rio Bonito, tendo Daemon \& Quadros (1970) ressaltado a contemporaneidade de alguns dos depósitos dessas duas unidades. Algumas das associaçöes da Formação Rio Bonito no sul da bacia (e.g. Ybert, 1975; Dias-Fabrício, 1981) são muito semelhantes com as do topo do Subgrupo Itararé em Santa Catarina (Pons, 1976ab; Canuto, 1985) e no Estado de São Paulo (Souza et al., 1993c; 1999; este trabalho). Para o Estado do Paraná as informações são mais precárias.

Em termos litoestratigráficos, vários autores já observaram passagem gradual entre estas duas unidades (e.g. Piccoli \& Bortoluzzi, 1981; Marques-Toigo et al., 1981; Castro, 1991), enquanto outros (e.g. Milani, 1987) verificaram discordâncias significativas. Segundo Bossi \& Piccoli (1979), as seqüências sedimentares das duas unidades apresentam similaridades, carecendo de limite preciso. Para Castro (1999), a análise das seqüencias deposicionais constitui a melhor ferramenta para divisão e mapeamento cronoestratigráfico das unidades superiores do Subgrupo Itararé. Provavelmente a integração desta ferramenta com os dados paleontológicos possa fornecer melhores contribuições.

Para o Estado de São Paulo, o problema é mais grave, visto que a Formação Tatuí nāo apresenta registros paleontológicos de precisão cronológica. Por outro lado, vários autores propuseram o posicionamento dos níveis de carvão de Cerquilho na Formação Tietê (Stevaux et al., 1985; Perinotto, 1987; Cabral Jr. et al., 1988; Perinotto \& Fúlfaro, 2000), pós-glacial, correlacionável à Formação Rio Bonito no sul da bacia.

Com base em análise de vários perfis, França \& Caldas (1983) concluíram que a Formaçāo Rio Bonito está geneticamente ligada ao Subgrupo Itararé; esta última, no seu topo, registraria o final da glaciação dentro do ambiente deltaico já implantado na bacia. Dessa forma, a distinção entre as duas unidades teria que ser feita sem se considerar a influência climática na sedimentação.

O nível de resolução da palinologia ainda é insuficiente para delimitar, em termos bioestratigráficos, qualquer horizonte de distinção entre o topo do Subgrupo Itararé e a base da Formação Rio Bonito. A Figura 4 de Daemon \& Quadros (1970), que mostra a distribuição dos intervalos propostos pelos autores em subsuperfície, evidencia contemporaneidade na deposição das duas unidades. De acordo com a distribuição dos palinomorfos utilizados na 
divisão bioestratigráfica por Marques-Toigo (1988, Tabela VI), não há nenhum elemento de desaparecimento ou aparecimento no limite das duas unidades. Somente logo abaixo e logo acima do contato litoestratigráfico ocorrem bio-horizontes significativos, embora nenhum constitua limite bioestratigráfico. 


\section{CONSIDERAÇÕES FINAIS}

\section{Conclusões}

O estudo e a análise integrada da Palinologia do Subgrupo Itararé na região nordeste da Bacia do Paraná (norte do Paraná e Estado de São Paulo) permitiram (i) um grande avanço no conhecimento palinológico da unidade, (ii) a proposição de um zoneamento formal e, como conseqüência, (iii) sugestão de novas idades, correlações e interpretações sobre a evolução geológica do Subgrupo Itararé. As principais conclusões deste trabalho são apresentadas, sinteticamente, nos itens que seguem.

1. As amostras analisadas contém, em seu conjunto, 139 espécies de palinomorfos, das quais 95 são detalhadamente apresentadas (descrição e ilustração), relativas a 51 espécies de esporos, 41 de grãos de pólen, duas de algas e uma de Acritarcha. Dentre estas espécies, muitas são noticiadas pela primeira vez no Subgrupo Itararé no Estado de São Paulo e Paraná, sendo oito inéditas para a Bacia do Paraná (Granulatisporites austroamericanus, $G$. confluens, Dibolisporites disfacies, Convolutispora muriornata, Cristatisporites spinosus, Cirratriradites veeversi, Protohaploxypinus panaki e Costapollenites ellipticus).

2. As duas zonas biointervalo propostas são delimitadas por níveis de aparecimento e desaperecimento de táxons selecionados e se referem, grosso modo, às porções inferior e média do Subgrupo Itararé, respectivamente: Zonas Biointervalo Ahrensisporites cristatus e Potonieisporites neglectus.

2a. Zona Biointervalo Ahrensisporites cristatus. Apresenta 11 espécies exclusivas de esporos. A seção do poço A-lG-85 constitui seu estratótipo. Ocorre em várias localidades aflorantes (Araçoiaba da Serra, Buri, Monte Mor, Itapeva) e em estratos relativos, em subsuperfície, à base da Formação Lagoa Azul. É correlacionada, em parte, aos intervalos informais $G$, Pré-G ou Associação Ahrensisporites \& Ancistrospora. Fora da Bacia do Paraná, as melhores correlaçōes são com a Zona de Ancistrospora ou Subzona Raistrickia-Plicatipollenites, do Grupo Paganzo (Argentina) e parte da Superzona Kraeuselisporites volkheimerii-Circumplicatipollis plicatus da Bacia de Tarija. O o posicionamento geocronológico é no Carbonífero Tardio, possivelmente Westphaliano (Bashkiriano/Moscoviano).

2b. Zona Biointervalo Potonieisporites neglectus. É limitada na base e no topo por biohorizontes de aparecimento e desaparecimento de um grande número de táxons, com presença exclusiva de somente uma espécie (Crucisaccites monoletus). Tem seu estratótipo na seção do poço IG-01/Itaporanga e ocorre em várias localidades aflorantes do Subgrupo Itararé (Jundiaí, Itu, seção da BR-053 no Estado do Paraná). Em subsuperficie, corresponde ao topo da Formação Lagoa Azul e grande parte da 
Formaçāo Campo Mourão. É correlacionada aos intervalos $\mathrm{G}$ (parte) e subintervalos $\mathrm{H}_{1}$ e $\mathrm{H}_{2}$. Fora da Bacia do Paraná as melhores correlações são com a Zona de Potonieisporites ou Subzona Raistrickia-Plicatipollenites do Grupo Paganzo, Zona Potonieisporites-Ludbladispora da Bacia Chacoparaná e zonas superiores da Superzona Kraeuselisporites volkheimerii-Circumplicatipollis plicatus, da Bacia Tarija. O posicionamento geocronológico é no Carbonífero Tardio, provavelmente Westphaliano/Stephaniano (Moscoviano/Gzheliano).

3. A base da Zona Vittatina, Subzona Protohaploxypinus goraiensis, foi verificada na porção superior (superfície e subsuperfície) do Subgrupo Itararé e é caracterizada pelo domínio de grãos de pólen bissacados teniados (e.g. Protohaploxypinus spp., Complexisporites polymorphus) e poliplicados (Hamiapollenites spp., Vittatina spp., Costapollenites ellipticus) sobre os morfogrupos dominantes nas associações das zonas inferiores, os esporos e grãos de pólen monossacados. É correlacionada ao intervalo $\mathrm{H}_{3}+\mathrm{l}$. Fora da Bacia do Paraná apresenta similaridades com a base da Zona Cristatisporites inferior, da Bacia Chacoparaná e Zona Pseudoreticulatispora confluens, ocorrente na Austrália, África e Península Arábica. Sugere-se idade no Permiano Inicial, provavelmente Asseliano/Sakmariano.

4. Propõe-se a renomeação da Zona Cannanoropollis korbaensis para Zona Vittatina e da Subzona Caheniasaccites ovatus para Subzona Caheniasaccites flavatus, mantendo-se suas caracterizações como originalmente propostas.

5. A distribuição das biozonas sugere que a maior parte dos sedimentos do Subgrupo Itararé teria sido depositada, na porção nordeste da bacia, durante o Carbonífero Tardio. O topo da unidade é referente ao Permiano Inicial, com registro generalizado em toda a bacia.

6. Em termos quantitativos, nas Zonas Biointervalo Ahrensisporites cristatus e Potonieisporites neglectus dominam esporos e grãos de pólen monossacados, com presença subsidiária de grãos de pólen bissacados e teniados, demonstrando o domínio da flora pteridofítica (Lycopsidas, Sphenopsidas, Filicopsidas, Gymnospermopsidas), típica de ambientes úmidos e terras baixas e altas. A Subzona Protohaploxypinus goraiensis registra o domínio de Gymonospermopsidas, cujos elementos são típicos de terras altas e ambiente mais seco. Embora também ocorram algumas formas relativas à Acritarca e algas, não há qualquer proposição ambiental mais definitiva em função das incertezas sobre o significado paleoambiental das espécies.

7. As idades propostas para o Subgrupo Itararé se coadunam dentro do modelo geral de evolução para o Gondwana. As Zonas Biointervalo Ahrensisporites cristatus e Potonieisporites neglectus estariam mais relacionadas à influência glacial, enquanto que o registro litológico e paleontológico da Subzona Protohaploxypinus goraiensis indicaria melhorias climáticas substanciais, mais ou menos sincrônicas em várias partes do mundo, com reflexo no conteúdo palinológico. Os depósitos de origem marinha do topo da unidade estariam relacionados à trangressão de caráter global verificada na base do Permiano. 
8. A identificação de 13 espécies de palinomorfos retrabalhados, incluindo esporos e acritarcas e um zoomorfo, indica a presença de sedimentos do Devoniano (Superior?) e do Carbonífero Inferior na bacia, que serviram como área-fonte do Subgrupo Itararé, pelo menos, durante o Carbonífero Tardio. Nas reconstruçōes paleogeográficas da Formação Ponta Grossa os limites da invasão marinha deveriam ser estendidos até a região da borda atual da bacia.

\section{Recomendações}

Algumas questões ainda ficam em aberto, necessitando estudos mais detalhados para melhores definições. A Zona Biointervalo Potonieisporites neglectus abrange um intervalo sedimentar relativamente espesso, incluindo grande parte da Formação Campo Mourão e a parte superior da Formação Lagoa Azul. Os limites dos intervalos $\mathrm{G} / \mathrm{H}_{1}$ e $\mathrm{H}_{1} / \mathrm{H}_{2}$, aos quais a Zona é correlacionada, não constituem marcos palinológicos significativos, como já discutido no Capítulo IV.2. Contudo, é desejado que estudos mais detalhados venham detectar diferenças palinológicas suficientes para a adequada subdivisão da Zona.

A passagem do Subgrupo Itararé para a Formação Rio Bonito, ou Formação Tietê/Tatuí, na região nordeste da bacia deve ser alvo de estudo bioestratigráfico mais detalhado, tendo em vista que os zoneamentos bioestratigráficos realizados, inclusive o apresentado nesta Tese, não apresentam qualquer resoluçāo na distinção das duas seqüências (glacial e pós-glacial). A Palinologia tem indicado similaridades nas associaçōes das duas seqüencias, que podem refletir a sincronicidade na deposiçâo ou o registro de comunidades diácronas, mas ecologicamente similares. A presença de vários elementos microplanctônicos, Acritarcas e Incertae Sedis no Subgrupo ltararé deve ser melhor avaliada como subsídio nas interpretações ambientais e reconstruções geográficas. Quase todas as espécies são longevas e muitos espécimes ocorrem com fortes indicaçōes de retrabalhamento. Entretanto, não se pode generalizar sua presença como elementos alóctones nas associações. 


\section{REFERÊNCIAS BIBLIOGRÁFICAS}

ACEÑOLAZA, F.G. \& VERGEL, M.M. 1987. Hallazgo del Pérmico Superior fosilifero en el Sistema de Famatina. In: CONGreso Geológico ARgentino, X, San Miguel de Tucumán, 1987. Actas.... ll1:125-9.

ALPERN, B. 1964. La stratigraphie palynologique du Stephanien et du Permien. In: Congres INTERNATIONAL DE STRATIGRAPHIE ET DE Géologie du CAFBONIFÈre, $5^{\text {eme }}$, Paris, 1963. Compte Rendus..., III:1119-29.

ALVES, L.S.R. 1994. Integração entre a lignoflora e a palinologia no afloramento Passo São Borja (Fm. Irati - Bc. do Paraná). Porto Alegre, inédito (Dissertação de Mestrado, Instituto de Geociências da UFRGS).

ANAN-YORKE, R. 1974. Devonian Chitinozoa and Acritarcha from exploratory oil wells on the shelf and coast region of Ghana, west Africa. Bulletin of the Geological Survey of Ghana, 37:1-216.

ANDERSON, J.M. 1977. The biostratigraphy of the Permian and Triassic. Part 3: a review of Gondwana permian palynology basin, South Africa. Memoirs of the Botanical Survey of South Africa, $n^{\circ} .41,67 p$.

ARAI, M. 1980. Contribuiçāo dos pólens estriados na bioestratigrafia neopaleozóica da parte nordeste da Bacia do Paraná. Boletim $/ G$. USP, 11:98-105.

ARAI, M. \& RÖSLER, O. 1984. Megásporos de São João do Triunfo, Paraná, Formação Rio Bonito (Permiano). Boletim IG-USP, 15:53 64.

ARAÚJO-BARBERENA, D.C. 1989. Estudo do material sulamericano de Pareiasauroidea. VI - Descrição do esqueleto axial de Pareiasaurus americanus Araújo, 1985. Anais da Academia Brasileira de Ciências, 61(9):295-309.

ARCHANGELSKY, S. \& CUNEO, R. 1987. Ferugliocladeceae, a new family from the Permian of Gondwana. Review of Palaeobotany and Palynology, 51(1/3):3-30.

ARCHANGELSKY, S. \& GAMERRO, J.C. 1979. Palinologia del Paleozoico Superior en el subsuelo de la Cuenca Chacoparanense, República Argentina. I. Estudio sistemático de los palinomorfos de tres perfaciones de la Província de Córdoba. Revista Española de Micropaleontología, XI(3):417-478.

ARCHANGELSKY, S.; AZCUY, C.L.; GONZÁLEZ, C.; MARQUES-TOIGO, M.; PINTO, I.D.; RÖSLER, O. \& WAGNER, R. 1980. The Carboniferous and Early Permian of South American Gondwana Area: a summary of biostratigraphic information. In: CONGRESO ARgENTINO DE PALEONTOLOGIA Y
BIOESTrATIGRAFIA, $2, \quad Y$ CONGRESO LATINOAMERICANO DE PALEONTOLOGIA, 1 , Buenos Aires, 1977. Actas..., IV:257-269.

AZCUY, C.L. 1975a. Miosporas del Namuriano y Westfaliano de la Comarca Malazán-Loma Larga, Província de La Rioja, Argentina. II. Descripciones sistemáticas y significado estratigráfico de las microfloras. Ameghiniana, XII(2):113 163.

AZCUY, C.L. 1975b. Miosporas del Namuriano y Westfaliano de la Comarca Malanzán-Loma Larga, Província de La Rioja, Argentina. I. Localización geográfica y geológica de la comarca y descripciones sistemáticas. Ameghiniana, Xl1(1):1-69.

AZCUY, C.L. 1978. Posible significado paleoecologico de microfloras gondwanicas del Paleozoico Superior, especialmente argentinas. Ameghiniana, XV(1-2):85-95.

AZCUY, C.L. 1979. A review of the early Gondwana palynology of Argentina and South America. in: INTERNATIONAL PALYNOLOGICAL CONFERENCE, 4, Lucknow, 1976. Proceedings..., 2:175-185.

AZCUY, C.L. 1986. Algumas precisiones sobre las palinozonas carbonico-pérmicas de la Cuenca Paganzo. Ameghiniana, 23(1-2):97100.

AZCUY, C.L. \& DI PASQUO, M. 2000. Palynology of the Late Carboniferous from the Tarija Basin, Argentina: a systematic review of monosaccate pollen genera. Palaeontographica, Abt. B 253:103-37.

AZCUY, C.L. \& GUTIÉRREZ, P.R. 1985. Palinología de sedimentitas carbónicas de La Cuenca San Rafael. Ameghiniana, 22(12):97-109.

AZCUY, C.L. \& JELIN, R. 1980. Las palinozonas del limite Carbonico-Pérmico en la cuenca Paganzo. In: CONGRESO ARGENTINO DE Paleontología Y Bioestratigrafía, II $Y$ CONGRESO LATINOAMERICANO DE Paleontología, I, Buenos Aires, 1978. Actas..., 4: 51.67.

AZCUY, C.L. \& LAFFITTE, G. 1981. Palinologia de la Cuenca Noroeste argentina. I. Características de las asociaciones carbónicas: problemas e interpretación. In: CONGreso Geológico ARgentino, VIII, San Luis, 1981. Actas..., IV:823-838.

AZCUY, C.L. \& OTTONE, E.G. 1987. Datos palinológicos de la Formación Retama en la Encañada de Beu, Río Alto Beni (Bolivia). In: CONGRESO LATINOAMERICANO DE Paleontología, IV, 1987. Memorias... $1: 235-49$

AZCUY, C.L.; GUTIÉRREZ, P.R. \& BARREDA, V.D. 1982. Algunas miosporas carbonicas de la Formación Água colorada, Provincia de La Rioja. Ameghiniana, XIX(3-4):289-302 
BACKHOUSE, J. 1991. Permian palynostratigraphy of the Collie Basin, Western Australia. Review of Palaeobotany and Palynology, 67:237-314.

BALME, B.E. 1963. Plant microfossils from the Lower Triassic of Western Australia. Palaeontology, 6(1):12-40.

BALME, B.E. 1970. Palynology of Permian and Triassic Strata in the Salt Range and Surghar Range, West Pakistan. In: Kummel, B. \& Teichert, C. (eds.), Stratigraphic boundary problems: Permian and Triassic of West Pakistan. University of Kansas, Special Publication, 4:305 453.

BALME, B.E, 1980. Palynology and the Carboniferous-Permian boundary in Australia and other Gondwana continents. Palynology, 4:43-55.

BALME, B.E. \& HENNELLY, J.P.F, 1956. Trilete sporomorphs from Australian Permian sediments. Australian Journal of Botany, 4(3):240-60.

BALME, B.E. \& PLAYFORD, G. 1967. Late Permian plant microfossils from the Prince Charles Moutains, Antarctica. Revue de Micropaléontologie, 10(3):179-92.

BANERJEE, M. \& D'ROZARIO, A. 1990. Palynostratigraphic correlation of Lower Gondwana sediments in the Chuparbhita and Hura Basins, Rajamahal Hills, Eastern India. Review of Palaeobotany and Palynology, 65:239-45.

BANGERT, B.; LORENZ, V. \& ARMSTRONG, R. 1998. Bentonitic tuff horizons of the Permo. Carboniferous Dwyka Group in Souther Africa: volcaniclastic deposits as ideal time markers. Journal of African Earth Sciences, 27(1A):18-9.

BARBERENA, M.C.; ARAÚJO, D.F.; LAVINA, E.L. \& AZEVEDO, S.K. 1985. O estado atual dos conhecimentos sobre os tetrápodes permianos e triássicos do Brasil Meridional. DNPM, Coletânea de Trabalhos Paleontológicos, p. 21-8.

BARREDA, V. 1986. Palinología de la Formación El Trampeadero, Paleozóico Superior, Província de La Rioja. In: CONGRESO ARgentino DE PALEONTOLOGÍA Y Bioestratigrafia, IV, Mendoza, 1986. Actas...., p.211.219.

BARSS, M.S. 1967. Carboniferous and Permian spores of Canada. Geological Sunvey of Canada, Paper 67-11, 18p.

BARSS, M.S. 1972. A Problem in Pennsylvanian Permian Palynology of Yukon Territory. Geoscience and Man, IV:67-71.

BATEZELLI, C.V.B. 2000. Análise estratigráfica e aspectos estruturais do Grupo Itararé na região de Jundiaí (SP). Rio Claro, em finalização (Dissertação de Mestrado,
Instituto de Geociências e Ciências Exatas da UNESP).

BATEZELLI, C.V.B.; SOUZA, P.A. de; PERINOTTO, J.A.J.; SAAD, A.R. 1999. O Grupo ltararé na regiáo de Jundiaí (SP). In: Simpósio de GEOLOGIA do SudESTE, VI, São Pedro, 1999. Resumos.... SBG/UNESP, p.72.

BATTEN, D.J. \& GRENFELL, H.R. 1996. Chapter 7D. Botryococcus. In: Jansonius, J. \& McGregor, D.C. (eds.), Palynology: principles and applications. AASP Foudation, 1:205-14.

BEK, J. \& OPLUSTIL, S. 1998. Some lycopsid, sphenopsid and pteropsid fructifications and their miospores from the Upper Carboniferous basins of the Bohemian Massif. Palaeontographica, Abt. B 248:12761.

BERI, A. 1987. Estudio preliminar del contenido palinológico de la perforación 201 (Carbonífero Superior/Pérmico Inferior) del NE del Uruguay. in: SIMPÓsIO ARGENTINO DE PALEOBotânica Y PALINOLOGIA, VII, Buenos Aires, 1987. Actas... p.33-6.

BERI, A. 1988. Estudio sistemático del contenido palinológico de una muestra de la Formación Tres Islas (Pérmico Inferior) del Uruguay. Paula-Coutiana, 3:27-48.

BERI, A. \& AGUILAR, C.G. 1998. Resultados palinológicos y estratigráficos de la Formación San Gregório (Pérmico Inferior), Uruguay. Revista Universidade Guarulhos, Geociências, III(6):108-19.

BESEMS, R.E. \& SCHUURMAN, W.M.L. 1987. Palynostratigraphy of Late Paleozoic glacial deposits of the Arabian peninsular with special reference to Oman. Palynology, 11:37-53.

BHARADWAJ, D.C. 1960 . The miospore genera in the coals of Raniganj stage (Upper Permian), India. The Palaeobotanist, 9(1/2):68-106.

BHARADWAJ, D.C. 1975. Palynology in biostratigraphy and palaeocology of Indian Lower Gondwana Formations. The Palaeobotanist, 22(2):150-157.

BHARADWAJ, D.C.; KAR, R.K. \& NAVALE, G.K.B. 1976. Palynostratigraphy of the Lower Gondwana deposits in Paraná and Maranhão basins, Brazil. Biological Memoirs, Paleopalynology, Series 3, 1(1-2):53-108.

BORTOLUZZI, C.A.; PICCOLI, A.E.M.; BOSSI, G.E.; GUERRA-SOMMER, M.; MARQUESTOIGO, M.; PONS, M.E.; WOLF, M. \& CORRËA-DA-SILVA, Z.C. 1978. Pesquisa geológica na bacia carbonífera de Santa Catarina. Pesquisas, 11:33-192.

BOSE, M.N. 1971. Palynostratigraphy of the Lukuga Series in Congo. Geophytology, $1(1): 16-22$. 
BOSE, M.N. \& MAHESHWARI, H.K. 1968. Palaezoic sporae dispersae from Congo. VII Coal measures near lake Tanganyika, South of Albertiville. Annales du Musée Royal de $L^{\prime}$ Africa Centrale, Tervuren, Série IN $8^{\circ}$, Sciences Geologiques, $n^{0}$ 60, p. 1-116.

BOSSI, G.E. \& PICCOLI, A.E.M. 1979. Interpretaçōes paleogeográficas na Bacia do Paraná, nordeste do Rio Grande do Sul: I. Grupo Itararé. In: SMPÓsıo REGIONAL DE Geologia, 2", Rio Claro, 1979. Atas... SBG, 1:157 74.

BRASIER, M.D. 1980. Microfossils. Londres: George Allen \& Unwin, 193p.

BRITO, I.M. 1978. Maranhites, um importante fóssil índice do Devoniano Superior (Acritarcha Schutellomorphitae). Boletim /GUSP, 9:80-5.

BROUTIN, J. 1981. Etude paléobotanique et palynologique du passage CarbonifèrePermien dans les bassins continentaux du Sud-Est de la zone d'Ossa-Morena (environs de Guadalcanal, Espagne du Sud). Implications paléogéographiques et stratigraphiques. Paris: inédito (These de Doctorat d'Etat, Université Pierre et Marie Curie).

BROUTIN, J.; DOUBINGEA, J.; EL. HAMET, M.O. \& LANG, J. 1990. Palynologie comparée du Permien nigérien (Afrique occidentale) et Péritéthysien. Implications stratigraphiques et phytogéographiques. Review of Palaeobotany and Palynology, 66:243-261.

BROUTIN, J.; DOUBINGER, J.; LANGIAUX, J. \& PRIMEY, D. 1986. Conséquences de la coexistence de flores à caractères stéphaniens et autuniens dans la bassins limniques d'Europe occidentale. Mémories Société Géologique de France, NS, 149:15. 25.

BURJACK, M.I.A. 1978. Estudo palinológico da jazida carbonífera de Charqueadas, Rio Grande do Sul, Brasil. Goiânia: Ed. da Universidade Federal de Goiás, 204p.

BURJACK, M.I.A. 1984. Caracterizaçăo da matéria orgânica dispersa nos sedimentitos da Formação Irati, Permiano Superior da Bacia do Paraná. Porto Alegre: inédito (Tese de Doutoramento, Curso de Pós-Graduaçäo em Geociências, UFRGS).

BURJACK, M.I.A. \& OLIVEIRA, S.F. 1989. Contribuição ao conhecimento morfológico $e$ sistemático do gênero Maranhites Brito. Boletim /G-USP, Publ. Esp., 7:45-70.

CABRAL JR., M.; CAMPANHA, V.A.; MOTTA, J.F.M. \& SAAD, A.R. 1988. Contribuição à estratigrafia e paleogeografia da interface Itararé e Tatuí (P) e consideraçôes sobre sua potencialidade para carvão no Estado de São Paulo. In: CONGRESSO BRASIlEIRO DE
Geologia, XXXV, Belém, 1988. Anais... SBG, 2:879-93.

CAETANO-CHANG, M.R. 1984. Análise ambiental e estratigráfica do Subgrupo Itararé (PC) no sudoeste do Estado de São Paulo. São Paulo: inédito (Tese de Doutoramento, Instituto de Geociências da USP), $310 p$.

CANUTO, J.R. 1985. Origem dos diamictitos e de rochas associadas do Subgrupo Itararé no sul do Estado do Paraná e norte do Estado de Santa Catarina. São Paulo: inédito (Tese de Doutoramento, Instituto de Geociências da USP) $187 \mathrm{p}$.

CANUTO, J.R.; ROCHA-CAMPOS, A.C. \& SANTOS, P.R. dos. 1997. Arcabouço cronoestratigráfico de $3^{\circ}$ ordem para a Formação Rio do Sul, Subgrupo Itararé (Neopaleozóico), Bacia do Paraná, Centroleste de Santa Catarina, Brasil. Anais da Academia Brasileira de Ciências, 69(3):4389.

CASTRO, J.C. 1991. A evolução dos sistemas glacial, marinho e deltaico das formaçóes Rio do sul e Rio Bonito / Mb. Triunfo (Eopermiano), sudeste da Bacia do Paraná. Rio Claro: inédito (Tese de Doutoramento, Instituto de Geociencias e Ciências Exatas da UNESP), $147 \mathrm{p}$.

CASTRO, J.C. 1999. Estratigrafia de seqüências das formações Campo Mourăo (parte superior) e Taciba, Grupo Itararé, Leste da Bacia do Paraná. Revista Brasileira de Geociências, 29(2):255-60.

CAUDURO, A.D. 1970. Lower Gondwana miospores from São Sepé Outcrop (Rio Grande do Sul, Brasil). Escola de Geologia de Porto Alegre, Publ. Esp., 17:1-34.

CAZZULO-KLEPZIG, M. \& GUERRA-SOMMER, M. 1983. Relationship bedtween the taphoflore of the Itararé Group, Paraná basin, South Brazil and the permocarboniferous boundary. In: CONGRESO INTERNACIONAL DE Estratigrafia Y Geologia del. CARBONIFERO, 10, Madri, 1983. Compte Rendus, p. 395407.

CÉSARI, S.N. 1984. Palinología de la Formación Tupe (Paleozóico Superior), Sierra de Maz, Província de La Rioja. Parte 1. Ameghiniana, 21(1):85-102.

CÉSARI, S.N. 1985a. La Palinozona Potonieisporites-Lundbladispora de la Cuenca Paganzo. Revista de la Asociación Geológica Argentina, XL(3-4):293-6.

CÉSARI, S.N. 1985b. Palinología de La Formación Tupe (Paleozóco Superior), Sierra de Maz, Provincia de la Rioja. Parte II. Ameghiniana, 22(3-4):197-212.

CÉSARI, S.N. 1986. Zonación palinológica del Carbonífero Tardio en Argentina. In: Congraso argentino de Paleontologia $y$ 
Bioestratigrafia, IV, Mendonza, 1986. Atas..., p.228-230.

CÉSARI, S.N. \& BERCOWSKI, F. 1997. Palinología de la Formación Jejenes (Carbonífero) en la Quebrada de las Lajas, Província de San Juan, Argentina. Nuevas inferencias paleoambientales. Ameghiniana, 34(4):497-509.

CÉSARI, S. N. \& GUTIÉRREZ, P.R. 1984. Microflora de la Localidad de Los Mogotes Colorados (Paleozóico Superior), Província de la Rioja, República Argentina. Boletim /GUSP, 15:20-31.

CÉSARI, S.N. \& GUTIÉRREZ, P.R. 1986. Revision taxonomica de algunas esporas del Carbonifero de la Cuenca Paganzo, Republica Argentina. In: CONGRESO ARGENTINA DE PALEONTOLOGIA $Y$ Bioestratigrafia, IV, Mendoza, 1986. Actas... 1: 205-10.

CÉSARI, S.N. \& LIMARINO, C.O. 1992. Palinomorfos eocarboníferos en la Formación Cortaderas, Provincia de San Juan, Argentina. Asociación Paleontológica Argentina, Publ. Esp. $n^{\circ} .2$, p.45 8 .

CÉSARI, S.N. \& LIMARINO, C.O. 1995. Primer registro palinologico de la Formacion Maliman (Carbonifero Inferior), Cuenca Rio Blanco, Argentina. In: CONGRESO ARGENTINO DE PALEONTOLOGÍA Y BIOESTRATIGRAFIA, VI, Trelew, 1995. Actas..., p.77-83.

CÉSARI, S.N. \& VÁZQUEZ-NISTICO, B. 1988. Palinologia de la Formación Guadancol (Carbonífero), Província de San Juan, República Argentina Revista Española de Micropaleontología, XX(1):39-58.

CÉSARI, S.N.; ARCHANGELSKY, S. \& SEOANE, L.V. 1995. Palinología del Paleozóico Superior de la perforación Las Mochas, Província de Santa Fé, Argentina. Ameghiniana, 32(1):73-106.

CHALONER, W.G. 1962. A sporangiostrobus with Densosporites microspores. Palaeontology, $5(1): 73-85$.

CHANDRA, A. \& LELE, K.M. 1979. Talchir miofloras from South Rewa Gondwana Basin, India and their biostratigraphical significance. In: INTERNATIONAL PALYNOLOGICAL CONFERENCE, IV, Lucknow, 1976-77. Proceedings..., 2:117-51.

CLAYTON, G.; COQUEL, R.; DOUBINGER, J.; GUEINN, K.J.; LOBOZIAK, S. \& OWENS, B. 1977. Carboniferous miospores of Western europe: illustration and zonation. Mededelingen Rijks Geologische Dienst, 29:1-71.

CLAYTON, G.; HIGGS, K.; GUEINN, K.J. \& VAN GELDER, A. 1974. Palynological correlations in teh Cork Beds (Upper Devonian-?Upper Carboniferous) of Southern ireland.
Proceedings of the Royal Irish Academy, 74B(10):145-55.

CLEMENT-WESTERHOFF, J.A. 1984. Aspects of Permian Palaeobotany and Palynology. IV. The Conifer Ortiseia Florin from the Val Gardena Formation on the Dolomites and the Vicentinian Alps (Italy) with special reference to a revised concepts of the Walchiaceae (Göppert) Schimper. Review of Palaeobotany and Palynology, 41(1-2):51-166.

CLOUTIER, R.; LOBOZIAK, S.; CANDILIER, A-M. \& BLIECK, A. 1996. Biostratigraphy of the Upper Devonian Escuminac Formation, eastern Québec, Canada: a comparative study based on miospores and fishes. Review of Palaeobotany and Palynology, 93:191-215.

CONTI, C.M. \& RAPALINI, A.E. 1993. La deriva polar aparente del Gondwana en el Paleozoico en funcion de nuevos datos paleomagnéticos de Argentina. Implicancias paleolatitudinales para América del Sur. In: Congreso Geológico ARgentino, XII $Y$ CONGRESO DE EXPLORACIÓN DE Hidrocarburos, 1I, 1993. Actas...., Hi:404-14.

CORREAA-DA-SILVA, Z.C. \& MARQUES-TOIGO, M. 1975. Carvão no Brasil: mina de Candiota - Rio Grande do Sul. In: CONGresso IBEROAmERICANO dE GEOLOGIa ECONÓMICA, Buenos Aires, 1975. Actas... 1:263-86.

COUPER, R.A. 1958. British Mesozoic microspores and pollen grains. A systematic and stratigraphic study. Palaeontolographica, Abt. $B$ 103:75-179.

COURVOISIER, J.M. \& PHILLIPS, T.L. 1975. Correlation of spores from Pennsylvanian coal-ball fructification with dispersed spores. Micropaleontology, 21(1):45-59.

COWIE, J.W. \& BASSET, M.G. 1989. Global stratigraphic chart. Episodes, 12:2.

CROWELL, J.C. 1978. Gondwanan glaciation, cyclothems, continental positioning, and climate change. American Journal of Science, 278:1345-72.

CROWELL, J.C. 1995. The ending of the Late Paleozoic lce Age during the Permian Period. In: Scholle, P.A.; Peryt, T.M. \& UlmerScholle, D.S. 1995, The Permian of the Northern Pangea. Berlin: Springer-Verlag, $1: 62-74$.

CUNHA, P.R.C. \& FRANÇA, A.B. 1993. Estudo das taxas de sedimentaçāo das formaçóes Teresina e Rio do Rasto - Bacia do Paraná. In: Simpósio SOBRE CRONOESTRATIGRAFIA DA BACIA DO PARANA, 1, Rio Claro, 1993. Resumos... SBG, p. 83.

DAEMON, R.F. 1966. Ensaio sobre a distribuição e zoneamento dos esporomorfos do Paleozóico Superior da Bacia do Paraná. Boletim Técnico da Petrobrás, 9(2):211-218. 
DAEMON, R.F. 1974a. Integração dos resultados palinológicos da fauna e flora das camadas fossiliferas da Bacia do Paraná - Implicações estratigráticas e paleogeográficas. Revista Unimar, 1:25-40.

DAEMON, R.F. 1974b. Palinomorfos-guias do Devoniano Superior e Carbonífero Inferior das bacias do Amazonas e Parnaiba. Anais da Academia Brasileira de Ciências, 46(34):549 587.

DAEMON, R.F. 1981. Controle litobioestratigráfico preliminar do Devoniano, Carbonífero Superior e Permiano da bacia sedimentar do Paraná. In: Simpósio REGIONAL. DE GEOLOGIA, $3^{\circ}$, São Paulo, 1981. Atas... SBG, p. $124-132$.

DAEMON, R.F. \& CONTREIRAS, C.J.A. 1971. Zoneamento palinológico da Bacia do Amazonas. In: CONGRESSO BRASLlEHAO DE GEOLogia, XXV, São Paulo, 1971. Anais... SBG, 3:79 88 .

DAEMON, R.F. \& FRANÇA, A.B. 1993. Sedimentos do Westfaliano (Carbonífero Médio) na Formação Lagoa Azul, Grupo Itararé. In: SIMPÓSIO SOBRE Cronoestratigrafia da Bacia do Paraná, $1^{\circ}$, Rio Claro, 1993. Resumos, p.36.

DAEMON, R.F. \& MARQUES-TOIGO, M. 1991. An integrated biostratigraphical column for the Paraná Basin, Brazil. In: INTERNATIONAL Congress of Carboniferous and Permian StRATIGRAPHY AND GEOLOGY, 12, Buenos Aires, 1991. Abstracts..., p.25-26.

DAEMON, R. F. \& QUADROS, L.P. de. 1970. Bioestratigrafia do Neopaleozóico da Bacia do Paraná. In: Congresso BRAsileiro DE GeologiA, 24, Brasíila, 1970. Anais... SBG, p. 359-412.

DAEMON, R.F.; QUADROS, L.P. de; PICARELLI, A.T.; MARQUES-TOIGO, M.; \& CAZZULO. KLEPZIG, M. 1992. Arcabouço bioestratigráfico da Bacia do Paraná . Grupo Itararé. Fase 1: Palinologia quantitativa e a evolução paleoambiental do Grupo Itararé. Relatório Interno PETROBRÁS, projeto 01.02.41, CENPESSUPEP-DIVEX-SEBIPE, Rio de Janeiro, $156 \mathrm{p}$.

DAEMON, R.F.; QUADROS, L.P. de \& SILVA, L.C. 1967. Devonian palynology and bioestratigraphy of the Paraná Basin. Boletim Paranaense de Geociências, 21-22:99-132.

DAEMON, R.F.; CASALETTI, P.L. \& CIGUEL, J.H.G. 1996. Biopaleogeografia da Bacia do Paraná. In: SIMPósio SOBRE O SILURODevoniano da Bacia do Paraná, 10, Ponta Grossa, 1996. Boletim de Resumos Expandidos..., p.55.71.

DELLAZZANA, J.G. 1976. Contribuição à palinologia da Formaçäo Irati (Permiano) Rio Grande do Sul, Brasil. Ameghiniana, XIII(1):1-42.
DETTMAN, M.E. 1963. Upper Mesozoic microfloras from South-Eastern Australia. Proceedings of Royal Society of Victoria, 77:1-148.

DI PASQUO, M. 1999. Palinologia, bioestratigrafia y correlacion de las asociaciones presentes en los Grupos Machareti y Mandiyuti, Neopaleozolco de la Cuenca Tarina, Provincia de Salta, Argentina. Buenos Aires: inédito (Tese de Doutoramento, Universidade de Buenos Aires), 480p.

DI PASQUO, M. \& AZCUY, C.L. 1997a. Palinologia del Grupo Mandiyuti, Carbonífero Superior, Cuenca Tarija, Argentina. In: Congreso Geológico Chlleno, VIII, 1997. Actas..., 1:475-479.

DI PASQUO, M. \& AZCUY, C.L. 1997b. Palinomorfos retrabajados en el Carbonífero Tardio de la Cuenca Tarija (Argentina) y su aplicación a la datación de eventos diastróficos. Revista Universidade Guaruhos, Série Geociências, Ill (Número Especial):28-42.

DI PASQUO, M. \& AZCUY, C.L. 1999a. Paleontologia, paleoclima y correlación de estratos carboníferos en la Província de Salta sobre la base de palinomorfos. In: González Bonorino, B.; Omarini, R. \& Viramonte, J. (ed.), Geología del Noroeste Argentino. Salta, 1:254-60.

DI PASQUO, M. \& AZCUY, C.L. 1999b. Interpretación paleoambiental del Grupo Mandiyutí (Carbonífero Superior), provincia de Salta, Argentina. Evidencias palinológicas, sedimentológicas y tafonómicas. Ameghiniana, 36(4):453-63.

DIAS, M.E.R. 1993. Palinologia do Grupo Itararé no Rio Grande do Sul. Porto Alegre: inédito (Tese de Doutoramento, Instituto de Geociências da UFRGS), 277p.

DIAS-FABRÍCIO, M.E. 1981. Palinologia da Formação Rio Bonito na área de Gravataí . Morungava, Rio Grande do Sul. Pesquisas, 14:69-130.

DÍASMARTÍNEZ, E; VAVRDOVÁ, M.; BEK, J. \& ISAACSON, P.E. 1999. Late Devonian (Famennian) glaciation in Western Gondwana: evidence from teh Central Andes. Gabhandlugen der Geologischen Bundesanstalt, 54:213-37.

DINO, R. \& PLAYFORD, G. 1997. Contribuiçāo ao conhecimento palinológico e biocronoestratigráfico do carvão de Buri, Subgrupo Itararé, Bacia do Paraná. In: SIMPÓSIO SOBRE CRONOESTRATIGRAFIA DA BACIA DO PARANÁ, 3․, Barra do Garças, 1995. Boletim de Resumos..., p.21-2.

DINO, R. \& RODRIGUES, M.A.C. 1995 Palinomorfos eodevonianos da Formaçáo Furnas -- Bacia do Paraná. Anais da 
Academia Brasileira de Ciências, 67(1):107. 16.

DINO, R.; LIMA, M.R. de \& ROCHA-CAMPOS, A.C. 1987. Palinologia do varvito (Subgrupo Itararé, Neopaleozóico) da região de Itu, São Paulo. In: Congresso Brasileiro de Paleontologia, $10^{\circ}$, Rio de Janeiro, 1987. Resumos das Comunicaçōes...SBG, p. 46.

DOLBY, G. \& NEVES, R. 1970. Palynological evidence concerning the DevonianCarboniferous boundary in The Mendips, England. In: CONGRÉS INTERNATIONAL Stratigratigraphie Et Géologie du Carbonifère, 6 eme, Sheffield, 1967. Compte Rendus..., Il:631-46.

DOUBINGER, J. \& BROUTIN, J. 1976. Premières études palynologiques dans le bassin autuno-stéphanien de Guadalcanal (Nord de la Province de Séville, Espagne du Sud). Bulletin Societé Geólogique de France, 7(4):1033-40.

DOUBINGER, J. \& RAUSCHER, R. 1966. Spores du Viséen marin de Bourbach-le-haut dans les Vosges du Sud. Pollen et Spores, 8(1/3):360-405

DRABKOVA, J. 1996. Upper Stephanian and Lower Autunian assemblages of miospores from the Bohemian Massif. In: QUADRIENNAL CONFERENCE OF THE INTERNATIONAL ORGanisation of PALAEOBOTANY, $5^{\mathrm{t}}$, Santa Barbara, 1996. Abstracts Volume..., p. 24.

DUNN, M. 2000. Palynology of the Carvoniferous/Permian boundary stratotype, Aidaralash Creek, Kazakhstan. In: INTERNATIONAL GEOLOGICAL CONGRESS, $31^{\mathrm{st}}$, Rio de Janeiro, 2000. Abstracts... (CD-ROM)'.

EGGERT, D.A. \& TAYLOR, T.N. 1966. Studies of Paleozoic ferns: on the genus Tedelea gen. nov. Palaeontographica, Abt B 118:52-73.

EVANS, C.R. 1969. Upper Carboniferous and Permian palynological stages and their distribution in Eastern Australia. In: GONDWANA STRATIGRAPHY, IUGS SYMPOSIUM, Buenos Aires, 1967. Proccedings..., 2:41-54.

EYLES, N. 1993. Earth's glacial record and its tectonic setting. Earth-Science Review, 35:1248.

EYLES, C.H.; EYLES, N. \& FRANÇA, A.B. 1993. Glaciation and tectonics in na active intracratonic basin: the Paleozoic Itarare Group, Paraná Basin, Brazil. Sedimentology, $40 ; 1-25$

FALCON, R.M.S. 1975. Palyno-stratigraphy of the Lower Karroo sequence in the Central Sebungwe District, Mid-Zambezi. Basin, Rhodesia. Palaeontologia Africana, 18:1-29.

FASOLO, Z. \& VERGEL, M.M. 1994. Palinología de la perforación Fraile Muerto (FM 2), Formación Tres Islas (Pérmico Inferiot) de la
Cuenca Parana de Uruguay. Acta Geologica Leopoldensia, XVII(39/2):679-89.

FAURE, K. \& COLE, D. 1999. Geochemical evidence for lacustrine microbial blooms in the vast Permian Main Karoo, Paraná, Falkland Islands and Huab basins of southwestern Gondwana. Palaeogeography, Palaeoclimatology, Palaeoecology, 152:189213.

FELIX, C.J. \& BURBRIDGE, P.P. 1967. Palynology of the Springer Formation of southern Oklahoma, U.S.A. Palaeontology, 10(3):349. 425.

FOSTER, C.B. 1975. Permian plant microfossils from the Blair Athol Coal Measures, Central Queensland, Australia. Palaeontographica, Abt. B 154:121-71.

FOSTER, C.B. 1979. Permian plant microfossils of the Blair Athol Coal Measures, Baralaba Coal Measures, and Basal Rewan Formation of Queensland. Geological Survey of Queensland, 372(45):1-154.

FOSTER, C.B. \& WATERHOUSE, J.B. 1988. The Granulatisporites confluens Oppel-Zone and Early Permian marine faunas from the Grant Formation on the Barbwire Terrace, Canning Basin, Western Australia. Australian Journal of Earth Science, 35:135-57.

FRAKES, L.A. \& FIGUEIREDO-FILHO, P.M. 1967. Glacial rocks of the Paraná Basin exposed along the Sorocaba Itapetininga Road. In: Bigarella, J.J.; Becker, R.D. \& Pinto, I.D. (eds.), Problems in Brazilian Gondwana Geology. INTERNATIONAL SYMPOSUUM ON THE GONDWANA STRATIGRAPHY AND PALAEONTOLogy, 1, Curitiba, 1967. p.103106.

FRANÇA, A.B. \& CALDAS, A.F.F.D. 1983. Diferenciação e evoluçāo dos sistemas deltaicos na parte superior do Grupo Tubarão, Bacia do Paraná. Revista Brasileira de Geociências, 13(1):56-67.

FRANÇA, A.B. \& POTTER, P.R. 1988. Estratigrafia, ambiente deposicional e análise de reservatório do Grupo Itararé (Permocarbonífero), Bacia do Paraná (Parte 1). Boletim de Geociências da Petrobrás, 2(2/4):147-91,

FÚl.FARO,V.J. \& LANDIM, P.M.B. 1976. Stratigraphic sequences of the intracratonic Paraná Basin. Newsleter Strattigraphy, 4(3):150-68.

FÚLFARO, V.J.; PERINOTTO, J.A.J. \& BARCELOS, J.H. 1991. Formação Tietê: o pós-glacial no Estado de Sāo Paulo. In: Simpósio de Geologia do Sudeste, 2", São Paulo, 1991. Atas... SBG/SP-RJ, p. 391.404.

GALTIER, J. \& SCOTT, A.C. 1979. Studies of Paleozoic ferns: on the genus Corynepteris. A redescription of the type and some other 
European species. Palaeontographica, Abt. B 170:81-125.

GAMA JR, E.G. \& PERINOTTO, J.A.J. 1992 Consideraçöes sobre a evolução paleogeográfica do Permo-Carbonífero da Bacia do Paraná. In: Congresso Brasileiro DE GEOLOGIa, $37^{\circ}$, São Paulo, 1992. Boletim de Resumos Expandidos... SBG/SP, 2:518.9.

GAMA JR., E.G.; PERINOTTO, J.A.J. \& RIBEIRO, H.J.P. 1991. Contribuição ao estudo de paraseqüências no Subgrupo Itararé ( $P$-C) no Estado de São Paulo. In: SimpósIO DE Geologia do Sudeste, 2, São Paulo, 1991. Atas... SBG/SP-RJ, p.385-9.

GARCIA, G.B. 1995. Palinologia de la Formación El Imperial, Paleozóico Superior, Cuenca San Rafael, Argentina. Parte 1: Esporas. Ameghiniana, 32(4):315-39.

GARCIA, G.B. 1996. Palinologia de la Formación El Imperial, Paleozóico Superior, Cuenca San Rafael, Argentina. Parte 11: Granos de polen, incertae sedis, Acritarcas. Ameghiniana, 33(1):7-33.

GARCIA, G.B. \& AZCUY, C.L. 1987. Dos asociaciones palinologicas de la Formación El Imperial, al sur del Rio Doamante, Provincia de Mendoza, Republica Argentina. In: Simpósio ARgentino de PALEOBOTANICA $Y$ PAlinologia, VII, Buenos Aires, 1987. Actas..., p. 59-62

GILBY, A.R. \& FOSTER, C.B. 1988. Early Permian palynology of the Arckaringa Basin, South Australia. Palaeontographica, Abt. B 209:167-91.

GOMANKOV, A.V.; BALME, B.E. \& FOSTER, C.B. 1998. Tatarian palynology of the Russian Platform: a review. Proceedings of the Royal Society of Victoria, 110(1/2):115-35.

GONZÁLEZ, C.R. 1996. The Mid Carboniferous Boundary and the beginning of the glacial age in Argentina. Newsletter on Carboniferous Stratigraphy, 14:12.

GONZÁLEZ, C.R. 1998. The origin of some endemic bivalves of Gondwana. Newsletter on Carboniferous Stratigraphy, 16:24-25.

GONZÁLEZ-AMICÓN, O.R. 1973. Microflora carbónica de la localidad de Retamito, Província de San Juan. Ameghimiana, $X(1): 1$ 35.

GÓRECKA, T. \& GÓRECKA-NOWAK, A. 1990. Palynostratigraphic studies of Upper Carboniferous deposits from the Intra-Sudetic Basin, southwestern Poland. Review of Paleobotany and Palynology, 65:287-292.

GOULD, A.E. \& DELEVORYAS, T. 1977. The biology of Glossopteris: evidence from petrified seed-bearing spores. Alcheringa, $1(3 / 4): 387-99$
GRADSTEIN, F.M. \& OGG, J. 1996. A Phanerozoic time scale. Episodes, 19(1/2):3 4.

GRAUVOGEL-STAMM, L. \& DOUBINGER, J. 1975. Deux fougères fertiles du Stéphanien du Massif Central (France). Geobios, 8(6):37 41.

GUERRA-SOMMER, M. \& CAZZULO-KLEPZIG, M. 1993. Biostratigraphy of the Southern Brazilian Neopaleozoic Gondwana sequence: a preliminary palaeobotanical approach. in: INTERNATION CONGRESS ON CARBONIFEROUS Permian, XII, Buenos Aires, 1993. Compte Rendus.... 2:61-72.

GUPTA, S. 1970. Miospores from the Desmoinesian-Missourian boundary formations of Texas and the age of the Salesville Formation. Geoscience and Man, I:67-82.

GUTIÉRREZ, P.R. 1988. Análisis paleoflorístico, bioestratigráfico y aspectos paleoambientales de la Formación Água Colorada en el sector sudoriental de la Sierra de Famatina, província de La Rioja, República Argentina. Buenos Aires: inédito (Tese de Doutoramento, Universidad de Buenos Aires), 595p.

GUTIÉRREZ, P.R. 1993. Palinología de la Formación Água Colorada (Carbonífero Superior), Sierra de Famatina, Província de La Rioja, Argentina. I. Granos de polen. Ameghiniana, 30(2):163-212.

GUTIÉRREZ, P.R. \& CÉSARI, S.N. 1988. Nuevas microfloras de la Formación Lagares (Carbonífero), Província de La Rioja, República Argentina. Ameghiniana, 25(1):8596.

GUTIÉRREZ, P.R.; CÉSARI, S.N. \& ARCHANGEL.SKY, S. 1997. Deusilites tenuistriatus $\mathrm{sp}$. nov. (Acritarca) en el Pérmico Inferior de la Cuenca Chacoparanense (Argentina). Ameghiniana, 34(2): $147-50$.

GUY-OHLSON, D. 1992. Botryococcus as an aid in the interpretation of palaeoenvironment and depositional processes. Review of Palaeobotany and Palynology, 71:1-15.

HABIB, D. 1966. Distribution of spore and pollen assemblages in the Lower Kittanning coal of western Pennsylvania. Palaeontology, 9(4):629-66.

HACHIRO, J. 1996. O Subgrupo Irati (Neopermiano) da Bacia do Paraná. São Paulo: inédito (Tese de Doutoramento, Instituto de Geociências da Universidade de São Paulo), 196p.

HAMER, J.J. \& ROTHWELL, G.W. 1983. Philipopteris gen. nov. - Anatomical preserved sporangial fructifications from the Upper Pennsylvanian of the Appalachian 
Basin. American Journal of Botany, 70(9): $1378-85$

HARLAND, W.B.; ARMSTRONG, R.L.; COX, A.V.; CRAIG, L.E.; SMITH, A.G. \& SMITH, D.G. 1989. A Geologic time scale. Cambridge: Cambridge University Press, 72p.

HART, G.G. 1969. Micropaleontology of the Karroo deposits in South and Central Africa. In: SYMPOSIUM ON GONDWANA STRATIGRAPHY, $1^{\text {st }}$, Mar del Plata, 1967. IUGS, p.161-72.

HART, G.F. 1971. The Gondwana Permian palynofloras. Anais da Academia Brasileira de Ciências, 43(suplemento):145-85.

HARTKOPF-FRÖDER, C. \& STREEL, M. 1993. Late Famennian miospore assemblages from the Bergisch Gladbach - Paffrath Syncline, Rhenish Slate Moutains, Germany. Annales de la Société Géologique de Belgique, 116(2):333-57.

HAVEN, P.H.; EVERT, R.F. \& EICHHORN, S.E. 1996. Capítulo 16. Plantas vasculares sem sementes e Capítulo 17. Gimnospermas. In: Kraus, J.E. (Coord.), Biologla Vegetal. Rio de Janeiro: Ed. Guanabara, Koogan, p.294353.

HIGGS, K.T. 1975. Upper Devonian and Lower Carboniferous miospores assemblages from Hook Head, County Wexford, Ireland. Micropaleontology, 3(4):301-24.

HIGGS, K.T. 1996. Taxonomy and systematic study of some Tournaisian (Hastarian) spores from Belgian. Review of Palaeobotany and Palynology, 93:269-97.

HIGGS, K.T.; DREESEN, R.; DUSAR, M. \& STREEL, M. 1992. Palynostratigraphy of the Tournaisian (Hastarian) rocks in the Namur Synclinorium, West Flanders, Belgium. Review of Palaeobotany and Palynology, 72:149-58.

HOEG, A.O. \& BOSE, M.N. 1960. The Glossopteris Fiora of the Belgian Congo. Annales du Musée Royal du Congeo Belge, Tervurem, Série in- $8^{\circ}$, Sciences géologiques, 32:109p.

HOLZ, M. \& DIAS, M.E. 1998. Taphonomy of palynological records in a sequence stratigraphic framework: na example from the Early Permian Paraná Basin of southern Brazil. Review of Palaeobotany and Palynology, 99:217 33.

HOROWITZ, A. 1974. Palynostratigraphy of the subsurface Carboniferous, Permian, and Triassic in Southern Israel. Geoscience and Man, IX:63 70.

HUGHES, N.F. \& PLAYFORD, G. 1961. Palynological reconnaissance of the Lower Carboniferous of Spitsbergen. Micropaleontology, 7(1):27-44.

HYDE, H.A. \& WILLIANS, D.W. 1944. Right Word. Pollen Analysis Circular, 8:6.
IANNUZZI, R. \& ROHN, R. 1995. Discussão sobre a presença do gênero Glossopteris na tafoflora de Cerquilho (Grupo Tubarão, Bacia do Paraná, Estado de São Paulo) e seu possível significado biocronoestratigráfico. In: Congresso Brasileiro de Paleontologia, XIV, Uberaba, 1995. Atas..., SBP, p.62.

IANNUZZI, R. \& RÖSLER, O. 2000. Floristic migration in South America during the Carboniferous: phytofeograhic and biostratigraphic implications. Palaeogeography, Palaeoclimatology, Palaeocology, 161:71-94.

ISAACSON, P.E; CANTER, K.L. \& SABLOCK, P.E. 1993. Late Paleozoic Copacabana Formation in NW Bolivia: paleogeographic significance of carbonates with siliciclastics. In: INTERNATIONAL CONGRESS ON Carboniferous-Permian, XII, Buenos Aires, 1991. Compte Rendus, 2:262-8.

IUGS/UNESCO. sem data. Explanatory note to the International Stratigraphic Chart. Division of Earth Sciences, UNECO, $16 \mathrm{p}$.

JANSONIUS, J. 1962. Palynology of Permian and Triassic sediments, Peace River Area, Western Canada. Palaeontographica, Abt. B 110:35-98.

JARDINÉ, S. \& YAPAUDJIAN, L. 1968. Lithostratigraphie et palynologie du dévonienGothlandien gréseux du Bassin de Polignac (Sahara). Revue de I'Institut Français du Pétrole, 23(4):439-69.

JARZEN, D.M. \& NICHOLS, D.J. 1996. Chapter 9. Pollen. In: Jansonius, J. \& McGregor, D.C. (eds.), Palynology: principles and applications. AASP Foudation, 1:261-91.

JERSEY, N.J. DE. 1962. Triassic spores and pollen grains from the Ipswich coalfield. Geological Survey of Queensland, Publication 307, p. 1-18.

JONES, M.J. \& TRUSWELL, E.M. 1992. Late Carboniferous and Early Permian palynostratigraphy of the Joe Joe Group, southern Galilee Basin, Queensland, and implications for Gondwanan stratigraphy. BMA Journal of Australian Geology \& Geophysics, 13:143-85.

KEEGAN, J.B.; RASUL, S.M. \& SHAHEEN, Y. 1990. Palynostratigraphy of the Lower Palaeozoic, Cambrian to Silurivan, sediments of the Hashemite Kingdom of Jordan. Review of Palaeobotany and Palynology, 66:167-80.

KEMP, E.M. 1975. The palynology of Late Paleozoic glacial deposits of Gondwanaland. In: Campbell, K.S.W. (ed.), Gondwana Geology. Camberra: Australian National University Press, Papers from the Gondwana Symposium, p. 397-416.

KEMP, E. M.; BALME, B.E.; HELBY, R.J.; KYLE, R.A.; PLAYFORD, G. \& PRICE, P.L. 1977. Carboniferous and Permian 
palynostratigraphy in Australia and Antarctica: a review. BMR Journal of Australian Geology and Geophisic, 2:177208.

KMIECIK, H. 1986. Palynostratigraphy of the Carboniferous at the margin of the Polish part of the East-European Platform. Review of Palaeobotany and Palynology, 48:327-45.

KOSANKE, R.M. 1950. Pennsylvanian spores of Illinois and their use in correlation. State Geological Survey of Illinois, Bull. 74, $128 \mathrm{p}$.

KYLE, R.A. \& SCHOPF, J.M. 1982. Permian and Triassic palynostratigraphy of the Victoria Group, Transantarctic Mountains. In: Craddock, C. (ed.), Antartic Geoscience. Madison: Univ. Wisconsin Press, p.649-59.

LANZONI, E. \& MAGLOIRE, L. 1969. Associations palynologiques et leurs applications stratigraphiques dans le Dévonien supérieus et Carbonifère inféreus du Grand Erg Occidental (Sahara algérien). Revist du Institut Frances de Pétrole, 23(4):441-65.

LAVEINE, J.P. 1969. Quelques Pécoptéridinées houillères à la lumière de la palynologie. Pollen et Spores, 11(3):619-88.

LAVEINE, J.P. 1971. Sporomorphs in situ de quelques Parispermées (Neuroptéridées) du Carbonifère. Annales Societé Géologique du Norde, $91(2): 155-73$.

LEGAULT, J.A. \& NORRIS, G. 1982. Palynological evidence for recycling of Upper Devonian into Lower Cretaceous of the Moose River Basin, James Bay Lowland, Ontario. Canadian Journal of Earth Sciences, 19(1):1-7.

LEIPNITZ, B. 1981. Estudo palinológico da Formação Palermo, Estado de Santa Catarina, Permiano, Bacia do Paraná, Brasil. Porto Alegre: inédito (Dissertação de Mestrado, Intituto de Geociências da UFRGS), $141 \mathrm{p}$.

LELE, K.M. 1964. Studies in the Talchir flora of India: 2. Resolution of the sporegenus Nuskoisporites Pot. \& KI. The Palaeobotanist, $12(2): 147-68$

LELE, K.M. \& KARIM, R. 1971. Studies in the Talchir flora of India - 6. Palynology of the Talchir Boulder Bed in Jayanti coalfield, Bihar. The Palaeobotanist, 19(1):52-69.

LELE, K.M. \& MAITHY, P.K. 1969. Miospore assemblage of the Ganjra Nalla Beds, South Rewa Gondwana Basin, with some remarks on teh age of the beds. The Palaeobotanist, $17(3): 298-309$.

LELE, K.M. \& SHUKLA, M. 1980. Studies in the Talchir Flora of India-12. Palynology of the Talchir Formation of Hutar Coalfield, Bihar. Geophytology, 10(2):231-8.

LELE, K.M. \& SRIVASTAVA, A.K. 1979. Lower Gondwana (Karharbari to Raniganj Stage) miofloral assemblages from the Auranga
Coalfield and their stratigraphical significance. In: INTERNATIONAL PALYNOLOGICAL CONFERENCE, IV, Lucknow, 1976-77. Proceedings..., 2:152-64

LIMA, M.R. de; DINO, R. \& YOKOYA, N.S. 1983. Palinologia das concreções calcíferas do Subgrupo Itararé (Neopaleozóico da Bacia do Paraná) na região de Araçoiaba da Serra, Estado de São Paulo. Ariais da Academia Brasileira de Ciências, 55(2):195-208.

LIMARINO, C. \& GUTIÉRREZ, P.R. 1990. Diamictites in the Agua Colorada Formation (northwestern Argentina): New evidence of Carboniferous glaciation in South America. Journal of South American Earth Sciences, $3(1): 9-20$.

LINDSTRÖM, S. 1995. Early Permian palynostratigraphy of the northern Heimefrontfjella mountain-range, Dronning Maud Land, Antarctica, Review of Palaeobotany and Palynology, 89:359 415.

LINDSTRÖM, S. 1996. Late Permian palynology of Fossilyggen, Vestffjella, Dronning Maud Land, Antarctica. Palynology, 20:15 48.

LOBOZIAK, S.; MELO, J.H.G.; DINO, R.; VACHARD, D. \& STRELL, M. 1997. Earliest taeniate bisaccates from the Amazon Basin are not older than Westphalian. Geobios, Lyon, 30(4):467,74

LOBOZIAK, S.; MELO, J.H.G.; PLAYFORD, G. \& STREEL, M. 1999. The Indotriradites dolianitii Morphon, a distinctive group of miospore species from the Lower Carboniferous of Gondwana. Review of Palaeobotany and Palynology, 107:17-22.

LOBOZIAK, S.; MELO, J.H.G. \& STREEL, M. 1998. Reassessment of Viséan miospores biostratigraphy in the Amazon Basin, northern Brazil. Review of Palaeobotany and Palynology, 104:143-55.

LOVE, L.G. \& NEVES, R. 1963. Palynological evidence on the age of the Carbonierous of Inninmore. Transactions of the Geological Society of Glasgow, XXV(1):61-71.

MAHESHWARI, H.K. \& BOSE, M.N. 1969. Palaeozoic sporae dispersae from Congo. VIII - The Kibamba River (Lukuga coalfield area). Annales du Musée Royal de L'Africa Centrale, Tervuren, Série IN $8^{\circ}$, Sciences Geologiques, $n^{\circ} 63$, p. 3-63.

MAITHY, P.K. 1965. Studies in the Glossopteris flora of India. 27. Sporae dispersae from the Karharbari beds in the Giridish coalfield, Bihar. The Palaeobotanist, 13(3):291-307.

MANGERUD, G. 1994. Palynostratigraphy of the Permian and lowermost Triassic succession, Finnmark Platform, Barents Sea. Review of Palaeobotany and Palynology, 82:317-49.

MARQUES.TOIGO, M. 1973. Estudo palinológico de concreções calcárias da 
Formação San Gregório, NE da República Oriental do Uruguai - Bacia do Paraná. Porto Alegre: inédito (Dissertação de Mestrado, Instituto de Geociências da UFRGS), 109p.

MARQUES-TOIGO, M. 1974. Some new species of spores and pollens of Lower Permian age from the San Gregório Formation in Uruguay. Anais da Academia Brasileira de Ciências, 46(3/4);601-16.

MARQUES-TOIGO, M. 1988. Palinologia, bioestratigrafia e paleoecologia do Neopaleozóico da Bacia do Paraná nos estados do Rio Grande do Sul e Santa Catarina, Brasil. Porto Alegre: inédito (Tese de Doutoramento, Instituto de Geociências da UFRGS), 259p.

MARQUES-TOIGO,

M.

1991.

Palynobiostratigraphy of the Southern Brazilian Neopaleozoic Gondwana sequence. In: INTEPNATIONAL GONDWANA SYMPOSIUM, $7^{\text {st }}$, São Paulo, 1988. Proceedings..., p.503-15.

MARQUES-TOIGO, M. \& PICARELLL, A.T. 1984. On the morphology and affinities of Lundbladispora Balme 1963, in the Permian of the Parana Basin, Brazil. Bol. IGUSP, 15:46-52

MARQUES-TOIGO, M. \& PONS, M.E. 1974. Estudo palinológico do furo de sondagem P7 Malha Oeste da bacia carbonífera de Iruí, RS, Brasil. In: CONGRESSO BRAsLleiro DE Geologia, XXVIII, Porto Alegre, 1974. Anais..., ll:277־88.

MARQUES-TOIGO, M.; CAZZULO-KLEPZIG, M.; PICARELLLI, A.T. \& QUADROS, L.P. de. 1995. The occurrence of disaccites Striatiti polen grains in the Amazonas Basin Namurian - palaeoclimatic and paleogeographic implications. In: INTERNATIONAL. CONGRESS ON CARBONIFEROUSPermian, Xlll, Kraków, 1995. Abstracts... Polish Geological Institute, p.97.

MARQUES-TOIGO, M.; DIAS-FABRÍCIO, M.E.; CAZZULO-KLEPZIG, M.; OLIVEIRA, L.M. \& DAVID, C.A.S. 1981. Caracterização palinológica de camadas de carvāo da área de Ribeirão Novo (PR), Paleozóico da Bacia do Paraná-Brazil. In: Simpósıo REGıONAL. DE GEOLOGIA, 3', Curitiba, 1981. Atas... SBG, 2:310-21.

MARQUES-TOIGO, $M_{i}$ SILVA, Z.C.C. \& HERTER, G.G. 1975. Geology and palynology of Candiota Coal Mine, RS, Brazil. In: CONGRESO ARGENTINO DE Paleontología Y BioestratigaAfía, I, Tucumán, 1975. Actas...., 1:401-27.

MASSOLI, M. 1991. Relaçäo entre o embasamento cristalino e os sedimentos basais do Subgrupo Itararé na regiáo de Salto de Pirapora, SP. Säo Paulo: inédito (Dissertação de Mestrado " Instituto de Geociências da USP), 94p.
MATOS, S.L.F. 1999. História deposicional e idade do intervalo portador de carvão da Formação Rio Bonito, Permiano da Bacia do Paraná, no depósito de carvão de Candiota, RS. São Paulo: inédito (Tese de Doutoramento, Instituto de Geociências da USP), 158p.

MAUTINO, L.R. \& ANZÓTEGUI, L.M. 2000. Esporas del Mioceno y retrabajadas del Mesozoico en la Formación Chiquimil, Vallecito, província de Catamarca. Ameghiniana, 37(1):13-22.

MAUTINO, L.R.; ANZÓTEGUH, L.M. \& VERGEL, M.M. 1998a. Palinología de la Formación Melo (Pérmico Inferior) en Arroyo Seco, Departamento Rivera, República Oriental del Uruguay. Parte IV: Esporas. Ameghiniana, 35(1):67-79.

MAUTINO, L.R.; VERGEL, M.M. \& ANZÓTEGUI, L.M. 1998b. Palinología de la Formación Melo (Pérmico Inferior) en Arroyo Seco, Departamento Rivera, Uruguay. Parte V: Granos de pólen, acritarcas e incertae sedis. Ameghiniana, 35(3): 299-314.

MCLEAN, D. 1995. Provenance of reworked palynomorfphs from the Greenmoor Rock (Langsettian, Late Carboniferous) near Sheffiel, England. Review of Palaeobotany and Palynology, 89:305 17.

MCLEAN, D. 1999. Namurian (Late Carboniferous) bisaccate pollen grom the Pennine Basin, UK. In: INTERNATION CONGRESS ON THE CARBONIFEROUS-PERMIAN, XIV, Calgary, 1999. Abstracts... Univ. Calgary, p.93.

MELO, J.H.G.; LOBOZIAK, S. \& STREEL, $M$. 1999. Latest Devonian to Early Late Carboniferous biostratigraphy of Northern Brazil: na update. Bulletin du Centre de Recherches ELF Exploration Production, 22(1):13-33.

MENÉNDEZ, C.A. 1965. Contenido palinológico en sendimentos com "Phacopteris ovata" (Mc Coy) Walk. de La Sierra de Famatina, La Rioja. Revista del Museo Argentino de Ciencias Naturales "Bernardino Rivadávia", I(3):45-80.

MENÉNDES, C.A. 1971. Estudio palinológico del Permico de Bajo de Velez, Província de San Luis. Revista del Museu Argentina de Ciencias Naturales "Bernardino Rivadavia", Paleontologia, 1(9):263-306.

MENÉNDEZ, C.A. 1976. Contenido palinologico de estratos permicos com "Mesosaurus" de Rio Claro, São Paulo, Brasil. Revista del Museo Argentino de Ciencias Naturales "Bernardino Rivadávia", II(1):1-30.

MENÉNDEZ, C.A. \& AZCUY, C.L. 1969. Microflora carbónica de la localidad de Paganzo, Província de la Rioja. Parte 1. Ameghiniana, VI(2):77-97. 
MENÉNDEZ, C.A. \& AZCUY, C.L. 1971. Microflora carbónica de la localidad de Paganzo, Província de la Rioja. Parte Il. Ameghiniana, VIII(1):25-36.

MENÉNDEZ, C.A. \& AZCUY, C.L. 1972. Ancistrospora un nuevo genero de miospora del Carbónico de la Argentina. Revista Española de Micropaleontología, IV(2):15768.

MENÉNDEZ, C.A. \& AZCUY, C.L. 1973. Microflora carbónica de la localidad de Paganzo, Província de la Rioja. Parte III. Ameghiniana, $X(1): 51-71$.

MENÉNDEZ, C.A. \& PÖTHE DE BALDIS, E.D. 1967. Devonian spores from Paraguai. Review of Palaeobotany and Palynology, 1:161-72.

MENNING, M. 1995. A numerical time scale for the Permian and Triassic periods: na integrated time analysis. In: Scholle, P.A.; Peryt, T.M. \& Ulmer-Scholle, D.S. (eds.), The Permian of the Northern Pangea. Berlim: Spring-Verlag, 1, $261 p$.

METCALFE, I. 1997. Revision of the Carboniferous part of the IUGS Global Stratigraphic Chart. Newsletter on Carboniferous Stratigraphy, 15:12-8.

MEZZALIRA, S. 1956. Novas ocorrências de camadas marinhas permo-carboniferas no Estado de São Paulo. Boletim da Sociedade Brasileira de Geologia, 5(1):61-9.

MILANI, E.J. 1997. Evolução tectonoestratigráfica da bacia do Paraná e seu relacionamento com a geodinâmica fanerozóica do Gondwana sul-orienta!. Porto Alegre: inédito (Tese de Doutoramento, Instituto de Geociências da UFRGS).

MILANI, J.E.; FRANÇA, A.B. \& SCHNEIDER, R.L. 1994. Bacia do Paraná. Boletim de Geociências da Petrobrás, 8(1):69-82.

MILLAN, J.H. 1987. Os pisos florísticos do carväo do Subgrupo Itararé no Estado de São Paulo e suas implicações. In: CONGREsso Brasileiro de Paleontologia, 10, Rio de Janeiro, 1987. Anais... SBP, p.832-857.

MILLAN, J.H. 1989. Sobre a presença de formas foliares mais primitivas de Glossopterídeas (gênero Gangamopteris no município de Cerquilho, carvão do Eogondwana do Estado de São Paulo. Anais da Academia Brasileira de Ciências, 61(2):201-13.

MILLAN, J.H; DOLIANITI, E. \& ANDRADE, A. 1980. Nota preliminar sobre uma nova tafoflórula na lapa do carvão de Mato Seco, município de Césari Lange, SP. Anais da Academia Brasileira de Ciências, 52(3):555. 8.

MILLAY, M.A. \& TAYLOR, T.N. 1982. The ultrastructure of Paleozoic fern spores: I
Botryopteris. American Journal of Botany, 69(7):1148-55.

MÜLLER, J. 1959. Palynology of recent Orinoco delta and shelf sediments: Reports of the Orinoco Shelf Expedition, Volume 5. Micropaleontology, 5(1): 1-32.

MURPHY, M.A. \& SALVADOR, A. (eds.) 1999. International Stratigraphic Guide - an abridged version. Episodes, 22(4):255-71.

NAHUYS, J.; ALPERN, B. \& YBERT, J-P. 1968. Estudo palinológico e petrográfico de alguns carvōes do sul do Brasil. Boletim Técnico, Instituto Tecnológico do Rio Grande do Sul, 46:3-61.

NAVALE, G.K.B. 1964. Palynological studies of Merlabach coals in conjunction with petrographic structure. The Palaeobotanist, 12(3):232-48.

NEVES, R. 1961. Namurian plant spores from the Southern Pennines, England. Palaeontology, 4(2):247-79.

NEVES, R. \& DOLBY, G. 1967. An assemblage of miospores from the Portishead beds (Upper old Red Sandstone) of the Mendip Hills, England. Pollen et Spores, IX(3):605-11.

NORTHFLEET, A.; MEDEIROS, R.A. \& MUHLMANN, H. 1969. Reavaliação dos dados geológicos da Bacia do Paraná. Boletim Técnico da Petrobrás, 12(3):291. 346.

NYAMBE, I.A. \& UTTING, J. 1997. Stratigraphy and palynostratigraphy, Karro Supergroup (Permian and Triassic), mid-Zambezi Valley, southern Zambia. Journal of African Earth Sciences, 24(4):563-83.

NYGREEN, P.W. \& BOURN, O.B. 1967. Morphological variation of Potonieisporites in the Late Pennsylvanian florule. Review of Palaeobotany and Palynology, $1(1 / 4): 115-28$.

OELOFSEN, B. \& ARAÚJO, D.C. 1983. Paleoecological implications of the distribution of Mesosaurid reptiles in the Permian trati sea (Paraná Basin), South America. Revista Brasileira de Geociências, 13(1):1-6.

OLIVEIRA, S. F. 1991. Acritarcas e prasinofíceas da Formação Ponta Grossa (Devoniano) no flanco noroeste da Bacia do Paraná. Säo Paulo: (Dissertação de Mestrado, Instituto de Geociências da USP), $205 p$.

OLIVEIRA, S.F. 1997. Palinologia da seqüência devoniana da Bacia do Paraná no Brasil, Paraguai e Uruguai: implicações biocronoestratigráficas, paleoambientais e paleogeográficas. São Paulo: inédito (Tese de Doutoramento, Instituto de Geociências da USP), 188p.

OTTONE, E.G. 1989. Palynoflores de la Formation Santa Máxima, paléozoïque 
Supérieur, République Argentine. Palaeontographica, Abt. B 213: 89-148.

OTTONE, E.G. 1991. Palynologie du Carbonifère Supérieus de la Coupe de Mina Esperanza, Bassin Paganzo, Argentina. Revue de Micropaléontologie, 34(2):118-35.

OTTONE, E.G. 1996. Devonian palynomorphs from the Los Monos Formation, Tarija Basin, Argentina. Palynology, 20:105-55.

OTTONE, E.G. \& AZCUY, C.L. 1986. El perfil de la Quebrada la Delfina, provincia de San Juan. Revista de la Asociación Geológica Argentina, XLI(1-2):124-36.

OTTONE, E.G. \& AZCUY, C.L. 1989. Datos palinologicos de la Formación Guadancol (Carbonífero) en la Quebrada la Delfina, Província de San Juan, Argentina. Ameghiniana, 26(3/4):191-208.

OTTONE, E.G. \& AZCUY, C.L. 1990. Palinología del carbon del Água Hedionda (Carbonífero). Huaco, Província de San Juan, Argentina. Ameghiniana, 27(1/2):3-18.

OTTONE, E.G. \& GARCIA, G.B. 1996. Organicwalled microphytoplankton from the Lower section of the Santa Máxima Formation, Upper Carboniferous, Argentina. Ameghiniana, 33(1):103-6.

OTTONE, E.G. \& ROSSELLO, E.A. 1996. Palinomorfos pérmicos de la Formación Puerta, Cordillera Frontal, Argentina. Ameghiniana, 33(4):453-5.

OTTONE, E.G.; ROSSELLO, E.A.; SIMANAUSKAS, T. \& VACHARD, D. 1998. Palaeontology and biostratigraphy of the Late Palaeozoic Copacaba Group at the Angosto del Beu, Bolivia. Ameghiniana, 35(1):87-96.

OUYANG-SHU \& ZHU-HUAICHENG. 1998. Palynological events and the midCarboniferous boundary. Newsletter on Carboniferous Stratigraphy, 16:14-6.

OWENS, B. 1983. Bascaudaspora gen. nov., a new reticulate miospores genus from the Namurian of Northern England. Report of the Institute of Geological Sciences, 83/10:46-9.

OWENS, B. 1996. Chapter 18D. Upper Carboniferous spores and pollen. In: Jansonius, J. \& McGregor, D.C. (eds.), Palynology: principles and applications. AASP, 2:597-606.

OWENS, B.; GUEINN, K.J. \& CAMERON, I.B. 1977. A Tournaisian miospore assemblage from the Altagoan Formation. (Upper Calciferous Sandstone), Draperstown, Northern Ireland. Pollen et Spores, XIX(2):313-24.

OWENS, B.; NEVES, R.; GUEINN, K.J.; MISHELL, D.R.F.; SABRY, H.S.M.Z. \& WILLIAMS, J.E. 1977. Palynological division of the Namurian of northern England and Scotiand.
Proceedings of the Yorkshire Geological Society, 41/3(30):381-98.

PANT, D.D. \& SRIVASTAVA, G.K. 1965. Some lower Gondwana miospores from Brazil. Micropaleontology, 11(4):468-78.

PEPPERS, R.A. 1997. Palynology of the Lost Branch Formation of Kansas - new insights on the major floral transition at the MiddleUpper Pennsylvanian boundary. Review of Palaeobotany and Palynology, 98:223-46.

PERINOTTO, J.A.J. 1987. Análise estratigráfica da seqüência portadora de carvão na regiấo de Cerquilho (SP). São Paulo: inédito (Dissertação de Mestrado, Instituto de Geociências da USP), 76p.

PERINOTTO, J.A.J. \& FULFARO, V.J. 2000. Permian post glacial coal bearing deposits in the Paraná Basin, State of São Paulo, Brazil. in: INTERNATIONAL GEOLOGICAL CONGRESS, $31^{\text {st }}$, Rio de Janeiro, 2000. Abstracts... (CDROM).

PETRI, S. 1964. Geologia do Estado de São Paulo. Boletim do Instituto Geográfico e Geológico, 41:56-63.

PETRI, S. 1992. Litofácies e significado paleoambiental dos sedimentos Itararé na região CapivarímRafard, Estado de Sáo Paulo. Revista do Instituto Geológico, 13(1):7-30.

PETRI, S. \& PIRES, F.A. 1992. O Subgrupo Itararé (Permocarbonífero) na região do Médio Tietê, Estado de São Paulo. Revista Brasileira de Geociências, 22(3):301-10.

PETRI, S. \& SOUZA, P.A. de. 1993. Síntese dos conhecimentos e novas concepçōes sobre a bioestratigrafia do Subgrupo Itararé, Bacia do Paraná, Brasil. Revista do Instituto Geológico, 14(2):7-18.

PETRI, S.; COIMBRA, A.M.; AMARAL, G. \& PONÇANO, W.L. 1986a. Guia de Nomenclatura Estratigráfica. Revista Brasileira de Geociências, 16:376-415.

PETRI, S.; COIMBRA, A.M.; AMARAL, G.; OJEDA y OJEDA, H.; FÚLFARO, V.J. \& PONÇANO, W.L. 1986b. Código Brasileiro de Nomenclatura Estratigráfica. Revista Brasileira de Geociências, 16:372-6.

PETRI, S.; VIEIRA, P.C.; ODA, G.H. \& BOTELHO, P.F. 1996. O Subgrupo Itararé, Permocarbonífero da região do Médio Tietê, Estado de São Paulo: estudos em subsuperfície. Revista do Instituto Geológico, 17(1/2):63-78.

PICARELLLI, A.T. 1986. Palinologia dos testemunhos de sondagem 2-TG-69-RS e 2-TG-99-RS da jazida carbonífera de Santa Terezinha, RS, Bras $\$$ - Permiano da Bacia do Paraná. Porto Alegre: inédito (Dissertaçāo de Mestrado, Instituto de Geociências da UFRGS). 
PICARELLI, A.T:; DIAS-FABRÍCIO, M.E, \& CAZZULO-KLEPZIG, $\quad$ M. 1987. Consideraçōes sobre a paleoecologia e a palinologia da jazida carbonifera de Santa Terezinha, RS, Brasil - Permiano da Bacia do Paraná. In: Simpósio Sul-Brasilefro DE GEOLOGIA, III, Curitiba, 1987. Atas.... 1:351. 72.

PICCOLI, A.E. \& BORTOLUZZI, C.A. 1981. Paleogeografia das seqüências ltararé e Rio Bonito (Permiano Inferior) - Região Carbonifera de Santa Rita, RS. In: Simpósio REgIONAL DE GeOlogia, 3 ${ }^{\circ}$, Curitiba, 1981. Atas... SBG, 2:133.46.

PICCOLI, A.E.M.; MENEGAT, R; GUERRASOMMER, M.; MARQUES TOIGO, M. \& PORCHER, C.C. 1991. Faciologia da seqüência sedimentar das folhas de Quitéria e Várzea do Capivarita, Rio Grande do Sul. Pesquisas, 18(1):31-43.

PINTO, I.D. 1990. A new Upper Carboniferous Paraplicopteran insect from South Brazil. Pesquisas, 17(1/2):7-10.

PINTO, I.D. 1995. Dados paleobotânicos e paleozoológicos e a idade de formações permianas e carboníferas na América do Sul. In: SIMPÓSIO SOBRE CRONOESTRATIGRAFIA DA Bacia do Paraná, 20, Porto Alegre, 1995. Boletim de Resumos Expandidos... ILEA. UFRGS, p. 87-8.

PINTO, I.D. \& ORNELLAS, L.P. 1978. Carboniferous insects (Protoorthoptera and Paraplecoptera from the Gondwana (South America, Africa and Asia). Pesquisas, 11:301-21.

PIRES, F.A. \& PETRI, S. 1991. O Subgrupo Itararé na região de Capivari-Rafard, Estado de Säo Paulo. In: SIMPósIO dE GEOLOGIA do SUDESTE, 2, São paulo, 1991. Atas... SBG/SP-RJ, p.391-6.

PLAYFORD, G. 1962. Lower Carboniferous microfloras of Spitsbergen. Palaeontology, $5(3): 550-618$.

PLAYFORD, G. 1964. Miospores from the Mississipian Horton Group, Eastern Canada. Geological Sunvey of Canada, Bull. 107, 47p.

PLAYFORD, G. 1971. Lower Carboniferous spores from the Bonaparte Gulf Basin, Western Australia and Northern Territory. Bulletin Mineral Resources Geology and Geophysics of Australia, 115:1-104.

PLAYFORD, G. 1978. Lower Carboniferous spores from the Ducabrook Formation, Drummond Basin, Queensland. Palaeontographica, Abt. B 167:105-160.

PLAYFORD, G. \& DETTMANN, M.E. 1996. Chapter 8. Spores. In: Jansonius, J. \& McGregor, D.C. (eds.), Palynology: principles and applications AASP Foundation, 1:227-60.
PLAYFORD, G. \& HELBY, R. 1968. Spores from a carboniferous section in the Hunter Valley, New South Wales. Journal of the Geological Society of Australia, 15(1):103-19.

PLAYFORD, G. \& McGREGOR, D.C. 1993. Miospores and organic-wallered microphytoplankton of DevonianCarboniferous boundary. beds (Bakker Formation), Southern Saskatchewan: a systematic and stratigraphic appraisal. Geological Survey of Canada, Bull. 445, 64p.

PLAYFORD, G. \& POWIS, G.D. 1979. Taxonomy and distribution of some trilete spores in carboniferous strata of the Canning Basin, Western Australia. Pollen et Spores, XXI(3):371-94.

PLAYFORD, G. \& SATTERTHWAIT, D.F. 1986. Lower Carboniferous (Visean) spores of the Bonaparte Gulf Basin, Northwestern Australia: part two. Palaeontographica, Abt. B 200:1 -32

PLAYFORD, G. \& SATTERTHWAIT, D.F. 1988 Lower Carboniferous (Visean) spores of the Bonaparte Gulf Basin, Northwestern Australia: part three. Palaeontographica, Abt. B 208:1-26.

PONS, M.E. 1976a. Estudo palinológico do SubGrupo Itararé na "Coluna White", Permiano Inferior, Santa Catarina, Brasil. Parte 1. Ameghiniana, 13(2):109 25 .

PONS, M.E. 1976b. Estudo palinológico do SubGrupo Itararé na "Coluna White", Permiano Inferior, Santa Catarina, Brasil. Parte II. Ameghiniana, 13(3/4):235-53.

POORT, R.J. \& VELD, H. 1997. Aspects of Permian palaeobotany and palynology. XVIII. On the morphology and ultrastructure of Potonieisporites novicus (prepollen of Late Carboniferous/Early Permian Walchiaceae). Acta Botanica Neerlandensis, 46(2):161-73.

POTONIÉ, R. 1956. Synopsis der Gattungen der Sporae dispersae. Beihefte zum Geologischen Jahrbuch, Heft 23, 103 p.

POTONIÉ, R. 1962. Synopsis der Sporae in situ. Geologisches Jahrbuch, 52:1-204.

POTONIE, R. 1967. New phylogenetic facts on fossil spores. Review of Palaeobotany and Palynology, 1:75-82.

POTONIÉ, R. 1970. Synopsis der Gattungen der Sporae Dispersae. V Teil: Nachträge zur allen Gruppen (Turmae). Geologischen Jahrbuch, 87:1-172.

POTONIÉ, R. \& KREMP, G.O.U. 1954. Die Gattungen der Paläozoischen sporae dispersae und ihre Stratigraphie. Geologischen Jahrbuch, 69:111-94.

POTONIÉ, R. \& KREMP, G.O.U. 1956. Die Sporae dispersae des Ruhrkarbons, ihre Morphographie und Stratigraphie mit Ausblicken auf Arten anderer Gebiete und 
Zeitabschnite. Teil III. Palaeontographica, Abt. B 100:85 191.

POTONIE, R. \& SAH, S.D.C 1960. Sporae dispersae of the lignites from Cannanore Beach on the Maslaber Coast of India. The Palaeotobanist, 7(2):121-35.

QUADROS, L.P. de. 1985. Distribuição bioestratigráfica dos Chitinozoa e Acritarchae na Bacia do Amazonas. Pio de Janeiro: inédito (Tese de Doutoramento, Instituto de Geociências da UFRJ), 179p.

QUADROS, L.P. de. \& MELO, J.H.G. 1987. Método prático de preparação palinológica em sedimentos pré-mesozóicos. Boletim de Geociências da Petrobrás, 1(2):205-14.

QUADROS, L.P. de; MARQUES-TOIGO, M. \& CAZZULO-KLEPZIG, M. 1995. Catálogo de esporos e pólen fósseis do Neopaleozóico. Boletim de Geociências da Petrobrás, 9(1): 1. 151

RAHMANI-ANTARI, K. 1990. Etude palynologique et évaluation de $1 /$ indice d'altération thermique du Paléozoique du forage DOT 1 (bassin des Doukkala Centre-Ouest marocain). Review of Palaeobotany and Palynology, 66:211-27.

ROCHA-CAMPOS, A.C. 1967. The Tubarão Group in the brazilian portion of the Paraná Brasil. In: Bigarella, J.J.; Becker, R.D. \& Pinto, I.D. (eds.), Probiems in Brazilian Gondwana Geology. IUGS, p.27-102.

ROCHA-CAMPOS, A.C. \& RÖSLER, O. 1978 Late Paleozoic faunal and floral sucessions in the Paraná basin, Southeastern Brazil. Boletim IG USP, 9:1-15.

ROHN, R. \& RÖSLER, O. 1987. Relaçōes entre a flora permiana do Gondvana e as floras das províncias setentrionais. In: CONGRESSO Brasileiro de Paleontologia, $X$, Rio de Janeiro, 1987. Anais... SBP, p. 885-99.

ROHN. R. \& STOLLHOFEN, H. 2000. The Permian age of the Passa Dois Group (Paraná Basin, Southern Brazil) re-affirmed. In: INTERNATIONAL. GEOLOGICAL CONGRESS, $31^{\text {st }}$, Rio de Janeiro, 2000. Abstracts... (CD. ROM).

RÖSLER, O. 1978. The Brazilian eogondwanic floral sucessions. Boletim IG-USP, 9:85-91.

RÖSLER, O. \& PERINOTTO, J.A.J. 1985. Nota sobre a ocorrência de Notorhacopteris sp. em siltitos de posiçāo médio-superior no Subgrupo Itararé em amostra de subsuperfície no município de Buri, Estado de São Paulo. Paleobotânica Latinoamericana (Circular Informativa da ALPP), 7(1):25.

ROTHWELL, G.W. 1982. New interpretations of the earliest conifers. Review of Palaeobotany and Palynology, 37(1/2):7-28.
RUSSO, A.; ARCHANGELSKY, S. \& GAMERRO, J.C. 1980. Los depósitos suprapaleozoicos en el subsuelo de la llanura ChacoPampeana, Argentina. In: CONGRESO ARGENTINO DE PALEONTOLOGÍA $Y$ Bioestratigrafía, \| $Y$ CONGRESO LATINOAMERICANO DE PALEONTOLLGÍA, I, Buenos Aires, 1980. Actas..., IV:45-9.

SAAD, A.R. 1977. Estratigrafia do Subgrupo Itararé no centro e sul do Estado de São Paulo. São Paulo: inédito (Dissertaçāo de Mestrado, Instituto de Geociências da USP), $107 p$.

SANTA ANA, H.; BERI, A.; GOSO, C. \& DANERS, G. 1993. Análisis estratigráfico de la Formación San Gregório (Pérmico Inferior), en los testigos del pozo Cerro Largo Sur $n^{\circ} 4$ (DI.NA.MI.GE.), Uruguay. Revista Brasileira de Geociências, 23(4):347-51.

SANTOS, P.R. dos 1979. Distribuição estratigráfica, características e fácies de diamictitos e rochas associadas do Subgrupo Itararé no centro e sul do Estado de São Paulo. São Paulo: inédito (Dissertação de Mestrado, Instituto de Geociências da USP), 135p.

SANTOS, P.R. dos 1987. Fácies e evolução paleogeográfica do Subgrupo Itararé/Grupo Aquidauana (Neopaleozóico) na Bacia do Paraná, Brasil. São Paulo: inédito (Tese de Doutoramento, Instituto de Geociências da USP), $128 \mathrm{p}$.

SANTOS, P.R. dOS: ROCHA-CAMPOS, A.C. \& CANUTO, J.R. 1996. Patterns of late Palaeozoic deglaciation in the Paraná Basin, Brazil. Palaeogeography, Palaeoclimatology, Palaeoecology, 125:165-84.

SCHNEIDER, R.L.; MÜHLMANN, H.; TOMAZI, E.; MEDEIROS, R.A. DAEMON, R.F. \& NOGUEIRA, A.A. 1974. Revisão estratigráfica da Bacia do Paraná. In: Congresso BrAsILERO DE GEOLOGIA, 28 , Porto Alegre, 1974. Anais.... SBG, 1:41-66.

SCHOPF, J.M.; WILSON, L.R.; BENTALL, $R$. 1944. An annoted synopsis of Paleozoic fossil spores and definition of generic group. Illinois State Geological Survey, Report of Investigations, 13:298-305.

SCOTESE, C.R. \& LANGFORD, R.P. 1995. Pangea and the paleogeography of the Permian. In: Scholle, P.A.; Peryt, T.M. \& Ulmer-Scholle, D.S., The Permian of the Northern Pangea. Berlin: Springer-Verlag, 1:3-19.

SEGROVES, K.L. 1969. Saccate plant microfossils from the Permian of Western Europe. Grana Palynologyca, 9(1/3):174-227.

SHU, B. \& HUAI-CHENG, Z. 1998. Palynological events and the mid-Carboniferous boundary. Newsletter on Carboniferous Stratigraphy, 16:14-6. 
SIMŌES, M.G. 1992. Pelecípodes da Formaçáo Palermo (Permiano) de São Sepé (RS) e Guiratinga (MT): implicaçốes na evolução da fauna neopaleozóica da Bacia do Paraná, Brasil. São Paulo: inédito (Tese de Doutoramento, Instituto de Geociências da USP), 286p.

SIMÖES, M.G.; ROCHA-CAMPOS, A.C. \& ANELLI, L.E. 1998. Paleoecology and evolution of Permian bivalves faunas (Paraná Basin) in Brazil. In: Johnston, P.A \& Haggart, J.W. (eds.) Bivalves: An Eon of evolution Paleobiological Studies in Honoring of Norman D. Newell. Calgary: University of Calgary Press, p.443-52.

SMITH, A.V.H. \& BUTHERWORTH, M.A. 1967. Miospores in the coal sequence of the Carboniferous of Great Britain. Londres: Special Paper in Palaeontology, 1: 342p.

SOARES, P.C.; LANDIM, P.M.B.; SINELLI, O.; WERNICK, E.; WU, F.T. \& FIORI, A.P. 1977. Associações litológicas do Subgrupo Itararé e a sua interpretação ambiental. Revista Brasileira de Geociências, 7:131-49.

SOMMER, R.W. \& TRINDADE, N.M. 1966. Lycopodiales do Gonduana brasileiro, Boletim do Departamento Nacional de Produçäo Mineral / Divisão de Geologia e Mineralogia, $\mathrm{n}^{\circ} 230,31 \mathrm{p}$.

SOUZA, P.A. de. 1996. Palinologia e bioestratigrafia do Subgrupo Itararé em Araçoiaba da Serra (Westphaliano, Bacia do Paraná), Estado de São Paulo, Brasil. São Paulo: inédito (Dissertação de Mestrado, Instituto de Geociências da USP), 192p.

SOUZA, P.A. de. 1997. Dados palinológicos do Carbonífero da Bacia do Paraná no Brasi\}. Revista Universidade Guarulhos, Geociências, III(Número Especial):43-8.

SOUZA, P.A. de. 1998. Palaeoenvironmental considerations about the Itararé Subgroup at Araçoiaba da Serra, State of São Paulo, (Upper Carboniferous, Paraná Basin), Brazil. Ameghiniana, 35(3):315-20.

SOUZA, P.A. de. \& PETRI, S. 1998. Reworked palynomorphs in the Upper Carboniferous sediments at Araçoiaba da Serra (Itararé Subgroup, Paraná Basin), State of São Paulo, Brazil. Ameghiniana, 35(4):379-85.

SOUZA, P.A. de; BATEZELLI, C.V.B.; DI PASQUO, M.; AZCUY, C.L.; SAAD, A.R. \& PERINOTTO, J.A.J. 2000. Ocorrência de palinomorfos no Subgrupo Itararé $(\mathrm{C} / \mathrm{P}$ da Bacia do Paraná) em Jundiaí (SP. Brasil). Revista Universidade Guarulhos, Geociências (no prelo).

SOUZA, P.A.de; DINO, R. \& PETRI, S. 1996. Palinoestratigrafia do Subgrupo Itararé em Araçoiaba da Serra (SP). Westphaliano da Bacia do Paraná. In: CONGresso BRAsILEIRO DE GEOLOGiA, XXXIX, Salvador, 1996. Anais.. SBG, 2:287-9
SOUZA, P.A. de; LIMA, M.R. de \& SAAD, A.R 1990. Palinologia dos carvões paleozóicos do Estado de São Paulo. 1 - O Carvâo de Buri. Paleobotânica Latinoamericana, Circular Informativa da AL.PP, $\mathbf{9 ( 1 ) : 5 5 . ~}$

SOUZA, P.A. de; LIMA, M.R. de \& SAAD, A.R. $1993^{\text {a }}$ Palinologia dos carvões paleozóicos do Estado de São Paulo. Brasil. I - O Carvāo de Buri. Revista do Instituto Geológico, $14(1): 5-20$.

SOUZA, P.A. de; LIMA, M.R. de \& SAAD, A.R. 1993b. Palinologia dos carvóes paleozóicos do Estado de São Paulo. Brasil. Il - O Carväo de Monte Mor. Anais da Academia Brasileira de Ciências, 65(3):327.

SOUZA, P.A. de; LIMA, M.R. de \& SAAD, A.P. 1993c. Palinologia dos carvões paleozóicos do Estado de São Paulo. Brasil. III - O Carvão de Cerquilho. In: CONGRESSO Brasileiro dE PALEONTOLOGIA, $13^{\circ}$, São Leopoldo, 1993. Resumos... SBP, p.62.

SOUZA, P.A. de; SAAD, A.R. \& LIMA, M.R. de 1997. Palinologia dos carvões paleozóicos do Estado de São Paulo. II - O Carvão de Monte Mor. Revista do Instituto Geológico, 18(1/2):7-21.

SOUZA, P.A. de; VESELY, F.F. \& ASSINE, M.L. 1999. Contribuição palinológica ao conhecimento do Subgrupo Itararé na Serra dos Paes, sul do Estado de São Paulo. Revista do Instituto Geológico, (no prelo).

SOUZA FILHO, E. E. de. 1986. Mapeamento faciológico do Subgrupo Itararé na Quadrícula de Campinas (SP). São Paulo inédita (Dissertação de Mestrado, Instituto de Geociências da USP), $121 \mathrm{p}$.

SRIVASTAVA, A.K. 1979. Studies in teh Glossopteris flora of India, 44. Raniganj plant microfossils and miospores from Auranga Coalfield, Bihar. The Palaeobotanist, 26(1):72-94.

SRIVASTAVA, S.C. 1970. Miofloral investigations in some coals of Talchir Coalfield (Orissa) India. The Paleaeobotanist, 18(2):154-66.

SRIVASTAVA,. S.C. 1980. Palynostratigraphy of Lower Gondwana sediments in Chirimiri Coalfield, M.P. India. Geophytology, $10(1): 62-71$

STANLEY, E.A. 1965. Use of reworked pollen and spores for determining the PleistoceneRecent and the Intra-Pleistocene boundaries. Nature, 206(4981):289-91.

STANLEY, E.A. 1966. The problem of reworked pollen and spores in marine sediments. Marine Geology, 4:397-408.

STAPLIN, F.L. 1960. Upper Mississippian plant spores from the Golata Formation, Alberta, Canada. Palaeontographica, Abt. B 107:1-40.

STAPLIN, F.L.; POCOCK, S.J. \& JANSONIUS, J. 1967. Relationship among Gimnospernous 
pollen. Review of Palaeobotany and Palynology, 3(1/4):297-310.

STEPHENSON, M.H. 1998. Preliminary correlation of palynological assemblage from Oman with the Granulatisporites confluens Oppel Zone of the Grant Formation (Lower Permian), Canning Basin, Western Austrália. Journal of African Earth Sciences, 26(4):521-6.

STEPHENSON, M.H. \& FILATOFF, J. 2000. Correlation of Carboniferous-Permian assemblages from Oman and Saudi Arabia. In: Al-Hairi, S. \& Owens, B. (eds.), Stratigraphic palynology of the Palaeozoic of Saudi Arabia. Bahrain: GeoArabia, Special Publication 1, Gulf Petrolink, p.168. 91.

STEPHENSON, M.H. \& MCLEAN, D. 1999. International correlation of Early Permian palynofioras from the Karro sediments of Morupule, Botswana. South African Journal of Geology, 102(1):3-14.

STEVAUX, J.C.; SOUZA FILHO, E.E. \& PERINOTTO, J.A.J. 1985. Análise paleogeográfica da ocorrência de carvão do bairro Aliança - Cerquilho (SP). In: SIMPósio Regional de Geologia, 5', São Paulo, 1985. Atas... SBG/SP, 1:221-33.

STEVAUX, J.C.; SOUZA FILHO, E.E.; TEIXEIRA, J.A. \& LANDIM, P.M.B. 1987. Sistemas deposicionais do Subgrupo Itararé ( $\mathrm{P}-\mathrm{C}$ ) na bacia hidrográfica do baixo rio Capivari, $S P$ : um modelo para prospecção de água subterrânea. in: Simpósio REGIONAL DE Geologia, VI, Rio Claro, 1987. Atas... SBG, 1:355-74.

STEWART, W.N. \& ROTHWELL, G.W. 1993. Paleobotany and the evolution of plants. Victoria: Cambridge University Press, 521p.

STOLLHOFEN, H.; BANGERT, B. \& LORENZ, V. 2000. Glacials, tuffs and tectonism: constrainst of Early intracontinental extension, Dwyka Group, Namibia. In: INTERNATIONAL GEOLOGICAL CONGRESS, $31^{\text {st }}$, Fio de Janeiro, 2000. Abstracts... (CD-ROM).

STREEL, M. \& THERON, J.N. 1999. The Devonian-Carboniferous boundary in South Africa and the age of the earliest episode of the Dwyka glaciation: New palynological result. Episodes, 22(1):41-4.

SULLIVAN, M.J. 1964. Miospores from the Drybrook Sandstone and associated measures in the forest of Dean Basin, Gloucestershire. Palaeontology, 7(3):351-92.

SULLIVAN, H.J. 1968. A Tournaisian spore flora from the Cementstone Group of Ayrshire, Scotland. Palaeontology, 11(1):116-31.

SUNDARAM, D. 1980 . Observações palinológicas sobre alguns sedimentos do Gondwana Inferior da Bacia do Paraná, Brasil. Boletim IG-USP, 11:161-89.
SUNDARAM, D. 1987. Palinologia do Subgrupo Itararé (Neopaleozóico da Bacia do Paraná) no Estado de Sáo Paulo, Brasil. Sáo Paulo: inédito (Tese de Doutoramento, Instituto de Geociências da USP), 311 p.

TAYLOR, T.N. 1981. Palaeobotany: an introduction to fossil plant Biology. New York: Edit. McGraw Hill, 589p.

TAYLOR, T.N. 1982. Ultraestructural studies of Paleozoic seed fern pollen: sporoderm developement. Review of Palaeobotany and Palynology, 37(1/2):21-53.

THOMAZ, S.L. 1980. As formações Rio do Sul e Rio Bonito no sudeste do Estado do Paraná. Porto Alegre: inédito (Dissertação de Mestrado, Instituto de Geociências da UFRGS).

TIWARI, R.S. 1965. Miospores assemblage in some coals of Barakar stage (Lower Gondwana) of India. The Palaeobotanist, 13(2):168-214.

TIWARI, R.S. 1968. Palynological investigations of some coal seams in the Ib-River Coalfield (Orissa), India. The Palaeobotanist, $16(3): 222-42$.

TIWARI, R.S. \& NAVALE, K.B. 1967. Pollen and spore assemblage in some coals of Brazil. Pollen et Spores, 18(3):38-60.

TIWARI, R.S. \& TRIPATHI, A. 1992. Marker Assemblage-Zones of spore and pollen species through Gondwana Palaeozoic and Mesozoic sequences in India. The Palaeobotanist, 40:194-236.

TRAVERSE, A. 1988. Paleopalynology. Londres: Unwin Hyman, 600p.

TRAVERSE, A. 1996. Chapter 2. Nomenclature and taxonomy: systematics. In: Jansonius, $J$. \& McGregor, D.C. (eds.), Palynology: principles and applications. AASP Foudation, 1:11-28.

TRINDADE, N.M. 1970. Megásporos carboníferos de Monte Mor, Estado de São Paulo. Anais da Academia Brasileira de Ciências, 42(3):459-70.

TURNER, N. \& SPINNER, E. 1993. A palynostratigraphuc study of NamurianWestphalian deltaic sequences of the southern central 
Britain. Review of Palaeobotany and Palynology, 80:39-54.

UTTING, J. 1978. Lower Karroo pollen and spore assemblages from the coal measures and underlying sediments of the Siankondobo Coalfield, Mid-Zambezi Valley, Zambia. Palynology, 2:53-68.

UTTING, J. 1994. Palynostratigraphy of Permian and Lower Triassic rocks, Sverdup, Canadian Artic Archipelago. Geological Survey of Canadá, Bull. 478, to7p.

UTTING, J. \& PIASECKI, S. 1995. Palynology of the Permian of Northern continents: a review. In: Scholle, P.A.; Peryt, T.M. \& UlmerScholle, D.S. (eds.), The Permian of the Northern Pangea. Berlin: Springer-Verlan, Berlin, 1, p.236-61.

VAN DE LAAR, J.G.M. \& FERMONT, W.J.J. 1990. Westphalian palynology of The Netherlands bases on six continuosly cored boreholes. Review of Palaeobotany and Palynology, $65: 275-85$

VAN WIJHE, D.H.; BLESS, M.J.M. \& DIJKSTRA, S.J. 1974. The Westphalian of The Netherlands with special reference to miospore assemblages. Geologie en Mijnbouw, 53(6):295-328.

VAVRDOVÁ, M. \& ISAACSON, P.E. 1999. Late Famennian phytogeographic provincialism: evidence for a limited separation of Gondwana and Laurentia. Gabhandlungen der Geologischen Bundesanstalt, 54:453-63.

VAVRDOVA, M.; ISAACSON, P.E.; DÍAS, E. \& BEK, J. 1993. Devonian-Carboniferous boundary at Lake Titikaka, Bolivia: preliminary palynological results. In: INTERNATIONAL CONGRESS ON CARBONIFEROUSPermian, XII, Buenos Aires, 1991. Compte Rendus, 1:187-99.

VAZQUEZ-NISTICO, B. \& CÉSARI, S. 1987. Nuevos elementos paleoflorísticos de la Formación Guadancol (Carbonífero) en la Cuesta de Huaco, Província de San Juan. In: Simpósio ARgentino de Paleobotánica $Y$ Palinología, VII, Buenos Aires, 1987. Actas..., p.71-4.

VEEVERS, J.J. \& POWELL, C.MCA. 1987. Late Paleozoic glacial episodes in Gondwanaland reflected in transgressive-regressive depositional sequences in Euramerica. Geological Society of America Bulletin, 98:475-87.

VENKATACHALA, B.S. \& KAR, R.K. 1968. Palynology of the Karanpura sedimentary Basin, Bihar, India - 1. Barakar Stage at Badam. The Palaeobotanist, 16(1):56-90.

VENKATACHALA, B.S.; TIWARI, R.S. \& VIJAYA. 1995. Diversification of sporte-pollen "character states" in the Indian Permian. Review of Palaeobotany and Palynology, 85:319-40.
VERGEL, M.M. 1986a. Consideraciones paleoecologicas sobre palinofloras neopaleozoicas de la Cuenca Chacoparanense, Republica Argentina. In: Congreso ARgENTINo de PALEONTOlogia $Y$ BIOESTRATIGRAFIA, IV, Mendoza, 1986. Actas..., 1:221-5.

VERGEL, M.M. 1986b. Palinologia del Paleozoico Superior en la perforacion YPG J1 (Josefina), Provincia de Santa Fé, Argentina. I. Antetura Proximegerminantes. $23(3 / 4): 141-53$

Ameghiniana,

VERGEL, M.M. 1987a. Consideraciones sobre el contenido microflorístico de la perforación UPF SE AB (Paleozóico superior), Arbol Blanco, Província de Santiago del Estero, Argentina. In: SIMPÓSIO ARGENTINO DE Paleobotánica y Palinologia, VII, Buenos Aires, 1987. Actas..., p.75-78.

VERGEL. M.M. 1987b. Palinología del Paleozóico Superior en la perforación YPF.SF - J (Josefina), Província de Santa Fé, Argentina. II. Anteturma Variegerminantes, Grupo Acritarcha e Incertae Sedis. Ameghiniana, 24(1-2):67-80.

VERGEL. M.M. 1993. Palinoestratigrafía de la secuencia neopaleozóica en la Cuenca Chacoparanense, Argentina. in: INTERNATIONAL CONGRES ON CARBONIFEROUSPERmian, XII, Buenos Aires, 1993. Compte Rendus, 1:201-212.

VERGEL, M.M. 1998. Palinología del Paleozóico Superior (Formación Sachayoj) en tres perforaciones de la subcuenca de Alhuampa, cuenca Chacoparanense (Argentina). Parte I: esporas. Ameghiniana, 35(4):387-403.

VERGEL, M.M. \& LUNA, F. 1992. Registros palinológicos en sedimentos del Neopaleozóico de la Sierra de Paiman, La Rioja, Argentina. Acta Geologica Lilloana, XVII(2):161-8.

VERGEL, M.M.; BUATOIS, L.A. \& MANGANO, M.G. 1993. Primer registro palinológico en el Carbonifero Superior del margen norte de la Cuenca Paganzo, Los Jumes, Catamarca, Argentina. In: INTERNATIONAL CONGRES ON CARBONifEROUS-PERMIAN, XII, Buenos Aires, 1993. Compte Rendus, 1:213-227.

VIEIRA, P.C. 1982. Hipótese sobre a origem da Depressão Periférica Paulista. Revista do Instituto Geológico, 3(2):61-7.

VISSER, J.N.J. 1997. Deglaciation sequences in the Permo-Carboniferous Karoo and Kalahari basins of southern Africa: a tool in the analysis of cyclic glaciomarine basin fills. Sedimentology, 44:507-21.

WAGNER, R.H. 1993. Climatic significance of the Major chronostratigraphic units of the Upper Palaeozoic. In: INTERNATION CONGRESS ON CARBONIFEROUS - PERMIAN, XII, Buenos Aires, 1993. Compte Rendus...., 1:83-108. 
WAGNER, R.H. \& WINKLER PRINS, C.F. 1994. General overview of Carboniferous stratigraphy. Société Géologique de Belgique, 116(1):163-74.

WHITE, I.C. 1908. Comissão de Estudos das Minas de Carvão de Pedra do Brazil Relatório Final. Brasília, DNPM, Ediçāo Fac-similar, 1988, 617p.

WIERICH, F. \& VOGT, A.W. 1997. Zur Verbreitung, Bioestratigraphie und Petrographie unterkarbonischer Sandsteine des Hörre-Gommern-Zuges im östlichen Thenoherzynikum. Geologica et Palaeontologica, 31:97-142.

WILSON, L.R. 1962. Plant microfossils Flowerpot Formation. Oklahoma Geological Survey, Circular 49, 47p.

WILSON, L.R. 1964. Recycling, stratigraphic leakage, and faulty techniques in Palynology. Grana Palynologica, 5(3):425-37.

WOPFNER, H. 1998. The Eariy Permian euxinic deglaciation event between East Africa and northwest Australia. Journal of African Earth Sciences, 27(1A):212-3.

YBERT, JuP. 1975. Etude des miospores du Bassin Houiller de CandiotaHulha Negra, Rio Grande do Sul, Bresil. Pesquisas, 5:181226.

ZALÁN, P.V.; WOLFF, S.; ASTOLFI, M.A.M.; VIEIRA, I.S.; CONCEIÇÄO, J.C.J.; NETO E.V.S. \& MARQUES, A. 1990. The Paraná basin, Brazil. in: Leighton, N.W.; Kolata, D.R.; Oltz, D.F. \& Eidel, J.J. (Eds.), Interior cratonic basins. AAPG Memoir, 51:681-708.

ZAMPIROLLI, A.P.; BERNARDES-DE-OLIVEIRA, M.E.C. \& SOUZA, P.A. de. 1999. Levantamento da composição e sucessão paleoflorísticas do NeocarboníferoEopermiano (grupo Tubarão) no estado de São Paulo. Il-1 - considerações sobre a tafoflora de pré-glossopterídeas de Itapeva, subgrupo Itararé, bacia do Paraná. Brasil. In: CONGRESSO BRASILEZRO DE PALEONTOLOG:A, XVI, Crato, 1999. Boletim de Resumos.. SBP, p. 127-8.

ZHOU, Y-X. 1994. Earliest pollen-dominated microfloras from the early late Carboniferous of the Tian Shan Mountains, NW China: their significance for the origin of conifers and palaeophytogeography. Review of Palaeobotany and Palynology, 81:193-211.

ZHU-HUAICHENG. 1993. A revised palynological sub-division of the Namurian of Jingyuan, northwest China. Review of Palaeobotany and Palynology, 77(3/4):273-300.

ZHU-HUAICHENG. 1995. Namurian miospores from China and their correlation with Europe and North America. Review of Palaeobotanyu and Palynology, 89:335-57.
ZWAN, C.J. van der; Van der LAAR, J.G.M.; PAGNIER, H.J.M. \& AMERON, H.W.J. van. 1993. Palynological and climatological synthesis of the Upper Carboniferous of the well de Lutte-6 (East Netherlands). In: INTERNATIONAL CONGRESS ON CARBONIFEROUSPermanan, XII, Buenos Aires, 1991. Compte Rendus, 1:167-86. 


\section{ANEXO 1}

Estampas Fotomicrográficas 


\section{LISTAGEM DOS TÁXONS, POR ORDEM ALFABÉTICA, COM INDICAÇÃO DAS DESCRIÇÕES E IL.USTRAÇÕES}

\section{ESPOROS}

Ahrensisporites cristatus Playford \& Powis, 1979

Anapiculatisporis argentinensis Azcuy, 1975

Apiculatisporis sp.

Apiculirelusispora variomata (Menéndez \& Azcuy) Menéndez \& Azcuy, 1971

Bascaudaspora canipa Owens, 1983

Calamospora hartungiana Schopf in Schopf, Wilson \& Bentall, 1944

Calamospora liquida Kosanke, 1950

Cirratriradites veeversi Playford, 1971

Convolutispora muriomata Menéndez, 1965

Convolutispora ordonenzii Archangelsky \& Gamerro, 1979

Cristatisporites connexus Potonié \& Kremp, 1955

Cristatisportes inconstans Archangelsky \& Gamerro, 1979

Cristatisporites indignabundus (Potonié \& Kremp) Staplin \& Jansonius, 1964

Cristatisporites inordinatus (Menéndez \& Azcuy) Playford, 1978

Cristatisporites menendezii (Menéndez \& Azcuy) Playford emend. Césari, 1985

Cristatisporites spinosus (Menéndez \& Azcuy) Playford emend. Césari, 1985

Cyclogranisporites firmus Jones \& Truswell, 1992

Densosporites annulatus (Loose) Smith \& Butterworth, 1967

Densosporites stellatus Azcuy, 1975

Densosporites triangularis Kosanke, 1950

Dibolisporites disfacies Jones \& Truswell, 1992

Dictyotriletes muricatus (Kosanke) Smith \& Butterworth, 1967

Foveosporites hortonensis (Playford) Azcuy, 1975

Granulatisporites austroamericanus Archangelsky \& Gamerro, 1979

Granulatisporites confluens Archangelsky \& Gamerro, 1979

Granulatisporites triconvexus Staplin, 1960

Granulatisporites varigranifer Menéndez \& Azcuy, 1971

Horriditriletes uruguaiensis (Marques-Toigo) Archangelsky \& Gamerro, 1979

Kraeuselisporites volkheimerii Azcuy, 1975

Leiotriletes virkkii Tiwari, 1965

Lundhladispora braziliensis (Marques-Toigo \& Pons) Marques-Toigo \& Picarelli, 1984

Lundbladispora riobonitensis Marques-Toigo \& Picarelli, 1984

Psomospora detecta Playford \& Helby, 1968

Punctatisporites gretensis Balme \& Hennelly, 1956

Punctatisporites lucidulus Playford \& Helby, 1958

Raistrickia paganciana Azcuy, 1975

Raistrickia pinguis Playford, 1971

Raistrickia rotunda Azcuy, 1975

Reticulatisporites passaspectus Ottone, 1991

\begin{tabular}{|c|c|c|}
\hline Pág. & Est. & Fig. \\
\hline $61-2$ & IV & 1 e 2 \\
\hline $54-5$ & II & 7 e 8 \\
\hline $53-4$ & II & $4,5 \in 6$ \\
\hline $52-3$ & $n$ & 3 \\
\hline $78-9$ & VI & $4 e 5$ \\
\hline $42-3$ & I & 2 \\
\hline 43 & 1 & 3 \\
\hline $79-80$ & VI & 7 \\
\hline $58-9$ & II! & 7 \\
\hline 59 & III & 8 \\
\hline 75 & VI & 2 \\
\hline 78 & $V_{1}$ & $3 e 6$ \\
\hline $74-5$ & VI & 1 \\
\hline 77 & V & 12 \\
\hline 76 & V & 9 \\
\hline $76-7$ & V & 10 e 11 \\
\hline 50 & 1 & $11 \in 12$ \\
\hline 67.8 & IV & 4 \\
\hline $69-9$ & IV & 5 \\
\hline 67 & IV & 3 \\
\hline 55 & 11 & $10 e 11$ \\
\hline 60 & IV & 9 \\
\hline $60-1$ & III & 9 \\
\hline $48-9$ & 1 & 8 \\
\hline 49 & 1 & 10 \\
\hline $47-8$ & 1 & 7 \\
\hline 48 & I & 9 \\
\hline $55-6$ & II & 9 e 12 \\
\hline 69 & IV & 6,7 e 8 \\
\hline 41 & 1 & 1 \\
\hline $64-5$ & IV & 11 \\
\hline $65-6$ & IV & 10 \\
\hline 82 & VI & 9 e 12 \\
\hline $44-5$ & 1 & 4 \\
\hline $45-6$ & 1 & 5 \\
\hline 57 & !II & $3 e 6$ \\
\hline $56-7$ & III & $1 \mathrm{e} 2$ \\
\hline 58 & III & $4 \oplus 5$ \\
\hline 63 & 111 & 11 \\
\hline
\end{tabular}


Reticulatisporites pseudopaliatus Staplin, 1960

Retusotritetes nigritellus (Lüber) Foster, 1979

Spelaeotriletes ybertii (Marques-Toigo) Playford \& Powis, 1979

Stenozonotriletes clarus Ischenko, 1958

Vallatisporites arcuatus (Marques-Toigo) Archangelsky \& Gamerro, 1979

Vallatisporites ciliaris (Lüber) Sullivan, 1964

Vallatisporites punctatus (Marques"Toigo) comb. nov.

Vallatisporites spinosus Cauduro, 1970

Vallatisporites vallatus Hacquebard, 1957

Velamisporites sp.

Verrucosisporites microtuberosus (Loose) Smith \& Butterworth, 1967

Verrucosisporites morulatus (Knox) Smith \& Butterworth, 1967

$\begin{array}{ccc}62 & \text { III } & 10 \\ 46-7 & \text { I } & 6 \\ 80-1 & \text { VI } & 8 \\ 63-4 & \text { III } & 12 \\ 72-3 & \text { V } & 4 \text { e } 7 \\ 70-1 & \text { V } & 2 \text { e } 3 \\ 73-4 & \text { V } & 8 \\ 71-2 & \text { V } & 5 \text { e } 6 \\ 69-70 & \text { V } & 1 \\ 81-2 & \text { VI } & 10 \text { e } 11 \\ 51 & \text { II } & 1 \\ 51-2 & \text { II } & 2\end{array}$

\section{GRÃOS DE PÓLEN}

Caheniasaccites flavatus Bose \& Kar emend. Azcuy \& Di Pasquo, 2000

Caheniasaccites sp.

Canmanoropollis densus (Lele) Bose \& Maheshwari, 1968

Camnanoropollis janakii Potonié \& Sah, 1960

Cannanoropolis perfectus (Bose \& Maheshwari) Dias-Fabricio, 1981

Cannanoropolis triangularis (Mehtae) Bose \& Maheshwari, 1968

Complexisporites polymorphus Jizba, 1962

Costapollenites ellipticus Tschudy \& Kosanke, 1956

Crucisaccites latisulcatus Lele \& Maithy, 1964

Crucisaccites monoletus Maithy, 1965

Divarisaccus stringoplicatus Ottone, 1991

Florinites sp.

Hamiapollenites fusiformis (Marques-Toigo) Archangelsky \& Gamerro, 1979

Hamiapollenites tractiferinus (Samoilovich) Hart, 1964

Limitisporites rectus Leschik, 1956

Limitisporites sp.

Plicatipollenites densus Srivastava, 1970

Plicatipollenites gondwanensis (Balme \& Hennelly) Lele, 1964

Plicatipollenites malabarensis (Potonié \& Sah) Foster, 1975

Plicatipollenites trigonalis L.ele, 1964

Potonieisporites barrelis Tiwari, 1965

Potonieisporites brasiliensis (Nahuys, Alpern \& Ybert) Archangelsky \& Gamerro, 1979

\begin{tabular}{|c|c|c|}
\hline $100-2$ & $x i$ & 1,2 e 3 \\
\hline 102 & $X I$ & $3,5 \odot 6$ \\
\hline $85-6$ & VII & 4 \\
\hline 84 & VII & 2 \\
\hline $86-7$ & VII & 5 \\
\hline 85 & V1I & 3 \\
\hline $112-3$ & XIII & 12 \\
\hline 117 & XIV & 3 e 4 \\
\hline $91-2$ & VIII & $3 e 4$ \\
\hline 92 & VIII & 5 \\
\hline $99-100$ & $x$ & $5 \bullet 6$ \\
\hline 83 & VII & 1 \\
\hline 112 & $X|\xi|$ & 6 \\
\hline 111 & XII & 9 \\
\hline $105-6$ & $x \|$ & 1 \\
\hline 106 & XII & $2 e 4$ \\
\hline $90-1$ & VIII & 2 \\
\hline 89 & VIII & 1 \\
\hline $87-9$ & VII & 6 e 8 \\
\hline 90 & VII & 7 \\
\hline 96 & IX & 5 e 6 \\
\hline $97-8$ & $x$ & $3 e 4$ \\
\hline 97 & IX & 7 e 8 \\
\hline $96-7$ & IX & 4 \\
\hline $98-9$ & $x$ & 1 e 2 \\
\hline $94-5$ & VI!I & $6,7 \in 8$ \\
\hline 93.4 & IX & 1 e 2 \\
\hline 95 & IX & 3 \\
\hline 107 & XII & $3 e 5$ \\
\hline $108-9$ & XII & 7 e 8 \\
\hline
\end{tabular}

Potonieisporites congoensis Bose \& Maheshwari, 1968

Potonieisporites densus Maheshwari, 1967

Potonieisporites magnus Lele \& Karim, 1971

Potonieisporites neglectus Potonié \& Lele, 1961

Polonieisporites novicus Bharadwaj emend. Poort \& Veld, 1997

Potonieisporites triangulatus Tiwari, 1965

Protohaploxypinus amplus (Balme \& Hennelly) Hart, 1964

Protohaploxypinus goraiensis (Potonié \& Lele) Hart, 1964

$108-9 \quad X I I \quad 7$ e 8 
Protohaploxypinus limpidus (Balme \& Hennelfy) Balme \& Playford, 1967

$\begin{array}{ccc}109 & \text { XIII } & 1 \text { e } 2 \\ 107-8 & \text { XII } & 6 \\ 109-10 & \text { XIII } & 3 \text { e } 4 \\ 104-5 & \text { XI } & 7 \text { e } 8 \\ 110 & \text { XIII } & 11 \\ 103-4 & \text { X } & 7 \text { e } 8 \\ 115 & \text { XIII } & 5 \text { e } 8 \\ 116 & \text { XIV } & 2 \\ 113-4 & \text { XIII } & 7 \\ 114-5 & \text { XIII } & 10 \\ 116-7 & \text { XIV } & 1\end{array}$

Protohaploxypinus micros (Hait) Hart, 1964

Protohaploxypinus panaki Utting, 1994

Scheuringipollenites maximus Tiwari, 1973

Striatoabieites sp.

? Striomonosaccites sp.

Vittatina costabilis Wilson, 1962

Vittatina saccata (Hart) Jansonius, 1962

Vittatina subsaccata Samoilovich, 1953

Vittatina viftifera (Lüber \&. Valtz) Samoilovich, 1953

Vittatina wodehousei (Jansonius) Hart, 1964

Botryococcus braunii Kützing, 1849

Tasmanites sp.

\section{ACRITARCAS}

Dousilites tenuistriatus Gutiérrez, Césari \& Archangelsky, 1997

120-1 XIV 7 e 8

\section{ESPÉCIES ALÓCTONES}

Duvemaysphaera angelae Deunff, 1964

126-7 XV 11

Emphanisporites annulatus McGregor, 1961

$124 \quad X V \quad 3$

Emphanisporites rotatus McGregor, 1961

$123 \times V \quad 2$

Grandispora brevispinosa Menéndez \& Pöthe de Baldis, 1967

$125 \quad X V \quad 7$

Grandispora pseudoreticulata (Menéndez \& Pöthe de Baldis) Ottone, 1996

Grandispora uncata (Hacquebard) Playford, 1971

$124 \quad X V \quad 9$

Indotriradites cf. I. daemonii Loboziak et al., 1999

$124 \mathrm{XV} \quad 8$

Indotriradites dolianiti (Daemon) Loboziak et al., 1999

Maranhites braziliensis (Brito) Burjack \& Oliveira, 1989

$126 \mathrm{XV} \quad 13$

Maranhites insulatus Burjack \& Oliveira, 1989

$126 \mathrm{XV} \quad 12$

Retispora lepidophyta (Kedo) Playford, 1976

$125 \mathrm{XV} \quad 6$

Retusotriletes crassus Clayton et al., 1980

$123 \mathrm{XV} \quad 1$

ANELIDEO 


\section{ESTAMPA I}

Figura 1. Leiotriletes vikkii Tiwari, 1965

Lâmina IG-P: 4B, coordenada England Finder: U43, procedência: Monte Mor (aumento: 1000x)

Figura 2. Calamospora hartungiana Schopf, Wilson \& Bentall, 1944 IG-P: 58C, Q47, poço IT-IG-85 (780x)

Figura 3. Calamospora liquida Kosanke, 1950 GP/4E: 1388 , B46, poço A-IG-85 (600x)

Figura 4. Punctatisporites gretensis Balme \& Hennelly, 1956 GP/4E: 1371, G22/2, poço A-lG-85 (780x)

Figura 5. Punctatisporites lucidulus Playford \& Helby, 1968 IG-P: 58C, Q32, poço IT-IG-85 (600x)

Figura 6. Retusotriletes nigritellus (Lüber) Foster, 1979 GP/4E: 1398, Y43/2, poço A-IG-85 (780x)

Figura 7. Granulatisporites triconvexus Staplin, 1960 GP/4E: 1383, P49, poço A-IG-85 (800x)

Figura 8. Granulatisporites austroamericanus Archangelsky \& Gamerro, 1979 IG-P: 4C, N40, Monte Mor (1000x)

Figura 9. Granulatisporites varigranifer Menéndez \& Azcuy, 1971 GP/4E: 1383, T40/4, poço A-IG-85 (1150x)

Figura 10. Granulatisporites confluens Archangelsky \& Gamerro, 1979 IG-P: 171A, S29/2, poço J.IG-93 (780x)

Figura 11. Cyclogranisporites firmus Jones \& Truswell, 1992 IG-P: 58C, N31/4, poço IT-IG-85 (780x)

Figura 12. Cyclogranisporites firmus Jones \& Truswell, 1992 IG-P: 43D, H43/3, poço IG-01 (Itaporanga) (780x) 
ESTAMPA I
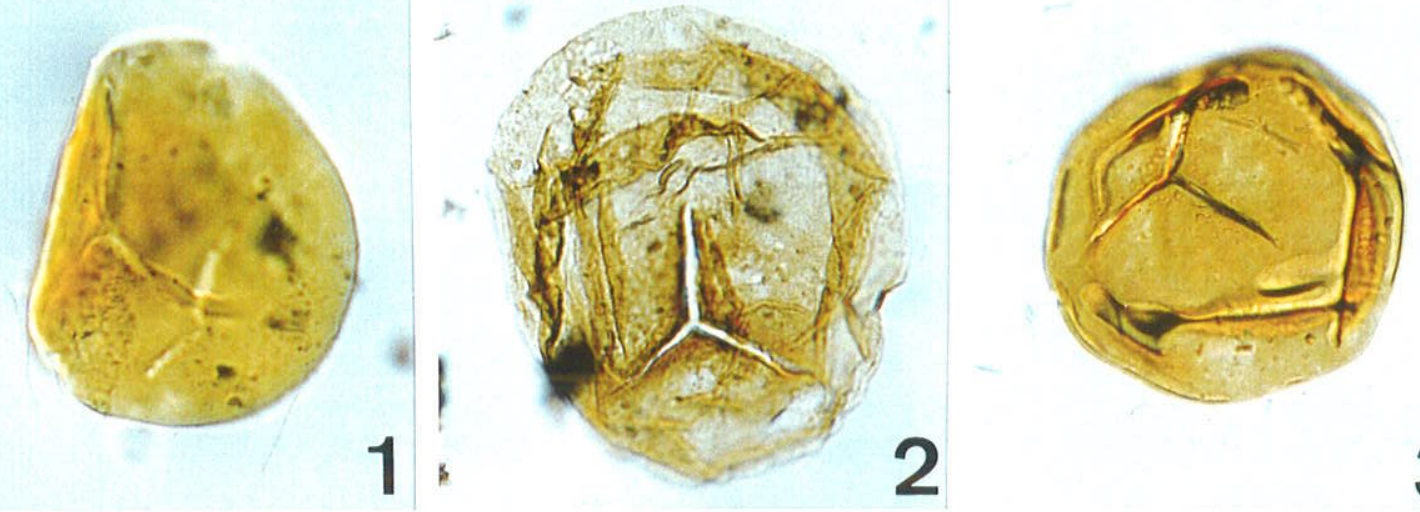

2
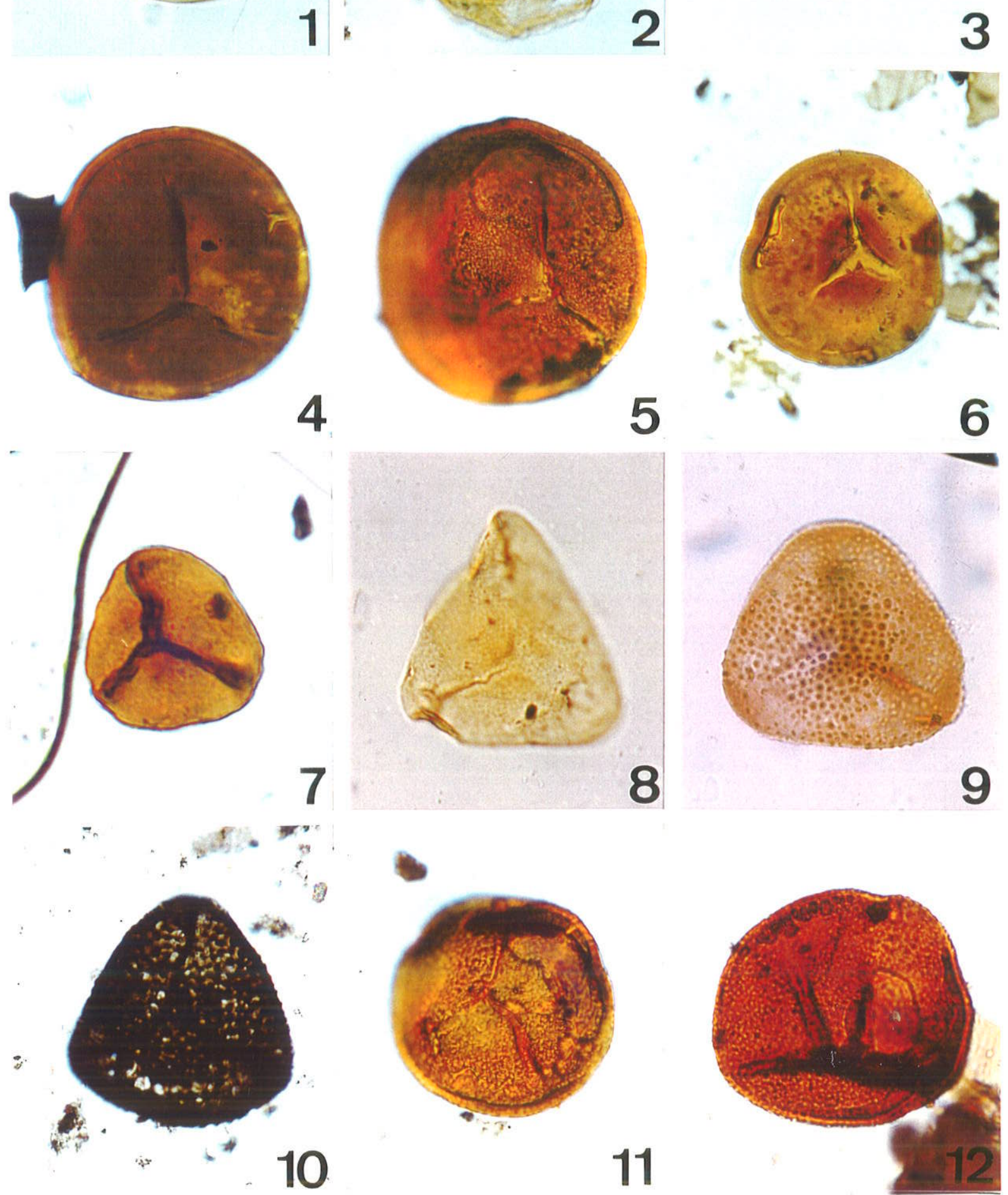


\section{ESTAMPA II}

Figura 1. Verrucosisporites microtuberosus (Loose) Smith \& Butterworth, 1967 IGm: 58C, coordenada England Finder: R34, procedência: poço IT.IG-85 (aumento: $780 \times)$

Figura 2. Verrucosisporites morulatus Smith \& Butterworth, 1967 GP/4E: 1397, W43, A-1G-85 (780x)

Figura 3. Apiculiretusispora variornata (Menéndez \& Azcuy) Menéndez \& Azcuy, 1971 GP/4E: 1420, C22/1, poço A-IG-85, foco da face proximal (860x)

Figura 4. Apiculatisporis sp. IG-P: 50, N45, poço IG-01 (Itaporanga) (780x)

Figura 5. Apiculatisporis sp.

GP/4E: 1401, P50, poço A-1G-85, foco da face proximal (780x)

Figura 6. Apiculatisporis sp.

GP/4E: 1401, P50, poço A-IG-85, foco da região equatorial (780x)

Figura 7. Anapiculatisporites argentinensis Azcuy, 1975

IG-P: 10A, W47/1, Buri $(780 x)$

Figura 8. Anapiculatisporites argentinensis Azcuy, 1975 GP/4E: 1387, H49, poço A-IG-85, foco da face distal (1000x)

Figura 9. Horriditriletes uruguaiensis (Marques-Toigo) Archangelsky \& Gamerro, 1979 IG-P: 2B, S45, Monte Mor (780x)

Figura 10. Dibolisporites disfacies Jones \& Truswell, 1992 IG-P: 43E, O39/1, poço IG-01 (Itaporanga), foco da região equatorial (1000x)

Figura 11. Dibolisporites disfacies Jones \& Truswell, 1992 IG-P: 43E, O39/1, poço IG-01 (Itaporanga), foco da face distal (1000x)

Figura 12. Horriditriletes uruguaiensis (Marques-Toigo) Archangelsky \& Gamerro, 1979 IG-P: 279A, R60/2, Capivari (780x) 

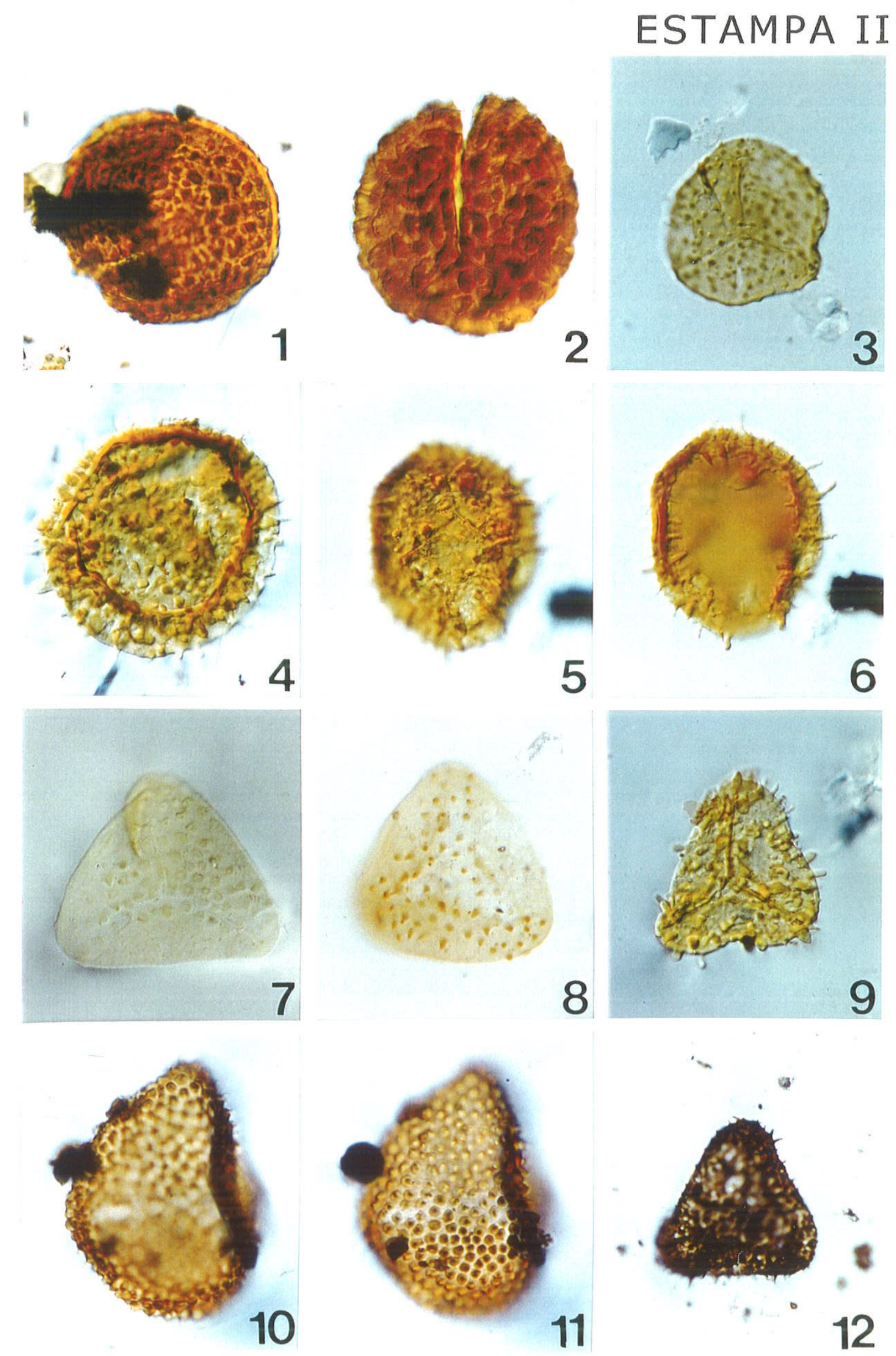


\section{ESTAMPA III}

Figura 1. Raistrickia pinguis Playford, 1971

Lâmina IG-P: 9A, coordenada England Finder : O37, procedência: Bưi (aumento: $780 \mathrm{x})$

Figura 2. Raistrickia pinguis Playford, 1971 IG-P: 12C, G40, Buri (780x)

Figura 3. Raistrickia paganciana Azcuy, 1975 IG-P: 132, R34, poço A-IG-85 (780x)

Figura 4. Raistrickia rotunda Azcuy, 1975 GP/4E: $1400, T 48 / 1$, poço A-IG-85 (780x)

Figura 5. Raistrickia rotunda Azcuy, 1975 IG.P: 10B, F41, Buri (860x)

Figura 6. Raistrickia paganciana Azcuy, 1975 IG-P: 11A, T31/2, Buri (1150x)

Figura 7. Convolutispora muriornata Menéndez, 1965 IG-P: 49E, R42/3, poço IG-01 (Itaporanga) (780x)

Figura 8. Convolutispora ordoñenzii Archangelsky \& Gamerro, 1979 IG-P: 49E, O37, poço IG-01 (Itaporanga) (780x)

Figura 9. Foveosporites hortonensis (Playford) Azcuy, 1975 IG-P: 12B, E47, Buri (780x)

Figura 10. Reticulatisporites pseudopalliatus Staplin, 1960 IG-P: 3A, 038/2, Monte Mor (600x)

Figura 11. Reticulatisporites passaspectus Ottone, 1991 GP/4E: 1397, O17/2, poço A-IG-85 (780x)

Figura 12. Stenozonotriletes clarus ischenko, 1958 IG-P: 11A, R42/2, Buri (780x) 


\section{ESTAMPA III}
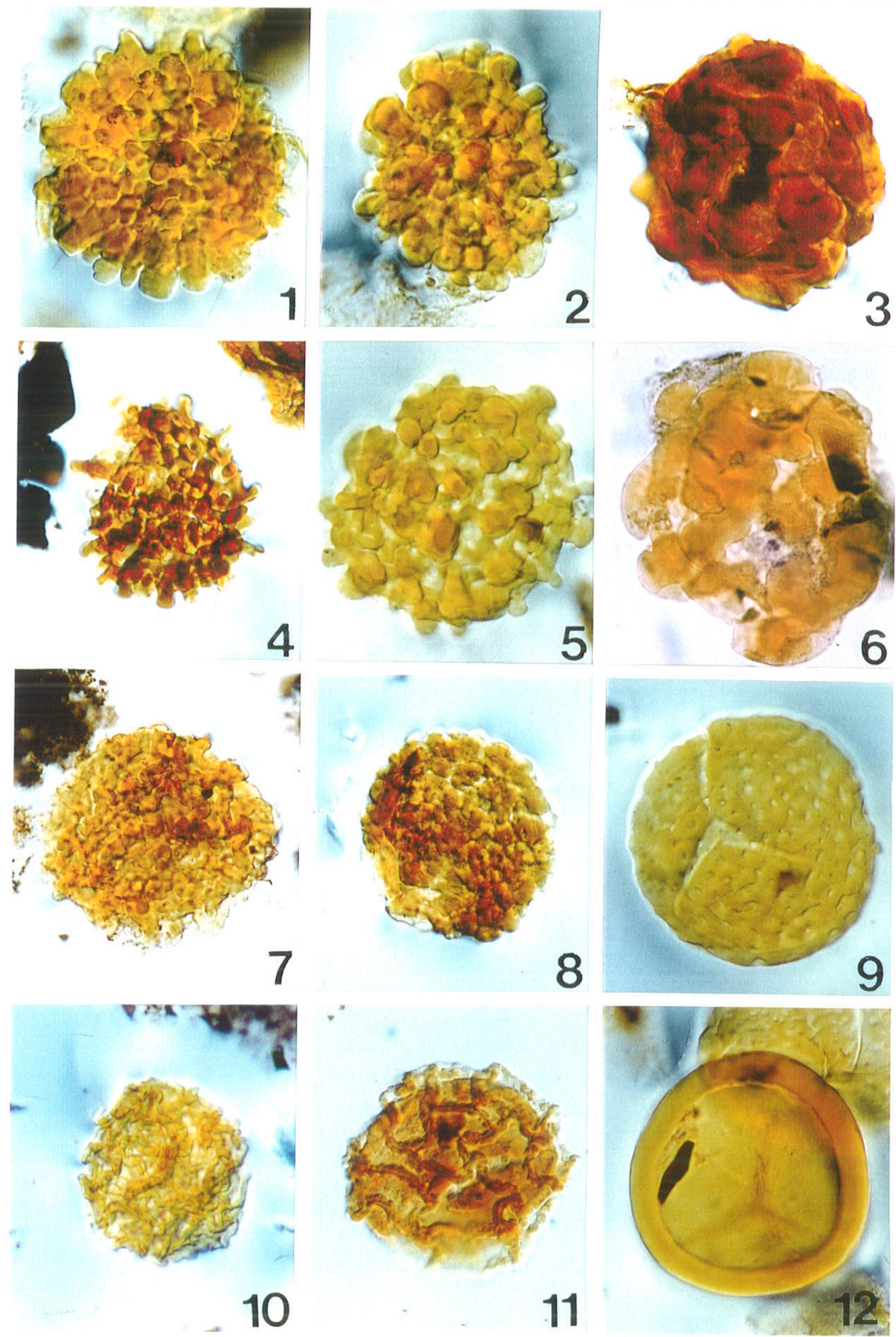


\section{ESTAMPA IV}

Figura 1. Ahrensisporites cristatus Playford \& Powis, 1979

Lâmina GP/4E: 1406 , coordenada England Finder : Q29/4, procedência: poço A.lG85 (aumento: 550x)

Figura 2. Ahrensisporites cristatus Playford \& Powis, 1979

IG-P: 130A, Y35, poço A-IG-85 (600X)

Figura 3. Densosporites triangularis Kosanke, 1950

IG-P: 126A, L42, poço A-IG-85 (600x)

Figura 4. Densosporites annulatus (Loose) Smith \& Butterworth, 1967

GP/4E: 1389, K35, poço A-IG-85 (780x)

Figura 5. Densosporites stellatus Azcuy, 1975

IG»P: 49E, R37/4, poço IG-01 (Itaporanga) (780x)

Figura 6. Kraeuselisporites volkheimerii Azcuy, 1975

IG-P: $12 \mathrm{C}, \mathrm{D} 44 / 1$, Buri $(780 \mathrm{x})$

Figura 7. Kraeuselisporites volkheimerii Azcuy, 1975

IG-P: 49F, S44, poço IG-01 (Itaporanga), foco da face proximal (780x)

Figura 8. Kraeuselisporites volkheimerii Azcuy, 1975

IG-P: 49F, S44, poço IG-01 (Itaporanga), foco da face distal (780x)

Figura 9. Dictyotriletes muricatus (Kosanke) Smith \& Butterworth, 1967

GP/4E: 1401, U36/4, poço A-1G-85 (780x)

Figura 10. Lundbladispora riobonitensis Marques-Toigo \& Picarelli, 1984

IG-P: 126A, L47/2, poço A-IG-85 (780x)

Figura 11. Lundbladispora braziliensis (Marques-Toigo \& Pons) Marques-Toigo \& Picarelli, 1984 IG-P: 2C, J39, Monte Mor (780x) 


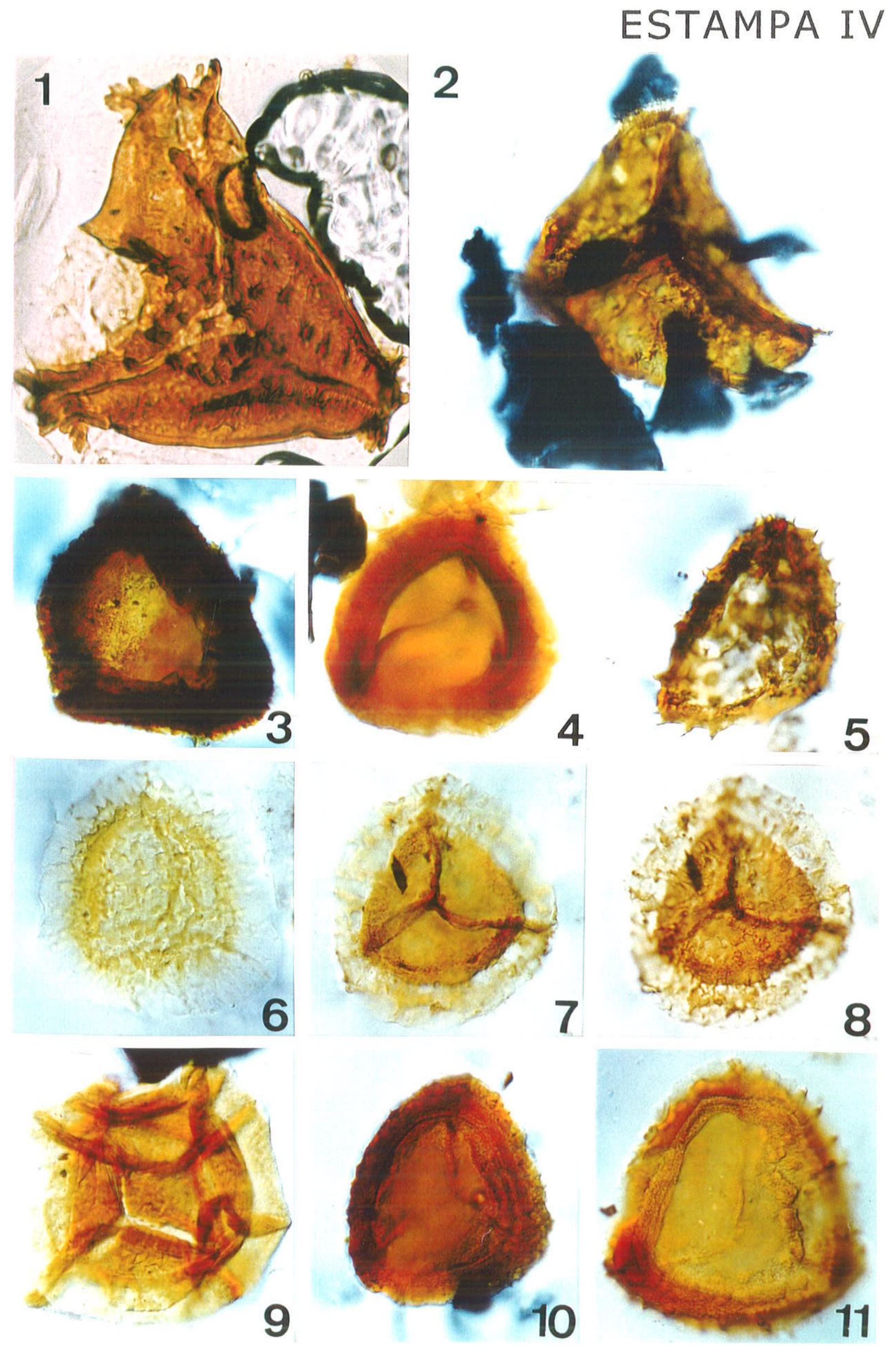




\section{ESTAMPA V}

Figura 1. Vallatisporites vallatus Hacquebard, 1957

Lâmina IG-P: 46D, coordenada England Finder : J33/2, procedência: poço IG-01 (Itaporanga) (aumento: 1150x)

Figura 2. Vallatisporites ciliaris (Lüber) Sullivan, 1964 IG-P: 50, N36, poço IG-01 (Itaporanga) (600x)

Figura 3. Vallatisporites ciliaris (Lüber) Sullivan, 1964 GP/4E: 1397, Z27/2, poço A-lG-85 (760x)

Figura 4. Vallatisporites arcuatus (Marques-Toigo) Archangelsky \& Gamerro, 1979 IG.P: 293A, O44/3, BR-53/PR (780x)

Figura 5. Vallatisporites spinosus Cauduro, 1970 IG-P: 43D, W45, poço IG-01 (ltaporanga) (600X)

Figura 6. Vallatisporites spinosus Cauduro, 1970 GP/4E: 1361, S28/2, poço A-IG-85 (780x)

Figura 7. Vallatisporites arcuatus (Marques-Toigo) Archangelsky \& Gamerro, 1979 GP/4E: $1420, U 48 / 1$, poço Am/G-85 (780x)

Figura 8. Vallatisporites punctatus (Marques-Toigo) comb. nov. GP/4E: $1391, F 48 / 3$, poço A-IG-85 (780x)

Figura 9. Cristatisporites menendezii (Menéndez \& Azcuy) Playford emend. Césari, 1985 GP/4E: 1397, C17/4, poço A-1G-85 (780x)

Figura 10. Cristatisporites spinosus (Menéndez \& Azcuy) Playford emend. Césari, 1985 IG-P: 195A, W54/1, poço 2 PN-1-SP (780x)

Figura 11. Cristatisporites spinosus (Menéndez \& Azcuy) Playford emend. Césari, 1985 GP/4E: 1397, T45/4, poço A-IG-85 (600x)

Figura 12. Cristatisporites inordinatus (Menéndez \& Azcuy) Playford, 1978 GP/4E: 1392, W35/2, poço A-IG-85 (780X) 


\section{ESTAMPA V}
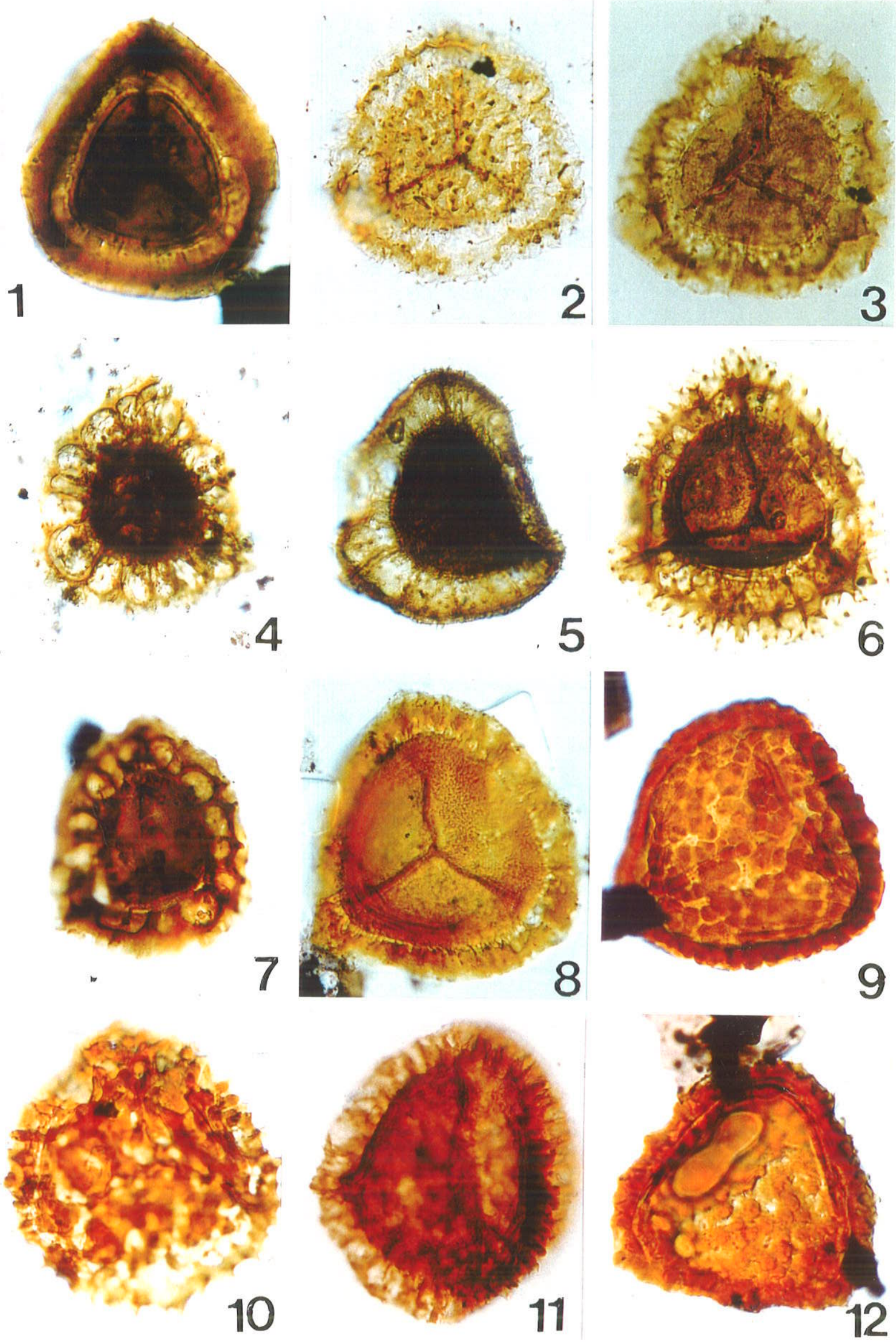


\section{ESTAMPA VI}

Figura 1. Cristatisporites indignabundus (Potonié \& Kremp) Staplin \& Jansonius, 1964 Lâmina GP/4E: 1419, coordenada England Finder : S48/3 , procedência: poço A-IG85 (aumento: $780 x$ )

Figura 2. Cristatisporites connexus Potonié \& Kremp, 1955

IG-P: 13B, K48, Buri (780x)

Figura 3. Cristatisporites inconstans Archangelsky \& Gamerro, 1979

GP/4E: $1415, X 44 / 4$, poço A-lG-85 (860x)

Figura 4. Bascaudaspora canipa Owens, 1983

GP/4E: 1412, 017, poço A-IG-85, foco da regiáo equatorial (780x)

Figura 5. Bascaudaspora canipa Owens, 1983

GP/4E: 1412, O17, poço A-IG-85, foco da face distal (780x)

Figura 6. Cristatisporites inconstans Archangelsky \& Gamerro, 1979

GP/4E: 1418, X41, poço A-IG-85 (780x)

Figura 7. Cirratriradites veeversi Playford, 1971

IG-P: 132A, H35/4, poço A-IG-85 (500x)

Figura 8. Spelaeotriletes ybertii (Marques-Toigo) Playford \& Powis, 1979

IG-P: 45, H41/3, poço IG-01 (Itaporanga) (600x)

Figura 9. Psomospora detecta Playford \& Helby, 1968

IG-P: 132A, U41/1, poço A-IG-85 (780x)

Figura 10. Velamisporites sp.

IG-P: 109C, P38, Jundiaí, foco da face distal (1000x)

Figura 11. Velamisporites sp.

IG.P: 109C, N37/4,Jundiai, foco da face proximal (780x)

Figura 12. Psomospora detecta Playford \& Helby, 1968

IG-P: 4C, M37/3, Monte Mor (860x) 


\section{ESTAMPA VI}
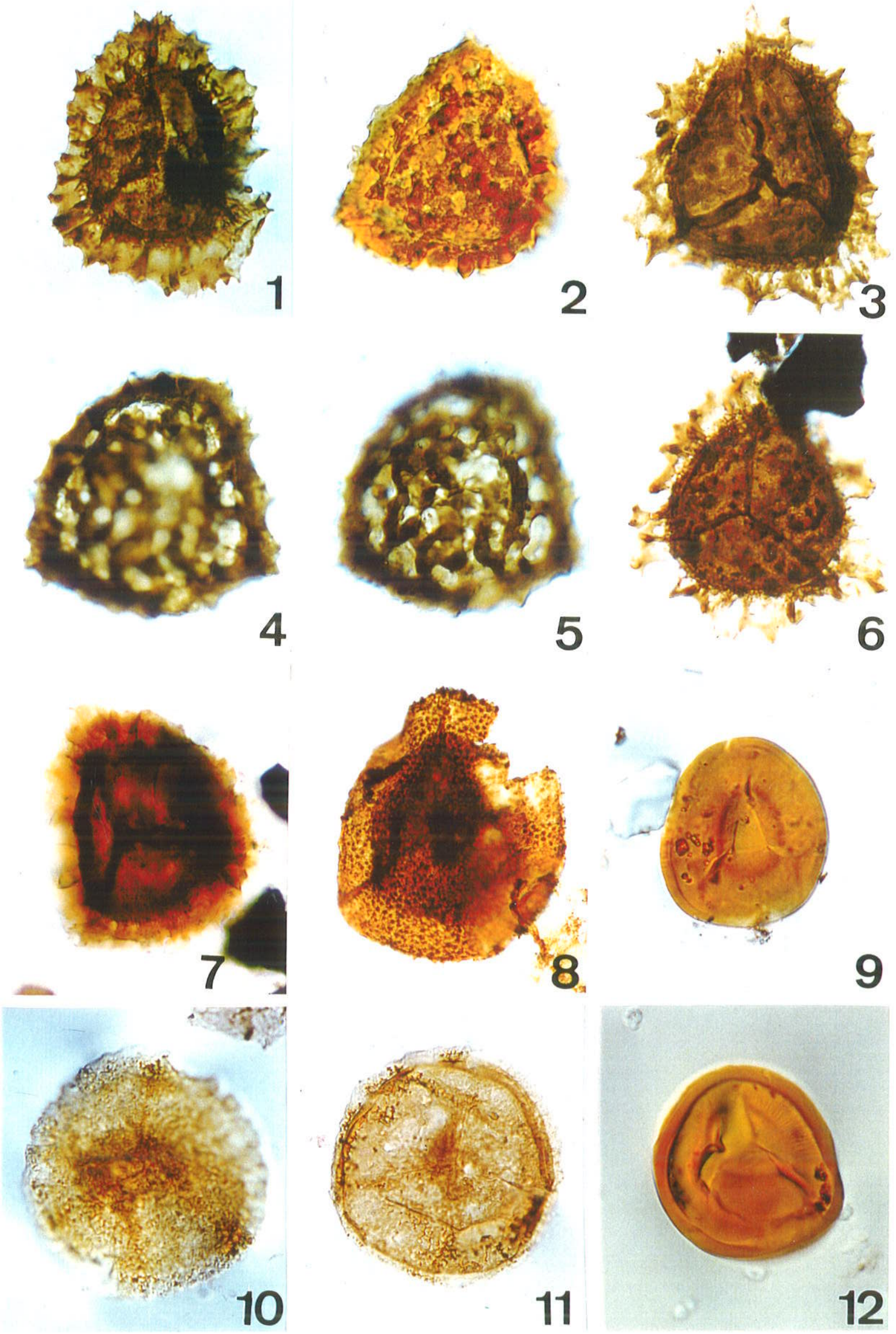


\section{ESTAMPA VII}

Figura 1. Florinites sp.

Lâmina IG-P: 114A, coordenada England Finder : P38/4, procedência: SP-270/SP (aumento: $390 x$ )

Figura 2. Cannanoropollis janakii Potonié \& Sah, 1960

IG-P: 2C, F42/4, Monte Mor (600x)

Figura 3. Cannanoropollis triangularis (Mehtae) Bose \& Maheshwari, 1968 IG-P: 109C, R43, Jundiaí (600x)

Figura 4. Cannanoropollis densus (Lele) Bose \& Maheshwari, 1968 IG-P: 136A, R46/2, poço A-IG-85 (500x)

Figura 5. Cannanoropollis perfectus (Bose \& Maheshwari) Dias-Fabrício, 1981 IG-P: 13C, U49, Buri (760x)

Figura 6. Plicatipollenites malabarensis (Potonié \& Sah) Foster, 1975 IG-P: $1300, K 32 / 3$, poço A-IG-85 (500x)

Figura 7. Plicatipollenites trigonalis Lele, 1964 IG-P: 40F, Q40/3, poço IG 01 (Itaporanga) (500x)

Figura 8. Plicatipollenites malabarensis (Potonié \& Sah) Foster, 1975 IG-P: 58A, M48/3, poço IT-IG-85 (500x) 


\section{ESTAMPA VII}
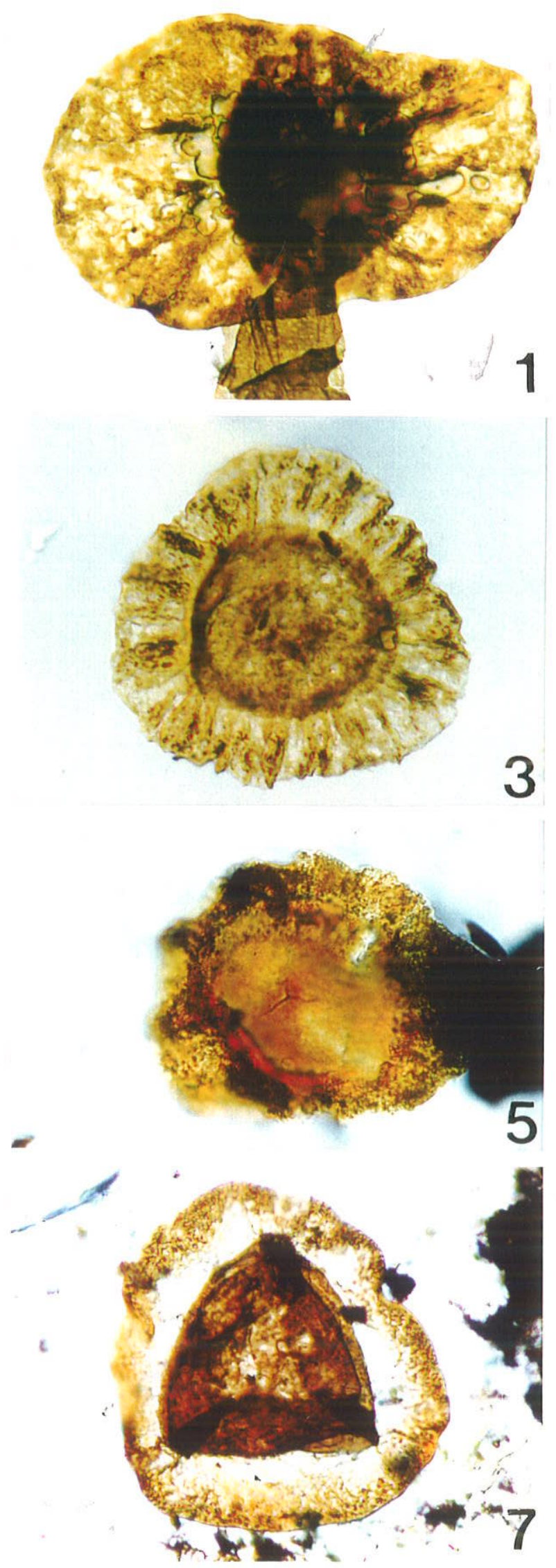
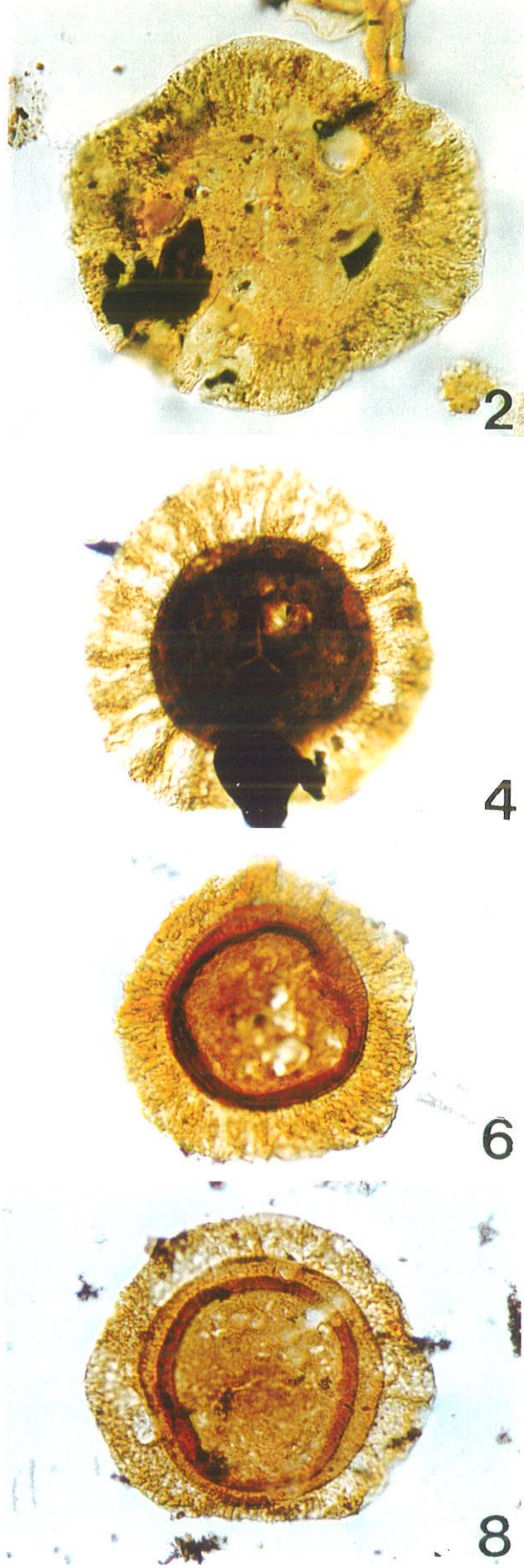


\section{ESTAMPA VIII}

Figura 1. Plicatipollenites gondwanensis (Balme \& Hennelly) Lele, 1964

Lâmina IG-P: 58A, coordenada England Finder: E35/1, procedência: poço IG-01

(Itaporanga) (aumento: 390x)

Figura 2. Plicatipollenites densus Srivastava, 1970

IG-P: 109A, N47/3, Jundiaí (500x)

Figura 3. Crucisaccites latisulcatus Lele \& Maithy, 1964

IG.P: 40D, J46/4, poço IG-01 (Itaporanga) (500x)

Figura 4. Crucisaccites latisulcatus Lele \& Maithy, 1964

IG-P: 13B, Q57, Buri (450x)

Figura 5. Crucisaccites monoletus Maithy, 1965

IG-P: 108C, Q45, Jundiaí (500x)

Figura 6. Potonieisporites neglectus Potonié \& Lele, 1961

GP/4E: 1415, O43, poço A-IG-85 (450x)

Figura 7. Potonieisporites neglectus Potonié \& Lele, 1961

IG-P: 109A, R38/2, Jundiaí (450x)

Figura 8. Potonieisporites neglectus Potonié \& Lele, 1961

IG-P: 40D, H35/2, poço IG-01 (taporanga) (390x) 


\section{ESTAMPA VIII}

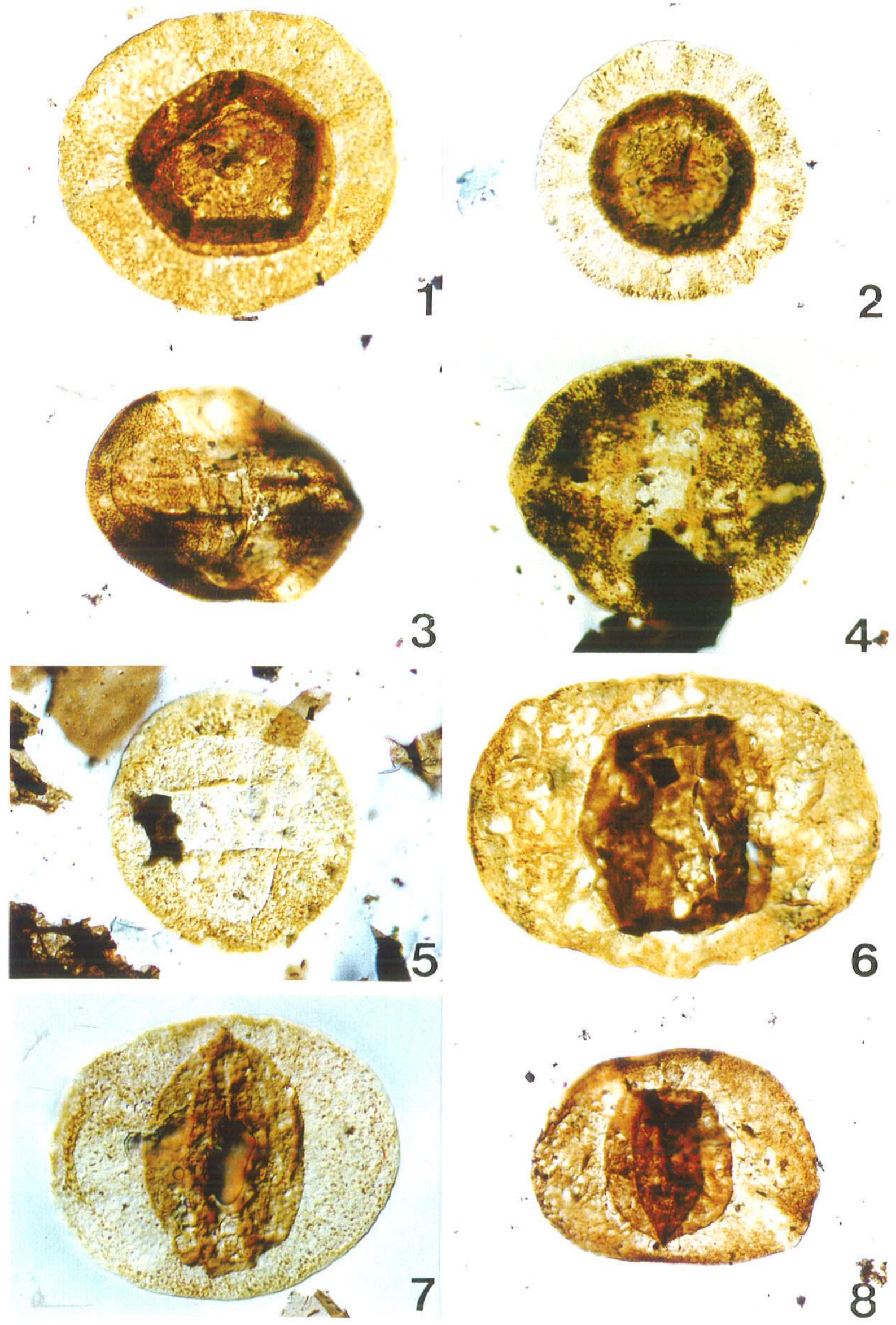




\section{ESTAMPA IX}

Figura 1. Potonieisporites novicus Bharadwaj emend. Poor \& Veld, 1997

Lâmina GP/4E: 1418 , coordenada England Finder : V43/3 , procedência: poço A-lG85 (aumento: $390 x$ )

Figura 2. Potonieisporites novicus Bharadwaj emend. Poor \& Veld, 1997

GP/4E: 1417, K30/2, poço A-IG-85 (390X)

Figura 3. Potonieisporites triangulatus Tiwari, 1965

IG-P: 281A, T30/1, Jundiaí (450x)

Figura 4. Potonieisporites densus Maheshwari, 1967

GP/4E: 1420 , W39, poço A-IG-85 (450x)

Figura 5. Potonieisporites barrelis Tiwari, 1965

IG-P: 40D, H48/4, poço IG-01 (Itaporanga) (390X)

Figura 6. Potonieisporites barrelis Tiwari, 1965

GP/4E: 1415,043 , poço A-IG-85 (450x)

Figura 7. Potonieisporites congoensis Bose \& Maheshwari, 1968

IG-P: 57A, E49/3, poço IT-IG-85 (450x)

Figura 8. Potonieisporites congoensis Bose \& Maheshwari, 1968

IG-P: $58 \mathrm{~A}, \mathrm{~N} 38 / 3$, poço IT.।G-85 (320x) 


\section{ESTAMPA IX}
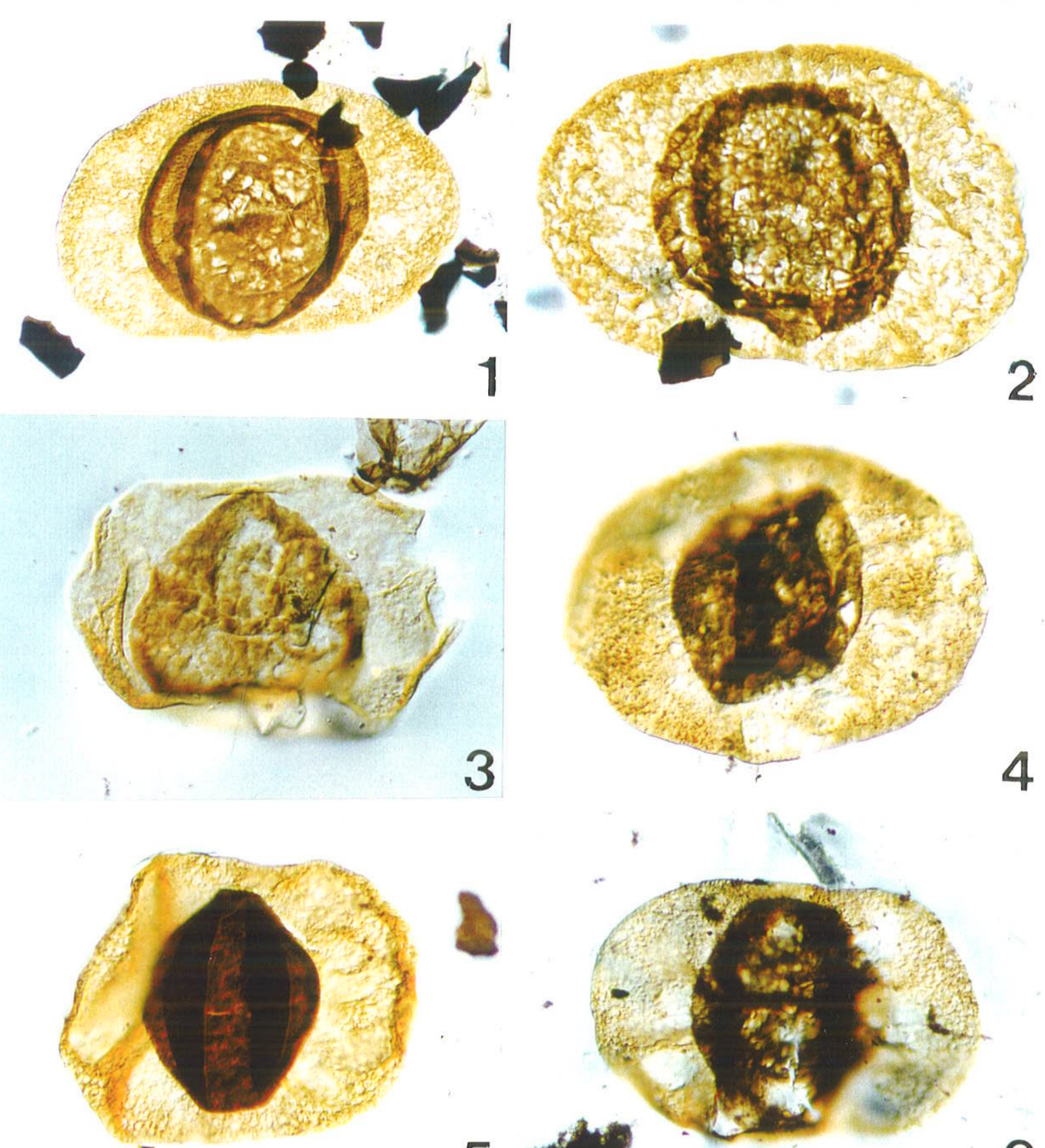

$\Rightarrow$
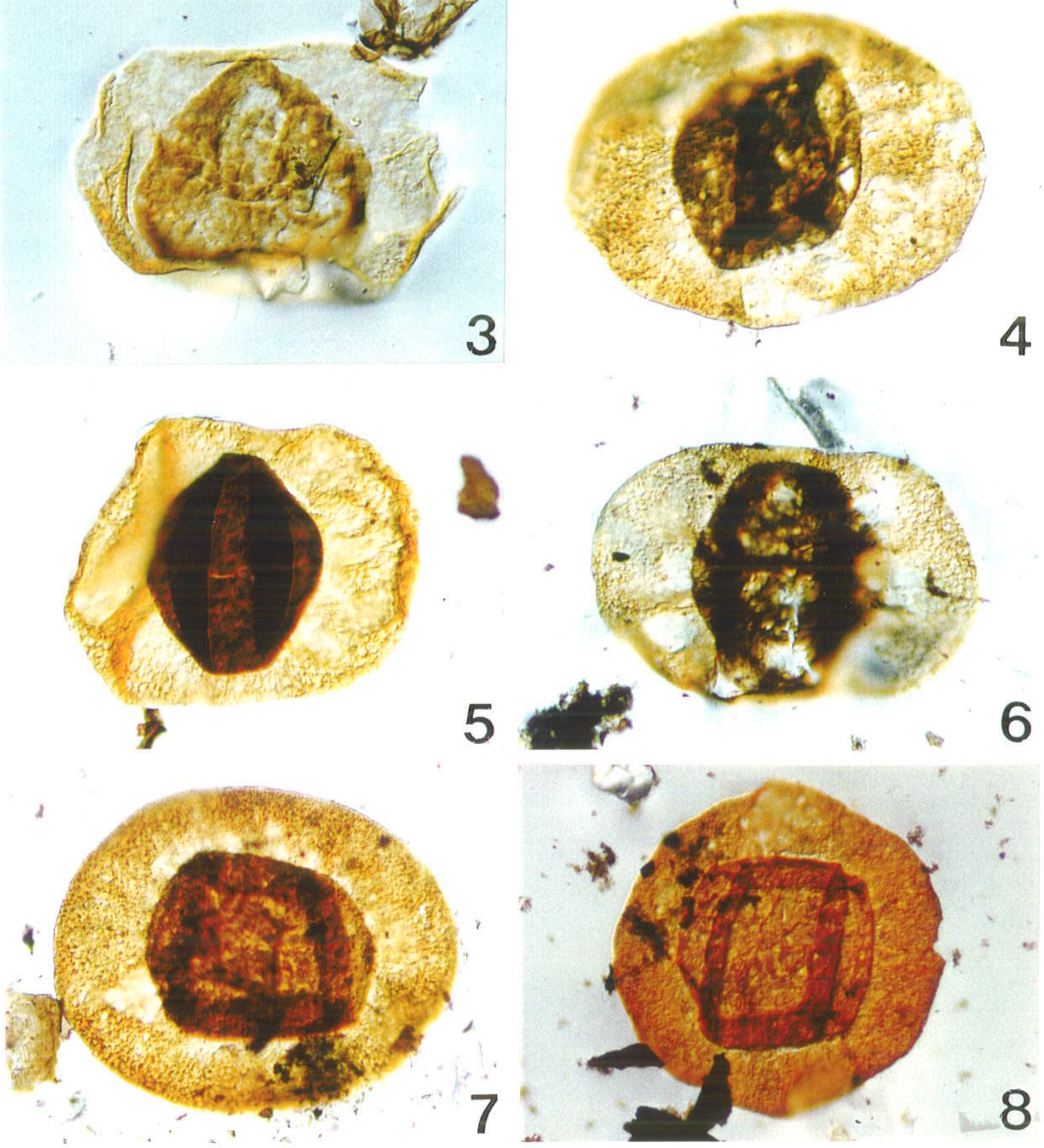


\section{ESTAMPAX}

Figura 1. Potonieisporites magnus Lele \& Karim, 1971

Lâmina IG-P: 109A, coordenada England Finder: P45/2, procedência: Jundiaí (aumento: 500x)

Figura 2. Potonieisporites magnus Lele \& Karim, 1971

GP/4E: $1415, N 48$, poço A-IG-85 (300x)

Figura 3. Potonieisporites brasiliensis (Nahuys et al.) Archangelsky \& Gamerro, 1979 GP/4E: 1420, D19/1, poço A-lG-85 (390x)

Figura 4. Potonieisporites brasiliensis (Nahuys et al.) Archangelsky \& Gamerro, 1979 GP/4E: 1397, U48/3, poço A-IG-85 (390x)

Figura 5. Divarisaccus stringoplicatus Ottone, 1991 IG-P: 108B, J42, Jundiaí (450x)

Figura 6. Divarisaccus stringoplicatus Ottone, 1991 IG-P: 109A, Q39, Jundiaí (450x)

Figura 7. ? Striomonosaccites sp. GP/4E: 1401, C28/1, poço A-lG-85 (500x)

Figura 8. ? Striomonosaccites $\mathrm{sp}$.

GP/4E: $1362, X 29$, poço A-IG-85 (500x) 

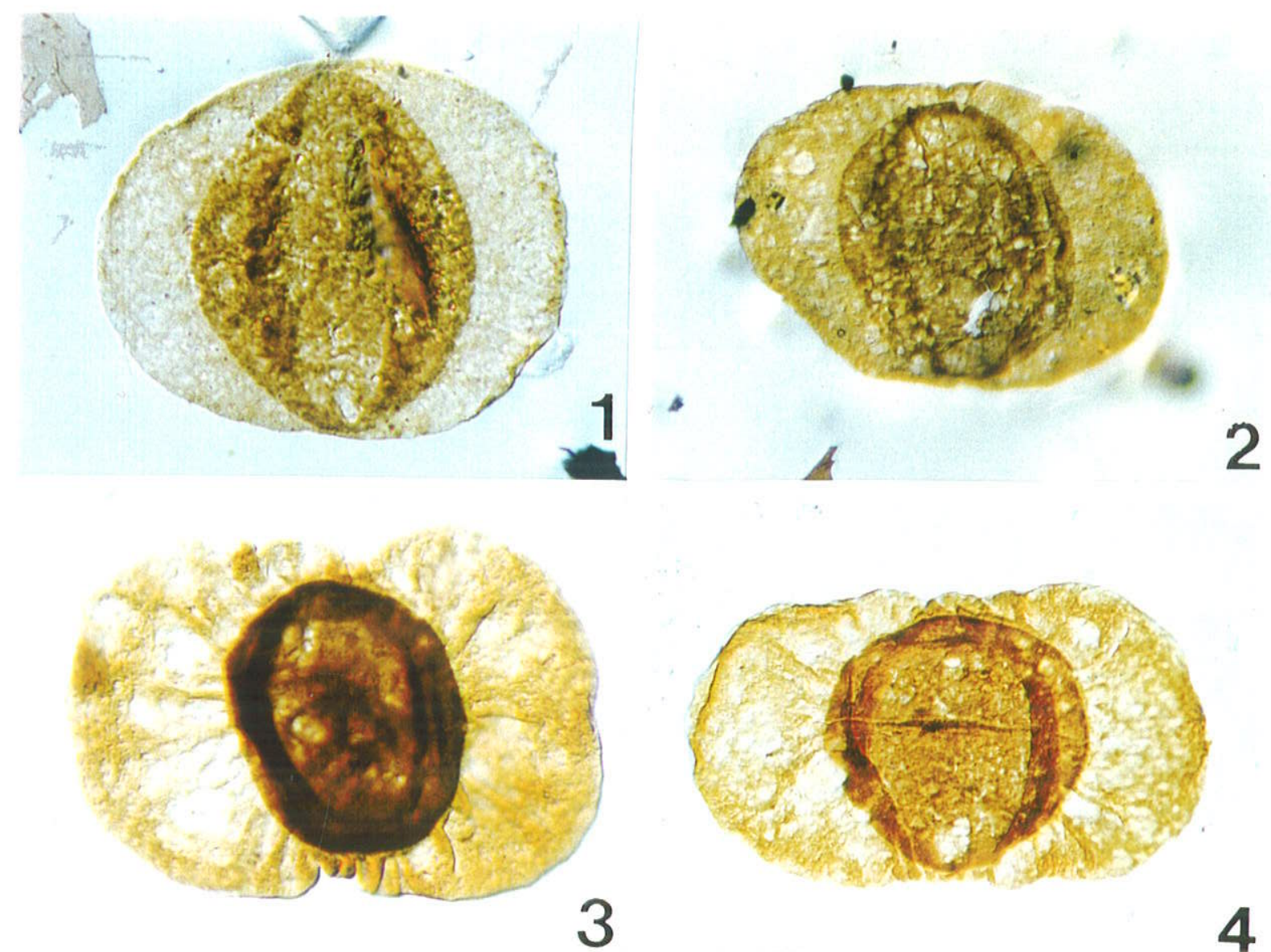

3

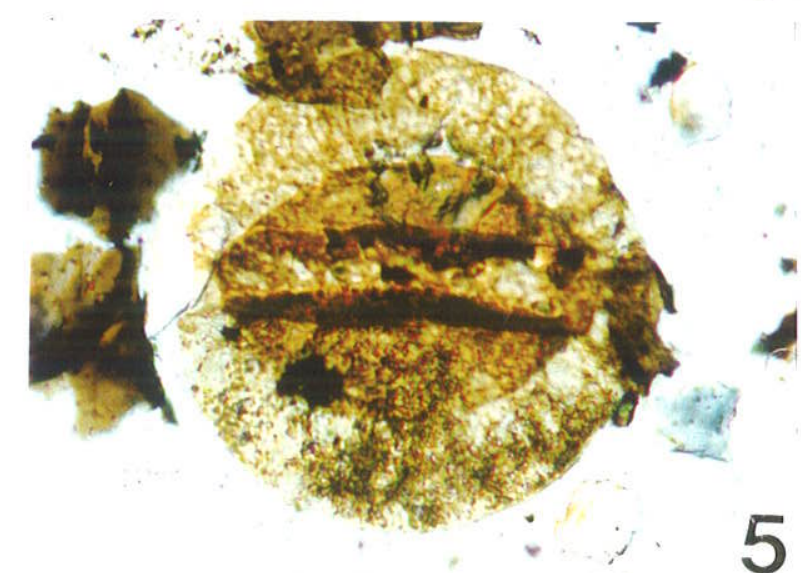

4
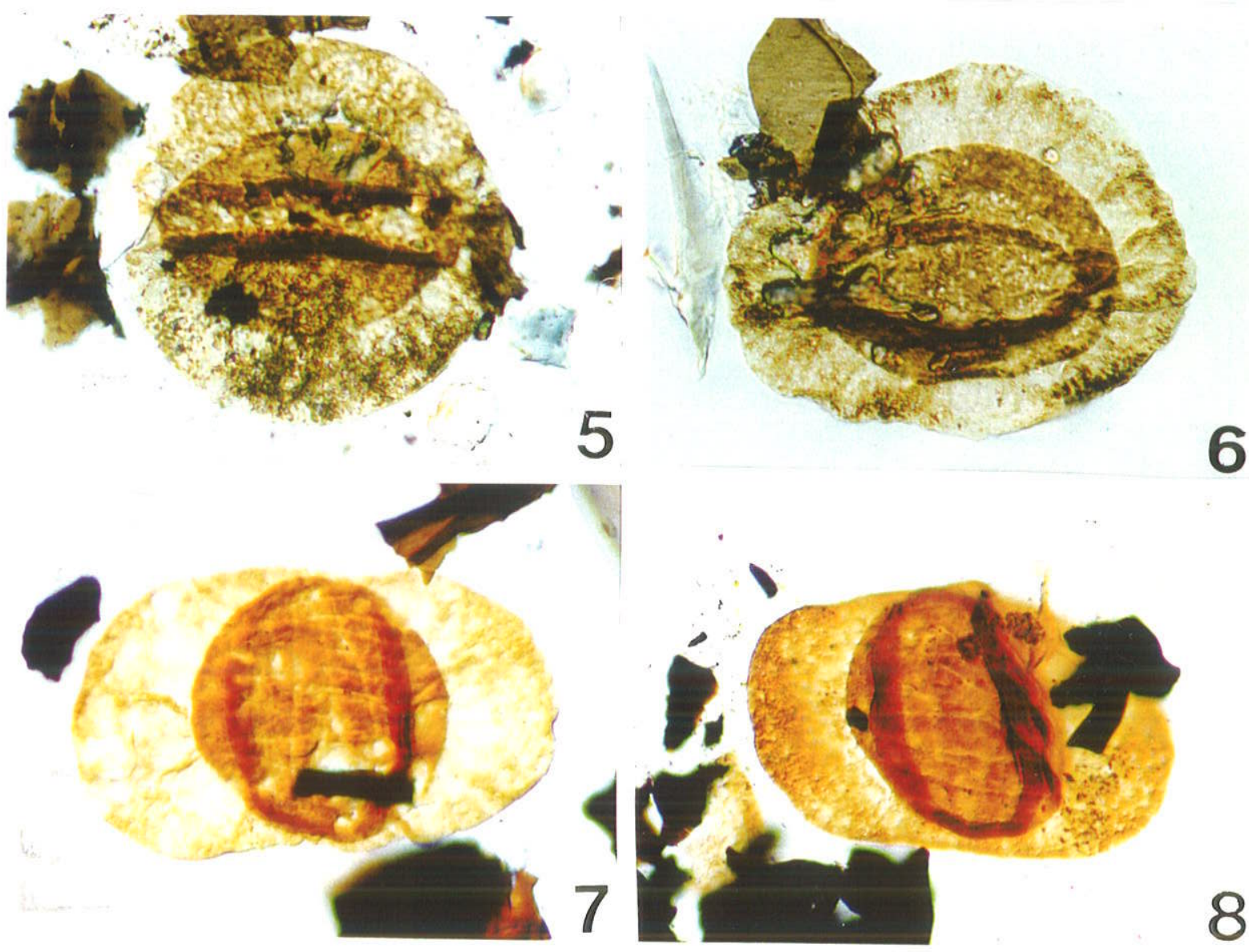

8 


\section{ESTAMPA XI}

Figura 1. Caheniasaccites flavatus Bose \& Kar emend. Azcuy \& Di Pasquo, 2000 Lâmina GP/4E: 1401, coordenada England Finder : U31, procedência: A-IG-85 (aumento: $390 x$ )

Figura 2. Caheniasaccites flavatus Bose \& Kar emend. Azcuy \& Di Pasquo, 2000 IG-P: 109A, L57, Jundiaí (500x)

Figura 3. Caheniasaccites sp.

GP/4E: $1412, Y 23$, poço A-1G-85 (450x)

Figura 4. Caheniasaccites flavatus Bose \& Kar emend. Azcuy \& Di Pasquo, 2000 IG-P: 109B, H46/2, Jundiaí (500X)

Figura 5. Caheniasaccites sp.

GP/4E: 1401, H50/1, poço A-IG-85 (450x)

Figura 6. Caheniasaccites sp.

IG-P: 118A, Q31/4, SP-270/SP (450x)

Figura 7. Scheuringipollenites maximus Tiwari, 1973

IG-P: 49E, G58, poço IG-01 (Itaporanga) (390x)

Figura 8. Scheuringipollenites maximus Tiwari, 1973

IG-P: 281A, J49/1, Jundiaí (390x) 
ESTAMPA XI
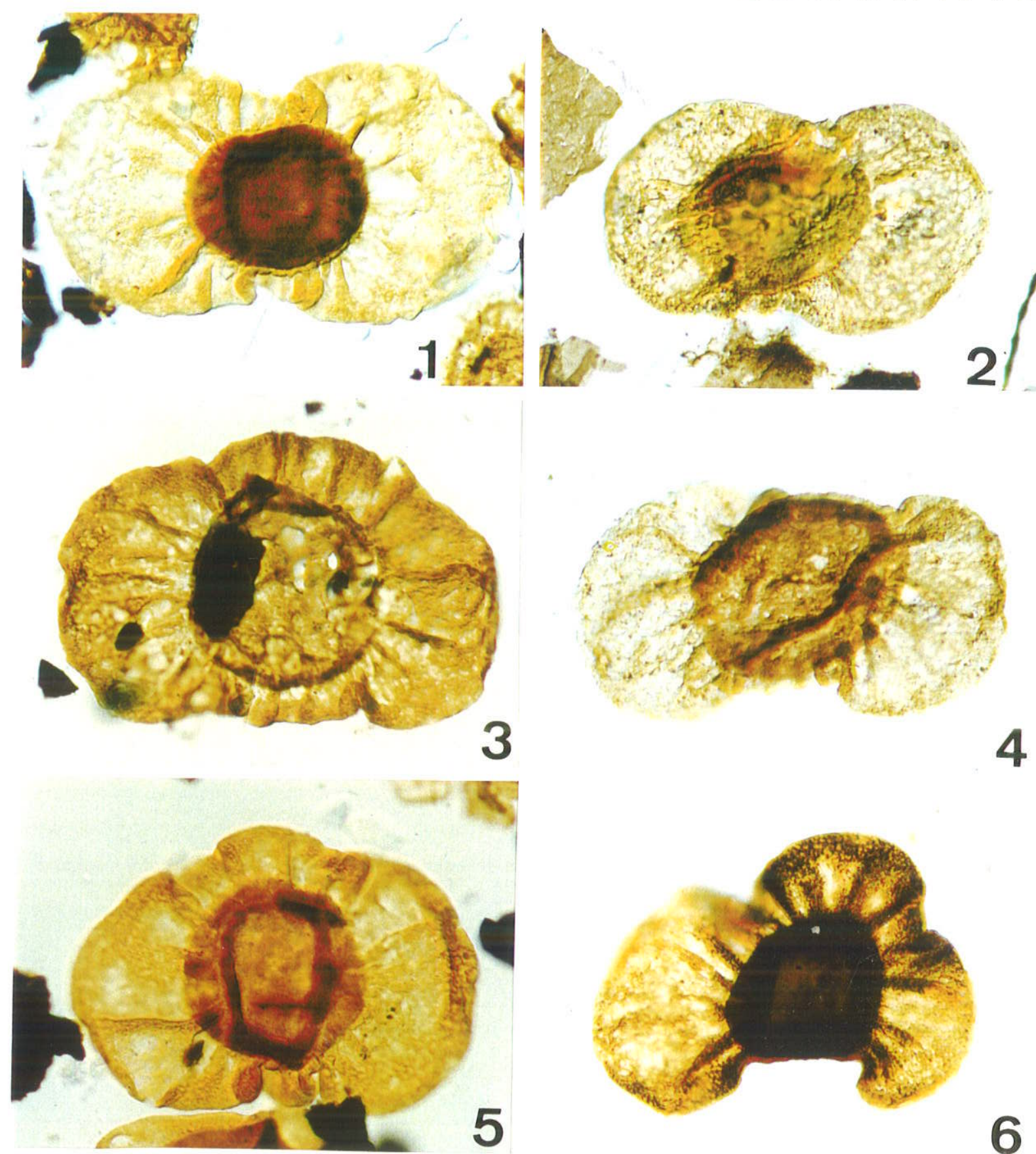

4
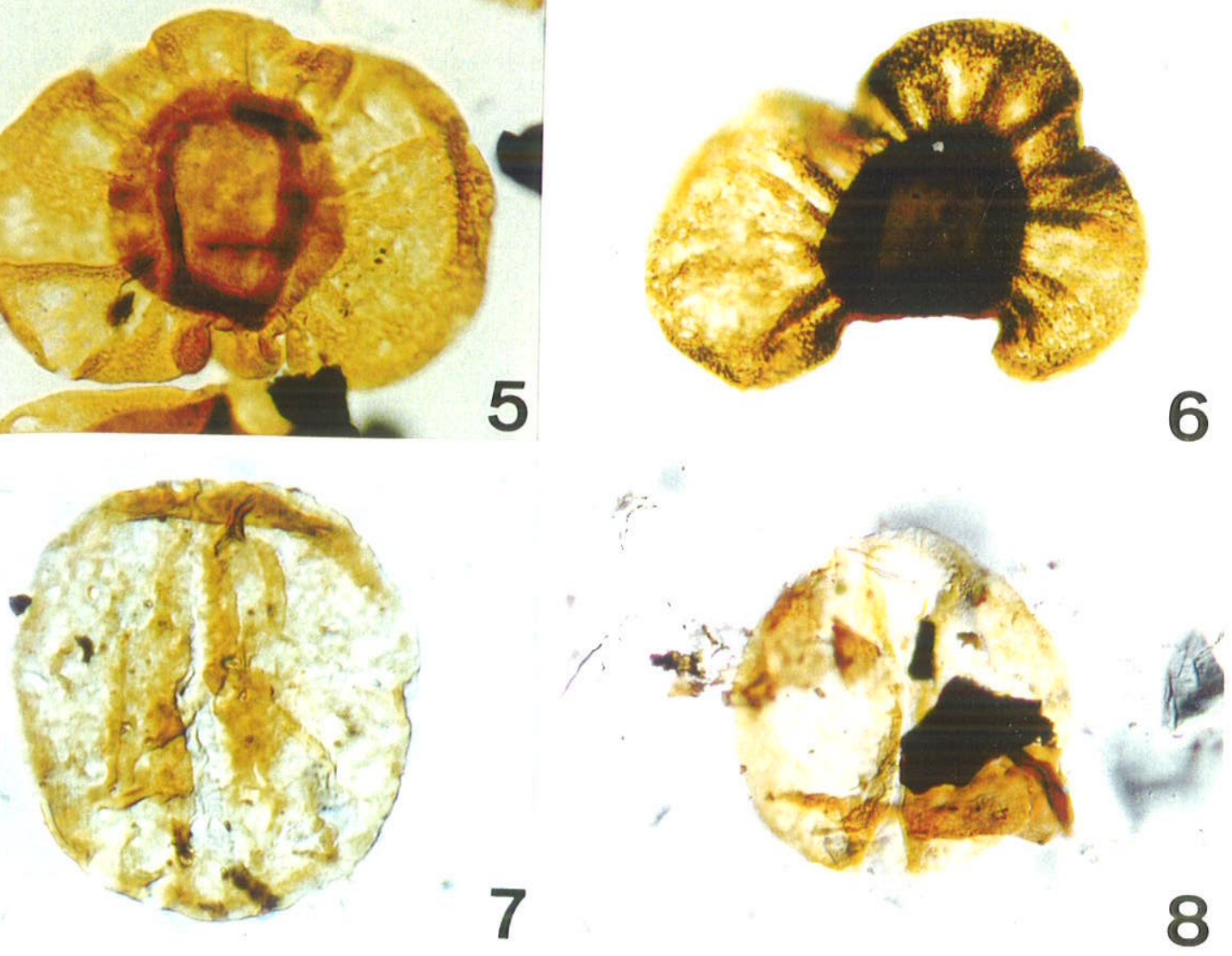


\section{ESTAMPA XII}

Figura 1. Limitisporites rectus Leschik, 1956

Lâmina GP/4E: 1416, coordenada England Finder : X40, procedência: A-IG-85 (aumento: $320 x$ )

Figura 2. Limitisporites sp.

IG.P: 43, R40/3, poço IG-01 (Itaporanga) (600x)

Figura 3. Protohaploxypinus amplus (Balme \& Hennelly) Hart, 1964 IG-P: 51, M48, poço IG-01 (ltaporanga) (450x)

Figura 4. Limitisporites sp.

GP/4E: 1357, S32, poço A-IG-85 (450x)

Figura 5. Protohaploxypinus amplus (Balme \& Hennelly) Hart, 1964 IG-P: 4A, L35/3, Monte Mor (450x)

Figura 6. Protohaploxypinus micros (Hart) Hart, 1964 IG-P: 301D, H44, PR-272, (600x)

Figura 7. Protohaploxypinus goraiensis (Potonié \& Lele) Hart, 1964 IG-P: 197A, H38, poço 2-CB-1-SP (600x)

Figura 8. Protohaploxypinus goraiensis (Potonié \& Lele) Hart, 1964 IG-P: 207A, K45, poço 1-SJ-1-PR (600x) 

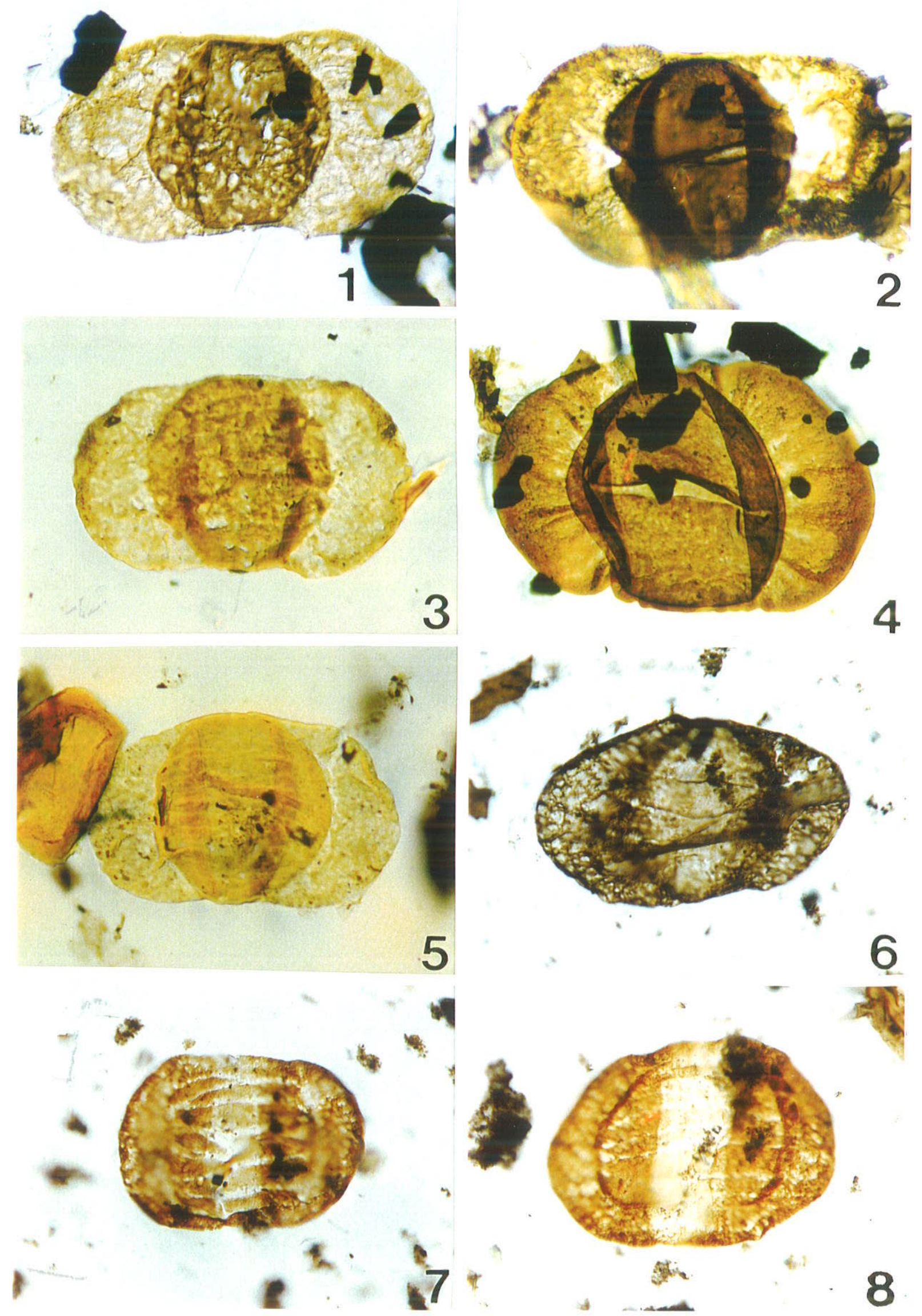


\section{ESTAMPA XIII}

Figura 1. Protohaploxypinus limpidus (Balme \& Hennelly) Balme \& Playford, 1967 Lâmina IG-P: 291A, coordenada England Finder : X29/3, procedência: Serra dos Paes (aumento: 780x)

Figura 2. Protohaploxypinus limpidus (Balme \& Hennelly) Balme \& Playford, 1967 IG-P: 301D, H44, PR-272 (760x)

Figura 3. Protohaploxypinus panaki Utting, 1994 IG-P: 291A, K47, Serra dos Paes (780x)

Figura 4. Protohaploxypinus panaki Utting, 1994 IG-P: 214, G46/2, poço 2-TB-1-SP (780x)

Figura 5. Vittatina costabilis Wilson, 1962 IG-P: 214A, N31, poço 2-TB-1-SP (780x)

Figura 6. Hamiapollenites tractiferinus (Samoilovich) Hart, 1964 IG.P: $300, H 38 / 4$, BR-53, (600x)

Figura 7. Vittatina subsaccata Samoilovich, 1953 IGM: 197A, Y47/3, poço 2-CB-1-SP (600x)

Figura 8. Vittatina costabilis Wilson, 1962 IG-P: 214A, W51, poço 2-TB-1-SP (780x)

Figura 9. Hamiapollenites fusiformis (Marques-Toigo) Archangelsky \& Gamerro, 1979 IG.P: 197A, W36, poço 2-CB-1-SP (600x)

Figura 10. Vittatina vittifera (Lüber \& Valtz) Samoilovich, 1953

IG-P: 214A, R46/2, poço 2-TB-1-SP (600x)

Figura 11. Striatoabieites sp.

GP/4E: 1335 , O55, poço A-IG-85 (600x)

Figura 12. Complexisporites polymorphus Jizba, 1962 IG-P: 153A, E45/3, poço J-IG-93 (780x) 


\section{ESTAMPA XIII}
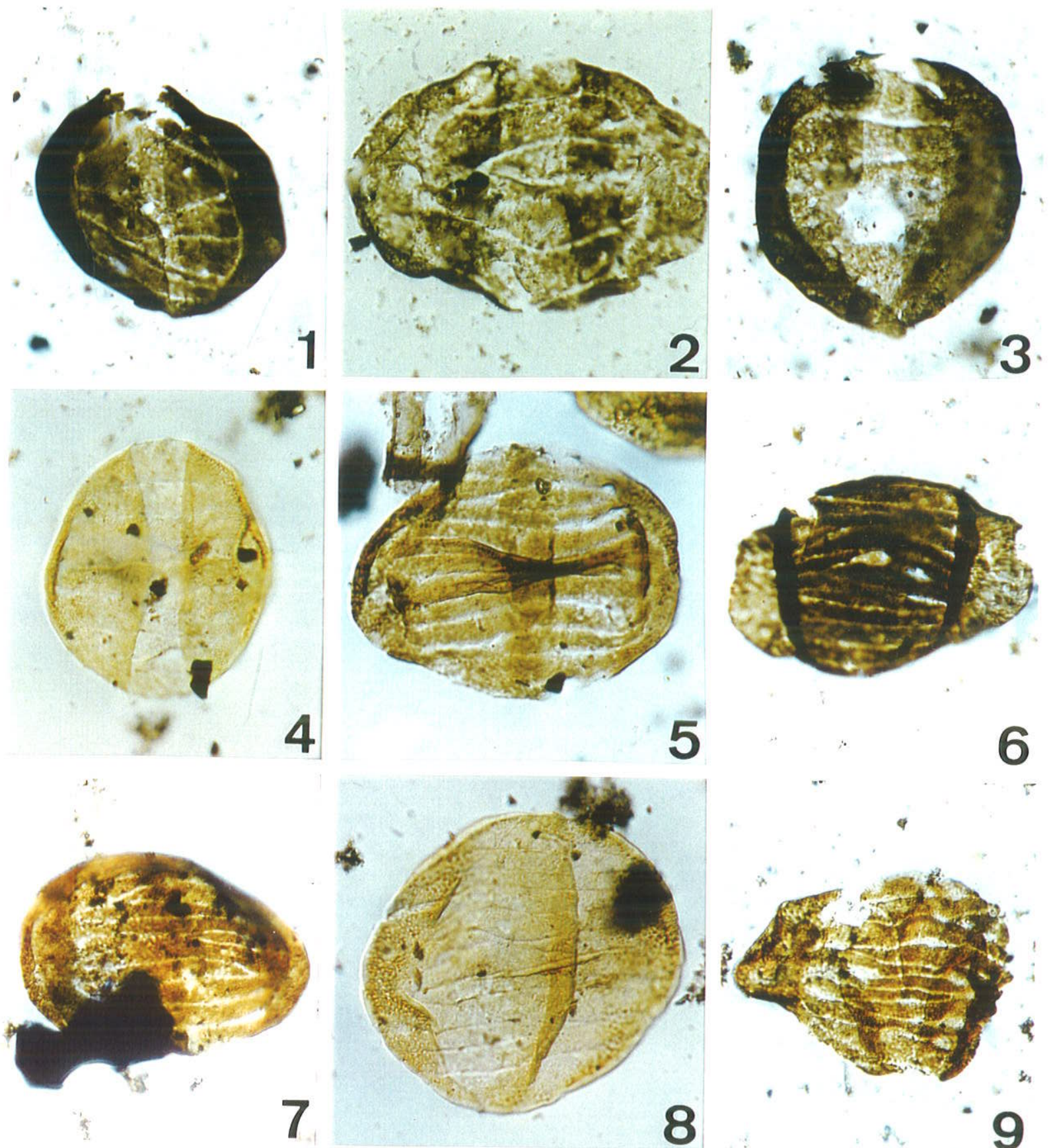

6
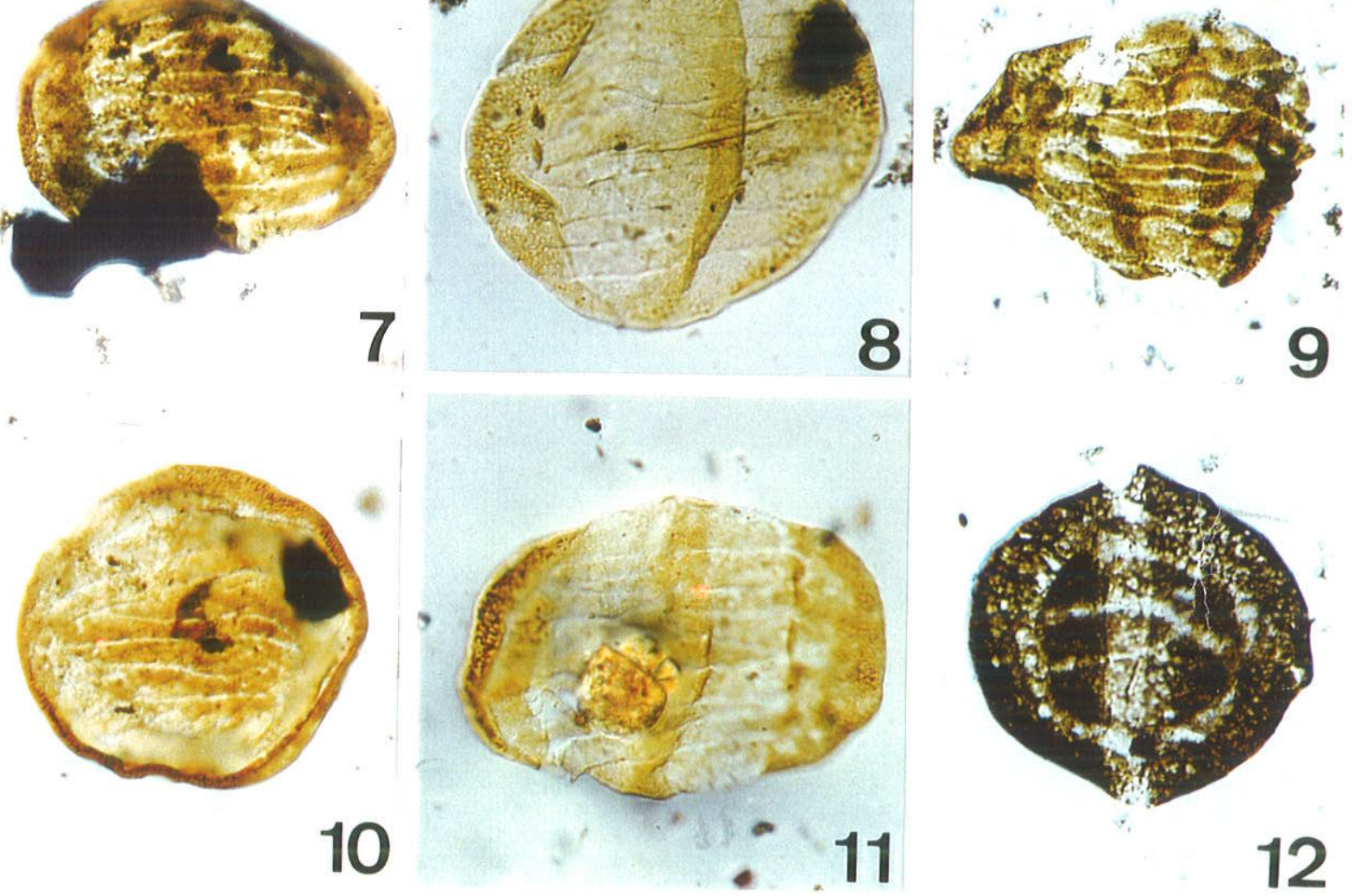

12 


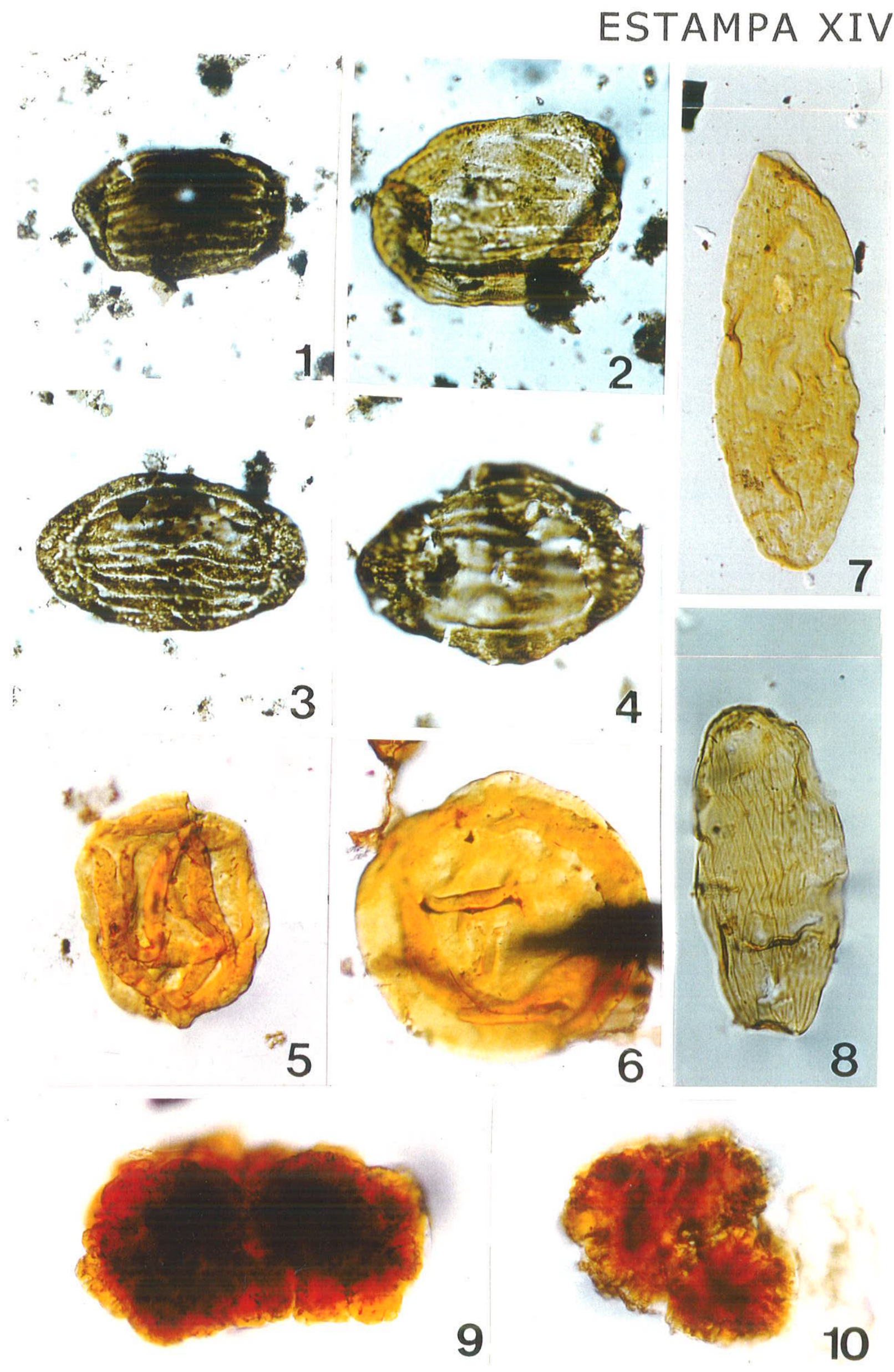




\section{ESTAMPAXV (ESPÉCIES ALÓCTONES)}

Figura 1. Retusotriletes crassus Clayton et al., 1980

Lâmina GP/4E: 1371, coordenada England Finder : X29/1, procedência: poço A-IG85 (aumento: $780 x$ )

Figura 2. Emphanisporites rotatus McGregor, 1961

GP/4E: 1397, S21/1, poço A.IG-85 (780x)

Figura 3. Emphanisporites anmulatus McGregor, 1961

IG-P: 195B, Q36/2, poço 2-PN-1-SP (780x)

Figura 4. Staurocephalites $\mathrm{sp}$.

IG-P: 236A, O51/1, poço 3-CB-3-SP $(600 \mathrm{x})$

Figura 5. Grandispora pseudoreticulata (Menéndez \& Pöthe de Baldis) Ottone, 1996 IG-P: 46F, H41/4, poço IG-01 (ttaporanga) (500x)

Figura 6. Retispora lepidophyta (Kedo) Playford, 1976

IG-P: 183B, K55, poço 2-PP-1-SP (600x)

Figura 7. Grandispora brevispinosa Menéndez \& Pöthe de Baldis, 1967 GP/4E: 1397, B28, poço A-lG-85 (390x)

Figura 8. Indotriradites cf. I. daemoni Loboziak et al., 1999 IG-P: 296A, 035, BR-053 (600x)

Figura 9. Grandispora uncata (Hacquebard) Playford, 1971 IG-P: 214A, V40/3, poço 2-TB-1SP (600x)

Figura 10. Indotriradites dolianitii (Daemon) Loboziak et al., 1999 IG-P: 183C, Q54/3, poço 2-PP-1-SP (780x)

Figura 11. Duvernaysphaera angelae Deunff, 1964 IG-P: 217B, S48/1, poço 1QT-1.PR (780x)

Figura 12. Maranhites insulatus Burjack \& Oliveira, 1989 IG-P: 58B, T31/4, poço IT-IG-85 (600x)

Figura 13. Maranhites braziliensis (Brito) Burjack \& Oliveira, 1989 IG-P: 58A, G33/3, poço IT-IG-85 (600x) 


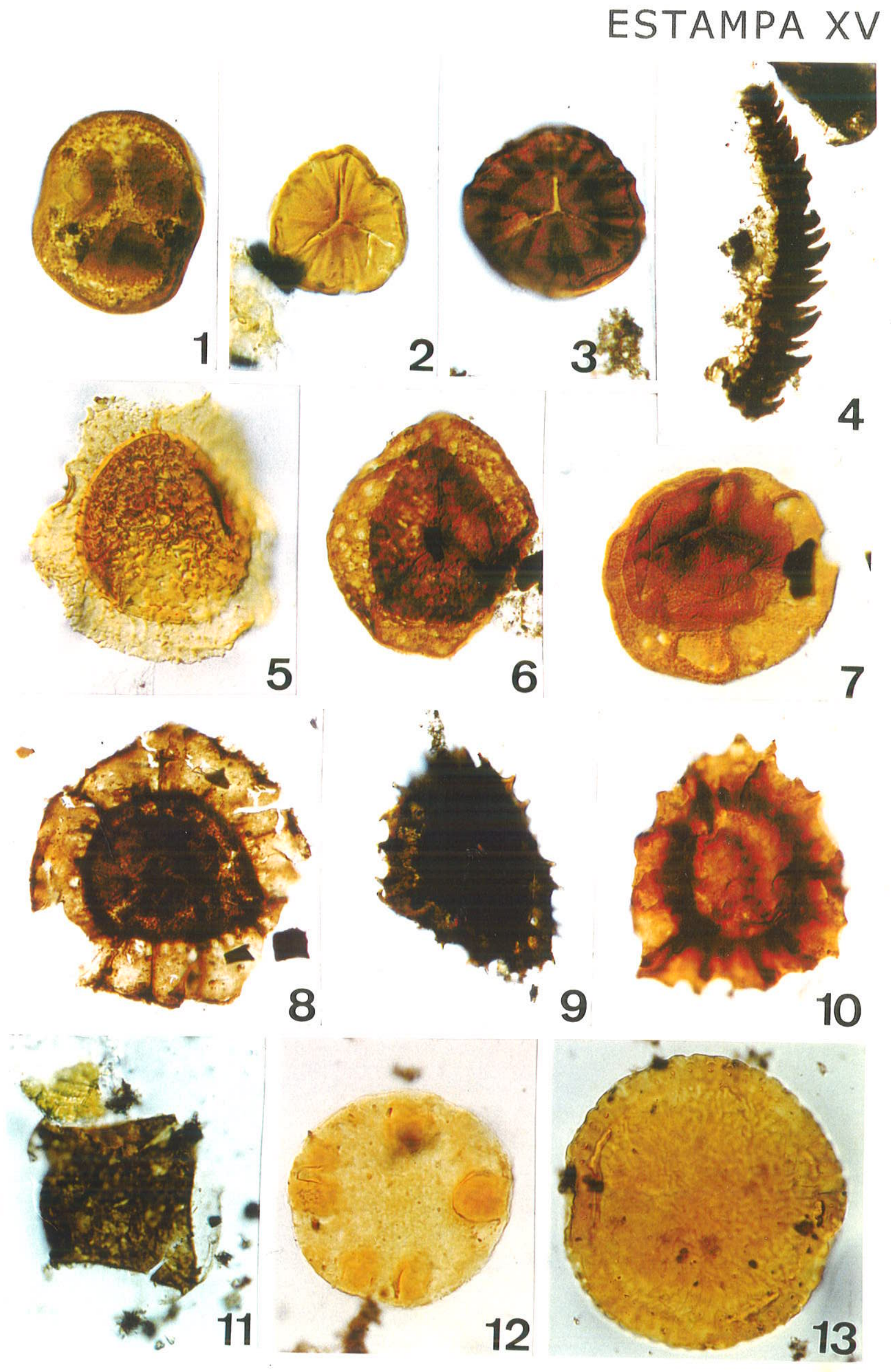




\section{ANEXO $2^{*}$}

\section{Relação dos Materiais Estudados e Distribuição das Espécies em Algumas Localidades}

* nas indicações das lâminas: IG-P é referente à Palinoteca do Instituto Geológico/SMA; GP/4E e T são referentes à coleção científica do Departamento de Geologia Sedimentar e Aplicado do IG-USP. 


\section{ANEXO 2 - Quadros}

2.1 Informações sobre procedência e localização dos poços estudados.

2.2 Informações sobre os afloramentos estudados.

2.3 Distribuição geral de todas as espécies nas biozonas propostas do Subgrupo Itararé (este trabalho) e na Formação Rio Bonito (com base em trabalhos publicados).

2.4 Distribuição das espécies no poço A-IG-85 conforme Souza (1996) e este trabalho.

2.5 Distribuição das espécies nos carvões e litologias associadas de Buri, Monte Mor e Itapeva (SP).

2.6 Distribuição das espécies nos afloramentos das pedreiras de Itu e Jundiaí (SP).

2.7 Distribuição das espécies no poço IG-01/ltaporanga (SP).

2.8 Distribuição das espécies na seção da Rodovia SP-270 (Raposo Tavares), entre Araçoiaba da Serra e Itapetininga.

2.9 Distribuição das espécies nos afioramentos do Estado do Paraná (Zpn= Zona Potonieisporites neglectus).

2.10 Distribuição dos táxons nos afloramentos da Serra dos Paes e Capivari e nos poços de Cerquilho, Estado de São Paulo.

2.11 Distribuiçăo dos táxons no poço J-IG-93.

2.12 Distribuição dos táxons no poço 1-TB-1-SP.

2.13 Distribuição dos táxons no poço 2-PN-1-SP.

2.14 Distribuição dos táxons no poço 2-CB-1-SP.

2.15 Distribuição dos táxons no poço C-IG-93.

2.16 Distribuição dos táxons no poço T-IG-93.

2.17 Distribuição dos táxons no poço †.RO-1-PR.

2.18 Distribuição dos táxons no poço 3-CB-3-SP.

2.19 Distribuição dos táxons no poço 1-SJ-1-PR.

2.20 Distribuição dos táxons no poço 1-CS-1-PR.

2.21 Distribuição dos táxons no poço T1-IG-91.

2.22 Distribuição dos táxons no poço 2-PP-1-SP.

2.23 Distribuiçāo dos táxons no poço 2-JT-1-PR.

2.24 Distribuição dos táxons no poço 2-J-1-PR.

2.25 Distribuição dos táxons no poço 1-CP-1-SP.

2.26 Distribuição dos táxons no poço IT-IG-85.

2.27 Distribuição estratigráfica de todos os esporomorfos estudados do Grupo Tubarão, conforme este trabalho e informaçōes publicadas*. 


\begin{tabular}{|c|c|c|c|c|c|c|}
\hline & \multirow{2}{*}{$\frac{\text { Sigla }}{1-R O-1-P R}$} & \multirow{2}{*}{$\frac{\text { Nome }}{\text { Roncador }}$} & \multirow{2}{*}{$\begin{array}{l}\text { Instituição } \\
\text { Paulipetro }\end{array}$} & \multicolumn{2}{|c|}{ Coordenadas geográficas } \\
\hline & 1 & & & & $24^{\circ} 36^{\prime} 33.9^{\prime \prime}$ Lat. S & $52^{\circ} 14^{\prime} 48.67^{\prime \prime}$ Long. $W$ \\
\hline$\stackrel{\pi}{=}$ & 2 & 1-SJ-1-PR & São Jerônimo da Serra & Petrobrás & $23^{\circ} 46^{\prime} 58.65^{\prime \prime}$ Lat. $S$ & $50^{\circ} 39^{\prime} 52.20^{\prime \prime}$ Long. W \\
\hline$\frac{\pi}{\pi}$ & 3 & $1-\mathrm{QT}-1-\mathrm{PR}$ & Quatingá & Petrobrás & $23^{\circ} 36^{\prime}, 5.81^{\prime \prime}$ Lat. $S$ & $49^{\circ} 55^{\prime} 50.30^{\prime \prime}$ Long. W \\
\hline 2 & 4 & 2-JT-1-PR & Joaquim Távora & Petrobrás & $23^{\circ} 28^{\prime} 15.64^{\prime \prime}$ Lat. $\mathrm{S}$ & $49^{\circ} 56^{\prime} 54.49^{\prime \prime}$ Long. W \\
\hline 帛 & 5 & $2-J-1-P R$ & Jacarezinho & Petrobrás & $23^{\circ} 13^{\prime} 15^{\prime \prime}$ Lat. S & $49^{\circ} 52^{\prime} 15^{\prime \prime}$ Long. $W$ \\
\hline & 6 & $2-C S-1-P R$ & Chapeu do Sol & Paulipetro & $24^{\circ} 57^{\prime} 49.78^{\prime \prime}$ Lat. S & $51^{\circ} 58^{\prime} 2.94^{\prime \prime}$ Long. W \\
\hline & 7 & 2-TB-1-SP & Taciba & Paulipetro & $22^{\circ} 21^{\prime} 36.75^{\prime \prime}$ Lat. S & $51^{\circ} 20^{\prime} 56.74^{\prime \prime}$ Long. W \\
\hline & 8 & 2-LA-1-SP & Lagoa Azul & Paulipetro & $21^{\circ} 39^{\prime} 14^{\prime \prime}$ Lat. S & $50^{\circ} 47^{\prime} 35^{\prime \prime}$ Long. $W$ \\
\hline & 9 & 1-PA-1-SP & Piratininga & Paulipetro & $22^{\circ} 28^{\prime} 01.81^{\prime \prime}$ Lat. S & $49^{\circ} 09^{\prime} 08.40^{\prime \prime}$ Long. W \\
\hline & 10 & 2-PP-1-SP & Paraguaçu Paulista & Paulipetro & $22^{\circ} 25^{\prime} 07.3^{\prime \prime}$ Lat. S & $50^{\circ} 36^{\prime} 13.49^{\prime \prime}$ Long. W \\
\hline & 11 & $2 \sim \mathrm{PN}-1 \sim \mathrm{SP}$ & Paranapanema & Petrobrás & $34^{\circ} 26.7^{\prime}$ Lat. S & $48^{\circ} 46^{\prime} 27.6^{\prime \prime}$ Long. $W$ \\
\hline & 12 & 1-CP-1-SP & Carlota Prenz & Petrobrás & $23^{\circ} 22^{\prime} 21.24^{\prime \prime}$ Lat. $S$ & $48^{\circ} 23^{\prime} 10.24^{\prime \prime}$ \\
\hline & 13 & 2-GU-4-SP & Guareí & Paulipetro & $23^{\circ} 26^{\prime} 22^{\prime \prime}$ Lat. S & $48^{\circ} 15^{\prime} 52^{\prime \prime}$ Long. W \\
\hline 윽 & 14 & 2-GU-3-SP & Guareí & Paulipetro & $23^{\circ} 24^{\prime} 00^{\prime \prime}$ Lat. S & $48^{\circ} 11^{\prime} 45^{\prime \prime}$ Long. $W$ \\
\hline 린 & 15 & 2-CBn1-SP & Cuiabá Paulista & Paulipetro & $22^{\circ} 18^{\prime} 11.9^{\prime \prime}$ Lat. S & $52^{6} 02^{\prime} 21.6^{\prime \prime}$ Long. W \\
\hline a) & 16 & 3-CB-3-SP & Cuiabá Paulista & Paulipetro & $22^{\circ} 19^{\prime} 30.35^{\prime \prime}$ Lat. $\mathrm{S}$ & $52^{\circ} 03^{\prime} 43.48^{\prime \prime}$ Long. $W$ \\
\hline 为 & 17 & B! 1 -SP & Buri-Itapeva & CESP/IPT & $23^{\circ} 45^{\prime}$ Lat. $S$ & $48^{\circ} 42^{\prime} 30^{\prime \prime}$ Long. W \\
\hline$\frac{0}{0}$ & 18 & $1 \mathrm{G}-01$ & Itaporanga & G/SMA & $-23^{\circ} 42^{\prime}$ Lat. $\mathrm{S}$ & $\sim 49^{\circ} 30^{\circ}$ Long. $\mathrm{W}$ \\
\hline 잉 & 19 & $1 T-1 \mathrm{G}-85$ & ltu & IG/SMA & 7428.70 UTMN & 259.55 UTME \\
\hline 品 & 20 & A-IG-85 & Aracoiaba da Serra & IG/SMA & 7392.80 UTMN & 231.60 UTM E \\
\hline H) & 21 & J-1G-93 & Jumirim & IG/SMA & 7444.95 UTMN & 214.15 UTM E \\
\hline & 22 & T-1G-93 & Tietê & IG/SMA & 7444.20 UTM N & 224.0 UTME \\
\hline & 23 & $\mathrm{~T} 1-1 \mathrm{G}-93$ & Tietê & IG/SMA & 7446.30 UTM N & 220.30 UTM E \\
\hline & 24 & C-1G-93 & Capivari & IG/SMA & 7455.10 UTM N & 242.25 UTM E \\
\hline & & SR-23-SP & Cerquilho & CESP/PT & 7436.82 UTM N & 217.10 UTME \\
\hline & & SR-25-SP & Cerquilho & CESP/IPT & 7437.38 UTM N & 217.54 UTM E \\
\hline & 25 & SR-14-SP & Cerquilho & CESP/IPT & 7436.82 UTM N & 217.10 UTM E \\
\hline & & SR-09-SP & Cerquilho & CESP/IPT & 7436.03 UTM N & 218.15 UTME \\
\hline
\end{tabular}

Quadro 2.1 - Informaçōes sobre procedência e localização dos poços estudados. 


\begin{tabular}{|c|c|c|c|c|}
\hline & Localidade & & Indicações geográficas & Lâminas \\
\hline \multirow{15}{*}{ 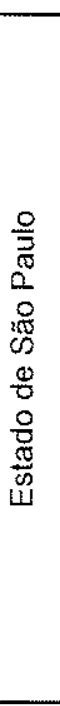 } & Buri & Mina de carvāo abando & ada (coord. nāo disponíveis) & GP4T: 299-303; IG-P: 9-12 \\
\hline & Monte Mor & Sítio do Mina (coord. nā & disponíveis) & IG-P: 1-8 \\
\hline & Itapeva & Faz. Santa Marta, $\sim 23^{\circ}$ & $46^{\prime}$ Lat. S/48 $50^{\prime} 30^{\prime \prime}$ Long. W & G-P: 256,286 \\
\hline & \multirow[b]{2}{*}{ Itu } & Pedr. Ituana & SP $75, \mathrm{Km} .28$, ao lado do Parque Ecológico do Varvito. & G-P: $251-255$ \\
\hline & & Pedr. Argiplan & SP 75, Km. 31.8, Av. Sete Quedas & G-P: $248-250$ \\
\hline & \multirow[b]{2}{*}{ Jundiaí } & Pedr. Windlin & 7436,797 UTM N/312,154 UTME & IG-P: 281 \\
\hline & & Pedr. Nivolone & 7437,968 UTM N/314,615 UTME & IG-P: $108,109,283$ \\
\hline & Cesário Lange & \multicolumn{2}{|c|}{ Faz. Santa Catarina (Mato Seco), $23^{\circ} 11^{\prime} 45,3^{\prime \prime}$ Lat. S / $47^{\circ} 50^{\prime \prime} 19,6^{\prime \prime}$ Long. W. } & IG-P:272 \\
\hline & \multirow[t]{2}{*}{ Cerquilho } & $\begin{array}{l}\text { Cera. Velho / Toca do } \\
\text { Indio }\end{array}$ & $\begin{array}{l}\text { Coleção de macrofósseis do IG/USP (GP3E) } \\
23^{\circ} 13^{\prime} 51,5^{\prime \prime} \text { Lat. W/ } 47^{\circ} 45^{\prime \prime} 24,7^{\prime \prime} \text { Long. W }\end{array}$ & IGP: $259-263,268-270,289$ \\
\hline & & Bairro Aliança & $23^{\circ} 09^{\prime} 15,4^{\prime \prime}$ Lat. S/ $47^{\circ} 46^{\prime} 5,8^{\prime \prime}$ Long W & IG-P: 271 \\
\hline & \multirow{5}{*}{$\begin{array}{l}\text { Araçoiaba da } \\
\text { Serra } \\
\end{array}$} & \multirow{5}{*}{ Rod. SP-270 } & Km. 118.6 & GP/4E: 1335; IG-P: 71 \\
\hline & & & Km. 121.9 & GP/4E: 1339; GP/4T: 83-86; IG-P: 70 \\
\hline & & & $\mathrm{Km} .122 .2$ & GP/4E: 1340-3; IG-P: 76-78 \\
\hline & & & Km. 123.7 & GP/4E: 1344; IG-P: 80 \\
\hline & & & Km. 125.8 & GP/4E: 1345-8; IG-P: $81-83,287$ \\
\hline \multirow{8}{*}{ 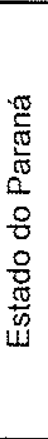 } & \multirow{7}{*}{$\begin{array}{l}\text { Seção Ventania } \\
\text { - Lbaiti (BR } 153 \text { ) }\end{array}$} & \multicolumn{2}{|c|}{ Lixão de lbaiti , $4 \mathrm{Km}$ oeste de lbaiti, $23^{\circ} 51^{\prime} 03^{\prime \prime}$ Lat. S/50 $14^{\prime} 03^{\prime \prime}$ Long. W } & IG-P: 300 \\
\hline & & $\mathrm{Km} 122.8$ & $23^{\circ} 57^{\prime} 42^{\prime \prime}$ Lat. S/50 $14^{\prime} 13^{\prime \prime}$ Long. W & IG-P:299A \\
\hline & & $\mathrm{Km} 125$ & $23^{\circ} 58^{\prime} 43^{\prime \prime}$ Lat. S/50 $14^{\prime} 15^{\prime \prime}$ Long. W & IG-P: 298 \\
\hline & & $\mathrm{Km} 133$ & & IG-P: 297 \\
\hline & & $\mathrm{Km} 141.1$ & $24^{\circ} 06^{\prime} 30^{\prime \prime}$ Lat. S/50 14'14" Long. W & IG-P: 296 \\
\hline & & $\mathrm{Km} 149.9$ & $24^{\circ} 10^{\prime} 16^{\prime \prime}$ Lat. S/50 $10^{\circ} 13^{\prime \prime}$ Long. W & IG-P:295 \\
\hline & & $\mathrm{Km} \mathrm{156.2}$ & $24^{\circ} 13^{\prime} 46^{\prime \prime}$ Lat. S/50 $12^{\prime} 46^{\prime \prime}$ Long. W & 1G-P: 294 \\
\hline & $\begin{array}{l}\text { Seção Ventania- } \\
\text { Curiúva }\end{array}$ & $\mathrm{Km} 72.7$ & $23^{\circ} 47^{\circ} 02^{\prime \prime}$ Lat. S / $49^{\circ} 58^{\prime} 36^{\prime \prime}$ Long. W & $1 G-P: 292$ \\
\hline
\end{tabular}

Quadro 2.2 - Informaçōes sobre os afloramentos estudados. 


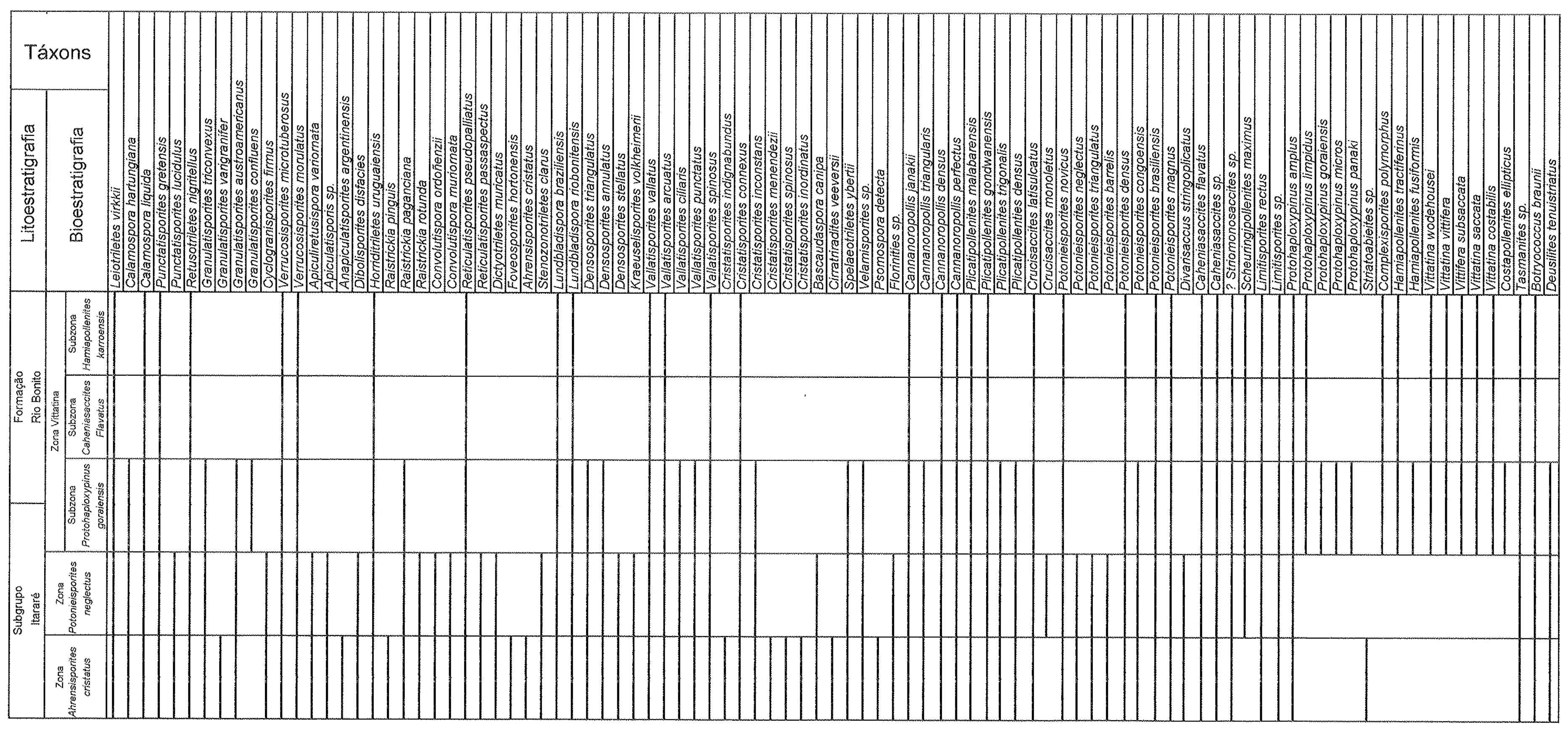

Quadro 2.3 - Distribuição geral de todas as espécies estudadas nas biozonas proposłas do Subgrupo ltararé (este trabalho) e na Formação Rio Bonito (com base em trabalhos publicados) 


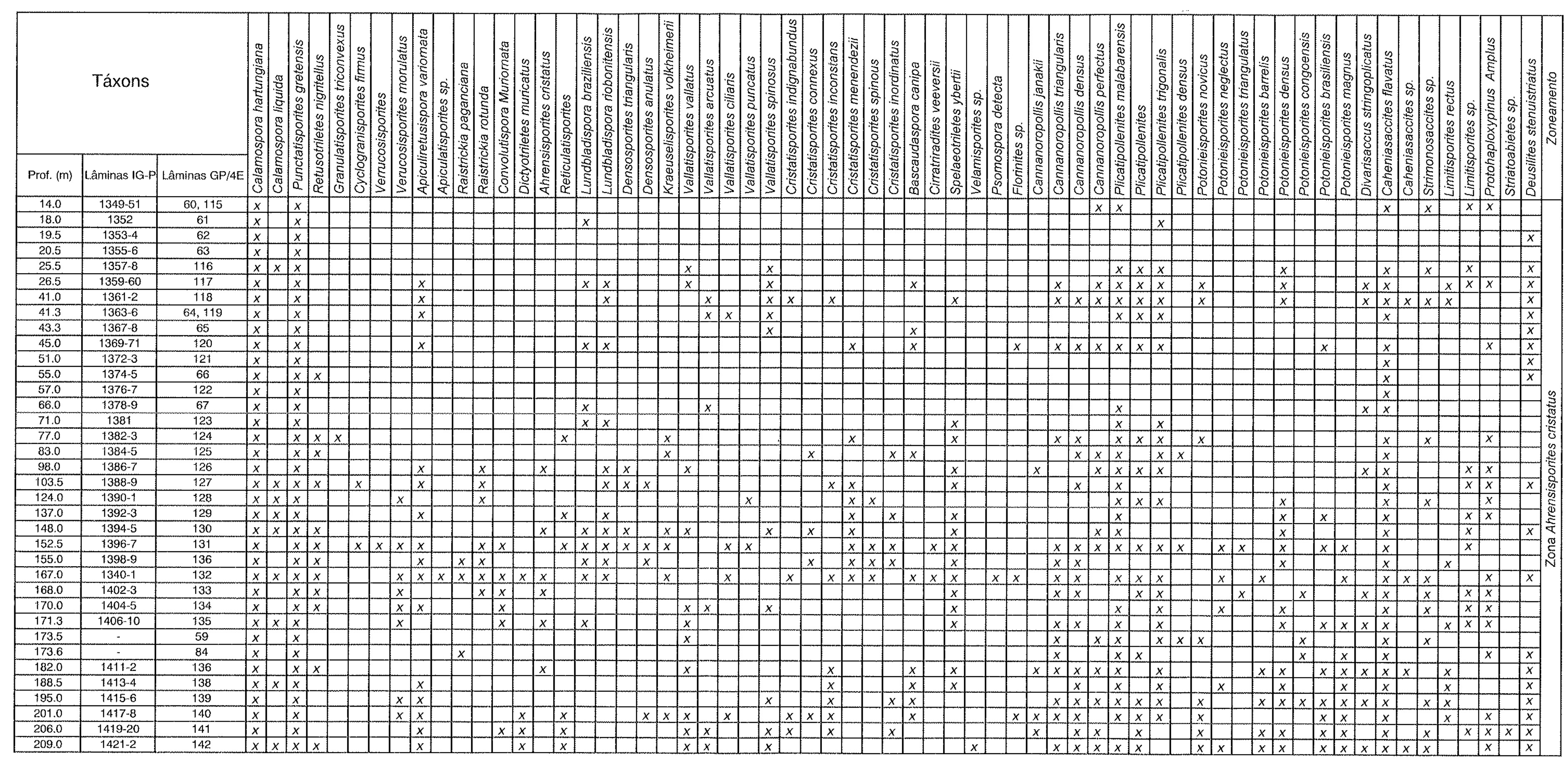

Quadro 2.4 - Distribuição das espécies no poço A-IG-85 conforme Souza (1996) e este trabalho. 


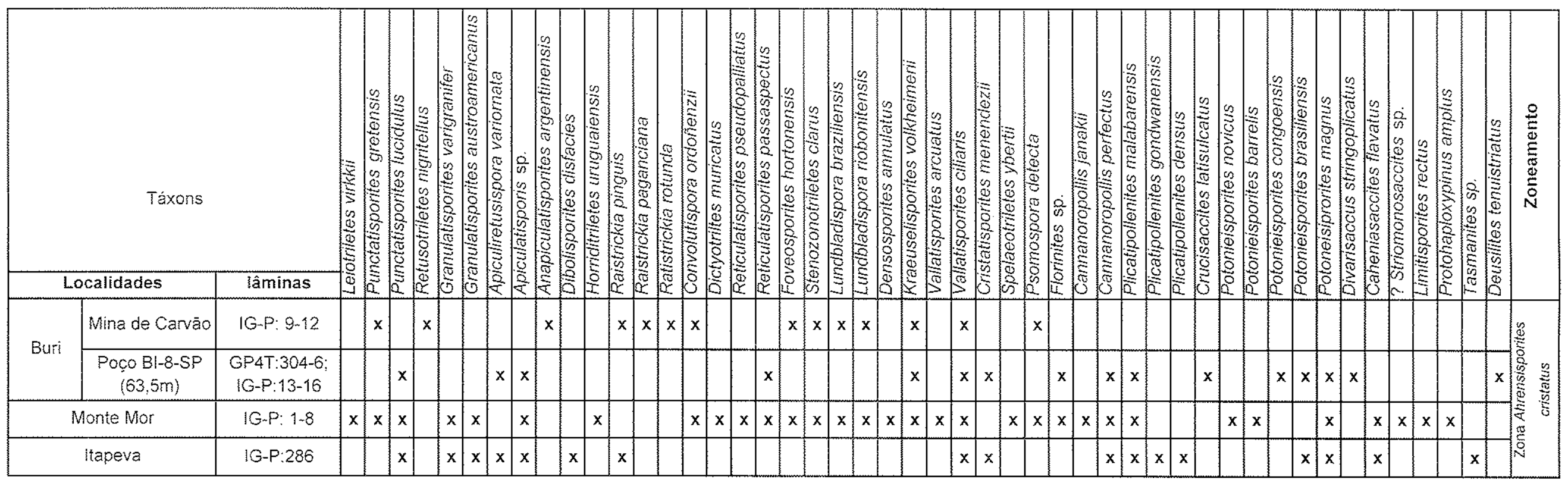

Quadro 2.5 - Distribuição das espécies nos afloramentos dos carvöes e litologias associadas de Buri, Monte Mor e ltapeva (SP).

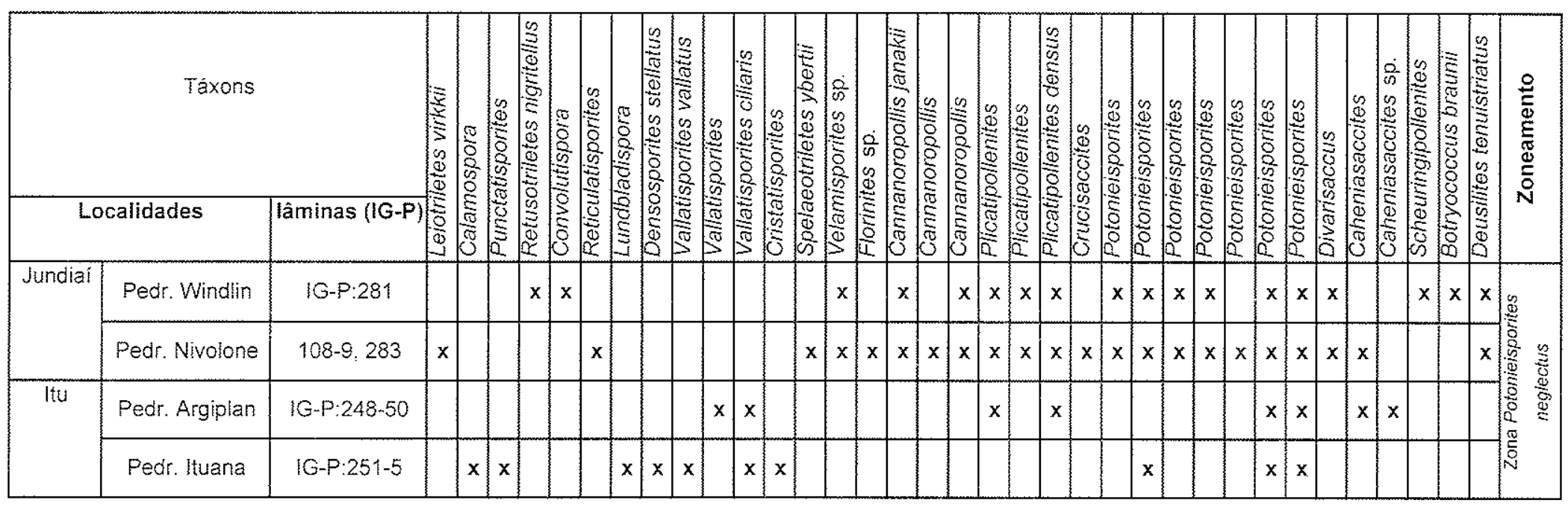

Quadro 2.6 - Distribuição das espécies nos afioramentos das pedreiras de ltu e Jundiai (SP). 


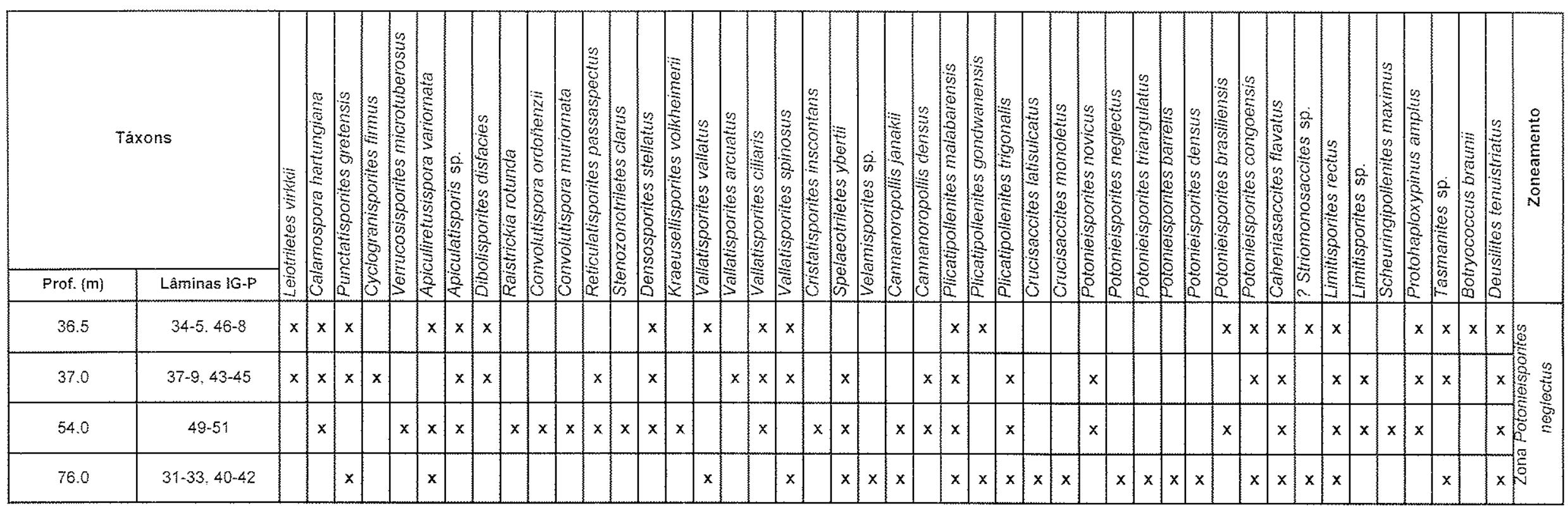

Quadro 2.7 - Distribuição das espécies no poço lG-01/ Itaporanga (SP).

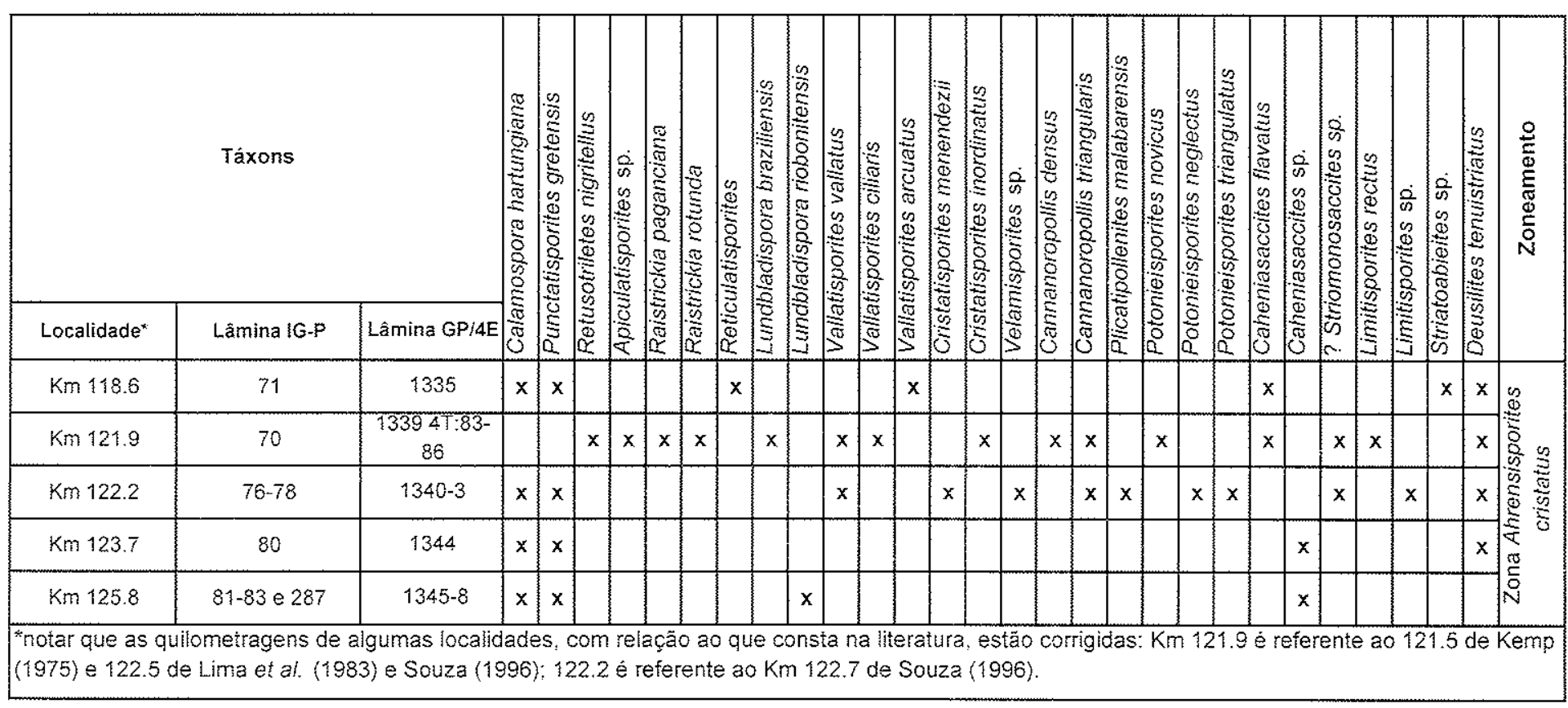

Quadro 2.8 - Distribuição das espécies na seção da Rodovia SP-270 (Raposo Tavares), entre Araçoiaba da Serra e Itapetininga. 


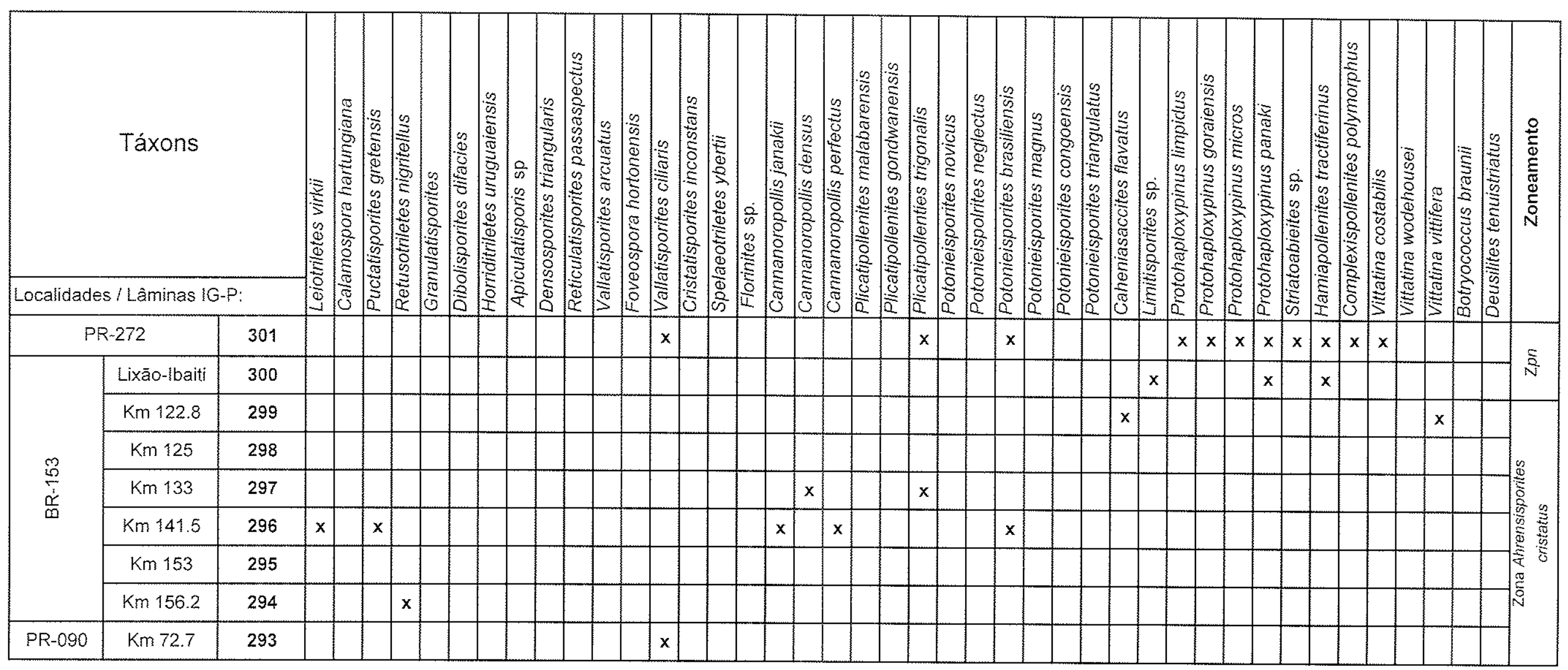

Quadro 2.9 - Distribuição das espécies nos afloramentos do Estado do Paraná. (Zpn = Zona Potonieisporites neglectus). 


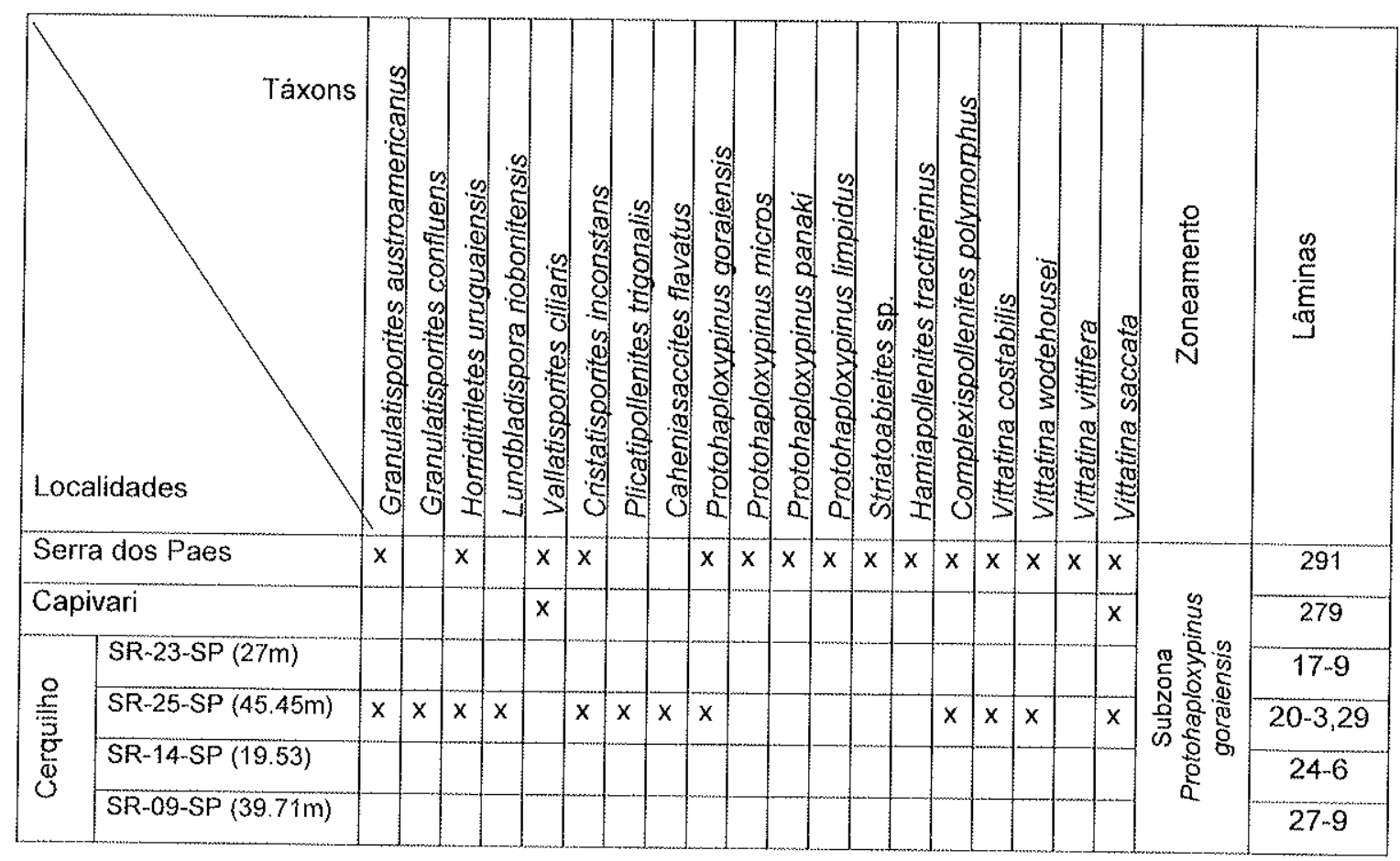

Quadro 2.10 - Distribuição das espécies nos afloramentos da Serra dos Paes e Capivari e nos poços de Cerquilho, Estado de São Paulo. 


\begin{tabular}{|c|c|c|c|c|c|c|c|c|c|c|c|c|c|c|c|c|c|c|c|c|c|c|c|c|c|c|}
\hline \multicolumn{27}{|c|}{$J-1 G-93$} \\
\hline Táxons & 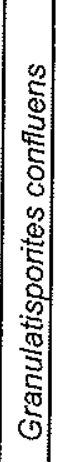 & 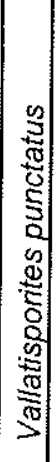 & 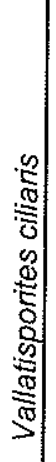 & 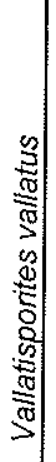 & : & 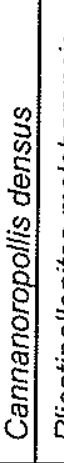 & 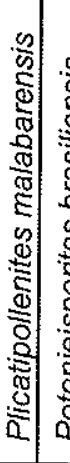 & & 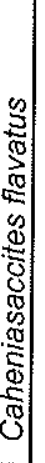 & 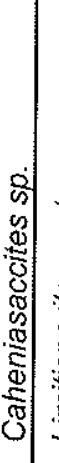 & 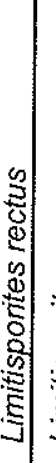 & है & \begin{tabular}{l|l}
0 \\
0 \\
0 \\
0
\end{tabular} & & 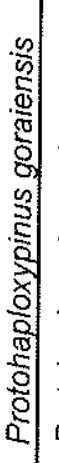 & 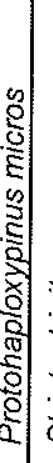 & 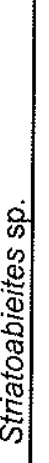 & 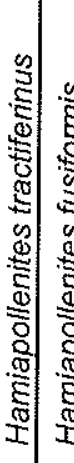 & 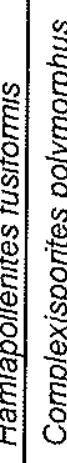 & 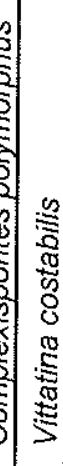 & 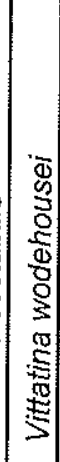 & 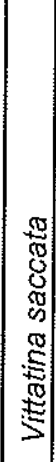 & 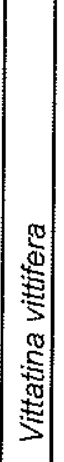 & 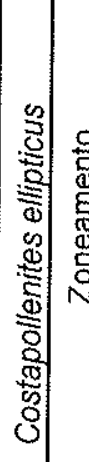 & & 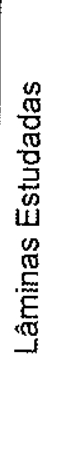 \\
\hline 13.0 & & & & & & & & & & & & & & & & & & & & & & & & \multirow{26}{*}{\multicolumn{2}{|c|}{ 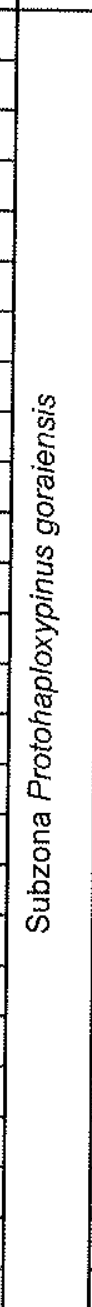 }} & 149 \\
\hline 18.2 & & & & & & & & & & & & & & & & & & & & & & & & & & 150 \\
\hline 26.2 & & & & & & & & & & & & & & & & & & & & $x$ & & & & & & 151 \\
\hline 30.5 & & & & & & & & & & & & & & & & & & & & & $x$ & & & & & 152 \\
\hline 34.0 & & & & & & & & & & & & & $x$ & $x$ & & & & & $x$ & & & & & & & 153 \\
\hline 36.0 & & & & & & & & & & & & & & & $x$ & & & & $x$ & & & & $x$ & & & 154 \\
\hline 120.0 & & & & & & & & & & & & & & $x$ & & & & & & & & & & & & 155 \\
\hline 122.7 & & & & & & & & & & & & & & & & & & & & & & & & & & 156 \\
\hline 124.0 & & & & & & & $x$ & $x$ & & & $x$ & & & & & & & & & $x$ & . & & & & & 161 \\
\hline 127.6 & & & & $x$ & & & & & & & 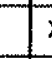 & $x$ & $x$ & $x$ & & & & & & $\bar{x}$ & $x$ & & & & & 157 \\
\hline 128.0 & & & & & & & & & & & & 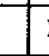 & $x$ & & & & & & & & & $x$ & & $x$ & & 158 \\
\hline 128.7 & & $\mathrm{x}$ & & & & & & & & & & -3 & $x$ & $x$ & & & & & & & . & & & & & 159 \\
\hline 129.8 & & & & & & $x$ & & & & & & & $x$ & $\bar{x}$ & & & & & & & $x$ & & $x$ & & & 160 \\
\hline 131.5 & & & $\bar{x}$ & & & & & & & & & 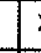 & $x$ & & & & & & & $x$ & & & & & & 162 \\
\hline 134.5 & & & & & & & $x$ & & $x$ & & & & & & & & & $x$ & & $x$ & & & $x$ & & & 163 \\
\hline 144.5 & & & & & & & & & & & & & & & & & & & & . & . & & & & & 164 \\
\hline 145.5 & & & & & & & $x$ & & & & & 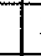 & $x$ & & & & & & $x$ & $x$ & $x$ & $x$ & & & & 165 \\
\hline 149.5 & & & & & & & & & & & $x$ & & & & $x$ & & $x$ & $x$ & & & & & $x$ & $x$ & & 166 \\
\hline 187.6 & & & & & & & & & & & & - & $\bar{x}$ & & & & & & & $x$ & & & & $x$ & & 167 \\
\hline 203.6 & & & $\mathrm{x}$ & & & & & & & $x$ & & & & & & & & & & & & & & & & 168 \\
\hline 223.0 & & & & & & & & & & & & & & & $x$ & & & & & & & & & & & 169 \\
\hline 236.8 & & & & & $x$ & & & & & & & & & & & & & & & & & & & & & 170 \\
\hline 268.1 & $x$ & & & & & & & & $\bar{x}$ & & & & $x$ & $x$ & \begin{tabular}{l|l}
$x$ \\
\end{tabular} & $x$ & & & & & & & & & & 171 \\
\hline 272.0 & & & & & & & & & & & & r & $x$ & & & & & & & & & & & & & 172 \\
\hline 282.9 & & & $x$ & & & & & & & & & & & & & $x$ & & $x$ & & & $x$ & & & & & 173 \\
\hline 288.0 & & & $x$ & & & & $x$ & & & & & & & & & & & & & & & & & & & 174 \\
\hline
\end{tabular}

Quadro 2.11 - Distribuição das espécies no poço J-IG-93. 


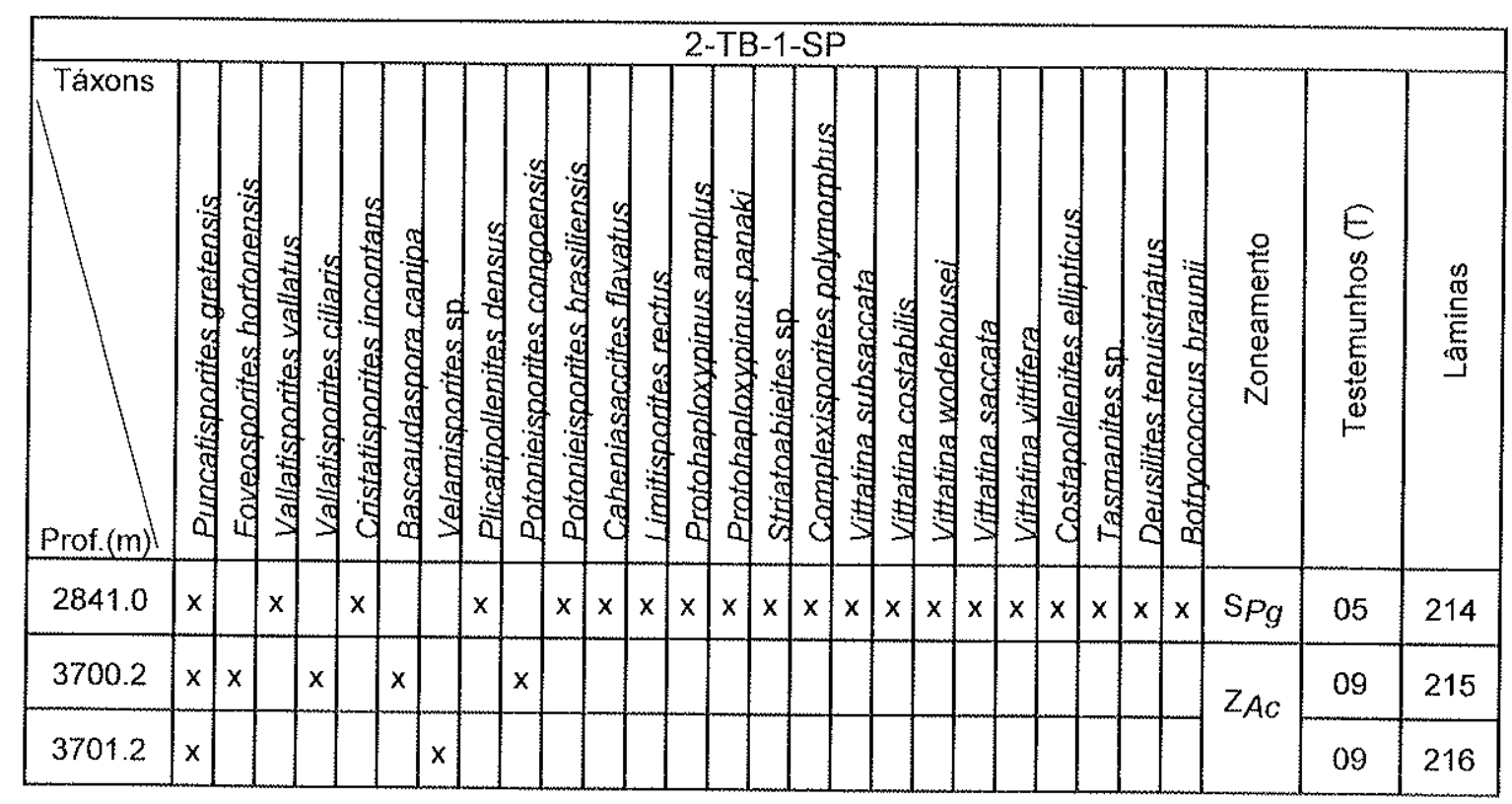

Quadro 2.12 - Distribuiçăo das espécies no poço 1-TB-1-SP.

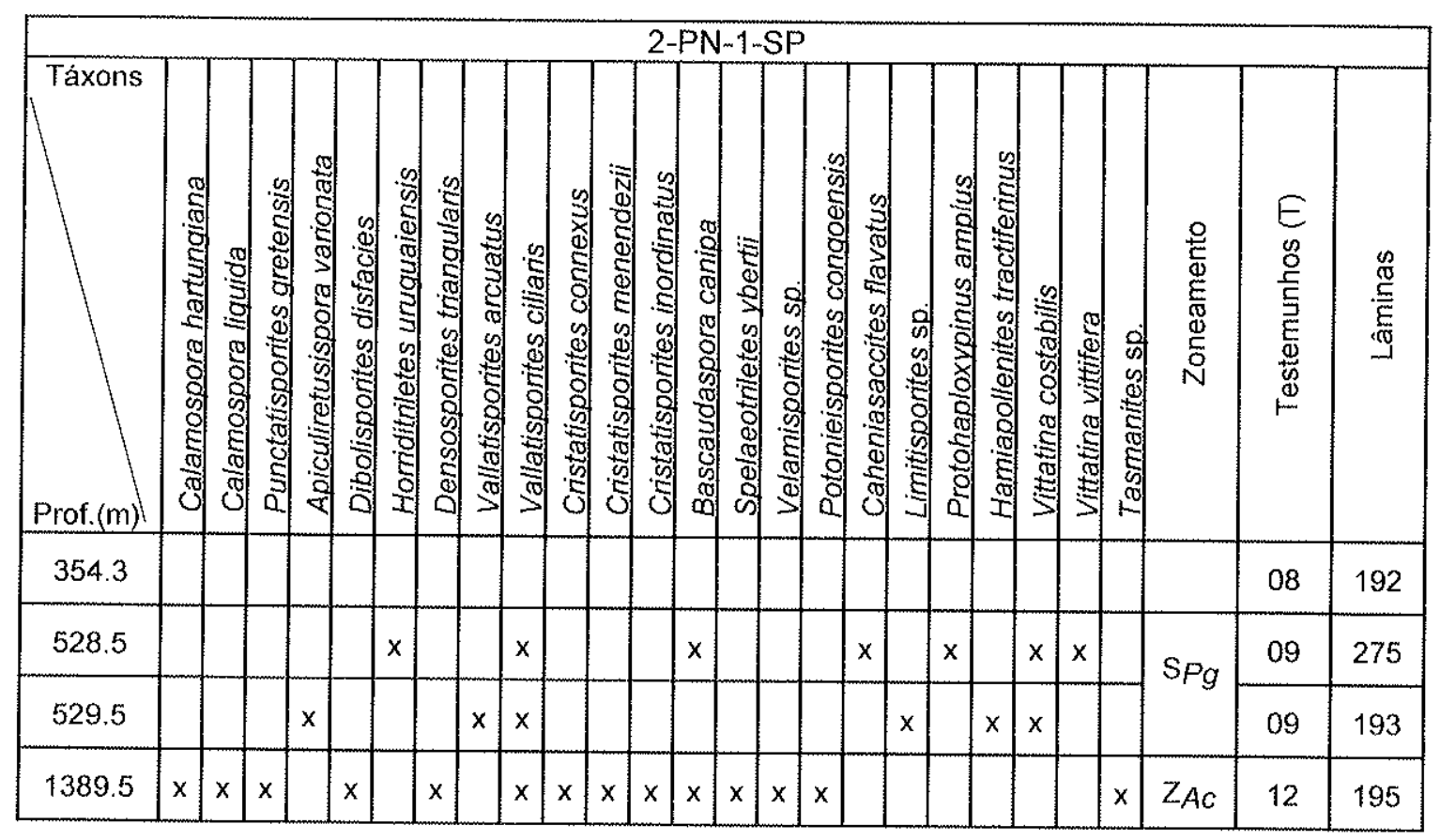

Quadro 2.13 - Distribuição das espécies no poço 2-PN-1-SP. 


\begin{tabular}{|c|c|c|c|c|c|c|c|c|c|c|c|c|c|c|c|c|c|c|}
\hline \multicolumn{19}{|c|}{$2-\mathrm{CB}-1-\mathrm{SP}$} \\
\hline Prof.(m) & 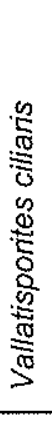 & 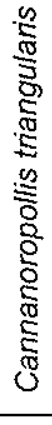 & 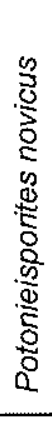 & 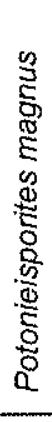 & 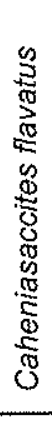 & 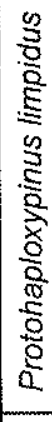 & 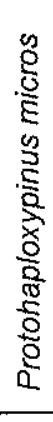 & 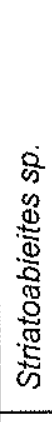 & 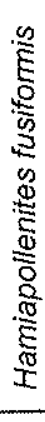 & 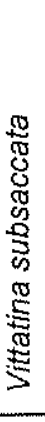 & 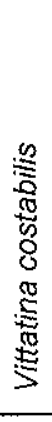 & 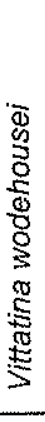 & 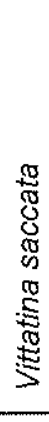 & 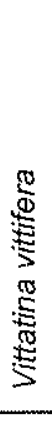 & 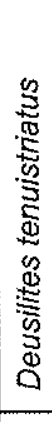 & 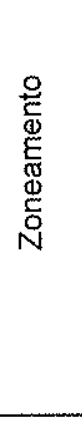 & 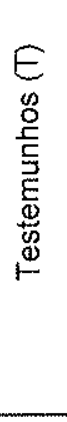 & 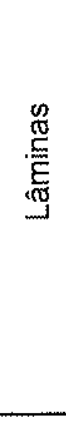 \\
\hline 3612.0 & & $x$ & & $x$ & & $x$ & & $x$ & & & $\mathrm{x}$ & & & & & & 04 & 196 \\
\hline 3624.0 & $x$ & & $x$ & $x$ & $x$ & $x$ & $x$ & $x$ & $x$ & $x$ & $x$ & $x$ & $\mathrm{x}$ & $x$ & $x$ & oPg & 04 & 197 \\
\hline 4629.3 & & & & & & & & & & & & & & & & & 07 & 198 \\
\hline 4689.3 & & & & & & & & & & & & & & & & & 08 & 199 \\
\hline
\end{tabular}

Quadro 2.14- Distribuição das espécies no poço 2-CB-1-SP.

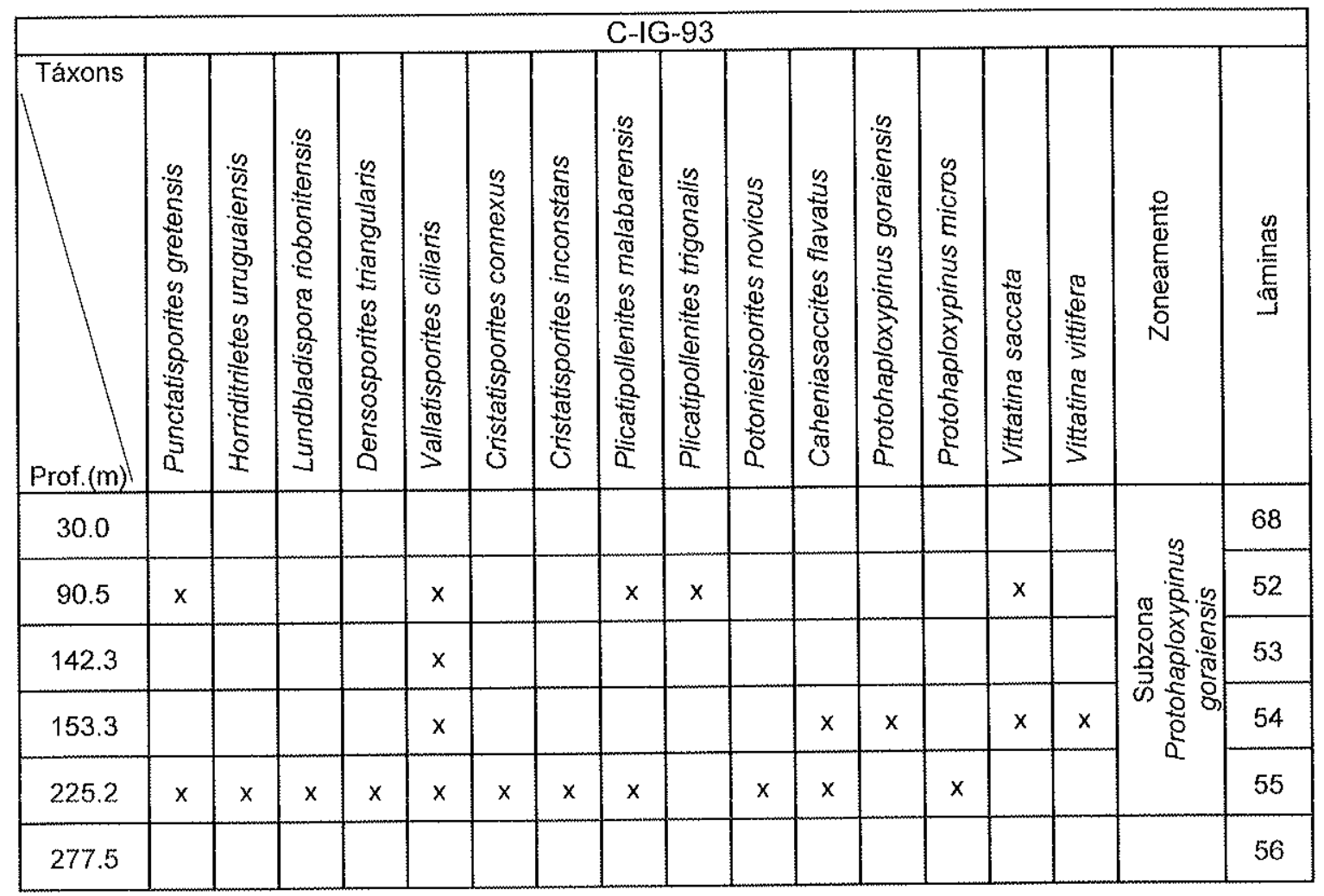

Quadro 2.15 - Distribuição das espécies no poço C-IG-93. 


\begin{tabular}{|c|c|c|c|c|c|c|c|c|c|c|c|c|c|c|c|c|c|c|c|c|}
\hline \multicolumn{21}{|c|}{ T-IG-93 } \\
\hline Táxons & 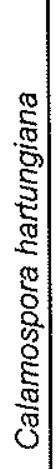 & 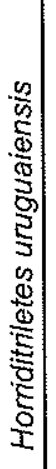 & 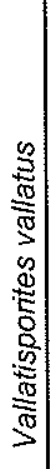 & 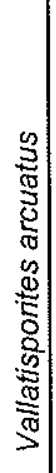 & 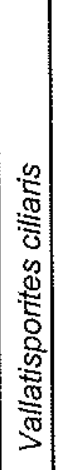 & 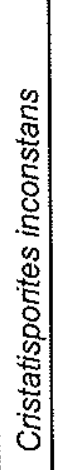 & 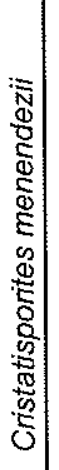 & 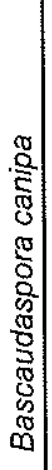 & 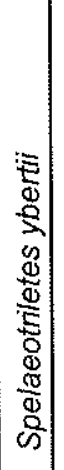 & 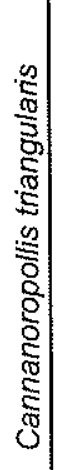 & 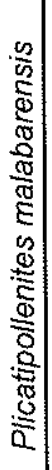 & 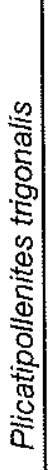 & 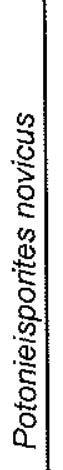 & 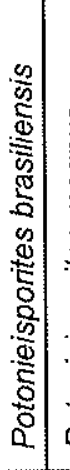 & 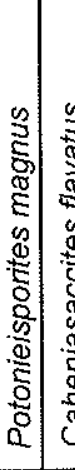 & 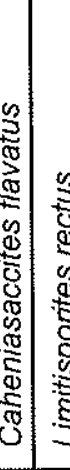 & 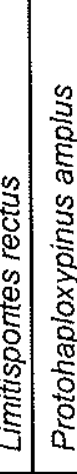 & 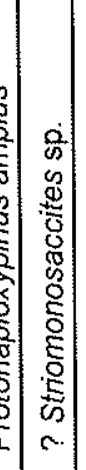 & 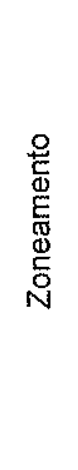 & 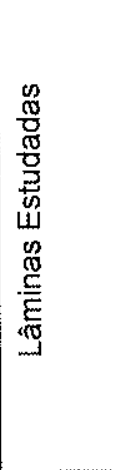 \\
\hline 44.8 & & & & $\mathrm{x}$ & & & & & & & & & & & & & & & \multirow{22}{*}{ 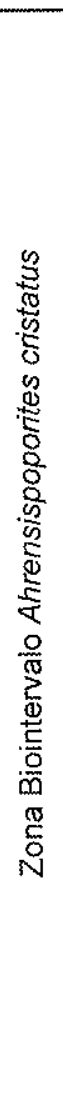 } & 100 \\
\hline 83.5 & & & & & & & & & & & & & & & & & & & & $101 / 5$ \\
\hline 86.2 & & & & & & & & & & & & & & & & & & & & 99 \\
\hline 124.4 & $x$ & & & & & & & & & & & & & & & & & $x$ & & 97 \\
\hline 157.5 & $x$ & & & & & & & & $x$ & & $x$ & & & & & & & & & 85 \\
\hline 158.6 & $\mathrm{x}$ & & & & $x$ & & & & & & & & & & & $x$ & & & & 94 \\
\hline 170.1 & $x$ & & & & & & & & & & & & & & & & & & & 89 \\
\hline 173.0 & & & & & $x$ & & & & & $\mathrm{x}$ & $x$ & & & & & & & & & 87 \\
\hline 180.2 & & & & & $x$ & & & & & & $\mathrm{x}$ & & & & & & & & & 98 \\
\hline 184.3 & & & & & $x$ & & & & & $x$ & $\mathrm{x}$ & & & & & $\bar{x}$ & & & & 90 \\
\hline 185.8 & & & & & & & & & & & & & & & & $x$ & & & & 93 \\
\hline 186.5 & & & & & $x$ & & & & & & $x$ & & & $x$ & & & & & & 95 \\
\hline 197.2 & & & & & & & & & & & & & & & & & & & & 86 \\
\hline 202.7 & & & & & $x$ & & $x$ & & & & $x$ & & $x$ & & $x$ & & \begin{tabular}{l|l}
$x$ & $x$ \\
\end{tabular} & & & 88 \\
\hline 203.8 & & & & & & & & & & & & & & & & & & & & 96 \\
\hline 204.2 & & & & & & & & $x$ & & & & & & & & & & & & 91 \\
\hline 207.2 & & & & & $x$ & & & & & & & & & & & & & & & 92 \\
\hline 227.1 & & & & & & & & & & & & & & & & & & & & 107 \\
\hline 231.1 & & & & & & & & & & & & & & & & & & & & 106 \\
\hline 250.9 & & & & & $x$ & & & & & & & & & & & & & & & 104 \\
\hline 264.8 & & $x$ & $x$ & & $x$ & $x$ & & & & $x$ & $x$ & $x$ & & & & & & & & 103 \\
\hline 264.3 & & & & & $x$ & & & & & & & $x$ & & & & & \begin{tabular}{l|l}
$x$ & $x$ \\
\end{tabular} & & & 102 \\
\hline
\end{tabular}

Quadro 2.16 - Distribuição das espécies no poço T-IG-93. 


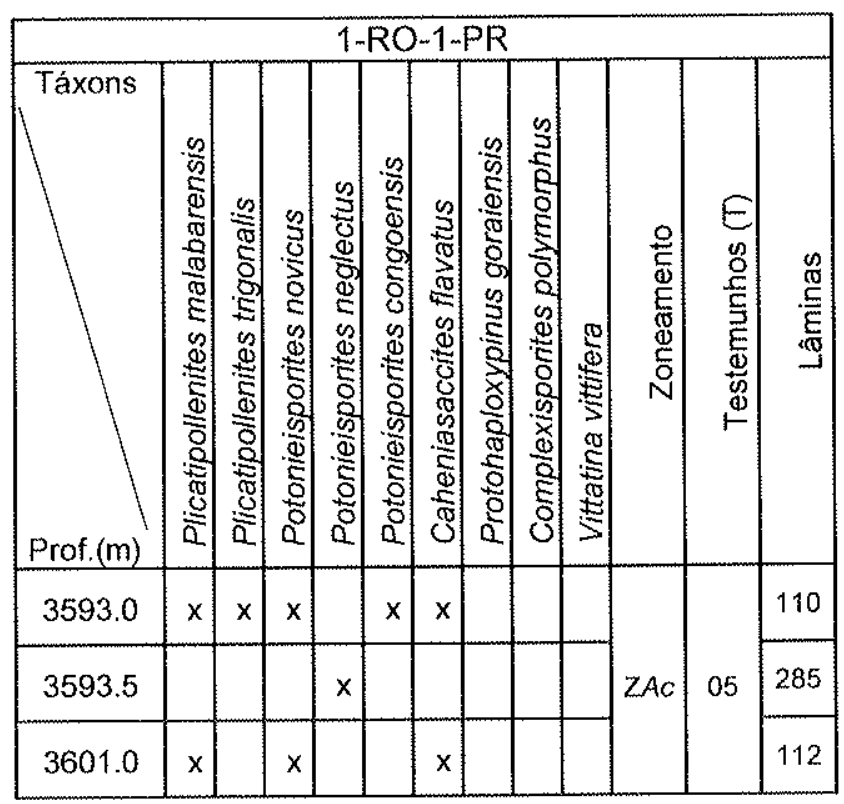

Quadro 2.17 - Distribuição das espécies no poço 1-RO1-PR.

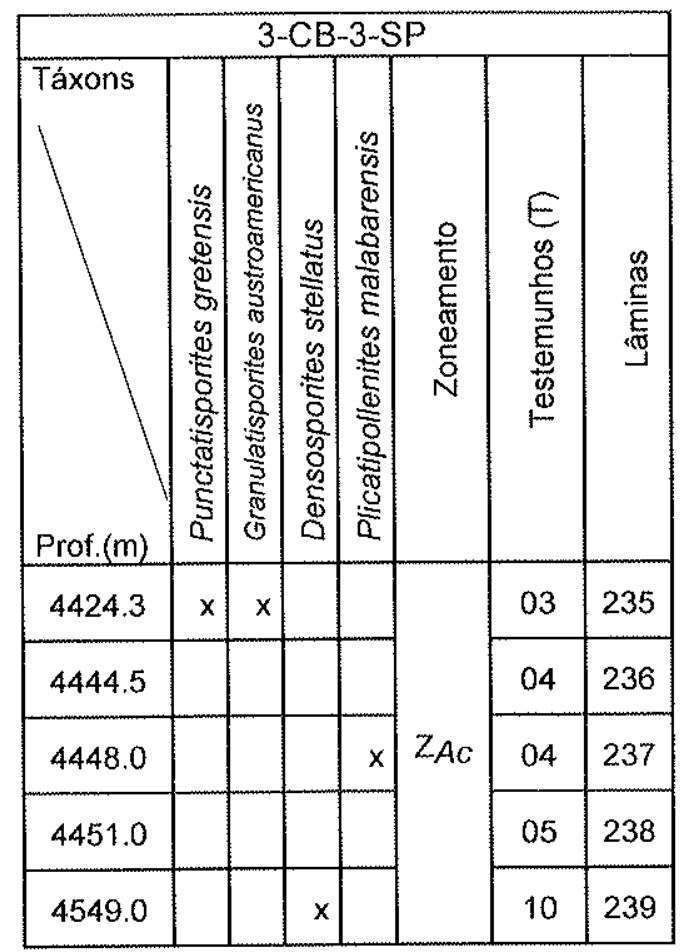

Quadro 2.18 - Distribuição das espécies no poço 3-CB-3-SP.

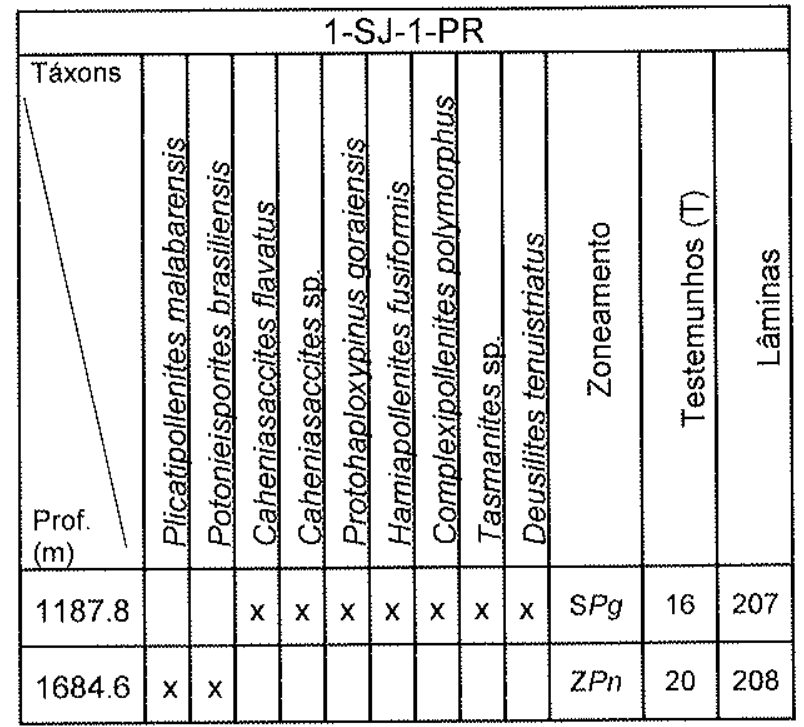

Quadro 2.19 - Distribuição das espécies no poço 1.SJ-1-PR.

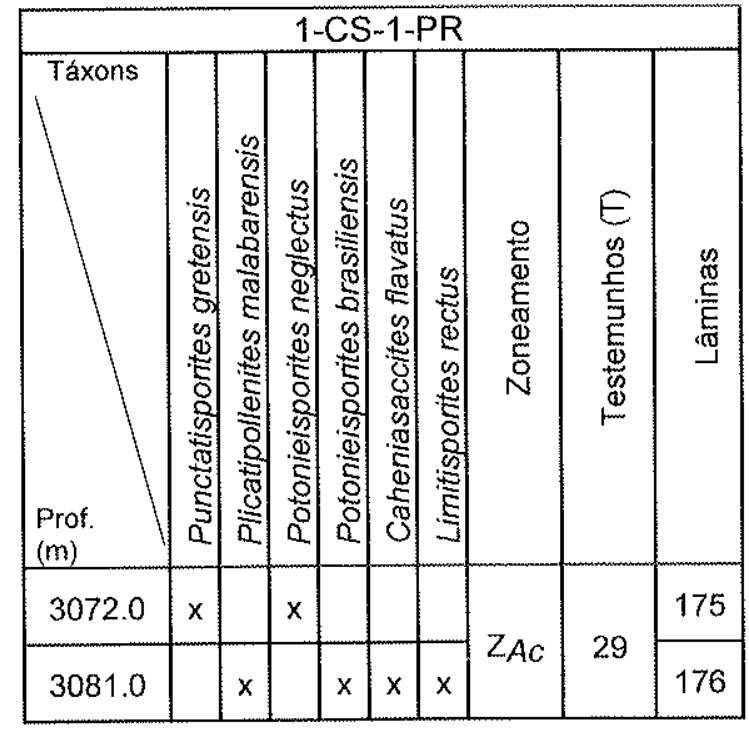

Quadro 2.20 - Distribuição das espécies no poço 1-CS-1-PR. 


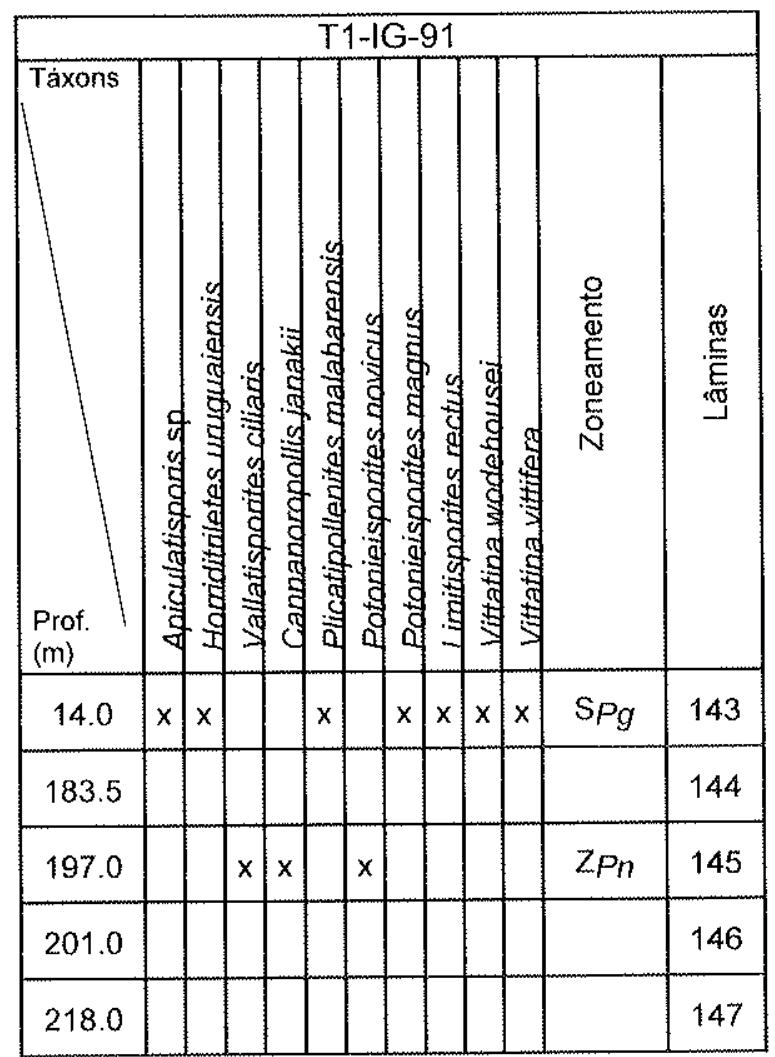

Quadro 2.21 -- Distribuição das espécies no poço T1-IG-91.

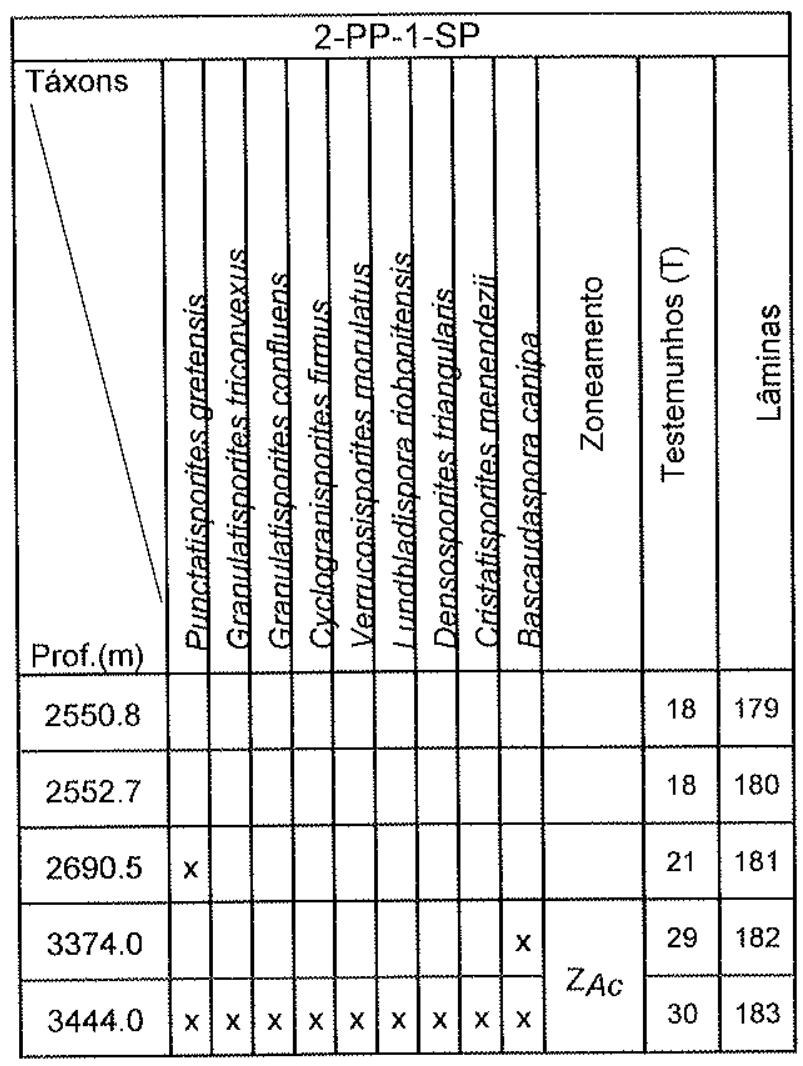

Quadro 2.22 - Distribuição das espécies no poço 2-PP.1-SP.

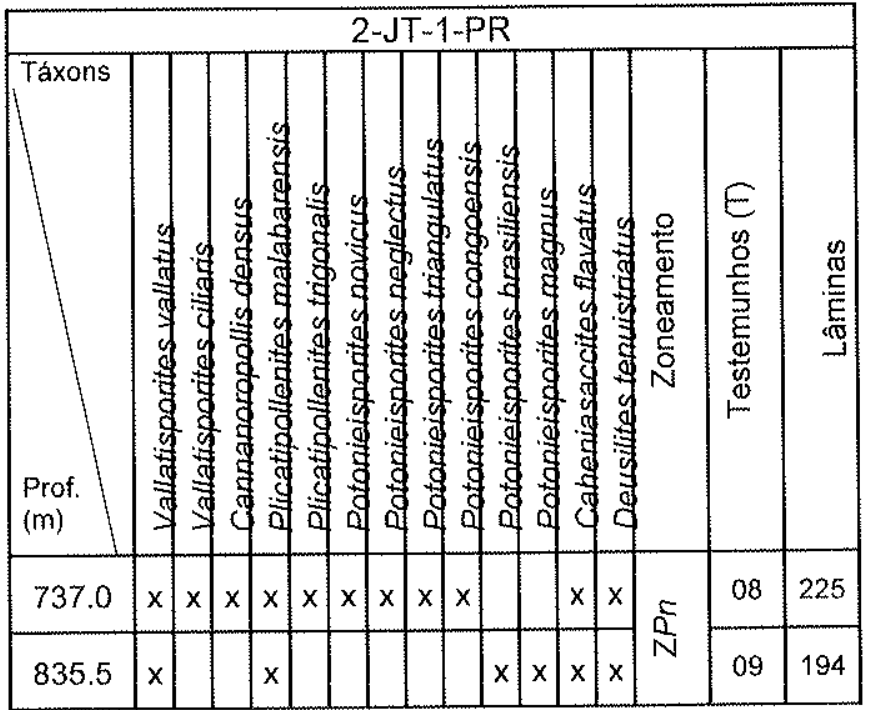

Quadro 2.23 - Distribuição das espécies no poço 2-JT-1-PR

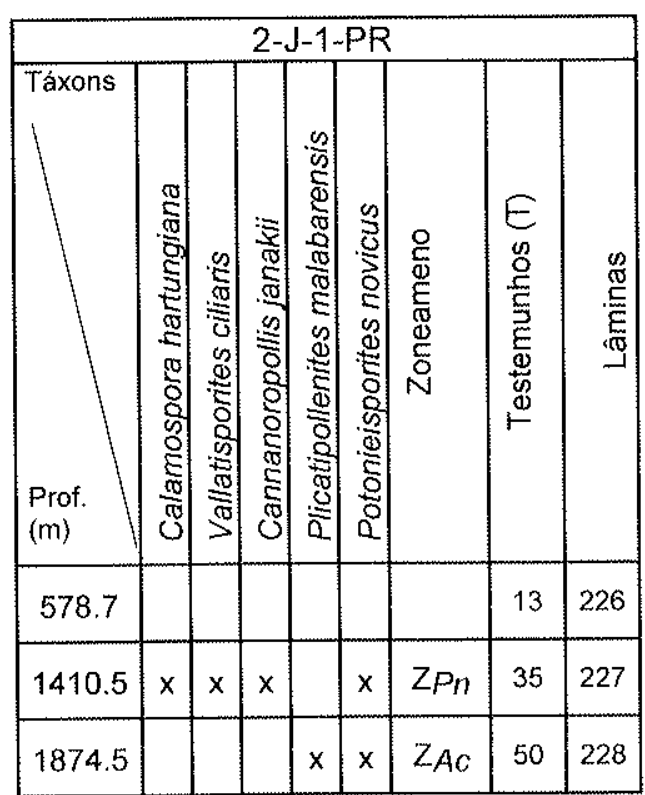

Quadro 2.24 - Distribuição das espécies no poço 2-J-1-PR. 


\begin{tabular}{|c|c|c|c|c|c|c|c|c|c|c|c|c|c|c|c|}
\hline \multicolumn{16}{|c|}{ 1-CP-1 SP } \\
\hline Táxons & 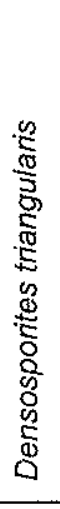 & 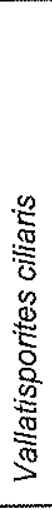 & 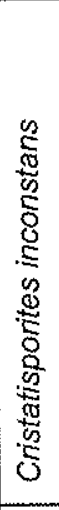 & 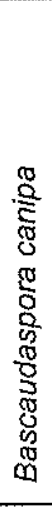 & 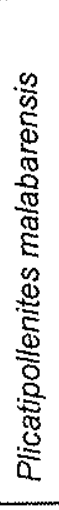 & 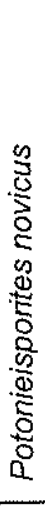 & 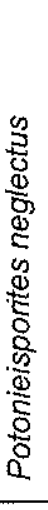 & 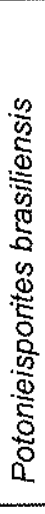 & 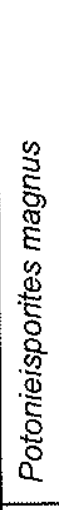 & 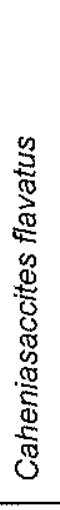 & 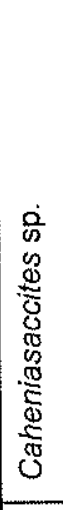 & 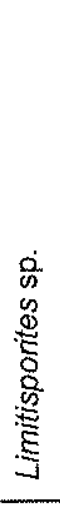 & 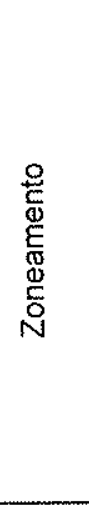 & 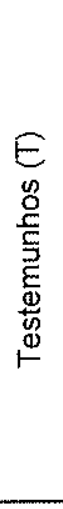 & 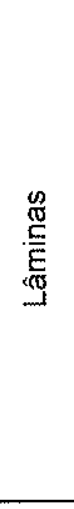 \\
\hline 686.0 & & & & & & & & & & & & & & 21 & 242 \\
\hline 754.2 & & & & & & & & & & & & & & 23 & 243 \\
\hline 887.4 & $x$ & $x$ & $x$ & $x$ & $x$ & & & & & $x$ & & $x$ & & 29 & 244 \\
\hline 1056.5 & & & & & $x$ & $x$ & $x$ & $x$ & $x$ & & $x$ & & $2 r \pi$ & 34 & 245 \\
\hline 1508.5 & & & & & & & & & & & & & & 58 & 246 \\
\hline 1530.7 & $x$ & $x$ & & & & & & & & & & & $Z A C$ & 60 & 247 \\
\hline
\end{tabular}

Quadro 2.25- Distribuição das espécies no poço 1-CP-1-SP.

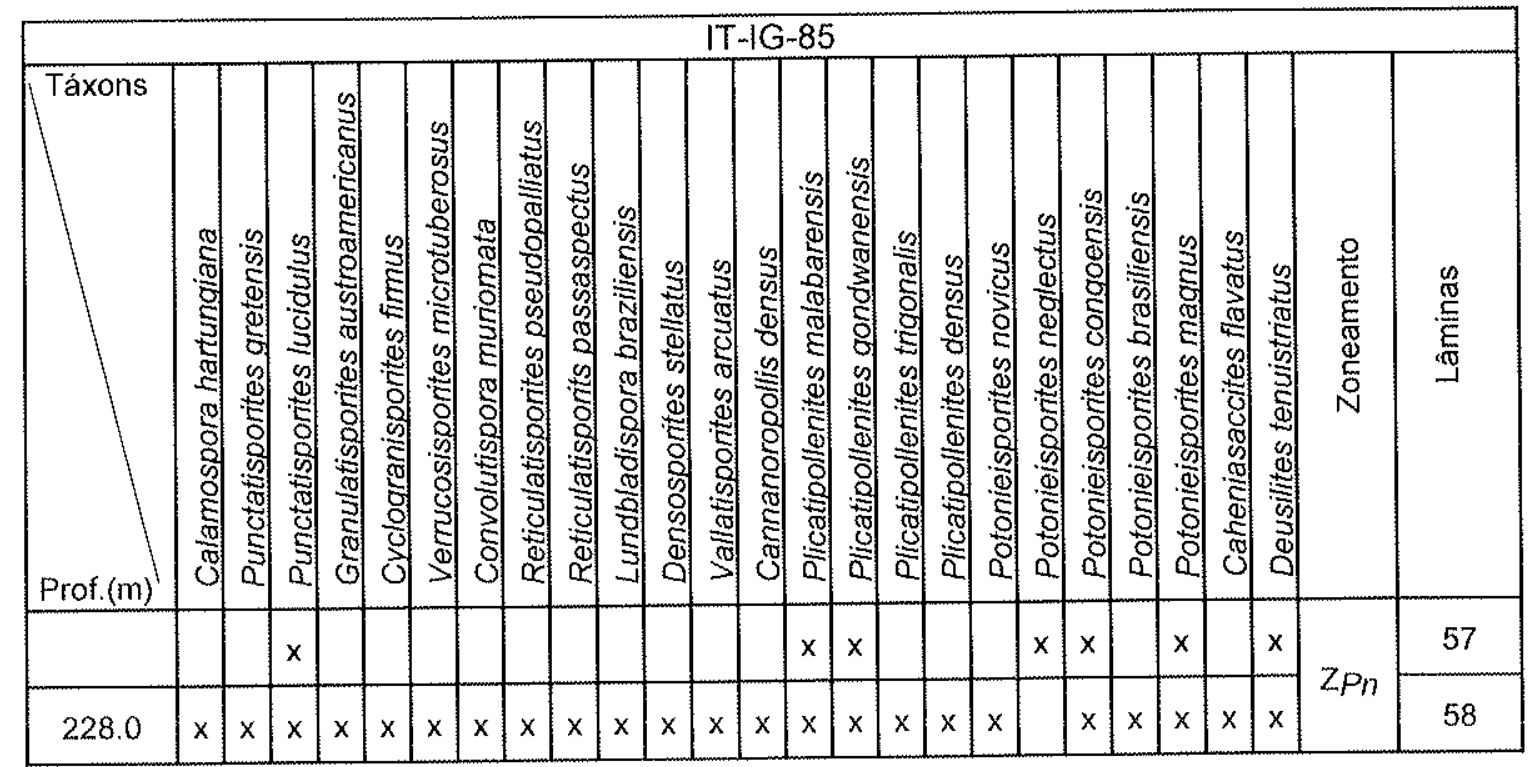

Quadro 2.26 - Distribuição das espécies no poço IT-IG-85. 


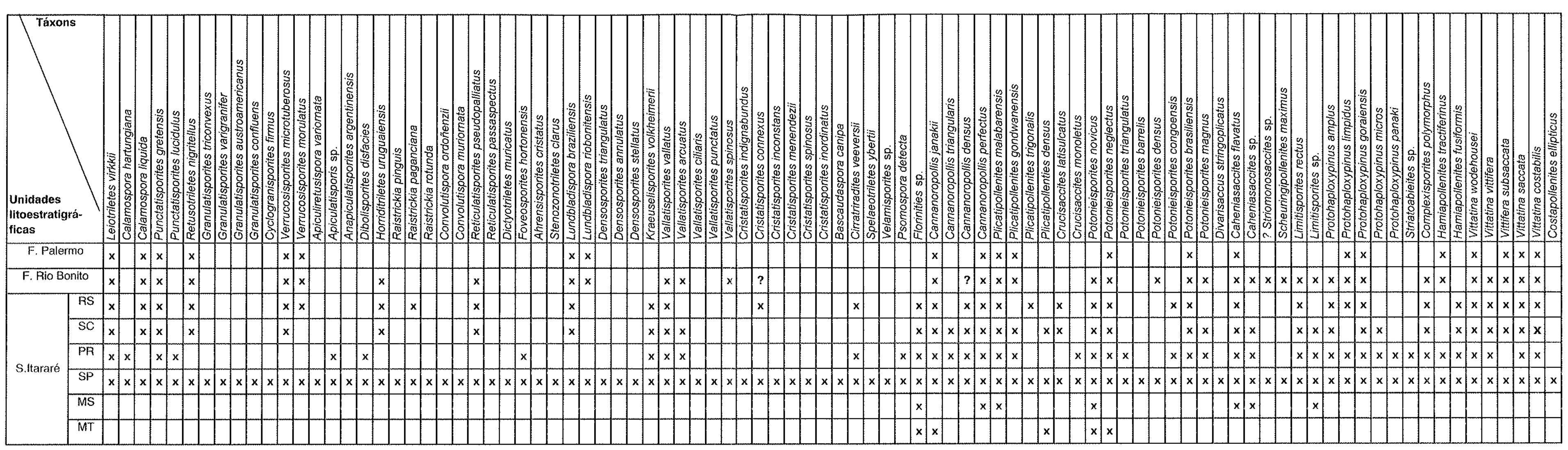

Quadro 2.27 - Distribuição estratigráfica de todos os esporomorfos estudados do Grupo Tubarão conforme este trabahho e informações publicadas*.

* Fontes do Subgrupo Itararé: Daemon \& Quadros (1970), Kemp (1975), Bharadwaj et al. (1976), Pons (1975, 1976ab), Lima et al., (1983), Picarelli (1986), Picarelli et al. , (1987), Sundaram (1987), Marques-Toigo (1988), Dias (1993), Souza et al. (1993a, 1997), Quadros et al. (1995) e Souza (1996).

Fontes da Formação Rio Bonito: Pant \& Srivastava (1965), Nahuys et al. (1968), Cauduro (1970), Daemon \& Quadros (1970), Marques-Toigo \& Pons (1974), Corrêa-da-Silva \& Marques-Toigo (1975), Ybert (1975), Bortoluzzi et al. (1978), Burjack (1978). Thomaz (1980), Dias-Fabrício (1981), Picarelli (1986), Picarelli et al. (1987), Marques-Toigo (1988), Piccoli et al. (1991) e Quadros et al. (1995). Fontes da Formaçăo Palermo: Daemon \& Quadros (1970), Bharadwaj et al. (1976), Leipnitz (1981), Picarelli (1986), Picarelli et al. (1987), Marques-Toigo (1988) e Quadros et al. (1995). (RS: Estado do Rio Grande do Sul; SC: Santa Catarina; PR: Paraná; SP: São Paulo; MS: Mato Grosso do Sul; MT: Mato Grosso;

As fontes selecionadas são as mesmas utilizadas na revisão que resultou nas sinonímias constantes das descriçōes sistemáticas, não se considerando resumos e/ou publicações sem descrições e/ou ilustrações). 